\title{
MASTER
}

ORO-5270-3

UC-78

SCEGIT-78-164

\section{INFORMATION MANAGEMENT FOR}

NUCLEAR POWER STATIONS

PROJECT DIRECTOR: DANIEL W. HALPIN, PHD.

PREPARED FOR: THE UNITED STATES DEPARTMENT OF ENERGY CONTRACT EY-76-S-05-5270

FORMERLY CONTRACT E-(40-1) 5270

MARCH 1978

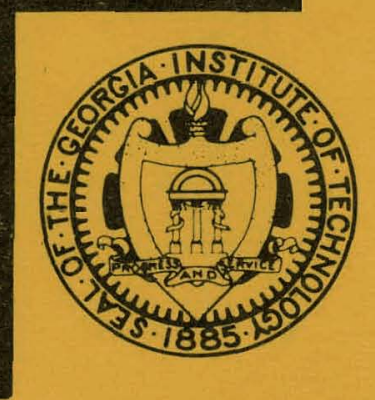




\section{DISCLAIMER}

This report was prepared as an account of work sponsored by an agency of the United States Government. Neither the United States Government nor any agency Thereof, nor any of their employees, makes any warranty, express or implied, or assumes any legal liability or responsibility for the accuracy, completeness, or usefulness of any information, apparatus, product, or process disclosed, or represents that its use would not infringe privately owned rights. Reference herein to any specific commercial product, process, or service by trade name, trademark, manufacturer, or otherwise does not necessarily constitute or imply its endorsement, recommendation, or favoring by the United States Government or any agency thereof. The views and opinions of authors expressed herein do not necessarily state or reflect those of the United States Government or any agency thereof. 


\section{DISCLAIMER}

Portions of this document may be illegible in electronic image products. Images are produced from the best available original document. 
ORO-5270-3

UC-78

SCEGIT-78-164

\title{
INFORMATION MANAGEMENT FOR
}

NUCLEAR POWER STATIONS

APPENDIX A-D

\author{
Daniel W. Halpin, Ph.D. \\ Project Director \\ School of Civil Engineering \\ Georgia Institute of Technology \\ Atlanta, Georgia 30332
}

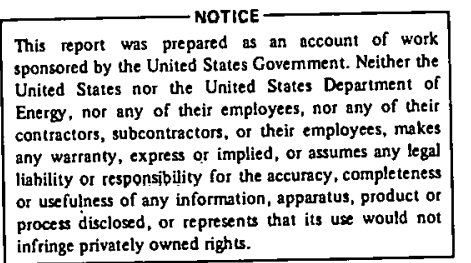

March 1978

PREPARED FOR THE DEPARTMENT OF ENERGY

UNDER CONTRACT NO. EY-76-S-05-5270

FORMERLY E-(40-1) -5270

PROGRAM MANAGER:- CHARLES A. THOMPSON 
This report was prepared as an account of work sponsored by the United States Government. Nelther the Unlited 3 lates nor the Unitad States Department of Energy, nor any of their employees, nor any of their contractors, sub-contractors, or their employees, makes any warranty, express or implied, or assumes any legal liability or responsibility for the accuracy, completeness, or usefulness of any information, apparatus, product or process disclosed or represents that its use would not infringe privately owned rights. Additional copies of this report can be obtained from the National Technical Information Service (NTIS), Springfield, Virginia 22161, USA. 
FOREWORD

This report consists of five volumes numbered ORO-5270-1 through ORO-5270-5. Volume I (ORO-5270-1), the Project Description, briefly describes the purpose, approach and results of the study. An extensive description of the study appears in Volume II, System Design Concept (ORO-5270-2). This volume, consisting of Appendices $A-D$, and the other appendices ( $E$ and $F$ ), contain supporting material upon which the concepts and results of Volume II are based. The appendices are bound as three separate volumes with the following designations:
(1) Appendices A-D
ORO-5270-3
(2) Appendix E
ORO-5270-4
(3) Appendix F
ORO-5270-5

Copies of all five volumes can be obtained from the National Technical Information Service. (NTIS), Springfield, Virginia 22161, USA. Further detalls regarding the contents of the volumes appear as Exhibit $I$ at the end of Volume I.

The information developed and the results realized during this study are the joint effort of a number of organizations and consultants. In directing this study, Georgla Institute of Technology was assisted by Construction Systems Associates, Inc. (Atlanta, Georgia) and Daniel. International Corporation (Greenv1lle, South Carolina). Both firms served as technical advisors to the project. Duke Power Company provided the utility viewpoint and played a major role in providing information and assisting personnel to the program. Other firms and utilities 
providing personnel and information to the project on a consulting basis include:
(1) Southern Company Services, Inc., Birmingham, Alabama
(2) Ebasco Services, Inc., Atlanta, Georgia
(3) Fluor-Pioneer, Inc., Chicago, Illinois
(4) Gilbert Associates, Inc., Reading, Pennsylvania

In addition, numerous utilities and nuclear construction support

groups were interviewed during the course of the study and provided valuable information and insights regarding existing methods of operation. 


\section{ACKNOWLEDGEMENTS}

Appendices $A$ through $D$ were produced as a cooperative effort and are based on the application area descriptions developed by members of the participating organizations during Stage I of the project. Individuals contributing to or responsible for portions of the Appendices are as follows:

Appendix A -- R. Lumadue, Duke Power, Team Leader

R. Comer, Georgia Tech

P. Coplen, Georgia Tech

H. Finlon, Duke Power Company

R. A. Lewallen, Daniel International Corporation William Wolter, CSA, Inc.

Appendix B. -- D. Halpin, Georgia Tech, Team Leader

P. Coplen, Georgia Tech

C. Steinbrecher, Georgia Tech

F. Spears, Georgia Tech

Appendix C -- C. R. Mashburn, Daniel International Corporation, Team Leader

D. Drachman, Georgia Tech

F. Spears, Georgia Tech

Appendix D -- A. M. Burger, CSA, Inc., Area Leader

G. Massey, Duke Power Company

C. Yang, CSA, Inc. 


\section{THIS PAGE WAS INTENTIONALLY LEFT BLANK}




\section{APPENDIX A}

TABLE OF CONTENTS

$\underline{\text { Page }}$

CHAPTER I: Project Management

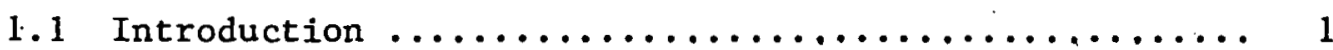

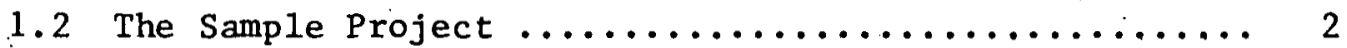

1.3 Control System Components .................. 7

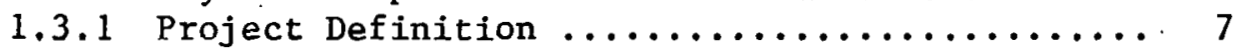

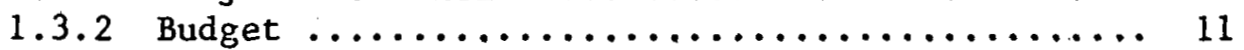

1.3 .3 . Schedule $\ldots \ldots \ldots \ldots \ldots \ldots \ldots \ldots \ldots \ldots \ldots \ldots \ldots \ldots$

1.3 .4 Integrated Control System .............. 26

1.3 .5 Project Evaluation .................. 30

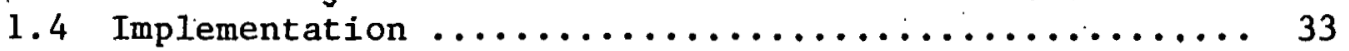

CHAPTER II: Construction Planning and Scheduling

2.1 Introduction $\ldots \ldots \ldots \ldots \ldots \ldots \ldots \ldots \ldots \ldots \ldots \ldots \ldots \ldots \ldots$

2.2 Daniel Planning and Scheduling System ........... 43

2.3 Bechtel Planning and Scheduling Approach ......... 49

2.4 Planning/Scheduling - Southern Company Services ..... 54

2.4.1 Network Development ................... 54

2.4.2 Develop and Code Resource Estimates......... 55

2.4.3 Controlling Domestic (Southern) Drawings ..... 55

2.5 Planning/Scheduling - Duke Power Company .......... 55

2.5.1 Long Range Planning ................. 56

2.5.2 Development and Maintenance of Working Level Schedules - IPS Level ................. 56

2.5.3 Construction Schedule Productivity ......... 58

2.5.4 Test and Start-Up Schedule .............. 59

2.6 Planning/Scheduling - Tennessee Valley Authority .... 59

2.6.1 Design Project Contro1 ................ 59

2.6.2 Construction Project Control ............. 61

2.6.3 Construction Productivity Monitoring ........ 62

2.7 Planning/Scheduling - Commonwealth Edison ......... 64

2.8 Planning/Scheduling - Westinghouse ............. 65

2.8.1 Project Level/System Scheduling ........... 65

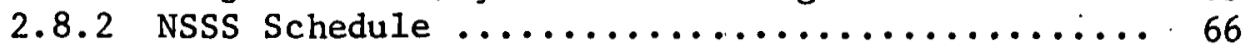

2.8.3 Intermediate Level Schedules (Level 2) .......66 66

2.8.4 Work Package Schedules ................ 66

2.8.5 Analysis of Progress ................ 67

CHAPTER III: Computerized Network Processors

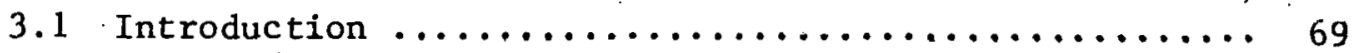

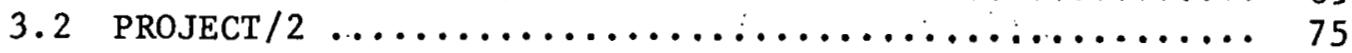

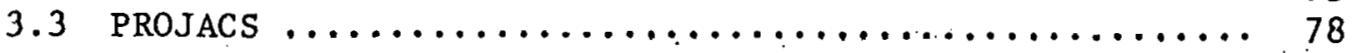


3.3 .1 General $\ldots \ldots \ldots \ldots \ldots \ldots \ldots \ldots \ldots \ldots \ldots \ldots . \ldots \ldots 7 . \ldots \ldots$

3.3.2. Advantages of PROJACS Scheduling ......... 79

3.3.3 Report Processor Characteristics ...........83

3.4 MCS - Construction Management System ............. 94

3.4.1 M.C.S. Summary Description ............. 94

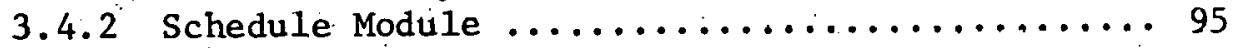

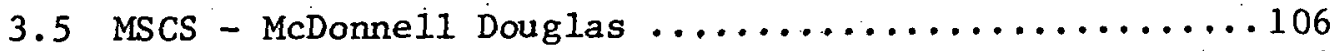

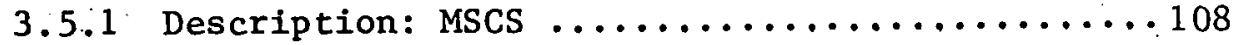

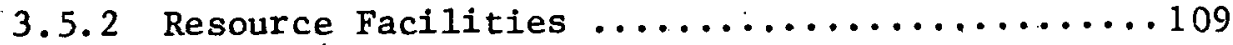

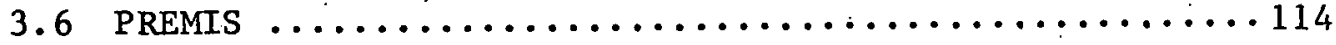

3.6.1 Network Creation and Analysis $\ldots \ldots \ldots \ldots \ldots \ldots 116$

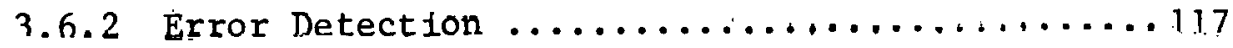

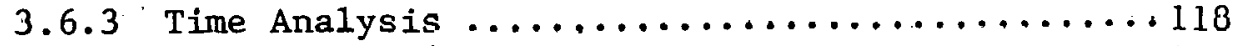

3.6.4 Resource Analysis and Scheduling ...........119

3.6.5 Nonexceedable Resources and Thresholds .......120

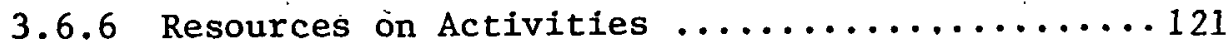

3.6.7 Scheduling Rules/Priorities ............. $121^{\prime}$

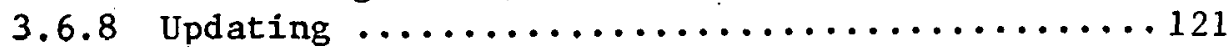

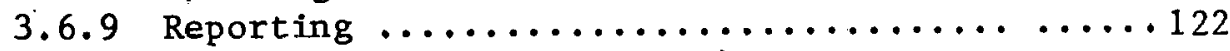

3.7 Project Management System (PMS IV) ............. 125

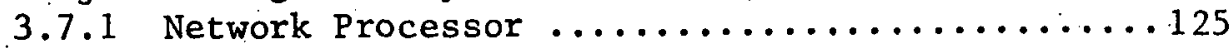

3.7.2 Resource Allocation Processor .............. 129

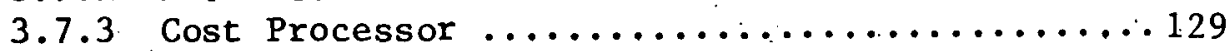

3.7.4 Report Processor ......................... 141

\section{CHAPTER IV: Project Services}

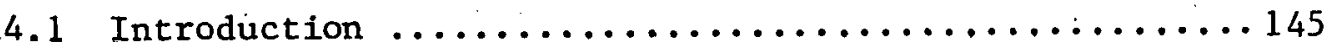

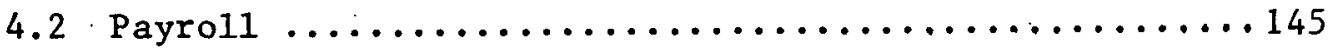

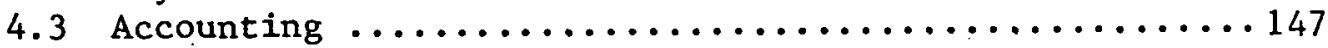

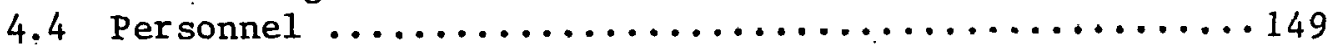

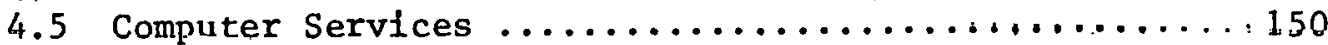

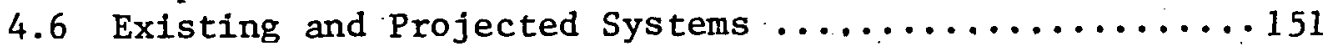

4.7 Productivity Reporting and Control ............... 154

4.7.1 Duke Power Company - Project Planning and

Performance. Program: Man-Hour Quantity

Analysis System and Quantity Control System ... 154

4.7.2 Daniel International Productivity Reporting .... 161 
CHAPTER I

$\underline{\text { Project Management }}^{*}$

\subsection{Introduction}

The success of an engineering project depends on the effectiveness of its management. Project management must supervise the design effort, identify design priorities through planning and scheduling, and evaluate progress. Management has both qualitative and quantitative functions in this regard. The effectiveness of qualitative management is a function of the manager's ability to utilize human resources. The engineering manager's qualitative objective is to accomplish an effective and technically sound engineering design resulting in a minimum total project cost (design, construction, and operation costs). Quantitative management relates to schedule and budget compliance as well as productivity measurement. The quantitative objectlve 1s to complete the project on time and within budget. Qualitative and quantitative aspects of project management are closely related at the project planning stage. A design project must be planned and budgeted in such a manner that a schedule can be met while achieving a good engineering design. During the life of the project, progress is evaluated with respect to the early planning and budgeting which becomes a basis for productivity measurement. The qualitative and quantitative objectives conflict since one constantly constrains the other. Without a schedule or budget constraint, a good design might evolve gradually through a trial and error process. However, the companies who support projects could not afford * This Chapter was written by Mr. William Wolter. 
this type of evolutionary development. For this reason, a project always has a set of dual problems: (1) maximize design effectiveness, and (2) minimize cost and elapsed time. Because of the dual problems, project managers need a systematic technique to use as a tool for maximizing total management effectiveness. The system described in the following sections is a combination of techniques which are already in use. The system is intended to be used as an aid to the management of the engineering portion of a large design-construct project. Relevance to total project management, including construction, is emphasized but not detailed. As a sample project, a typical power plant is used to illustrate the various components of the management system. While viewing the system for power plant design management, application to other industrial-type design projects can be realized.

\subsection{The Sample Project}

A project is a temporary organization whtch is created to accomplish an objective. When its work is completed, the project is closed out or disbanded. A project may be compared to a company which starts with a small group of key personnel. The company expands in personnel and equipment for $70-80 \%$ of its life and then quickly diminishes as the objective reaches final achievement. Consider a typical power plant (over $500 \mathrm{MW}$ ) which must be designed and conserucled. Tu accomplish this objective, a project is created. The power plant project can be divided into its major subprojects: ENGINEERING and CONSTRUCTION. ENGINEERING designs the numerous systems which operate the plant, 
purchases permanent equipment, and produces construction drawings. CONSTRUCTION builds the plant in accordance with the construction drawings. Then ENGINEERING must publish plant operation manuals and furnish expertise for starting the power plant. When construction is complete and the plant is in full operation, the objective is completed, and the project is terminated.

Because of the high initial investment cost of a power plant (several hundred million dollars), it is necessary to expedite engineering and construction as much as feasible so that an early commercial operation date can be realized (about 8-10 years for nuclear plants from start: of engineering). This requires that engineering and construction phases have considerable overlap in time. Foundations are of ten constructed before super-structure designs are completed. Site facilities are given tentative arrangements prior to design of such systems as fuel handling, rad waste handling, and auxiliary systems in order to expedite earth- . work drawings and enable the start of construction. Typical time-phases of the project are illustrated in Figure 1:1. Examination of the project phases will bring out the significance of phase overlaps:

1. Proposal phase -- Preliminary estimates, schedules, and technical qualifications of the company are presented to the potential client in a bid to obtain an engineering and/or construction contract.

2. Preliminary engineering - Design parameters are established and major equipment is purchased such as the nuclear steam supply system (NSSS), turbine generator, other mechanical equipment, main power and auxiliary power transformers. Design parameters are established as 
YEAR

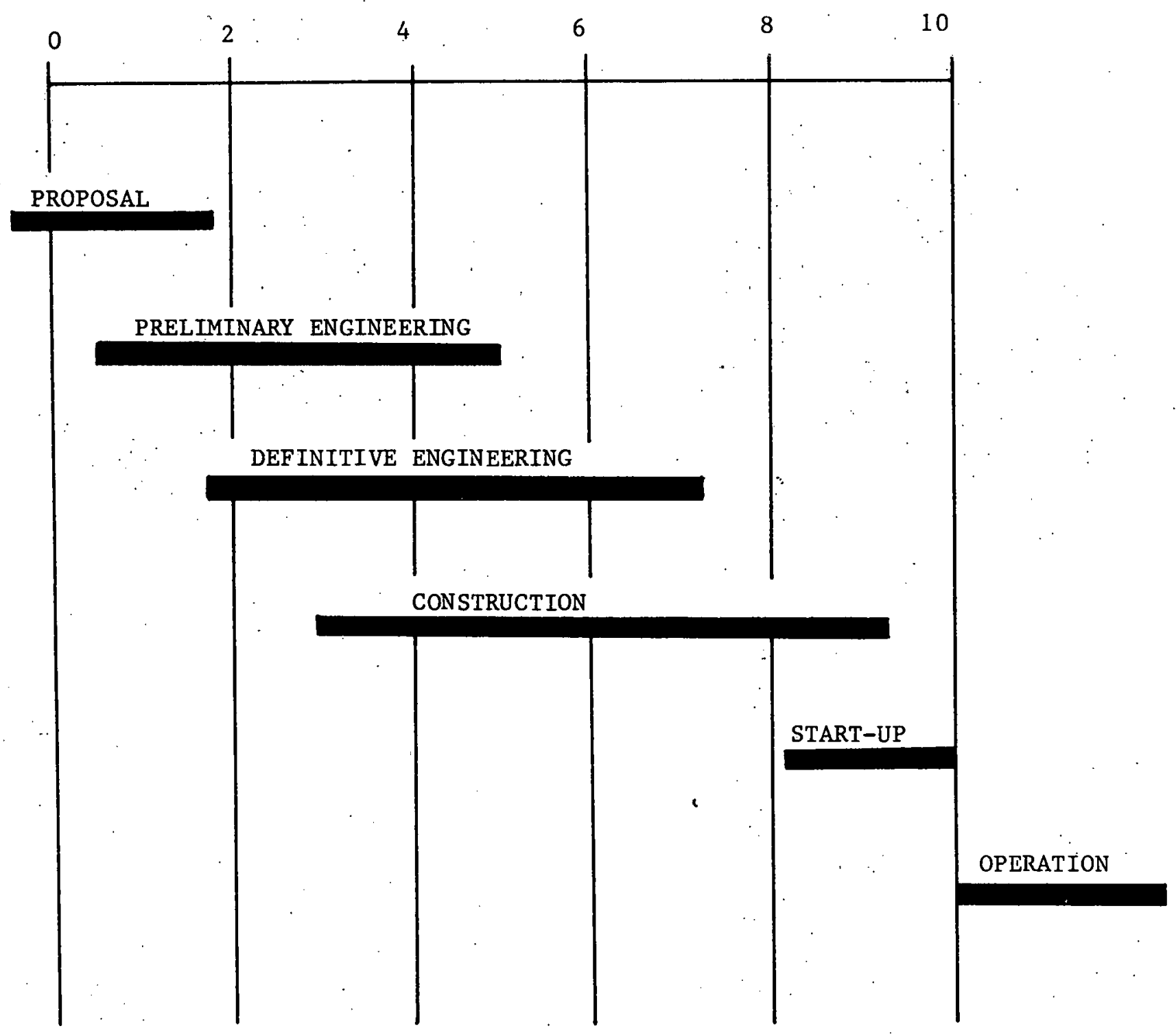

FIGURE 1.1: TIME-OVERLAP OF PROJECT PHASES 
systems are defined and as major equipment is selected. As design parameters become finalized, definitive design (for fabrication and construction) can proceed. Expediting of the project schedule requires producing construction drawings as early as possible, usually before completion of the preliminary engineering phase.

3. Definitive 'Engineering -- Construction drawings are produced and equipment purchases are completed during this phase. Designers and draftsmen use design information generated in the Preliminary Engineering Phase to prepare construction drawings. However, the construction phase sometimes places schedule demands on drawing production and equipment deliveries at the expense of good engineering. For example, structural engineers are compelled to proceed with final steel prior to knowledge of specific equipment loads, or even systems' configurations. This results in expensive, overly-designed structural members and a high probability of design modification after drawings have been released for fabrication. The impact of project scheduling problems is first realized in the definitive engineering phase because. of (1) the need for design parameters required to start design, and (2) pressure from the construction phase to produce drawings. The dual problems of the project are explicit. The engineers are attempting to produce a design of good quality. On the other hand, they are constrained by a tight schedule. In the absence of a systematic technique to assist in identifying design priorities early in the project, one or both of the dual problems must be sacrificed, 
4. Construction -- The construction phase requires the least explanation. Although there are alternative construction sequences, the alternatives are restricted by site conditions, climatic conditions, area accessibility, availability of labor, and precedence constraints (earthwork before foundations; foundations before superstructure, etc.). Because of the restricted nature of a construction sequence, and because of the relatively high cost of construction vs. engineering, the construction schedule will establish time parameters for completing the definitive engineering phase. To effectively schedule definitive engineering, the construction schedule must be conceived during the preliminary engineering phase.

5. Start-Up - Start-up should be the responsibility of the engineers who designed the plant systems (mechanical, piping, instrumentation and control, and electrical). Since the project schedule is to be expedited whenever possible, systems and equipment checkout begins before power plant construction is completed. An efficiently scheduled project will have allowed for the time and sequence of plant start-up. When a large engineering project, having complex system designs, is characterized by considerable phase overlapping, a management system for defining and controlling the project is necessary. An effective project management system should provide the tools for defining, budgeting, scheduling, supervising, and evaluating the project. As mentioned previously, the functions of management are both qualitative and quantitative. Engineers are rigorously trained for technical competence and are conscientious in striving for high quality performance. 
A management system, at best, can enhance the technical aspects of design. The system's most tangible purpose is to assist in quantitative engineering management, more specifically, to answer the following questions:

1. Exact1y what work has to be done?

2. What is the estimated cost of the work?

3. In what order or sequence should the work be done?

4. What -resources will be required over the life of the project?

5. How should the project's progress be evaluated?

The management system described here has the following major components: which will be described separately: PROJECT DEFINITION, BUDGET, SCHEDULE, AND PROJECT EVALUATION. The system combines the major components into a dynamic tool which is useful during all project phases. The system provides a means for modifying the project and for management decision analysis.

\subsection{Contro1 System Components}

\subsection{Project Definition}

The components of the project management system will be described in terms of the sample power plant project. The first step in design management is to define the project: What and how much work has to be done? To do this, a special kind of outline is developed called a work breakdown structure, an outline of successive levels of work packages. Each work package represents a well-defined portion of the 
total work (Figure 1.2). The first level of the work breakdown structure is the total power plant project. The power plant project is composed of two major subprojects, ENGINEERING and CONSTRUCTION, which form the second level of the work breakdown structure. The third level subdivides the second level, the fourth subdivides the third, etc., until a desirable level of detail is reached. The most detailed work package should be the detail required to monitor and control the job. Figure 1.2 illustrates the work breakdown frou the Power Plant Project 1eve1, through Engineering Design levels, down to the detail of selecting a specific item of equipment or preparing a flow sheet drawing. A fundamental characteristic of a work breakdown structure is that each work package is a segment of its next highest level, or conversely, a work package can be expanded to more detailed levels. For example, the "Condensate System Design" is composed of the following (from Figure 1.2):

System Definition

Plpe Design

Instrumentation and Electrical Design

Equipment Specification

Under "System Definition," the tangible products of that Work Package are 1isted:

System Description

Design Criteria Study

Flow Sheet Drawing

Components Listing 


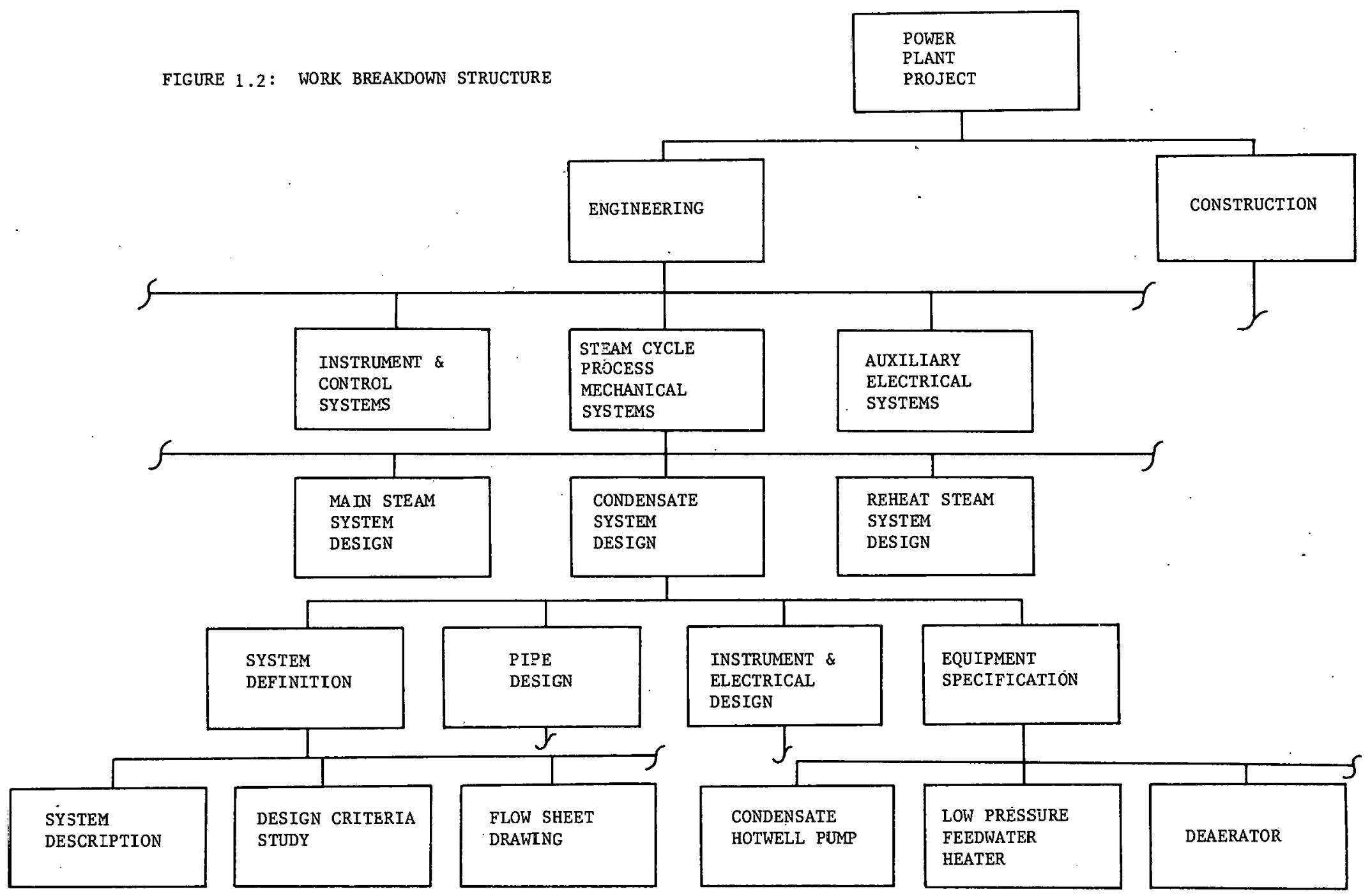

FIGURE 1:2: WORK BREAKDOWN STRUCTURE 
The work breakdown structure enables the manager to evaluate the content of a design package at any level of detail. Knowing the content of any. design package is probably the most valuable information provided by the work breakdown structure. The work breakdown structure is a means for achieving a refined systems analysis of a complex engineering design. It becomes an important tool for communication between successive management levels, and for design coordination among several engineering disciplines. In general, a broad scale level of the work bredkuluwu strue: ture will be more interdisciplinary than a more deralled wulk packä́t. The types of personnel. involved in the level 4 work package, "Condensate System Design," are as follows:

Mechanical Engineers

Electrical Engineers:

Civil Engineers

Instrumentation Engineers

Stress Analysis Specialists

Piping Designers

Draftsmen

Specification Writers

Not until. the sixth level is reached is the responsibility defined to an individual. A piping supervisor is, for example, responsible for a flow sheet drawing. The work breakdown structure can illustrate to an engineering specialist, who is highly qualified but limited in range of expertise, exactly where his work fits in the overall project. It also shows him the impact of his design on closely related design areas. 
In effect, the work breakdown structure is a working tool for all project personnel.

\section{3 .2 Budget}

Development of the work breakdown structure is the proposed method for attaining project definition. How can this tool be used in quantitative management? It tells what work has to be done and offers various levels of detail for describing the work. By estimating the cost of completing each work package, the manager can state in quantitative terms (dollars, manhours, etc.) how much work has to be done by the project.

Assume that the Power Plant Manager has requested a manhour estimate from his project engineer. The engineering project organization is charted in Figure 1:3. Traditionally, the chief engineer from each discipline would be asked for an estimate of the engineering cost for his area of responsibility. The chief mechanical engineer, for instance, can classify his responsibility into two categories: drawings and nondrawings. The drawings are the end products of mechanical and piping design. The non-drawing activities include conceptual system designs and equipment specification. Based on past experience, he knows about how many drawings will be required to design a power plant of a particular size, and he has relained manhour data for each type of drawing. He also knows that in the past his non-drawing manhours have been a certaln percentage of his total mechanical design effort. With the above data, he can estimate the total manhours for this design and, 


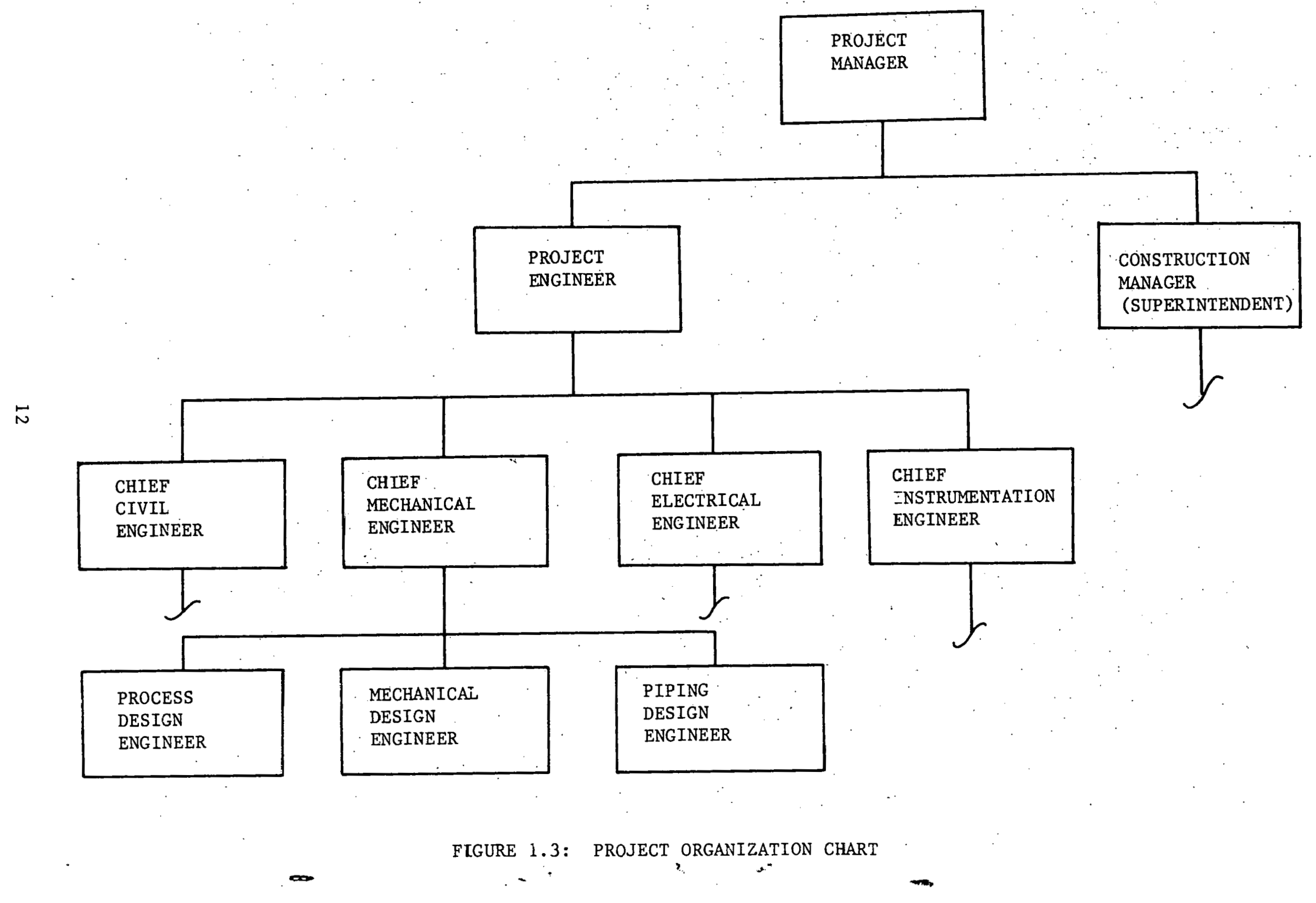


based on previous experience can allocate those manhours among the. specialty personnel who work for him (pipe designers, process systems engineers, tank and vessel designers, etc.). Using historical data, the engineering estimate is quickly compiled and held within acceptable tolerance for establishing a preliminary budget.

A more exacting method for obtaining a manhour budget is proposed as follows:

Step 1. Develop a work breakdown structure.

Step 2. Estimate the manhours and personnel required to complete each work package at the most detailed level (level 6 of Figure 1.2).

Step 3. By summing the estimates of the detailed work packages one level lower, obtain an estimate for the work packages at each level of the work breakdown structure.

Step 4. Compare the engineering estimate achieved by using the work breakdown structure with that obtained using historical data, and check for significant deviations between the two èstimates.

Step 1 forces a comprehensive study of the project scope of work. Step 2 enables the engineer or one of his supervisors to estimate the manhours required to complete a tangible product of design, such as a spectfic group of drawings or an analysis of a specific system. "Step 3 allows a summarization for the benefit of those who do not require the work activity detail of level 6 . Summarization of the manhour estimate at levels 3 or 4 points out the major areas of management concentration 
for the project. Step 4 verifies that the estimate is reasonable, or shows that it is above or below the average job of that size.

Applying an estimate to a work breakdown structure is illustrated by Figure 1.4. In Figure 1.4, the responsibility for three work packages is divided among three chlef engineers, each in a different discipline. A further refinement of responsibility can be obtained by adding a succeeding level to the work breakdown structure. By subdividing the work packages into specific tasks, the job can be defined and budgeted in greater detail. For instance, the chief mechanical engineer can divide his budget among his more speclalized supervisors in terms of the work packages of level 5 (Figure 1.5). Applying the estimate to the work package is a good test to see if the detailed level of the work breakdown structure is sufficient for job control. If a work package must be subdivided to obtain a good estimate, then the subdiviston is necessary for job control.

Using the work breakdown structure as an estimating basis enables specific documentation of the scope of the work to be performed under the engineering contract and provides a direct tie of that scope of work to the estimated cost. Subsequent changes to the work scope are inevitable and are brought about by the client, design decisions, economics, equipment selection, regulatory requirements, and site conditions. Such changes can be documented readily by modifying or adding to the work breakdown structure and by assessing the cost of the modified or additional work packages. At all times, a client can be made aware of how his design money is being spent and of all deviations from the initial estimate. 
FIGURE 1.4: ESTIMATE DEVELOPMENT WITH A WORK BREAKDOWN STRUCTURE

(Chief Discipline Responsibility)

"X" INDICATES PARTICIPATION IN DESIGN EFFORT

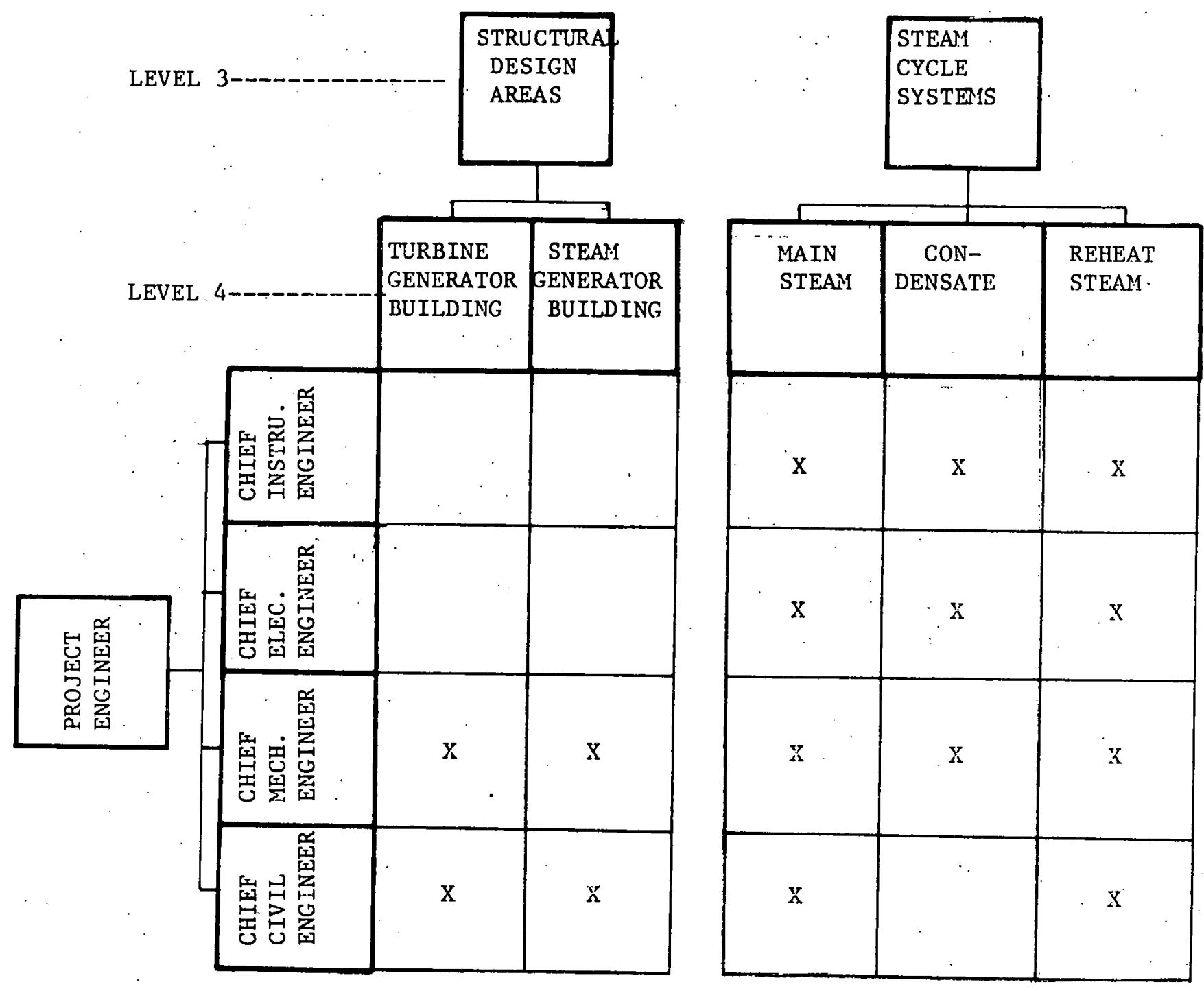


FIGURE 1.5: ESTIMATE DEVELOPMENT WITH A WORK BREAKDOWN STRUCTURE

$$
\text { (Design Engineer Responsibility) }
$$

"X" INDICATES PARTICIPATION

IN DESIGN EFFORT
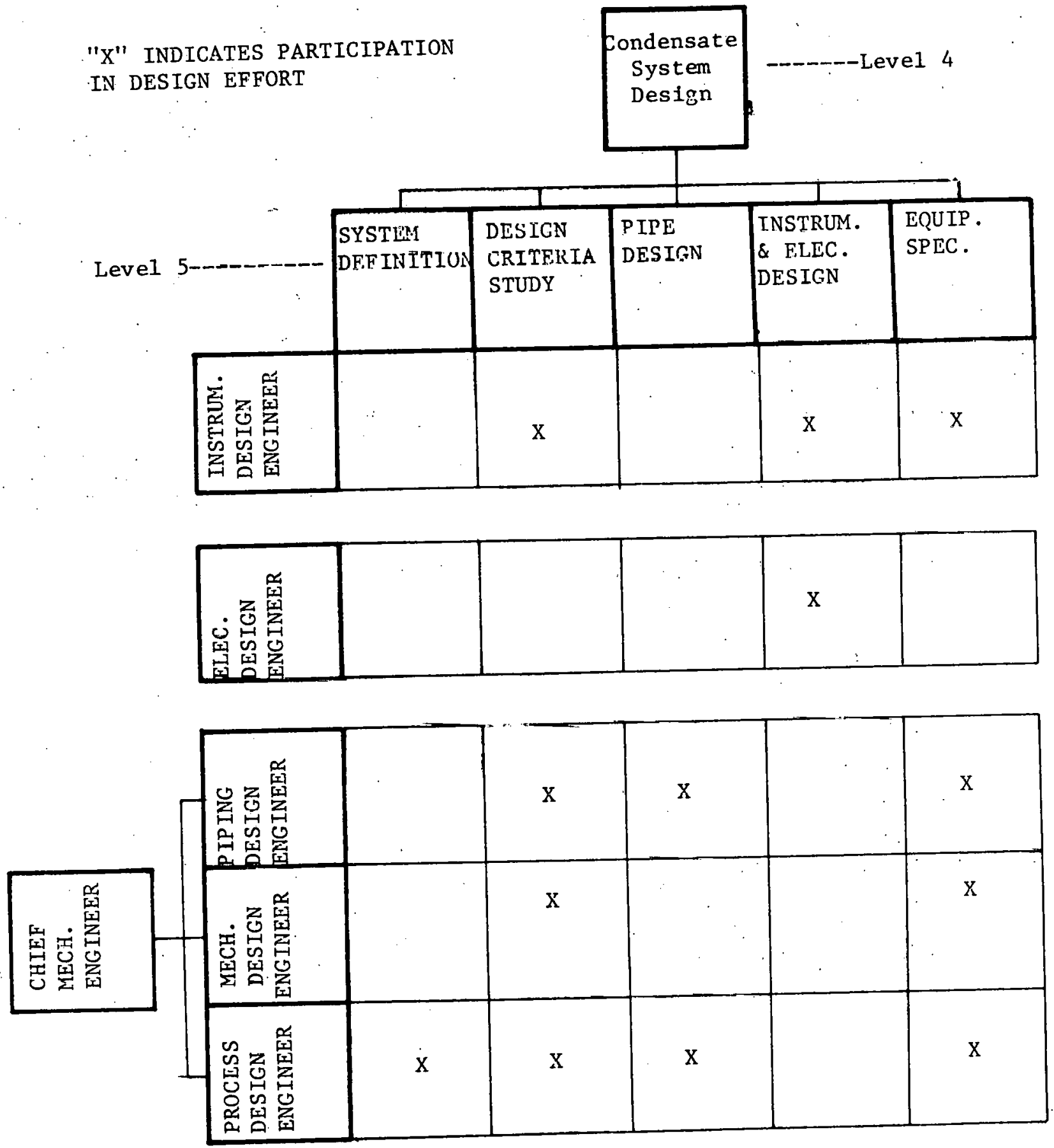
By analyzing such a change on a design system basis, the total project cost of a change in work scope can be more accurately determined. The project engineer or project manager may find that the systems analysis of project cost is an efficient means of conveying to a client that an additional one thousand dollars spent in design might result in several thousand dollars savings in construction and operation. Thus, the work breakdown structure and the estimate can become a communication medium between the client and the engineer, and provide a potential means of involving the client in engineering decisions. This promotes a good working relationship between the client and englneer, which results in better plant design and mutual satisfaction.

The estimate for the cost of engineering is normally reviewed by both the project manager and the client. After necessary adjustments are made and approvals are obtained, a manhour budget can be established, based on the estimate. Then, the project is well defined in terms of what and how much work has to be done.

\subsubsection{Schedule}

The next component of the control system is the schedule. Its purpose is to tell when the work has to be done in order to meet the required project completion date. (It is assumed that a realistic project completion date has been previously accepted by both the engineer and the client.) The description of the project phases in Section 1.2 presents an overview of the project schedule. The phases are reviewed as follows: 
1. Proposal

2. Preliminary Engineering

3. Definitive Engineering

4. Construction

5. Start-Up

The necessity for deta1led planning of each project phase is based on the time overlaps between phases, typical of a multiphase project in general, and a power plant project in particular. The performance during each phase depènds on the sueccooful completinn of work in the preceding phase. For example, among other activities in the preliminary engineering phase, the steam-generator (boiler) and the turbine-generator . . are purchased. These major purchases establish the basis for the power : plant general arrangement and for detailed design of the steam-turbine piping systems.

The engineering schedule includes the preliminary engineer ing and definitive engineering phases. A primary objective of scheduling engineering is to efficiently support the construction phase. Schedule development normally begins early in the project by establishing key events, indicating completion of significant amounts of work. Parameters set for the engineering schedule are normally construction start dates for which engineering drawings, plant equipment, and construction materials are required. The project engineer should establish target dates for key events within engineering which would assure compliance with the construction start activities. Traditionally, an engineering supervisor of each discipline might be asked to schedule his drawing production 
and equipment procurement in accordance with given target dates. : The engineer can then predict his manpower requirements over the life of the project. For this, he relies on previous experience and historical data which he has collected in the past." Like the estimate that is based entirely on historical data, the schedule is accepted as reasonable, and is checked against the key event dates which were established by management.

Separate scheduling efforts by each engineering discipline can, however, lead to problems in project design coordination. For instance, as in Figure 1.6, the chief civil engineer schedules his foundation design and drafting based on a preliminary construction schedule. In a similar fashion, the chief mechanical engineer schedules his plant equipment purchases based on the construction installation schedule. In the simple example illustrated by Figure 1.6, the mechanical equipment fabrication drawings (from the manufacturer) are needed by the civil engineer to design the foundations, but the purchase of equipment is scheduled too late by the mechanical engineer to accommodate the need. If the design schedule is not satisfied, neither is the construction schedule. Thus, the situation may result in a more costly construction sequence. A systematic method is now described which is intended to be used as a tool to promote interdisciplinary communication while scheduling engineering design.

The proposed technique of scheduling utilizes a multi-disciplined effort and is based on the work breakdown structure previously developed. A1so, certain construction schedule parameters must be determined, to 


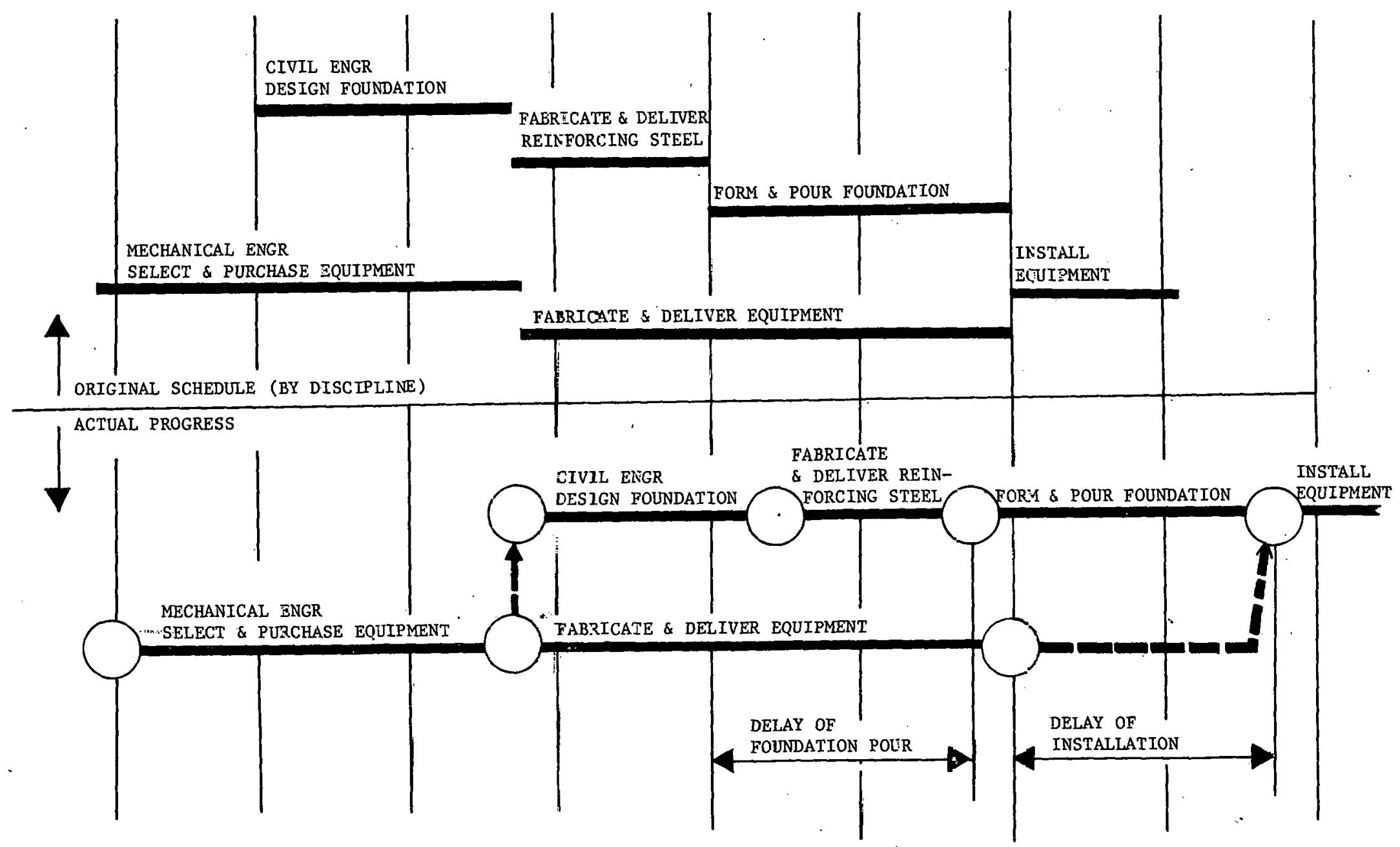

FIGURE 1.6: INDIVIDUAL DISCIPLINE SCHEDULING PROBLEMS 
include:

1. Project completion date

2. Required start of construction

3. Start and completion dates of major construction activities. The steps followed by the scheduling engineer are as follows:

Step 1. Select an appropriate level of the work breakdown structure to schedule engineering. The detail level selected should tangibly describe design work packages. From Figure 1.4, level 4 is selected because it is the highest (most summarized) level which defines a single end-product of engineering. Work packages at level 4 are design system oriented.

Step 2. For each work package at the level selected in Step 1, develop a logical plan to engineer that work package. The planning logic should be that of the chief engineer assigned to that work package, perhaps, compiled by a scheduling specialist. Planning activities will be derived from a more detailed level of the work breakdown structure. For example, the summary level for scheduling has been defined as leve1 4. In Figure 1.7, a planning network has been constructed from level 5 work packages, which become planning activities. Precedence relationships are defined by the logical arrows in the drawing,

Step 3. Determine the precedence relationships between the summary level work packages. The execution of each level 4 work 


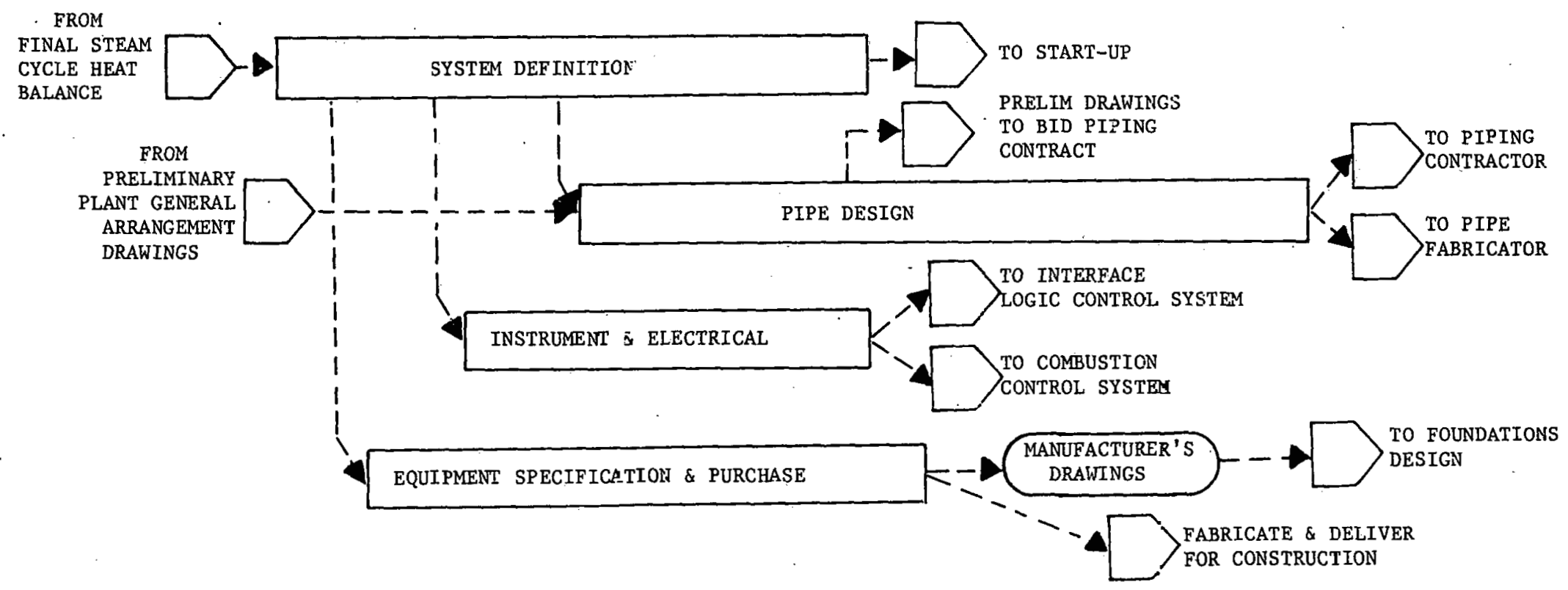

FIGURE 1.7: CONDENSATE SYSTEM PLANNING NETWORK

DENOTES AN INPUT TO OR OUTPUT FROM ANOTHER WORK PACKAGE 
package has a logical plan represented by a precedence network as in Figure 1.7. For each activity in the network, determine what inputs are required to accomplish the work and what happens to the end products (drawings, design data, equipment selection) generated by engineering for the work package. The inter-work package relationship is illustrated in Figure 1.7 .

Step 4. From the precedence relationships determined in Step 3, consider all outputs from engineering to construction. A required date for each engineering-construction interface is derived from the "preliminary" construction schedule.

Step 5: Apply all "fixed" durations (predicted elapsed time) to each of the planning activities. Perhaps the most prevalent example of a "fixed" duration is the time required for a manufacturer to fabricate an item of equipment (such as a pump). Such an elapsed time cannot be altered except through expensive expediting.

Step 6. Construct a time-scaled chart (either Gantt or network) at the summary level determined in Step. 1 (level 4 in the example). Use more detail if necessary to show the relationships derived in step 3: Allow for a reasonable elapsedtime duration for activities not having a "fixed" duration."

*Drawing a time-scaled precedence network is not an easy task. It is not suggested that this time-scaled drawing be a totally encompassing diagram. For this reason, the summary level is used whenever possible. The drawing, however, will serve several purposes, since it: (continued next page) 
Step 7. Determine "variable" activity durations (activities which may be expedited by project action) within the date parameters set by the time-scaled drawing.

Step 8. Determine scheduled start and completion dates for each activity of each level 4 network developed in Step 2.

Step 9. Allocate resources to the schedule by assigning the engineering manhour estimate for each work package, by discipline, to each activity, and distributing the allocated manhours over the elapsed time of each activity. A manpower utilization schedule for each engineering discipline can be developed by summing manhour requirements per day, week, or month of the project duration. Figure 1.8 shows the relationship between the budget, schedule, and resource allocation.

Actually steps $1-9$ are just the beginning of schedullng a project. The schedule changes continuously as engineering progress is realized and as the scope of construction becomes better defined. The "preliminary" construction schedule is derived without definitive design drawings and is based only on past experience and limited site knowledge. Inevitably, the construction plan will be altered, and new priorities will result for engineering. It is imperative, however, that throughout the life of the

a) provides a preliminary overview of the engineering schedule;

b) points out obvious scheduling problems immediately;

c) provides a communication media through which each project member may examine the preliminary schedule; and

d) helps determine "varlable" activity durations required to meet the schedule. 
project, the project manager, project engineer, chief engineers of separate disciplines, and supervisors have an intelligent means of predicting when the work has to be done, and how many men will be required in the succeeding months.

The schedule becomes the tool for executing the scope of work. Changes to the scope of work should be reflected by modifying the schedule. This is done systematically by revising the network activities, adjusting start and completion dates, and allocating resources for affected work packages. The modular technique of developing a small network for each design system (identified by a leve1 4 work package) enables easy segregation of schedule. revisions. The schedule is used to monitor progress by replacing the scheduled start and completion dates with actual dates as activities are executed. Each time such updating is done, the dates of the remaining activity schedule must be adjusted to reflect the actual dates realized to date. If completion dates fall behind schedule, succeeding activities' durations must be shortened and/or planning logic must be revișed in order to meet the project completion date. Computer scheduling programs as described in Chapter III are available and allow efficient updating and progress documentation.

The resource utilization schedule becomes the baseline for measuring progress in terms of cost (in manhours). Each time a schedule update is made, actual resource usage should be recorded against each work package which was completed or is in progress. For each work package in progress, an estimate of manhours required to complete that work package should be 
made. Then the percent complete of any work package is equal to the (actual to date manhours) divided by (actual to date + estimate to complete manhours). Percent complete can be calculated for any summary level of the work breakdown structure. Also, by summarizing actual and estimated manhours for each engineering discipline, percent complete can be calculated for civil, mechanical, and electrical engineering, etc. Resource utilization data are used in project evaluation as explained in Section 1.3.5.

\subsubsection{Integrated Contro1 System}

The control system components have been defined as follows:

1. Project definition -- An outline of work that has to be done by the project in the form of a work breakdown structure.

2. Budget -- Derived from an estimate of each work package in the wnrk breakdown structure, an approved allocation of resources (dollars, manhours, etc.) to the project.

3. Schedule -- Based on a logical sequence of work packages of the work breakdown structure and on the allocated budget, a prediction of when each work package will be started and completed, and a required distribution of resources over the life of the project. These three components, when used together, become a comprehensive system for management control. Figure 1.8 illustrates the Incentelalionshipo of the components. Within the system, the work is defined, budgeted, and scheduled. From the resource utilization schedule, a cash flow prediction is derived. 


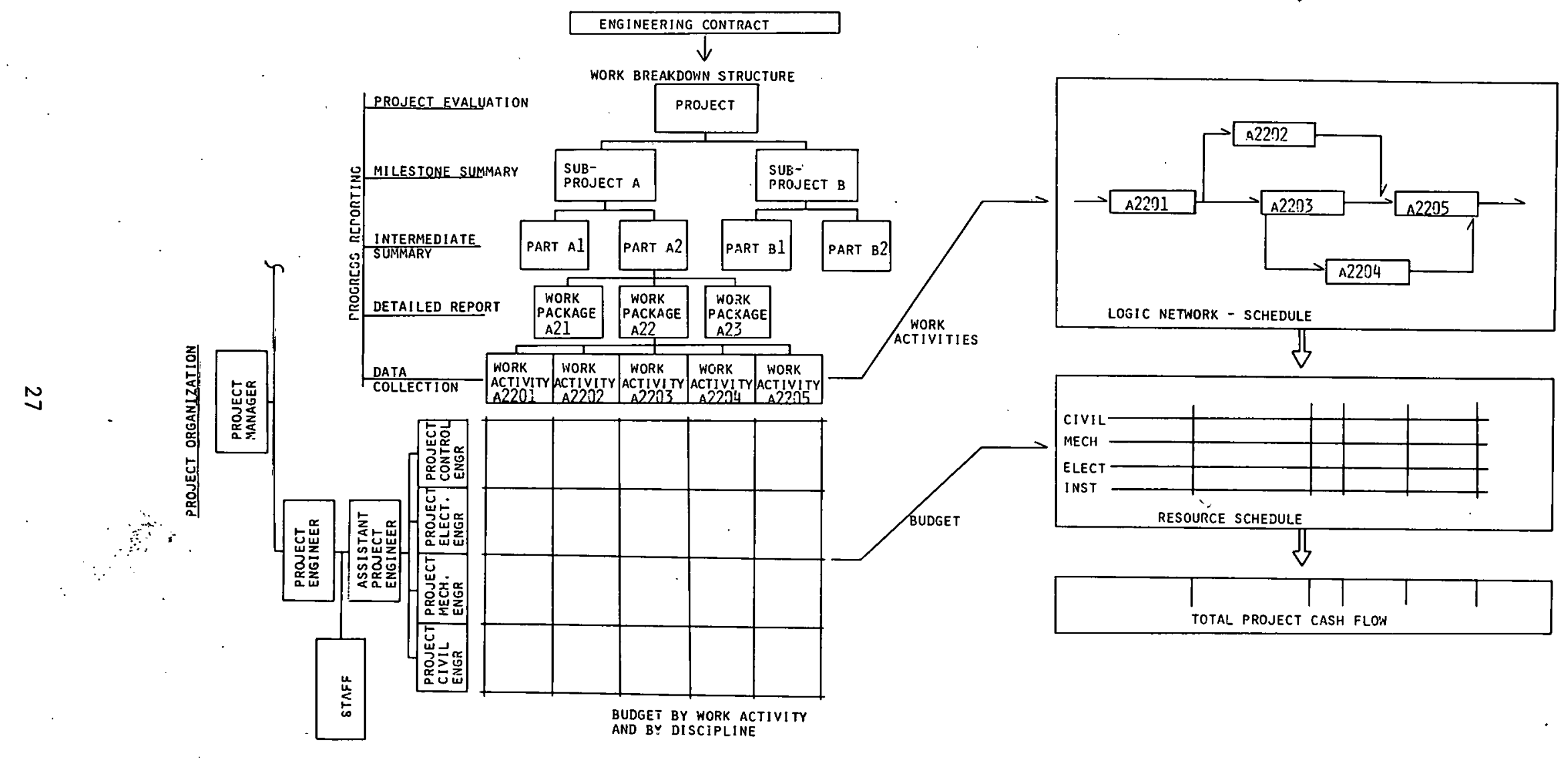

FIGURE 1.8: MANAGEMENT SYSTEM FOR PROJECT CONTROL 
As engineering progresses, the scope of work becomes more refined and is almost always modified. Changes to the work definition enter the system through the work breakdown structure. Then, the budget and schedule are adjusted accordingly. Revisions to schedule are continuously considered. The most significant schedule revisions impact the budget. For instance, expediting the work can result in a higher cost (overtime, temporary job-shop assistance, etc.). Sometimes a rigid schedule causes additions to the work definition. The schedule can dictate that mutually exclusive design alternatives be completely engineered with equipment purchased prior to the selection of the final alternative. In this situation, the schedule is used to determine how much parallel design effort is necessary in order to assure operation date compliance. Then, the additional work is factored into the work breakdown structure, budgeted, and scheduled like any other scope of work modification. When analyzing a design alternative, the impact to the project can be traced from initial introduction through construction and start-up. In short, the impact on cash flow of any proposed action can be presented to a client.

Changes to project scope deserve special attention because of their cumulative impact on total project evaluation. Changes to project scope are changes in contractual commitment, and such changes almost always require budget and schedule adjustments. To effectively control the project, the project manager and/or project engineer must document and carry out all scope additions or deletions. A good client-engineer relationship depends on timely notification of budget and schedule 
adjustments resulting from scope changes. With a large engineering budget (100,000-1,000,000 manhours), documenting relatively small changes to scope is easily neglected. However, the complexity of an engineering project of large magnitude virtually prohibits initial work definition which is $100 \%$ complete. It is for this reason that the project scope should be documented as early in the project as possible in order to formulate a basis for potential scope, budget, and schedule adjustments. If changes to scope, along with their impacts to budget and schedule, are documented and relayed to the client throughout the life of the project, there will be no surprises of budget overrun or late schedule. For project financing purposes, the client must be allowed to evaluate trends in total project cost which emanate from changes of eng ineering scope.

Implementation of the management system as a supervisory tool depends on the effectiveness of the schedule. Planning logic must be correct, and work activities must be in sufficient detail to control the project. The schedule must be a comprehensive representation of the scope of work for total project control. Furthermore, a change in project scope should be reflected by an updated schedule, as should be all problems associated with the work in progress. If scope and budget are both included in the schedule, then it follows that the project can be controlled, monitored, and analyzed on the basis of the schedule. Although the work breakdown structure and the budget may be used separately as valuable management tools, the proposed system implementation depends on a good schedule. 


\subsubsection{Project Evaluation}

When work is in progress, and progress is reported against the schedule, then project management and the client can evaluate the current status of the project with respect to the current definition. The last phrase is underlined because it points out an important benefit from implementing this management system: effective progress evaluation. Management effectiveness depends on the ability to pinpoint current project status with respect to the current project definition. The system provides the baseline for evaluating progress. Questions to be answered are as follows:

1. How much work has been scheduled to date?

2. How much work has been done to date?

3. What is the budget for the work done to date?

4. What has been the actual cost of the work to date?

The management system answers questlous nuwles 1 and 3 . Numbers 2 and 4 are answered by collecting progress data with regard to the schedule and the budget to complete the project as introduced in Section 1.3.3.

For the best results in project evaluation, progress data should be collected for the most detailed work packages of the work breakdown structure. Ideal1y, these work packages would be the activities in the schedule which provide the basis for resource allocation. Accurate data collection is extremely important and it must be emphasized that the cost of performing each activity must be documented on a regular basis (week1y periods at minimum). Section 1.3 .3 indicated that an estimate to complete each work package must be obtained for all activities 
in progress for the following reasons:

1. It enables a percent complete measurement of the activity or work package based on objective data (as opposed to estimating percent complete directly), where, $\%$ complete $=\frac{\text { cost to date (manhours) }}{\text { total expected cost (manhours) }}$

2. It provides a current projection of manhour totals which must be applied to the updated schedule.

Progress reporting data may be summarized at any level of the work breakdown structure, by engineering discipline. Figure 1.8 illustrates possible report summary levels. The information, listed below, is useful in evaluating a project:

1. Actual vs. Scheduled Percent Complete of Work

2. Actual vs. Budgeted Cost of Work Performed

3. Efficiency $=\frac{\text { Budgeted Cost of Work Performed }}{\text { Actual Cost of Work Performed }}$

4.. Schedule Compliance Measurement $=\frac{\text { Actual } \% \text { Complete of Work }}{\text { Scheduled \% Complete of Work }}$

5. Total Project Cost Trend $=$ Total Budget $\div$ Efficiency

6. Percent Complete (Trended) $=\frac{\text { Cost to Date (Manhours) }}{\text { Total Project Cost Trend (Manhours) }}$

7. Total Project Duration Trend $=\frac{\text { Schedule Duration }}{\text { Schedule Compliance Measurement }}$ The evaluation components should be examined carefully. The actual percent complete used in the Item 1 comparison is not the same as percent complete of trend in Item 6 . The actual percent complete is based on the following:

Total projected cost $=($ actual cost to date $)+($ estimated cost to complete activities in progress) + (budgeted cost for activities not started). 
The percent complete (trended) is based on total project cost

$$
\underline{\text { trend }}=(\text { total budget }) \div(\text { efficiency }) \text {. }
$$

If the efficiency is less than 1.0 , the total project cost trend provides an expected upper bound on the total cost. The total project cost provides that cost which is still within reason to obtain, where future activities are unhiased by current efficiency. Early in the project, the manager might place more confidence in the unbiased calculation. Huwever, latar in the project, the trend calculation will become more accurate.

How does the project manager use the evaluation as a management tool? First he examines the trends. Will the project finish within budget; if not, how many weeks behind or ahead of schedule is expected? He might then examine the "Milestone Summary" evaluation (Figure 1.3) and find that out of ten milestone work packages, only one is demonstrating poor performance. The manager can find the root of the problem by tracing it through the work breakdown structure to the most datailed. work package without having to review the total evaluation at that level of detail. Now he can become involved in solving the problem at a greater degree of detail without having to manage the project at that level of detail.

The system just described offers the ability to monitor and control, in a quantitative manner, the budget and schedule. Through the work breakdown structure, it offers a means of comprehensive project definttion. Through its evaluation technique, the system offers management by exception, enhancing the qualitative aspects of management. The management system provides a tool designed to help maximize total management effectiveness for time and budget constrained projects. 


\subsection{Implementation}

An example of a work breakdown structure for the engineering of a typical power plant is given in this section. In the example, the project manager wants to study the scope of the condenser cooling water design. He is especially interested in the condenser cooling circulating water system. The activities required to design the system are extracted from the work breakdown structure. Also provided is a list of other systems, under different categories of the work breakdown structure, which interface the condenser cooling water mechanical systems.

Following the work breakdown structure is a detailed planning logic diagram which would assist in scheduling the work activities and required manpower to complete the condenser cooling circulating water system design:

The complexity of incorporating two to five hundred logical planning diagrams into a meaningful activities schedule is beyond the scope of the time-scaled "PERT-chart" or Gantt (Bar) chart. Commercial computer packages are available which would adequately maintain the entire management system to include work breakdown structure, budget, schedule, and progress reporting. Most of the scheduling systems are based on Critical Path Method (CPM) or Program Evaluation and Review Technique (PERT). The key to effective computer set-up of the management system is to develop a numbering or coding system for the work activities which is a representation of the work breakdown structure. To illustrate this, reference is made to the work breakdown structure example. The numbers on each work 
package are organized in such a manner that the first digit is representative of "Engineering," the second digit stands for the major category within Engineering, and the third and fourth digits make up the "System" number. The sequential sorting capability of the computer enables reporting on any category or summary level of the work breakdown structure such as the "Condenser Cooling Circulating Water System." By the same type of coding system; the responsibility structure can be created by computer sorting. In fact, the entire system for project control; as illustrated in Figure 1.8, can be realized using a scheduling and resource allocation computer package. 


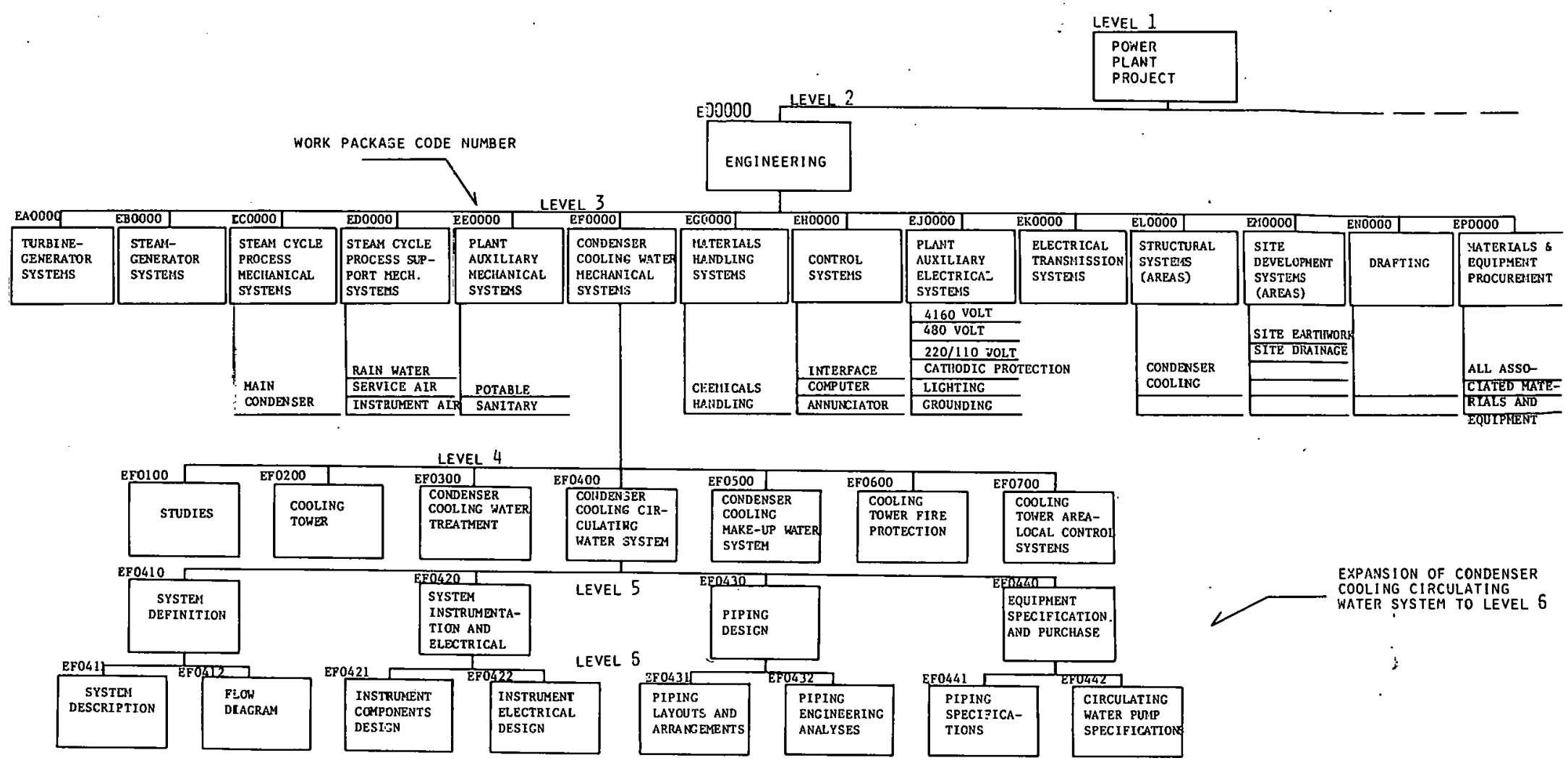

FIGURE 1.9: POWER PLANT PROJECT ENGINEERING WORK BREAKDOWN STRUCTURE 


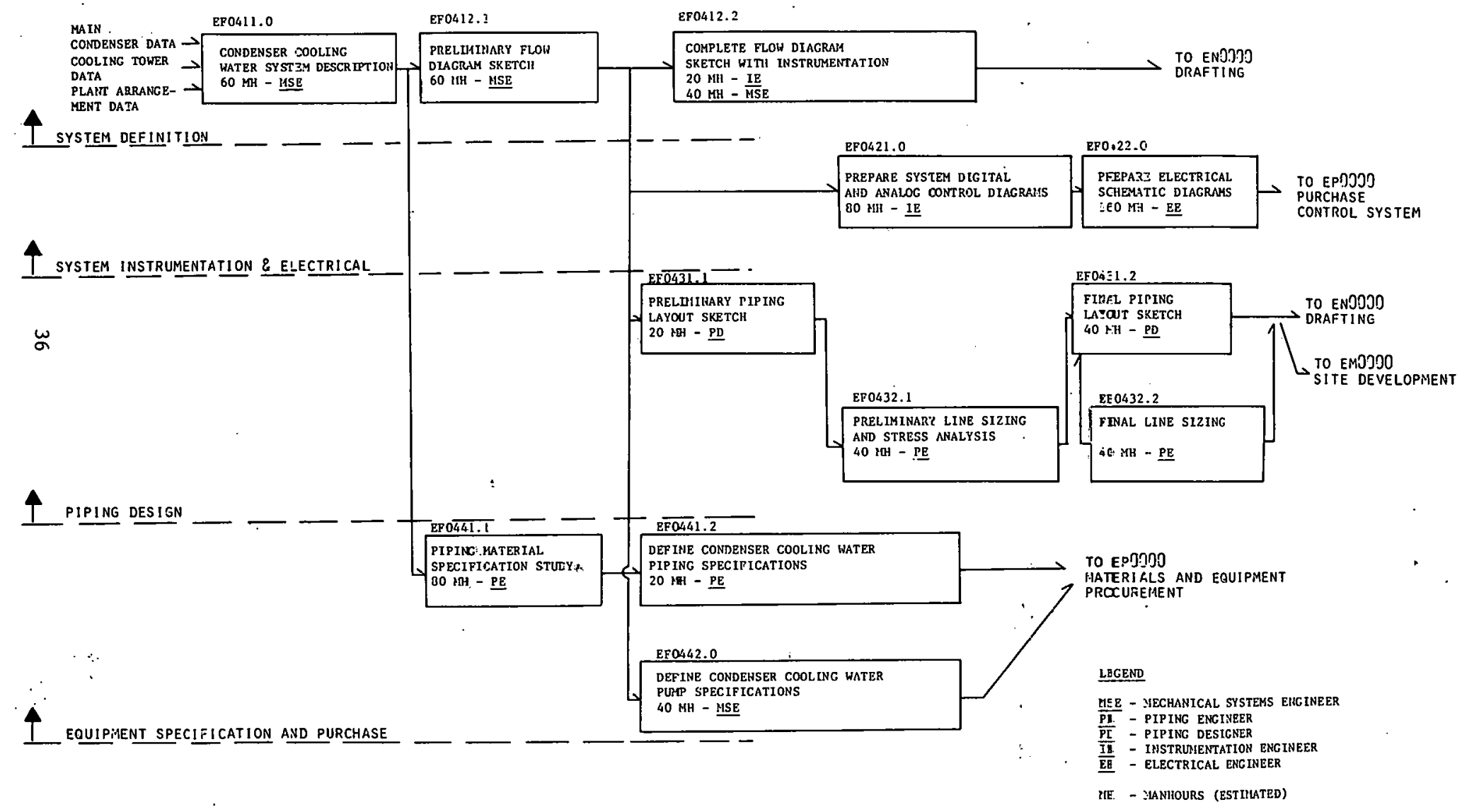

FIGURE 1.10: CONLENSER COOLING CIRCULATING WATER SYSTEM

PLANNING LOGIC DIAGRAM

$\omega_{\alpha}$ 
CHAPTER II

Construction Planning and Scheduling

\subsection{Introduction}

The work breakdown structure (WBS) used to organize activity during the ensineering phase provides the framework for scheduling during the engineering and construction phases. In fact, both engineering and construction schedules tend to interact as design detail progresses and are greatly impacted by the work breakdown procedure. At the outset of a project a milestone event schedule is established. This is a very high level schedule and is designed to indicate when major events : such as the completion of the Preliminary Safety Analysis Report (PSAR), completion of major project elements (e.g., completion of turbine building), and plant start-up are to occur. A typical milestone event schedule for a nuclear plant is shown in Figure 2.1. Based on the milestone event. schedule, design requirements and dates for availability of design documentation can be established. These dates in conjuction with WBS approach generate a design schedule. The engineering and design schedule typically consists at any point in time of several thousand design activities. The design schedule, in turn, becomes the basis for procurement and construction schedules: The construction schedule which derives from the design schedule usually consists of from 6 to 8 thousand activities and is commonly referred to as the DEFINITIVE SCHEDULE. There is continual interaction between the engineering-design, the procurement, and the construction schedules and delays in one inevitably feed back and lead to changes in 


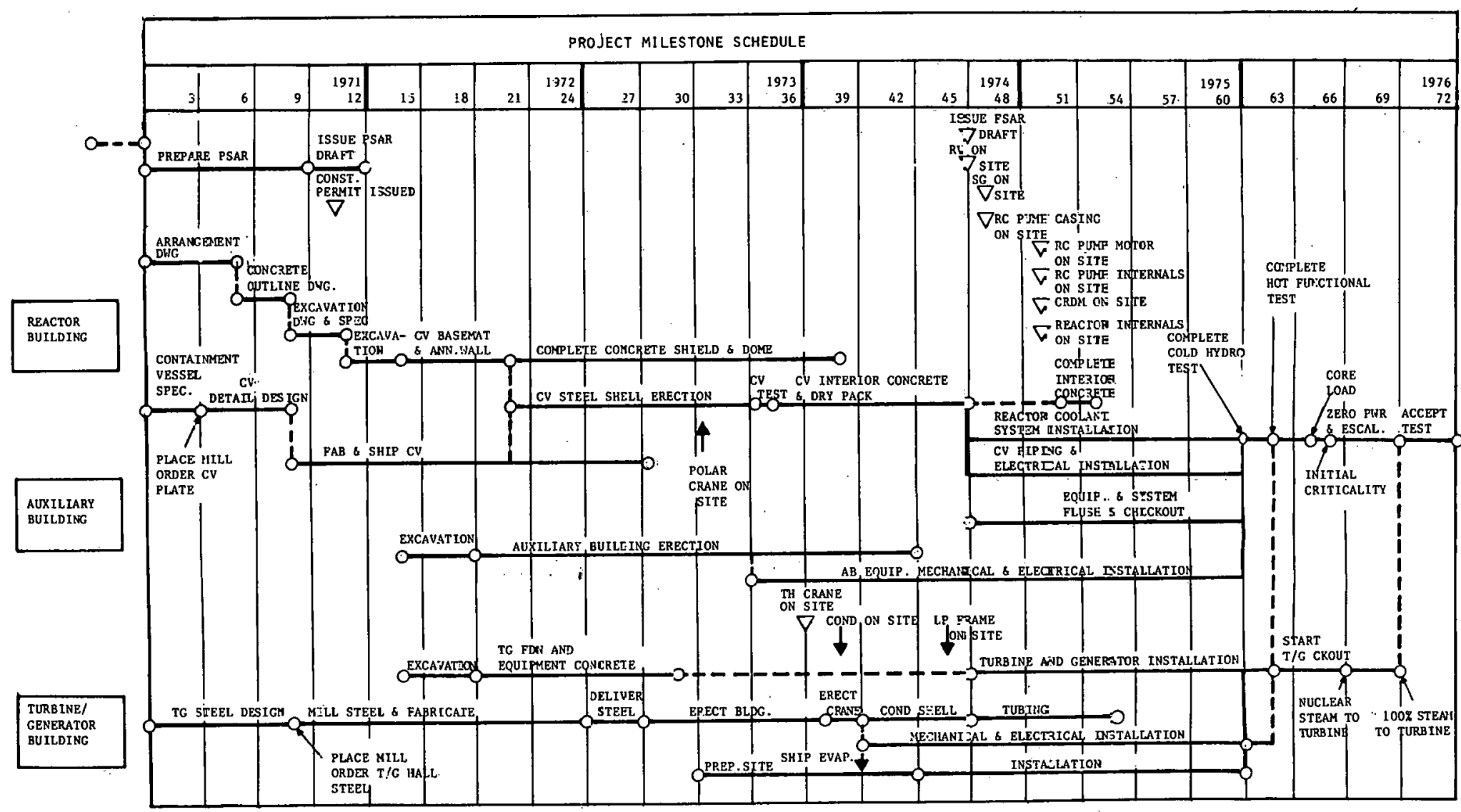

FIGURE 2.1: PROJECT MILESTONE SCHEDULE 
the others. This dynamic relationship between the schedules means that the details of these schedules are in a constant state of flux. This leads to a continuing updating requirement and maintenance of large data structures. The combination of engineering/design, procurement, and construction schedules can be referred to as the Integrated Project Schedule (IPS) and implies the generation, control, and statusing of massive amounts of information. As design and construction progress a start-up sequence for bringing the plant on line is also established and results in the definition of a start-up schedule. This schedule is also integrated into the IPS. The interaction of these schedules is shown conceptually in Venn diagram format in Figure 2.2.

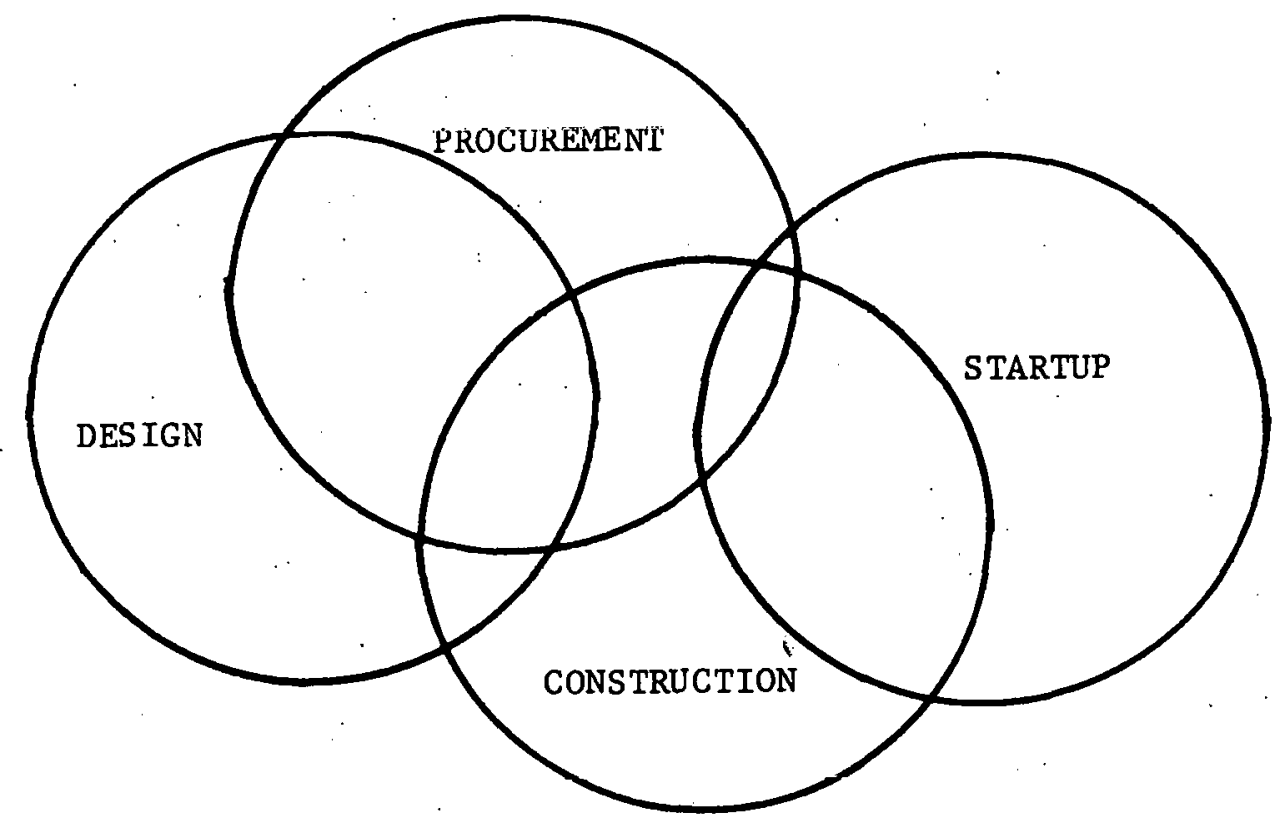

FIGURE 2.2: CONCEPTUAL REPRESENTATION OF INTEGRATED PROJECT SCHEDULE (IPS) 
Schedules in excess of 30,000 activities have been developed in an attempt to integrate these complementary phases. . In practice, however, this integration is usually in concept only and interflow of data is accomplished manually. Southern Company Services, for example, maintains an engineering schedule for each project using the Project 2 network processor (see Chapter 3), while a separate construction schedule is maintained using a separate schedule proccosor. Interittion betwcen these two schedules is accomplished manually.

Since these schedules are in a dynamic state of change and revision, shorter range construction schedules for control over an immediate time horizon such as a quarter or month must be derived from the definitive schedule. This leads to the concept of scheduling levels with the milestone schedules at Leve1 1 , the definitive schedule at level 2 , and shorter range schedules at levels 3 and below. These lower level detail schedules can take the form of networks or detailed bar charts. As wi.1.1 be explained in a later section, Daniel International Corporation utilizes an Intermediate Range Bar Chart Schedule (IRBCS) at level 3, covering a three-month period, a Short Range Bar Chart Schedule (SRBCS) at level 4, which is utilized for weekly schedule purposes, and a Work Order concept at level 5 which defines individual work packages to be assigned to field crews for accomplishment. ${ }^{* *}$. The use of milestone and definitive schedules to controi construction at levels 1 and 2 io falibly gtandard throughout

\footnotetext{
* Such a network was developed at the Hatch II plant of Georgia Power to integrate the construction and start-up schedules using the IMPERT schedule processor. ** See footnote next page.
} 
the industry: The definition of level 3 and below varles from constructor to constructor. Stone and Webster uses a slightly different system as shown in Table 2.1. The table indicates four levels of "Basic Planning and Control Documents." The use of "levels" to establish measures for controlling construction also implies a structure for data collection and aggregation for reporting purposes. In the Stone and Webster system, the lowest level of definition and, therefore, the first point of data acquisition, is at leve1 4. Data aggregated at level 4 feeds the fragnet schedules and other reports at level 3. A sinilar process allows aggregation of information at levels 2 and 1 as necessary.

In the following sections, planning and scheduling systems either presently being utilized or projected for use will be discussed. The scheduling orientation of the systems varies according to the organizational viewpoint of the support organization. The use of the planning and scheduling function to support construction activity predominates in the Daniel and Bechtel systems. The utility viewpoint emphasizes. control of a number of functions, as reflected by the Commonwealth Edison, Duke, TVA, and Southern Company Services systems. The system used by Westinghouse emphasizes the vendor's viewpoint in production scheduling.

**The use of levels to define construction level detail should not be confused with the definition of levels of work breakdown structure presented in Chapter I. In both cases the higher the level, the greater the detail. However, no attempt is made to cause level 4 of the engineering WBS to link with level 4 construction schedules in the field. 
Levels of

Planning \& Control

Leve1 1

Leve1 2

Level 3

Leve1 4
Basic Documents

Project Summary Network

Area or Discipline Networko

Engineering and Procurement Schedule Drawing Schedule Fragnets

Material Control Reports
Description and Use

Summary of entire project plan and schedule. Used by Project Manager when reporting schedule status to client.

Semi-detailed summary of eash huilding or area/major. discipline. Used by Project Engineer and Construction Manager to provido overall project visibility to supervisors.

Detailed plan and schedules for each discipline or craft. Used by supervisors to control the production of work.

Detailed listing of deliverable material and equipment. Used by supervisors to identify and account for deliverable items.

Input froin supervisuss.

TABLE 2.1: BASIC PLANNING AND CONTROL DOCUMENTS 


\subsection{Daniel Planning and Scheduling System}

The following information is based on interviews and materials developed during visits to the Daniel Callaway project site. The project is being constructed for Union Power and is a Standard Nuclear Unit Power Plant System (SNUPPS) project with design being done by Bechtel Corporation. The levels of planning and scheduling interest and reporting are as follows:

(1) Milestone Summary Schedule level

(2) Project Master CPM (Definitive) Schedule

(3). Intermediate Range Bar Chart (3 month) Schedule

(4) Short Range Bar Chart Schedule

(5) Process Project Work Orders

The Milestone Summary Schedule includes major construction events as we11 as projected pre-operational acceptance, fuel loading, and system start-up dates. The dates are developed jointly by the Construction Manager and the Constructor (i.e., Daniel). This schedule establishes the basic project objectives and provides a basis for high level reporting on construction progress. The schedule is usually maintained in a bar chart format and defines event descriptions and dates as well as major activity descriptions and durations.

The Project Master (Critical Path Method)* Schedule provides the next level of detail below the Milestone Summary Schedule. This network schedule identifles all construction and start-up work as defined in the design

*The Critical Path Method will be referred to as CPM throughout the remainder of this Appendix. 
documentation and shows the logical relationship between all work activities. The interface between the construction network and the design and procurement networks is maintained manually. The ArchitectEngineer is responstble for identifying drawings and releasing them in time to support the construction schedule. At the Callaway project this is accomplished using a Bechtel developed system called CEBUS. The level of detail in this definirfve schedule is expanded as data becomes available. Individual activities are established based on the following criteria:

(1) Physically defined unit of work

(2) Single discipline within a defined area

(3) Management accountability

(4) Compatibility with Cost Code System

(5). Packaging to retain continuity

The total size of this network ranges between 3 and 10 . thousand activities. This schedule provides a basis for the 3 month Intermediate Range Bar Chart Schedule (IRBCS). It also establishes the primary framework within which design, procurement, and test activities must be ultimately coordinated.

This schedule is processed automatically using the computer, The CPM system used at the Callaway job utilizes the PROJACS processor. The following information is required for network specification and is typical of CPM processors in general:

(1) Activity Code and Description

(2) Activity Duration 
(3) Calendar and Work Week Specification

(4) Activity Progress Status

(5) Activity Early Start and Early Finish Information

(6) Activity Late Start and Late Finish Information

(7) Organization Code

(a) Area/Building/Elevation

(b) Organizational Responsibility

(c) Discipline

(d) Account Codes

User reports generated by the system include:

(1) Schedule Reports

(2) Work Status Reports

(3) Exception Reports

(4) Resource Utilization Reports

(5) Schedule Analysis Reports

(6) Milestone Reports

The Intermediate Range Bar Chart Schedule (IRBCS) is used to schedule over a 3 month period. This schedule breaks the CPM activities defined in the Project Master (Definitive) Schedule into controllable, single responsibility work items. The IRBCS is totally derived from the CPM master and is used as a basis for updating the CPM project master schedule. The IRBCS is a manually prepared and updated bar chart. Daniel top level management review the project'status as reflected in the IRBCS on a monthly basis. 
Data utilized in the development of this schedule include:

(1) Work Item Description

(2) Work Item Percent Complete

(3) Projected Work Item Completion Date

(4) Work Item Quantity

(5) Work Item as a percent of total CPM master activity

(6) Quantity Installed to Date

(7) Work Item remaining duration

The Short Range Bar Chart Schedule (SRBCS) is one level of detail below the three month schedule. This schedule serves as the basis for daily and weekly craft meetings. Each task on the schedule is the responsibility of a single foreman who is held accountable for its satisfactory completion. This schedule is prepared and updated manually within the framework established by the IRBCS. This schedule provides a source of data for updating the IRBCS and a basis for field status reporting. Data required for generation of this schedule Includes:

(1) Time Frame covered by SRBCS

(2) Work Zone and Area

(3) Supervisor's Name

(4) Task Description

(5) Assigned Foreman's Name

(6) Average Number of Men Kequired

The Daniel Work Order System is constructed around a Work Order Package which consists of several CPM master schedule activities. The work order package defines a unit which is common to both the Cost 
Accounting system and the Project Master (Definitive).Schedule. This unit provides, a unfform method of monitoring estimates, schedules, drawing releases, material requirements, and Quality Control requirements. Activities within the work order are man-loaded and a composite manhour curve is generated for the package. Actual manhours are collected and plotted against the composite manhour figure. Work order status is updated from the SRBCS. Manhour estimates are generated by the estimating section. A work package release sheet is shown in Figure 2.3. Before a work package can be released the following information must be available:

(1) Statement of work

(2) Project breakdown structure relationship

(3) Budget

(4) Schedule

(5) Design documents

(6) Cost account code

(7) Responsible organization/individual.

The unit of work actually released by the project office is the work package and it is generally released to a functional field organization.

Input information from other organizational units to the following questions must be developed:

(1) Is the material available to start work? -Material Controi/ Quality Control

(2) Are the engineering and vendor drawings available? -Engineering

(3) Is the manpower available? -Construction 
PROGRAM TITLE

TASK TITLE

CHARGE NO.

TASK LEADER ACCEPTED BY

DATE

GROUP OR DEPT. SUPERVISOR APPROVAL DATE

PROGRAM MANAGER AUTHORIZED BY DATE

TASTK :

SCHEDULED START DURATION OF EFFORT DESCRIPTION

END REQUIREMENTS :

BUDGET :

LABOR

HOURS

OTHER DIRECT (MATERIAL, TRAVEL)

WORK PACKAGE COMPLETED:

HOURS EXPENDED

DATE COMPLETED

FIGURE 2.3: WORK PACKAGE RELEASE SHEET 
(4) Is the equipment available? -Construction

(5) Are the procedures avallable? -Quality Control/Quality Assurance, Engineering/Construction QA/QC

(6) Has the budget been established? -Cost Control

(7) When is the activity scheduled to start? Complete? Scheduling?

(8) Have construction prerequisites been completed? -Construction/ Scheduling

(9). Has the rate of progress (budget expenditure) been forecast? Scheduling/Cost Control

During the construction and installation process, there may be * several hundred work packages in process at any particular time. Reports indicating which work package CPM master activities are scheduled to start within the next 90 days as well as exception reports indicating those activities scheduled to start but delayed are generated to support the system.

\subsection{Bechtel Planning and Scheduling Approach}

The Bechtel planning and scheduling philosophy is described in the publication, "Power Plant Construction - Planning and Scheduling Procedures." The concepts outlined in this report are primarily oriented towards scheduling of construction although Bechtel also operates as a design-constructor. The system defines five scheduling functions required to implement a construction control environment:

(1) Development of Project Master Schedule

(2) Development and Maintenance of 3 month schedules 
(3) Preparation of Three Week and Dafly Schedules

(4) Progress Monitoring

(5). Maintenance of Project History

These functions imply three scheduling levels.

In the development of the Project Master Schedule, a central planning group is responsible for establishing consensus between Project Management, Engineering, Procurement, Construction, and StartUp. Based on input from each of these entities, Central Planning prepares a Project Milestone Schedule similar to the one shown in Figure 2.1 which provides the basis for the. Project Scheduling System to be used on site. The Project Master (Definitive) Schedule is derived from the Milestone Schedule. The Project Master Schedule is a network representation of the project and a standard CPM processor such as IMPERT or PMS IV is used for processing of update information and generation of reports. Typical reports include:

(1) Milestone Summary Schedule

(2) Critical Path Print-Out

(3) Procurement Status Report

(4) Bulk Quantity Installation Rates

(5) Preliminary Craft Manpower Curves

(6) Quantity Estimates

(7). Scoped Piping and Instrument Diagrams (P\&IDs)

(8) Start-Up Schedule

(9) Indices (Circuit Schedule; Raceway Schedule, etc.) 
All of the above reports are not produced within the planning and scheduling. function. They are, however, processed by planning and scheduling and become part of the package to be forwarded to the field for use in preparing detailed site schedules.

The field or site team develops a three month projection of work based on the Project Master Schedule. This Three Month Construction Schedule by physical area and system (e.g., Turbine Bullding, System P17) is produced in sufficient detail to support the following site functions:

(1) Procurement

(2) Deta11 Work Sequencing

(3) Subcontract Coordination

The schedule forms the basis for the daily and weekly schedules and is subject to the review of the craft superintendents for verification of durations, logic and manloading. Field engineering is consulted to establish material availability. Utilizing data from the computerized Master Schedule, this schedule is manually developed.

Within the confines of the Three Month Schedule, the area planner develops a detalled level of work logic and durations. In addition, he establishes equipment requirements, shortage lists, as well as holds and restraints for the next three week period. Progress against the Three Week Schedule is reviewed on a daily basis. Both the Daily Schedule and the Three Week Schedule are subject to the review and approval of Field Engineering and Craft Supervision. The Daily Schedule provides the basis for the Daily Status Meeting. Data required for the generation of the three week and daily schedules include: 
(1) Three Month Schedule

(2) Equipment Status

(3) Material Status

(4) Drawing Status

(5) Hold Status

This schedule is manually generated in a form to be utilized at the craft level.

The area planner monftors progress by collecting summarles of installed quantities from Field Engineering. The actual field quantities and manpower figures are compared with the projected values. An evaluation of productivity is avallable utilizing a spread sheet. Initially, spread sheets are prepared by area. Approximately six months prior to system turnover for test, these sheets are recompiled by start-up system. The spread sheet is designed to establish the following information:

(1) Quantity Scheduled per Week

(2) Quantity Installed per Week

(3) Total Quantity Required

(4) Total Installed to Date

(5) Total Received to Date

(6) Quantity Ahead or Behind Schedule to Date

(7) Allowance for Recovery of Schedule by. Adjusting Installation Rates and Manpower

Approximately six weeks prior to system turnover, a "punch" list is developed which includes all remaining construction items. Progress 
Is then monitored on each item individually until the system is conplete for turnover.

Field Engineering is responsible for the accuracy of the quantity estimates and verifies that material has been purchased. The reporting of installed quantities is the responsibility of the Craft superintendent. Records of installed quantities are maintained by Field Engineering. The area planner has the responsibility of advising the Project Office of the effects of schedule delays.

The field planning group has the responsibility for maintenance of project history. This is accomplished by documenting actual progress in terms of an "As-Builtt" Schedule. This schedule is developed using the Project Master Schedule by noting actual durations and "as-built" logic. on this schedule. In addition, the following information together with its impact on schedule is recorded:

(1) Material Delays

(2) Strikes or Shutdowns

(3) Shift work

(4) Extended Work Weeks

(5) Weather Conditions

(6) Engineering Delays

(7) Innovations enhancing productivity

(8) Outside agency delays

This project record is maintained manually by project planning and receives input from Field Supervision, Field Engineering, and the Start-Up group. 


\subsection{Planning/Scheduling - Southern Company Services}

The following notes on the Southern Company Services approach to planning and scheduling of engineering effort were extracted from a series of interviews and notes obtained during a visit to the Birmingham office of Southern Company Services.

\subsubsection{Network Development}

The Design Scheduling group receives a list of "Interface Activities" from the Construction Scheduling group. The early start dates for these activities establish the site required dates for procurement and design information. The design effort is then modeled by about 5000-6000 activities covering the transfer of information within the design effort (rather than the physical products of the design effort - drawings, specs,. etc.). The CPM network is segregated by discipline and covers only the design effort being done at Southern. Vendor design efforrs are Lled to the project network using interface events. The CPM for design is developed independently from the CPM for procurement and the CPM for construction. Each CPM is done using precedence logic. The networks are processed separately using the Project 2 Network Scheduling package. Once processing is complete, interfacing between the two networks is accomplished manually. The design CPM is used to monitor design progress, and prepare variance reports. 


\subsubsection{Develop and Code Resource Estimates}

Manhour estimates for engineering effort are developed describing the work in terms of work packages (see Chapter 1). These work packages are defined both in terms of construction and engineering work elements (engineering $\log 1 \mathrm{c}$ networks and Schedule Activity Codes). There are about 2,500 activities that have estimates associated with them. These estimates can be segregated into drafting and engineering manhours for each of seventeen different disciplines. Actual manhour expenditures are collected by work package and compared to projections.

\subsubsection{Controlling Domestic (Southern) Drawings}

The project planner is responsible for collecting the input sheets listing the specific drawings required from the approprlate design managers: A drawing list is compiled by responsible project engineers. Each drawing has three assoclated dates: The forecast/actual finish date, the required finish date, and the transmittal date. The source of the "required" date is the construction schedule. The source of the "forecast/ actual" date is the design schedule. The drawing file is updated on a per drawing basis.

\subsection{Planning/Scheduling - Duke Power Company}

The following notes on the Duke approach to planning were extracted from a series of notes and interviews obtained during visits to Charlotte and the McGuire Nuclear Station construction site. This information emphasizes the use of the scheduling network as a construction management 
tool. This is in contrast to the previous section on the Southern Company which emphasizes the use of the network in controlling the engineering effort only.

\subsubsection{Long Range Planning}

The project is defined in terms of a list of manageable tasks (systems, structures, 1leusling, ete.). Each tack: for whinh equipment must be procured is identifled in terms of the equipment, quantity, responsibility, and location. The start, finish, and duration of each construction task is identified by the Planning Section in the Construction Division. The start, finish, and duration of the design effort necessary to support the construction effort for each is identified separately by the planning section in the design division. The two estimates are then manually interfaced to form an Integrated Project Schedule (IPS). The IPS provides the basis for coordination of design, procurement, construction, and test schedules.

\subsubsection{Development and Maintenance of Work1ng Level Schedules} -- IPS Level

The primary purpose of the IPS is to coordinate the design and procurement efforts such that the needs of construction are satisfled. Each design task is defined in terms of the following:

(1) Activities - Work on a task by an organization within the scheduled start and complete dates of the task.

(2) Milestone - A specified plece of work that is to be fintshed 
by a scheduled date.

(3) Requirement - A request for information, etc., needed by a organization to support the completion of an activity.

(4) Commitment - A "requirement" turned around and shown to the organization responsible for supplying the information, etc.

The milestones are key events noted over the entire duration of the task. Activities, requirements, and commitments are subordinate to the milestones. Commitment dates are established to identify required issue dates for drawings, purchase orders, and similar documents. Activity and commitment reports are projected on a three (3) month look ahead basis every two (2) months. These reports provide the basis for systematic review, status, potential exception determination, and noting changes. All activities and commitments are updated by those organizations responsible and checked by those organizations establishing the requirements. The scoping and scheduling of work within the activity is left to the discretion of the responsible organization. The completeness of the end product is verified by the receiving organization. Reports generated by the working level schedule Include:

(1) Requirements vs. commitments

(2) Commitment Exception Report

(3) Activity Exception Report

(4) Commitment Critical Items Report 


\subsubsection{Construction Schedule Productivity}

The schedule for site work (at McGuire Nuclear Station for example) is established on an area basis using a start and completion date and a given quantity of work to be performed. The start and completion dates of an "activity" are input to the "MAPS" Program. As used here an activity is a given function on a system within a given area (i.e., piping-fire protection system-auxiliary building). The quantity of work (pipe welds and joints) is established by the site planning and scheduling group. The quantity of work divided by the time avallable equals the required production rate. Actual production rates are monitored against projected production rates on a weekly basis. The required production rate is increased or decreased based on the remaining time available vs. the remaining work to be completed (1.e., a type of line leveling). The required production rate is multiplied by a unit manhour factor and conver led to manning requirements. The schedule is established assuming the availabllity of drawlngs and materials. Exceptions and bottlenecks are handled in the weekly status meetings attended by craft foremen, field engineering, and planning. When a system is $95 \%$ complete, 1 is dropped from the rate tabulation program. Status is then maintained on an item by item basis using a detailed punch 11 st until the system is complete and goes through checkout and flush. 


\subsubsection{Test and Start-Up Schedule}

The test and start-up sequence is modeled using a CPM network to note the interdependencies of the system test sequence, e.g., hydro and functional tests. This logic is prepared by the Construction Planning Group working with dates established by the Operations Group. The Operations Group (Start-Up) uses a status board to note the expected start dates of key test activities and their prerequisite system completions.

\subsection{Planning/Scheduling - TVA}

The following discussion of the TVA approach to planning and scheduling is based on a TVA publication entitled, "Tennessee Valley Authority - OEDC - Project Control" and a series of interviews with planning and scheduling personnel in Knoxville.

\subsubsection{Design Project Control}

The design effort is managed and controlled separately from the construction effort because the structure and flow of work differs. The interface point between the two areas is established at the activity leve1. The first step in initiating a project is the development of Conceptual Studies. Once the need for new capacity has been identified by the Division of Power Resource Planning, the Project Control staff, along with Cost and Estimating sections and the Design Division branches, have the responsibility for examining viable alternatives by comparing designs, schedules, and estimates. Both the desirable and undesirable features of each alternative are noted in a report to upper management 
to assist in final selection.

Once the project go-ahead has been given, a project team is formed within the Division of Engineering Design to control project planning and scheduling. This group identifies various engineering, design and procurement activities required to complete the project. These activities are then broken down into tasks such as preparation of engineering drawings, criteria documents, and procurements. These networks: consist of about 5,000 activities with about 3-4 tasks per activity. Estimates of manhours are prepared for each task and durations are assigned to each activity. Activities are then related logically by determining information prerequisites. The resulting activity networks are then. processed using an in-house program called PC III.

The Network Report is the basis for a series of "Activity Production Reports" where a comparison of actual vs. planned progress is made relative to a reporting period within the schedule (data date). Progress on the design effort is established based on the subjective judgment of the Iine supervision (Division of Design Engineering). These production reports are broken down into ten informational levels that range from complete detail to a three line summary for the entire project. The highest summary level groups design drawings and documents, NSSS, and procurements.

Successive information levels are as follows:
(1) Engineering Organization
(2) Engineering Organization - Discipline*

*This level is used by the Branch Chief, the Project Manager, and the Project Engineer. 
(3) Building or Area

(4) Profect Activities (i.e., groups of drawings)

(5) Drawing/Purchase Order

$(6,7,8)^{\prime}$ Levels reserved from special sorts

(9) Task

An estimate of the manhours required to complete each task is made. The utilization rate is approximated by selecting one of nine curves which is fitted to the task duration.

The "Activity Production Reports" include the following formatted output:

(1) Design Productivity/Bar Chart

(2) Duration Update Report

(3) Activity Production Report

(4) Manhour Exception Report

(5) Trend Analysis Report

\subsubsection{Construction Project Control}

The construction effort, while postdating the design effort, provides the basis for scheduling drawing releases and procurement deliveries. The Division of Construction provides the Initial project schedule which in turn provides the basis for all subsequent scheduling efforts. There Is a Jolnt effort by the project control staff of the Design and Construction Departments to monitor and coordinate work throughout the project development cycle.: 
The construction schedule is prepared through a series of successive iterations. As the vendors are selected for major procured items (NSSS), general arrangement or equipment drawings are prepared by the successful bidder or by the Design Division (TVA). This information provides the basis for identifying the basic work units or components of the project. These components are defined as activities. There are approximately 3000 construction activilles identified for a nurlear plant profect. Each activity can be subdivided into tasks (about seven per activity on the average). The actual schedule or network is developed on the basis of the activities. As detail design drawings become avallable, the structure of activities and tasks that make up the construction schedule is refined.

\subsubsection{Construction Productivity Monitoring}

During the process of developing the construction schedule, estimates of manhours and material quantities are made for each task. These est1mates are used along with historical productivity rates to establish the validity of the duration assigned to the activity. These quantity estimates are spread over the duration of the activity using one of the nine standard curves that best approximate the utilization of the particular resource for a particular task. Once a distribution is selected for a given type of task (e.g., pipe installation), the same curve is used for all tasks of the same type. The assignment of productivity rate curves provides a projection of productivity and forms a basis for productivity reporting and evaluation. The production and collection of 
resource utilization is broken down into the following levels of Information summary:

(1) Total project

(2) Unit number

(3) Major project feature

(4) Engineering discipline

(5) System of each discipline

(6) Activity

(7) Sort

(8) Sort

(9). Tasks

The basis for collecting and summarizing planned and actual progress up through this hierarchical information structure utilizes the relative number of manhours assigned to each task times the actual progress for the task measured by actual quantities installed. The Productivity Report forms the basis for Cost Control. Reports generated by the system include:
(1) Labor Productivity Bar Chart
(2) Manhour History Report
(3) Unit Manhour Report
(4) Duration Update Report
(5). Activity Production Report
(6) Exception Report
(7) Overview of Project Status
(8) Two Week Look Ahead - Schedule Tasks 


\section{(9) Weekly Progress Report \\ (10) Trend Analysis}

\subsection{Planning/Scheduling - Commonwealth Edison}

The role of planning and scheduling relative to project control begins by developing an initial Milestone Schedule. This effort consists of outlining 20 or 30 key events throughout the project wilh lieavy emphasis on the early years. This is the highest level of summary schedule and is developed as early as possible. This schedule serves as the basis for developing more detailed schedules and for repurting status to upper management.

Using the Milestone Schedule as a base, a CPM net of approximately 1000 activities is developed. This net reflects predominantly construction activities. Its purpose is to establish demand dates for design and procurement and to provide an outline of schedule requirements to construction subcontractors. This schedule 1s actually developed over the life of the project. During early phases of the project, the schedule has a high level of detail in the early activities and only a gross level. of detail in later activities. As work progresses, more detall is added and the labor activities become more precisely defined. This leads to a rolling wave increase in detail as the project progresses.

The schedule covers the entire project, but is reviewed by upper management on a three (3) month look ahead basis. Each construction subcontractor is responsible for developing his own schedule which is tied manually to the Master Schedule (most use the same CPM processor - PMS IV). 
Design and procurement efforts are not covered by the CPM. Although the CPM network is the one most important 1tem produced by the processor, most reports issued to users are in the form of bar charts.

\subsection{Planning/Scheduling - Westinghouse}

The following notes were prepared from some system descriptions and procedures issued by Westinghouse in its role as Lead Reactor Manufacturer on the Clinch River Breeder Reactor Plant project. From the'vendor's point of view, four functions are considered during planning and scheduling:

(1) Project level definition

(2) Preparation of NSSS schedule

(3) Preparation of intermediate level schedules

(4) Development of work package schedules

(5) Analysis of progress

\subsubsection{Project Leve1/System Scheduling}

The Project Master Schedule (Level 1) is a high level schedule for building construction and for major component design and procurement. It defines the fabrication schedules required to support the construction schedule. This schedule is not segregated by work packages or participants. It is prepared by the Architect/Engineer and approved by the project office. This schedule contains NSSS milestones submitted and agreed to by the Lead Reactor Manufacturer (LRM). These milestones represent contractual obligations and require the approval of the project office to change. 


\subsubsection{NSSS Schedule}

The NSSS schedule includes all elements of the project work

breakdown structure that are within the Lead Reactor Manufacturer's (LRM) scope. The NSSS illestones from the Level 1 schedule are included. as part of the NSSS Schedule. This schedule identifies NSSS control milestones. These dates represent dates that have to be met in order to insure completion of the contract milestous and are the rocponsibility of the LRM. Both the Project/System and NSSS schedules arc processed manua11y.

\subsubsection{Intermediate Level Schedules (Leve1 2)}

These schedules are maintained for systems, subsystems, and components that fall under the LRM's scope. These schedules are oriented to elements of the contract work breakdown struclure for performance measurement and reporting. The types of activities depicted on Level. 2 schedules inlude design phases, design reviews, technical documentation, procurement chains, fabrication releases, fabrication phases, component site deliveries, and component system interfaces. Events and activities are updated monthly. These schedules are processed using the PMS IV network processor.

\subsubsection{Work Package Schedules}

The work packages represent the lowest level of work scope for which schedules are developed. Work package milestones represent physical accomplishments and are discrete and verifiable tasks. Work package 
milestones identify completed work for which earned monies are calculated. The work package schedule is subordinate to and supports one Leve1 2 schedule. Work package schedules are reviewed every three months and project work for the next nine months. They are also processed using the PMS IV CPM program.

\subsubsection{Analysis of Progress'}

Milestone (event) status is summarized, reviewed, and analyzed as part of the schedule update process. The following levels of milestones are considered:

(1) Major project milestones (Level 1 schedule)

(2) Top logic milestones (NSSS milestones)

(3) Summary logic milestones - All top logic milestones plus Purchase order placement and delivery dates for major items.

(4) Control milestones - All summary logic milestones plus those dates necessary to control procurement placements, equipment, and construction package deliveries.

Control milestones which are of interest include:
(1) Conceptual Design Release
(2) Preliminary Design Release
(3) Final Design Release
(4). Equipment Specification Release
(5) Purchase Order Placement
(6) Delivery dates - material or components 
Network $\log i c$ orients the above mentioned events in terms of preceder and successor relationships and.time sequences the activities necessary to complete each milestone. The updating of the LRM schedule is done jointly with all organizations supporting the manufacturing process (Westinghouse - LRM, Westinghouse - Advanced Reactor Division, General Electric Company, etc.), on a monthly basis. The resulting reports include Control Milestone, Status, Schedule Narrative, and • Problem Analysis. The schedule reporting and analysis is done jointly with the cost reporting and analysis reporting. It is based on the lowest level of the work breakdown structure and the cost account (which consists of a grouping of work packages). This is the level where the actual cost of work performed is compared to the budgeted cost of work performed and the budgeted cost of work scheduled. A variance analysis is prepared based on the comparison of these numbers. Cost and schedule comparisons are additive up through the hlerdrchical atructuro of the schedule. Variance reports are also summarized up through the hierarchy in the same way. Monthly meetings are. held by the Project. ... Manager to review the status of schedule (and cost) performance, the status of participant interfaces and commitments, and to identify any corrective actions required. 
CHAPTER III

\section{Computerized Network Processors}

\subsection{Introduction}

The planning and scheduling systems described in the previous chapter depend upon computerized network processors to handle the calculation of large definitive level schedules.: Since the inception of the Critical Path Method (CPM) as a scheduling tool, a large number of such processors have been developed to implement a wide range of scheduling features. The complexity of nuclear power plant construction has led to networks ranging in size up to 30,000 activities. Many processors are not capable of handling such large networks or are very inefficient. Several processors have established a high degree of utilization in the nuclear power construction field due to their ability to process large networks efficiently and provide a wide range of scheduling reports. This chapter w111 discuss six of these processors, as follows:

(1) PROJECT/2

(2) PROJACS

(3) MCS

(4) MSCS

(5) Premis

(6) PMS IV

These systems are representative of those being used on nuclear projects. They also incorporate features which management has found to be desirable 
for planning and scheduling as well as cost and cash flow control. The following chart indicates some of those features and provides a basis for comparing the various systems. It also shows at a glance the capabilities and some of the technical specifications given for each system. 


\begin{tabular}{|c|c|c|c|}
\hline \multirow{2}{*}{$\begin{array}{l}\text { TECHNICAL } \\
\text { FEATURES }\end{array}$} & \multicolumn{3}{|c|}{ EVALUATED SYSTEMS } \\
\hline & PROJECT-2 & PMS IV & $\begin{array}{c}\text { IBM } \\
\text { PROJACS }\end{array}$ \\
\hline $\begin{array}{l}\text { NETWORK } \\
\text { DIAGRAII }\end{array}$ & $\begin{array}{l}\text { PRECEDENCE AND } \\
\text { ARROW (PDM \& ADM) }\end{array}$ & $\begin{array}{l}\text { ARROW, PREC. ALSO } \\
\text { AVAILABLE }\end{array}$ & $\begin{array}{l}\text { PRECEDENCE AND } \\
\text { ARROW }\end{array}$ \\
\hline $\begin{array}{l}\text { NUMBER OF } \\
\text { ACTIVITIES }\end{array}$ & 32,767 & $\begin{array}{l}\text { NO. OF ACTIVITIES LIM. } \\
\text { BY MACHINE CONFIG. }\end{array}$ & 15,000 \\
\hline $\begin{array}{l}\text { NUMBER OF RESOLCES } \\
\text { PER ACTIVITY }\end{array}$ & NO LIMIT & $\begin{array}{c}18 \\
(w / 0 \text { alternatives }-25)\end{array}$ & 32 \\
\hline $\begin{array}{l}\text { MAXIMUM NUMBER } \\
\text { OF RESOURCES }\end{array}$ & NO LIMIT & 32,767 & 500 (25 GROUPS) \\
\hline MILESTONES & NO LIMIT & $32,767 /$ per level & NO LIMIT \\
\hline $\begin{array}{l}\text { START /FINISH } \\
\text { ACTIVITIES (NO.) }\end{array}$ & No LIMIT & MULTIPLE & NO LIMIT \\
\hline CALENDAR & $\begin{array}{l}\text { MULT IPLE CALENDAR } \\
\text { CAPABILITY }\end{array}$ & $\begin{array}{l}2 \text { CAL. (COST MODULE) } \\
1 \text { CAL. (SCHEDULE) }\end{array}$ & 8 CALENDARS \\
\hline $\begin{array}{l}\text { NUMBER OF WORKING } \\
\text { DAYS PER } \\
\text { NETWORK }\end{array}$ & . & 15 YEARS & \\
\hline $\begin{array}{l}\text { RESPONSIBILITY } \\
\text { CODES }\end{array}$ & $\begin{array}{l}27 \text { DIGITS OF } \\
\text { RESPONSIBILITY } \\
\text { CODING }\end{array}$ & $\begin{array}{l}13 \text { SEP. CHAR. - RESP.CODES } \\
16 \text { SEP. CHAR. -ACCT . CODE: } \\
16 \text { SEP. CHAR. - CONTR. NO. }\end{array}$ & $\begin{array}{l}\text { ORGANIZATION TABLE } \\
500 \text { ORGAN. CODES } \\
4 \text { ORGAN. CODES FOR } \\
\text { ONE ITEM }\end{array}$ \\
\hline $\begin{array}{l}\text { NUMBER OF } \\
\text { RELAT ION SHIP S }\end{array}$ & UNT. TMITED & NO LIMIT & 30,000 \\
\hline $\begin{array}{l}\text { PRECEDENCE REL. } \\
\text { START - START SS } \\
\text { START - END SE } \\
\text { END - END EE }\end{array}$ & $S S, S E, E E$ & $S S, S E, E E, E S$ & $\mathrm{SS}, \mathrm{SE}, \mathrm{EE}, \mathrm{ES}$ \\
\hline $\begin{array}{l}\text { HAMMOCK ACTTVITIES } \\
\text { (NULTTLEVEL } \\
\text { NETWORK) }\end{array}$ & $\begin{array}{l}\text { ANY NUMBER OF } \\
\text { PROJECT S/SUB- } \\
\text { NETWORKS }\end{array}$ & $\begin{array}{l}\text { NETWORKS COMBINATION } \\
\text { SUBNETS EQUAL TO } \\
1,000 \text { HAYRIOCKS }\end{array}$ & $\begin{array}{l}500 \text { NETWORKS } \\
50 \text { NETWORKS FOR } \\
\text { RESOURCE ALLOC. }\end{array}$ \\
\hline $\begin{array}{l}\text { COMPUT ER } \\
\text { HARDWARE }\end{array}$ & $\begin{array}{l}\text { IBM } 360 / 370 \text { WITH } \\
360 / 40 \text { MINIMUM }\end{array}$ & IBM $360 / 370$ OS & IBM 370 DOS/VS \\
\hline REQUIRED CORE & $208 \mathrm{k}-1,000 \mathrm{k}$ & $\begin{array}{l}66 \mathrm{~K} \text { COST PROCESSOR, } \\
\text { NETWORK PROCESSOR }\end{array}$ & $96 \mathrm{~K}$ \\
\hline
\end{tabular}




\begin{tabular}{|c|c|c|c|}
\hline \multirow{2}{*}{$\begin{array}{l}\text { TECHNICAL } \\
\text { FEATURES }\end{array}$} & \multicolumn{3}{|c|}{ EVALUATED SYSTEMS } \\
\hline & MSCS & $\begin{array}{l}\text { CONST, HGT SYSTEMS } \\
\text { MARK II (MCS) }\end{array}$ & $\begin{array}{l}\mathrm{K} \& \mathrm{H} \\
\text { PREMIS }\end{array}$ \\
\hline $\begin{array}{l}\text { NETWORK } \\
\text { DIAGRAM }\end{array}$ & $\begin{array}{l}\text { PRECEDENCE AND ARROW } \\
(\text { PDM \& ADM) }\end{array}$ & ARROW, PRECEDENCE & $\begin{array}{l}\text { ARROW, } \\
\text { PRECEDENCE }\end{array}$ \\
\hline $\begin{array}{l}\text { NUMBER OF } \\
\text { ACTIVITIES }\end{array}$ & $\begin{array}{l}P D M-60,000 \\
A D M-42,800\end{array}$ & 30,000 & $\begin{array}{l}\text { PDM - 64,000 } \\
\text { ADM - UNLIMITED }\end{array}$ \\
\hline $\begin{array}{l}\text { NO. OF RESOURCES } \\
\text { PER ACTIVITY }\end{array}$ & 12 & 10 & $=200$ \\
\hline $\begin{array}{l}\text { MAXIMUM NUMBER } \\
\text { OF RESOURCES }\end{array}$ & 150 & 99 & No LIMIT * \\
\hline MILESTONES & No LIMIT & 30,000 & NO LIMIT \\
\hline $\begin{array}{l}\text { START/FINISH } \\
\text { ACTIVITIES (NO.) }\end{array}$ & No LIMIT & & NO LIMIT \\
\hline CALENDAR & $\begin{array}{l}1 \text { CALENDAR } \\
\text { HOURLY, DAILY, WEEKLY }\end{array}$ & $\begin{array}{ll}1 & \text { CALENDAR } \\
7 & \text { YEARS }\end{array}$ & $\begin{array}{l}8 \text { CALENDARS } \\
\text { USER DEFINABLE }\end{array}$ \\
\hline $\begin{array}{l}\text { NO. OF WORKING } \\
\text { DAYS PER } \\
\text { NETWORK }\end{array}$ & $\begin{array}{l}10-5 \text { YEARS }(6 \text { days } / w) \\
12-6 \text { YEARS }(5 \text { days } / w) \\
15-7 \text { YEARS }(4 \text { days } / w)\end{array}$ & . & \\
\hline $\begin{array}{l}\text { RESPONSIBILITY } \\
\text { CODES }\end{array}$ & $\begin{array}{l}10 \text { DIGIT VARIABLE } \\
\text { CONE. }\end{array}$ & $\begin{array}{c}8 \text { CHAR . RESP: / LOC.CODE } \\
8 \text { DIGIT ACCOUNT NO. } \\
3 \text { DIGIT PURCHASE } \\
\text { ORDER NO. }\end{array}$ & $\begin{array}{l}\text { USER } \\
\text { DEFINABLE }\end{array}$ \\
\hline $\begin{array}{l}\text { NUMBER OF } \\
\text { RELATIONSHIPS } \\
\end{array}$ & & 60,000 & UNLIMITED \\
\hline $\begin{array}{l}\text { PRECEDENCE REL. } \\
\text { START - START } \\
\text { STA } \\
\text { ENART - END } \\
\text { END END }\end{array}$ & $S S, S E, E E$ & $S S, S E, E E, E S$ & $\mathrm{SS}, \mathrm{SE}, \mathrm{EE}$ \\
\hline $\begin{array}{l}\text { HAMMOCK ACTIVITIES } \\
\text { (MULTILEVEL } \\
\text { NETWORK) }\end{array}$ & $\begin{array}{l}\text { MULTIPROJECT } \\
\text { CAPABILITY }\end{array}$ & $\begin{array}{l}\text { UNLIMITED NUMBER OF } \\
\text { NETWORKS }\end{array}$ & UNLIMITED \\
\hline $\begin{array}{l}\text { COPPUTER } \\
\text { HARDWARE }\end{array}$ & $\begin{array}{l}\text { IBM } 360 / 40 \text { OR } 370 / 135 \\
\text { OR ABOVE }\end{array}$ & IBM $360 / 370$ OS & $\begin{array}{l}\text { IBM } 360 / 370 \\
\text { OS/VS } 2\end{array}$ \\
\hline REQUIRED CORE & $94-350 \mathrm{k}$ & $120 \mathrm{~K}$ & \\
\hline
\end{tabular}




\begin{tabular}{|c|c|c|c|}
\hline \multirow{2}{*}{$\begin{array}{l}\text { TECHNICAL } \\
\text { FEATURES }\end{array}$} & \multicolumn{3}{|c|}{ EVALUATED SYSTEMS } \\
\hline & PROJECT-2 & PMS IV & $\begin{array}{c}\text { IBAI } \\
\text { PROJACS }\end{array}$ \\
\hline $\begin{array}{l}\text { RESOURCES } \\
\text { DISTRIBUTION }\end{array}$ & No & YES & $\begin{array}{c}\text { YES } \\
16 \text { OPERATIONS } \\
\text { PER ACTIVITY }\end{array}$ \\
\hline LIBRARY NETS & YES (LIMITED) & $\begin{array}{l}\text { CAN BE DONE, NOT } \\
\text { STANDARD FEATURE }\end{array}$ & $\begin{array}{l}\text { AVAILABLE, STAND } \\
\text { MODULE FACILITY }\end{array}$ \\
\hline $\begin{array}{l}\text { PLOTS } \\
\text { AVAILABLE }\end{array}$ & YES (INDEPENDENT) & $\begin{array}{l}\text { COINERCIAL PACKAGES } \\
\text { AVAILABLE }\end{array}$ & FRAIEED PLOT \\
\hline $\begin{array}{l}\text { COST } \\
\text { INTEGRATION }\end{array}$ & $\begin{array}{l}\text { COST INFORMATION } \\
\text { INCLUDED IN COMMON } \\
\text { DATA BASE }\end{array}$ & $\begin{array}{l}\text { SYSTEM HAS COST } \\
\text { MODULE }\end{array}$ & $\begin{array}{l}\text { COST } \\
\text { PROCESSOR } \\
\text { AVAILABLE }\end{array}$ \\
\hline $\begin{array}{l}\text { REPORTS } \\
\text { AVAILABLE }\end{array}$ & 30 OUTPUT REPORTS & $\begin{array}{l}\text { REPORT PROCESSOR UITH } \\
\text { BUILT IN HIGH LEVEL } \\
\text { LANG., STANDARD REPORTS }\end{array}$ & $\begin{array}{l}\text { GREAT FLEX. IN } \\
\text { OUTPUT SELEC. } \\
\text { LARGE NO. REPORTS }\end{array}$ \\
\hline $\begin{array}{l}\text { RESOURCES } \\
\text { ALLOCATION } \\
\end{array}$ & YES & $\begin{array}{l}\text { HAS RESOURCE ALLOC. } \\
\text { MODULE }\end{array}$ & YES \\
\hline $\begin{array}{l}\text { RESOIJRCES } \\
\text { LEVELING }\end{array}$ & YES & YES & YES \\
\hline SPECIAL FFATURES & $\begin{array}{l}\text { FREE FORMAT INPUT } \\
\text { KEY BOARD TERM. INPUT }\end{array}$ & $\begin{array}{l}\text { GOOD REPORTING CAPAB. } \\
\text { VARIABLEE INPUT FORMAT }\end{array}$ & \\
\hline $\begin{array}{l}\text { SIZE OF ACTIVITY } \\
\text { CODE }\end{array}$ & $\begin{array}{l}9 \text { DIGIT/ } 1 \text { ACTIVITY } 3 \\
\text { NUMERIC CODES }\end{array}$ & 10 CHARACTERS & 10 CHARACTERS \\
\hline $\begin{array}{l}\text { SIZE OF COST. } \\
\text { CODE }\end{array}$ & NO $\cos T \operatorname{coDE}$ & 18 CHARACTERS & $\mathrm{N} / \mathrm{A}$ \\
\hline $\begin{array}{l}\text { PROGRAMMING } \\
\text { LANGUAGE }\end{array}$ & & BAL & $\mathrm{PL} / \mathrm{I}$. \\
\hline SOURCE DOCUMENTS & NOT AVAILABLE & AVAILABLE & YES \\
\hline $\begin{array}{l}\text { COMPANIES USING } \\
\text { THE SYSTEM }\end{array}$ & $\begin{array}{l}\text { COMMONWEALTH ASSOC., } \\
\text { FLUOR PIONEER } \\
\text { GIBBS \& HILL, INC. } \\
\text { GILBERT ASSOC., INC. } \\
\text { UNITED ENGINEERS }\end{array}$ & $\begin{array}{l}\text { BROWN \& ROOT } \\
\text { PMS } \\
\text { STONE \& WEBSTER } \\
\text { COMBUSTION ENGR. } \\
\text { FLUOR PIONEER }\end{array}$ & \\
\hline
\end{tabular}




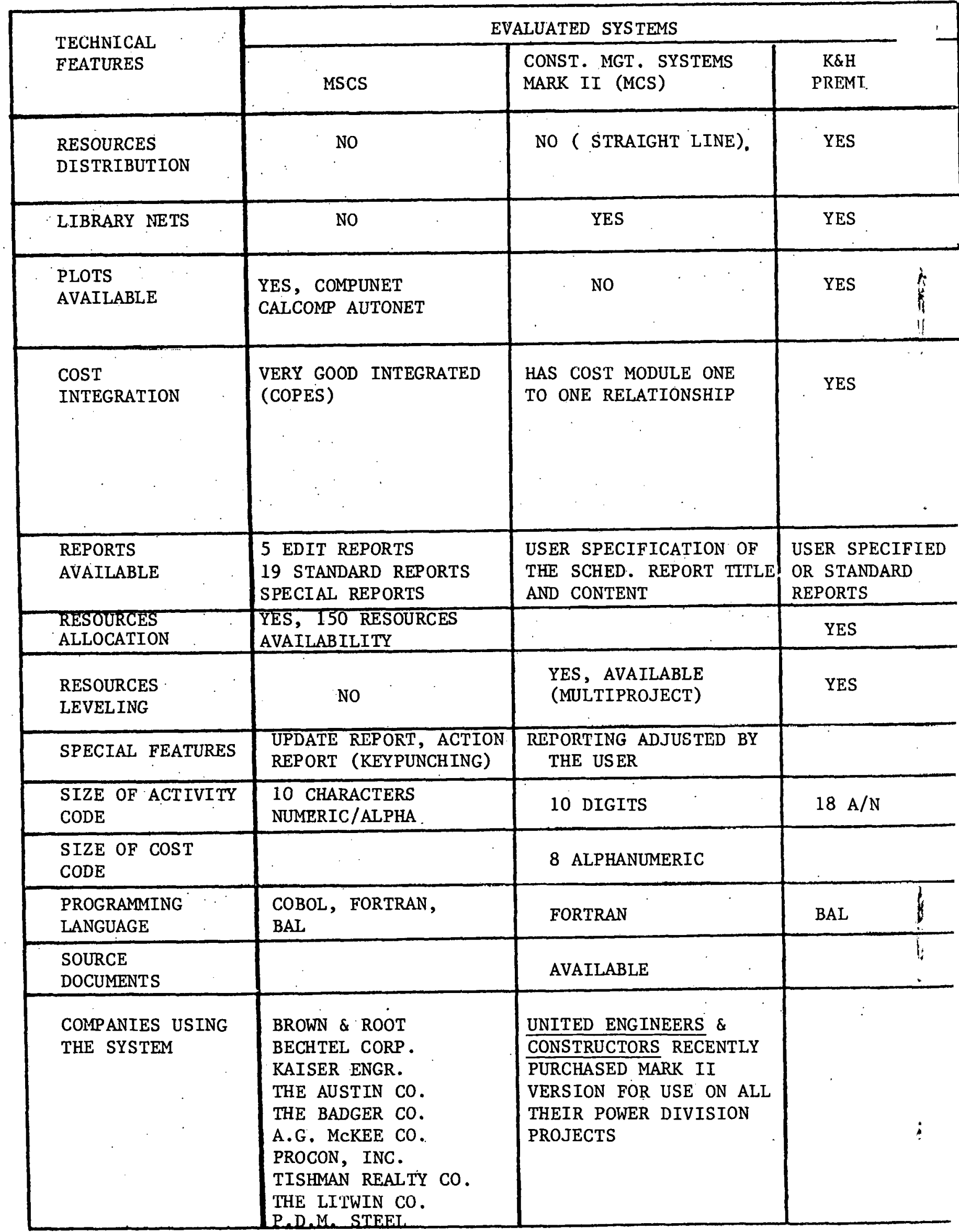




\subsection{PROJECT $/ 2 *$}

PROJECT/2 is a total software package for network based project scheduling and control. Over 40 tabular and graphic reports can be produced to provide the specific information needed by each level of management within an organization. It has the capability to process activity on arrow or activity on node networks using sophisticated scheduling algorithms. PROJECT/2 can be eas1ly installed on most hardware and has a user orlented free-format command language. As a scheduling tool, PROJECT/2 offers network plotting, CPM scheduling, progress control, cost processing, resource allocation and constraining, and multiproject features. A listing of the major processors and their capabilities follows.

The Basic Network Processor takes the basic network data and establishes the network logic. This Processor handles the project calendar speciffcations, the expanded activity descriptions, and the code assignments. Using the Ifulticalendar option, as many as 100 different calendars can be accommodated and scheduled within a single network. Modifications to network logic are handled by this Processor.

The CPM Schedule Processor calculates and displays both the Basic Schedule, a critical path schedule based upon network logic, and the Current Schedule, a critical path schedule that considers actual progress

*Material contained in this section is based upon and/or excerpted from "A System for Network Based Project Scheduling and Control" by Project Software \& Development, Inc, 14 Story Street, Cambr1dge, Mass. 02138. 
to date as well as the network logic. This Processor also produces input forms for updating, lists activities that must have action between specified dates, and produces many types of schedules and bar chart reports.

In the Target Processor, after a Current Schedule has been calculated, it may be compared to a variety of other benchmark or Target Schedules. Up to bU user-detined l'arget schedules may be recalned und compared to the Current Schedule, elther by activity or by summary group. Target Schedules may be produced in tabular or bar chart formats. The Target. Processor also produces a list of activitles targeted for action as of a specified date.

The Resource Allocation Processor assigns resources to activities and distributes. resources over schedules. An activity can have any number of resources assigned to it, and a resource may be assigned to any number of activities. Resource allocation reports may be generated project-wide, by activity, or by resource. Distributed resource usage (cumulative or time interval) is output in tabular and/or graphic format.

The Cost Processor handles all data related to the input, calculation, and output of project costs. It generates cashflow histograms and cumulative S-curves over the project schedules based upon estimated and actual cost. It can compare the Latest Revised cost to the profect Budget in detailed or summarized forms. The Cost Processor can also produce Earned Value reports based upon progress and a payments schedule. The Resource Constraining Processor computes and saves up to 50 schedules based upon resource limitations, time constraints, and activity 
resource allocations. The scheduling is performed via a dynamic user-controlled procedure resulting in a most economical use of computer time. Resource Schedules can be displayed or saved as Target Schedules.

The Multiproject Processor combines the Data Bases of two or more separate projects into a Multiproject Data Base. The Multiproject Processor can produce all of the standard PROJECT/2 reports for the combined. Multiproject and balance resources over all projects. In addition, it can transfer Multiproject Resource Constrained schedules back into the Data Bases of the individual member projects.

PROJECT/2's Network Graphics Processor produces plotter-drawn network diagrams. Only three commands are necessary to output your stored data as a plotted network. Many options, including activity selection, paging by codes, time scaling, and control of sheet size and relative location of activities on the plotted pages via zoning, are available. Milestones are indicated by special notations, and critical paths can be highlighted in red or with double lines.

The system parameters of PROJECT/2 show its versatility and usefulness as a planning, scheduling, and management tool. In plotting and scheduiling networks it can handle up to 32,000 activities with no practical limit on the number of relationships at the activity or network level. For activity identification, PROJECT/2 uses 9 numeric characters rather than alphanumeric identification, which most of the Industry has preferred. For activity descriptions, 48 alphanumeric characters are allowed with unlimited spáce for sublistings. PROJECT/2 
also has a one calendar per project capability with time segments being in hours, days, or weeks.

The inputs on the PROJECT/2 system are very simple. In addition to free.format commands, the system has the capability to verify and run a feasibility check on all input statements. There is also a user defined error override that gives a listing of all errors in. an input. Somc other features are an open end detector with automatic closure and listings and a multiple loop detector that isolates each 1oop.

The PROJECT/2 system has a multiproject capability of an unlimited scope. All outputs and reports enumerated under each processor are available for each project or for the total.

PROJECT/1 was the parent program for PROJECT/2 and is basically identical to its more versatile and expanded successor.

\subsection{PROJACS*}

\subsubsection{General}

Limited manpower, expedited requirements, cost controls, shortages of resources, and energy limitations have all increased the need for improved and sophisticated planning and control tools for project management. Regardless of the size of the construction project, the project managers must plan the activities, assign the resources, and develop the schedule for the job.

Material contained in this section is based upon and/or excerpted from "IBM System/370 Project Analysis and Control System," General Information, \#GH1 9-1055-1. 
The IBM program PROJACS (Project Analysis and Control System) has been selected by many construction companies to help project managers perform more efficiently, with greater control of the whole project. Though sophisticated, the system is easy to use, quick to operate, and flexible in providing the manager just the information he needs in an easy to read report. It is presently being used on the Callaway Nuclear Station, two SNUPPS units being constructed by Daniel International Corporation.

\subsubsection{Advantages of PROJACS Scheduling}

The primary advantage of computerized scheduling is the speed and accuracy in processing the massive number of calculations necessary and the flexibility of the reporting of the results to provide the managers at various levels only the information they require to perform their functions.

The system provides many features, such as:

(1) A convenient set of forms on which to collect and submit data.

(2) Accurate and rapid calculations of dates, floats, daily resource requirements.

(3) A highly flexible report processor. Provided are a basic set of standard reports plus the ability for the user to format his own repurts.

(4) Savliuy the daces and tloats from one analysis to be used in comparison with results from later analyses.

(5) True exception reporting by selecting the activities whose 
start dates, durations or floats have deviated in excess of some specified value.

(6) Ability to update the network rapidly, allowing the manager to test the "what if" conditions and see the impact this has on the manpower levels or project delay. This can be done without affecting the master schedule.

(7) Up to 32 resources can be allocated ovcr 311 or any part of the duration of an activity.

(8) With the addition of a resource rate table, cash flows can be determined by the quant1ty of resources required and distributed according to the project schedule. Provision is made in the table to allow for escalating rates.

(9) A five tiered organizational tree structure to allow for sorting and selecting of activities on reports by location, discipline or other desired breakdown.

(10) Backward calculation from a required completion dace to the start date.

(11) Time now feature processing to atd progress reporting.

(12) User specification of new report formats without reprogramming.

(13) Library of standard networks and/or subnets.

(14) Printer drawn plot of network.

(15) Eight different work week definttions and eight different calendars to allow for varying work weeks and holiday schedules by subcontractors. 
A key part of a project plan is assigning resources to the project's tasks. Ordinarily, resource requirements are ignored while the tasks are developed and sequenced. But once that part of the planning has been done, the resources required by each task and the total resources required by the project can be identified. Usually, the initial plan may call for more units of some resources than are ava1lable. The resource allocation modules of PROJACS can help solve these problems. It can indicate the areas of resource contention and highlight them for management. It can also make use of float, allowable delay of the end date, and additional resources that can be made available to arrive at a "best". schedule, or to level the resources and meet the required end date of the project.

It is recognized that activities require certain amounts of various resources which may be required during a part or all of the duration of the activity. Some major resources may be needed for the entire duration, some for only part of it. Some resources may be overlapped. In order to provide this flexibility in resource assignment, PROJACS has introduced the concept of the operation. An operation is defined as an amount of work corresponding to a certain part of an activity. An operation is specified by identifying the interval of time from the start of the activity to the start of the operation, and the duration of the operation. Operations may start and overlap at will.

Up to sixteen operations can be assigned to one activity. Each operation can have one or two resources associated which are in use 
throughout its duration. Therefore, up to 32 resources can be distributed over the duration of the activity.

The operations are not taken into consideration during the network analysis and calculation. Therefore, their start and finish dates are , computed with reference to the start date of the related activity. An operation is defined by an identification (activity code + sequence number), a description (24 characters), a delay and a duration (the combination of these two data items is called the operation span), and up to two resource codes and the corresponding amounts required to perform the operation. If the resource is. of the carried-forward type, the amount is specified as an intensity. The amount corresponds to a permanent need during the entire performance of the operation. If the resource is of the used-by-job type, the amount is speciffed as that quantity which is consumed per work unit.

It has already been noted that the operation concept allows specification of the way various resources are planned for an activity. Some other interesting facilities are provided by the introduction of this concept. Some activities can cause resource generation; for example, an activity which corresponds to the manufacturing of pipes will generate a given amount of the resource called "Pipe.". This resource will be used by other activities corresponding to pipe-fitting. This facility, used later on by the Resource Allocation Processor, allows solving some scheduling problems which could not have been solved previously.

Within each activity, certain operations can be specified as alternates in case of resource shortages. This other factlity, used 
later on by the Resource Allocation Processor, allows simulating various situations. If a given operation cannot be performed on time because: there are no available resources to do it, the operation may be replaced by another operation using different resources, or greater duration.

Instead of the two resource requirements, the operation can specify a group requirement; this means that the operation requires a certain amount of any one of the resources making up the group. This feature is useful for the Resource Allocation user. The Resource Allocation Processor will select one individual resource from the group based on some priority rule such as least used resource or most used resource.

\subsubsection{Report Processor Characteristics}

The system provides a highly flexible report processor which consists of a collection of basic report formats. Beyond this, the user has the capability to define his own set of reports with the user's own selection and layout of the data on the report, the selection or conversion of time units, the sort sequence of the data, selection of time spans, method of including or excluding activities. Up to ninety different such reports can be established without any programming required.

The reports are grouped into six categories:

(1) Activity-orlented reports such as Schedule, Work Status and Progress, Bar Chart, Exception, Milestone, Activity Cost Reports

(2) Aggregate Activity. Report 
(3) Resource Utilization Report

(4) Financial Reports

(5) Network Diagram

(6) Display Reports

Below we have described some standard report formats. It should be emphasized that these are provided only as a typtcal example of how the report can look. Any organization of this or any of the other data elements from the file can be included. Also, operations can be included in many of the reports below the activity line.

Schedule Report

The Schedule Report can provide the following information regardless of options exercised for each work item included in the report:

(1) Activity Code - Identification of activity of the work item.

(2) Description - This space is provided for the verbal identification of the work, item.

(3) Current Duration - Work items not yet begun will have their total duration input by the planner. Work in progress will have durations calculated by the formula: Current Duration = (Data Date - Eaxly Start) + Remaining Duration.

(4) Calendar and Work Week Indicators - These indicators show the number of working days in a week, the first working day of the week and whether holidays are observed in the schedule.

(5) A flag to indicate completed or in-progress activities. $C=$ Complete, $\mathrm{P}=$ In Progress. 
(6) Early and Late Start and Completion Dates - These dates are computed by the scheduling program based on the network and durations input into the computer.

(7) Total Float - The float indicates the span of time a work Item can slip without affecting the overall project completion date.

(8). Free Float - This float indicates the span of time a work item can stop without affecting the start of any succeeding activities.

(9) Scheduled Dates - Those dates that are fixed due to contractual agreements. A code indicates if the start or finish'date is requested and the mode of regulation.

The selection and format of the Schedule Report is totally flexible. Any data in the file can be displayed in any order on the page. Options are available for sorting and selection of the activities to be included. Options

These options may be exercised individually or in various combina- : tions. Each option has several alternatives which permit a variety of reports focussing on any desired subject.

A listing of options and alternatives follows:

(1) Span Dates - Either a complete or partial report may be requested as follows:

(a) A complete report would include all work items in the network. Thus, it would include work already completed, work in progress, and remaining work for the entire project duration. (b) By selective use of span dates, the report may be limited only to work items scheduled during a user specified time 
span, i.e., a two week or three month report.

(2) Sorting - The report can be specified for categorization by any of the following work item arrangements:

(a) Activity Code Sequence - The principle use of this sort is to readily find specific work items.

(b) Early Start - The report can be sorted chronologically by earliest start dates. The report is primarily used to select upcoming work.

(c) Total Float - The report lists all work items in order of criticality; i.e., most critical first and in order of decreasing criticality. This report is also used for selecting upcoming work and assigning priorities for manpower allocation.

(d) Early or Late Finish - The report lists all work items by the early and late finish, chronologically. This report is seldom used.

(3) Organization Code - All reports may, in addition, be sorted by responsibility codes, i.e., Engineering, Procurement, Construction, Mechanical, Civil, etc. Four such codes may be assigned to every work item and all reports may be sorted by these codes. These sorts, when used judiciously, provide capability for "exception" reporting and limit the attention to specific areas of interest.

\section{Precedence Report}

This report, which is called P.W.I., is intended for use by the planner in checking the network structure. It provides a listing of all work items in the network and shows the logical restraints and 
inter-relationships of these work items for diagnostic purposes.

The P.W.I. report lists all work items and sequences them by numerical code only.

(1) Description of Work Item (W.I.)

(2) Lists all W.I.'s preceding described W.I.

(3) Relationship between:W.I. and preceding work item(s) (PWI), i.e., start-to-start, completion-to-start, and completionto-completion

(4) Time Delay (Lag Values)

(5) Early and late start and completion dates

(6) Floats

(7) Scheduled dates

Bar Graph Report

The Bar Graph Report indicates the days or weeks in which actual work is scheduled to be performed on all or selected work items.

The same options for the graph report content and format, i.e., time span included, sequence of listing, etc., are available as for the Schedule Report.

The data presented is the same as in the Schedule Report but is shown graphically in the form of bar graphs. Time spans may be used to produce 3 -month and 2-week bar charts. This feature may eliminate the need for manual bar charts if a sufficiently detalled network is input in the computer to make these schedules usable. The bar chart codes are:

$\mathrm{R}=$ Duration 


$$
\begin{aligned}
& C=\text { Critical Duration } \\
& -\quad=\text { Total Float } \\
& F=\text { Free Float } \\
& A=\text { Actual } \\
& \text { * }=\text { Operation }
\end{aligned}
$$

\section{Work Status and Progress Report}

This report contains the following informarion:

(1) Description - Identification (Work Item) number and description of work.

(2) Operation Code and Description - Those operations which make up the activity are 1 isted.

(3) Current Duration - The duration of the activity, as discussed in the Schedule Report. Also, the duration and delay of the operation are shown.

(4) The resources assigned to the operation and their quantity are shown.

(5) The progress status of the activity is shown.

(6) Early start and finish dates for the activity and operations are given.

(7) The data date on which progress was reported.

(8) The remaining duration as input by the planner and is the estimate of the time required to complete the activity.

(9) Percent work done. The value used in the cost processor to calculate current costs. 
The Work Status and Progress Report is subject to the same sequencing or sorting capability as the Schedule and Bar Graph Reports.

\section{Resource Utilization Report}

Th1s report projects histograms of resource requirements on a period and cumulative basis. Where the Resource Allocation Report shows resource usage per work 1tem daily for each resource, the Resource Utilization Report shows the total project resource requirements on a weekly and cumulative basis and by individual resource. The report contains the following information:

(1) Resource Identification and code

(2). Period Scale, Cumulative Scale. Scales are provided for graphical display of resource needs for the period, usually weekly, and cumulative.

(3) Amount or Resource - The calculated quantity is based upon input data for all work items.

The Resource Utilization Report provides a pictorial representation of resource utilization. It may be used to project manpower needs for the project by craft and in total. If dollars are input as a resource, a cash flow is depicted with each report run. Since the data is directly related to the schedule, manpower and cash flow projections are automatically updated with each schedule update.

\section{Activity Cost Report}

This report provides estimated and actual costs by work item. The following information is included: 
(1) Work item code and description

(2) Current and Remaining Duration - This can be either calculated or input as a manual override if the estimated remaining duration is different from that calculated.

(3) Estimate Cost - The cost of the activity is derived from the Estimate Integrated Schedules, and input into the scheduling program. No computations or projections are made by the computer. . It wili oniy list the amount manually input into the system.

(4) Current Cost - The actual cost plus any estimate to complete.

(5) Actual Cost - The actual cost per activity, when available, may be manually input into the system for comparison with estimated cost. These figures are not calculated or projected by the computer but are. manually input.

(6) Work done value - The percent complete times current cost.

(7) Work item early start and finish dates.

\section{Organization Cost Report}

This report summarizes by Organization Code the distribution of monthly costs. The result is a cash requirements projection of the project.

The information contained is:

(1) Organization code and description

(2) Period start - The month and year

(3) Current cost - The actual plus estimate-to-complete

(4) Actual cost - As reported to the system or as calculated by the cost processor from the percent work done. 
(5) Estimated cost - The original estimate as entered or as computed and stored from the direct extension of resources at their current rate.

(6) CU/ES percent - The ratio of cumulative current cost to cumulative estimated cost.

(7) Work Done Value - The part of the estimated cost which corresponds to the work done for in progress or completed activities.

(8) AC/WC percentage - The ratio of actual cost to work done value.

(9) Overhead - The cumulation of the overhead costs allocated to activities by direct input.

(10). Total - Current cost plus overhead.

(11) Budget - Value cumulated from direct input.

\section{Milestone Report}

Certain activities in the schedule can be designated as key work items or milestones. The Milestone Report isolates these key events and reports the following information:

(1) Milestone Code and Description - This description is associated with the start or completion of a key work item and is input into the program during network generation or update.

(2) Milestone Date - The start of completion date of the key work item date may be calculated or actual if the date has passed.

(3) Float - The allowed delay for the milestone is calculated and shown in the Milestone Report.

(4) Scheduled Date

(5) Subnet code 
(6) Work Item Identification - This is the W.I. number of the relevant schedule work item.

(7) Milestone level code.

The objective of this report is to provide management information of job progress at a high summary level. This is the computerized version of the Manual Milestone Report discussed elsewhere in the guidelines. Exception Report

This is probably the single most innovative addition to the report processor. The system provides the facility to save the dates from any time analysis or resource allocation run in a separate storage area. After making changes in the network, or after following a time analysis with a resource leveling run, the exception report can be run to analyze the resulting change in the dates, durations or floats. These changes can be displayed together with the before and after data from which they are derived. It is also possible to select and report only those activities whose dates or floats have deviated by some specified value or whose values are less than or greater than some quantity.

A typical format of an Exception Report is as follows:

(1) Activity code and description.

(2) Previous Duration - The duration saved from an earlier analysis.

(3) Current Durations - The duration calculated in the present analysis.

(4) Variation Duration - The difference in the current and previous values. 
(5) Previous Finish Date - The early finish date from a previous run.

(6) Early Finish - The date calculated in the present analysis.

(7) Var. Finish - The difference in the previous and current dates.

(8) Previous Float - The value calculated in earlier analyses.

(9) Total Float - As calculated in the present analysis.

(10) : Var. Float - The difference in the above two items. 


\subsection{MCS - Construction Management System *}

The Management Control System (MCS) is a Critica1 Path method based on a series of integrated modular computer programs developed and marketed by Construction Management Systems. It has been used extensively in the construction industry and has been specifically used to schedule numerous nuclear power projects.

\subsubsection{M.C.S. Sumary Description}

The system performs the basle fuictions of loading, updating, computing ( $C P M)$, sorting and printing. In addition, it provides multi-project leveling of the resources, a forecast of the monthly dollars or mandays required, prepares payment application documents, as well as providing cost reports with forecasted remaining costs. The input may be either in the traditional $I-J$ or precedence relation- .. ship.

The output formats have been planned to produce a clear and simple document. A unique feature is the starring of activities with one to three stars, depending upon their need to start during the next month. The system is immediately available on the IBM $370 / 165$, (180K plus system sort), $360 / 40(90 \mathrm{~K})$ and 1130 (8K).

There are a number of additional modules available for detail or summary barcharts, verification 11stings, consolidation of networks to delete finished activities, duplication of selected "fragnets" while incrementing the activity numbers, floor numbers, etc.

Material contained in this section is based upon and/or excerpted from a Brochure on MCS by Construction Management Systems, P.0. Box 70, Haddonfield, New Jersey 08033. 


\section{3:4.2 Schedule Module}

\section{Data Base}

The programs store and edit check rigid format CPM records. This input may contain a $9 *$ digit activity number, 2 digit Resource Requirement, 3 character Duration, percent complete, a 5 character alphameric responsibility/resource code, 3 character alphameric location code, 32 character description, 3 digit overlap with each follower, 8 character alphameric account number, 8 digit labor and material dollars and amounts, actual start and finish dates ${ }^{a}$, target finish date, print code, compute code, and 8 digit alphameric purchase order number ${ }^{b}$ Basic cPM input requires only one card. Loading in Account Numbers, Labor Value; Purchase Order Numbers," etc., requires the second input card.

There are edit checks to prevent inclusion of fundamentally unacceptable data. File size is established by the user, with multiple project per disk capability, and housekeeping by the MCS Supervisor. File Updating

The file may be updated using a 1 or 2 card rigid input format depending on whether the new or revised information is on the first or second card. The file is maintained in activity number sequence so that changes are made rapidly.

A listing of all changes made is standard output and edit checks are performed on the change cards. Duplicate or conflicting changes are flagged as error messages.

a - Labor value or actual finish date on the 1130 - not both. b - Not on the 1130 . 
After the changes are read, they are merged with the main file and the results are stored in the "subordinate file." Error messages are produced for all requested changes to the file which have not been accomplished. The 1130 system allows 1500 change cards to be loaded at one time while the limit for the 360 is the size of the user defined main data file.

\section{Calendar Generation}

The calendar program produces a project tlme vs calendar date table (up to seven years) with the flexibility of handling from a 1 to 7 day work week. In addition, standard holldays such as Christmas. and New Year's may be stated, as well as variable holidays.

\section{Computation Routine}

The normal CPM calculation of the Early Start and Late SLart times for each activity in the file is accomplished by a series of eight routines. These routines provide such functions as conversion of the multiple follower record information Into logic statement (I-J form), counting of followers and then predecessors for determination of "open ends," as well as for use in the "loop" dlagnostic. To improve computation time, a topological sequencing is Included so that multiple iterations are not required in the forward and backward pass. One of these programs also provides for setting an arbitrary Early start, Early Finish and Late Start of any activity prior to the beginning of a computation. A final program writes the computed times from the work tables into the main record. The user may select to complete the computation even if there are "open ends" or data card errors. 
The program provides for multi-project resource leveling (merging) multiple projects and computing of up to $100,000^{*}$ activities.

\section{Loop Diagnostic}

This sophisticated program determines which activities constitute single or multiple loops. All activities on all loops are pointed out at one time as opposed to identifying one loop for each computation.

\section{Sorting}

The 360 system packages utilize the IBM system sorts. The 1130 sort program is an efficient program for sorting up to 8 keys of the record.

\section{Extracting}

This program provides for extracting specific records for selective sorting, resource leveling, printing, cost forecasting, etc. Its main purpose is to reduce computing time when the entire content of a file is not required for succeeding operations. Extraction criteria may be dates, float, responsibility and location coding, account code number or any of the last eight characters in the activity description. Printing/Totaling

This very flexible program provides for printing up to 5 different CPM formats, while totaling at two levels. There are quite a number of Print or No Print Options.

Týpical Run Times

The average run time to compute (CPM Early and Late dates) and print a 3,000 activity precedence network is approximately: 
IBM 1130

- 60 minutes

IBM $360 / 40$

- 14 minutes

IBM $360 / 50$

- 5 minutes

IBM $370 / 165$

- 2 minutes

Other system modules are generally of proportional speeds. Resource Leveling

Execution of this program usually follows completion of an acceptable CPM computation: There are two limits available, a lower limit and upper threshhold. The program attempts to schedule all activities within the lower limit of user input resource availability levels. The program attempts to schedule the activity at its early start or as close as possible to it, within the lower limits set by the user. If the late start would be exceeded due to a limitation of resources, the lower limit is exceeded and the activity is scheduled as close as possible to its early start within the upper limit. If insufficient resources are avallable at the upper limit the schedule will be extended until such time as these resources are again available. All following activities would then have their early start dates bumped accordingly

\section{Cash/Expenditure Forecasting}

This program calculates the amount of dollars forecasted to be required for each month of the project for both labor and material and can compute interest during construction and retentions. An alternate of this program is a monthly incremental and cumulative forecast of either dollars or mandays on both an early and late start basis. 
These programs are executed after resource leveling, the dollars or mandays forecast on an early start basis would be the incremental and cumulative dollar/resources required on an optimum basis to complete the project on schedule:

These forecasts may be run for the entire project or selectively per trade, responsibility, location, etc.

The input is the basic CPM data file with either material and labor dollars and/or crew size.

Cost Reporting

Actual costs for each work package (activity or a group of simflar activities combined into one account code) are accrued in a separate cost file. The remaining costs are derived from the CPM data files and added to the actual costs to produce the total probable cost for each work package. These total probable costs are compared to the estimate to produce a deviation for use in exercising control. A virtually unlimited number of cost reports are available, tailored specifically for various levels of management. This near ultimate flexibility is achieved through the user specifying which account codes at what level are to be included in any report. Detailed analytical and reference reports are also available.

The Progress Payment Report may be a by-product of the regular CPM Updating. In addition to providing detailed support of a contractor's payment application, this program accounts for the number and amounts for each Change Order to the contract. to date, pre-payments for materials on site, retainage percentage, previous payments, net amount due, etc. 
Barchart

This system module provides a conversion of the calendar information In the CPM schedule into the familiar barchart form, with an "X" representing a day, week, 2 weeks or month selectively, and an optional "dash" to the right. with the same time unit representing the float associated with each activity. Unlike many programs, however, the user may specify whether the barchart is to be a printoul of sulected activitiaf, or. whether multiple activities are to be summarized into one bar. Variable scales are avallable wherein a barchart symbol represents a day, week, 2 weeks or a month.

Network Plotter.

Both detailed or summary scalar or non-scalar networks may be produced at speeds substantially greater than manual drafting. Curves may also be plotted relating 1tems in the data base, as: cost-time, manpower-time, time-percent complete, etc.

Utility Programs.

There are a number of programs to produce special data listings as well as file manipulation, calculation of the labor value for each activity from the wage rate applicable during any period of time and the mandays associated with the activity, dumping of a file or any portions of a file onto cards, etc. In addition, consolidation of data and autogeneration of fragnets are avallable, as are verification listings, change 1istings, error printouts and diagnostics. MCS Supervisor

This supervisor program operates under control of the computer 
operating system and directs the execution of al1 system programs. Entry to the main line programs is through the MCS Supervisor. Upon completion of each program it exits back to the MCS Supervisor or if directed, to other associated programs.

One of the prime responsibilities of the Supervisor is file allocation and maintenance. Data files may be variable in size and the name of each file, its size and starting address is stored by the MCS Supervisor. This program also provides for housekeeping; it both adds and deletes files and provides, on request, a printout of the file names, sizes, and addresses.

\section{$\underline{\text { Reports }}$}

The system contains the capability for producing an extensive variety of diagnostic and output reports. These reports may be tailored as needed to the specific application. Specifications provide for including only those activities on the report as desired as well as sup-. pression of most of the data fields if needed. There are basically 5 different categories of reports.

(1) Diagnostics: These reports include a verification listing showing all of the changes planned to be input as well as additions or the full listing of initial loading; this includes error messages where alphabetic characters appear in numeric fields, illegal characters, embedded blanks in numeric action fields, etc.; a complete 1isting of all changes as input into the data files; a total float by early start listing with followers (successors) and a full listing of the file by activity number order with followers (successors) for analysis of the 
computations; a predecessor listing is available which includes each predecessor's total float and early project start day. In addition, during the next use of the program, there are a number of error messages printed out for such things as open ends, a complete loop diagnostic, operator errors, control card format errors, etc.

(2) Schedules: These are available in a wide variety. These schedules may be sorted by any one of the data fields and may include or exclude any activity or field. A special flagging feature is provided wherein one, two or three asterisks appear next to an activity when its early start and total float fall within user specified boundaries. These schedules are of ten produced by project, by prime responsible department, by supervisor, by reporting period, by criticality, by resource type, etc. They include an indication whether the early start and finish for the activity has been determined by resource leveling, whether the early start and finish, late start and finish have been preset by the user. The schedules may contain information concerning the purchase order or account number, labor and material dollars for each activity, the number of mandays originally estimated and mandays remaining for each activity, (summarized by supervisor, by department, by project, etc.) The activity information may also include the estimated payment dollar value for the activity which when extended by its percent complete wi11 show the amount of money which has been "earned." The report form is so designed that the necessary updating information such as remaining duration, percent complete, start and finish dates, may be recorded adjacent to the existing information so that the keypunching may be 
directly accomplished from the marked up schedule. The formats have been carefully designed to portray the maximum amount of information obtainable on one line without having to go to voluminous two line or more report printouts.

(3) Updating: A special form is provided to display the full contents of the data record as well as providing a means for keypunching directly from a full schedule. In actual practice, the variable information is usually transferred from the individual reporting departments schedules onto the master updating schedule at which time it is scanned for correctness and subsequent impact upon the schedule, resources, or cost. Since this form is formated identically with the data cards number 1 and 2 (with the card columns shown), keypunching and subsequent verification may be accomplished directly from this report by operators completely unfamiliar with the system.

(4) Resources: These reports may be produced prior to or following resource leveling. Such reports are believed to be unique in that they may be printed for every day, averaged for every week or month, and may be produced in either tabular or graphical form. The reports may be obtained selectively by responsibility, resource type, location, etc., either unleveled-leveled, holding the project duration to determine the number of resources required or holding the limit of the available resources and determining the project completion date predicted upon those resources.

(5) Expenditure Forecasting: These reports are divided into two categories, an expenditure forecast diagnostic and the month by month 
expenditure forecast. The diagnostic shows the amount of labor and/or material money for each activity and its associated codes and the time span over which the money is scheduled to. be expended. The expenditure forecast shows the labor or material, or total dollars expected to be expended for every month, for each project. It includes a provision for calculating the interest during construction, retention withheld from invoicing for later payment as well as the total bookings.

(6) Cost Reports: These reports include a cost audit for detailed analysis of the current labor and material costs compared to the previous issue for both the estimate, actuals remaining and deviations thereof. In addition, the reports are available for varying levels of management. Reports can be generated showing only those activities or accounts which are expected to deviate by more than $\mathrm{X}$ dollars from the estimate for labor or material or both. A full printout of the project estimate is available, as is a printout of the progress payments due to each vendor or subcontractor. This report is the byproduct of updating the schedule and may be automatically obtained. The cost information is contained in a separate cost file with remaining cost information transferred from the main data file.

(7) Networks: A computer driven plotter network report is a time scaled graph of either a fragnet of a small project or a total project. It is quite flexible in that the user specifles the horizontal and vertical scale to be used and includes a provision for specifying which activities will appear upon which lines. It also includes a feature wherein the current status of the original network may be portrayed 
in the form of a vertical line from the current date down to each activity in the network so that ahead or behind schedule activities may be quickly seen as deviations from the vertical line. The system is designed for a.fixed plotter and where the network would overflow in time, a second and subsequent sheet would be plotted for later taping together.

The reports have been designed for maximum flexibility and modification by the user. The basic data record contains four unused words ( 32 bits - 4 bytes) so that such additional activity information as quantity, etc: may be added to the basic data record and included on user modified reports. The system provides for using multiple copies of any report merely by enclosing as many repetitive print command cards as may be desired for any report or variation thereof. 


\subsection{MSCS - MCDonnel1 Douglas*}

MSCS is an integrated family of computer programs providing Critical Path Method (CPM) or Precedence,Planning Method (PPM) calculations, activity casting, resource allocation, and a complete library of standard reports and plotter graphics enhanced by a selection criteria language allowing the user to easily design his reports to suit his requírements.

The program was designed as a comprehensive information handling system with extensive diagnostics, versatile 30 year calendar, and reduced complexity of input so that the user system interface is minimized. The software design of MSCS is modular to facilitate integration of new application modfication and to allow the user to select only those capabilities required at the time of processing.

The major modules and their description follow.

Executive Module - This master control module selects the various MSCS modules and controls their operations.

Update and Master File Maintenance Module - Encompassed in this module are features for updating, editing, and maintaining the MSCS master and background files. Also included are features which allow for punching and copying the master file, building multiproject files and data editing. Critical Path Time Calculations Module - Two networking techniques, ADM and PDM, are supported, both of which perform standard start and finish, total float and free float calculations. MSCS also allows the user to employ actual start and completion dates, a time-now specification, and

\footnotetext{
* Material contained in this section is based upon and/or cxcerpted from "MSCS - Project Management," by McDonnell Douglas Automatic Company, Suite 144, Two Northside 75, Atlanta, GA Phone (404) 355-0610.
} 
a host of externally imposed conditional dates (mandatory start, mandatory completion, expected completion, not-later-than finish, and not-earlier-than start). ADM Identifies activities by five-digit "I" and " $J$ " nodes (sometimes called events in PERT terminology) and operates under the basic principle that no activity may begin from a node until all activities into that mode are completed.

PDI defines the individual relationship of each activity (or work item) to each activity that immediately precedes or constrains it (precedent work item, or PWI). Various "lag factors" define the type of relationship of the start or finish of one work item to another. Resource Allocation Module - This module schedules activities based on resource availability. The scheduling basis is the relative priority of the activities vying for scarce resources. Relative priority is dynamically calculated and is a function of user-applied priority numbers, total float, actual resource requirements and activity durations. General Report Processor Module - This module produces an extensive number of standard reports and provides the facllity through selective criteria to develop reports tailored to user specifications. Major capabilities are:

Standard Reports - MSCS contains a comprehensive set of standard reports sufficient to satisfy most requirements. Extensive sort capabilities allow for the selection of cascaded sorts (five levels) each report request, each run. Selection Criteria - This feature allows for user-tailoring of report content and format through the use of special MSCS input 
control words. It provides for the selective printing or exclusion of activity information on reports, the sorting and processing of reports using user-defined control information and the user assignment of special titles to reports.

Off-Line Plotter Graphics - MSCS produces magnetic tapes compatible with off-1ine plotters. These tapes contain sufficient information to plot resource usage and cash requirement curves, plotted bar charts and network diagrams. Information for plotters may be transmitted to a user's computer for remote plotting. Report Writer Macro Language - With this feature you can format or reformat reports according to your specific requirements. The macro language allows for the generation of completely new reports with relative ease and speed.

MSCS Flow - As a modular system, MSCS can be executed in whole or in part by user option. Only those modules required for a given type of processing are selected. Module selection is controlled through user input parameters and does not require manipulation of IBM Job Control Language.

\subsubsection{Description: MSCS}

MSCS is a full-scale CPM-resource program. It accepts arrow or precedence notation, levels resources within duration constraints or allocates within resource constraints. Cost features include updating and progress reporting; up to 18,000 activities, multi-project scheduling with up to 25 independent networks; up to 12 resources per activity. 
MSCS is available at data centers that are part of McDonnell Douglass' Computer Telecommunications Network. The most powerful tool is the ability to adjust the scheduling to optimize or control resource usage. By inputting a maximum resource pool for each resource, activities may be delayed if necessary to maintain a ceiling on restrictive resources. The programs accept splitting the activities into several segments of minimum length.

For scheduling, activities are considered in one of four states or lines :

(1) Waiting line - for scheduling an activity the waiting line must meet both the following conditions:

a. The time is greater than early start.

b. All precedence activities of this activity have been completed.

(2) Process line - an activity remains in the process line the same number of legal work units as its remaining duration, providing each specified resource is simultaneously available.

(3) Finish line - after an activity has spent its required duration in the process line it is a scheduled activity:

(4) Non-scheduled line - these are activities not moved in the waiting line because of precedence constraints or their early start time.

\subsubsection{Resource Facilities}

Resource Availability Pool - Several options are available to the user for controlling the pools at available resources. Pools may be scheduled to constant value or to stepped values. The user's manual provides detailed explanations and examples. 
Resource Leveling Options - MSCS allows two methods of leveling a project.

(1) Time limited - Hold the project end date as calculated by CPM (earliest finish). Resource pools are maintained whenever it is possible but are exceeded if it is necessary to complete the project on time.

(2) Resource 1imiced - The resource pools are the primary constraint. The project end date is delayed if it becomes necessary to schedule the activities within the resource limitation.

An extensive number of reports and variations can be produced by MSCS for management evaluation, as follows:

Update Report

This report lists all data input into MSCS. Data shown here has been validity checked; where noted, editing takes place. Errors are Iisted on the report and are summarized and classified at the end of the report for easy reference. This report may be used as an input document when deleting and modifying MSCS data. Card columns are listed in the report heading for direct keypunching, and space is provided in the report body. for input of both progress information and data changes. When using the Update Report as an input document, all user-defined fields may be modified, including activity numbers. It is only necessary to input corrected information when modifications take place.

Network. Report

All user input activity information along with calculated remaining 
duration, start, finish, and total float values, is contained in this report. It may be sorted and grouped by any character or group of characters input to or calculated by MSCS. The Project Report is similar in format to the Network Report but lacks completed activities, CPM dummy activities, resource data, cost data, and PDM relationship data.

\section{Leveled Profect Report}

Reports produced after resource leveling contain the scheduled start. and finish times resulting from the resource leveling process but continue to show early start and late finish as reference dates. The total float previously printed on reports is replaced by remaining float which is the difference between the CPM or PDM calculated late finish and the scheduled finish date resulting from resource leveling. All but one MSCS reports are automatically changed to this new format after resource leveling is performed. The one exception, the Project Report, can be requested in the resource leveling format. It is then called a Sample Leveled Project Report.

\section{Bar Chart}

The MSCS bar charts show the time relationship of activities in a conventional format. All MSCS calculations are shown for each activity through the use of special symbols selected by the user. In the sample, the " $\forall$ " represents the period over which the activity will occur if scheduled by early start and early finish. The plus (+) and minus (-) signs represent positive and negative total float. Resource leveled and pasteup bar charts are also available. 
Action Report

This report lists all activities which must show action (progress) during a subsequent user-defined time period. Possible progress is listed in the column headed "Action," along with the date on which. the progress should take place. The report may also be used as a progress input document with keypunch card columns listed in the report heading and space provided within the report for progress information. The report may be sorted and the data grouped according to user requirement and can be requested so only critical activities are contained. The Action Report is an excellent tool for collecting progress feedback i information.

Work Log

The Work Log Report shows for each day (week or hour may be requested) the activities which may be in progress. Each time an activity is included in a day's schedule, the remaining duration shown for the activity is adjusted for that day. The Work Log Report is similar in format to work logs a user might produce by manual methods.

Plotted Bar Charts

MAPS is a program within MSCS which plots bar charts on off-line plotters. The MAPS output is not limited in dimension by computer printers and therefore can be used to show entire projects in a bar chart format against a continuous time reference line. MAPS bar charts can be used to compare target schedules to schedules calculated by MSCS.

Milestone Reports

Activities may be defined as milestones and reported upon at different 
levels. Nine milestone levels are allowed by MSCS and cascading of these milestone levels is available by user option.

Resource Activity Report

The Resource Activity Report groups activities by resource code. If an activity requires more than one resource type, the activity is included in each of its resource groupings.

Compunet Network Plots

Compunet $^{\mathrm{TM}}$, a proprietary computer program which interfaces with MSCS, produces plotted network diagrams (either ADM or PDM) on off-line plotters. A feature of the program is the plotting of non time-phased networks. 


\subsection{PREMIS*}

PREMIS is the latest, most powerful generation of CPM processors for the K\&H Computer Systems Company. It is a comprehensive project resource evaluation management information system that uses the precedence or the arrow technique to represent the logical interrelationships between the activities that make up a project. This system is marketed and sold in the USA by Informatics. PREMIS runs on Informatics IBM 370/138 under 05/v52. Informațics clients can also access and use PREMIS at a time sharing terminal or at a remote job entry terminal.

PREMIS has integrated modules to do time-analysis, resource scheduling, comparative reporting (using targets), summary reporting, multiproject scheduling, and cost processing.

PREMIS can provide management with information in a clear and concise form on which to base decisions necessary to ensure that resources are available when required by the project, the project is completed on schedule, and the project is completed within cost and manhour budgets.

The resource-analysis and scheduling capabilities of PREMIS can provide management with insights into the following practical alternatives:

If the available resources are used, by how much will the project completion date be extended? (manpower-constrained, resourcelimited)

If the project completion date is to be met, what extra resources (if any) will be required? (time-constrained)

If overtime is worked on the project, by how much will the completion date be brought forward? (combination of time and manpower constraining)

* Material contained in this section is based upon and/or excerpted from "Premis; An Overview," copyright 1976 by Informatics, Inc., Doc \#035 110. 
What is the cash flow on the project? And how does it vary as constraints change?

Is each individual item, and the project as a whole, over or under or on budget?

How w111 a design change affect the project schedule, the resources required, and the budget?

If project $A$ is given top priority, how will this affect projects $B, C$, and $D$ ?

If activity schedule dates are changed, what will be the effect on the project schedule and resources?

Using the network diagram and other project data (resources, resource-constraints, costs, etc.), PREMIS can simulate various situations and provide management with meaningful and realistic information on which to base decisions.

Extremely flexible report-generation facilities are an integral part of PREMIS and can be used to select only that information relevant to the various levels of management receiving the reports.

The sorting and report-generation facilities of PREMIS can be used to provide virtually any format of detailed reports for operations on site and summary reports for management.

In addition to sophisticated project-scheduling and sorting and report-generation techniques, PREMIS also has integrated input and update generation facilities that can accept a varlety of formats of input and update data at the activity or detail levels, which are converted to a standard format within PREMIS for processing. 
Overall control of the various (generation and project scheduling) modules of PREMIS is directed by a System Control Language (SCL). Various sets of SCL control cards can be stored on disk and recalled by a single control statement. Project-scheduling modules can be defined and retrieved in the same way.

In summary, PREMIS may be thought of as a PROJECT MANAGEMENT and INFORMATION SYSTEM GENERATOR.

\subsubsection{Network Creation and Analysis}

Input

Activity Coding: PREMIS has an Input Generator module (GEN) which lets you define the format of input most suitable to your needs, or you can use a set of Standard Input.

The sizes, in PREMIS, of the input parameters generally used in project control are as follows:

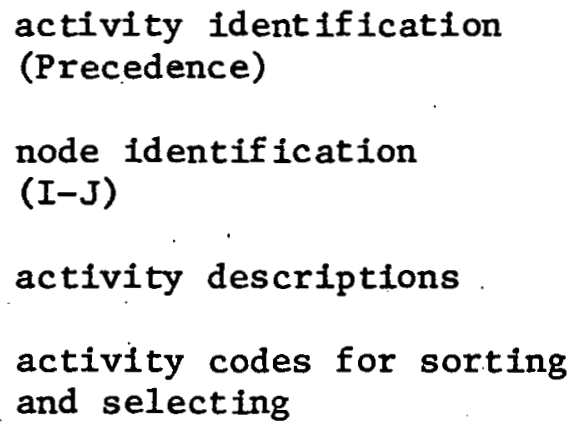

activity durations up to 18 alphanumeric characters

up to 8 alphanumeric characters

no practical limit

no practical limit on the number of alphanumeric characters; and they may be grouped in any series of combinations for selection, sorting, and page-skipping, if required.

may be in days, weeks, hours, or smaller units of time for applications such as maintenance scheduling. These may be used in 
combinations on the same activity; e.g., weeks and days; and different activities within the same network may have different time units.

activity relations (links to preceding activities)

normally up to 200, depending on how much other data is stored for an activity.

\section{Network Generation Using Jibrary Modules}

In any large project, there may be several groups of tasks or activities that are similar in logical interrelationships and descriptions. For example, the logic for the design, manufacture and installation of a pump may be basically the same even though the pump specifications may differ.

PREMIS has a library module facllity that you can use to create a standard module for a pump and store the module away in a library on disk or tape under a unique 6-character name. The module can then be called from the library for use in an actual project by means of a single card, and can be modified to give the specific pump name and to increase or decrease its durations or resource levels, etc., before inclusion in the project network.

\subsubsection{Error Detection}

PREMIS has extensive standard error detection routines; and, in addition, you can define extra conditions for your particular application.

Each standard error is identified by a unique number and each number has an explanatory message. 
Standard messages relating to each number are already included in PREMIS, but you can change the message to something more meaningful to your application. This is especially important when PREMIS is being used in a foreign country, since the error messages can be redefined in the language of the user.

Conditions can be defined, using the error numbers, to abort the run, depending on the seriousness of the error.

Some typical error messages are:

ERROR IN NUMERIC FIELD

DUPLICATE ACTIVITY

INVALID START (no predecessors)

INVALID END (no successors)

UPDATE CARD UNMATCHED

UNSPECIFIED ACTIVITY

RELATION - ACTIVITY

CARD CODE UNKNOWN

LOOPS DETECTED IN THE NETWORK

With the last message, all the activities and relations compirising the loop (or loops) are detected. The loops are broken down into subloops, and an indication is given as to which activity is most likely to be causing the loop.

\subsubsection{Time Analysis}

All the usual results such as Earliest Start, Earliest Finish, Latest Start, Latest Finish, Total Float, Free Float and others, such 
as Independent Float, can be calculated.

Activities may have imposed dates applied in one of five modes:

Start not earlier than

Finish not later than

Earliest start at the imposed date

Finish imposed at the early finish (or the early finish plus a value)

Earliest and latest starts imposed

Each project may have up to 7 different calendars, plus a base calendar. This is essential for maintenance scheduling projects to simulate shift patterns of resource availability and very desirable for multinational projects where the holldays in the various countries are different. Multiple calendars can also be useful when different departments and operations have different work weeks. Time units can also be used without calendar dating.

Equipment-delivery activities may be scheduled just prior to the activity requiring the equipment, to avoid premature delivery that may invite pilferage, deterioration, or congestion.

\subsubsection{Resource Analysis and Scheduling}

\section{Project Resources}

There is no practical limit on the number of different resources that can be specified in a project.

Resource profiles: There are three basic profiles on resources in a project: 
Fixed or constant - where there is a constant availability of the resource throughout the project.

resource.
avallability

resource availability

Stepped - where the availability builds up at the beginning of the project and drops down toward the end.

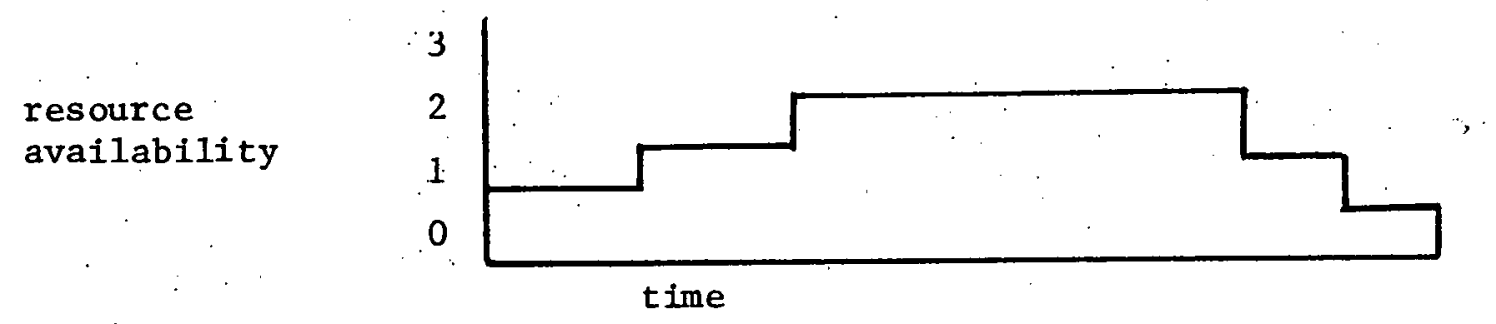

Cyclic - typical of maintenance projects dependent on shift-working.

resource availability

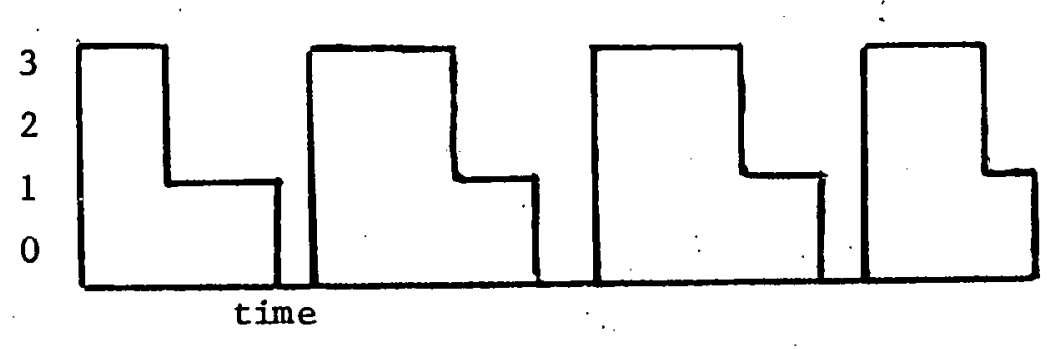

\subsubsection{Nonexceedable Resources and Thresholds}

Projects, or parts of projects, will be either time limited (to meet a set schedule) or resource-limited (constrained by the availability of resources). In defining resources, resources can be defined as nonexceedable (for instance, the physical layout of a plant may make it impossible to have more than one overhead crane avallable to an activity) 
or exceedable up to a threshold (a certain craft can be scheduled to work up to 2 hours overtime per day). In scheduling, another way to compensate for the unavailability of a specific resource is to specify an alternative resource (for example, engineers can make up a shortage of draftsmen).

\subsubsection{Resources on Activities}

Up to 200 different resources can be related to an activity. These resources can be specified as "total work content" (man-days) or "rate constant" (men per day).

Complex resources - Levels of resources on an activity may vary during the activity.

Splittable and tied activities - Certain activities can be tagged as splittable, as necessary, for resource-leveling. This allows resources to be taken off one activity for use by others. Activities can be tagged as tied to other activities; that is, they must start as soon as the immediately preceding activities are complete.

\subsubsection{Scheduling Rules/Priorities}

A wide variety of scheduling rules are avallable, and the user can define his own rules. Priorities can be assigned specifically to activities, to groups of activities, or to projects.

\section{6 .8 Updating}

As a project progresses, reports come in showing which activities 
are completed, partially completed, changed, etc. Periodic reanalysis of the network provides management with a regular up-to-date assessment of the project status, whether it is on schedule or will be late, which activities need to be expedited, and where extra effort should be made to keep the project on schedule.

The usual updating of a network, such as activity deletion, activity modification, and the reporting of actual starts and completions can be done.

PREMIS has standard conventions and formats for updates, but the Update Generator (UGEN) lets you define your own update specifications, and the Input Generator. (GEN) lets you design the input formats of the update cards, if you wish to.

Any of the results of a particular update can be stored as historical data and used to produce "Comparative or Target Reports" which compare the current situation with the situation as of previous updates.

\subsubsection{Reporting}

Reporting usually takes place in three stages:

(1) Selection of Data: Selection of specific information for a report is done using the Selection Generator (SGEN).

Examples: .

Select key milestone activities at the activity level for reporting vertically to any higher level in the hierarchical structure.

Select activities with less than a specified criticality value 
and occurring within a certain time frame.

A virtually unlimited range of possible conditions and combinations of conditions is available to let you eliminate all Irrelevant activities as well as irrelevant data for the selected activities.

In fact, it is possible to scan any column or group of columns (including the description) on the activity records in the master file and to select or reject based on any condition or combination of conditions .

(2) Sorting of Data: Sorting of activities into any desired sequence is done using SGEN. Sorting can be on any column or combination of groups of columns on the activity master file record.

Typical sorts are:

activity number sequence

department/scheduled start/activity number

total float/activity number

subsystem/project/subnet/activity scheduled start

department across subsystem and/or project and then scheduled start, etc.

(3) Report Writing: You have complete control over the format of reports by using the Report Generator (RGEN).

Typical reports are:

Activity listings containing input data, computed values, and derived values (such as extended descriptions from codes or other activities) Bar charts containing any of the above with any scale factor and any bar-chart symbols 
Resource tables showing resources required at the system, subsystem, project, subnet, or activity levels on usage, early start, late start, or average of early and late start Cumulative cost or material usage curves based on scheduled start Summary bar chart and key milestone reports for higher levels in the management structure. Summarizing may be based on activity selection codes, or by reporting on the activities defined, in the logic, as summary (or hammock) activities, or by a combination of the two methods

Target schedule reports comparing the current status with any of several previous update situations (up to 50 previous target schedules can be stored on the master file). 


\subsection{Project Management System (PMS IV)*}

Project Management System (PMS.IV) is a set of four programs, or processors, which are destgned as a comprehensiye system to guide and monitor projects. The user makes his selection, according to his requirements, among the first three processors, but draws the reports he wants only from the fourth. For further information on the capabilities of PMS IV, see the chart at the end of this chapter. There follows here an outline of the job performed by each processor and of the way that the processors relate to each other.

\subsubsection{Network Processor}

The Network Processor (NP) performs PERT analysis of activity networks and precedence analysis of precedence networks, using a deck of data and specification cards as input. It edits the input and creates or updates from it an edited master file. From the master file it generates and analyzes the networks submitted by the user, and selectively sets up output files to pass to one of the other processors. An outline of the structure of the Network Processor is given here. The Network Processor consists of four procedures. These are programs which accept as input either data cards or files output by a precedịng procedure. A processing run may be halted after any procedure is complete; then, using the files established by this procedure, the run may be resumed at a later time or on a separate computer.

* Material contained in this section is based upon and/or excerpted from "Introduction to Project Management System IV," Program Product 非GH20-0855-1. 


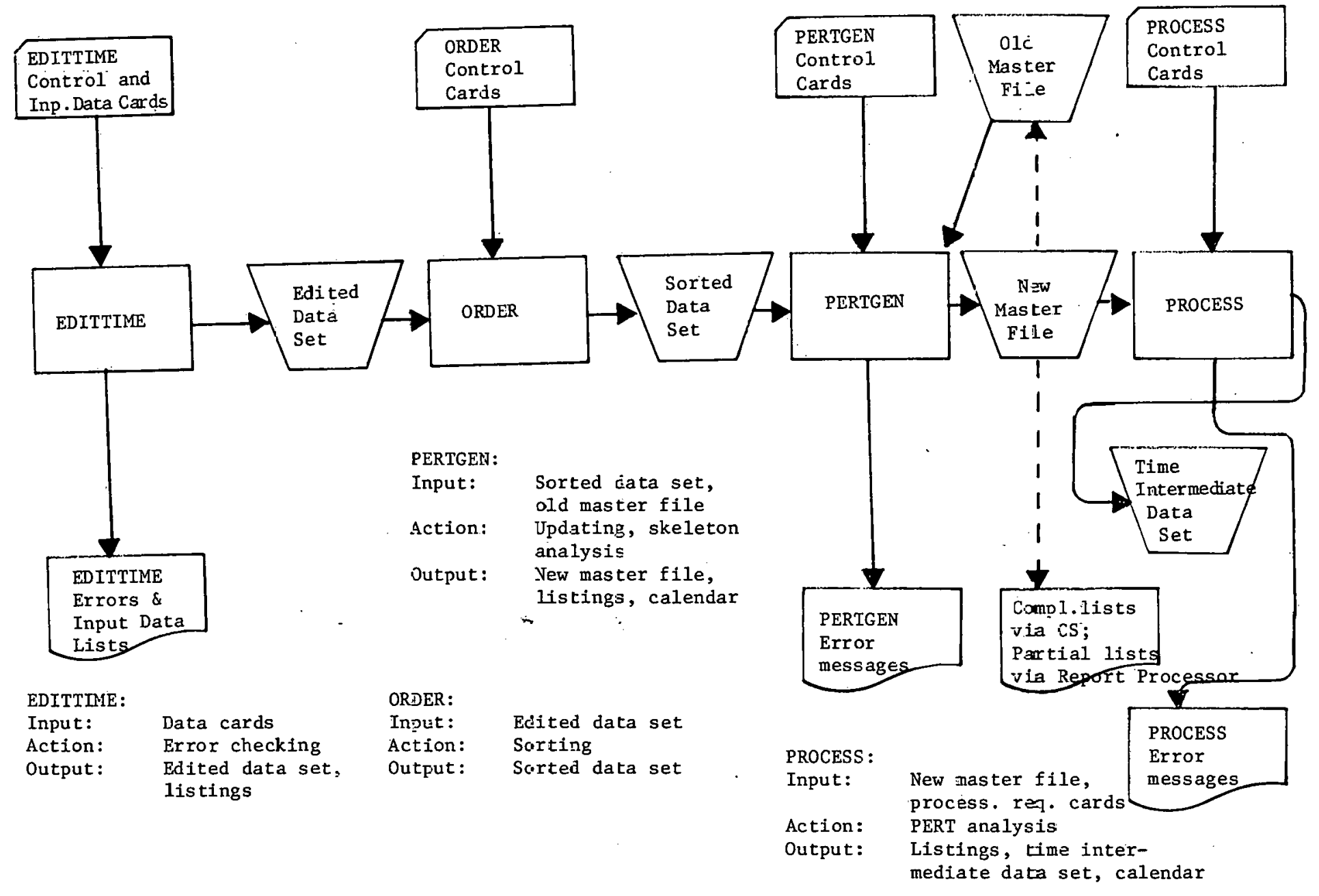

FIGURE 3.1: INFORMATION FLOW IN THE NETWORK PROCESSOR 
The advantage of this system structure is that computer usage can be optimized. Each procedure has its own requirements for core storage and input/output devices, so that it may sometimes be advantageous to run the procedures on different computer configurations. Alternatively, when the user runs the procedures sequentially as job.steps of the Operating System, he can test the condition codes that are set by each procedure. These condition codes have values that vary with the severity of errors detected by the procedure, and if any procedure returns an unacceptable condition code value, the user may stop processing.

A description of the four procedures follows below.

\section{(1) EDTTTIME}

The job of this procedure is to check the format of the input cards and to correct them where possible. It is designed to give

$\because$ the user as much control as possible over editing and error handling, and distinguishes errors of varying importance.

(2) ORDER

The second procedure is ORDER. It sorts the edited data cards by type number within subnet within network. It accepts the file EDITOUT from the procedure EDITTIME, and produces XORDER to be passed to the next procedure. The sort is performed by the Operating System sort using intermediate work files called SORTWK01, $-02,-03$, etc. Therefore the user should optimize this procedure by giving the sort as much core storage as possible, and he will need to allocate more workfiles in some cases. 


\section{(3) PERTGEN}

The third procedure is called PERTGEN. If there is no existing master file, the procedure creates one by copying the sorted input file XORDER, passed by the procedure ORDER, onto a file called XNMF. If an old master file exists, it is called XOMF and PERTGEN updates it with the records on XORDER to form XNMF. The new master file can then be passed to the fourth procedure, PROCESS, or it can be updated again by PERTGEN, in which case it will, of course, be called XOMF.

PERTGEN reads XNMF and carries out comprehensive error detection routines on the data. It also calculates skeleton data which is written onto XNMF. Two tables are set up, organized by subnet, which contain respectively all events from which an activity begins and all events at which an activity terminates. The user must specify the start, end, and interface events he wants, and all others will be detected as errors. Duplicate cards and network logic errors such as loops and incorrect updates are likewlse detected.

PERTGEN offers the user the facility of deleting and modifying records on the master file by the submission of update cards with the appropriate update code and identifying fields; no other fields need be present on the update cards. Master file records may be deleted or modified individually; the user may also delete all records which belong to a spectfied network or subnet. Records may also be added to the master file. All of these methods of adding to, deleting from, and modifying the master file may be used on a single processing run. It is therefore simple to control the master file even when it is large. 


\section{(4) PROCESS}

This procedure generates a detailed analysis of specified networks and subnets from the edited, sorted, and logically checked data passed to it by the procedure PERTGEN. The user has process request cards, which control which networks and subnets are to be processed, whether subnets are stand-alone or interfaced, and whether various sorts of summary activity are to be calculated.

If report generation from an existing master file is all that is required, PROCESS is the only procedure of the Network Processor that will be used. For this reason PROCESS checks for certain errors, such as 1llogical actual dates, in the data it processes.

\subsubsection{Resource Allocation Processor}

The Resource Allocation Processor (RAP) allocates resources to activities in a network. It requires as input the files produced by the Network Processor, and certain additional information supplied by the user. RAP schedules the start dates of activities which are subject to resource constraints, and produces a file of scheduled activities which can be passed either to the Cost Processor or to the Report Processor.

\subsubsection{Cost Processor}

The Cost Processor ( $\mathrm{CP}$ ) performs cost analysis of input data. It requires as input a file of analysis specification cards which define the way in which costs are to be analyzed and aggregated; the user may 
define a table of rates, different types of cost, varying accounting periods, rainbow categories, an organization table, work package breakdown structures, and so on. In addition, it requires data cards detailing costs for analysis.

The common feature of all cost analysis is that it asks what resources are being expended, when they are being expended, and who is responsible for expending them. In essence, this means that the analyst asks, for each accounting period; what is being expended in each group of resources. Suppose the user's organization is building houses for sale; when the analyst asks what resources are being expended, his groups are money, man-hours, cubic yards of concrete, specialist manpower, and so on. In this manual all such resource expenditures are called costs. When he asks who is responsible for each expenditure, his groups are the legal services department, the purchasing department, the site clearance team, the transport department, and so on.

The grouping of costs and the time base'used are more fully described immediately below.

GROUPING COSTS

Costs may be grouped in any way which suits the analyst. For instance, costs may be grouped by contract to which they belong, by type of work in which they were incurred, by geographical location of the work center involved; or by any other suitable factor.

The Cost System of PMS IV analyzes the costs submitted to it in the way which best suits the user's requirements and existing procedures. 
It allows the analyst to submit costs which are simultaneously assigned to many groups and then totals costs either within each group or across as many groups as the user wants.

\section{ACCOUNTING PERIODS}

A cost analysis is normally required to show the time when each cost has occurred or will occur. The standard practlce is to establish an accounting period of a week, a month, a quarter, or of any other convenient length, and to assign costs to the accounting periods in which they fall. The cost Processor allows the user complete freedom to. specify the accounting periods he wants; thus it is easy for him to use the Cost Processor without altering his current procedures.

The user describes each cost to the Cost Processor by attaching codes to it. These codes are of two types: the first type is used to group costs and to specify how they are to be summarized and broken down, and the second type specifies the units in which the cost is expressed. This section describes the seven methods of grouping costs offered by the Cost Processor.

(1) WORK PACKAGE

A project can normally be divided into parts for the purpose of analyzing costs. Each part is an item of work, more or less distinguishable from the rest of the project, to which the user can conveniently assign costs. These items of work are called work packages, and the user may specify a total of over $1,000,000$ of them to the Cost Processor. A work package might be, "Clear and bulldoze site 1 " or "Construct house 4 at site 1 from foundation to 
2nd floor," or any other identifiable item of work at a convenient. level of detail: Naturally, the size of a work package may vary greatly with the needs of each user.

\section{Charge Number}

A charge number is an identification code given to a work package. A cost is assigned to a work package by attaching the proper charge number to 1t. So within the Cost system the charge number simply identifies a work package, although normally the user establishes a system of charge numbers which relates in some way to his existing procedures.

\section{Work Breakdown Structure (WBS)}

A project of any complexity will require analysis at various levels of detail, according to the requirements of different levels of management within the user's organization. It is therefore usual to order the work packages into levels, forming a Work Breakdown Structure or Project Analysis Table. A work package at one level may then be part of a work package at a higher leve1; the work package at leve1 1 may be the complete project to be analyzed. Work packages at the lowest level are normally items of work, or jobs, which can easily be controlled and measured:

The Cost Processor accepts a WBS of as many as nine levels, and cost reports are available to display costs at any WBS level. Some cost reports show only costs attached directly to charge numbers at a particular level. Others display for any WBS level except the lowest 
al1 costs directly chargeable to charge numbers at that level and all costs summarizing into that level according to the WBS.

\section{(2) PERFORMING DEPARTMENT}

A second way of analyzing a project is by department performing each section of the work. A performing department might be a team of laborers under a foreman, the group responsible for building site 1 , the management services department, or any other part of the user's organization to which costs can conveniently be assigned, either directly or in summary.

Organization Analysis Table (OAT)

It is usual to order the performing departments into levels, thus forming an Organization Analysis Table. A performing department at one level may then be part of a performing department at a higher level; the organlzation at level 1 may be the organization responsible

$\because$ for the whole project. The performing department at the lowest level is normally the unit responsible for a deflnable job. The size of the lowest level department will vary widely from user to user, depending upon the complexity of the project being analyzed.

\section{(3) RESOURCE CODE}

A third method of analyzing a project is by the resources it uses. According to the importance of each item to the user, he decides whether to cost it separately or to aggregate it with others into a single resource. For instance, one user might separately cost diesel ofl, kerosene, and gasoline, whlle another user might consider all such fuel as a single resource. 

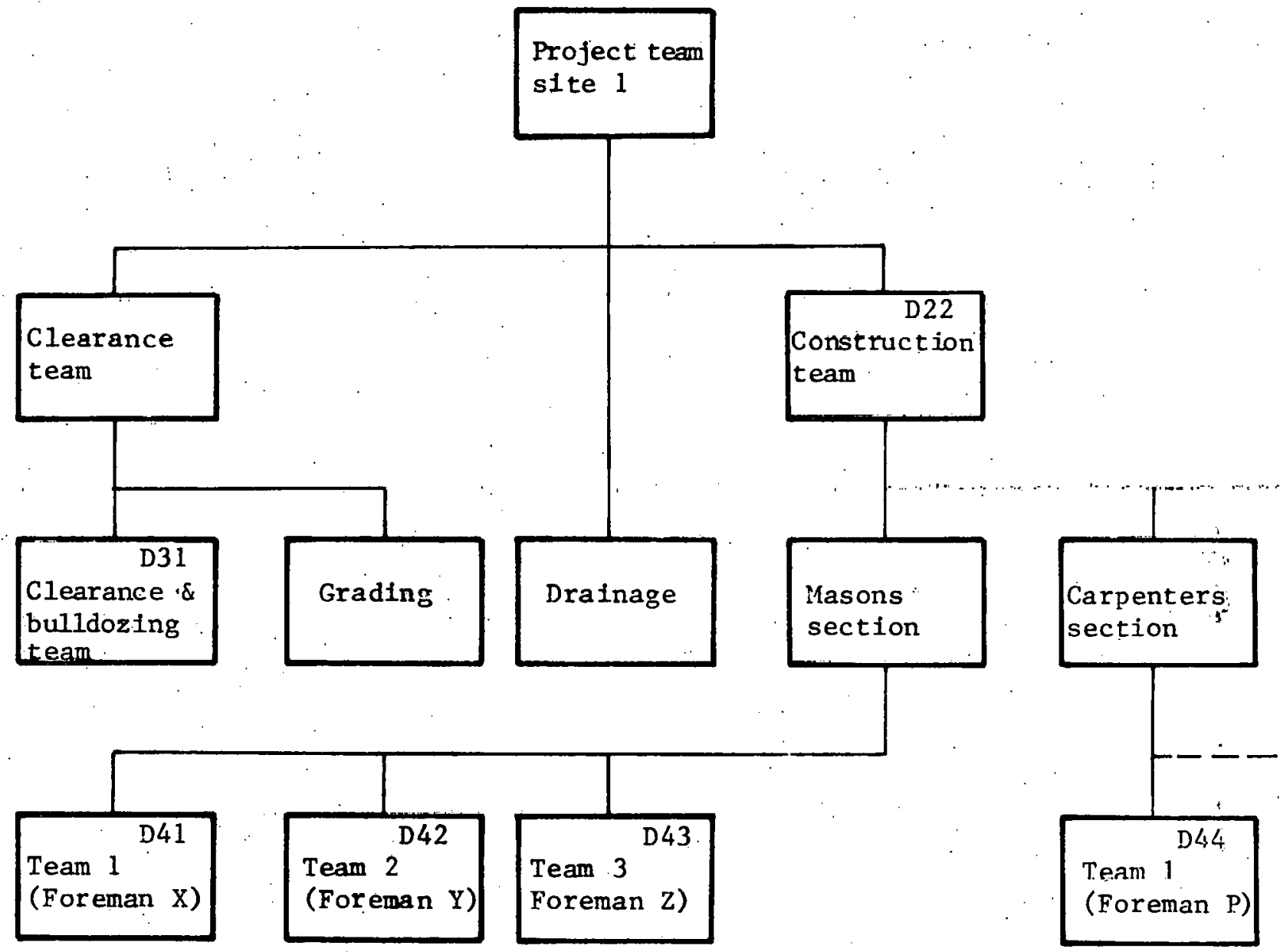

FIGURE 3.2: SAIPLE ORGANIZATION ANALYSIS TABLE 
The Cost Processor permits the user to specify any number of resource codes; in effect, it allows the user to choose the level of detail of reports.

\section{(4) COST CATEGORY CODE}

A fourth method is to assign costs to a particular combination of performing department, resource code, and (optionally) costing code. This combination is given a cost category code which the user arbitrarily selects. Normally, the cost category code indicates the resource which the performing department applies to a work package.

This is the standard or intended use of the cost category code, but the user may, of course, employ it in any other more convenient way, or not at all. There is no system-imposed limit on the number of cost category codes which may be defined.

\section{(5) RAINBOW CATEGORY CODE}

This code, the fifth possible method, is defined in the same way as the cost category code and is thus a code assigned arbitrarily to a particular combination of performing department, resource code, and (optionally) costing code. Although it is, in effect, the same as the cost category, the computer system keeps the two types of code separate and there are standard output reports based on the rainbow category codes only.

\section{(6) CONTRACT NUMBER}

The sixth grouping code of the Code Processor is the contract number. This code allows the user to group work packages, and it is attached not to the individual cost records but to the charge numbers 
which Identify the work packages. The user may give a contract number to one or more charge numbers, and thus gather in one report all the costs of a particular contract.

\section{(7) GROUP OR SUBNET NAME}

A seventh alternative is to assign each cost to a group or subnet. When a cost analysis is being performed independently of a PERT time analysis, costs may be divided into groups by attaching to each an arbitrarily chosen group name. When cost analysis follows PERT time analysis, the PERT subnet names are used as the group names, although both subnet and group names may be mixed in the same cost analysis if the user wants.

A cost is an amount of a resource which the user expends. Normally costs are expressed as units of money; but they may be expressed in other units when the user prefers. The type of unit in which each cost is expressed is indicated to the Cost Processor by a code attached to each cost record.

A different division of costs is by the sort of expenditure which each cost represents; costs may be expenditure which has actually occurred, or has been budgeted, or is anticipated, and so on. The type of expenditure to which each cost belongs is indicated to the Cost Processor by a. further code attached to each cost record. This code is the Cost Type code. 
This section describes the way in which the Cost System extends the user's cost records within the accounting periods he requires. The section explains how costs which are not expressed in units of money are converted to money if the user so desires, how overhead rates are applied to the direct costs, and how the accounting periods may be specified and used.

\section{(1) RATES DIRECT OR UNIT}

The user often wants to convert nonmoney costs to money. The Cost System does this for him if he specifies how much money each unit, each man-hour, each bulldozer, foot of timber, and so on, is worth. The amount of money in each case is the direct rate at which the units will be converted.

\section{(2) RATES BURDEN}

Any cost, if expressed in or converted to money, may be increased by a burden rate. The burden rate normally represents additional costs at a low level in the organization. The burden rate, with the indirect rate described below, forms the overhead rate.

\section{(3) RATE-ID}

Every cost record submitted by the user has a three-part code attached to it. This code is called the rate identifier, or rate-id, because it identifies the direct and burden rates which are to be applicd to this cost. Of cuurse, if a cost is expressed in direct money, only the overhead rate is applied, and if the cost is total money, neither rate is applied. 


\section{(4) COSTING CODE}

The costing code is the third component of the rate-id, and has no use apart from it. The first two parts of the rate-id are the performing department and resource codes, which means that the applicable rates may be varied by performing department or resource; the costing code is made available to cater for cases where the applicable rate does not depend on these factors.

(5) RATE TABLE

The Rate Table is a table which sets out what direct and burden rates apply to each rate-id. Since every cost is given a rate-id, the Cost Processor is able to refer to this table, using the rate-id, whenever a cost requires conversion to money. or the addition of a burden rate.

(6) UNIT ADJUSTMENT FACTOR (DEPARTIENT EFFICIENCY FACTOR)

The user may attach to any rate-id in the race cable a unll adjuslment factor. The factor is defined as a percentage, and it is applied only to estimate costs which are expressed as a number of men, of hours, or of overtime hours, before the costs are converted to money. For instance, if for a particular rate-id the user specifies a UAF of $85 \%$, all estimate overtime-hour costs which have that rate ID are reduced by $15 \%$ by the Cost System before they are converted to money.

The UAF is normally used to make allowance for the variation in efficiency between work-centers, and so is sometimes called the department efficiency factor. 


\section{(7) INDIRECT RATE}

Any cost which is expressed in, or converted to, money may be increased by an indirect rate. The indirect rate normally represents additional costs at a higher level in the organization. For example, suppose general and adminstrative overheads, director's fees, and so on are estimated to add $20 \%$ to all direct costs. Then the user might define an indirect rate of $20 \%$ by which costs would be extended to total money. If both a burden and an indirect rate are defined for a cost, the cost is extended by the burden rate and the sum thus calculated is further extended by the indirect rate.

(8) CHARGE NUMBER RATE TABLE

The Charge Number Rate Table is the table which defines the user's indirect rates to the Cost Processor. The table relates the indirect rates to charge numbers; that 1 , costs which are accountable to a particular charge number may be extended by the indirect rate defined for that charge number. Thus, whereas the burden rate is attached to the rate-id in the rate table, the indirect rate is attached to work packages identified by charge numbers. Indirect rates may vary by charge number accounting period and cost type.

\section{(9) ACCOUNTING PERIODS}

Except at the highest level of summarization, cost.analysis normally shows the time when costs are incurred, and so costs are assigned to the day, week, month, quarter, or year in which they fall. The time period which the cost analyst chooses is called the accounting period. 


\section{(10) THE ACCOUNTING CALENDAR}

Accounting periods are, for various reasons, not always of the same length. For instance, the period might be the calendar month, or the user may divide the year into eight periods of four weeks and four periods of five weeks.

The Cost Processor allows the user complete freedom to set out an accounting calendar which sules his requlremenls. He may separately define a virtually unlimited number of accounting periods, and may specify the span of each individually. If he prefers not to specify an accounting calendar, the Cost Processor will construct one for him in which the accounting period is the calendar month.

(11) CONVERSION FACTOR

When a cost is submitted as a number of men or man-hours, the Cost System may convert it to man-accounting-periods. Normally a five-day, 40-hour week is defined, so a cost of 400 man-hours is converted to man-accounting-periods as 10 man-weeks.

The Cost System takes account of holidays and nonwork days in performing this conversion. In the example above, if Wednesday was the birthday of the managing director and so a holiday, the cost of 400 man-hours would be converted to man-accounting-periods as the cost of 12.5 man-weeks.

\section{(12) ALLOCATION OF COSTS TO ACCOUNTING PERIODS}

When a cost falls into more than one accounting period, the Cost Processor allocates it according to the number of workdays in each 
period or part-period spanned. This method of allocation is applied to all costs, not only to man-hour costs.

\subsubsection{Report Processor}

The Report Processor (RP) accepts the files produced by any of the three preceding processors, or Independent data from outside the system. From the files, the user may generate either standard or modified reports. A range of standard reports is provided, but the user may specify his own reports using options to select, sort and suppress data, and to control format.

Figure 3.: 3 shows the ways in which data may flow through the system to the Report Processor.

The Report Processor is a collection of programs which print reports from files of data created by the Network, Resource Allocation, $\because$ and Cost Processors or from an independent source. This introduction describes it in three sections. The first section describes the basic way of using the processor; the second section explains how the user can, to some extent; control report format and content; and the third section describes how the user can print reports which he has defined completely.

\section{(1) THE BASIC REPORT PROCESSOR}

'l'he basic Report Processor consists of a control program and between 50 and 60 report-writing programs. The control program reads one or more control cards and executes the report-writing programs specified on them. The user needs to make no modification to any 


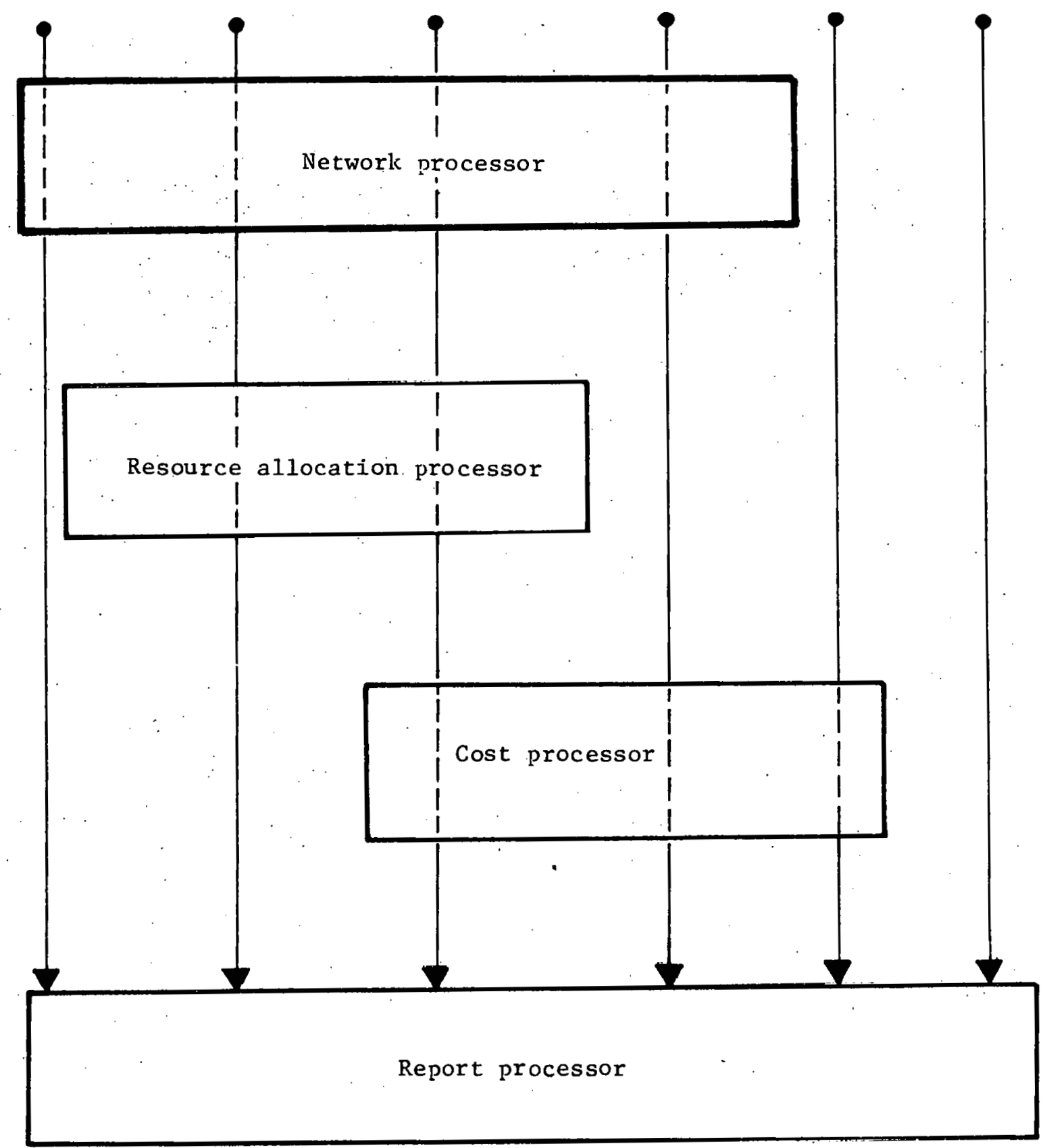

FIGURE 3.3: THE PMS IV SYSTEM 
program if he wishes to process his data in this way. If he executes the standard, unmodified report-writing programs, he can obtain any of a wide range of cost, PERT, precedence, and resource allocation reports which may display data not only in lists and tables, but also in graphs, histograms, and charts. For many purposes the standard reports are sufficient.

(2) CONTROL OVER THE STANDARD REPORTS

The user can control the printing of the standard reports by submitting further control cards. Broadly, the control cards may be used to select data, and to control report formats. Data may be selected by specifying an acceptable set of group or subnet names, an acceptable range of values for particular fields, a. list of unacceptable values for particular fields, or a particular acceptable value for a particular field.: Data may be selected at a particular level of summarization within the time or cost analysis systems. The format of $y$ reports can, to some extent, be controlled. The user may specify the heading line to appear on each page, and may specify the scale to be used for printing histograms. For cost reports only, the user may specify certain other format details and a scaling factor.

Reports can be written that will process request cards that specify complete sorting, formatting, and paging parameters.

Note that some or all of these control cards are likely to be used each time the Report Processor is used. This method of controlling the content and layout of reports is flexible and simple. It makes it possible to construct a report-writing program of general application, 
but on any occasion to direct it to a particular set of data. For this reason the user will probably continue to use control cards even if he has adopted the methods (described immediately below) of completely designing his own reports.

(3) REPORT DESIGN BY THE USER

The user is encouraged to compose his own report-writing programs. He may do this in one of two ways. Firsc, he can take a slandard piougram and adapt it. He can alter the content and positions of headings, the selection and ordering of data, and the symbols used on charts. He can print selected data more prominently; for instance, he might print certain PERT activities, or certain charge numbers, with special spacing, underlining, or flags. Normally, this sort of adaption is extremely simple, particularly in the case of PERT time and precedence reports. Second, he may design and write his own program. The Report Processor offers the user what is, In effect, a very high-level language, designed to make report-writing as easy as possible. The user will find that writing his own programs ranges from the extremely simple to the rather difficult. To construct a PERT time report-writing program whose outlines are similar to those of a standard report might take just a few minutes. However, it would naturally take longer to compose a sophisticated cost report program. 
CHAPTER IV

\section{Project Services}

Purpose, Approach, and Definitions

\subsection{Introduction}

On a construction project the size of a nuclear power station, Project Services normally performs the following functions:

Payro11

Timekeeping

Accounting

Personne1

\section{Computer Services}

While not providing the same potential for improved performance through better information management as material tracking or field construction contro1, these are nevertheless essential functions which must be performed. In fact, payroll and accounting are normally the first functions to be computerized at a construction site.

\subsection{Payro11}

The primary function of payroll processing is to provide weekly paychecks and earning statements to craft and overhead employees; payro11 must also comply with Federal, State, and local regulations regarding reporting of taxes, provide required reports to unions, and provide labor cost data to Cost Engineering. To be more spectfic, a construction payroll system should provide the functions of accumulating 
hours worked at yarious rates of pay, calculating pay for straight time and overtime, deducting required taxes and other items; reporting employee deductions and: employer contributions to union benefit funds, reporting withholding tax deducted, producing a billing for the owner, and accumulating cost data for use by the Labor Cost System.

Payroll has the following relationships to other functions:

Taxes - interfaces with $941 /$ W2 tax repuiling functions

Average Rates - compures average rate for each craft and passes this data to the Labor Cost System

Personnel data - may interface with personnel systems to report vacation days and sick days, record termination date, salary increases, etc.

To perform these functions, a payroll system requires the following data:

Foreman's Time Cards (craft)

Weekly Employee Time Cards (Salaried and non-exempt)

Payroll Prelist (or list of all employees and their hours worked)

New Hires/Terminations

Salary/Rate Changes.

The following data is generated while processing the payroll:

Gross Pay and Deductions

Employer Contributions

Average Craft Rates

Owner's Billing 
The following steps are followed in performing the payroll:

Process craft employee hours from Foreman's Daily Time Cards onto Daily Time Check and Weekly Summary Sheet. Verify with Attendance Clock records.

Post hours worked to Payroll Prelist as follows:

- from Daily Time Check and Weekly Summary Sheet (craft)

- from weekly Employee Time Cards (salaried and non-exempt)

Process Payroll Prelist against Payroll System, producing payroll checks and associated reports.

The following reports are typically produced from a payroll system:

Payroll Prelist

Payroll Checks and Earnings Stubs

Payro11 Reg1ster

Tax Summary

Craft Summary

Union Fringe Benefit Supplement

\subsection{Accounting}

Accounting at a construction site consists primarily of the accounts payable function, although some of the accounts receivable functions may also appear. This discussion is restricted to accounts payable only. The purpose of the accounts payable function is to provide prompt processing and payment of vendor invoices, including payment and reporting of taxes. Accounts payable relates to other functions at the 
construction site as follows:

Purchase Orders - received from Purchasing

Material Receiving Reports - received from Warehousing

Expenditures - pass to Cost Engineering

The following data is required for accounts payable:

Purchase Orders

Receiving Reports

Vendor Invoices

In processing accounts payable information; the following data is generated:

Discounts

Tax rates and accrued tax

Accounts payable processing includes the following elements:

Check invoice against Purchase order for unit price, quantity, freight, and discount terms

Check invoice against receiving report for quantity and freight. terms

Calculate discounts and determine taxable rates

Calculate accrued tax and net due the vendor

Complete Invoice Approval Form (include cost code)

Prepare weekly material billings for owner

The following items are produced as outputs of the accounts payable function:

Accounts Payable Checks

Check Register 
Accounts Payable Register

Accounts Paid Register

Cost Distribution by Check Register

Material Billing

Tax Distribution Report

Vendor Listing

\subsection{Personne1}

Personnel systems at construction sites are usually fairly simple, involving manual record files or simple computer files. More sophisticated systems may be used at the constructor's or utility's home office; these systems may provide on-line inquiry into a data base containing a wide range of employee information. However, access to this personal employee information should be restricted for privacy reasons; thus, access to the company's personnel management system is usually not avallable to a construction project.

One project surveyed uses a simple computer file to record the following information: title, name, department, date of hire, date of last increase, percent of last increase, and current salary. Reports can be produced, with or without current salary, in various sequences.

While they may not involve data processing, the following functions are usually part of the personnel operation at a construction site: 


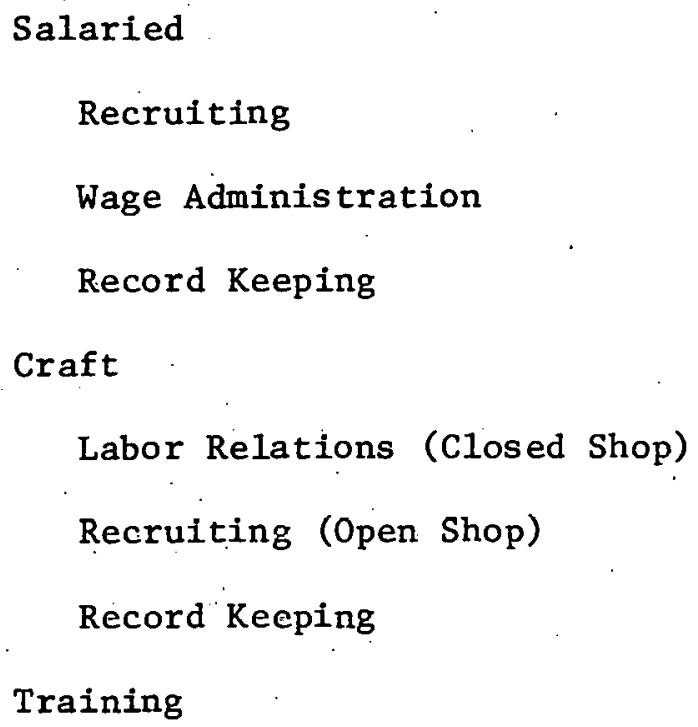

\subsection{Computer Services}

This function normally consists of performing data entry and editing, using remote job entry (RJE) facilities to run systems on the home office computer, and printing, bursting, decollating, and distributing the various reports. All this sounds simple enough, until the volume of work is considered. At one project surveyed, 19 different systems were being run on a regular basis from the jobsite RJE terminal. Five full-time operators were used for data entry, the computer terminal was used for three shifts per day, and the print volume reached $7,500,000$ print lines per month during peak construction activity.

Another alternative available to a construction site involves the use of an on-site computer. This is normally thought of as a minicomputer, although with the volume of work occurring at a nuclear construction site, a small to medium general purpose computer can 
probably be justified. A split of computing functions between the job site and the home office may be used, with the simpler functions being performed at the job site, while the home office computer provides service for large file searches, payroll processing for all company projects, etc.

\subsection{Existing and Projected Systems}

For the utilities and construction companies whose systems were studied, all are currently using the same basic types of systems for supporting project services. These are typically stand-alone systems, running in a batch environment, using sequential files. Transactions may be passed from one system to another using magnetic tape or other types of sequential transaction files.

One exception to the above statement is the Tennessee Valley Authority, which is currently developing a Project Cost Accounting subsystem, to be run as an integral part of MAMS (Materials Management System). See Chapter II of Appendix B for a description of the MAMS system.

The following is a brief description of the systems currently in use at several projects:

Daniel International

Farley Nuclear Plant - Alabama Power Company

- Payroll - Weekly processing of timecards to produce employee paychecks; feeds average craft rates to Labor Cost System (Payroll system Is unique to this project). 
- Accounts Payable - Twice-weekly processing of outstanding invoices and preparation of payment checks.

(Project uses RJE terminal to access Southern Services Datacenter in Atlanta.)

Callaway Project - Union Electric

- Payroll - Weekly processing of standard Daniel payroll system (with enhancements for union benefits reporting) to produce employee paychecks; feeds average craft rates to Labor Cost Systen.

- Accounts Payable - Weekly processing and payment of involces under the control of the Project Accountant (individual invoices may be selected for payment or held until the next cycle). Expenditure transactions are passed to the Material Cost System manually.

(Project uses RJE terminal to access Union Electric Datacenter in St. Louis).

Enrico Fermi Unit II - Detroit Edison

- Payroll - Standard Daniel payroll system run weekly to pay a11 Daniel employees and some subcontractor employees; Labor Cost System not used due to this being a construction management job.

- Accounts Payable - Performed by Detroit Edison. 
(Project uses RJE terminal to access Daniel International Datacenter in Greenville, South Carolina).

Wolf Creek Project - Kansas Gas and Electric/Kansas City Power and Light

- The Payroll and Accounts Payable systems used on this job are essentially identical to those used at Callaway.

(Project.uses RJE terminal to access Danfel International Datacenter in Greenville, South Carolina).

\section{Duke Power Company}

All payroll and accounting functions are performed at the company headquarters in Charlotte, North Carolina. Hours worked by each employee are reported by each project's Payroll Section weekly via a scannable document; these documents are read by an optical scanner. The payroll for all projects is run biweekly; the checks are printed in Charlotte and delivered to the projects.

Accounts Payable is handled almost entirely in Charlotte. Invoices are approved by each project's Accounting Section and forwarded to Charlotte for weekly processing. The Plant Accounting System (run in Charlotte) picks up Labor Cost data from the Payroll System and Material Cust data from Accounts Payable and merges these two to produce a total picture of project cost. 


\subsection{Productivity Reporting and Contro1}

We have discussed six canned systems which can be purchased from various software houses. This is the approach taken by most of the companies surveyed. It was found that of ten the canned packages do not include all the systems needed and the contractor or utility. sometimes finds it necessary to design ad hoc systems to fill in the gaps. TThe following two sections are examples of two of these types of systems.: Each deals with the problem of productivity reporting and analysis. These reports show the different approaches taken by Duke Power Company and Daniel International to solve these thorny problems.

\subsubsection{Duke Power Company - Project Planning and Performance}

Program: Manhour Quantity Analysis System and Quantity

Control System

Early in the construction phase of McGuire Nuclear Site, it became apparent to management that a realistic basis for evaluation of construction performance was necessary. Published standards for similar work in industry were available, and some historical information for previous non-nuclear work in Duke Power existed. However, there was no really good information based strictly on Nuclear Power Construction as Duke Power performs it. It was also desired that a method of comparison among various work crews performing similar tasks be provided. Further, a means of projecting and tabulating the schedule of work performed over the estimated duration of the task, with an updating 
of actual work accomplished to monitor progress, would be worthwhile. A11 of these features would be useful both in managing the current job and in making estimates more realistic for future construction.

The Man-hour Quantity Analysis System and the Quantity Control System are two modules of the Project Planning and Performance Program (P4), a total management concept aimed at controlling and optimizing the cost and duration of construction generating facilities. Purpose and Scope

This is a computer application designed to establish a uniform method of collecting, tabulating, and reporting manhours and completed quantities of work as well as displaying projections of work schedules and standards against which the progress and productivity may be measured.

The Man-hour Quantity Analysis System is designed to do the following :

(1) Provide a basis for evaluating the man-hour per unit of quantity completed figure for each account (by crew) against a standard man-hour per unit figure.

(2) Provide status report by account and crew to indicate the productivity of each account relative to the standard figure associated with each account.

(3) Provide a historical file to be referenced by future major generating projects to indicate an actual man-hour per unit installed productivity figure for each account.

The Quantity Control System is aimed at achleving the following:

(1) Forecast estimates of quantity completions by bi-weekly 
periods and post actual quantities completed against these estimates.

(2) Determine, by individual account analysis, how the total project is progressing.

(3) Prepare, on an exception basis, reports showing the activities which are behind schedule.

System Description

The responsibility for setting up the account masters and bi-weekly period quantity estimates rests with the $\mathrm{P}-4$ section at each site, as does the subsequent input of actual data and the handling of output reports.

There are basically two types of input:

(1) Man-hours expended by account

(2) Quantities of work performed in that account

Actual time sheets are coded by $\mathrm{P}-4$ personnel for work order and account number: This is both to insure accurate coding by a small, central, wel1-trained group, and to aid the $\mathrm{P}-4$ group in keeping up with the areas in which different crews are working.

Quantities of work are given on a 2-week basis, being entered and run on the Thursday or Friday after the payroll run is made. Quantities for formwork, rebar, and steel are derived from take-offs of construction drawings. These quantities are given as the work is performed. Actual concrete yardage is used. This is taken from concrete placing tickets. Piplng, welding, placement of mechanical equipment, and other more specialized activities and accounts are reported via various documents and interpreted by the $\mathrm{P}-4$ section for purpose of input to the Man-hour 
and Quantity systems. In some instances, no specific documentation is applicable and the $\mathrm{P}-4$ people are trained to determine quantities by visual observation.

A formal Construction Department Procedure has been published and issued covering the administration and mechandes of these two systems as performed at the construction site.

Performance standards were established both empirically and from reference texts, plus fudgment of construction management. All standards have been subject to revision as actual experience provides more specific information. Theoretically, as one construction site is completed, there is enough good data for all accounts so that the performance at that site can be used in establishing realistic but somewhat more ambitious standards and goals for the next site. The specific method of development of the initial standards at McGuire is as follows.

In developing the standards used at McGuire, three sets of basic figures were obtained or calculated:

(1) Man-hours per unit of production based on actual performance at Marshal1 1 and 2 .

(2) Man-hours per unit of production based on actual performance at Allen 1 and 2 .

(3) Derivations from standard textbook figures for similar activities (Source: Construction Estimates and Costs - H.E. Pulver). The proposed standards; then, were based on these three sources, plus discussion with personne1 at McGuire, Mt Holly Storage Yard, and Charlotte Construction Services. There were certain specific considerations 
due to the limited availability of data:

(1) Reactor building and auxiliary building were considered the same as the turbine bullding, for most steel and concrete situations, where no direct information on these structures was available. This was discussed with various people in the department and the consensus was that it would be acceptable in the initial development of standards. As actual experience provides better information, the standards are being updated.

(2) Generally, in setting the figures,

(a) If all three figures were close, the lowest, or most strict, was taken.

(b) If there was wide variation among all three, an average was takẹ.

(c) If Marshall and Allen generally agreed, and book figure was significantly different, the book figure was thrown out and a standard figure slightly lower (more strict) than Marshall or Allen was proposed.

(3) While it would have been preferable to use Oconee information in many instances where nuclear type construction was involved, this was not done because there was not suffictent Information of this type available from Oconee records. This fact only further serves to point out the necessity for good data base information of this type.

Output reports are detailed in a previous section, and cover a multitude of topics and summaries of man-hour and quantity data. The data may be organized by crew, by account total, or by exception 
DUKE, POUER COMPANY

CONSTRUCTION MANAGEMENT SYSTEM

WORK ORDER NO 10402
ACCT NO 340512 QUANTITY UNIT CUYD AB 2 INT WALL-PLACE CONCRETE

WORK ORDER NO 10402
ACCT NO 340512 QUANTITY UNIT CUYD AB 2 INT WALL-PLACE CONCRETE

DATE $4 / 20 / 75$

$\begin{array}{cccc} & \text { MANHOURS } & \text { QUANT } \\ \text { U. CREW } & \text { EXPENDED } & \text { COMP } \\ \text { NO } & \text { THIS PERIOD } & \text { THIS } \\ & & & \\ 000 & 0 & \\ 001 & 0 & \\ 002 & 0 & \\ 003 & 0 & \\ 004 & 42 & \\ 005 & 0 & \\ 009 & 0 & \end{array}$

$\begin{array}{lr}\text { QUANTITY } & \text { MANHOURS } \\ \text { COMPLETED } & \text { EXPEND } \\ \text { THIS PERIOD } & \text { TO DATE } \\ 0 & 58 \\ 0 & 3 \\ 0 & 752 \\ 0 & 27 \\ 702 & 2578 \\ 0 & 17 \\ 0 & 829\end{array}$

QUANTITY STANDARD

COMPLETED MANHOURS

TO DATE PER UNIT

THIS P
MANHOURS
PER UN

0.0
0.0
0.0
0.0
0.4
0.0
0.0

THIS PER.

CREU MANHOUR PER QUANTITY ANALYSIS

$\begin{array}{rll}0 & 0.7 & 0.0 \\ 0 & 0.7 & 0.0 \\ 1211 & 0.7 & 0.0 \\ 0 & 0.7 & 0.0 \\ 5120 & 0.7 & 0.4 \\ 0 & 0.7 & 0.0 \\ 1412 & 0.7 & 0.0\end{array}$

DEVIATION

TO DATE

DATE DEVIATION

MANHOURS MANHOURS

PER UNIT PER UNIT PER UNIT

$\cdot$

$\begin{array}{lll}0.0 & 0.0 & 0.0 \\ 0.0 & 0.0 & 0.0 \\ 0.0 & 0.6 & 0.0 \\ 0.0 & 0.0 & 0.0 \\ 0.3 & 0.5 & 0.2 \\ 0.0 & 0.0 & 0.0 \\ 0.0 & 0.5 & 0.2\end{array}$

ASTERISK INDICATES

CREW PERFORMANCE

IS OVER STANDARD

THIS PERIOD TO DATE

FIGURE 4.1: DUKE POWER COMPANY CREW MANHOUR PER QUANTITY ANALYSIS 
DUKE POUER COMPANY

CONSTRUCTION MANAGEMENT SYSTEM

QUANTITY BY BIUEEKLY PERIOD

WORK ORDER NO 104J2 ACCOUNT NO 340512

\section{QUANTITY UNIT CUYD}

ACCOUNT DESCRIPTION

$A B Z$ INT WALL-PLACE CONCRETE

\section{$\mapsto \quad$ BIUEEKLY}

$\begin{array}{lr}01 & 0 \\ 02 & 158 \\ 03 & 575 \\ 04 & 617 \\ 05 & 320 \\ 06 & 116 \\ 07 & 79 \\ 08 & 0\end{array}$

\section{QUANTITY \\ ESTIMATED}

BY PERIOD

\section{QUANTITY \\ DEVIATION}

BY PERIOD

QUANTITY
COMPLETED

TO DATE

79
80
383
383
383
383
236
136

$-79$

78
1,25

1,22
228

-23
$-23 ?$

$-23 ?$
$-3 ?$

$-136$

\section{QUANTITY \\ ESTIMATED}

TO D ATE

0
158
663
2274
1634
1780
2879
1879

79

259

542

925
1308

1.

1827

1963
DATE $4 / 11 / 75$

ASTERISK INDICATES

THAT WORK COMPLETED

IS LESS THAN EST.

QUANTITY

TO DATE

BY PERIOD

TO DATE

-79
$-\quad 1$
121
349
326
89
52
-84

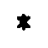

*

$*$
$*$
$*$
$*$ 
condition to show potential problem areas. The reports are subdivided and distributed to applicable foremen and managers by the $\mathrm{P}-4$ section as deemed suitable for their specific needs and interests. It is the objective to supply only that information needed and used, and not to burden any supervisor or manager with extra material.

A number of one-time analytical reports for special management purposes, such as Project Review Meetings, are taken from the routine computer output reports described herein, and these two systems also furnish much of the data used in preparing the site's Quarterly Status Reports.

\subsubsection{Daniel International Productivity Reporting}

For construction projects of the size, complexity, and duration of nuclear power plants, it is desirable to be able to measure work performance, both in quality and quantity, of the work crews on a routine basis.

The Man-hour Quantity Analysis System uses the computer to collect, sort, compute, and print out information which allows evaluation of man-hours per unit of quantity completed by crews and comparing this to a standard.

The Quantity Control System simflarly uses the computer to assimilate information on the quantities of each element of work, estimates of amounts completed per bi-weekly period, and measurement of actual progress against the estimated quantities. 
MAN-HOUR QUANTITY ANALYSIS

AND

QUUANTITY CONTROL

SYSTEMS

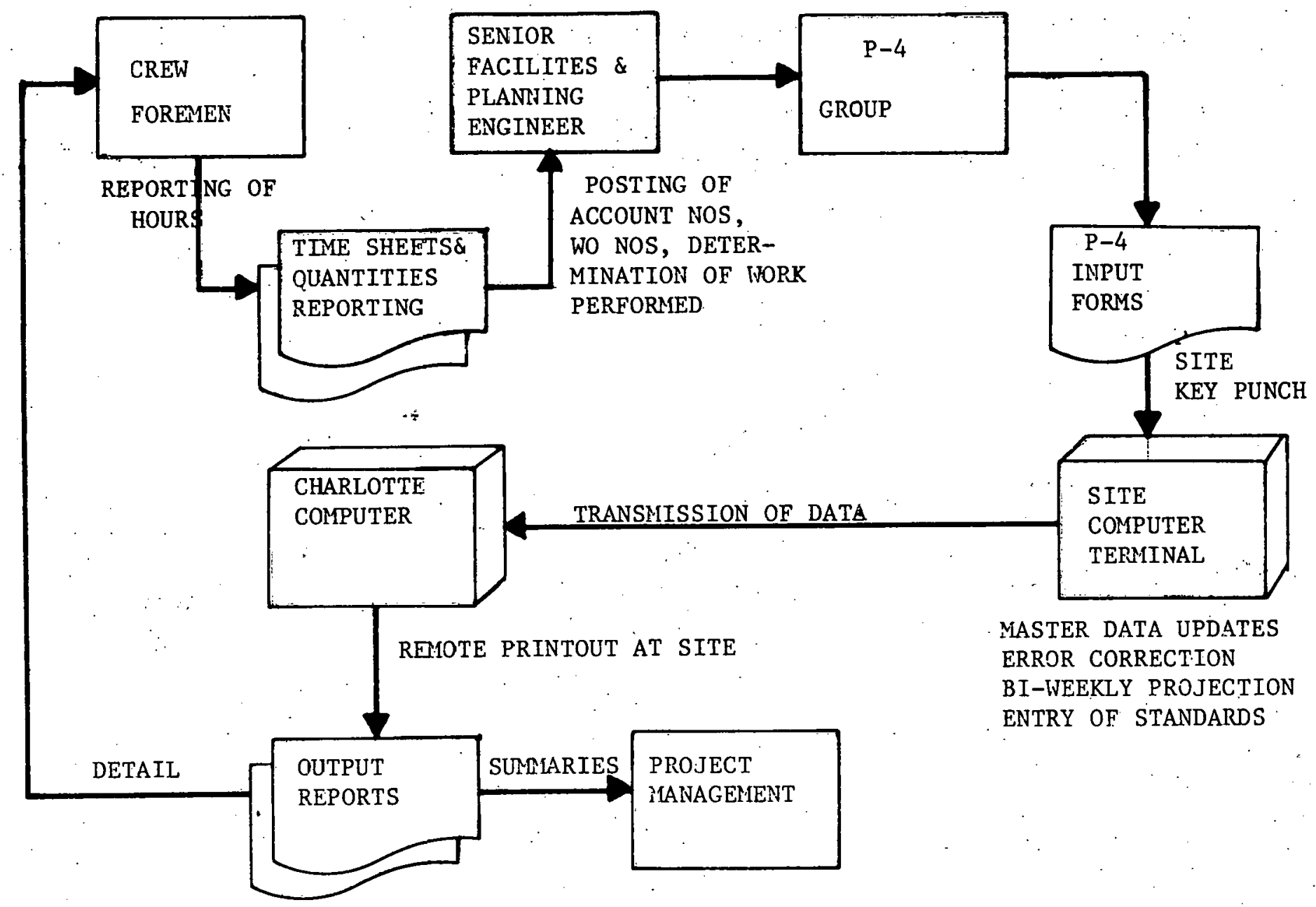

FIGURE 4.3: DANIEL ILAN-HOLR AND QUANTITY. ANALYSIS AND OQEALITY CONTROL - \$YSTEM 
MAN-HOUR ANALYSIS AND QUANTITY CONTROL *

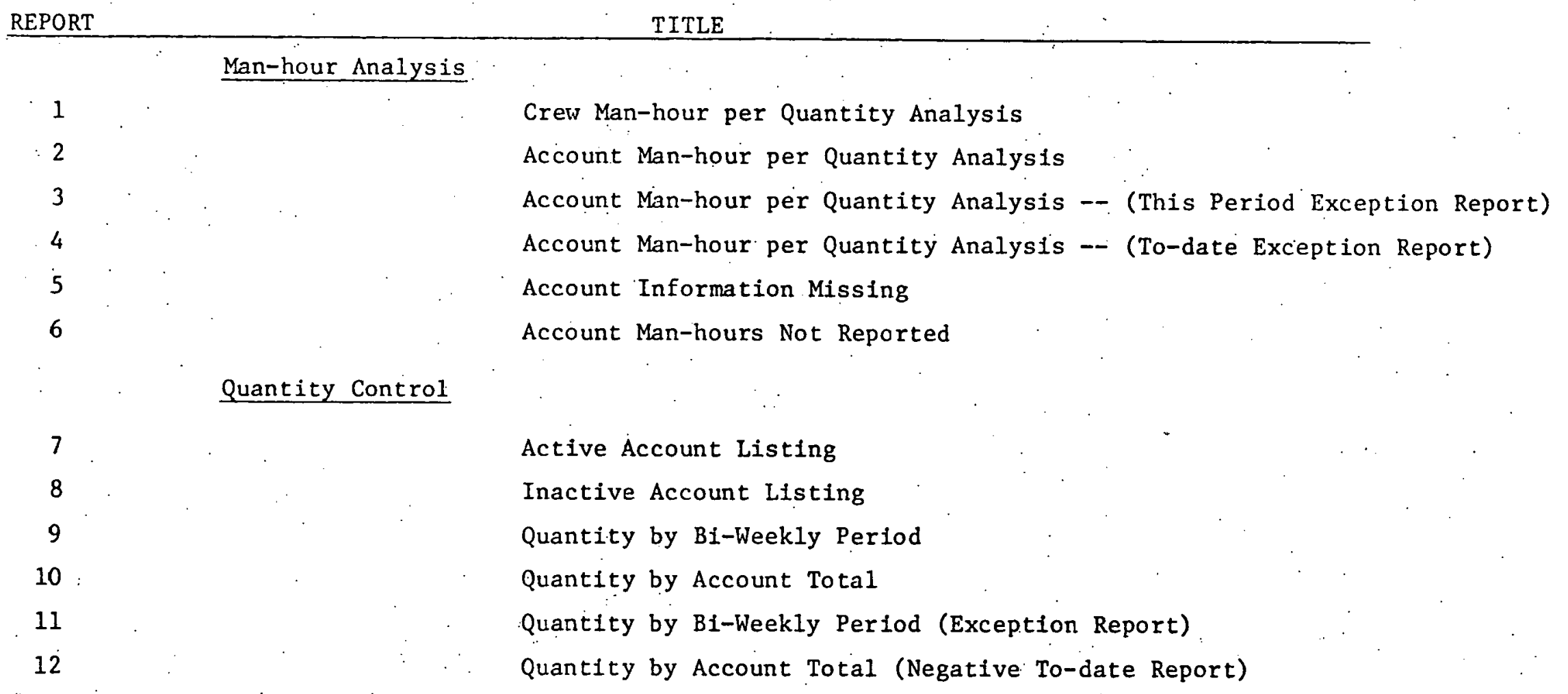

* Descriptions and functions of these reports are given on following pages.

TABLE 4.1: MAN-HOUR ANALYSIS AND QUANTITY CONTROL 
In short, the Man-hour Analysis System tells how well the work is being done, and the Quantity Control System tells how much is being done.

The objectives of the Man-hour Quantity Analysis and Quantity Control Systems are to:

(1) Provide a basis for evaluating the man-hour per unit of quantity completed figure for each account (by crew) against a standard man-hour per unit figure.

(2) Provide a status report by account and crew to indicate the progress of each account relative to the standard figure associated with each account (activity).

(3) Provide a historical file to be referenced by future major generating projects to indicate an actual man-hour per unit installed productivity figure for each account (activity).

(4) Forecast estimates of quantity completions by bi-weekly periods and post actual quantities completed against these estimates.

(5) Determine, by individual account analysis, how the total project is progressing.

(6) Prepare, on an exception basis, reports showing the activities which are behind schedule. Crew Man-Hour per Quantity Analysis Report

This report contains for each account crew designations showing man-hours expended and quantity completed for the current bi-weekly period and to date. This report also contains where a standard manhour per. unit amount is entered the man-hour per unit completed deviation 
from the designated standard for the current period and to date for each crew. A negative (-) sign indicates that the actual man-hours expended per unit exceeds the standard man-hours per unit figure. The number of consecutive bi-weekly periods that a crew has negative deviation of man-hours per unit completed for this period and to date are also shown. An account total is also printed which summarizes all the crews within an account.

Account Man-Hour per Quantity Analysis Report

This report shows only the account totals within each work order from the above report. This is, in effect, an account summary report and when greater detail is desired concerning an account then the Crew Man-Hour per Quantity Analysis Report is referenced. Account Man-Hour per Quantity Analysis Report (This Period Exception Report)

This report shows account totals within each work order which have negative deviation of man-hours per unit completed for this period. Account Man-Hour per Quantity Analysis Report (To Date Exception Report)

This report shows account totals within each work order which have negative deviation of man-hours per unit completed to date. Account Information Missing Report

This report shows the accounts which were not set up using bi-weekly estimates, but were created by entering a quantity completed entry for this account. The blank fields indicate areas where information for this account is needed. If this account has not been previously estimated then this information is entered at the same time that bi-weekly estimates are entered. If this account already contains bi-weekly period estimates 
then this information is entered separately.

Account Man-Hours Not Reported

This report shows crews within accounts (By Work Order) to which quantity was reported for the current bi-weekly period but no man-hours expended were reported for this crew. A form may be used to post manhours expended to these crews. If the man-hours were recorded to the wrong account-crew, then these man-hours must be subtracted out of this account-crew and recorded to the correct account-crew. This condition can also exist when man-hours are reported and quantity is not reported for an account. The same correction procedure applies. Active Account Listing Report

This report shows the active accounts (account with unreported quantity estimated bi-weekly periods) to which actual quantity completed should be reported. It is necessary to refer to the Man-Hour Quantity Analysis System for this account to determine the crew numbers to use in each account for reporting quantity completed. Inactive Account Listing Report

This report shows accounts which do not have any unreported quantity estimated bi-weekly periods remaining. These accounts may still be active and completed quantity may. be reported against these accounts for the current bi-weekly period but this also includes an estimate for the additional bi-weekly period. The reason for this account being on the inactive account list is shown beside each account. Quantity by Bi-Weekly Period Report

This report shows for each account by bi-weekly period the quantity 
estimated and completed (for each period and to date) along with the deviation of the actual completed quantity from the estimated quantity. An asterisk will indicate that the designated bi-weekly period has a negative quantity deviation for this period or to date. Quantity by Account Total Report

This report shows the current status of all accounts within work order regarding the to date actual completed quantity vs. the estimated to date quantity. Also shown is the total estimated quantity remaining to be completed and the number of estimated bi-weekly periods remaining. This report is a summarization of the Quantity by Bi-Weekly Period Report. Quantity by Bi-Weekly Period - (Exception Report)

This report shows the accounts and accompanying bi-weekly periods for which actual quantity completed figures have been worked but which do not contain an estimated quantity amount. It will be necessary to report an estimated quantity figure to the bi-weekly periods shown on this report:

Quantity by Account Total - (Negative To Date Report)

This report shows the accounts with a negative deviation (meaning behind schedule) of the to date quantity completed against the estimated quantity. This report will show on a summary basis the accounts which are behind schedule and the Quantity By Bi-Weekly Period Report can show which bi-weekly periods were actually behind schedule. 


\section{THIS PAGE}

\section{WAS INTENTIONALLY \\ LEFT BLANK}


INFORMATION MANAGEMENT FOR NUCLEAR POWER STATIONS

APPENDIX B 
APPENDIX B

TABLE OF CONTENTS

$\underline{\text { Page }}$

CHAPTER 1: Materia1 Tracking Systems --

Purpose, Approach, and Definitions

1.1 Purpose and Approach $\ldots \ldots \ldots \ldots \ldots \ldots \ldots \ldots \ldots, 1$

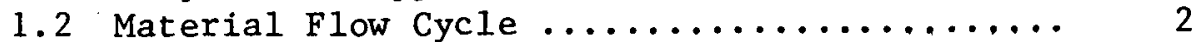

1.3 Organization of Study $\ldots \ldots \ldots \ldots \ldots \ldots \ldots \ldots$

1.4 Design Procurement .................. 7

1.4.1 Steps in Design Procurement ......... 8

1.5 Engineering Quantity Take-Off ........... 12

1.5.1 Objectives of Engineering Quantity

Take-off .................... 13

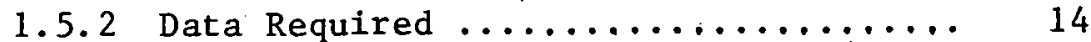

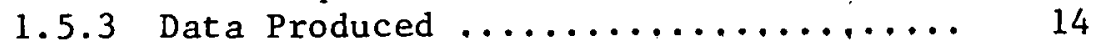

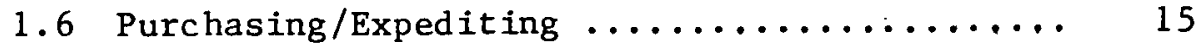

1.6.1 Purchasing Functions ............ 16

1.6.2 Purchasing Information ............ 16

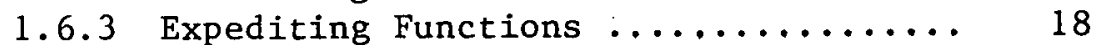

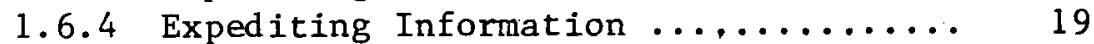

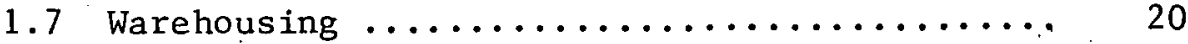

1.7.1 Warehousing Function ............ 20

1.7.2 Warehousing Information .......... 22

CHAPTER II: Existing and Projected Systems

2.1 Introduction $\ldots \ldots \ldots \ldots \ldots \ldots \ldots \ldots \ldots \ldots \ldots \ldots . \ldots \ldots$

2.2 Warehouse File Processing, A Manual System Daniel International ................. 26

2.3 Improved Material Control System (IMCS) -

Tennessee Valley Authority ............ 31

2.4 Material and Equipment Status System (MESS) Duke Power Company ................... 2.4.1 Scope of Materials Tracking .......... 2.4 .2 MESS Output .................

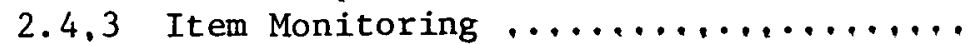

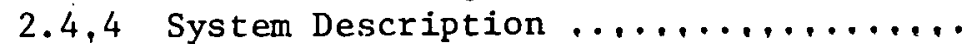

2.5 Piping Material Inventory Control (PMICS) -

Duke Power Company ...................

2.6 Stores Accounting System (SAS) - Duke Power

Company .......................

2.6.1 SAS Master Files ..............

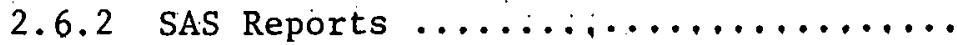


2.7 Punch List Program - Georgia Power Company. .

2.8 Quantity Tracking System (QTS) - Bechtel Power Corporation .................. 56

2.9 Material Control Module - GPU Services ..... 59

2.10 Material Management Information System (MMIS) - Florida Power Corporation ........ 60

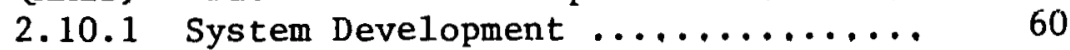

2.10 .2 MIS output ................ 61

2.11 Material Management System (MAMS) - Tennessee Valley Authority ................

2.11.1 Engineering Subsystem ..........

2.11.3 Power Stores Inventory Subsystem .. 76

2.11.4 Accounts Payable Subsystem ....... 77

2.12 Major Project Management System (MPMS) -

Georgia Power Company ............... ' 80

2.13 Structure of Numbering Systems ........., 82

2.13 .1 QTS ..................... 83

2.13.2 System in Use at Vogtle Nuclear

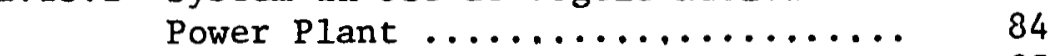

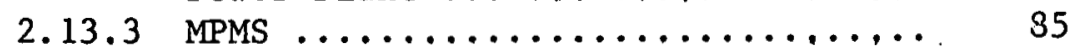

2.13 .4 Punch List $\ldots \ldots \ldots \ldots \ldots \ldots \ldots \ldots . \ldots 2$

CHAPTER III: Problems with Existing Systems

3.1 Introduction ..................... 95

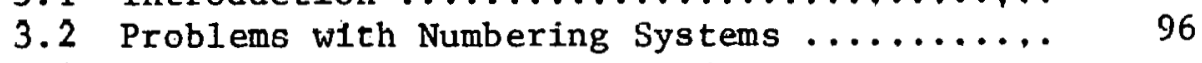

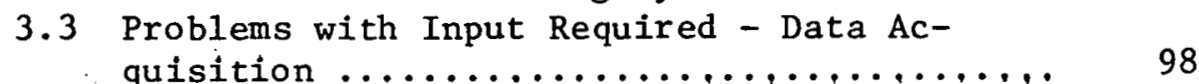

3.4 Problems with Output Usability - Timeliness and Forn of $0 / P \ldots \ldots \ldots \ldots \ldots \ldots \ldots \ldots$

3.5 Problems with Implementation ............. 101

3.6 Problems of Integration Between Systems .... 102

3.7 Problems Concerning Over-Design of System ... 103

3.8 Organizational Problems ........................ 104

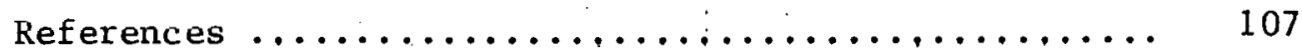

ADDENDA
Addendum A: Application Area Outlines Quantity Take-Off
Purchasing/Expediting
Warehousing
Addendum B: Supporting Material for Material and Equipment Status System (MESS)
Addendum C:: Supporting Material for Piping Material Inventory Control System (PMICS) 
Addendun D: Supporting Material for Stores

Accounting System (SAS)

Addendum E: Supporting Material for Punch List

Addendum F: Supporting Material for Material

Management Information System

Addendum G: Supporting Material for Numbering Systems 


\section{THIS PAGE \\ WAS INTENTIONALLY \\ LEFT BLANK}




\section{CHAPTER I \\ Material Tracking Systems -- \\ Purpose, Approach, and Definitions}

\subsection{Purpose and Approach}

Traditionally, the basic components of construction have been referred to as the four "M's" -- Manpower, Machines, Money, and Materials. Materials are a particularly important factor in nuclear power construction projects, since safety and quality control considerations require that a sizable amount of information be maintained regarding the physical components of the construction. From the time that a material item is defined in the Engineering Phase of the project's development until a nuclear power station is decommissioned, material components develop a "pedigree" and a "paper trail" consisting of a wide variety of information. Such diverse items as the heat number of the billet from which the component was rolled, reference requisitions, bills of materials, line item numbers, purchase orders pertaining to the item or component, vendor and owner numbers, to name just a few, must be maintained. The list of information which must be monitored for a particular weld, valve, cable, or concrete pour is quite formidable.

The approach of this appendix is to examine existing systems to establish a "state of the art" in systems presently in operation or under development for the control of materials information. Descriptions and analysis of several systems which define an existing "state of the art". are presented in Chapter II. 


\subsection{Material Flow Cycle}

In order to provide a framework for this study, it is necessary to define the life cycle of material items which are to be monitored and controlled. As noted, this cycle begins when the item or material component is incorporated into the design by the engineer, and ends when either the component is replaced or the entire system is deactivated. The periods during which the information environment surrounding a component is most active and dynamic are during the design, procurement, cunstruction, and start-up phases. During these periods, the basic component "pedigree" is established. Therefore, our investigation will concentrate on these periods of time. Discrete actions which affect the information "weight" associated with each material item are shown in the flow diagram of Figure 1.1. As the item takes on a greater level of detail, the data content associated with it increases.

Four partially overlapping application areas are required and performed during the component flow cycle shown in Figure 1.1. Muring the following discussion, these application areas will be referred to as:

(1) Design Procurement

(2) Engineering/Quantity Take-off

(3) Purchasing/Expediting

(4) Receiving/Warehousing

Addendum A contains abbreviated outlines of the following descriptions. Activities 1 to 8 in the figure are normally considered to be within the Design Procurement function as defined in its broadest sense. 


\begin{tabular}{|c|c|c|c|c|c|}
\hline $\begin{array}{l}\text { 1. Component } \\
\text { designated on a } \\
\text { drawing. }\end{array}$ & $\begin{array}{l}\text { 2. Component is } \\
\text { taken-off drawing } \\
\text { and listed on a } \\
\text { Bill of Materials. }\end{array}$ & $\begin{array}{l}\text { 3. Requisition is } \\
\text { prepared, listing } \\
\text { full material spech } \\
\text { QC requirements. }\end{array}$ & $\begin{array}{l}\text { 4. Approved by } \\
\text { (a) Engineer } \\
\text { (b) Management } \\
\text { (c) Cost Engineer }\end{array}$ & $\begin{array}{l}\text { 5. Purchasing re- } \\
\text { quests quotations } \\
\text { from vendors. } \\
\text { rendor selected. }\end{array}$ & $\begin{array}{l}\text { 6. Purchase Order } \\
\text { prepared, typed, } \\
\text { distributed. }\end{array}$ \\
\hline
\end{tabular}

$\begin{aligned} & 7 . \text { Expediting } \\ & \text { tracks delivery } \\ & \text { status until } \\ & \text { item arrives. }\end{aligned}$
.

9.QC inspector checks for con-

formance, approves or places "Hold."

10. Recelving Report is issued and distributed. 11. Component is stored - records establish location.

\begin{tabular}{|c|c|c|c|c|c|}
\hline $\begin{array}{l}\text { 13. FMR or BOM } \\
\text { used to update } \\
\text { inventory reco:ds } \\
\text { (deduct). }\end{array}$ & $\begin{array}{l}\text { 14. Engr. \& QC } \\
\text { approval for } \\
\text { installation. }\end{array}$ & $\begin{array}{l}\text { 15. Subcomponent } \\
\text { installed and } \\
\text { traveler signed. }\end{array}$ & $\begin{array}{l}\text { 16. Traveler put } \\
\text { on hold pending } \\
\text { sys tem checkout. }\end{array}$ & $\begin{array}{l}17 . \text { Record of } \\
\text { installation re- } \\
\text { corded in progres } \\
\text { reporting system. }\end{array}$ & $\begin{array}{l}\text { 18. Component ac- } \\
\text { cepted by start- } \\
\text { up, traveler } \\
\text { compl. \& filed. }\end{array}$ \\
\hline
\end{tabular}

FIGURE 1.1: LIFE CYCLE OF A MATERIAL COMPONENT 
Activities 2 and 3 pertain directly to the Engineering/Quantity Takeoff application area. Purchasing/Expediting is performed to procure and move the material items to the construction site (activities. 5 through 8). Receiving/Warehousing is concerned with how the material is handled, stored, and issued after arriving on the site. This application area is described in activities 8 through 15. Artivities 15 through 18 pertain to the material interface with other major functions, to include Quality Control, Field Installation, and acceptance of the installed material by the Start-Up team.

The activities shown in Figure 1.1 are orfented in particular to the procurement of discrete components, such as pumps, transformers, major spools, etc., from a fabricator at a remote location, which arrive ready for installation. Bulk materials which are used to fabricate construction components on-site (i.e., used in field fabrication) have a slightly different cycle. This is indicated by the PMICS (Piping Material Inventory Contrn1 System) described in Chaptcr II. Typical of those items which are bulk procured to support field fabrication are small bore ( $2 \frac{1}{2}$ inch diameter and below) spool material, structural steel for field-fab hangers, cement, aggrcgate, and certain electrical cables. Engineering personnel estimate quantities of bulk materials required for field fabricated: items based on drawings. Requisitions are prepared, approved, and the materials are procured. As bulk materials are issued in the field, a running account is maintained indicating the amount issued against the original quantity received. If the level 
of material drops below a reorder point, engineering is notified and corrective action is taken.

\subsection{Organization of Study}

In order to study the problem of Material Tracking, each of the four application areas described above w111 be examined in detail. First, each of the areas will be defined in a general format with emphasis as follows:
(1) Description
(2) Objective
(3) Implied Sub-Functions
(4) Data Required
(5) Data Generated - Reports to Users
(6) Relationship to Other Functions

The emphasis in these discussions will be to establish a base line or reference point against which existing and projected systems can be evaluated. These application area definitions will hopefully provide a frame of reference in terms of which the systems presented in Chapter II can be viewed. Outline discussions of each of the application areas supporting the narrative discussion of this chapter are presented in Addendum A. Given the global description of the function established in this chapter, and the existing state of the art presented in Chapter II, problems and short fall inherent in the existing systems will be discussed in Chapter III. 
This chapter will consider the various interfaces between the Material Tracking System and other major systems such as the Project. Control System, the Plant Performance Control System, and the Field Reporting/Control System. The general relationship between Material Tracking and other major systems is shown in Figure 1.2, It can be seen that the information contained in the Material Tracking programs forms part of a storehouse of information. This storehouse, or data base, is referenced by project management, plant performance control, and field control, which form the project construction team. In the next four sections, the four functions within Material Tracking will be presented in general terms.

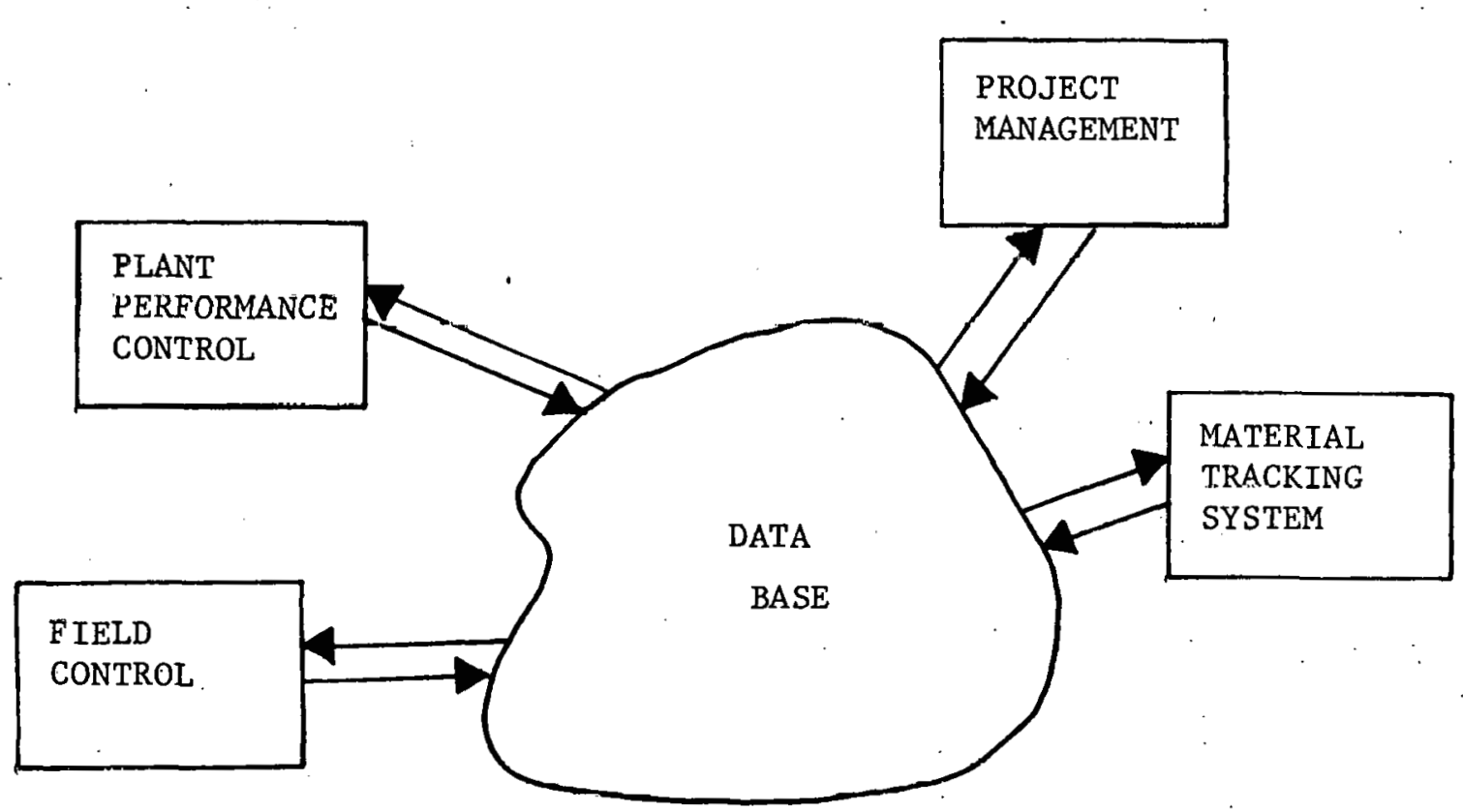

FIGURE 1.2: MAJOR SYSTEM RELATIONSHIPS 


\subsection{Design Procurement}

During the design/construction of a nuclear power plant, a number of relationships have been developed. The five basic approaches are: In-house effort - Total design, procurement, and construction is carried out by the utility's personnel. Duke Power Company works on this basis.

Turnkey project - Total design, procurement, and construction by an engineer constructor acting as agent for the utility. The Vogtle project is being built by Bechtel for the Georgia Power Company on this basis.

Engineer-architect/contractor - Design is carried out by an engineer architect engaged by the utility and construction is completed by a general contractor also engaged by the utility. The Callaway project being built for Union Electric is designed by Bechtel and is being built by Danlel International.

Owner acting as Construction Manager - In this situation the design is carried out by an engineer architect employed by the utility and construction is carried out by subcontractors employed by the utility, with the utility acting as Construction Manager. The Hatch project is being constructed by the Georgia Power Company based on a design by Bechtel with a number of major subcontractors actually carrying out the construction.

Owner design - The utility carries out the major design, acts as a Construction, Manager, and subcontracts out the actual construction. The Diablo Canyon Project was designed by Pacific Gas and Electric 
with Guy F. Atkinson supplying grading and completing major civil work, Pullman Kellogg completing the power piping, Foley carrying out the electrical work, and a number of other minor subcontractors doing other miscellaneous work.

This list does not encompass all relationships as there are of course additional relationships which overlap at varying degrees.

During the design process, engineering personnel interact with vendor designed systems groups, in-house construction advisors, client project personnel, material advisors on material availability, procurement personnel of the engineering firm or of the client purchasing group, and other groups fulfilling vital and responsible roles. Because of the various "modus operandi," it is difficult to describe a single system without inadvertently deleting someone else's concept. But there are certain basic pieces of information that must be accounted for in some fashion. They may go by a different name or they may be part of another piece of information. These "pieces" flow in generally the same direction but perhaps by different paths.

\subsubsection{Steps in Design Procurement}

The following description of the Design Procurement function is intended to describe the pieces of information required and their flow. Not only are there a number of functional steps which must be completed, but in many cases a number of different organizations must be transcended. 
The ensuing political conflicts created often complicate matters. To aid the reader, the flow chart of Figure 1.3 has the same sequenced numbers as the following paragraphs and supports the following discussion:

(1) Once a design and specifications, along with any pertinent description, are complete, it is necessary to continue to develop data which completely describes the inquiry package or bid package to be sent out. The design and specifications must be complete and able to stand on their own as regards what is going to be built. The drawings are the main part of the design.

(2) A Take-off and Bill of Materials (B.0.M.) must be prepared. The design engineer or a group very close to the design group will usually make the take-off and prepare the Bill of Materials. Sometimes, especially with regard to "civil" type items, a Bill of Materials is not necessary, since a list of parts and items is not part of the design. The take-off provides detailed data to be shown in a Proposal Form or on pricing sheets used by some companies. The listing from the take-off is also used in making a complete tabulation of all prices received. The B.O.M. could be used similarly in developing a tabular format to compare all prices in determining the successful bidder.

(3) An initial meeting with the Procurement personnel and engineer in charge of coordinating all aspects of the design is held. The timetable for completing the inquiry package, receiving bids and evaluating them, and then making the award, is determined. This "Package Schedule" is adhered to as closely as possible. A requisition number is obtained 


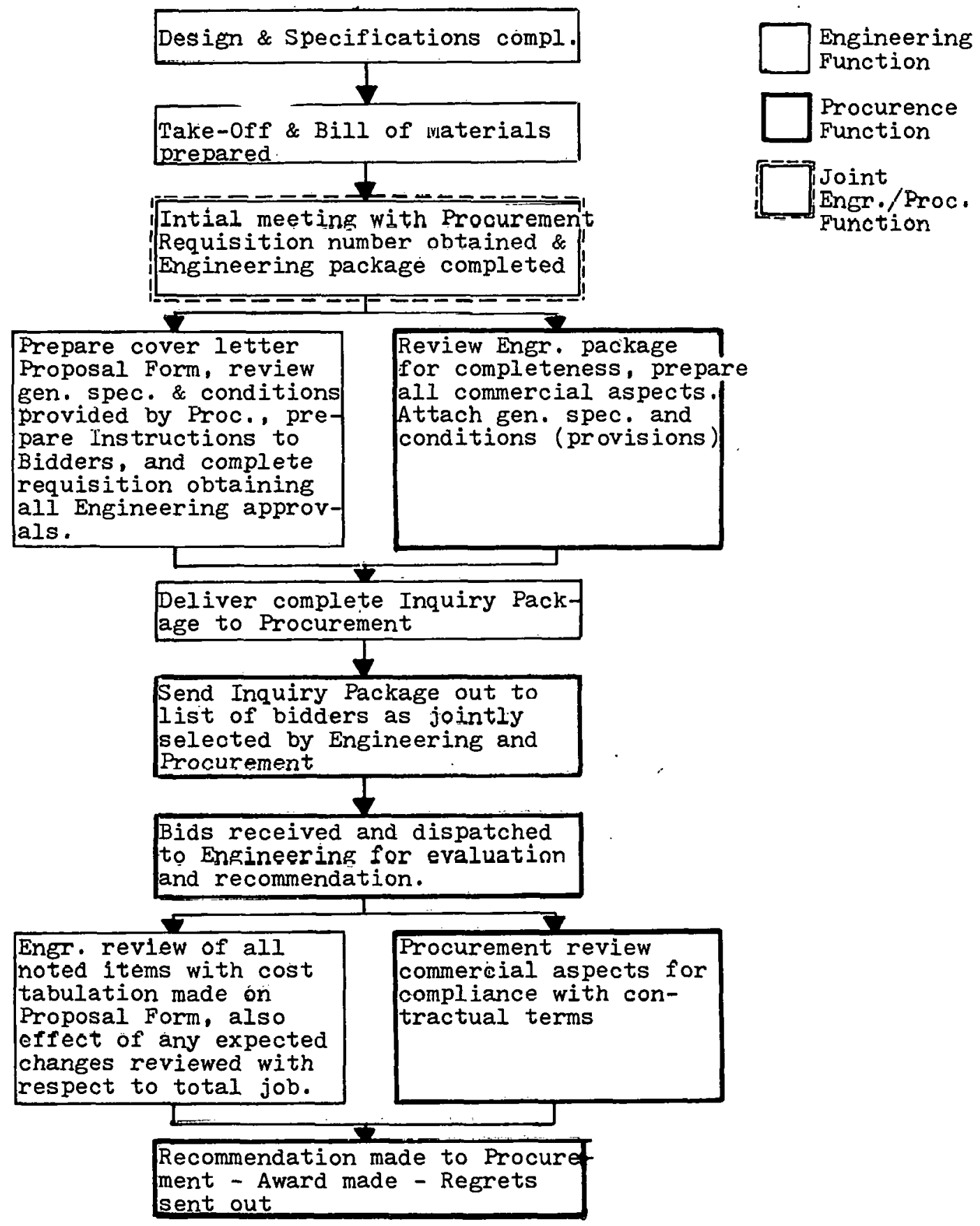

FIGURE 1.3: INFORMATION FLOW, DESIGN PROCUREMENT 
and the requisition processing proceeds.

(4) Engineering must now 1 ist al1 items, drawings, and documents which will make up the engineering design package. An "Instructions to Bidders" is prepared by Engineering to fully describe the bid process, the location of the job, expected schedule of construction, fabrication or delivery, bidder responsibilities and qualifications, coordinating engineer's name and telephone number, and other pertinent information.

(5) Procurement reviews the engineer's package for completeness, considering what the bidder will need to bid the job, and then prepares most of the Proposal Form, reviewing its development with the design engineer. This commercial data relates the cost back to design and will later be referenced on the purchase order. Procurement also develops a set of General Provisions (or General Specifications) for the job and attaches those to the package. These standards reference pertinent building codes (ACI, AISC, etc.), material and performance specifica- : tions such as ANSI, and ASTM paragraphs.

(6) The prepared material with all necessary approvals is delivered to Procurement for consolidation of material (reduction of prints, etc.) and mailing to bidders.

(7) The inquiry package is sent out by Procurement to the selected bidders. During the time period allocated for the preparation of the bid, questions relating to the design are answered by Engineering and any other questions are answered by Procurement.

(8) The bids are received, copies made, and sent to Engineering for evaluation, tabulation, and recommendation for award. 
(9) Engineering reviews the bids and in cases of questions contacts the bidder for clarification. If any changes to the design are foreseen at this point, cost projections are made. A tabulation is made, and Engineering Management determines the most valid bid (usually the lowest, since all are prequalified) and makes recommendations to Procurement.

(10) Procurement also reviews the bids from a business viewpoint for any discrepancies and advises Engineering of same. Any noncompliance is fully reviewed and further information is requested from the bidder, if appropriate.

(11) Award is announced and verbally made to the successful bidder. At the same time, the unsuccessful bidders are contacted and informed of the award.

\subsection{Engineering Quantity Take-Off}

'The Quantity Take-off application area is considered by many to be the most important of all construction activities. Quantity Take-off provides the base information in the form of a material list or Bill of Material for activities such as procurement, estimating, planning, scheduling, cost control, progress reporting, warehousing, etc. Quantity Take-off is the systematic counting or measuring of a specific item from a drawing or specification or both, and the recording of these counts and measurements. A particular item is usually classified according to its cost code or sometimes by specification division. The Bill of Material (B.O.M.) is an organized set of data describing a 
quantity of material by its composition, by the assembly to which it belongs, and by the end product of the assembly.

Quantity Take-0ff is performed by three groups throughout the project's duration. They are: Primary Engineering, Subcontractor Engineering, and Site Engineering. Primary Engineering has the responsibility for Quantity Take-off for major components. When subcontractors have fabricated items within their contract, they must prepare a B.O.M. for their sub-components. All other items are the responsibility of Site Engineering.

\subsubsection{Objectives of Engineering Quantity Take-Off}

The first and most important objective of Quantity Take-off is to supply an accurate listing of material quantities for completion of the project within the schedule. Within this objective, the primary stress is upon accuracy and time or schedule. If quantities are inaccurately taken from the drawings and specifications, the end result will be delays in construction activities and costly manhours correcting the take-off error. Since Quantity Take-off is a rather lengthy activity, careful coordination must be carried out within the planning and scheduling group so that Quantity Take-off proceeds on a timely basis within the schedule.

The second objective of Quantity Take-off is to serve as a support activity for other project activities. Quantity Take-off information provides the base for many other activities in completing the project. The Bill of Material developed by Quantity Take-off should be utilized by as many other project groups as possible to minimize the redundancy. 
of taking off the same material several times. Thus it is important that the format of the B.0.M. be structured so that as many project groups as possible can use it, i.e., presenting the quantities according to $\mathrm{QA} / \mathrm{QC}$ status; cost code, schedule activity, etc.

\subsubsection{Datà Required}

In order to complete the Quant1ty Take-off, data is required from three general areas. Quantity Take-0ff, first of all, requires detailed, up-to-date drawings and specifications. Any master identification lists for piping, equipment, etc. must also be available to ensure uniformity of identification. Secondly, for the purpose of setting take-off priorities and coordination with construction activities, a detailed status report on previously procured items and scheduled activities information is needed. Third, cost account information for proper listing of B.O.M. items and their appropriate codes is essential.

\subsubsection{Dat a Produced}

The end result of the Quantity Take-Off activities is a group of records, namely: the Bill of Materlals, requisitions, expedite requests, requests for clarification and information, and bulk-ordered material records. The Bill of Material, the most important result, was previously discussed. The requisition takes the Bill. of Material information and summarizes it into basic material groups normally supplied by a specific vendor. The requisition is used by Purchasing for the issuing of purchase orders and change orders. In some instances, the original take-off 
person will issue expedite requests to the particular expediting group handing material for which he is responsible. A $\log$ is generally kept of these requests so that status can be monitored. The request for information and clarification usually arises in the take-off stage and is an excellent way to record decisions made by Engineering or others concerning conflict. Materials that are taken-off and ordered with no specific line, system, etc. assignment are recorded and monitored through bulk inventory records.

Reports issued by Quantity Take-off generally are in the form of status reports. Quantity Take-off issues status reports for B.0.M.'s $\because$. issued, requisitions issued, expediting requests, requests for information, and bulk materials inventory. These reports are essential for review by top management of the Quantity Take-off function so that there is an effective interface with other groups.

\subsection{Purchas1ng/Expediting}

In the material cycle; Purchasing and Expediting establish two of the vital links between Design Engineering and the actual construction functions. The Purchasing function involves selection of bidders, obtaining and evaluating quotations, issuing purchase orders and change orders, and maintaining vast files on procurement, cost trends for materials and services, and bidders. Expediting takes the responsibility of insuring the timely delivery of these materials and services. 


\subsubsection{Purchasing Functions}

The Purchasing functions can be divided into five broad categories: (1) selection of bidders, (2) soliciting and processing quotations, (3) issuing purchase orders and change orders, (4) maintaining procurement files, and (5) transferring of Purchasing information. Selection and evaluation of prospective bidders may involve investigating available suppliers and contractors as to their reputation, dependability, financial conditions, and any other pertinent "track record" information that. would help to establish the bidder's qualifications. Equally important is the maintaining of an up-to-date bidders' 1ist for reference throughout the project. These lists can also be used on future projects when conditions permit. Following the selection of the bidders for a particular material item or service, quotations are requested. Often quotations are not submitted in a timely manner and must be expedited in order to speed up the Purchasing function. However, once a quotation is received, it is checked for conformance with the design concept and a successful bidder is selected. A purchase order is then issued for the material or service to the selected bidder. If the quotation was for an addition or deletton to an existing purchase order, a change order is issued.

\subsubsection{Purchasing Information}

The above activities generate a tremendous amount of information $\therefore$ that must then be organized and maintained in procurement files. Periodically, problems arise due to discrepancies in the purchase orders 
and other files that interface with purchase orders. However, it is most important that all procurement information be kept as accurate as possible to prevent errors in purchasing and delivery. These errors could be costly in construction time as well as in overhead expenditures. Through the Purchasing process, information on Purchasing lead time trends, shortages, or value engineering may be generated. This information should be passed along to the appropriate management group. Lead time.trends and shortages may seriously affect the construction schedule, and therefore field construction management should be kept abreast of such matters. Value engineering information may be generated from bidders and should be sent through Design Engineering for evaluation. Purchasing is heavily related to other management functions from the time of receipt of requisition through delivery. Initially, manufacturer release dates and job site delivery dates for a particular item must be coordinated and established with construction supervision and scheduling. After inclusion into the purchase order or change order, the completed order may have to receive final approval from Design Engineering. The importance of the item will dictate whether or not an interface with Design Engineering is necessary. Purchasing's relationship with the Material Cost System is to relay purchase order and change order commitment amounts along with the appropriate cost coding. Purchasing must also interface "on order information" with Warehousing and Material Control. The interfacing of information with Cost Control and Warehousing is the important beginning in "quantity tracking" the life of a particular item in these groups. Upon receipt 
of the item, Warehousing must report to Purchasing, and, unless a discrepancy exists, the life of the item ends for the Purchasing function. Of course, discrepancies between material order and that which was received do occasionally occur. The clue here is to follow through on all items and make certain all are resolved. Often, the discrepancies may be critical to the use of the material item.

'I'he above functions and their relationships with other functions outside of Purchasing can be summarized in terms of data required and data generated. Data requirements include manufacturers' release dates and construction delivery dates, approved bidders' 1ist, purchase requisitions, and material receiving reports. Data generated within the Purchasing function includes quotation evaluations, purchase orders, change orders, and procurement files.

The reports generated by Purchasing play an important role in effectively carrying out the various Purchasing functions and the interfacing required with outside functions.

\subsubsection{Expediting Functions}

The Expediting functions involve two basic activities. First, Expediting must take whatever action is necessary to ensure the timely delivery of materials and services. The Expediting group usually receives a list of deliveries that are to be expedited. This is usually done through phone calls, letters, or direct personal contacts. The 1ist, in some instances, is generated through a computer printout, showing purchase orders and their delivery dates. However, a manual 
"log" system may. generate the items to be expedited. The second function is that which records the results of Expediting, or updating the current status of material locations and expected delivery dates. This data is either input into the computer system or recorded in the manual "log" book. The expected delivery date may represent the original scheduled release date or delivery date, or it could represent a variation. Both functions are vital since they keep project management informed and in control of all deliveries.

Through its two functions, Expediting is related to other outside functions. Expediting keeps Engineering, Material Control, and Scheduling informed of current status and revised delivery dates of onorder material and services. Also, the Expediting group aids Warehousing and Material Control in identifying shipments received. This function becomes especially important when Expediting has been Informed of a shortage, damage, or other discrepancy in the delivery.

\subsubsection{Expediting Information}

As in Purchasing, Expediting functions have various data requirements and in turn generate data within the function. In order to insure timely delivery and update on material status, Expediting needs such information as (1) purchase order status reports, and (2) report of warehouse receipts. Then the Expediting function issues reports on the status and location of materials and their expected delivery dates. The generated information may be compiled into an Expediting Report which summarizes the data on a monthly or quarterly basis. 
The Purchasing and Expediting functions revolve around the purchase order number. All reporting and corresponding are tied directly to this number, and it becomes the material's "identity" while traveling through Purchasing and Expediting. Therefore it is important that it be designed to contain as much descriptive information as possible, and yet not be so large and complicated that it becomes difficult to use: An individual should be able to quickly determine the project number, safety relation, work category (civil, mechanical, etc.), and change order number from the purchase order number.

\subsection{Warehousing}

Warehousing in a large nuclear power plant construction project is a highly complex undertaking. It involves the receiving, inspecting, storing, accounting of, and disbursing of owner and contractor materials. The receiving records which are developed and maintained become part of the permanent plant records. Possibly, at some future time, it may become necessary to determine the details surrounding the receipt of a particular item.

\subsubsection{Warehousing Function}

The warehousing section of the construction project must receive all incoming goods. Warehousing must have sufficient manpower, equipment, and space to quickly and efficiently process the arriving shipments, which must be checked for correct quantity and type of material. While Warehousing determines the type of material in general terms, the 
exact conformance or non-conformance is determined by Quality Control/ Quality Assurance,

After it has been established that the correct type and quantity of material has been received, it is necessary to mark each individual piece to allow easy identification. The materials must then be stored so that they can be easily found and identified, but also in compliance with the appropriate ANSI specification (1.e., temperature, humidity, dust, etc.).

Having received and stored the materials, Warehousing must be able to issue the materials in response to field material requests. They must issue the correct materials and insure that the person receiving them has the appropriate authority to do so. In addition to materials and equipment, Warehousing must also be able to track all tools necessary for the construction process.

In order to efficiently carry out the primary tasks assigned to it, Warehousing must develop a number of internal systems and procedures. Security must be maintained to a sufficient degree to minimize theft and pilferage. Materials checked into the system must still be there when required. A stock coding system must be developed and maintained. A11 outbound shipments must be prepared for transportation. Where necessary for specific materials, a minimum/maximum stock system must be developed and maintained. All of these procedures are necessary to help insure that the correct materials are available when they are required. 
In achieving its objectives, Warehousing interfaces with many other areas. Close coordination is required with Quality Assurance and Quality Control in order to isolate non-conforming items as soon as possible. The Project Management team must be informed of arrivals of material so that short term crew assignments can be worked out as efficiently as possible. Planning and scheduling should be kept informed of the arrival status of important items so that their updated schedules will be as accurate as possible. Information should be available as requested by Accounting to maintain a smooth flow of vendor payments. ANSI storage level is determined by the Design/Procurement department and must be maintained by Warehousing. Insuring the correct types and quantities of arriving materials requires close coordination with Purchasing and Expediting. Proper distribution of receiving reports and packing slips will be insured by work1ng with Document Contro1. The Data Base function serves as a central reference point for all participants and must therefore be informed of the latest changes in material status.

\subsubsection{Warehousing Information}

In order for Warehousing to perform its functions adequately, certain data inputs are required. Of primary importance are the quantities and types of equipment arriving, and the length of time before their incorporation within the project. This information must be supplied in order that sufficient space and manpower can be allocated. In addition, the ANSI storage level must be determined to insure the construction of the correct type of storage facilities. 
The input data is correlated with the activities occurring within Warehousing, and several pieces of information are generated and recorded: quantities and location of items within the warehouse system; quantity of items arriving; quantities of items issued; date of arrival; date of issue; and to whom items are issued. This, and other, information is assembled and issued in the form of construction equipment inventory records, stock on hand reports, stock catalogs, small tools inventory status reports, etc. 


\section{THIS PAGE \\ WAS INTENTIONALLY \\ LEFT BLANK}


CHAPTER II

Existing and Projected Systems

\subsection{Introduction}

Approximately 60 nuclear stations are presently licensed to operate within the U.S. Quite obviously. a variety of systems have been developed to cope with the need to procure and install materials. Within the context of the application areas presented in Chapter $\mathrm{I}$, some functions are supported by sophisticated and tested computerized systems. In other instances; viable and efficient manual systems have been developed which satisfactorily meet the needs of management. In some cases, voids exist and procedures are not well documented. In such cases, information is passed by word of mouth and is not documented or retrievable. This situation leads to a certain "muddling through" in which project and system status is unclear and management must work intuitively, often at great cost and with considerable loss of productivity. This lack of clear-cut information transfer leads to delays.

In this chapter, an overview of existing or planned systems is presented. Although this presentation could not possibly be comprehensive, the systems and procedures described represent a fair cross-section of industry thinking regarding the best means of controlling and tracking materials. Information regarding these systems has been developed during trips and interviews with utilities throughout the Eastern U.S. and utilizing published materials regarding systems in the U.S. and Canada. 
Some of the systems presented are themselves in the design stage. and have not been implemented on an actual nuclear job. For those systems which are operationa1, an attempt has been made to describe systems which appear to be successful and responsive to the needs of management within the utility, at the designer's office, and in the constructor's field organization.

2.2 Warehouse File Processing, a Manual System - Daniel International Material processing is not always carried out on a computer. A manual system used by companies such as Daniel Construction Company in a general contractor-construction management-owner relationship is described in this section. A manual system requires the existence of four main types of files:

(1) A purchase order file arranged by issuing firm, purchase order number, and material control reports;

(2) Stock record card files arranged by item class, subclass, and item number;

(3) Purchase order files arranged by vendor; and

(4) Follow-up file on maintenance and inspection.

Initial preparation of the warehouse files is as illustrated in Figure 2.1. Discipline engineers within the prime contractor's organization prepare material control reports and requisitions. The material control reports are received by the material control section and are used to prepare in-storage maintenance and inspection file cards. Before being filed in (1) and (3) (see above), requisitions are first 

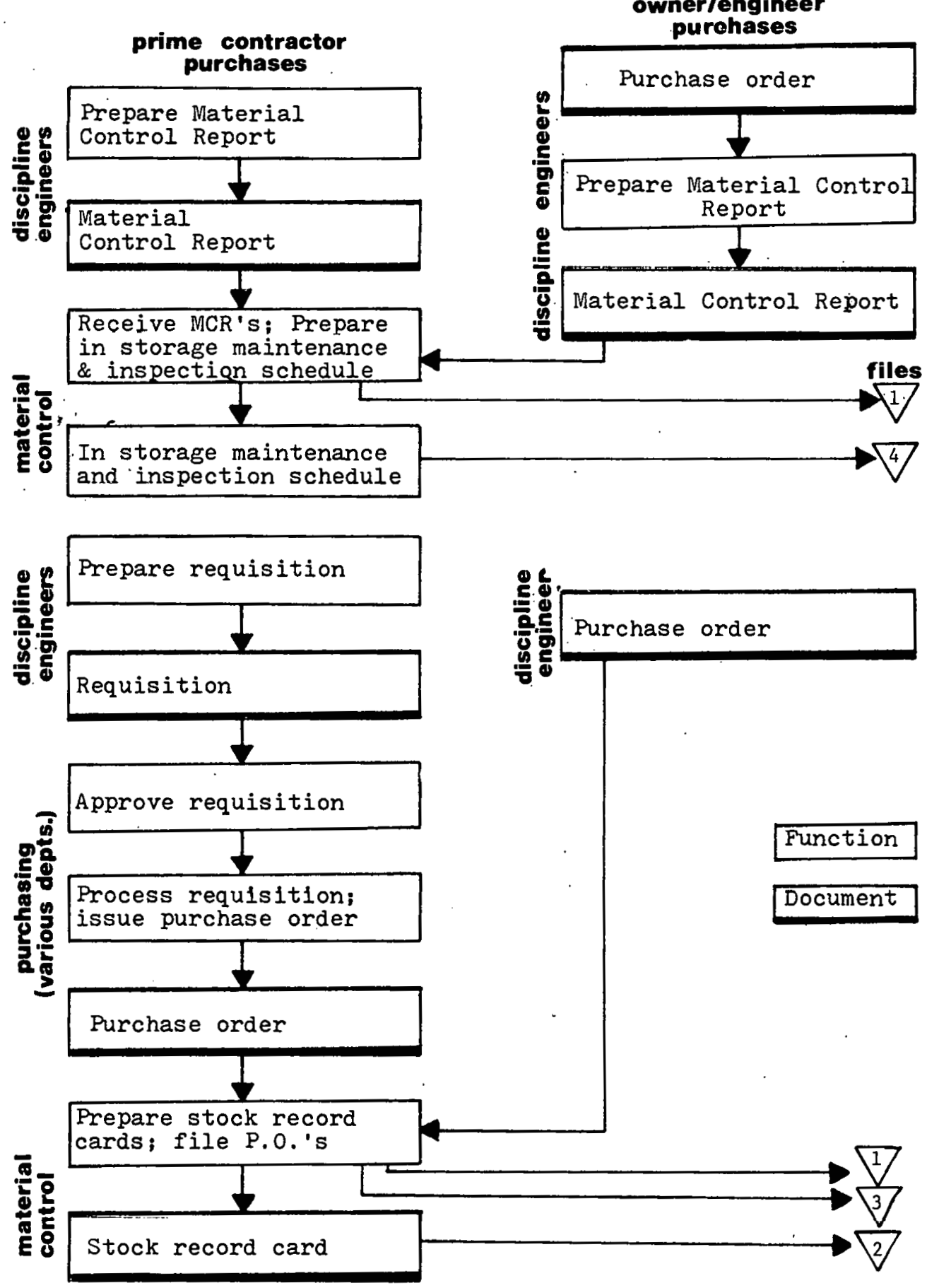

FIGURE 2.1: INITIAL PREPARATION OF WAREHOUSE FILES 


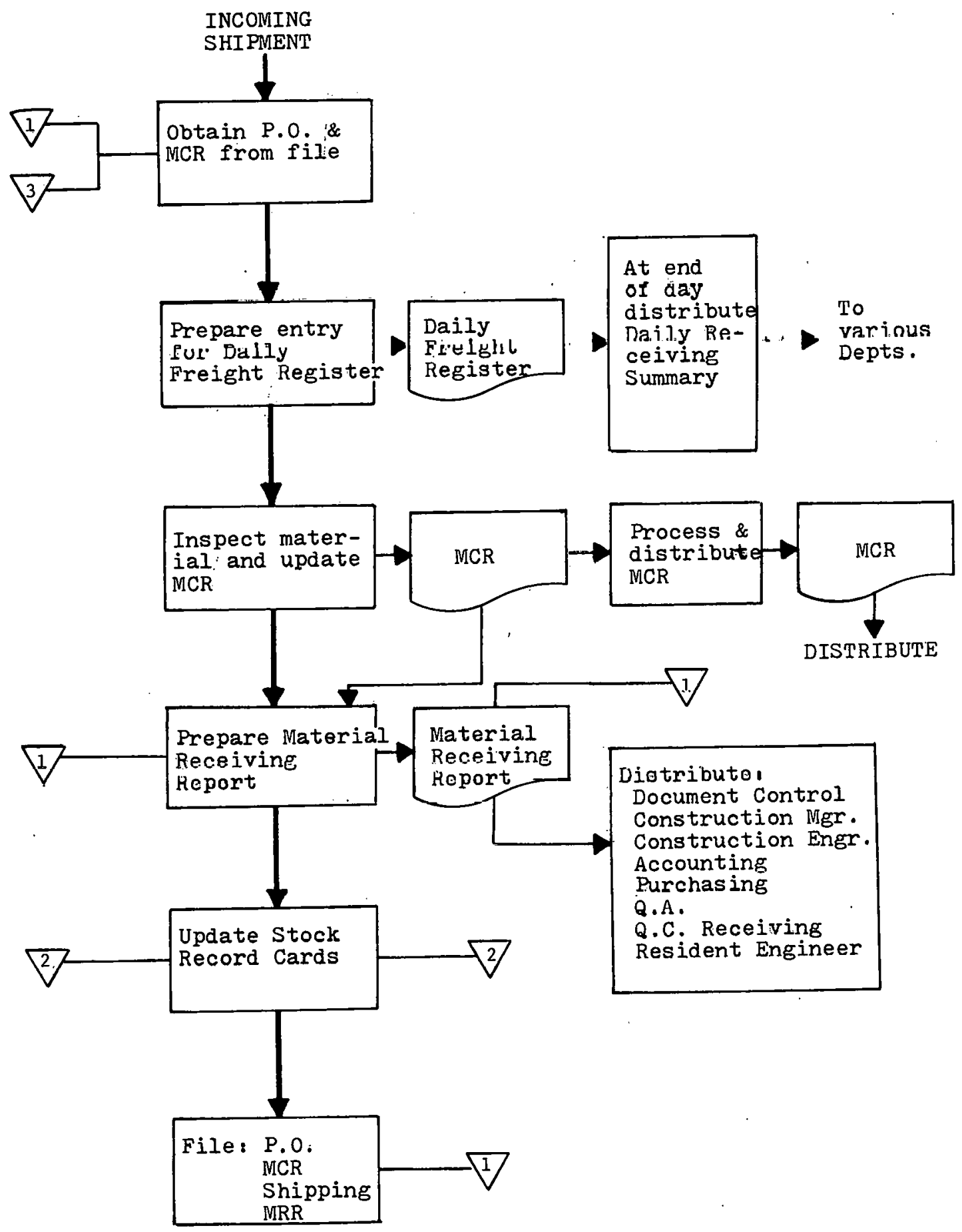

FIGURE 2. 2: MATERIAL RECEIVING 
Material Issue: FIGURE 2.3

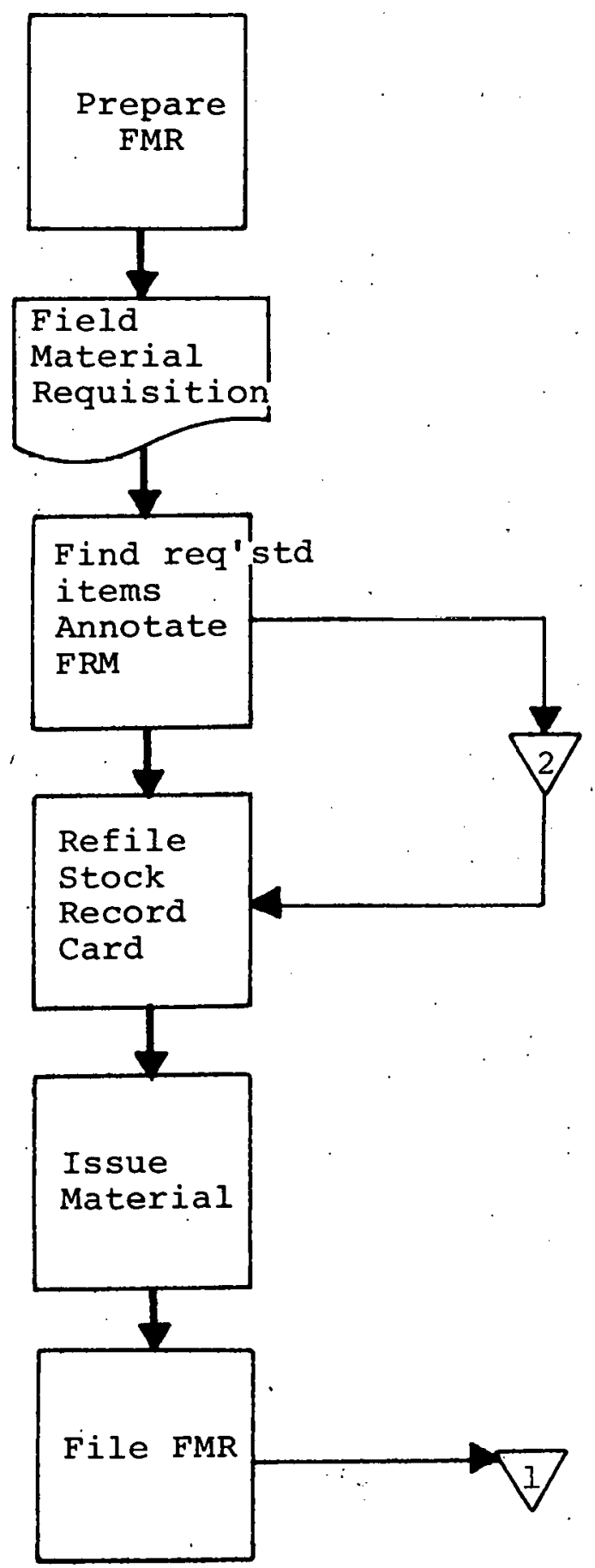


Legend: FIGURE 2.3a

$\mathrm{UE}$

$S \& P$

7

2

3

4

Union Electric

Sverdrup and Parcel

Purchase Order Files by issuing firm, P.O.\#'s and MCR's (Material control reports)

Stock Record Card Files by item class/Subclass/ item \#

Purchase orders by vendor

Follow-up file (maintenance \& inspèction)

Function

Documẹnt 
routed through various departments for approval and to Purchasing for preparation of the purchase order and stock record cards, after which entries for files (1), (2), and (3) are prepared. The owner/engineer performs similar functions for their purchase of the major pieces of equipment .

The material receiving sequence is illustrated in Figure 2.2. Purchase orders and material control reports are both drawn for each incoming shipment. The daily freight register is annotated and materials are inspected for compliance with the material control report. A material receiving report is prepared and filed or distributed to the appropriate departments. Stock record cards are updated and refiled. Finally, the purchase order, material control report, shipping ticket, and material receiving report are properly filed.

The material issuing cycle begins with a field materlal requisition presented to the warehouse. The items are obtained, the field material requisition annotated, the stock record card updated and refiled. Only then is the material issued and the field material requisition filed.

\subsection{Improved Material Control System (IMCS) - Tennessee Valley Authority}

The IMCS (Improved Material Control System) is the first stage in computerizing material tracking for the Tennessee Valley Authority. Eventually it will be modified and incorporated in the Material Management System program. As it is now constructed, IMCS computerizes many of the functions performed manually. 
Material Control, as defined for IMCS, consists of the following seven functions with associated organizations:

(1) The identification of deliverable line items and the collectIon, consolidation, storage, and maintenance of information necessary to control and provide relevant management information concerning the material during its procurement and delivery ryc1es. Expediting and Material Control, Project Control, and Engineering would be coordinated at this point.

(2) The identification, storage, formal receipt, posting of ledgers, pricing, and accounting summarization of delivered materials. Receiving and issue warehouses, Project Services, and Inspection Engineering would be associated with this function.

(3) Determining the availability of permanent material for a construction activity, the identification of substitutes where needed and possible, and reserving permanent material for approved artivities to assure availability. Coordination with Engineering, issue warehouses, and Project Control would be needed at this point.

(4) Identifying and locating materials approved for issue. Issue warehouses are coordinated at this step.

(5) Posting issues to ledgers, pricing, assigning permanent plant account numbers to issues, and summarizing issues. Coordination with issue warehouses and Project Services is required,

(6) Collecting, consolidating, and processing information for controlling and providing management information about issued permanent material. Engineering and issue warehouses are required here. 
(7) Policing and controlling issued and approved for issue permanent materials. This last function must be coordinated with Engineering. There will be a great many advantages in implementing the IMCS system. It will provide up-to-date information from a single source on the status and availability of material to all organizations on site. This will permit the engineers to reserve permanent material for specific activities. Redundant card systems will be eliminated with an automated ledger system eliminating the use of ledger cards. The need for pulling and searching contract folders to identify material at the time of receipt and formal processing will be eliminated. Receiving documents will be prepared by computer and material will be priced at the time of receipt. Thus receipt processing will be speeded up and will enable the use of more discounts. Computer retrieval of storage location information will be provided. Readily accessible records of issued permanent material will be maintained; particularly what material was issued to whom for what purpose and when. On selected items, specific tracking after warehouse issue is possible. It will have the capability at the point of receiving and warehousing to explode a line item into its individual components. This is particularly important in tracking construction status after issuance. The explosion decision is made by Field Engineering. IMCS will also have the ability to accept and track spare parts and to track material for other plants.

The following example illustrates the simplicity which is introduced by using IMCS. The left-hand column shows the steps in storing. material as performed by hand, and the right-hand column shows the steps 
as carried out by IMCS.

\section{STORAGE OF MATERIAL}

\section{MANUAL}

1. Obtain acquisition document file.

2. : Obtain packing slip when available.

3. Check shipment for overages, shortages, or damages.

-- Overages are determined from the acquisition document.

-- Shortages are determined from shipment packing slip.

-- Damages are determined from inspection.

4. Perform al1 required engineering inspections.

-- Inspection requirement found in acquisition file.

5. Determine storage location.

-- Available on ledger card.

-- Available on previously completed receiving reports.

-- Special storage requirements are found in acquisition file.

6. Store and tag material.

7. Hand prepare receiving report.

-- Copy information from acquisition document.

-- Record receiving information.

8. Price receiving reports.

9. Type receiving reports.

\section{IMCS}

1. Check shipment for overages, shortages, or damages.

- Overages are determined from the worksheet.

-- Shortages are determined from shipment packing slip.

-- Damages are determined from inspertinn.

2. Perform all required engineerin inspections.

-- Inspection code on worksheet

3. Determine storage location.

-- Previous storage locations on worksheet.

-- Special storage requirements are found on worksheet.

4. Store and tag material.

5. Record receiving information.

6. Input recorded information (computer prices and type receiving reports and transmitta. letters). 
2.4 Material and Equipment Status System (MESS) - Duke Power Company In order to collect, sort, and print all of the information from concept through design, manufacture, shipping, and receiving activities, the Material and Equipment Status System has been developed by Duke Power. The objectives of the program are as follows:

(1) Consolidation of all information into a standard form for use by all departments and Mill Power* to improve communication and accountability.

(2) Elimination of extraneous departmental lists and correspondence by providing a central file for maintaining a record of the status of material and equipment.

(3) Access to the central file from remote locations (yia CRT or teletype).

(4) Objective evaluation of vendors based on a listing of promised delivery dates, actual dates, etc.

(5) Creation of exception reports for Mill Power "expediting."

(6) Creation of status reports, particularly exception reports of late delivery items to simplify expediting and scheduling.

(7) Timely release of items based on "required manufacturer's release date" listing.

(8) Maintenance of individual item status.

(9) Register of general on-site storage location.

*Mill Power fulfills all purchasing functions of major items. for the Duke Power Company. 


\subsubsection{Scope of Materials Tracking}

As the MESS system was developed, it became apparent that all items were not to be included in the system. The original purpose had been to include only those items which, from a delivery standpoint, were essential or potentially critical (there had never been the intention to make it an all-inclusive system). To maintain some sort of consistency, the following guidelines were developed to establish which items were not to be included in the system:

(1) Items not directly involved in the operation of the plant.

(2) Items' considered to be "stock" in nature (i.e., not likely to present problems of supply or delivery).

(3) Items which, in the judgment of construction and engineering personnel, would have a short delivery time even though directly involved in plant operation.

(4) Items considered to be "shelf" 1tems (i.e., numerous or low in value).

(5) Items associated on their requisition with a specific plant system but not considered to be irreplaceable.

\subsubsection{MESS Output}

The MESS system is capable of presentation of the results of its collection and sorting functions in 21 report formats. The report numbers and contents are as follows:

(1) Lists all new material or equipment entering the system. Serves as a complete review of the previous report period's activities. (2a) Master list of all items sorted on purchase order number. 
(2b) Master list of ali items sorted on engineering item number.

(2c) Master list of all items sorted on vendor number.

(2d) Master list of all items sorted on line item number.

(3) Lists all items with changed manufacturer's required release dates.

(4) Lists all items having a manufacturer required release date within the next 30 days. This report acts as an "engineering tickler."

(5) Lists all items which have not been released by the "required manufacturer release date."

(6) Lists all items with promised delivery dates exceeding the site want date.

(6A) Lists all items showing revisions to the delivery dates. Initially the completed report was sent to vendors with instructions to indicate any changes necessary. However, it seemed that no changes were being made, implying that the vendor had not looked at the report. Therefore, the reports were revised to eliminate all dates. This format was sent to the vendor with instructions to fill in the missing information, thus insuring at least a minimal amount of thought and a re-evaluation of the vendor's projected delivery date.

(7) Lists a11 items which have not been reviewed by the projected expediting date. Corporate policy dictates the maximum time interval between expediting dates to be sixty days.

(8) Lists all material promised for delivery between specified dates. This report is useful to Warehousing for projecting space requirements. (9) Lists all items which have not been received by the promised 
delivery date.

(10) Lists all items which have been received at each plant site (master file printout).

(11) Lists all items where the purchase order has not been received by the target date.

(12) Lists all material received during the previous weck.

$(14,15,16)$. Relates to drawing control between vendor and engineering. $(17,18)$ Lists safety-related material and equipment by QA area of responsibility.

Table 2.1 indicates the distribution of each report to divisions within the company. Addendum B contains these reports for closer examination.

\begin{tabular}{|c|c|c|c|c|c|c|c|c|c|c|c|c|c|c|c|c|}
\hline Co. Division & 1 & $2 a$ & $2 b$ & $2 c$ & $2 d$ & 3 & 4 & 5 & 6 & $6 \mathrm{~A}$ & 7 & 8 & 9 & 10 & 11 & 12 \\
\hline CONSTRUCTION SITE & * & * & + & * & * & & & & * & * & & + & + & + & & + \\
\hline CONSTRUCTION SERVICES* & & * & * & * & * & & & & * & $\star$ & & & * & * & & \\
\hline MILL POWER & & * & * & * & *. & * & * & * & * & * & * & * & $*$ & & * & \\
\hline DESIGN ENGINEERING & * & * & * & * & * & * & * & * & $*$ & * & & & & $*$ & $*$ & \\
\hline
\end{tabular}

Note: Reports 14-18 are not at present actively used.

+Particularly useful for the construction site personnel.

TABLE 2.1: DISTRIBUTION CHART

*Home Office support for construction site. 


\subsubsection{Item Monitoring}

The monitoring of an item is divided into two time phases dealing with procurement and delivery. The procurement phase is concerned with the status of an item from the time bids are requested until the purchase order is released. The system provides limited monitoring of this cycle due to: the variable nature of these activities. Although not comprehensive in scope, the system supplies various procurement reports to assist in controlling the release by the Purchasing Department of items on a timely basis.

The primary function of the delivery phase is to monitor the delivery status of items after the purchase order has been released. To do this effectively, the delivery status must be reviewed periodically so that shipment delays or manufacturer promised delivery dates inconsistent with schedule requirements may be noted in time for corrective action. This phase also provides a facility for systematic monitoring on a periodic basis of items on which delivery requirements are critical to the construction schedule.

\subsubsection{System Description}

The responsibility of setting up a material or equipment item on the master file is handled by the Construction Control Section. The Design Engineering Department routes all specifications and item sheets to the Construction Department. All pertinent information is provided in the definition of an item on the specification or "item" sheet.

The Control Section in the Construction Department presently has the responsibility of entering all initial data into the MESS system, although 
Design Engineering may at some time assume some of this responsibility. In the example in the preceding paragraph, the data are entered on-1ine through a cathode ray tube terminal and immediately create a master record for the specified item. All other data entries by the Control Section are made to an existing master record and the change is in effect at the time of the entry (i.e., real time processing).

When a new entry has been made to the master file hy the above mentioned procedure, a report is generated and sent to the plant site. Personnel at the plant site fill in the required construction delivery date (if it has not already been provided on the item sheet) and route the report to the Material Management (Construction. Control) section, where this data is entered to the master file.

After Mill Power receives the specifications or item sheets from the Construction' Department, they solicit proposals from vendors for the items shown on the specifications. These proposals are then sent to the Engineering Department for approval if applicable. When the item sheets and recommendation for purchase are released by Design Engineering, the Construction Control section adds all known additional Information to the master record, or, in some cases, Design Engineering enters some of the information directly.

Upon receipt of a requisition, Mill Power should enter all pertinent information relating to the purchase order release. This information allows the system to set up a cross reference file, providing access to items on the file by use of the purchase order and line item number as an alternative to the plant code or engineering item number. 


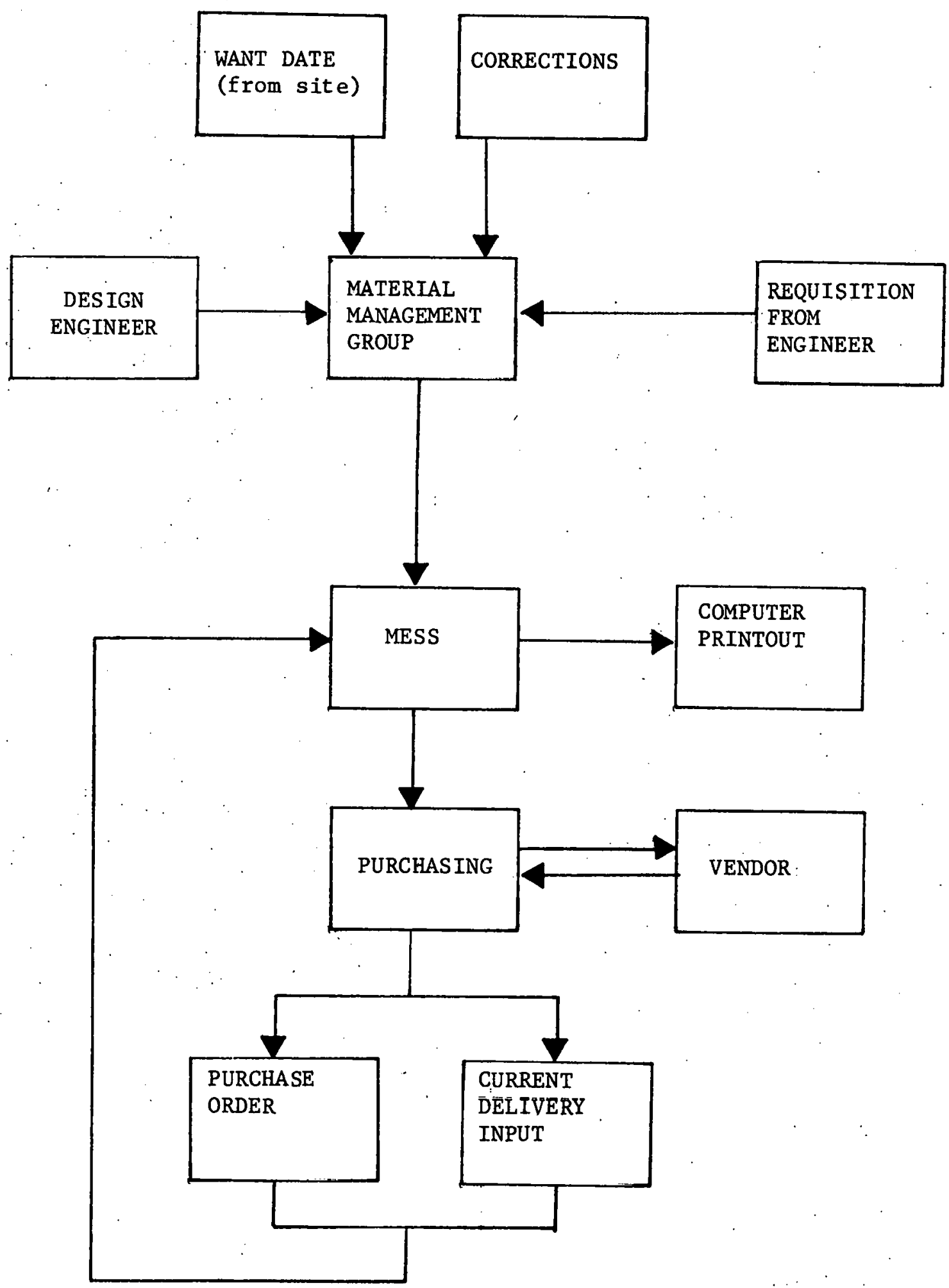

FIGURE 2.4: MESS INFORMATION FLOW 
Mill Power then requests that the vendor acknowledge the order and either confirm that he can meet the required delivery or supply a revised date. This becomes the original promised delivery date and remains permanently on the record. The vendor is also asked to furnish the date on which he must receive release for manufacture in order to meet this original date.

As soon as Mill Power receives the acknowlcdgement, it is entered into the MESS master file. Any other correspondence from the vendor regarding delivery dates, etc. is also entered.

The receiving date, storage location, quantity received, and quality assurance status are entered by the personnel at the plant site through a teletype. This information, like all other entries by the Control Section, is done on-line and becomes part of the master file. All on-hand items will be shown on the Material On Hand Report for three (3) months and after that period of time will he available on1y on a request basis.

The flow of information in the system is summarized in Figure 2.4.

\subsection{Piping Material Inventory Control (PMICS) - Duke Power Company}

The Piping Material Inventory Control System was developed for Duke Power Corporation's Engineering Design Division and is typical of systems developed to handle bulk procurement of pipe spool material needed for field fabrication. It consists of a relatively simple program which keeps track of piping material purchased and allocated, Pipe is ordered in large bulk quantities based on the P\&ID drawings 
before the detailed isometric drawings are developed.' This information is recorded in the PMICS system. Long lead times in some highly specialized pipes make it necessary to proceed in this fashion. As the detailed isometric drawings are prepared, the quantities of particular types of pipe allocated to each drawing are recorded in the PMICS system.

As can be seen from Addendum $\mathrm{C}$, a great deal of information is contained in the report. In both ordered and allocated portions of the report, accumulated quantities are kept and can be weighed against each other for purchasing purposes. The lot number is an "intelligent" number in which each of the characters has a definite meaning. The system is run on the Duke Power Company's IBM 360 system.

\subsection{Stores Accounting System (SAS) - Duke Power Company}

of the many items involved in the construction of a nuclear power plant; a good number fall outside the scope of the MESS system. These are smaller items included in the structure and consumable items needed for the construction process. In the interest of good project management, it is important to account for and properly control these items. The large quantities of the items involved establishes an environment similar to that of a retail store (Duke Power Company also engages in the retail sales of some large electric appliances). To account for these smaller items, a computerized stores accounting system (SAS) was implemented. SAS keeps träck of the following types of company stores: 
Water operation

Transportation operation

Construction department materials

Reels and drums

Steam station operations

As SAS was developed, it was to perform the following functions as related to construction activities:

(1) Maintenance of magnetic tapes in the Datacenter with detail summary stock ledgers for each stores type and stores location.

(2) Updating of these ledgers each week by receiving and posting of all stores activity input transactions,

(3) Preparation of the following stock status reports:

Semi-weekly Purchase Order Status Listing

Weekly System Stores Ledgers

Weekly Transaction Listing

Monthly Location Stores Ledger

(4) Recomputation weekly of the system-wide average unit costs of stock items and identification of significant variations between (a) previous cost and new purchase order cost and (b) purchase order cost and invoice cost.

(5) Preparation from purchase orders of punch-printed material receipt cards and printed material receiving reports to facilitate and automate the subsequent reporting on stores receipts and invoices.

(6) Preparation of physical inventory worksheets and punched-printed cards to facilitate the taking and reporting of stores inventories.

(7) Preparation of quarterly comparative reports of stores turnover ratios and inventory analyses for each stores class by location and the entire company. 
(8) Preparation of month-end.stores distribution listings and updating and output of work order entries:

\subsubsection{SAS Master Files}

The Stores system has four magnetic tape master files. They are as follows:

Purchase Order File: This file is set up from cards punched from the.Accounting Department copy of all Mill Power Supply Company purchase orders for SAS stores items, M11l Power Supply Company shipping orders, local purchase orders, or consigned lamp requisitions. Records set up may subsequently be changed by purchase order change orders if the original purchase order data'is changed. Purchase material receipts and purchase invoices are matched against and posted to the purchase order records when received. Materlal receipts are priced from the purchase order price and purchase invoice prices and quantities are matched and compared. Twice weekly, the Purchase order Status Listing is made, showing the status of each order and calling attention to price and quantity discrepancies between purchase orders, receipts, and invoices. Records are automatically deleted on a systematic basis after final receipt following invoice posting and check-out. Purchase order data on this file consists of the following:

Stores lot number

Stores location number

Purchase order number

Purchase order date

Purchase order basic unit price

Quantities, ordered, received, invoiced Amounts, ordered, received, invoiced

Last receipt and invoice dates, reference, and codes 
Assembly File: This file contains a record of frequently used major units of construction showing, for each major unit or assembly, the number and quantities of individual items of stores making up the assembly. The purpose of the file is to facilitate expansion of assembly requistions into individual item requisitions for each item included in the assembly. Since many of the items included in assemblies are bulk charge out items, already charged out of stores to the bulk charge accounts, the computer makes provision to credit the bulk charge accounts instead of the stores account for all credit requisitions for bulk charge items.

Stores Unit Cost File: This file contains one unit cost and description record for each SAS stores lot number. It is used to price transactions for all stores locations. System-wide unit costs are recomputed weekly for all items having new purchase receipts or journal entries and the new unit cost is used to price transactions received during the same week. New items are set up on this file by means of , EDP stores orders issued by the General office Stores Accounting Department. Unit cost records contain the following data:

Stores lot number

Stores description and unit of issue

Current system-wide quantity and value

Current unit cost

Unit cost history

Quarter to date average unit cost

Year to date average unit cost

Last year's average unit cost

Previous four quarter ending actual unit costs

Last invoice actual unit cost

Current resale price

Miscellaneous data 
In addition to the unit cost records, this file also contains a system stores summary record for each stores type or general ledger stores account number. They are used for internal balancing and as a record for accumulating monthly activity for each stores account number. SAS programs make certain that detail stores master files are in balance with these control records at all times. The control record totals are printed out weekly and must balance with general ledger stores account balances and activity at month end. The following data is kept:

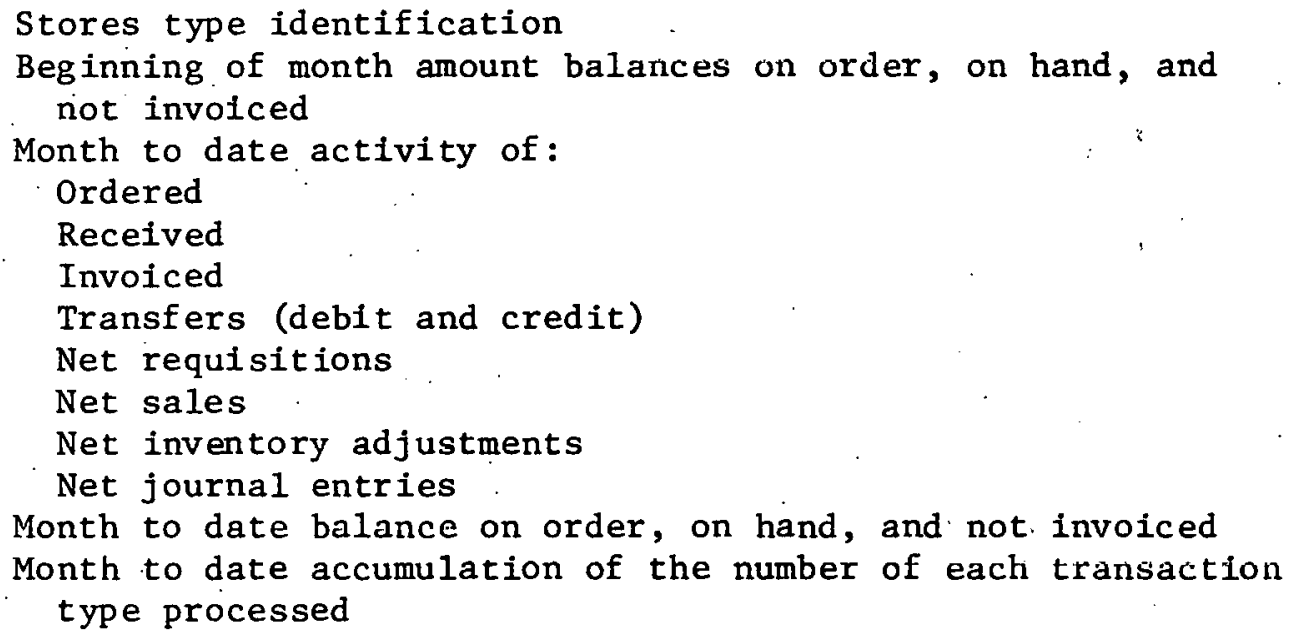

Stores Location File: The stores location master tape file contains a quantity only record for each lot number for each stores location which stocks the item. This is the largest master file, replacing all previously kept stores ledger sheets, stock cards, or other detail stores item records. The quantity balances are updated weekly by posting of stores transactions received, and SAS maintains a balance between these records, priced by the system unit cost records, and the stores type summary records.

Location records

Stores lot number

Stores location number 
Current quantities on hand and on order

Current month's activity of quantities

Received from suppliers

Net company transfers

Net usage and sales

Last four weeks actual normal usage and an average for

this period

Quarter to date total usage

Year to date total usage

Last year's total usage

Previous balance on hand history

Quarter to date average balance on hand

Year to date average balance on hand

Last year's average balance on hand

Last month end average balance on hand

Previous four quarter ending actual balances on hand

Insurance code, No. of weeks history counter, last issue

date, previous week's unit cost, and other miscellaneous codes and data

\subsubsection{SAS Reports}

The SAS system produces the following reports applicable to construction as a result of its sorting and cataloguing function:

\section{Semi-Weekly Reports:}

Material Receiving Reports (Normal Purchase Order): This report

is printed twice weekly. Both copies are sent to the ordering

location for later stores invoice processing.

Materlal Receiving Card: These cards are printed twice weekly. Transaction Error Listing: This listing is printed twice weekly

for general accounting and service parts divisions. SAS transactions

are checked for validity and reasonableness by computer programming

prior to posting to master files. Some are rejected because of

invalid data and others may be questionable but are posted. Both

types are listed for investigation and/or correction. 
Purchase Order Status Listing: This listing is prepared twice weekly for general accounting and Mill Power Supply Company. It is a status listing of all SAS purchase orders; points out any discrepancies in quantities and amounts between orders, receipts, and invoices; indicates other possible errors; and expresses an age factor of outstanding orders.

\section{Weekly Reports:}

System Stores Ledger: This listing is a printout of the SAS stores master files. It is prepared for Service Parts Division, General Stores, Distribution, Buildings, and Water Operations, Transit, Construction field office.

Stores Transaction Listing: This report provides a detailed listing of each stores transaction received from the field or created by the computer, supporting the summary activity totals and balance changes on the periodic stores ledger. It also provides an error column where, by means of codes, attention is called to actual or probable irregularities encountered during the processing of each transaction. It is prepared for general accounting and the stores location.

Stores Material Requests: Each week, material requests are printed. on a basis coordinated with transportation schedules. Automatic ordering has been programmed to automatically generate reorder intervals for each applicable stores location. All copies are sent to General Stores for further distribution. 
Stores Inventory Listing: The listing is prepared weekly as requested by general accounting and establishes criteria for physical inventories. Included are "when to prepare" dates, 1ocations, stores types, and the from and through lot number, to be used by local personnel or internal auditors for checking physical inventories.

Stores Inventory Card: A card is punched and printed for each item on the stores inventory, except reels and drums, and accompanies the report to the location for automatic SAS reentry.

\section{Monthly Reports:}

Location Stores Ledger: The ledger is a printout of the SAS master files with the specific locations indicated, Service Parts Revenue Summary: This listing is a printed monthly report for Service Parts Division to show a system-wide listing of repair parts sold.

Stores Distribution Listing: This listing is printed monthly for General Accounting Stores and Plant Accounting to show a systemwide listing of all stores items charged or credited to each plant work order or expense account with cost, plus stores expense and use tax allocations. Sub-totals are printed for each work order analysis tape record prepared.

Stores Journal Entry Listing: This listing is made monthly for General Financial Accounting. It is a summary by reference of all journal entries prepared during EDP processing of the Stores Distribution 1isting. 
Inventory Value Report: This report is prepared for General Accounting, General Stores, and Service Parts Division. This is a summary for each location showing value on hand. for each type of stock.

\section{Quarterly Reports:}

Stores Turnover and Inventory Analysis: This report is printed for General Accounting and General stores. It is for use in analysis and control of inventories and activity as to class of stores, individual stores responsibility locations, and retail and company grand totals:

Annual Reports:

Stores Cost Analysis: This report is printed for General Accounting and Mill Power Supply Company. This analysis indicates (for each lot number) the current system inventory quantity, value, unit cost history, and cost change percentage. Summaries at the end of each stores type, each steam plant, and system total show the current inventory value at the current unit cost, the inventory value based on each category of previous unit cost history, and its difference from the value of current unit cost.

Use of System -- An Example

Of interest is the use of the computerized system in actual nuclear power plant construction. A site visit revealed the following sequence of events. 
When material is received, a receiving record is filled out and a Duke Power Company label is placed on the item (see Addendum $D$, Exhibit 1). Of the information on the receiving record, only the order number, lot number, and quantity received are entered into SAS. Before being entered, the handwritten copy is put into typed form, This has helped to increase the accuracy of the information as input into the computer. The input is via CRT. Copies of the receiving record are kept at the warehouse, and sent to Purchasing for invoice approval, to the MESS input station, and to Engineering for notification of arrival. In addition, warehouse makes copies and files them on site under the vendor name, item number, date received, and shipment number. Items are more easily located if they can be recalled on these bases.

The warehouseman places the materials into the warehouse and places a Duke Power label on the individual items. The Duke Power Label includes the vendor company name, the order number, the Duke item number, the date received, the shipment number, description of the material, and the ANSI storage level. In the case of NSSS items, the item number becomes the vendor item number to help prevent confusion.

To withdraw materials from the warehouse, a warehouse stock order must be filled out (see Addendum D, Exhibit 2). Of the information on this card, the lot number, amount, account number, group number, and crew number are entered into SAS. The original warehouse stock order is sent to the Main Office in Charlotte for documentation control.

The SAS system prints 25 reports for the Duke Power Company. The two most widely used reports on the site.are an inventory (updated weekly 
on microfiche, quarterly on paper) and breakdown by crew number of the materials used (reviewed during weekly foremen's meetings). By entering group and lot number, SAS supplies on-line information with respect to quantities of items on hand, items on order, the system average price, and the number used. Although SAS's capabilities are much greater, this type of information is most widely used by the field warehousing operation.

\subsection{Punch List Program - Georgia Power Company}

Georgia Power Company is presently using a program called

"Punch List" as a status scheduling tool during their construction and start-up phases at Plant Hatch near. Baxley, Georgia. The program tracks the status of components from the time they arrive in the warehouse until they are turned over to the start-up team. In all, 16 different steps can be monitored.

In the design of the Punch List system it was decided that not all items were to be listed in the program. No Civil/Structural items are included in the program. Electrical components for some instruments are listed on another schedule. Presently, approximately 35,000 Mechanical items are monitored by the program.

For Mechanical items the following information is maintained:

Equipment number

Isometric drawing number

Revision (of above)

Areá

Size

Purchase order number

Turchase ordir itcm number 

Mark number
Weld specification number
Required date
Scheduled ship date
Received date
Temporary Turnover number
System Turnover number
Flush number need date
Pre-op number need date
Estimated earliest flush
Estimated earliest pre-op

In addition, the following status points can be monitored:

Hold

Document

Received

In building

Installed

NDE (Non-Destructive Testing)

Hyd ro (Hydro test)

CAT (Construction Acceptance Test)

Temp T.O. (Temporary turnover)

Perm T.0. (Permanent turnover)

Sys T.0. (System turnover)

Operational

painted

Welded

Insulated

Pino pullod (Pino havo boen pullod from hangori)

Addendum E, Exhibit 1, shows a typica1 printout for the Punch List.

To compile all the information for a program such as this, several major sources of information were used. Master Parts List is an in-. ventory program used by the Southern Company System. It was developed by General Electric and is a primary source of information to the team which will operate the plant. It lists all major items which are required for plant operation. As soon as purchase order data is developed, information regarding major items is input to the program to initialize MPL program master files. 
Equipment Location Index is a program originally written by the Bechtel Corporation to locate mechanical and electrical equipment. In addition to finding a location for a particular piece of equipment, items of equipment can be listed by specific zones or drawing numbers. Given the equipment number, the equipment location index has the ability to indicate which area code, P\&ID drawing number, and layout drawing the piece in question is located in. For a given electrical equipment number, the electrical layout drawing number, electrical element drawing number and electrical connection drawing number are given. For some items the location is shown by referencing a coordinate system. The entire project is divided into sections by a three-dimensional quadrant system. Elevations are chosen at periodic intervals and subdivided by a two-dimensional coordinate system. Locations could be indicated by referencing a particular set of coordinates.

In addition, a hand take-off of a11 pipe spools was undertaken. This required.14 engineers about three months to complete.

The updating procedure proceeds as follows. A card such as the one shown in Addendum E, Exhibit 2, is maintained for each component. These are generated from the master file and have a pre-punched input code. These cards are maintained for all items in computer card storage cabinets. Superintendents in the appropriate disciplines are responsible for status updating. Each day the appropriate superintendent inspects work in progress and establishes whether a status change has occurred (e.g., a spool piece previously "In bullding" is now "installed"). At the close of work, he pulls the status cards for each component which 
logged a status change and places a mark in the appropriate position on the left side of the card. For instance, if the instrument with code $\mathrm{F} 2 \mathrm{~N} 22-\mathrm{N} 313 \mathrm{C}$ TX2N22-274 is now installed, having previously been "in building," he pulls the pre-punched card with this code and checks the blank next to $36 / \mathrm{E}$. After all cards are pulled and checked for items with changed status, the cards are given to a key punch operator. The operator punches a one (1) in the column, indicating the new status. In the above example, a "1" would be punched in column 36 of the prepunched instrument card. An action code and number is punched in columns 54-55. ( $C=$ change status, $A=$ add component status). The code $\mathrm{Cl}$ in columns $54-55$ indicates the status is changed in the master 1ist. Following key punching of each card to update status, they are read onto a diskette and run against a verification program on-site to determine whether any key punch errors have been made. If there are no errors, the data is sent from site to the host computer for processing. Following processing, a replacement card is punched, returned to the site, and filed in the card storage cabinet to be used for further status change updates.

Reports can be printed on many different sorts. In all, it is possible to make up to seven nested specifications. This permits the production of all necessary management reports.

\subsection{Quantity Tracking System (QTS) - Bechtel Power Corporation}

The Quantity Tracking System is an organized method of tracking bulk quantities of material which was developed and implemented by the 
Bechtel Power Corporation. The system tracks quantities from the early stages of a nuclear power facility until project completion, and Bechtel uses it as a basic element in project control.

Five general areas of materials are presently being tracked by the Q.T.S. system. They are as follows:

General Quantity Area

Piping (large and small)

Concrete (civil/structural)

Electrical

Equipment

Instruments

\section{Specific Quantities Tracked}

Welds, hangers, and valves

Forms, rebar, concrete, and embedments

Trays, conduit, wire, and cable

Mechanical, electrical, civil All types

The Quantity Tracking System is operated by the "field control group" which is directed by the Material Control Supervisor. Five Material Control Coordinators are under the supervisor. Their main responsibilities are to collect and input the status cards for updating the system. These cards are grouped as construction data system cards, concrete pour cards, pull cards, connection cards, and equipment status cards. The following diagram, Figure 2.5, depicts the Material Control group that Bechtel plans to set up on the Vogtle Nuclear Plants.

Summarizing the flow chart, the Material Control group interfaces with the owner's field operations, quality assurance, planning and scheduling, construction, cost engineering, and the home office. Also, the cost and schedule control groups.' CPM programs, Manpower Analysis Program, Action Program (manual labor performance), and quantity forecast ledgers are supplied needed information. Supplying of information to various groups is accomplished through a number of sorts, 
TO

QUALITY ASSURANCE

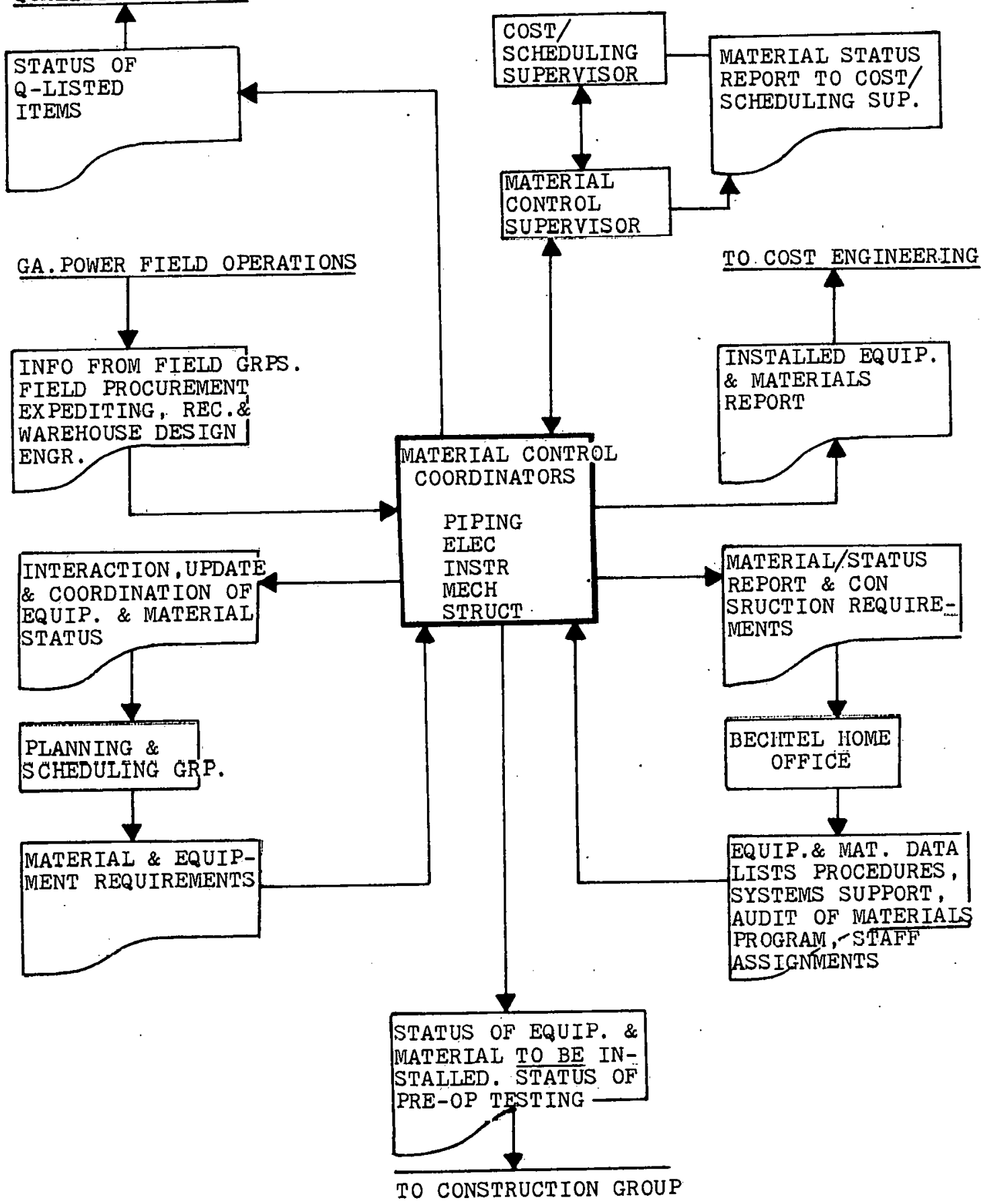

FIGURE 2.5: Q.T.S. INFORMATION FLOW CHART 
Present uses of the system include: (1) quantity base for estimates/ forecasts; (2) quantity reporting; (3) cost trend base;: (4) material pricing base; (5) material billing information; (6) historical quantity base; (7) design status tool; (8) planning data base; (9) expediting list; (10) field status tool; (11) action card generator; (12) material pre-ordering base; and (13) system punch list.

Much of the mechanics of the QTS system with respect to hardware used and reports produced is the same as in systems previously described. The reader is referred to those reports for details.

\subsection{Material Control Module - GPU Services}

The material control module was developed by GPU Services Corporation as part of a comprehensive planning tool. The details of operation are simflar to the previously mentioned MESS system with the added ability to sort on work package designations. The module permits the assignment of direct responsibility for on-time procurement, not only to a work package, but, if required, to an individual within the responsible organization. By uniquely identifying all significant equipment items, including pipe spools and instruments, as they are initially entered on the flow diagrams, each item can be tracked from procurement through expediting and final delivery to the storeroom.

The three reports that are prepared by the Material Control Record are:

(1) Master Listing: This is a listing of the entire file sorted by work package and indicating the following data elements: system code, 
description, QA/QC code, drawing number, responsible organization or individual, vendor name, purchase order, quantity data, purchase order dates, package number, FPC account and special codes.

(2) Warehousing Report: A listing of all ordered items including quantity data, which have not been received. When the item arrives, the quantity, bin location, and standard stock number are written in the blank space provided and the report then becomes. the data input document for the subsequent computer run.

(3) Expediting Report: This is a subsort of the master listing itemizing those items which are overdue or due to ship in the next 90 days for expediting review and update. When the expediting function acquires more current expected delivery information, it is written in the blank spaces provided and the report then becomes the data input document for the subsequent computer run.

\subsection{Material Management Information System (MMIS) - Florida Power Cuipuralion}

The Material Management Information System developed by the Florida Power Corporation in conjunction with Arthur Andersen Associates is a comprehensive material tracking system following the material cycle from purchase through material issue. The most significant feature of this system is its attempt to forecast material demand.

\subsubsection{System Development}

MMIS was developed originally for the transmission and distribution department. There is application in construction projects on a nuclear : 
power plant scale also. To determine forecastability, materials were divided into three broad categories: those used 0-11 weeks per year, those used 12-29 weeks per year, and those used 30-52 weeks per year. Items were observed for a period of two years to determine in what categories they should be placed. It was determined that those items used between 0 and 11 weeks were very difficult to forecast. Those used between 12 and 29 weeks per year were forecasted manually; that is, intuitive assumptions were made. Those used between 30 and 52 weeks per year were predicted using a model developed based on past performance of materials. This model includes basic minimum quantities, general long term trends, and seasonal variations. Although the major construction aspects of nuclear power plants are not continually ongoing activities, for many of the longer term activities general trends could be established. This would allow use of the forecasting model built into the MMIS system.

The MMIS system is very similar to the Material Management System used by the Tennessee Valley Authority. It operates on the same centralized computer system and requires a centralized warehouse arrangement.

\subsection{0 .2 MMIS Output}

Some of the reports produced by MMIS are as follows:

\section{Warehouse Steck Reports:}

System Stock Status: Each part stored is shown by warehouse, the 12 months net usage, item type, lead time in weeks, economic order quantity, safety stock, reorder policy, projected weekly usage, amount on hand, amount staged (committed for particular usage), 
net available, projected number of weeks supply on hand, amount on order, and projected.week's' supply on order.

Inter Stores Transfer Prelist; In a centralized warehouse system with multiple satellite warehouses, it becomes necessary to transfer materials between warehouses. To optimize use of equipment, routes are created with certain limits on weight and volume. The prelist shows which items are to be moved to which locations within the rnute parameters. Tn aditition, it shows the order policy, amount. on hand, amount staged, net available, projected weeks supply on hand, projected usage over the next few weeks, reorder index, standard packing quantity, standard packing weight, standard packing volume, suggested transfer quantity, and the cumulative weight and volume to be transferred.

Interstores Transfer listing: The actual document used in the transfer policy is also produced. Shown are the location, amounts to be shipped, with room left to show discrepancies.

Stores Material Requisition: Used to requisition material from vendors. It is an in-house document and shows possible catalogue numbers as well as different possible vendors.

Cycle Count List: Used to hand verify quantities stored with quantities recorded in the computer.

Cycle Count Reconciliation Report: Used to verify the actual count data placed into the computer.

Open Purchase Order Status: Produced on a regular basis, it helps to insure that all vendors fully meet their obligations. 


\section{Model Analysis Reports:}

Forecast Performance Report: The äbility of MMIS to forecast anticipated need is one of its primary strengths. It is important to determine how well the model has performed. This report presents a variety of Information to assist in this analysis. Shown are order policy, estimated demand, actual demand, and the variance. Semiannual usage is shown in actual usage and usage forecasted by the model. The demand filter unit is a reasonable range developed directly from historical records, Records for the past year are maintained and the number of times the demand filter has been violated (tripped) is noted and the number active is also shown. The track signal is an indicator of how well the model forecasts the actual usage: This is of great interest to the designers of the model in assessing its capabilities. For the previous month, records are kept as to the number of stock outs and number of orders filled.

Forecast Analysis Report: A complete projection over a series of several. weeks is presented. Lead times, quantities on hand, forecasted amounts, scheduled receipts, and the projected amounts on hand are shown.

Forecast Simulation Report - Summary: A summary is produced for each part kept on the system. Analysis can be made on the validity of the forecasting model by examining the actual usage, forecast usage, variance, demand filter trips, mean average deviation based on units and dollars; : and the average tracking signal, Forecast S1mulation Report-Detail: A breakdown on a week by week 
basis of the summary report ishown..above.

Stock Outs and Manual: Allocation Listing: This report shows what stock outs might be anticipated prior to the delivery of additional parts,

Commitment Planning Report by Part Number for the Commitment Year ( ):

For any particular year the commitments can be shown on a monthly basis.

Historical Usage Report by Part Number for the Past 12 Months:

\section{Inventory Reports:}

Inventory Control Summary by Inventory Categories: A summary report broken down by inventory categories. It shows inventory balance, current monthly usage, 12 months net usage, annualized turnover ratio, value of safety inventory, value of average inventory, and the value of the maximum inventory.

Inventory Control Summary by Storeroom: The same information as above is shown broken down by storerooms.

Inventory Control Summary by Inventory Order Policy - System Wide:

The same information as above is shown broken down by inventory order policy.

Inventory Control. Summary by Inventory Order Policy - Storerooms:

The same information as above is shown broken down by inventory order policy on a storeroom basis.

Inventory Value by Storeroom;

Inventory Adjustments for the Period Ending ( ): Each storeroom is 
analyzed as to averages and shortages on a monthly and a yearly basis.

Route Capacity Report: To optimize the use of available fleet equipment, delivery routes have been established between the central warehouse and outlying warehouses. These routes are based on a demand- ! capacity analysis.

Quarterly Activity Report by Storeroom:

Obsolete Material: In the construction process of a nuclear power plant, some materials become obsolete due to design changes. These materials are shown and it is indicated how much dollar volume is located in which warehouses.

Slow Moving Material: Some materials are used only very infrequently. In such cases it may not be necessary to maintain a stock in a particular warehouse. This report will help to assess whether or not elimination from active warehousing is possible.

Bin Locator Report: Precise warehouse location is presented in this report.

\section{Buyer Reports:}

Purchase Agreement Status Report: This' report helps to ascertain to what degree a purchase agreement has been carried out. It contains such information as quantities received, quantities released, current balance, respective percentages, start date, and expiration date. Vendor Activity Report: This report helps to assess vendor performance. Each vendor has the number of orders, average number of days 
to acknowledge, promises received, promises changed, number of overshipments, number of partial shipments, number of early shipments, number of late shipments, and number of duplicate shipments. Purchase Order: Automatically produced by the computer. Purchase Order - Receiving Report: Automatically produced by the computer.

\section{Expeditor Reports:}

Open Order Status Report: This report presents information to help analyze if any action should be taken on open purchase orders. Some of the information presented is: Purchase Order status, required date, expediting status, expediting date, changed dates, number of change, new promise date, and other identification 'information. Request for Acknowledgement Letter: This letter is automatically produced when no acknowledgement to an issued Purchase Order is received.

Request for Delivery Date Verification Letter:

Request for Revised Delivery Date Letter: This letter is produced when a particular. shipment is past due.

\section{Management Reports:}

Purchasing Department Status Report: This report chronicles the activities of the Purchasing Department.

Purchasing Department Monthly Activity Report: Same as above, only in more detail. 
Vendor Lead Time Variance: This report presents vendor lead times and shows variances between changes on the same vendor for the same item.

Appendix F contains samples of many of the above mentioned reports.

\subsection{Material Management System (MAMS) - Tennessee Valley Authority}

The Materials Management System being developed by the Tennessee Valley Authority will be a totally integrated system encompassing all phases in the construction process. Figure 2.6 shows what MAMS will encompass during its several phases. Under detailed development at this time are six subsystems, with the others to be implemented at a later date. The six subsystems are: (1). Engineering - designed to support the material management functions of the Division of Transmission Planning and Engineering in the Office of Power; (2) Procurement - to assist the Division of Purchasing for better control over procurement and expediting activities; (3) Power Stores Inventory - includes all material functions for receiving, storing, and issuing material stock; (4) Accounts Payable; (5) Plant Accounting - assists the Division of Finance in meeting the asset records requirements of the FPC; and (6) Classification - maintains material specifications for TVA-wide use.

The heart of the proposed system is the development of an extensive data communications network to allow organizations to transmit to and receive data from a central data base. Terminal devices are located at strategic potints in user organizations to connect into the communications 


\section{MATERIALS MANAGEMENT SYSTEM}

\section{Diagram of Materials Management Applications}

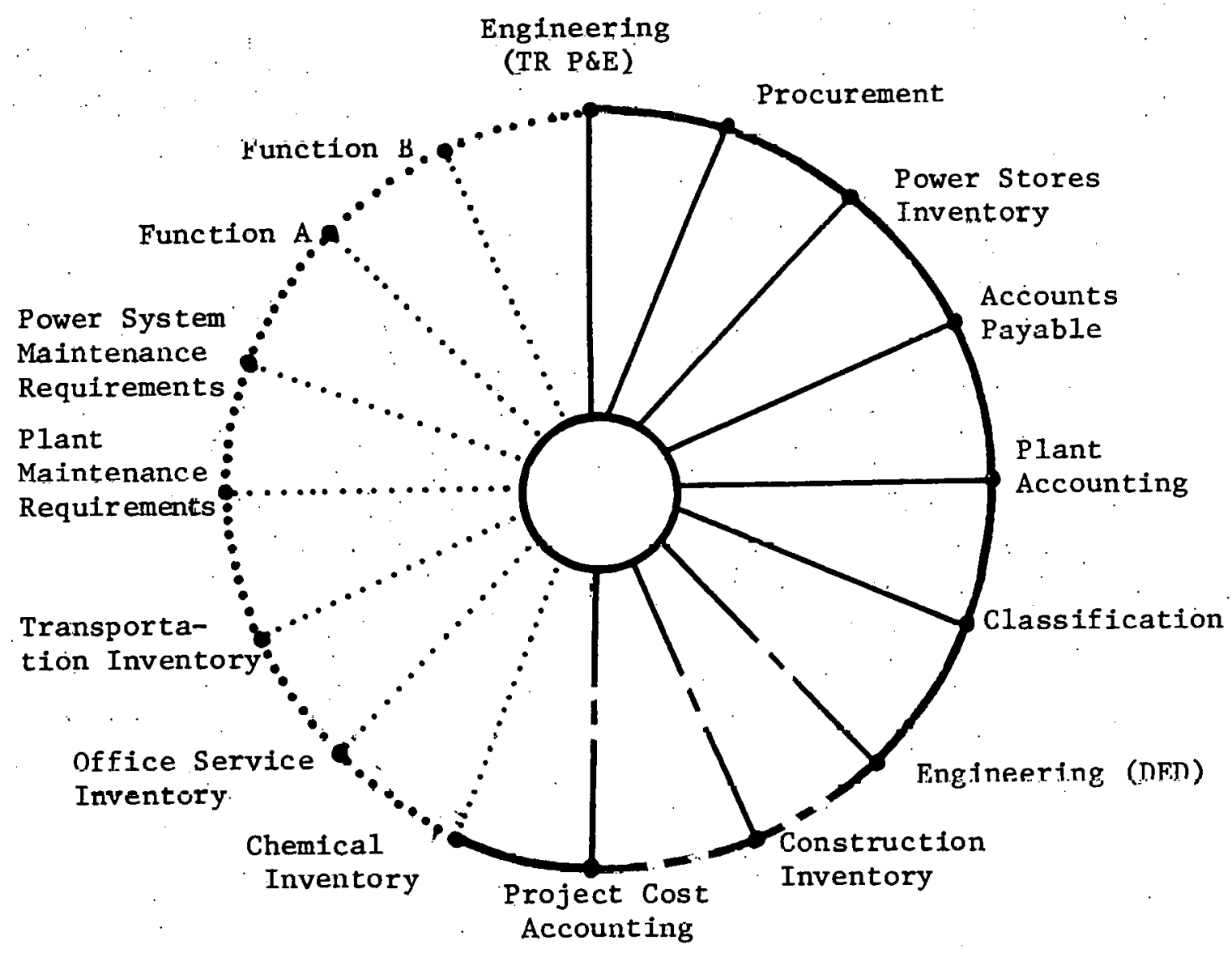

Phase I

Phase II

Future functions

FIGURE 2.6: MATERIALS MANAGEMENT SYSTEM (MAMS) 
network. The central data: base is located in the Computing Center and contains all active files of information about the status of materials.

\subsubsection{Engineering Subsystem}

The Engineering Subsystem begins the materials management process; it is designed to capture material specifications during design and to make the information available to other subsystems later in the process. In addition, the subsystem aids the design process by offering the project engineer the ability to call out computer stored model bills of materials used for past projects. The subsystem provides the capability to control the status of material called for on bills of material because of interfaces with the procurement inventory control and accounts payable system later in the process.

The Transmission System Planning (TSP) Branch initiates the engineering procurement process by requesting preliminary work order estimates from the three engineering branches. The branch assigns the work order to a project engineer. Then, the project engineer reviews the singleline drawing and does the necessary work to establish a computer data base for the bills of material. The project engineer adjusts the work order bill of material file to correspond with requirements of the singleline work order drawing and prepares preliminary work order estimates for TSP. TSP reviews the preliminary estimates and requests a final printed work order estimate. From a terminal, the project engineer issues a command to print work order estimates and a bill. of material summary, 
The project engineer examines the work order estimates and single-line drawing to determine if all major items are reserved. If the major items have not been located within TVA, a purchase requisition is requested. The printed purchase requisitions are approved by the division director and are returned to the project engineer. A command is issued from the terminal to release the purchase requisitions to the Procurement Subsystem. The project then awaits approval of the work order by the TVA Board of Directors.

Once the project is approved by the Board, TSP prepares a specification drawing and forwards it to the project engineer. The project engineer examines the inventory data base to determine if certain special items like relays, current transformers, potential transformers, etc., could be obtained from within TVA. If the items are not available within TVA, a purchase requisition is typed at the terminal with the MAMS system providing complete descriptions and latest prices. At about the same time, the project engineer receives drawings from the vendors for major equipment that was requisitioned earlier and forwards both the specification and vendor drawings to the various sections within the branch for use in developing construction drawings. As design progresses, and as more of the items in the bills of material are identified, the project engineer adds them to the computer-stored bills of material. At appropriate intervals, the project engineer requests that purchase requisitions be printed at the terminals and sends them through the approval process. The process of printing requisitions, getting them approved, and transferring them to the material requisition file continues 
until the design is complete. After design is complete, the work order bill of material data base is made available to the Division of Power Construction and the Plant Accounting Branch for use in their subsystems.

There are seven principal elements in the engineering subsystem. The inventory data base provides a single centralized source for inventory information. The data base is made up of records that indicate such information as stock status, quantities on order, future requirements, and past usage for each item in a storeroom. It forms a subset of the MAMS data base and is designed to link up with other subsets in the system.

The Material Data Base provides a single centralized source for material specifications, eliminating the need for each organization to keep its own files. Information such as physical characteristics, manufacturers, and units of measure is maintained in the data base. This data base 1 s accessed by every subsystem that uses material specifications and is therefore updated continuously.

The Model Bill of Material provides a mechanism for quickly establishing a complete bill of material for new work orders. It represents the materials that are likely to be needed to build typical substation or transmission line structures.

The Plant Records File stores the final adjusted bills of material for plant structures. It is updated when modifications are made to one of the structures.

The Requisition Data Base is a temporary holding file for requisitions from the time they are prepared by the originating organization until the contract is awarded. 
The Work Order Bill of Material Data Base contains bills of material for work orders that are in active status - that is, planned work orders and approved work orders.

The engineering subsystem has seven principal output forms:

Bill of Material Summary: A working document for the engineer in the electrical, civil, and communications branches,

Retirement File Display: Enables the Division of Transmission, Planning and Engineering to determine if major retired or planned to be retired files could be used on a current work order.

Inventory File Display: Enables the Division of Transmission, Planning and Engineering to determine if major items needed for a work order are available in TVA storerooms.

Bill of Material Display: Shows the status of all items on a particular bill of material.

Work Order Estimate: Used by the Tranmission Planning Branch to substantiate requested funds for a project.

Purchase Requisitions: Used by the project engineers in the electrical; civil, and communications branches to procure materials required for the project.

Material. Status Report: Used to bring to the attention of the managers on TRP\&E any activity or problems that need action in the material management process.

\subsection{1 .2 Procurement Subsystem}

The second major subsystem is the procurement subsystem. It is designed to provide up-to-date status of each requisition assigned to 
purchasing. Computerizing the purchasing function in a central data base has a number of significant benefits. Verification for item noun. names, description consistency, and accuracy is automatically ensured. Responsibility for problems with mismatched and misdirected invoice data is centered in the Accounts Payable Subsystem. Redundant data entry is eliminated by providing ready access by all users to itemrequisition-contract status, including expediting, inspection, drawing requirements, and payment status. Consolidation of like line items is permitted to accomplish large purchase discount leverage, and further reduce paper handling. Stock availability at other locations will have been screened as a feature of the Power Stores Inventory Subsystem to eliminate redundant requisitions. Interdivision reviews of quotes and bids are monitored and delays are highlighted. The requisitioner can preselect applicable quality assurance standards; after receipt, the field can indicate QA and inspection results. "Emergency" telephone requisitions are reduced because item need requirements are electronically transmitted from the requisition point. Standard times are stored within the system to automatically monitor progress. Workload planning, balancing, and status reports are provided at all management levels. Vendor performance information is accumulated as a byproduct of the receiving process.

Many of the purchasing processes can be revised when the use of computers is introduced. Open market purchases require the most flexibility and can make the most use of individual purchasing agent terminals. Each day the purchasing agent can review the requisition data base for 
his next assignment. He may then request information on a specific requisition (price history, vendor history, etc.) and indicate the disposition. Review of the requisition is logged and award of the contract (including vendor, date wanted, expediting, and quality assurance requirements) is input into the requisition data base.

Advertised purchases differ from the open market in that a more complicated flow with a lower volume is involved. Requisitions from user organizations are retrieved by a subsystem program and are used to print a daily bid work sheet and requisition status report. Each morning, along with his daily status report, the purchasing agent receives invitation to bid worksheets for requisitions which were first In the priority queue. A requisition status program will also schedule the requisitioner's review timing and will flag overdue recommendations. As recommendat1ons are made on requisitions and contracts awarded, the requisitioner leaves the requisition data base for the open contract data base.

The expediting function is carried out in a combination automatic/ manual method. Some notices are generated automatically; others are sent upon request of the expediting unit.

The principal elements of the procurement subsystem consist of all three data bases. The Requisition Data Base contains information (supplied by Materials Management requisitioning organizations) necessary for purchasing to act. The Open Contract Data Base serves as a record for awarded contracts which have not been delivered and paid. When payment is made and discrepancies reconciled, the contract record will be written 
to a history file. Vendor information (addresses, history of performance) is contained in the Vendor Master Data Base. Periodically the data bases will be purged after being recorded on annual magnetic tapes.

The proposed design of the procurement subsystem does not lock in any particular types of reports, allowing the user to tailor the output to his needs. A number of reports will however be built into the system at conception.

Requisition Receiving Log: Lists all requisitions received by purchasing. Requisition Queue: Lists the requisitions assigned to purchase agents and the priority of each.

Purchase Requisition Information: Contains all stored information about a purchase requisition.

Price Histories: Contain prices on a particular commodity.

Vendor Performance: Shows dellvery and quality performance for the past purchases for that commodity.

Requisition Status: Outlines the status of requisitions.

Invitation to Bid Worksheet: Shows all information required for processing the requisition.

Expediting Notice: Produced when the contract performance date or need performance date is within six months or other specified period. Workload Input Report: A supervisor's report for scheduling the purchase agent's workload in his section.

Critical Date Delivery List: Shows those contracts which are seriously late in delivery. 


\subsubsection{Power Stores Inventory Subsystem}

The Power Stores Inventory Subsystem allows any organization with a terminal device to have access to material stock records at all inventory locations. Receiving reports are preprinted on the terminal device at the receiving location when the material is received. Orders, receipts, and issue data from remote storerooms are electronically transmitted. Availability of material for future projects is controlled by notifying Stores when requisitions must be released. Material receipts are automatically priced by matching them to the original contract records stored in the MAMS data base. Requisitions are áutomatically screened against the MAMS data base and requests for delivery are printed when appropriate. The storeroom functions are carried out much as has been described in the Stores Accounting System description:

In the design of the system, there are a number of outputs which have been placed into it.

Requisition Analysis Report: Shows the requisitions entered into the MAMS system on the previous day.

Inventory Analysis Report: Item usage is listed in descending order by dollar value used per year.

Stock Status Report: Stock status and stock which has not moved in a particular period of time are shown.

Order Variance and Overdue Order Book: Items which have not been delivered within the time stipulated on the contract are listed.

Requirements Generation Report: A forecast report, it lists monthly requirements for items for the next six months. 
Transfer Form: Provides authority to move materịal from one storeroom to another.

Inventory Summary Report: Various levels are produced.

Recommended Stock Reorders: Statistics concerning usage over the past year and six months, and the average lead time, are reproduced. Reserve Items - Review for Requisition: Items reserved for specific jobs are tracked.

Recommended Stock Transfers: Indicates when common items in a local storeroum reach minimum levels and transfer from the central warehouse is required.

Material Delivery Schedule for Cancelled Jobs: Used to redirect the flow of material when a job is cancelled or delayed. Analysis of Field Purchase Orders: Shows the amount of material purchased on field purchase order forms in a geographic area and the stock status of the items at the main storeroom serving the area.

\subsection{1 .4 Accounts Payable Subsystem}

The Accounts Payable Subsystem is designed to minimize the clerical work and time required to pay vendors for material and services received. The subsystem has the capability to match the data contained on receiving reports, invoices, and contracts, and then print vouchers. Vouchers are held by the system unt1l they are due to be paid: Automation allows all invoices to be paid on their due dates, which allows TVA to take prompt payment discounts, as well as strengthen vendor relations, Clerical workloads are reduced by eliminating the need to handle invoices, receiving 
reports, and contracts when amounts are in balance. Use of a vendor master file eliminates the need to keypunch vendor name and address information for each invoice and provides the basis for accumulating vendor payment records. Management of cash flows is improved because invoices are paid only when they are due, and future requirements can be more accurately forecast. "Check volume can be reduced because all invoices due during a payment period can be consolidated on one check. A combined check and remittance form could eliminate clerical effort now required to match the documents.

The cycle begins on the day of receipt, when vendor invoices will be coded for payment, keyed, controls prepared, and prooflists printed to ensure accuracy. Field purchase orders are mailed to the Accounts Payable Section daily from other TVA organizations for coding, keying, preparation of controls, and prooflists. Finally, error corrections from the previous day's voucher preparation computer run that have been reconciled and corrected are keyed into the system. Invoice data, field purchase order and invoice data, and the previous day's corrections are transmitted to the MAMS system at the end of the day. I'hrough terminals located in Purchasing, Power Stores, and other TVA organizations, new contracts, receiving reports, and other pertinent data are transmitted daily into the MAMS system, where the data is matched to the data from H'inance, and a voucher tile is created. 'l'he edit and voucher data is transmitted back to the Accounts Payable Section, and reports are printed. Adjustments are keyed for the changes made to voucher proofs and for any changes that may have been made to the final vouchers as they were reviewe 
and certifled. Nonmaterial vouchers are prepared outside of the MAMS system, but-will merge with material vouchers at this point and will enter into the process.

At the end of the day, the voucher adjustments and nonmaterial vouchers are transmitted back to the MAMS system and are used to update an accounts payable data base. Periodically, vouchers due are pulled off of the accounts payable data base and are used to print checks, remittance advices, and a check register. At the same time, the open contract data base and the accounts payable data base are used to prepare several management reports. The open contract data base and the vendor master data base are used continuously for search and display in researching contract or payment status on any involce or receipt.

The principal elements of this subsystem consist of three major bases. The Vendor Master Data Base provides a central source of information pertaining to vendors. The Open Contracts Data Base contains a complete record of all material contracts awarded by TVA and stores them until properly fulfilled or cancelled. The Accounts Payable Data Base stores voucher data until the payment due date arrives.

The Accounts Payable Subsystem outputs a number of forms and reports to aid the payment of vendors.

\section{Vouchers-}

Voucher Proofs: Indicate that a manual review of documents is required for certification. Checks and Remittance Advices:

Commitments Reports: Shows the commltments that yendors have to TVA. 
Cash Requirements: Predicts cash.requirements for the next 12 months. Contract Follow-Up Report: ' Printed at the receiving location, it lists those contracts missing documents required for payment.

Unpaid Vendor Queries: A CRT query can be made of the system to determine if payment has been made.

\subsection{Major Project Managcment Syetcm (MPMS) - Georgia Power Company}

The Southern Company is developing a data base system which is referred to as the Major Project Management System (MPMS). In a sense, it is an outgrowth of certain existing programs on-line in the system at various construction sites. Not all the plants under construction utilize all the existing programs. It is hoped that in two years the detailed design of MPMS will be complete.

Five primary: areas have been identified along with their respective first level areas. They are as follows:

Scheduling

Document Control

Vendor Drawing Control System Domestic Drawing Control System

Procurement Control Reports

Materia1 Contro1

Equipment/Material Identification System (EMIDS)

Procurement Tracking System

Warehousing System

Start-Up Tracking

Cost

Commitments

Expenditures

Estimating 


\section{Labor.}

\section{Manpower Data \\ Productivity}

A further breakdown into components which have been identified but may not be part of the final system design is included in the exhibits for this section. The two detailed breakdowns are on the Equipment/Material Identification System and Procurement Tracking System. The two Iists are composed of data components which support management and should be available for quick retrieval.

In the development of the overall system, the present design is to develop each sub-system separately so that it will stand on its own. After individual sub-systems are operational, they will be integrated into the total data base system. The logic being used in the development of each system utilizes the following steps:

(1) General system design memo

(2) Functional specifications

(3) Detail program/system design

(4) Write and test software package

(5) Develop users manual

(6). Develop implementation procedures

(7) Initial implementation and testing

The prnjert development people admit that the MPMS system has bugs in some segments and probably has been over-designed in other areas. But it has been well thought through conceptually and through more refining and development it should be an excellent tool with which management 
can control the construction of a power plant and build a better product more efficiently:

\subsection{Structure of Numbering Systems}

The objectives of a numbering system for material control are essentially two-fold. The first and primary objective is to give a standardized identity to a material or service quantity so that it is unique, quickly identifiable, and can be easily communicated. The second objective is to build into that identity the ability to link it to other systems at all steps of the life cycle of the identified material or service.

In the highly computerized field of nuclear construction, the computer is the tool that is used for tracking and controlling products from inception through start-up. Thus, an efficient identity number for material and service quantities is of key importance now and in future tracking systems.

Presently, no numbering system exists which establishes a unique number that carries through the entire life cycle of a material or component. Material quantities are given Bill of Material numbers, requisition numbers, purchase order numbers, material tracking numbers, cost accounting numbers, etc. Each time a quantity which must be uniquely tracked changes identity, there is a loss of efflciency and the task of tracking is complicated. The reason this problem exists stems from the tremendous amount of information associated with components and the number of actors and organizations which contribute component data. The 
amount of information gains momentum through the life cycle of a given item and/or action. The following is a list of basic information categorfes which are associated with material items:
(1): Project number
(2) Piping and Instrument Drawing (P\&ID)
(3) Specifications
(4) Schedule work activity
(5) Cost accounting
(6) : Purchasing and vendor numbers
(7) Vendor drawing numbers
(8) Iso drawing numbers
(9) Location (spoo1, system, area, building)
(10) Safety or non-safety related status
(11) Class or group of equipment or material
(12) Warehousing and storage information
(13) Origin (primary engineering, site, home office, etc.)
(14) Other specific or non-standard description

It is evident that a single identity number which contains all of the above information will be tremendously long and cumbersome to use.

\subsection{3 .1 QTS}

The numbering system employed by Bechtel in their Quantity Tracking System is an example of this type of an intelligent numbering structure. The Bechtel 11-digit number given to pipe, valves, or hangers in the Large Pipe Tracking System contains system and spool number (location), area (location), and drawing number (ISO and $P \& I D)$. There are also various numbering systems in existence for requisitions or schedule activities which are partially used during material life cycles. For instance, the Construction group at Georgia Power Company uses a sixdigit schedule activity code for construction activities and has made it flexible enough for filing, cost accounting, purchase orders, and even englneering cost coding. 


\subsubsection{System in Use at Vogtle Nuclear Power Plant}

The area of document: control interfaces directly with material tracking. The amount of data associated with procurement documents and required cross-referencing necessitates a separate numbering system. This system starts in design and is finally utilized in the field and by project management. An example of an active system being utilized presently in the construction of Vogtle Nuclear Plant for Georgia Power Company is given as Exhibits 1 and 2 in Addendum $G$. Only a few sample sheets are included on the detailed breakdown of sub-category subject and number. The system was jointly developed by Bechtel's E \& I Divi-' sion (Electrical and Industrial) in conjunction with Georgia Power and Southern Company Services personnel. The actual number is a six-digit alphanumeric number which is hierarchically ranked with most specific information at the right. The number can be utilized at any level which allows certain general data and corrcspondence to be filed at that level. The number can be used manually and is adaptable to computer use as well. Presently the computerized use of the number is primarily as a listing and scheduling service. Status of completeness of documents (according to a predetermined number) is being looked at now. Paragraphs 3.1 to 3.6 in Addendum $G$ describe the system, numbering components, initiator responsibility for the number, filing responsibility, specification/ purchase order filing system, and other filing usages.

The sheet entitled "FILE NUMBER AND DESIGNATORS" gives the complete list (at present) of the third element codes being considered for the file number: Sheets C3-17through C3-61/62 are typical subcategory 1ists which 
comprise the master control document. Comparison can be made between the two groups composed of sheets C3-17 through $\mathrm{C} 3-21 / 22$ and sheets $\mathrm{C} 3-55$ through C3-61/62. The first group is the Spec./P.0. File and the second is the Subject File.

\section{$2.13 .3 \cdot \underline{\text { MPMS }}$}

The basic codes which are proposed for use in MPMS are as follows:

$$
\begin{aligned}
& \text { SAC -- Schedule Activity Code } \\
& \text { COA -- Classification of Accounts } \\
& \text { ESC -- Engineering System Code } \\
& \text { EMN -- Equipment/Matertal Number } \\
& \text { SUAC -- Start-Up Activity Code } \\
& \text { RUC -- Retirement Unit Code }
\end{aligned}
$$

The SAC code is the key to the whole system. It represents actual construction activities of approximately two weeks duration and interrelates all activities to the actual construction of the plant. All other areas support the construction function of building the plant. The SAC code is segmented. The first three digits of the six-digit number represent major construction categories. A sample master schedule listing SAC numbers is attached as Exhibit 3, Addendum G, and a sample SAC code master control sheet is attached as Exhibit 4, Addendum G. This sheet depicts the codes and the sub-component categories. The remalning three digits are simply used for sub-category breakdowns. The MPMS filing system being implemented on-site is based on the SAC codes. Even purchase orders will be filed according to their SAC code.

The SAC code will appear on design drawings (but not on general arrangement type drawings); on purchase orders, on correspondence, on 
al1 schedules, and on equipment material lists (in Procurement Tracking System.). Scheduling initializes the use of the SAC codes when they prepare the schedules. At the same time, Engineering begins to post the SAC codes on the drawings. There is a standing list of code numbers which is utilized from plant to plant. The following figure, Figure 2.7, depicts the usage of the SAC code and shows how it binds the support activities together. Only SAC codes cross the boundaries as shown. Filing is a dependent support activity for any other activity, and therefore is not shown as a separate activity in the figure. The maximum number of SAC's for a project is approximately 30,000 .

The Classification of Account (COA) code is utilized for accounting , purposes and the first three digits correspond to the 13 Federal Power Commission (FPC) accounts. The four digits after the decimal are tied Into the ESC code. A typical COA code would be 312.5211. A SAC code only references a single COA. There are approximately 1,000 COA numbers. The Engineering System Code (ESC) is a four digit number used by Engineering to schedule their design activities. A checklist is developed based on ESC codes so that materials listed for a particular system can be evaluated. All engineering costs are posted to an ESC code (timesheets, etc.), which then end up in a COA code. ESC codes are posted on drawings in order to make sure that all system interfaces are corrected in the design process. The number of ESC codes is determined by the number of systems. At present, the total is as follows:

70. Structural 100 Mechanical 80 Electrical 


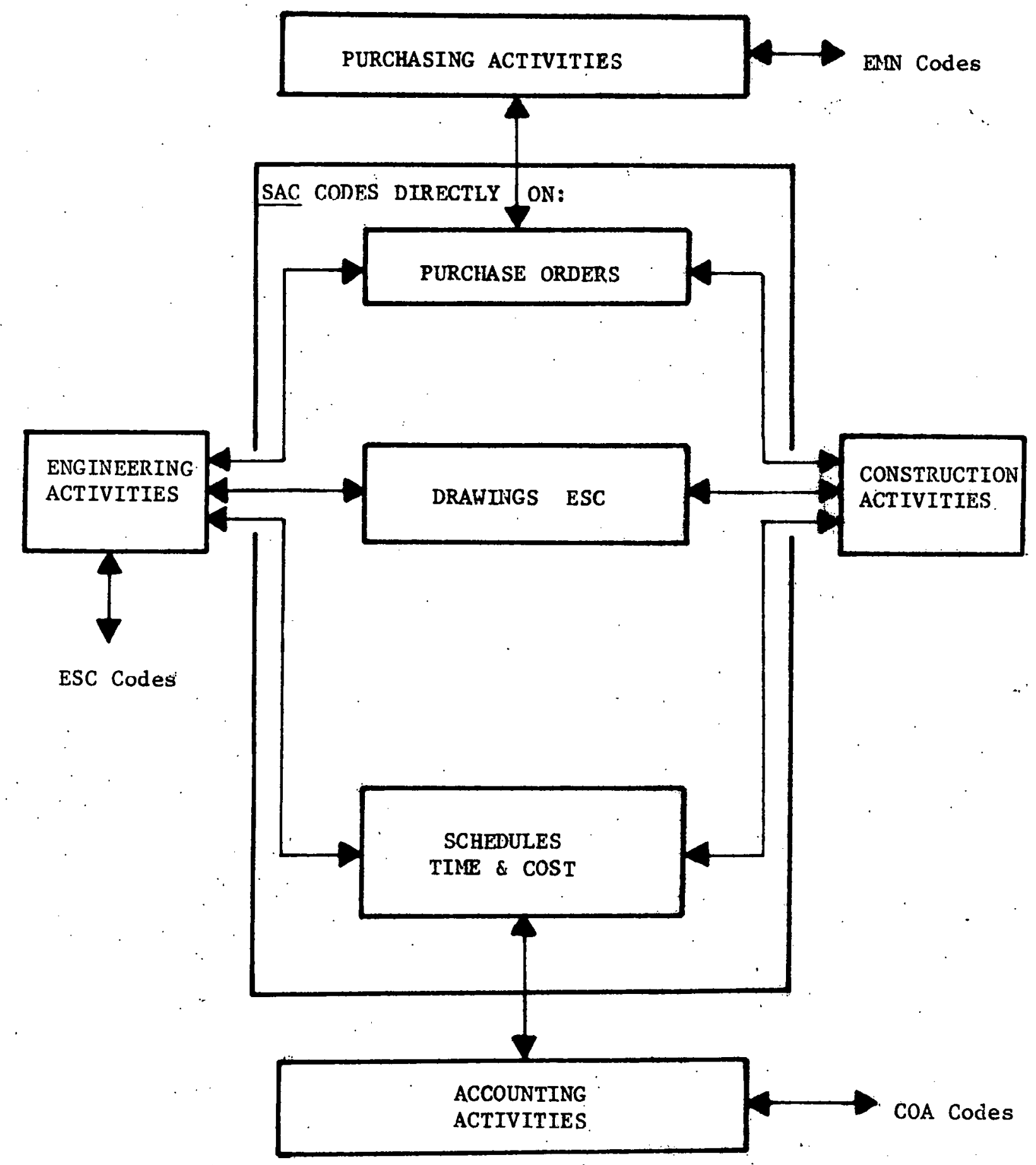

FIGURE 2.7: USAGE OF THE SAC CODE 
totalling 250 ESC codes. These are then grouped into about 1.50 work packages:

The Equipment/Material Number (EMN) code is referenced to SAC code numbers and to purchase orders. A major piece of equipment is assigned an EMN code which stays with it from then on. The following is a detailed description of the EMN,

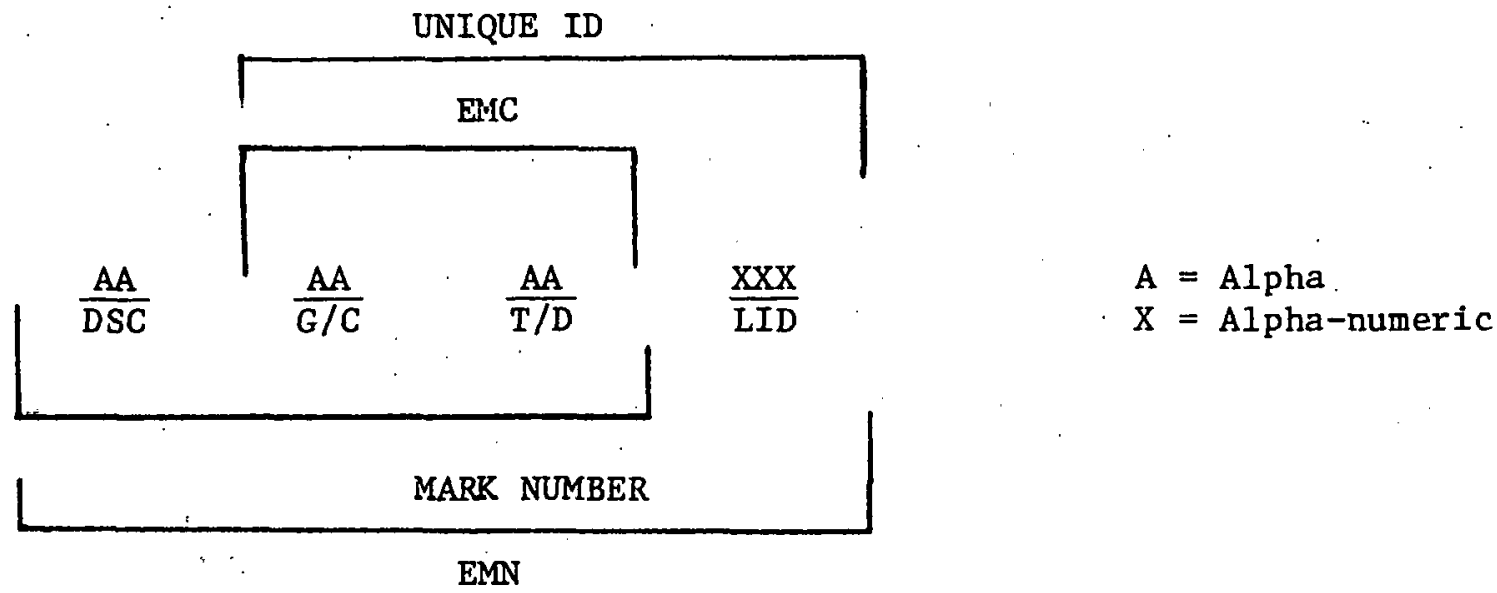

Meanings of Codes:

A. DSC -- (Detail Specifications Code). The two alpha character DSC is an arbitrarily assigned code which is used to differentiate non-interchangeable items having the same EMC. Conversely, two items having the same DSC and EMC (Mark Number) are interchangeable.

B. G/C -- (Group or Class Code). The two alpha character G/C is a preassigned code to identify the general class of equipment and material and, in the case of instruments, instrument systems.

C. T/D -- (Type Descriptor Code). This is a two alpha character that, when added to the $G / C$, will define the type of equipment or material. 
D. LID

E. EMC

F. Unique ID

G. Mark Number --
-- (Location Identification Code). The three digit alphanumeric character LID is used to differentiate items of a given EMC so as to provide both a unique identification and location (on a drawing) for the Item. LID numbers may be used with Mark Numbers; however, uniqueness in an item number is established only by EMC plus LID. The LID will be generally numeric characters.

-- (Equipment Material Code). This is a four character code that consists of the $\mathrm{G} / \mathrm{C}$ and $\mathrm{T} / \mathrm{D}$ codes. Each EMC will yleld only one equipment or material type description.

This is the EMC plus a non-blank LID. For example, this is the key to accessing the computer stored records in a separate program, Cable Routing.

Consists of the DSC plus EMC codes. The Mark Number is different for each item of equipment which is different, but it must be the same for multiple or "like" items which are interchangeable. Once a Mark Number has been associated with a technical description, the use of that Mark Number within a given project must always be associated with the same technical description.

The EMN is still lacking the basic Information needed in a quantity's number, However, the approach of segmenting and grouping a number may be the clue to providing a large amount of information in a compact, efficient numerical format.

The Equipment Material Number code is similar to the SAC in the sense that it crosses some system boundaries. It is printed on the output sheets of the Equipment and Material Identification System (EMIDS). It serves as the main input to EMIDS. Assignment dates of each number are retained. Assignment responsibility of the code falls to the discipline responsible for identifying the equipment type and class. The EMN code will be shown on the following documents: 
Functional Control Diagrams. (FCD's)

Wiring Diagrams

Line Diagrams (unique I.D. only)

Cable Pull Cards (unique I.D. only)

Raceway : Installation Cards (unique I.D. only)

Detail Drawings

Detail Installation Drawings

System Design Specifications

Test Specifications

Procurement Specifications (mark numbers only)

Bills of materials (mark numbers only)

Data Sheete (mark numbere only)

Requisitions (mark numbers only)

Vendor drawings (where the drawings are required as installation drawings)

MPMS Equipment I.D. Printout ("Equipment List")

The Start-Up Activity Code (SUAC) will probably be a three or four digit number hierarchically assigned. It will be used to designate start-up activities in the start-up network. In this context, it will serve as a schedule and status control during the start-up phase of the plant. Whether costs will be collected at its level as they are at the SAC level (lowest level costs are collected) is not known at present. Detailed information regarding the SUAC will be forthcoming during later phases of MPMS development.

The Retirement Unit Code (RUC) is still a tentative candidate code. More information on its use and prime function will be obtained later as its role is better defined.

Another numbering system used in document control is as shown on the following page; 


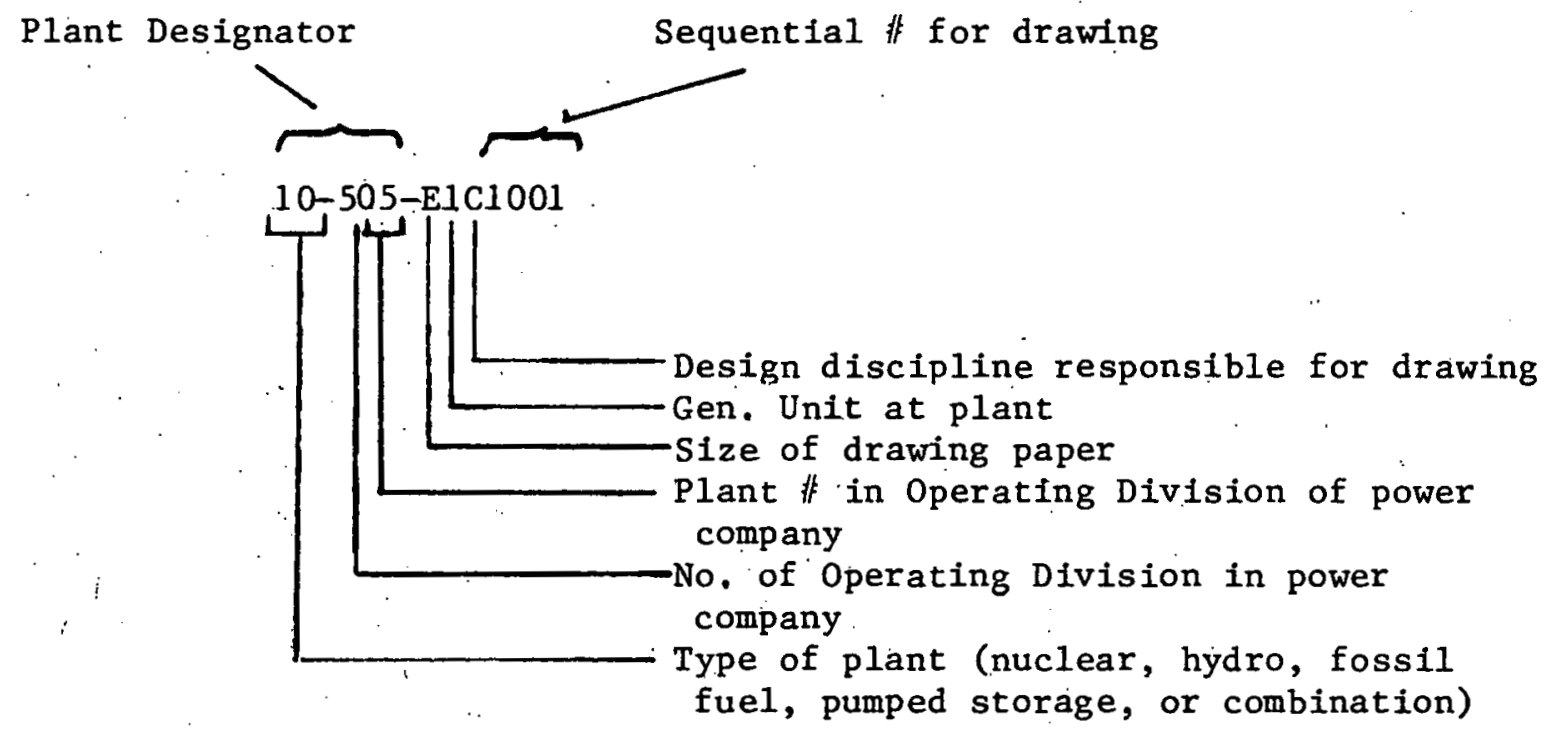

The number above represents a typical domestic drawing number. The following number is a typical number representing a vendor drawing assigned number:

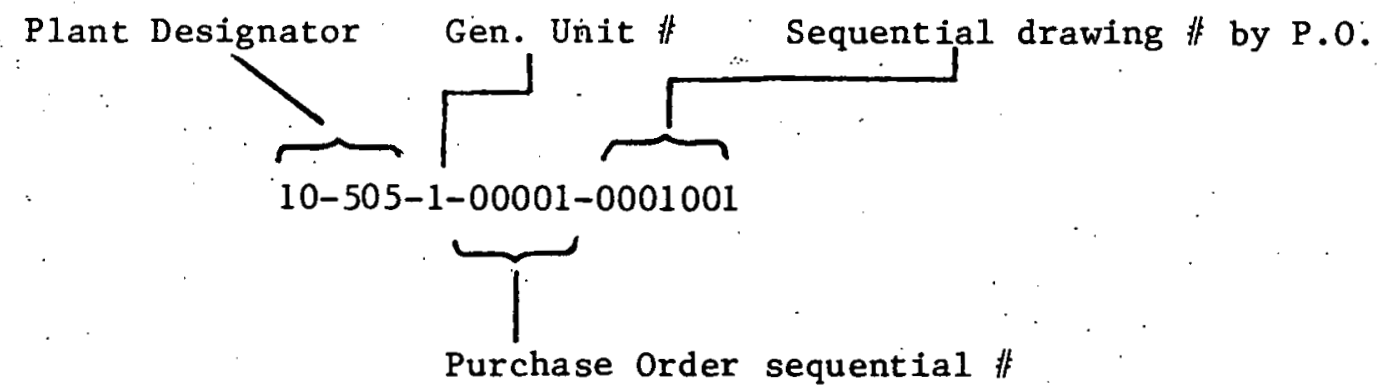

The sequential numbers are assigned.in blocks by Project Procurement and input Into the Document Control system by the processor of the drawing. 


\subsection{3 .4 Punch List}

The numbering system in the Punch List 'Program provides

information requiring drawings and component availability for systems to be scheduled in the coming week. A typical input code is as follows:

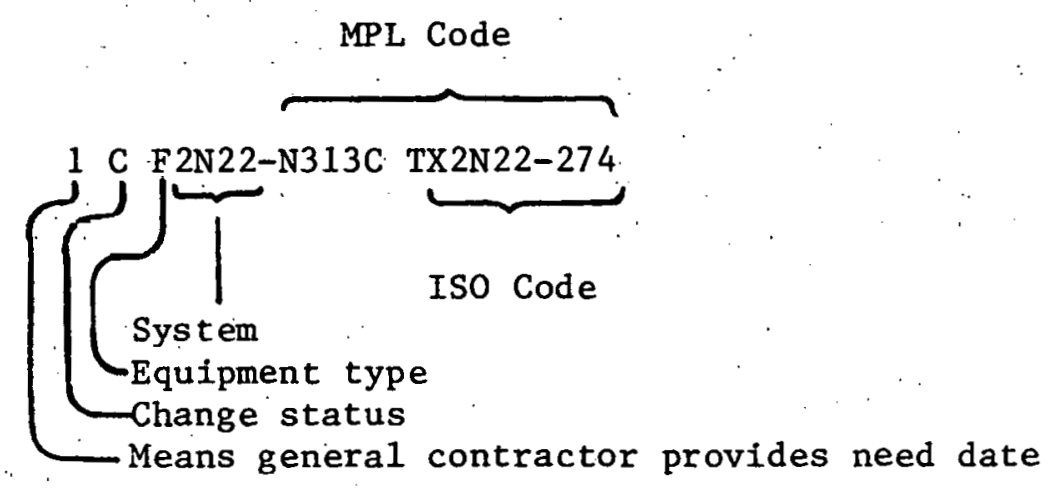

The code is input on five different long sheets which represent 80 lines each for card input. The letter and name respectively for the types of components are as follows:

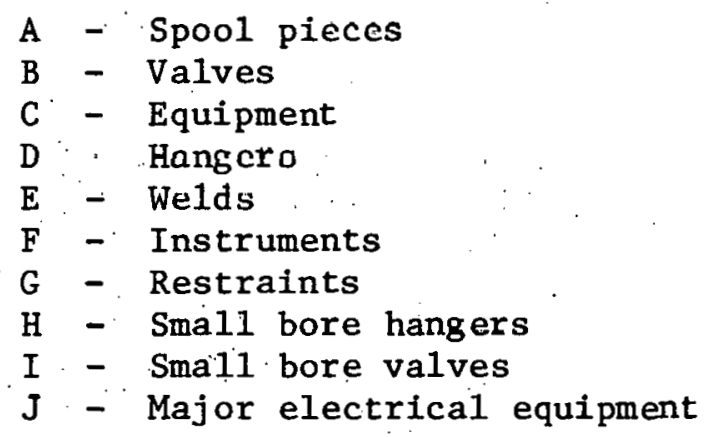

System output formats the following component attributes (see Output Report in Appendix F):
(1) Type
(2) Equipment Number
(3) Iso Drawing Number
(4) Revision
(5) Area
(6) Size
(7) P.0. Number
(8) P.0. Item Number
(9) P.0. Sub Item
(10) Mark Number

(11) Hold
(12) Documentation
(13) Received
(14). In Building
(15) Installed
(16) NDE
(17) Hydro
(18) CAT
(19) Temp. T.0.
(20) Perm. T.0.



(21) System T.0.
(22) Operationa1
(23) Painted
(24) Welded
(25) Insulated
(26) Pins Pulled
(27). Weld Spec

(28) Req'd Date

(29) Sched. Ship Date

(30) Rec'd Date

(31) Temp T.0. Number

(32) Perm T.0. Number

(33) System T.0. Number

(34) Discipline

The remainder of the items pick up Flush Number, Need Dates, Pre. Op. No. Need Dates, Required Status, Estimated Earliest Flush, and Pre. Op. Three letters are printed to indicate status (from Hold to Pins Pulled above). These letters are N (Not Required), R (Required), and A (Completed). A number of the items are not used and a new form is being developed. 


\section{THIS PAGE \\ WAS INTENTIONALLY \\ LEFT BLANK}




\section{Problems with Existing Systems}

\subsection{Introduction}

As can be seen from the previous pages, the sample of systems examined during the course of this study runs the full gamut from a simplistic manual system to a totally integrated system such as the Material Management System used by the Tennessee Valley Authority. The following chart summarizes what general sections in the life cycle the system covers and a subjective evaluation as to level of sophistication (on a scale of 1 to 5 , where 1 = low).

\begin{tabular}{|c|c|c|c|c|c|}
\hline System & $\begin{array}{l}\text { sign } \\
\text { urement }\end{array}$ & Purchasing & Expediting & $\begin{array}{c}\text { Ware- } \\
\text { housing }\end{array}$ & Evaluation \\
\hline $\begin{array}{l}\text { MESS } \\
\text { PMICS } \\
\text { SAS }\end{array}$ & $\mathrm{X}$ & $\mathrm{X}$ & $\mathrm{X}$ & $\mathrm{X}$ & $\begin{array}{l}4 \\
2 \\
4\end{array}$ \\
\hline $\begin{array}{l}\text { MPMS } \\
\text { Punch List } \\
\text { QTS }\end{array}$ & $\mathrm{X}$ & $\begin{array}{l}\mathrm{X} \\
\mathrm{X} \\
\mathrm{X}\end{array}$ & $\mathrm{X}$ & $\begin{array}{l}\mathrm{X} \\
\mathrm{X}\end{array}$ & $\begin{array}{r}5 \\
4 \\
\end{array}$ \\
\hline $\begin{array}{l}\text { Manual } \\
\text { Material Con- } \\
\text { trol Module } \\
\text { MMIS }\end{array}$ & $\begin{array}{l}\mathrm{X} \\
\mathrm{X}\end{array}$ & $\begin{array}{l}\mathrm{X} \\
\mathrm{X}\end{array}$ & $\begin{array}{l}X \\
X\end{array}$ & $\mathrm{X}$ & $\begin{array}{l}4 \\
5\end{array}$ \\
\hline $\begin{array}{l}\text { MAMS } \\
\text { IMCS }\end{array}$ & $\mathrm{x}$ & $\begin{array}{l}\mathrm{X} \\
\mathrm{X}\end{array}$ & $\begin{array}{l}\mathrm{X} \\
\mathrm{X}\end{array}$ & $\begin{array}{l}\mathrm{X} \\
\mathrm{X}\end{array}$ & $\begin{array}{l}5 \\
4\end{array}$ \\
\hline
\end{tabular}

TABLE . 3.1

From the above chart it is obvious that there is a great deal of overlap between the various systems. Most of the efforts which created these systems were independent ventures: 
In spite of the fact that a number of different groups proceeded in the development of material tracking systems, there are quite a few problems which are commion to all systems. How should the materials be tracked, what sort of numbering system should be utilized? How should the data be collected and what sort of methods should be used to insure that the collected information is correct? How should the output be structured for ease of tinding the desired informatlon? What surL Uf hardware should be implemented to achieve a satisfactory response time while still keeping costs under contro1? What sort of resistance was encountered from project management when the existing systems were altered? Was it necessary to change the company organization in order to implement the new system? In addition to these rather general problems, many of the individuals interviewed had specific suggestions as to what problems in the nuts and botts range were encountered when some of the existing systems were set up (these have not been included, as the level of detall of this report is not great enough).

\subsection{Problems with Numbering Systems}

In developing numbering systems, two main considerations arise. The first is the development of the number itself. Should the number be a random number or a so-called "intelligent" number? An intelligent number would contain information as to the origin of the component described. Such data as isometric drawing code, system, equipment type, activity codes, etc, would be intrinsic. The primary difficulty which arises in a number design such as this is what happens when some of the 
information contained in the number is revised. The design/construction of a nuclear power plant is done on a fast track basis; that is, design is on1y partially complete (usually 20\%) when actual construction begins. As the design proceeds, revision of items already in the construction phase is inevitable. Should a new number be implemented, or should, the old one be revised? Should the decision be made to revise the number, it becomes necessary to implement the change through all levels from design engineering to vendor. Needless to say, a great deal of confusion arises during the transition to the new change. This is substantially complicated when it is realized that the process of revision is a continually ongoing process. It becomes obvious that for certain large components intelligent numbers would be the best way to proceed. The choice of numbers on bulk items for such things as purchase order or requisition number could be done on either a random or intelligent basis. Duke Power Company has determined that for bulk items the use of intelligent numbers for requisitions or purchase orders required too much effort for the benefits gained.

The second major difficulty with numbering systems is attempting to maintain the same number through all steps in the material cycle. Usually this is not too difficult within the same organization. But often there are a great many different organizations involved, each with their own accounting method. Imposing a unified numbering system will require that the firms whose systems differ from that imposed change the1r system or maintain a dual system. Obvious1y both of these 
require additional effort which will be reflected in the prices of the products offered,

\subsection{Problems with Input Required - Data Acquisition}

In the process of making many of the systems described herein work, a great deal of information must be collected and "input" into the system. As a result, many problems arise. Defining what information is needed is important. An incorrect determination could either result in insufficient data being collected, resulting in additional efforts in data collection being required, or too much information being collected and considerable energy being wasted. A concerted effort must be made in the case of each system to organize a data collection system which will efficiently collect the necessary information at the correct level of detail.

In the process of collecting input, accuracy is vital. No system can be more accurate than what is fed 1nto 1t; garbage in-garbage uut. The best way to maintain correctness is to insure its accuracy at the source. In spite of this, however, some sort of checking system should be implemented. Duplicating the entire collection process may not be warranted, so some sort of random checks should be used. In the case of high-risk items, however, it may be necessary to double-check the entire collection procedure. In any case, because of a snowballing effect, it is much easier to maintain veracity by catching errors before they enter a system, rather than trying to pinpoint an error already in a system. Some errors do get into any system. As a result, some sort 
of sensitivity analysis must:be undertaken. What end results do errors have in the overa11 system objectives? How can the errors be rectified and how much effort is required?

The method used for inputting into the system can create some problems while eradicating others. An overnight batch process creates the pressure of deadlines. A real time access system via CRT or teletype allows suffictent flexibility to permit entry at any time, thus eliminating deadlines. On the other hand, ease of entry may result in more errors entering the system due to the elimination of a psychological pressure.

The source of the input information also creates several problems. The data generally comes from either in-house or vendor/subcontractor sources. If the information is not in-house, some efforts must be made at coordination to minimize the amount of redundant work. Different numbering systems may require recoding. The mere existence of systems such as described previously may require organizations to make efforts in the area of documentation and quality control which had not previously existed. As a result a certain amount of "run-in" time may be necessary before the collection procedures are "debugged." More than one source also compounds the problems described above. More coordination and skilled management are required to achieve the same degree of success.

\subsection{Problems with Output Usability - Timeliness and Form of $0 / P$} During many of the visits and interviews which were undertaken In the writing of this paper it was noticed that there were great. 
quantities of computer printout to be found. Obviously there is a problem with the information produced; it is either unavallable when required or much more information is produced than is actually sought.

Many of the systems which have been described do not allow a great deal of specificity in determining precisely what information is produced. A complete listing of items falling into one of ten or twelve different categories is presented. There are a few systems, notably Punch List and MMIS, which can become quite specific in determining what is presented. Punch List allows up to seven nested directives and MMIS can be modified to meet almost any demand. Oftentimes the ease with which particular items can be pinpointed depends on the program construction.

Once a particular item or piece of information has been presentëd it becomes evident that the form of presentation is important. The average computer page contains 132 spaces in width, which limits the amount of information that can be presented. Many. of the presentations use two lines. Punch List uses alternately white and yellow bands with each pair of bands corresponding to a particular item. Many times, however, it is difficult to keep track of headings when reading at the bottom of pages. Some programs utilize specially produced paper to remedy this. It is necessary that some thought be given to the presentation of the material in order that the desired information may be easily located,

of great importance to the user is that the desired information be obtained within the desired time framework. Late information is many 
times as good as no information. The timespan within which information is desired can be divided into two categories: those at regular inter vals and those at instant demand. Much of the information used in administration is required at regular intervals, i.e., end of week for payrol1, end of month for vendor payment, etc. This information can be produced on overnight batch bases. The necessary data are delivered to a central location and the required information is received thereafter. At the production end of management, however, critical situations arise and certain information is needed immediately. Many times this information can be determined from the regularly produced reports. Sometimes, however, the published information may not be recent enough or not contain what is desired. In such cases, the ideal solution is a teletype or CRT connection directly with the computer. In this way information can be retrieved immediately. The primary disadvantage is the cost involved. Real time hookups become economical only if a great deal of usage is made of them. If the information desired is of great significance, however, the cost may become justified.

\subsection{Problems with Implementation}

Implementation problems can be divided into two broad areas -those attributable to user acceptance and those attributable to personnel training. User acceptance problems can vary widely depending on how great the need for some sort of modification is. If the upper echelons of the management do not get the information they need or see a bottleneck at some point because of an informational problem, no doubt some 
sort of tracking system may be the result. Lower levels, however, do not have the same overview of the sttuation and hence may not appreciate why certain changes are being carried out. They may even believe the alteration to be a step in the negative direction, requiring more effort with no discernible improvement: In the early steps of implementation, it is important that the results be as accurate as possible. User reliance on the tracking systems will only occur if the results attained are better than the existing methods. It is at this point, however, that the system still requires extensive debugging and therefore does not give the best results. Most of these problems, however, can be circumvented if upper level management shows a strong interest in the successful implementation of any material tracking system. Personnel training problems are the same as faced by any other level of management. After doing things one way for a longer pertod of time, it generally takes a formal training effort to convert to another system. This training should be carried out from program inception. High turnover among personnel can become quite expensive. Many of these training sessions can last some time and involve a degree of expense. If this must be repeated for the same position of ten, then much money must be expended and the efficiency of the system suffers.

\subsection{Problems of Integration Between Systems}

As can be seen from Table 3.1, many of the systems overlap. Transfer of information between systems is in most cases a manual process. The Material and Equipment Status System (MESS), Piping Material Inventory 
Cọntrol System (PMICS), and the Stores Accounting System (SAS) are all developed and used by the Duke Power Company. The relationships in terms of materials covered can be illustrated as follows:

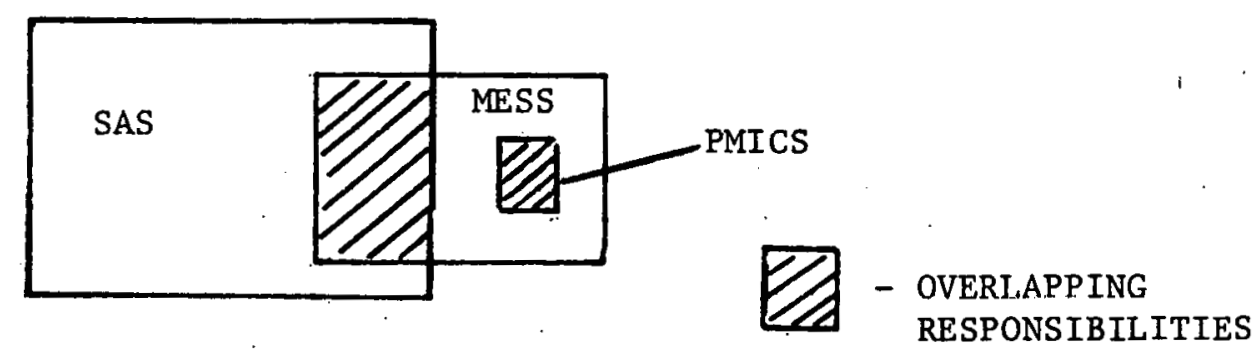

FIGURE 3.1: INTERRELATIONSHIPS BETWEEN MATERIAL TRACKING SYSTEMS

Although there is some overlap, it is not possible to directly transfer information between SAS, MESS, and PMICS. If it is desirable to do this, the information must first be recompiled before it can be used by any of the other programs. Two of the systems reviewed herein make total integration a part of the program set up. The Material Management System of the Tennessee Valley Authority and the Major Project Management System (MPMS) of the Georgia Power Company are both still very much in the planning stage. The other systems reviewed were set up to perform a specific function rather than interact with the complete project management structure.

\subsection{Problems Concerning Over-Design of System}

The development of many of the systems included in this report proceeded in the following fashion. A.need was discerned by either 
project management or upper level company management; systems analysts were assigned to research and develop solutions; and the system was implemented in the field. The problem of over-design enters when it is seen that the people who design the system are not the ones who use it. As the analysts examine the situation, they must rely on field interviews and personal assumptions. These ideallzations are then incorporated into the sygtem degign. When used in practical application, however, it is sometimes found that the assumptions made in the office are not borne out. Georgia Power Company's Punch List program has the capability of tracking the status of 16 different points in the construction process. When finally used by the job site personnel, only four or five of these points were actual1y used. It was found that the benefits reaped were not worth the effort of maintaining exact information on all of the 16 points. It was pointed out that it may have been of interest to maintain all points in order to establish a historical record.

\subsection{Organizational Problems.}

Many times in the process of implementing systems, it becomes obvious that the organizational make-up of the company does not lend 1tself to an effective use of a material tracking system. Also it may become obvious that the organizational relationships already in use can be improved. In many cases a centralization procedure is involved. A company may have a geographical area broken up into zones with each zone acting more or less independently. In the process of implementing a 
material tracking system it may become obvious that there is much duplication of effort; many of the materials are purchased by all sectors even though not required by each. Centralization may streamline material procurement efforts by reducing duplication of effort and reducing inventorles. The Material Management System used by the Florida Power Corporation reduced their inventories 40 per cent by centralizing the warehousing system. Previously a decentralized zone system had been used. In the process of realigning corporate structure company politics may play a significant role in determining what is feasible and what is not. These factors may on occasion be significant and in any case should not be discounted. 


\section{THIS PAGE WAS INTENTIONALLY LEFT BLANK}




\section{REFERENCES}

Bontadelli, James, Tennessee Valley Authority (IMCS), Personal Communication, 4-19-77.

Borman, Dick, Florida Power Corporation, Personal Interview, 9-6-77.

Daniel International Corporation, "Material and Equ1pment Receiving," Procedure AP-IX-02, Construction procedures produced for internal use.

Daniel International Corporation, "Warehouse Procurement Documents Filing System," Procedure AP-IX-01, Construction procedures produced for internal use.

Dixon, Tom, Florida Power Corporation, Personal Interview, 9-7-77.

Dourough, Ron, Georgia Power Company, Personal Interview, 8-31-77.

Duke Power Company, "Accounting Procedure Manual, Section X-1, Stores," Internal procedure manual, 11-1-67.

Garrot, Henry, Georgia Power Company, Personal Communication, 4-19-77.

Georgla Power Company, "Vogtle Nuclear Plant Project References Manual," Internal procedure manual, 10-11-74, Rev. 1976.

Georgia Power Company, "Material Control Classifications - Vogtle Nuclear Power Plant," Internal document.

Georgia Power Company, "Schedule Activity Code Index, Plant Scherer," Internal document.

Lumadue, R: B., "Material and Equipment Status System," February 24, 1976, Internal system description at Duke Power Company.

Lumadue, R. B, , Duke Power Company, Personal Communtcation, 4-5-77.

Lynn, Robert, Duke Power Company, Personal Communication (MESS, PMICS, SAS ), 4-5-77.

Manley, Max, Duke Power Company, Personal Communication (MESS, PMICS, SAS), 4-24-77. 
Mashburn, C.R.; and R. Lewallen, Daniel International Corporation, "Quantity Tracking System," Preliminary ERDA. write-up, 4-11-77.

Northern States Power Company, "Northern States Power Co, Computer Reports and File Procedures."

Southern Company Services, Inc, MPMS write-up, Internal Document, 1976 .

Tennessee Valley Authority, "General Briefing on Division of Construction Improved Material Contro1 System," 1-27-77, Unpublished outline.

Tennessee Valley Authority; "Materials Management System Project; Design in Principle," June 1976, Unpublished report.

Usher, Ronald, Duke Power Company, Personal Communication, 5-25-77.

Willenbrock, Jack H:, "Volume 1 Seminar Proceedings, State of the Art of Power Plant Construction," Presented at the Pennsylvania State University, University Park, Pennsylvania, August 12-13, 1976; P. 45. 
A.DDENEUM A

APPLICATION AREA OUTLINES

Quantity Take-off

Purchasing/Expediting

Warehousing 
ADDENDUM A

Exhibit 1

APPLICATION AREA: Quantity Take-off

\section{INDEX}

1.0 Description

2.0 Objective

3.0 Functions

3.1 Develop accurate quantities for purchase of material on a timely basis as required by the schedule.

3.1.a Description of functions

3.1.b Relationship with other functions and application areas

3.1.c Data requirements

3.1.d Data generated within the function

3.1.e Processing

3.I. R Reports to users 


\subsection{Description}

Among the applications considered, Quantity Take-off can be considered a keystone of the overall system. It provides the material list or bill of material (B.O.M.) for many subsequent activities, such as procurement, estimating, planning, scheduling, cost control, progress reporting, warehousing, and documentation. The bill of material (B.O.M.) or parts list describes what goes into an assembly. Quantity Take-off is performed by three or more groups for procurement and then repeated by many more groups during the life of the project for other applications. The primary engineering firm has the responsibility for the major components. Subcontractors with fabrication contracts have to prepare a B.O.M. for their sub-components with related documentation. Site engineering has to procure the remaining components not previously defined and ordered to complete the plant. Subsequent activities such as estimating, etc. listed above repeat this Quantity Take-Off procedure to perform their tasks.

\subsection{Objective}

The first objective of Quantity Take-off is to supply an accurate listing of material quantities required for completion of the project within the schedule. The second objective would be to provide information to the other application areas as required to accomplish this end result. The bill of material developed by Engineering should be utilized by as many of the other departments as possible to minimize the redundancy of taking off the material for their purposes.

\subsection{Functions}

3.1 Develop accurate quantities for purchase of material on a timely basis as required by the schedule.

\section{1.a Description of functions}

(1) Plan structure of bill of material (B.0.M.) in order to permit explosion to component level or summary to highest level of end product (see Figures A.1.1 and A.1.2).

(2) Perform detailed Quantity Take-Off and accurately record on spread sheets for incorporation into bill of material. B.O.M. is defined as the organizing of data describing a quantity of material as to what raw material is in each component, components used in an assembly, and the assembly used in each end product. 
(3) Prepare B.O.M. and submit for preparation of requisition. Include cost codes, Q.C. requirements, etc.

(4) Prepare requisition and submit to Purchasing.

(5) Interface bill of material and requisition with necessary departments (see Figures A.1.1 and A.1.2).

(6) Keep accurate records and files of take-offs, B.O.M.'s issued, and requisitions issued.

(7) Report on status of all Quantity Take-off data.

3.1.b Relationship with other functions and application areas (see Figure A.1.3)

(1) B.O.M. is utilized by Estimating for developing the definitive estimate.

(2) Planning and Scheduling develop manpower requirements and activities from B.O.M.'s.

(3) B.O.M. is needed in Cost Control for accurate field. reporting of quantities installed and labor costs associated with this material.

(4) Requisition is used by Engineering and Estimating to monitor purchase orders and subcontracts.

(5) Material Control utilizes B.O.M. information for tracking quantities from manufacturer to warehouse through installation.

(6) Warehousing utilizes B.O.M. for monitoring materia1 location and for material issuing.

(7) Q.C. needs.B.O.M. for checking proper installation of all materials.

(8) Field Supervision assigns work for crafts through B. O.M.'s and can check availability of material.

(9) B.0.M. is incorporated into the "traveler" that accompanies a quantity of material from warehouse through start-up.

(10) Requisition is used by Purchasing for issuing of purchase orders and change orders.

(11) B.0.M. is used to coordinate delivery date with Construction Field Supervision for use in requisition.

(12) Q.A. and Q.C. status are taken from B.O.M. for inclusion in the requisition.

(13) B.0.M. is used to coordinate Take-off activities wj those of Planning and Scheduling. 
3.1.c Data requirements

(1) Specifications.

(2) All drawings that are related to specific disciplines or interface with other disciplines.

(3) Master identification lists, such as piping line list, etc.

(4) Status reports on engineering procured items and subcontracts.

(5) Schedule.

(6) Cost accounts.

3.1.d Data generated within the function

(1) Bill of materials.

(2) Requisitions.

(3) Expediting requests.

(4) Requests for clarification and information. (R.C.I.).

(5) Bulk ordered material inventory records and cost transfers of bulk material.

3.1.e Processing (steps of preparation)

(1) Bi11 of materials (see Figure A.1.2).

a. Review drawings and specifications and perform take-off.

b. Review cost accounts and schedule to determine structure of B.0.M. (see Figure A.1.2, B.O.M. sample).

(2) Requisitions (see Figure A.1.4).

a. Need B.0.M. for preparation.

b. Assign requisition number from $\log$ and cost codes.

c. Determine delivery dates, Q.A. or Q.C. status (see Figure A.1.4, requisition sample).

(3) Expediting (see Figure A.1.5).

a. Quantity Take-off man or requisitioner issues expediting request on all materials for which he is responsible.

b. Maintain expedite request $10 \mathrm{~g}$.

c. Forward request to expeditor (see Figure A.1.5):

(4) Request for clarification and information (see Figure A.1.6).

a. Issue R.C.I. form for conflicts or clarification during take-off phase.

b. Assign number and record in $\log$ book. 
c. Used for documenting Take-off when necessary (see Figure A.1.6).

(5) Bulk order materials inventory

a. Material without specific end use at time of purchase.

b. Keep inventory files.

c. When material is assigned, record quantity, cost account, and B.O.M.

3.1.f Reports to users

(1) Status reports for:

a. B.O.M.'s issued.

b. Requisitions issued.

c. Expediting reports.

d. Requests for information.

e. Bulk ordered materials. 
Exhibit 2

APPLICATION AREA: Purchasing/Expediting

\section{INDEX}

1.0 Description

2.0 Objectives

2.1 Purchasing

2.2 Expediting

3.0 Functions

3.1 Purchasing

3.1.a Description

3.1.b Relationship to other functions

3.1.c Data requirements

3.1.d Data generated within the function

3.1.e Reports to users

3.2 Expediting

3.2.a Description

3.2.b Relationship with other functions

3.2.c Data requirements

3.2.d Data generated within the function

3.2.e Reports to users

4.0 Code number or keys

4.1 Requisition number

4.2 Purchase order number

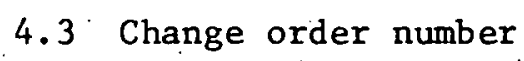

5.0 Documentation 


\subsection{Description}

Purchasing/Expediting responsibilities are to assure that purchasing, expediting, and traffic functions are carried out in accordance with established procurement policies and procedures.

\subsection{Objectives}

2.1 Purchasing: To maintain a list of bidders, request and evaluate quotations, issue purchase orders, maintain procurement tiles, take action to close out purchase orders, and track purchasing trends which might affect material procurement lead time.

2.2 Expediting: To ensure the timely delivery of material and services.

\subsection{Functions}

3.1 Purchasing

3.1.a Description: Purchasing is responsible for the following functions:

(1) Selection and evaluation of prospective bidders.

(2) Updating prospective bidders' 1ist.

(3) Verification that requests for quotation are complete.

(4) Solicitation of quotations from prospective sources of supply.

(5) Evaluation of quotations and recommendation of bidder selection.

(6) Issuance of purchase orders to the selected bidder.

(7) Issuance of change orders to previously issued purchase orders.

(8) Maintaining required procurement files.

(9) Taking action as required to assure that purchase order discrepancies are closed.

(10) Keeping project management informed of purchasing trends which might affect material procurement lead time.

(11) Maintaining listing of major materials in short supply that could affect the project schedule. 
(12) Transfer of value engineering information to design engfneering that is generated in solicitation of quotations.

3.1.b Relationship to other functions

(1) Obtain approvals of purchase orders and change orders from Design Engineering, when necessary, before issuance.

(2) Material commitments -- interfaces with material cost system by feeding it commitment amounts and cost codes.

(3) On order information -- interfaces with Warehousing/ Material Control by passing. on order information.

(4) Assist in resolving discrepancies between invoices and recelving reports.

(5) Receipts - interfaces with Warehousing/Material Control by either receiving or sending receiving reports.

(6) Coordination with construction, Scheduling, and Design Engineering as to manufacturer's release dates and required delivery dates.

3.1.c Data requirements

(1) Manufacturer's release dates and required delivery dates.

(2) Approved bidders' list.

(3) Purchase requisitions.

(4) Material recelving reports.

3.1.d Data generated within the function

(1) Quotation evaluations.

(2) Purchase orders.

(3) Change orders.

(4) Procurement files.

3.1.e Reports to users

(1) Purchase order status report.

(2) Report of warehouse recelpts.

(3) Commitments to material cost.

(4) Master file listing.

(5) Master file update 11sting. 


\subsection{Expediting}

3.2.a Description: Expediting is responsible for the following functions:

(1) Taking action as necessary to ensure the timely delivery of material and services.

(2) Updating current status of material locations and expected delivery dates.

3.2.b Relationship to other functions

(1) Shipment identification -- interfaces with Warehousing/Material Control to assist in identifying shipments received.

(2) Material Status -- interfaces with Engineering, Material Control, and Scheduling for current status/revised delivery dates of on-order material.

3.2.c Data requirements

(1) Purchase order status report.

(2) Report of warehouse receipts.

3.2.d Data generated within the function

(1) Locations of material in transit.

(2) Expected de1fvery dates.

3.2.e Reports to users

(1) Expediting report.

4.0 Code number or keys

4.1 Requisition number

$\mathrm{xxxx}-\mathrm{Xx}-\mathrm{xxxxx}-\mathrm{xx}$

(1) (2) (3) (4)

(1) Project number

(2) Safety-related: SR Non safety-related: NS

(3) Work category 00001-24999 Civil 25000-25999 Open for warehouse use 26000-26999 Rental equipment

1 etc.

(4) Change code (01, 02, etc.) 
4.2. Purchase order number: same as requisition number; no change code.

4.3 Change order: same as purchase order number with change code.

\subsection{Documentation}


Exhibit 3

APPLICATION AREA: Warehousing

\section{INDEX}

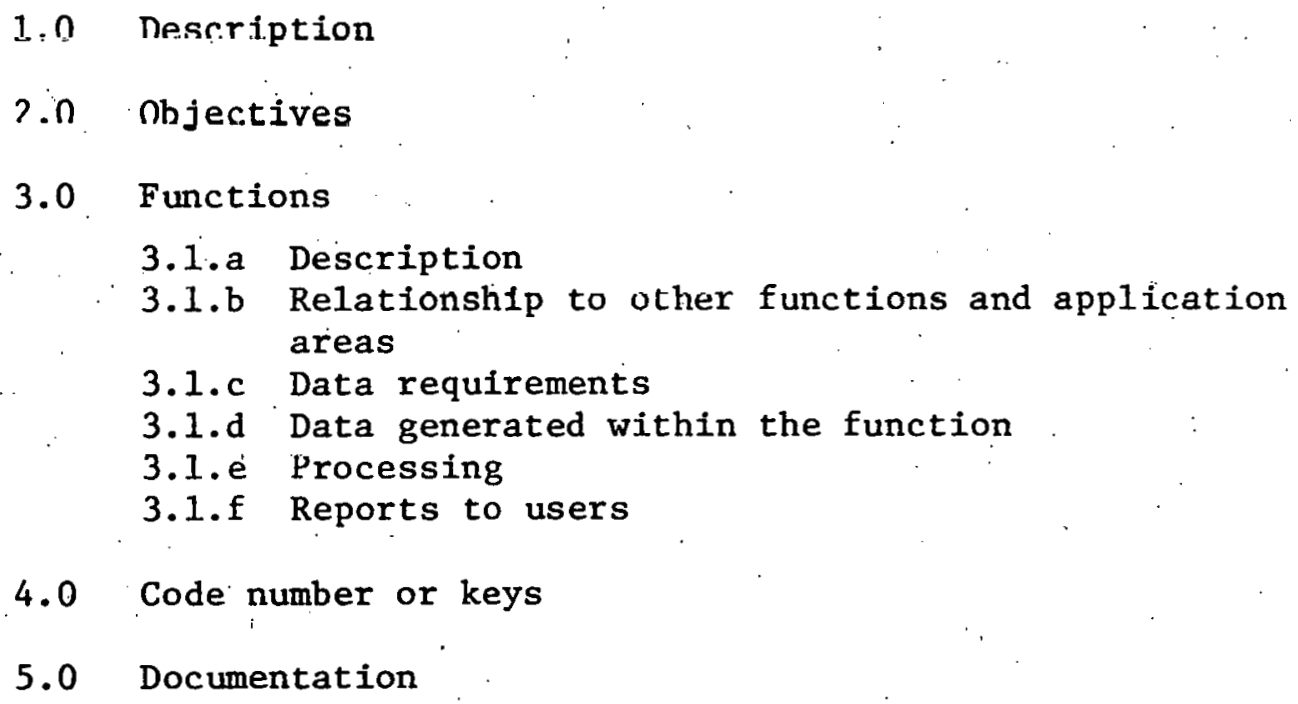

4.0 Code number or keys

5.0 Documentation 


\subsection{Description}

Receiving, inspecting, storing, accounting of, and disbursing owner and contractor materials. The receiving records which are developed and maintained will become part of the permanent plant records.

\subsection{Objectives}

To provide the facilities and personnel necessary to receive and assure proper storage of materials and equipment at the job site and proper disbursement to the field.

To check and receive material purchased by owner and contractor.

\subsection{Functions}

\section{1.a Description}

(1) Receive all material and equipment.

(2) Check individual shipments for compliance with purchase orders with respect to quantities and type.

(3) Mark individual pieces to permit ready identification.

(4) Store material and equipment in such a way so as to permit easy access.

(5) Store material and equipment at appropriate ANSI level.

(6) Issue the correct materials in response to field material requests.

(7) Insure that materials and equipment are issued only to those with sufficient authority to receive them.

(8) Maintain sufficient security around materials and equipment so as to minimize theft and pilferage.

(9) Operate tool rooms.

(10) Maintain a physical inventory.

(11) Maintain a minimum/maximum stock system where required.

(12) Maintain a stock ordering system.

(13) Handle a11 outbound shipments.

(14) Establish the existence of damage to received shipments.

3.1.b Relationsh1p to other functions and application areas

(1) Q.A/Q.C. -- close coordination required to establish conformity or non-conformity as early as possible.

(2) Project Management -- inform of arrival of materials to permit work to proceed smoothly. 
(3) Planning/Scheduling -- inform of arrival status of materials to permit accurate updating of schedules.

(4) Accounting -- supply arrival status to permit proper payment/billing of vendors.

(5) Design/Procurement -- establ1sh proper ANSI storage level.

(6) Purchasing/Expediting -- close coordination required to insure that the correct quantities and types of material have arrived.

(7) Document Control -- coordination required to insure that appropriate distribution of receiving reports, shipping tickets, etc. is achieved.

(8) Data Base/Data Dictionary -- help insure that the Data Base contalns the correct status on received materials and equipment.

\section{1.c Data requirements}

(1) Quantities of materials and equipment arriving to forecast space and manpower required.

(2) ANSI storage level to establish storage environment.

(3) Approximate time of removal of materials and equipment from warehousing system to forecast space and manpower requirements.

3.1.d Data generated within the function

(1) Quantities of items within the warehousing system.

(2) Location of items within the warehousing system.

(3) Quantity of 1tems 1ssued.

(4) Data of receipt.

(5) Date of issue.

(6) To whom items were issued.

3.1.e Processing

(1) Updating of data generated within the system.

3.1.f Reports to users

(1) Rail car logs.

(2) Construction equipment inventory records:

(3) Stock on hand reports.

(4) Stores catalog. 
(5) Small tool inventory status.

4.0 Code number or keys

4.1 Varies widely depending on system used. See the State-of-theArt report.

5.0 Documentation

5.1 Varies widely depending on system used. See the State-of-theArt report. 
ADDENDUM B

SUPPORTING MATERIAL FOR

MATERIAL AND EQUIPMENT STATUS SYSTEM (MESS)

$\dot{\mathrm{B}}-1$ 
$* * * * * * * * * * * * * * * * * * * * * * * * * * * * * * * * * * * * * * * * * * * * * * * * * * * * * * * * * * * * * * * * * * * * * * * *$ THE FOLLOWING LINE ITEMS ARE ADDITIONS TO THE MESS MATER FILE. A CONSTRUCTION DEPARTMENT REQUIRED DELIVERY DATE MUST BE ENTERED FOR EVERY ITEM. SIMPLY ENTER THE DATE IN DAY-MONTH-YEAR FORMAT AND SEND. TO THE MESS CONTROL SECTION: \{EXP. *25*MAR*?6*\}

$* * * * * * * * * * * * * * * * * * * * * * * * * * * * * * * * * * * * * * * * * * * * * * * * * * * * * * * * * * * * * * * * * * * * * * * *$

\begin{tabular}{|c|c|c|c|c|c|c|c|c|c|}
\hline \multirow[t]{5}{*}{ KEYWORD * } & $\begin{array}{r}\text { PLANT } \\
\text { CODE } \\
\text { K } \quad \text { PLT }\end{array}$ & $\begin{array}{l}\text { ENG INEERING } \\
\text { ITEM NUMBER } \\
\text { ENGITEM }\end{array}$ & $\begin{array}{l}\text { LINE } \\
\text { ITEM NO. } \\
\text { LINE }\end{array}$ & $\begin{array}{l}\text { REQ. CONST. } \\
\text { DELIVERY DATE } \\
\text { CONSIDEL }\end{array}$ & LINE ITEM & DESCRIF & PTION & $\begin{array}{c}\text { QTY } \\
\text { ORDER }\end{array}$ & $\begin{array}{l}\text { QTY } \\
\text { UNIT }\end{array}$ \\
\hline & $\mathrm{CN}$ & 3204.00 & ICF -2 & *0I*SEP*77* & FEED!UATER & HEATER & IAZ & ג00001 & $\mathrm{EACH}$ \\
\hline & $\mathrm{CN}$ & $1,204.00$ & ICF -3 & $* 01 * 5 E P * 77 *$ & FEEDUATER & HEATER & $2 B I$ & גדo000 & EACH \\
\hline & $\mathrm{CN}$ & 1204.00 & ICF -4 & *Q1*SEP*?? & FEEDWATER & HEATER & $2 B 2$ & ג00000 & EACH \\
\hline & CN & 1204.00 & ICM- 10 & $* 01 * S E P * 77$ & LP HEATER & 161 & & ג000000 & $\mathrm{EACH}$ \\
\hline \multirow[t]{8}{*}{$r$} & $C N$ & 1204.00 & $3 C M-1]$ & *DU*SEP*?? & LP HEATER & 362 & & ג0000 & EACH \\
\hline & $C N$ & 1204.00 & $3 \mathrm{CM}-32$ & $* 01 * S E P * ? 7$ & LP HEATER & $1, G 3$ & & נינס0000 & $\mathrm{EACH}$ \\
\hline & $\mathrm{CN}$ & 3204.00 & $2 C M-2$ & $* 01 * S E P * ? 7$ & LP HEATER & $1<2$ & & ג0000 & EACH \\
\hline & $\mathrm{CN}$ & $1,204.00$ & ICM-3 & *!I*SEP*77 & LP HEATER & IDI & & ג00001 & $\mathrm{EACH}$ \\
\hline & $\mathrm{CN}$ & 1204.00 & $2 \mathrm{CM}-4$ & $* \square\} * S E P * ? 7$ & LP HEATER & IDZ & & ג00000 & $\mathrm{EACH}$ \\
\hline & $\mathrm{CN}$ & $1,204.00$ & $3 \mathrm{CM}-5$ & $* 01 * S E P * 77$ & LP HEATER & $\mathrm{l} E \mathrm{l}$ & & ג00000 & EACH \\
\hline & $C N$ & 1204.00 & $1<M-6$ & $* \square I * S E P * ? ?$ & LP HEATER & LEZ & & נוס0000 & $\mathrm{EACH}$ \\
\hline & $C N$ & 3204.00 & $1, \mathrm{CM}-7$ & $* 02 * S E P * ? 7$ & LP HEATER & JFI & & 00000נ: & EACH \\
\hline
\end{tabular}




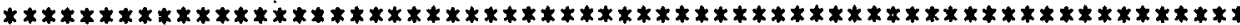

THIS LISTING IS INTENDED TO BE USED AS A REFERENCE GUIDE TO

RELATE TO INDIVIDUAL MATERIAL \& EQUIPMENT ITEMS ON THE COM-

PUTER FILE.

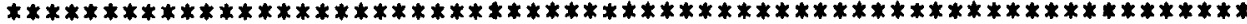

QTY
ORDER

QTY

LINE ITEM DESCRIPTION

VENDOR

NIMBER

REQUIRE

CONST
DEL DATE

ORIGINAL

MFG

DEL DATE

EACH RADUASTE PROC.INST \&CONTROL 73120001 15 SEP B2 15 SEP 83

00000

037645 2WS-9

$037645 \quad 305-1$

$037645 \quad 365-10$

037645 365-13

037645 3wS -12

037645 3WS-

037645 3wS-3

$0376453 \omega 5-4$

037645 3WS-

037645 3us-

037645 JUS-?

037645 . 3WS-B

$037645345-9$

1230,00-00-0001

$1230,00-00-000$

2ट30,00-00-000

1230,00-00-0001

$1230,00-00-000$

, 230,00-00-000

, $230,00-00-0001$

$1230,00-00-0001$

1230,00-00-0001

3230,00-00-0001

1230,00-00-0001

330,00-00-0001

$1230,00-00-0001$

037651 20M-1

037651 20M-

037651 20M-1

1.203,05-00-000)

1203,02-00-0003

1203,02-00-0001

037651
000001

000001

000001

000001

00000

000001

00000

000001

000001

000001

000001

व0000

000001

EACH DECON RSMEAR TEST EQUTP.

737200035 SEP \& 15 SEP \&3

EACH RESIN DEWATERING TANK SKID ?3120001 1,5 SEP 84 15 SEP 85

EACH LOT OF 27 VALVES

T312000J 45 SEP 84

EACH TV OBSERVATION PAC

EACH COPPER UNIT AND CONTROL

EATH CEMENT STOR - \&TRANS.SYSTEM

EACH LOTON BRIDGE CRANE

EACH RADWASTE PROC. INST.8CONTROL ?3120001 15 SEP B4

EACH DECON.\&SMEAR TEST EQUIP.

731200115 SEP 84

D00003 EACH HOTUELL PUMPS

DODO03 EACH CONDENSATE BOOSTER PUMPS

D00003 EACH HOTUELL PUMPS

000003
EACH CONDENSATE BOOSTER PUMPS 90550003 OI AUG 80 90550003 QI AUG B己

90550003 01 AUG B己
25 SEP BS

15 SEP 85

25 SEP B4

15 SEP 85

15 SEP B5

15 SEP 85

15 SEP BS

25 SEP 85

15 SEP 85

15 SEP 85

15 SEP B5

18 JUL 80

25 JUL $B D$

23 JUL 82

30 JUL BD
90550003 O1 AUG BD
CURRENT

MFG

DEL DATE

15 SEP $A 2$

15 SEP B2

15 SEP B4

15 SEP 84

15 SEP 84

15 SEP 84

15 SEP B 4

15 SEP 84

15 SEP 84

b 5 SEP 84

15 SEP B4

15 SEP 84

15 SEP 84

25 SEP 84

01 JUN BI

व) JỤN Bl

0) JUN $B 3$

Q J JUN $B 3$ 
REPORT $2 B$

PLANT CODE - PK

PERKINS NUCLEAR STATION

***********************************************************************

THIS LISTING IS INTENDED 10 BE USED AS A REFERENCE. GUIDE TO RELATE

TO INDIVIDUAL MATERIAL \& EQUIPMENT ITEMS ON THE COMPUTER FILE.

**********************************************************************

\section{ENGINEERING}

$0203,08-00-0005$ 0203,08-00-000ट

0205 , 25-00-0001 $0205,12-00-0001$ $0205,22-00-0001$

$0213,03-00-0001$ 0515,03-00-0001 $0215,03-00-0001$ $0515,03-00-0001$ 0 एद्र,03-00-0001 $0212,03-00-0001$

0213,00-00-0002 $0213,00-00-0002$

$1113,00-01$ $21,3,00-03$

ㄴา3,00-01

1.13,00-01

\section{LINE ITEM \\ NUMBER \\ PURCHASE}

2KC-1

उKC-I

1SM-1

2SM-1

$35 M-1$

IKC $-\mathrm{I}$

IKF - 1

ZKC -1

ZKF -2

$\exists K C-1$

$3 K F-1$

028-1

02B-2

00002

00003

00004

00005

(56371

C6 3482

C6 3482
DUKE POWER COMPANY

MATERIAL \& EQUIPMENT STATUS SYSTEM

\section{COMPONENT COOLING PUMPS}

C56371 MAIN STEAM ISOLATION VALVE

C5637I MAINSTEAM ISOLATION VALVE

MAIN SIEAM ISOLATION VALVE

COMP. COOLING HEAT EXCHAN

FUEL POOL COOLING HEAT EX

COMP. COOLING HEAT EXCHAN

FUEL POOL COOLING HEAT EX

COMP. COOLING HEAT EXCHAN

FUEL POOL COOLING HEAT EX

BREATHING AIR SUPPLY PACK AIR RECEIVER

IOO LB HEAD FREE JOINT BA 1:X 5.75 iTRACK BOLT, SQUAR ANTI-CREEP ANCHOR FOR IDO GUAGE ROD FOR IDO LB RAIL EACH OODOOL DODOOD

PAIR 001700 .000000

EACH ODLBOD ODODOO

C $-F T$ OODI Z

EACH DOJJBO OOODOD
PAGE 119

DATE $12104 / 76$
QTY QTY QTY

UNIT ORDER RECEIPT

EACH 000004 000000 EACH 000004 DOOCOD

EACH 000004 000000 EACH D00004 0000DD

EACH 000004 000000

EACH 000002 000000

EACH O000D2 000000

EACH DODOOZ DODOOD

EACH. 000002 000000

EACH DODOD2 DODOOD

EACH DDONDZ 0000ก!

EACH 000001 000J0I

VENDOR REQ CON DEL DAY

ORG MFG CUR MFG SHP DAY SHP DAY

OIDEC B2 DIDEC 84

29350001 OJJAN 82 19350001 OLJAN BL Z9350001 DIJAN BL

DIAPR 80 DIMAY $B D$ DIAPR Bᄅ DIMAY 82 OIAPR B4 OIMAY BY

2000.101 255EP BI 22070101 $255 E P$ BI 
REPORT 2C

VENDOR OLDZ2TO1

MECHANICAL PRODUCTS CO

DUKE POUER COMPANY

MATERIAL \& EQUIPMENT STATUS SYSTEM

***************************************************************

THIS LISTING IS INTENDED TO BE USED AS A REFERENCE GUIDE TO

RELATE TO INDIVIDUAL MATERIAL \& EQUIPMENT ITEMS ON THE COM-

PUTER FILE.

涼

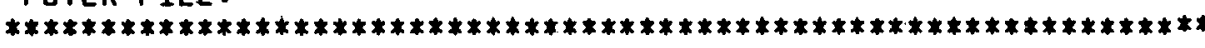

PAGE 010

DATE $12 / 04 / ? 6$

PURCHASE

ORDER

NUMBER

LINE ITEM

NUMBER

ENGINEERING

ITEM NUMBER

$\begin{array}{ll}\text { PLANT } & \text { QTY } \\ \text { CODE } & \text { ORDER }\end{array}$

QTY

REQ
CONST
LINE ITEM DESCRIPTION DEL DAY

ORIG

CURRENT

MFG

LATEST

OLBOT2

KR $3 B 2$

VALVE

마8072

KR 383

VALVE

Ob8072

EKR 3B2

VALVE

O68072

2KR3B 3

VALVE

MC

b EACH

CONST.FLOW CONTR.VALV $350 C T$ TL

CONST.FLOW CONTR.VALV $250 C T 76$

ZAOCT?6

290CT?6

SHP DAY

EXP

068202 RV2?3

VALVE

$\begin{array}{llll}M C & 1 & \text { EACH } & \text { CONST.FLOW CONTR.VALV ISOCT76 } \\ M C & 1 & \text { EACH } & \text { CONST.FLOW CONTR.VALV I,5OCT76 }\end{array}$

$\begin{array}{llll}M C & 1 & \text { EACH } & \text { CONST.FLOW CONTR.VALV ISOCTP6 } \\ M C & 1 & \text { EACH } & \text { CONST.FLOW CONTR.VALV ISOCT76 }\end{array}$

590CT 76

IENOVT6

IENOVT6

IENOVTb

LENOVT6

$290 \mathrm{CT} 76$

IENOV76

1 INOVTb

i $E A C H$

CONST.FLOW CONTR. VALV $250 C T 76$

290CT76

IENOVPG

OLA776 MVOTI VALVE

Ob8?76 MVOqZ VALVE

068776

MV093

VALVE

MC b. EACH 3/4 FLOW CONTROL VALV 15NOVPG

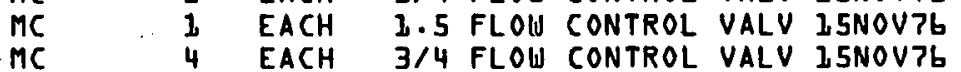

D5NOV?b

DSNOV7b

O5NOV76

O5NOVPL

DSNOV?b

$270 \mathrm{CT} 76$

270CT76

270CT76 
REPORT ED

PLANT CODE - CK

CHEROKEE NUCLEAR STATION

岪

\begin{tabular}{|c|c|}
\hline $\begin{array}{l}\text { L.INE ITEM } \\
\text { NUMBER }\end{array}$ & $\begin{array}{l}\text { ENGINEERING } \\
\text { ITEM NUMBER }\end{array}$ \\
\hline $\begin{array}{ll}0 & R Y-1 \\
0 & R Y-1 \\
0 & R Y-1 \\
0 & R Y-I\end{array}$ & $\begin{array}{l}1203,03-01 \\
2318,20-00-0001 \\
1318,21,00-0001 \\
1320,28-00-0001\end{array}$ \\
\hline $\begin{array}{ll}0 & R Y-2 \\
0 & R Y-2 \\
0 & R Y-2 \\
0 & R Y-2\end{array}$ & $\begin{array}{l}1203,03-01 \\
1313,20-00-0001 \\
1313,21-00-0001 \\
1323,28-00-0001\end{array}$ \\
\hline 0 RY-3 & $12003,03-01$ \\
\hline $0 R Y-4$ & $1203,03-01$ \\
\hline D YF-1 & 1 \\
\hline $0 Y M-1$ & $1208,02-00-0001$ \\
\hline $0 Y M-2$ & $1,2[8,02-00-0001$ \\
\hline
\end{tabular}

DUKE POUER COMPANY

MATERIAL \& EQUIPMENT STATUS SYSTEM
PAGE QQ4 DATE ID/DU/?6

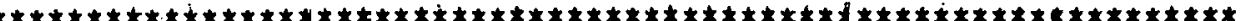 \\ THIS LISTING IS INTENDED TO BE USED AS A REFERENCE GUIDE TO \\ RELATE TO INDIVIDUAL MATERIAL \& EQUIPMENT ITEMS ON THE COM- \\ PUTER FILE.

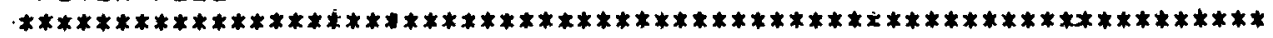

\section{PURCHASE \\ ORDER}

NUMBER

QRDER

QTY

UNIT

LINE ITEM DESCRIPTION

C20652

000001

EACH

FIRE PROTECTION PUMPS MKA

C 32499

000002

EACH

MAIN FIRE PUMP MOTORS A TE

C 38328

000002

EACH

MAIN FIRE PUMP MOTORS

C20652

EACH

FIRE PROTECT.JJCK PMP.

\section{C32499}

0300כ3

$0 J 0005$

EACH FIRE PROTECTION PUMPS MKB

00005

EACH MAIN FIRE PUMP MOTORS $C_{T}$

(1)

00003

EACH

MAIN FIRE PUMP MOTORS

C20652

000002

FIRE PROTECT.JOCK PMP.

C20652

000001

EACH JOCKEY PUMP MARK A

C5b 330

coonos

codoos

EACH JOCKEY PUMP MARK $B$

cioocoz

\section{EACH FILTERED UTR SYS FILTER}

EACH MIXED BED DEMJNER. TANK

EACH CARBON FILTER ASSEMBLY
REQUIRED

QTY CONST

REC . DEL DATE

0] JUN ??

D1 JUN ??

OI JUN ??

02 JUN 79

al JUN 79

חI JUN ??

a1 JUN ??

0] JUN ??

DL MAY $B D$

DL. APR BD

DI. APR BO
ORIGINAL CURRENT MFG MFG DEL DATE DEL DATE OL MAR 77 DUKDEL 30 JUN 77 30 JUN ?? DL JUN 77 29 APR ?7 DI MAR 77 DUKDEL 30 JUN 7930 JUN 79

QL MAR 77 DUKDEL

01 MAR 77 DUKDEL DJ MAY BO DI MAY BO 
REPORT 3

SPONSORING ENGINEER - $X X X$
DUKE POUER COMPANY

MATERIAL \& EOUIPMENT STATUS SYSTEM
PAGE 999 DATE $99 / 99 / 99$

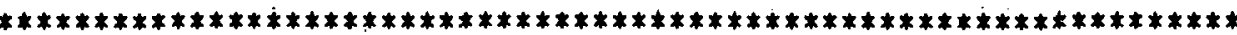

THIS REPORT LISTS THE LINE ITEMS WHICH HAVE A NEU OR CHANGED

MANUFACTURER REQUIRED RELEASE DATE.

********************************************************************

$\begin{array}{ll}\stackrel{\infty}{1} & \text { ENGINEERING } \\ \sqrt{ } & \text { LINEM NUMBER ITEM }\end{array}$

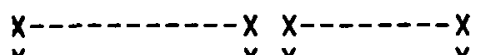

\section{PURCHASE}

ORDER

NUMBER

PLANT

CODE

LINE ITEM DESCRIPTION

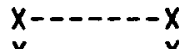

$x x$

\section{VENDOR}

NUMBER

QTY

ORDER

$\begin{array}{lll}x-\cdots-x & 9-\cdots-9 & x--x \\ x-\cdots-x & 9-\cdots-9 & x--x\end{array}$
MILLPR REQ CURRENT REQ PURORD MFG MFG CONST RELDAY SHPDAY SHPDAY DELDAY

$9 \times \times \times \times 9 \quad 9 \times x \times \times 9 \quad 9 \times x \times \times 9 \quad 9 \times \times \times \times 9$ $9 \times \times \times \times 9 \quad 9 \times \times \times \times 99 \times \times \times \times 9 \quad 9 \times \times \times \times 9$ 
REPORT 4

SPONSORING ENGINEER - $\ddot{x} X X$
PAGE 999 DATE $99 / 99 / 99$

$\underset{1}{\infty}$

********************x*************************************x******)

THIS REPORT LISTS -HE LINE ITEMS UHICH REQUIRE THAT THE MANU-

FACTURER MUST EE RCLEASED UITHIN THE NEXT LI DAYS

*******************x*************************************2******

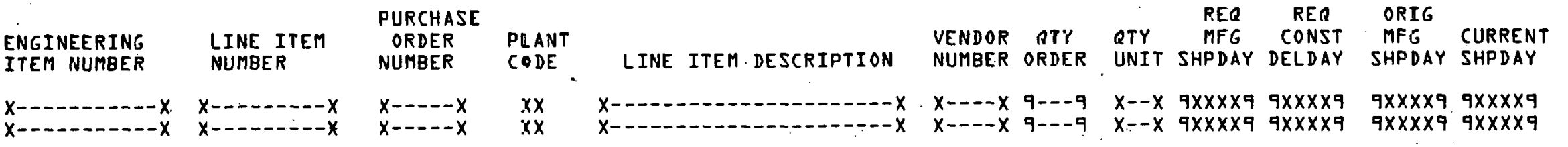


REPORT 5

SPONSORING ENGINEER -
DUKE POUER COMPANY

MATERIAL \& EQUIPMENT STATUS SYSTEM
PAGE DO1

DATE $32 / 04 / 76$

草

\section{ENGINEERING LINE ITEM ITEM NUNBER \\ NUMBER}

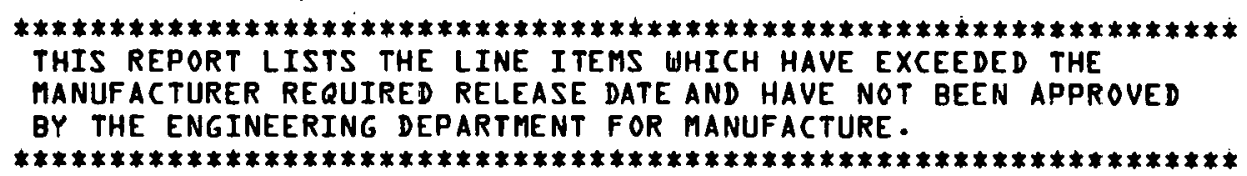

PIPE
PIPE

PIPE

PIPE

$1210,03-26$

$1304,00-02$

$1306,00-02$

2 306, 00-02

$1306,00-01$

$1306,00-01$

131,2,01-01

3312,01-01

$231,2,02-01$ I3le, 02-01

00001

00001

00002

00003

00004

00001
PUR.

ORDER PLANT

NUMBER CODE LINE ITEM DESCRIPTION

A98406 CN 10-LR 90 ELLS

A98406 CN 10 LR 45 ELBOW

C4.306 CN 24 150. TUBE TURNS T-BOLT

CL9270 MC 28 SID/WALL CS SRL KCTO

Aq4611 MC CONTROLLERS

W93218 MC 750 HVA TRANSFORMER

A 3370

A 33708

A 33708

A 33708

MC TRANSFORMER IATÁ

MC TRANSFORMER ZATA

MC TRANSFORMER EATA

MC TRANSFORMER EATB

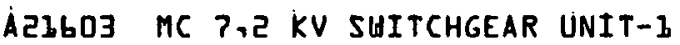
A24603 MC ?,Z KV SUITCHGEAR UNIT-2

A2L635 MC 4LLOV, SUITCHGEAR UNIT-1 A23635 MC YLLOV, SUITCHGEAR UNIT-2 $\begin{array}{lllcccc}\text { UENDOR } & \text { QTY } & \text { QTY } & \text { REQ } & \text { RER } & \text { ORIG } \\ \text { NUMBER } & \text { ORDER } & \text { CONST } & \text { MFG } & \text { CURRENT } \\ \text { UNI REL DAY DEL DAY DEL DAY } & \text { DEL DAY }\end{array}$

9480ח401 OODO40 EACH IMARTb 1JUL75 3DSÉP74 3ODEC75

94800401 DO0004 EACH IMAR76 1JUL75 30SEP74 JODEC75 94800401 D00045 EACH LMAR76 bJUL75 3lDEC75 MOSEP7b 10940301 DOOH4O FEET JOSEP75 LSEP75 30SEP75 OBMAR?b

91130501 DODLO5 EACH 25MAY74 25MAY74 5JUL?4 13SEP74

90220910 QNO002 EACH IJUN?4 32AUG?4

90220910 O0D001 EACH lJAN74

90220930 DחODOl EACH 35 FEB?4

90220920 00000 EACH 3JAN75

90220910 0DO001 EACH 15FEB75 15FEB75

90500305 000DOI -LOT MJAN?4

90500305000001 -LOT LJAN?5

90500305 000001 -LOT 1JAN74

905003 D 00DOOL -LOT JJAN75 
REPORT b

PLANT CODE - CK

DUKE POUER COMPANY

PAGE DQ1

CHEROKEE NUCLEAR STATION

\section{ENGINEERING \\ ITEM NUMBER}

1159,00-00-0001 $1,59,00-00-0001$ 1,59,00-00-0001

h205,00-01
$1,505,00-01$

1,202,D0-D)

$1,203,05-00-0001$ $1,203,05-00-0001$ 1,203,02-00-0001 1203 、02-00-0001

1,203.02-00-0001

2,203.02-00-0003

$* * * * * * * * * * * * * * * * * * * * x * * * * * * * * * * * * * * * * * * * * * * * * * * * * * * * * * * * * * 2 * *$

THE ITEMS LISTED HAVE A MANUFACTURER SHIPPING DATE WHICH

EXCEEDS THE REQUIRED CONSTRUCTION DELIVERY DATE BY MORE

THAN 30 DAYS.

*************************************************************

LINE ITEM PURCHASE NUMBER ORDER NO

LINE ITEM DESCRIPTION

C56537

00001

00002

00003

00001

00002

00003

1CM-1

1CM-2

2CM-1

2CM-

$3 \mathrm{CM}-1$

उCM-2
24 SLUICE GATE

GD SLUICE GATE

C56537 36 SLUICE GATE

C23580

C23580

C23580

C 37651

C 37551

C 37651

C 37651

C 37651

C37651

HOTWELL PUMPS

HOTWELL PUMPS

HOTWELL PUMPS
CONDENSATE BOOSTER PUMPS

CONDENSATE BOOSTER PUMPS

CONDENSATE BOOSTER PUMP
QTY RTY

QTY RECEIJT

EACH 000001 - 000003

EACH 00000

EACH DODOOJ

वरण000

MAIN COND./RELATED EQUIPI

MAIN COND./RELATED EQUIPD

MAIN COND./RELATED EQUIPJ
EACH 00ח0D1 D00000

EACH 000001 D00000

EACH 00000I

000000

EACH 000003 000000

EACH ODO003

EACH Oก

CH 000003

EACH 000003

000050

EACH OOODOJ OODODO
VENDOR REQ CON ORG MFG NUMEER DEL DAY SHP DAY

94080301 01JULPb 27AUG?6 94080201 BlJUL?6 27AUG?6 94080101 OLJUL?b 2PAUG?b

92690602 01JUNBI OJJULBj 92690601 0JJUN83 OHJUL83

92690601 01JUN85 01JULB5

9055D003 DLAUGBD TBJULBD 90550003 OLAUGBO 25JULBD 90550003 DLAUGBD $2 \exists J U L B 2$ 90550003 DLAUGBZ 30JULB2 90550003 OLAUGBY टDJULAY

90550003 DJAUG84 ट7JULB
CUR MFG SHP DAY

2RAUG?L ZTAUG?6 27AUG76

DIJ JANB2 OLJANBH DIJANBG

OLJUNBI

DIJUNBI

DIJUNB3

Q1JUNB

OIJUNBS

OI JUNB 5 
REPORT BA

PLANT CODE - CK

CHEROKEE NUCLEAR STATION

DUKE POUER COMPANY

MATERIAL \& EQUIPMENT STATUS SYSTEM
PAGE DOL

DATE $22 / 04 / 76$,
******************************************************************* THE ITEMS LISTED HAVE RECEIVED A REVISION TO THE SHIPPING DATE SINCE THE LAST REPORT.

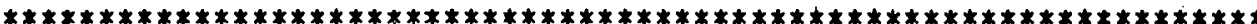

\section{ENGINEERING ITEM NUMBER} LINE ITEM
NUMBER

0000l

$1202,00-01$ $1,505,00-01$ I200, 00-01 00002 00003

1208,00-00-0001 OYF-1

1208,03-00-0001 1, CM-1 3208,03-00-0001 $2 \mathrm{CM}-2$ $1508,03-00-0001$ I $\mathrm{CM}-3$ $1208,03-00-0001,2 \mathrm{CM}-1$ 1,$208 ; 03-00-0001$ 2CM-ट 1208,03-00-0001 2CM-3 $1208,03-00-00013 \mathrm{CM}-1$ $1208,03-00-0001$ 3CM-2 1208,03-00-0001 3CM-3

1318,21-0-0001 ORY-1 1318,21-00-0001 ORY-2

- 13ं20,40-00-0001 1ECM1

\section{PURCHASE ORDER NO}

\section{C23580}

C 23580

C23580

C 56130

C56373

C56373

C 56373

656373

C56373

C56373

C 56373

C 56373

C56373

C 32499

C3249

C65485

\section{LINE ITEM DESCRIPTION}

MAIN COND./RELATED EQUIPI MAIN COND./RELATED EQUIPZ MAIN COND./RELATED EQUIP3

FILTERED UTR SYS FILTER

POLISHING DEMIN CELL ASSY RESIN PRECOAT SYSTEM ASSY POLISHING DEMIN CONTROL POLISHING DEMIN CELL ASSY RESIN PRECOAT SYSTEM ASSY POLISHING DEMIN CONTROL POLISHING DEMIN CELL ASSY RESIN. PRECOAT SYSTEM ASSY POLISHING DEMIN CONTROL

MAIN FIRE PUMP MOTORS MAIN FIRE PUMP MOTORS
FJLIZI-AIR CONDITIONING
QTY QTY UNIT ORDER RECEIPT NUMBER

EACH nחNOOL EACH DODOD1. EACH ONOQOI. 00000

9루90601

EACH 000001

EACH ODOOOS EACH DODDOL EACH DODOOL EACH 00D005 EACH QDחODL EACH 00000I EACH 000005 EACH OOODOL EACH OOOOOI

EACH DODODZ EACH ONOODE 000000 EACH OODODZ O00000 000000 000000

9 92690601

o00000

000000 000000 000000 0000ก0 000000 000000 000000 0000ก0 000000

95060201

9пเ60301 90660301 9п660301 90660301 90660301 90660301 90660301 90660301 90660301

92820805 92820805

16650201
REQ CON ORG MFG CUR MFG DEL DAY SHP DAY SHP. DAY

DL JUNBI OI JUNB QLJUNBS

DIJULBI QIJULB OJJANBY OIJULBS QIJANBL

DIMAYBO

DLMAYBO DLMAYBO

DIAUGBD DLAUGBO DIAUGBO DLAUGBZ OJAUGB? DIAUGBZ DLAUGBY DIAUGB4 DIAUGBY

DAUGBD DHAUGBD DLAUGBO DJAUGBO DIAUGBO DJAUGBO DLAUGBZ DLAUGBZ DIAUGB? RHAUGBC DIAUGB2 OIAUGBZ DLAUGB 4 DIAUGBY OIAUGBY OJAUGBY DLAUGB 4 DLAUGBL

0hJUN?? 30JUN?? 30JUN?? DIJUN79 30JUN79 30JUN79

DLFEB?7 DIFEB?7 OLFEB?? 
REPORT ?
VENDOR OLOZ2TOL

MECHANICAL'PRODUCTS CO

$\stackrel{\text { 罢 }}{N}$
DUKE POUER COMPANY

\author{
MATERIAL 8 EQUIPMENT STATUS SYSTEM
}

PAGE 002 DATE $\mathrm{B} 2 / 04 / 76$

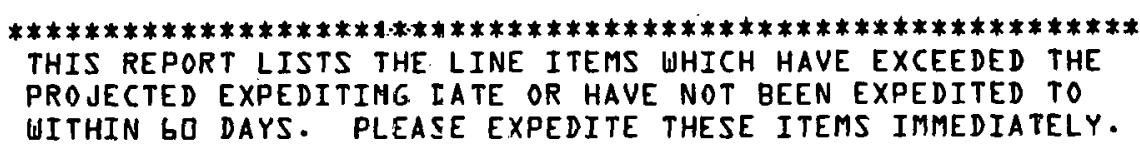

UITHIN bO DAYS. PLEASE EXPEDITE THESE ITEMS IMMEDIATELY.
$* * * * * * * * * * * * * * * * * * * * * * * * * * * * * * * * * * * * * * * * * * * * * * * * * * * * * * * * * * * *$

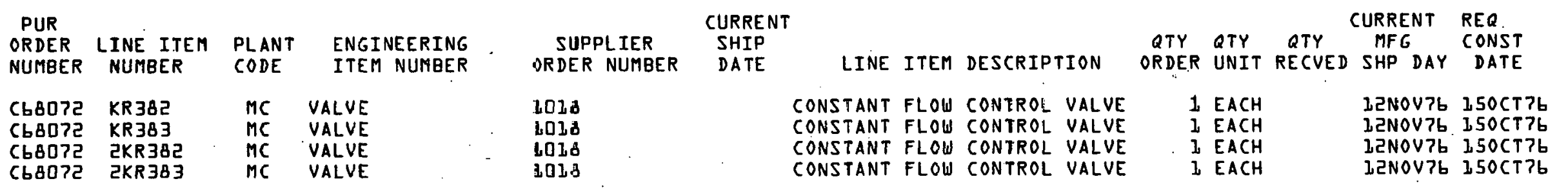


CHEROKEE NUCLEAR STATION

BEGINNING DATE ZDAUG?L

ENDING DATE JIDEC११

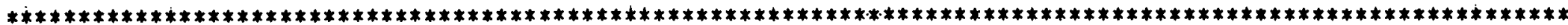
THIS REPORT LISTS THE EQUIPMENT DUE TO BE RECEIVED UITHIN THE GIVEN BEGINNING AND ENDING CURRENT MANU-

FACTURER DELIVERY DATES

\begin{tabular}{|c|c|c|c|c|}
\hline $\begin{array}{l}\text { ENGINEERING } \\
\text { ITEM NUMBER }\end{array}$ & $\begin{array}{l}\text { LINE ITEM } \\
\text { NUMBER }\end{array}$ & $\begin{array}{l}\text { PURCHASE } \\
\text { ORDER } \\
\text { NUMBER }\end{array}$ & $\begin{array}{l}\text { VENDOR } \\
\text { NUMBER }\end{array}$ & LINE ITEM DESCRIPTION \\
\hline $\begin{array}{l}1159,00-00-0001 \\
1159,00-00-0001 \\
1159,00-00-0001 \\
1159,00-00-0001\end{array}$ & $\begin{array}{l}00001 \\
00002 \\
00003 \\
00004\end{array}$ & $\begin{array}{l}C 56537 \\
C 56537 \\
C 56537 \\
C 56537\end{array}$ & $\begin{array}{l}94080101 \\
94080101 \\
94080101 \\
94080101\end{array}$ & $\begin{array}{l}24 \text { SLUICE GATE } \\
\text { 30 SLUICE GATE } \\
\text { 36 SLUICE GATE } \\
\text { 36 FLAP GATE }\end{array}$ \\
\hline $\begin{array}{l}1200,00-01 \\
1200,00-01 \\
1200,00-01\end{array}$ & $\begin{array}{l}00001 \\
00002 \\
00003\end{array}$ & $\begin{array}{l}A B 2791 \\
A B 2791 \\
A B 2791\end{array}$ & $\begin{array}{l}90220910 \\
90220910 \\
90250910\end{array}$ & $\begin{array}{llll}\text { TURBINE } & \text { GENERATOR UNIT } & 1 \\
\text { TURBINE } & \text { GENERATOR UNIT } \\
\text { TURBINE } & \text { GENERATOR UNIT } & 3\end{array}$ \\
\hline $\begin{array}{l}1,200,01-01 \\
1200-01-01\end{array}$ & $\begin{array}{l}1 C F-1 \\
2 C F-1\end{array}$ & $\begin{array}{l}A B 2795 \\
A B 2795\end{array}$ & $\begin{array}{l}\text { 902ट0910 } \\
\text { 90टट0910 }\end{array}$ & $\begin{array}{l}\text { FEEDWATER PUMP TURBINES } \\
\text { FEEDWATER PUMP TURBINES }\end{array}$ \\
\hline $1208,00-00-0001$ & CYF-I & $C 56320$ & 95060201 & FILTERED WTR SYS FILTER \\
\hline $\begin{array}{l}1,208,03-00-0001 \\
1208,03-00-0001 \\
1208,03,00-0001\end{array}$ & $\begin{array}{l}1 C M-1 \\
1 C M-2 \\
1 C M-3\end{array}$ & $\begin{array}{l}556373 \\
C 56373 \\
C 56373\end{array}$ & $\begin{array}{l}90660301 \\
90660301 \\
90660301\end{array}$ & $\begin{array}{l}\text { POLISHING DEMIN CELL ASSY } \\
\text { RESIN PRECOAT SYSTEM ASSY } \\
\text { POLISHING DEMIN CONTROL }\end{array}$ \\
\hline
\end{tabular}

\begin{tabular}{|c|c|c|}
\hline $\begin{array}{l}\text { QTY } \\
\text { ORDER }\end{array}$ & $\begin{array}{l}\text { QTY } \\
\text { UNIT }\end{array}$ & $\begin{array}{l}\text { REQUIRED } \\
\text { CONST } \\
\text { DEL DATE }\end{array}$ \\
\hline $\begin{array}{l}000001 \\
000001 \\
000001 \\
000001\end{array}$ & $\begin{array}{l}E A C H \\
\text { EACH } \\
\text { EACH } \\
\text { EACH }\end{array}$ & $\begin{array}{l}\text { d1JUL ?b } \\
\text { d]JUL ?b } \\
\text { DIJUL?b }\end{array}$ \\
\hline $\begin{array}{l}000001 \\
000001 \\
000001\end{array}$ & $\begin{array}{l}\text { EACH } \\
\text { EACH } \\
\text { EACH }\end{array}$ & $\begin{array}{l}\text { OLMARBZ } \\
\text { OLAPRAY } \\
\text { OLAPRBL }\end{array}$ \\
\hline $\begin{array}{l}\text { 00002 } \\
000002\end{array}$ & $\begin{array}{l}\text { EACH } \\
\text { EACH }\end{array}$ & $\begin{array}{l}\text { OJUNBO } \\
\text { QIJUNBC }\end{array}$ \\
\hline 100000 & EACH & OLMAYBD \\
\hline $\begin{array}{l}000005 \\
000001 \\
000001\end{array}$ & $\begin{array}{l}\text { EACH } \\
\text { EACH } \\
\text { EACH }\end{array}$ & $\begin{array}{l}\text { DLAUGBO } \\
\text { OLAUGBO } \\
\text { OLAUGBD }\end{array}$ \\
\hline
\end{tabular}

ORIGINAL CURRENT MFG CURRENT DEL DATE DEL DATE ETAUGPB 2TAUGPL ERAUG?b टPAUG76 टPAUGPG ट20CT>6 $220 C T 76$

OLDECBZ

DUKDELA DUKDELA DUKDELA

DUKDELA DUKDELA

DLMAYBO OLMAYBO

c56373 qObGOJO1 POLISHING DEMIN CONTROL 
DUKE POUER COMPANY

REPORT 9

VENDOR T7BBOTOY

RELIANCE ELECTRIC CO

$\stackrel{\varpi 0}{\stackrel{1}{\leftarrow}}$

\section{PUR}

ORDER

NUMBER

LINE ITEM

NUMBER

$\begin{array}{ll}C 38349 & 2 V V-1 \\ C 38349 & 2 V V-1\end{array}$

CI2209 OUL-1
MATERIA_ \& EQUIPMENT STATUS SYSTEM
PAGE O56

DATE $12 / 04 / 76$
$* * * * * * * * * * * * * * * * * * * * * * * * * * * * * * * * * * * * * * * * * * * * * * * * * * * * * * * * * * * * * z * * * * * *$

THIS REPORT LISTS THE EQUIPMENT. UHICH HAS NOT BEEN RECEIVED BY

30 DAYS AFTER THE CURRENT MANUFACTURER SHIPPING DATE. PLEASE

EXPEDITE THESE DELIVERIES IMMEDIATELY.

*********************************************************************

\section{PLANT ENGINEERING SUPPLIER \\ CODE ITEM NUMBER}

ORDER NUMBER

CN $1320,07-00-0001$

CN $1320,07-00-0001$

CN L L $20,33-00-0010$
QTY OTY QTY

RER
C.ONST CURRENT CURRENT
MFG SHIPPING LOWER CONT. COOLING FAN MTRS. 4 EACH LOUER CONT. COOLING FAN MTRS. $\quad 4$ EACH

WASTE EVAP FEED TNK SMP PMP MT 2 EACH
DIOCTZB $55 A U G 7 B$ 0LOCT79. ESAUG?6

DJaUg?a dLaUg?b 
REPORT 10

PLANT CODE -BC

BELEWS CREEK PLANT

MATERIAL ON HAND REPORT

DUKE POWER COMPANY

MATERIAL \& EQUIPMENT STATUS SYSTEM

PAGE OOI

DATE $12 / 04 / 76$

\begin{tabular}{|c|c|c|c|c|c|c|c|c|c|c|c|}
\hline & $\begin{array}{l}\text { ENGI NEERING } \\
\text { ITEM NUMBER }\end{array}$ & $\begin{array}{l}\text { LINE ITEM } \\
\text { NUMBER }\end{array}$ & $\begin{array}{l}\text { PURCHASE } \\
\text { ORDER } \\
\text { NUMBER }\end{array}$ & LINE ITEM DESCRIPTION & $\begin{array}{l}\text { VENDOR } \\
\text { NUMBER }\end{array}$ & $\begin{array}{l}\text { QTY } \\
\text { ORDER }\end{array}$ & $\begin{array}{l}\text { RTY } \\
\text { UNIT }\end{array}$ & $\begin{array}{l}\text { QTY } \\
\text { REC }\end{array}$ & $\begin{array}{c}\text { QUANTITY } \\
\text { RECEIPT } \\
\text { DATE }\end{array}$ & $\begin{array}{l}\text { STORAGE } \\
\text { LOCATION }\end{array}$ & $\begin{array}{l}\text { QA } \\
\text { STATUS }\end{array}$ \\
\hline & $\begin{array}{l}\text { VALVE } \\
\text { VALVE } \\
\text { VALVE }\end{array}$ & $\begin{array}{l}28010 \\
20001 . \\
26008\end{array}$ & $\begin{array}{l}\text { TRLOOB } \\
\text { TRLODB } \\
\text { TRZOOL }\end{array}$ & $\begin{array}{l}4 \text { GATE MC- } 150-3 \\
4 \text { GATE MC-300-3 } \\
b \text { GOD CS GATE VALVE. }\end{array}$ & $\begin{array}{l}\text { MCGUIR } \\
\text { MCGUIR } \\
\text { MCGUIR }\end{array}$ & $\begin{array}{l}\text { D00001 } \\
\text { 000001 } \\
000002\end{array}$ & $\begin{array}{l}\text { EACH } \\
\text { EACH } \\
\text { EACH }\end{array}$ & $\begin{array}{l}000001 \\
000001 \\
0000 ! 2\end{array}$ & $\begin{array}{r}\text { SEP76 } \\
150 C T 76 \\
030 C T 75\end{array}$ & & \\
\hline & $1,182,00-01$ & 00001 & TRLO02 & METAL DOOR TFRAME \& HARDUARE & MCGUIR & 000001 & EACH & $0000 ! 1$ & SEPTb & & . \\
\hline & $1200.00-04$ & 00001 & TR2006 & FU PUMP TURBINE SPEED CONTROL & MCGUIR & 000002 & EACH & 000002 & SEPTE & & \\
\hline & $\begin{array}{l}1334,00-00-0029 \\
1334,00-00-0029\end{array}$ & $\begin{array}{l}00001 \\
00002\end{array}$ & $\begin{array}{l}\text { TRLO05 } \\
\text { TR } 2005\end{array}$ & $\begin{array}{l}\text { 4XLO MOUNTING CHANNEL } \\
\text { GLASTIC MATERIALS/ATC CABİNET }\end{array}$ & $\begin{array}{l}\text { MCGUIR } \\
\text { MCGUIR }\end{array}$ & $\begin{array}{l}000020 \\
\text { 00ח0חट }\end{array}$ & $\begin{array}{l}\text { EACH } \\
\text { EACH }\end{array}$ & $\begin{array}{l}-400000 \\
000005\end{array}$ & $\begin{array}{l}\text { SEP76 } \\
\text { SEPPG }\end{array}$ & & \\
\hline & $\begin{array}{l}1346,05-00-0020 \\
3346,05-00-0040\end{array}$ & $\begin{array}{l}\text { LEEAl } \\
\text { LEEAZ }\end{array}$ & $\begin{array}{l}\text { TRIO04 } \\
\text { TRIO04 }\end{array}$ & $\begin{array}{l}\text { TGB2C2 AH-GDAMP, SAFETY SUITCH } \\
\text { TCI00,1 OUTDOOR HUB }\end{array}$ & $\begin{array}{l}\text { MCGUIR } \\
\text { MCGUIR }\end{array}$ & $\begin{array}{l}\text { 00000ट } \\
\text { 00000ट }\end{array}$ & $\begin{array}{l}\text { EACH } \\
\text { EACH }\end{array}$ & $\begin{array}{l}000002 \\
000002\end{array}$ & $\begin{array}{l}\text { SEP?b } \\
\text { SEPTb }\end{array}$ & . & \\
\hline
\end{tabular}




\begin{tabular}{|c|c|c|c|c|c|c|c|}
\hline \multirow[t]{2}{*}{$\begin{array}{l}\text { REPORT } 11 \\
\text { PLANT CODE - CK } \\
\text { CHEROKEE NUCLEAR }\end{array}$} & \multicolumn{6}{|c|}{$\begin{array}{l}\text { DUKE POWER COMPANY } \\
\text { MATERIAL \& EQUIPMENT STATUS SYSTEM }\end{array}$} & DAT \\
\hline & \multicolumn{7}{|c|}{ 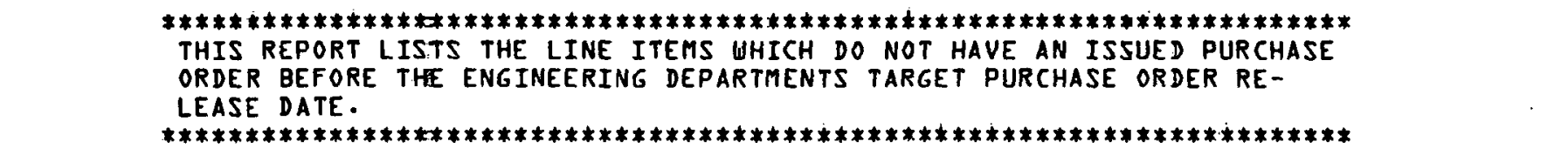 } \\
\hline $\begin{array}{l}\text { ENGINEERING } \\
\text { ITEM NUMBER }\end{array}$ & $\begin{array}{l}\text { LINE ITEM } \\
\text { NUMBER }\end{array}$ & LINE ITEM DEŚRCRIPTION & $\begin{array}{l}\text { QTY } \\
\text { ORDER }\end{array}$ & $\begin{array}{l}\text { QTY } \\
\text { UNIT }\end{array}$ & $\begin{array}{l}\text { TARGET } \\
\text { PUR ORDER } \\
\text { REL DRTE }\end{array}$ & $\begin{array}{l}\text { REQUIRED } \\
\text { CONST } \\
\text { DEL DATE }\end{array}$ & $\begin{array}{l}\text { SPONSOR } \\
\text { ENGINEER } \\
\text { INITIALS }\end{array}$ \\
\hline $\begin{array}{l}\operatorname{lil} 3,00-01 \\
\operatorname{lil}, 3,00-01 \\
\operatorname{lil} 3,00-01 \\
1213,00-01\end{array}$ & $\begin{array}{l}00002 \\
00003 \\
00004 \\
00005\end{array}$ & $\begin{array}{l}\text { 1OD LB HEAD FREE JOINT BARS } \\
\text { 1X5.75;-TRACK BOLT, SQUARE NUT } \\
\text { ANTI-CREEP ANCHOR FOR IOQLB RL } \\
\text { GUAGE RODS FCR LOOLB RAIL }\end{array}$ & $\begin{array}{l}001950 \\
007800 \\
000225 \\
001180\end{array}$ & $\begin{array}{l}\text { PAIR } \\
\text { EACH } \\
\text { C-EA } \\
\text { EACH }\end{array}$ & $\begin{array}{l}\text { DLSEP } 55 \\
\text { OLSEP>5 } \\
\text { DLSEP>5 } \\
\text { OLSEP>5 }\end{array}$ & & $\begin{array}{l}\text { IUP } \\
\text { IUP. } \\
\text { IUP } \\
\text { IUP }\end{array}$ \\
\hline $12123,00-02$ & 00001 & CROSS TIES $8 \times 7 ;-8 \times 6 ;-I$ DOLB RL & 000225 & $C-E A$ & DUSEP?5 & & IUP \\
\hline $\begin{array}{l}1,43,00-01 \\
1,1,43,00-01 \\
1,1,43,00-01 \\
1,43,00-01 \\
1,1,43,00-01 \\
1,1,43,00-01\end{array}$ & $\begin{array}{l}00002 \\
00003 \\
00004 \\
00005 \\
00008 \\
00009\end{array}$ & $\begin{array}{l}\text { 1OO LB HEAD FREE JOINT BARS } \\
\text { 1X5.75; -TRRACK BOLTS, SQUARE NUT } \\
\text { ANTI-CREEP ANCHORS LOOLB RL } \\
\text { GUAGE RODS FOR LIOLB AREA RL } \\
\text { NO \& TURNOUTS } \\
\text { SUITCH. STANDS }\end{array}$ & $\begin{array}{l}002000 \\
004000 \\
000117 \\
009200 \\
000018 \\
000018\end{array}$ & $\begin{array}{l}\text { PAIR } \\
\text { EACH } \\
\text { C-EA } \\
\text { EACH } \\
\text { EACH } \\
\text { EACH }\end{array}$ & 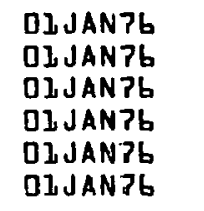 & & $\begin{array}{l}\text { IWUP } \\
\text { IWPP } \\
\text { IUP } \\
\text { IWP } \\
\text { IUP } \\
\text { IUP }\end{array}$ \\
\hline $\begin{array}{l}1143,00-02 \\
1143,00-02 \\
1143,00-02 \\
1143,00-02\end{array}$ & $\begin{array}{l}00002 \\
00002 \\
00003 \\
00004\end{array}$ & $\begin{array}{l}\text { CROSS TIES } 8 \times ? ; B \times b ;-1 \text { TOLB RL } \\
\text { CROSS TIES } 8 \times ? ; B \times 6 ;-100 L B \text { RL } \\
\text { TIES FOR NO } 3 \text { TURNOUT } \\
\text { TIES FOR NO } 3 \text { TURNOUT }\end{array}$ & $\begin{array}{l}015300 \\
006400 \\
000014 \\
000004\end{array}$ & $\begin{array}{l}\text { EACH } \\
\text { EACH } \\
\text { SETS } \\
\text { SETS }\end{array}$ & 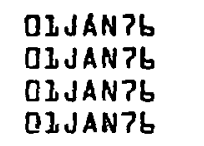 & & $\begin{array}{l}\text { IUP } \\
\text { IUP } \\
\text { IUP. } \\
\text { IUP }\end{array}$ \\
\hline
\end{tabular}

PAGE DOL ATE $12 / 04 / 76$ 
REPORT 12

DUKE POWER COMPANY

PAGE 001

QA STATUS -

MATERIAL \& EQUIPMENT STATUS SYSTEM

DATE $12 / 104 / 76$

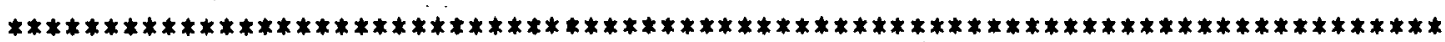

LISTING OF ALL MATERIAL AND EQUIPMENT RECEIVED DIJRING THE PREVIOUS WEEK.

***************************************************************************

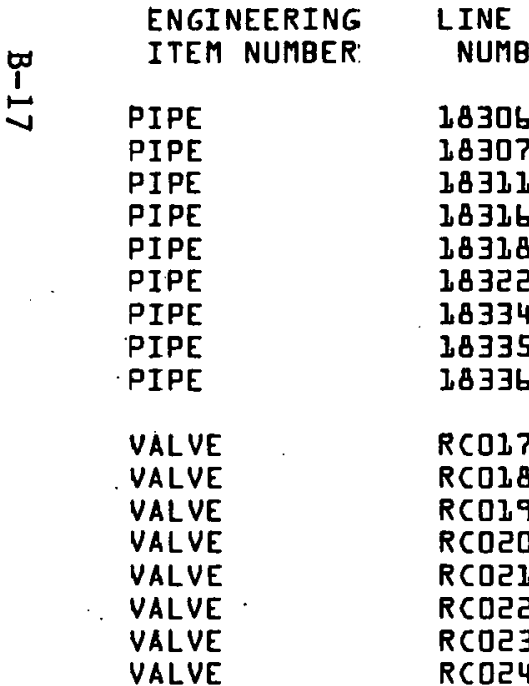

ITEM PLANT PUR ORD

18306

831

8316

8318

48334

18335

8336

RCOLB

$\operatorname{RCOL9}$

$\operatorname{RCOJF}$

RCOZ4

$1148,00-00-0002$ 16G-1
CODE NUMBER LINE ITEM DESCRIPTION

$C N$

CN

CN

CN

$C N$

$\mathrm{CN}$

$\mathrm{CN}$

CN

CN

CN

CN

CN

CN

CN

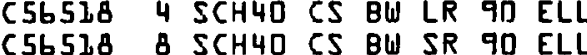

C56518

C56518

4 SCH4O CS B BW 45 ELL

C 56518

A98532 B4 BUTTERFLY

A98532 84 BUTTERFLY

A98532 84 BUTTERFLY

A98532 84 BUTTERFLY

A98532 72 BUTTERFLY

A98532 ?2 BUTTERFLY

A 98532 72 BUTTERFLY

A98532 ?2 BUTTERFLY
VENDOR RTY OTY NUMBER UNIT

ORDER

QTY RE

QTY REC

STORAGE

92310902 EACH

000250

THIS UK TO DATE

LOC

C56518 $10 \times 4$ SCH40 CS BW. CONC.RED.

C56518 $4 \times 2$ SCH40 CS BU CONC.RED.

JX2 SCH4O CS BU CONC.RED.

92310901 EACH

000100

000250

000100

000250

92310901 EACH 000020 000003 0000n3

92310901 EACH 000001 0ח0001 000001

9231ח901 EACH 000020 000020 000020

923य०901 EACH 0000נ0 000010 000010

92820805 EACH OOOODZ

92820805 EACH

000005

000001

000002

000002

000001

EACDBO5 EACH DO0002 000001 000001

92BटDAO5 EACH

92820805 EACH 0000กट 000002 000002

92820805 EACH DO0002 000001 000001

9282D805 EACH 000002 000001 000001

D?590601 EACH 000008 ODO002 000008 
REPORT 14

PERKINS NUCLEAR STATION

92950L1 COMBUSTION ENGINEERING INC POWER SYSTEMS DIV
DUKE POUER COMPANY

MATERIAL \& EQUIPMENT STATUS SYSTEM
PAGE :002

DATE $12 / 04 / 76$ $\underset{\infty}{\infty}$

\section{********************************************************}

THIS REPORT LISTS THE STATUS OF ALL DRAUINGS.

***************k************************************

ENGINEERING
ITEM NUMBER

LINE ITEM DESCRIPTION

SCHEDULED QTH

ACTUAL SCHEDULED ACTUAL CURRENT NUMBER

QTY

UNIT FROM MFG

REC DATE REL DATE REL DATE MFG SHP

NSSS

NSSS

NSSS

00001

00002

00003

00004

00005

0000:

0000?

00008

$0000^{\circ}$

00010

onobl

00012

00013.

00014

00035

00016

0001?

CORE SUP BAR ASSY

UP GUIDE STRUC ASSY

REAC VESSEL NOZZLE PADS

RV COLUMN INTEGRAL SUPP PLATES

RI UNIV LIFTING RIG ASSY

RI UPPER GUIDE STRUC SUPP PADS

REAC INTERN SHIPPING RIG

RI CORE SUPP BARREL STOR PADS

CEA CONTR ELE DRIVE MECHANISM

CEA CONT ELE DRI MECH INSTRU

CEA CEDM POWER SUPPLY

CEA CEDM SERVICING ERUIPMENT

CEDM COOLING SHROUDS

NSTS

NSHT SURVEI SPECIMEN COMP ASSY

NSHT STEAM GENERATOR ASSEMBLY

NSHT STEAM GENERATOR SUPP STRU

NSHT STE GEN SHIF EREC EQUIP

NSSS

NSSS

NSSS

00018

NSHT STE GEN SERV EQUIP

D0D25 REA CO PUM LOCA SUP SKI COL SN

00033

CEA CHANGE PLATFGRM

00035

DRY SHIPPING EQUIPMENT

REFUELING POOL SEAL ASSEMBLY

10000

EACH

Q00001 EACH

DO0004 EACH

000004 EACH

DOODO1 EACH

DO0001 SET

OODODI EACH

ODODI SET

00009? EACH

000001 SET

000002 EACH

DO0002 SET

000002 EACH

DODOQI SET

O00002 EACH

DOחDO2 EACH

O00002 EACH

O00001 SET

000004. SET.

DO0001 EACH

DODOD2 EACH

DOOODL EACH

DUKDELA

DUKDELA

DUKDELA

DUKDELA

DUKDELA

DUKDELA

DUKDELA

DUKDELA

DUKDELA

DUKDELA

DUKDELA

DUKDELA

DUKDELA

DUKDELA

DUKDELA

DUKDELA

DUKDELA

DUKDELA

DUKDELA

DUKDELA

DUKDELA 
REPORT ib

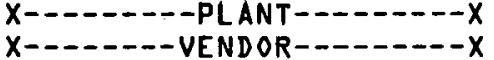

DUKE POLER COMPANY

MATERIAL \& EQUIPMENT STATUS SYSTEM
PAGE 999

DATE $99 / 99 / 99$

***************************************************************** THIS REPORT LISTS ALL DRAUINGS DUE FROM THE VENDOR DURING THE NEXT MONTH.

****************************************************************

ENGINEERING ITEM NUMBER

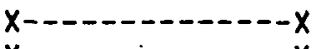

$x---1---1----x$

\section{LINE ITEM}

NUMBER

LINE ITEM DESCRIPTION

QTY

UNIT FROM MFG

$x$
QTY REC DATE

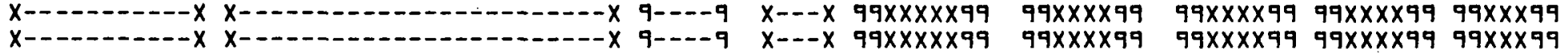

ACTUAL SCHEDULED ACTUAL CURRENT REC DATE REL DATE REL DATE MFG SHP FROM MFG BY ENGR BY ENGR DATE

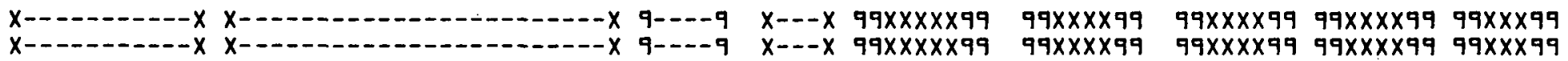


REPORT $1 \mathrm{H}$

X-D-

*************************************************************************

THIS REPORT LISTS. DRAUINGS UHICH WERE SCHEDULED FOR SUBMISSION TO

DUKE BY THIS DATE \{SDREL\} AND HAVE NOT BEEN SUBMITTED BY THE VENDOR.

DUKE BY THIS DATE ISDREL\} AND HAV
THESE ITEMS ARE THEREFORE LATE.

\section{************************************************************k*********}

LINE ITEM NUMBER

\section{LINE ITEM DESCRIPTION}

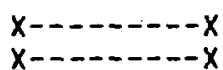

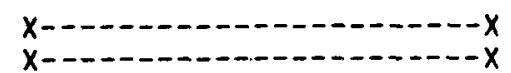

\begin{tabular}{|c|c|c|}
\hline QTY & $\begin{array}{l}\text { QTY } \\
\text { UNIT }\end{array}$ & $\begin{array}{l}\text { SCHEDULED } \\
\text { REC DATE } \\
\text { FROM MFG }\end{array}$ \\
\hline & $\begin{array}{l}x--x \\
x--x\end{array}$ & $\begin{array}{l}99 \times \times \times \times 99 \\
99 \times \times \times \times 99\end{array}$ \\
\hline
\end{tabular}

ACTUAL REC DATE FROM MFG RELDATE

ACTUAL CURRENT RELDATE MFG SHP BY ENGR DATE
$99 \times \times \times \times 99$ $99 \times \times \times \times 99$
BY ENGR

$99 \times \times \times 99$

$99 \times \times \times 99$
$99 \times \times \times 9999 \times \times \times 99$ $99 \times \times \times 9999 \times \times \times 99$ 
REPORT 1 ?

SEQUENCED. BY

INSPECTOR - OZ

A.W. ROY
DUKE POUER COMPANY

MATERIAL \& EQUIPMENT STATUS SYSTEM
PAGE DOI

DATE $W / 15 / 76$

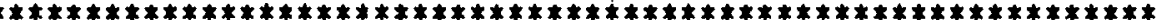

THIS REPORT LISTS UNDELIVERED SAFETY RELATED ITEMS.

*************************************************************

WO PURCHASE

C52103 MAUNEY PIPING SUPPLY COMPANY

C52103 MAUNEY PIPING SUPPLY COMPANY

C56513 MAUNEY PIPING SUPPLY COMPANY

C56513 MAUNEY PIPING SUPPLY COMPANY

C56513 MAUNEY PIPING SUPPLY COMPANY

C57843 MAUNEY PIPING SUPPLY COMPANY

C57843 MAUNEY PIPING SUPPLY COMPANY

C57843 MAUNEY PIPING SUPPLY COMPANY

C57843 MAUNEY PIPING SUPPLY COMPANY

C57843. MAUNEY PIPING SUPPLY COMPANY

C57843 MAUNEY PIPING SUPPLY COMPANY

C57843 MAUNEY PIPING SUPPLY COMPANY

C57843 MAUNEY PIPING SUPPLY COMPANY

C57843 MAUNEY PIPING SUPPLY COMPANY

C57843 MAUNEY PIPING SUPPLY COMPANY

C57843 MAUNEY PIPING SUPPLY COMPANY

C57843 MAUNEY PIPING SUPPLY COMPANY

C57843 MAUNEY PIPING SUPPLY COMPANY

C57843 MAUNEY PIPING SUPPLY COMPANY

$\begin{array}{lll}\text { PLANT } & \text { ENGINEERING } & \text { LINE ITEM } \\ \text { CODE } & \text { ITEM NUMBER } & \text { NUMBER } \\ \text { MC } & \text { PIPE } & \\ M C & \text { PIPE } & 72002 \\ M C & \text { PIPE } & 72005 \\ M C & \text { PIPE } & 76713 \\ M C & \text { PIPE } & 76712 \\ M C & \text { PIPE } & 76715 \\ M C & \text { PIPE } & 75301 \\ M C & \text { PIPE } & 75302 \\ M C & \text { PIPE } & 75303 \\ M C & \text { PIPE } & 75304 \\ M C & \text { PIPE } & 75305 \\ M C & \text { PIPE } & 75306 \\ M C & \text { PIPE } & 75307 \\ \text { MC } & \text { PIPE } & 75308 \\ M C & \text { PIPE } & 75309 \\ M C & \text { PIPE } & 75310 \\ M C & \text { PIPE } & 75311 \\ M C & \text { PIPE } & 75312 \\ M C & \text { PIPE } & 75313 \\ \end{array}$

LINE ITEM DESCRIPTION ORD RTY

2 3000 F.ALUM SU 90 ELLS 000010 000000 2 3000 F.ALUM SU 45 ELLS 000040 D0D000 CLASS B $6 \times 6 \times 4$ SCH4D RED. DOOOLD DODODO CLASS B $6 \times 4$ SCH4M HU CON.0OOI4D DOOODO CLASS B $4 \times 2.5$ SCH4O CON. DOOD25 000000 CL.B $1.5 \times 3 / 43000$ SW RED.000008 000000 CL.B 2X1.25 3000 SU RED. DODDOZ D00000 CLASS B 2X.5 3 JDO SW RED.00DDOZ 000000 CLASS B $1.5 \times 3 / 43000$ SW. 0000L 000000 CLASS B .5 3000 SU HALF DODOLZ 000000 CLASS B .5 3000 THRD HALFOOOL5D ODODOD CLASS B .5 3000 THRD PIPEDOOIZ5 000000 CLASS B $1.5 \times 3 / 43000$ RED 000008000000 CLASS B $3 / 43000$ HALF CP DODLOD DODODI CLASS B .5 3000 THRD FCS 000050000000 CLASS B $1 / 43000$ FCS SW 00000 5000000 CLASS B $\mathrm{b} / 2$ 3000 THRD STDODO030 000000 CLASS B $\mathrm{W} / 43000$ SW STD DחDO40 0000DO CLASS B $1 / 23000$ THRD CPLOONO30 000000
QA HOLD QA HOLD 5 NOV? $5 N O Y>B$ QA HOLD QA HOLD QA HOLD RA HOLD QA HOLD QA HOLD QA HOLD QA HOLD QA HOLD QA HOLD QA HOLD QA HOLD QA HOLD QA HOLD 
REPORT 18

SEQUENCED BY

PURCHASE ORDER

PURCHASE
N
ORDER
NUMBER

DUKE POUER COMPANY

MATERIAL \& EQUIPMENT STATUS SYSTEM
PAGE OOZ

DATE 2Z/2T/76

\section{**********************************************************************}

THIS REPORT LISTS UNDELIVERED SAFETY RELATED ITEMS.

**************************************************************

VENDOR NAME

\author{
INSPECTOR
NAME---OCODE
}

NOT ON FILE

NOT ON FILE

NOT ON FILE

NOT ON FILE

NOT ON FILE

NOT ON FILE

NOT ON FILE

NOT ON FILE

NOT ON FILE

NOT ON FILE

NOT ON FILE

NOT ON FILE

NOT ON FILE

NOT ON. FILE

NOT ON FILE

NOT ON FILE

NOT ON FILE

NOT ON FILE

NOT ON FILE

NOT ON FILE

NOT ON FILE
ENGINEERING
ITEM NUMBER

0ג15.01-00-00ח

0l13.0ก-00-0004

$0113.00-00-0004$

$0113.00-00-0004$

$012.3 .00-00-0004$

$0113.00-00-0004$

$013.3 .00-00-0004$

$0113.00-00-0004$

0113.00-00-0003

0113.00-00-0003

0113.00-00-0003

0113.00-00-0002

0l13.00-00-000ट

0113.00-00-0002

$0113.00-00-0002$

0113.00-60-000ट

$0113.00-00-0002$

Q1, 3.00-00-nחפ

Qน13.00-00-0001

0.1. $3.00-00-0001$

0123.00-00-0001

\section{LINE ITEM DESCRIPTION}

CURRENT

MFG

SHP DATE
MECHANICAL DRAFT COOLING TOUER $24^{n}$ 34GA.CORRUGATED STL.PIPE $24^{n}$ 34GA.CORRUGATED STL.PIPE. $24^{n}: 4 G A$. CORRUGATED STL.PIPE $24^{n}$ "4GA.CORRUGATED STL.PIPE $24^{n}$ 4GA.CORRUGATED STL.PIPE 24" -46A.CORRUGATED STL.PIPE $24 \pi$ 46A.CORRUGATED STL.PIPE

No. LEFT-HAND CROSSOVER

No. LEFT-HAND TURNOUTS

NO. RIGHT-HAND TURNOUTS

$5 / 8^{n}=0 . \times 5^{n}$ TIE PLUG 200/BUNDLE 7X9" SUITCH TIES/NO.B TURNOUTS ?X9" SUITCH TIES/NO.8 TURNOUTS $7^{n} \times 9^{n} \times 10^{\prime} T I M B E R S$ FOR CROSSINGS $7^{n} \times 9^{n} \times 8^{\prime}-6^{n}$ CROSS TIES $7^{\prime \prime} \times 9^{n} \times B^{\prime}-6^{n}$ CROSS TIES BUMPING POST

STEEL FLANGEUAY

5/8n:312" SPIKES

5/En:K6" SPIKES \{250/KEG\} 
ADDENDUM C

SUPPORTTNG MATERIAL FOR

PIPING MATERIAL INVENTORY CONTROL SYSTEM (PMICS)

C-1 
DUKE PONER COMPANY

PIFING MATERIALS INVENTORY

PLANT: CATAWBA

DATE: $04 / 12 / 77$

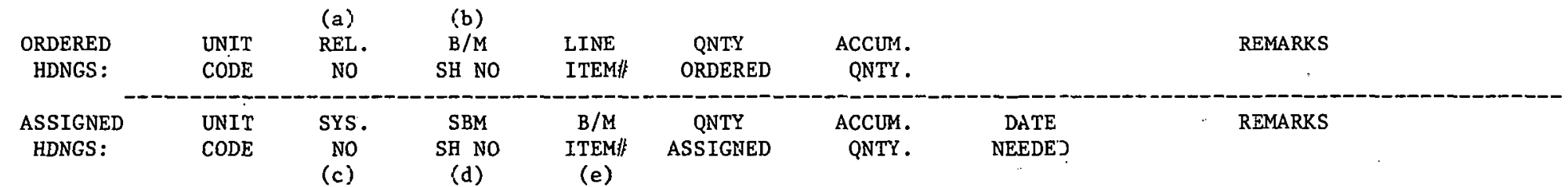

-Pipe Grade (Grade B carbon steel)

Lot Number (Intelligent No.)

Schedule (Schedule 80)

Pipe Size (Inches - eights, 4-1/8 inches)

Material Description ( $90^{\circ}$ long radius elbow)

Material Type (Fitting)

Welding Type

Pipe Type (Seamless)

Pipe Grade

Material Specification

CN100303DE1F0B040 B

B C.S.

234 WPB SMLS EFW

ORDERED:

$\begin{array}{ll}0 & 0.128 \\ 0 & 0217 \\ 0 & 0283\end{array}$

047
156
250

013
0154
002

0.54
003
002
0.22
004
002

FTG

(a) Release Number

(b) Bill of material

sheet number

(c) System number

(d) Summary bill of mate-

rial (accumulated

material for given sys-

tem in a given area)

(e) Bill of material item number

ASSIGNED:

$\begin{array}{llll}1 & \text { BBO2 } & 001 & 004 \\ 1 & \text { BB02 } & 002 & 003 \\ 1 & \text { BB02 } & 003 & 002 \\ 1 & \text { BE02 } & 004 & 002 \\ 1 & \text { BB02 } & 006 & 004 \\ 1 & \text { BB02 } & 007 & 002\end{array}$

$\begin{array}{rrr}100 & 100 & \text { FBS } \\ 100 & 200 & \text { FBS } \\ 30 & 230 & \text { FBS }\end{array}$

$4 \quad 11 / 01 / 77 \quad 1491-B B 002 \quad 11-24-76$

$806 / 15 / 77 \quad 1451-\mathrm{BBDO} 3 \quad 11-24-76$

$11 \quad 10 / 01 / 77$ 14؟1-BBDO04 11-24-76

13 11/01:77 14c1-BBO06 11-24-76

16 06/15/77 14@1-BBO07 11-24-76

Iscmetric Drawing No.

Date Drawn - 
ADDENDUM D

SUPPORTING MATERIAL FOR

STORES ACCOUNTING SYSTEM (SAS)

$$
\text { D-1 }
$$


COMPANY NAME Westinghouse

ORDER NUMBER W-35924

PO $\quad 172547$

ITEM 001 .

SO $185 \quad$ UN IT 1

SHIPMENT\#_7449_REC. 4-25-77

CRANE

HO I ST

2 BOXES OF MISC. PARTS

FOR UNIT \#1

STORAGE LEVEL___ C Hoist Adn Boxes

D Crane

CATAWBA STORES LABEL 


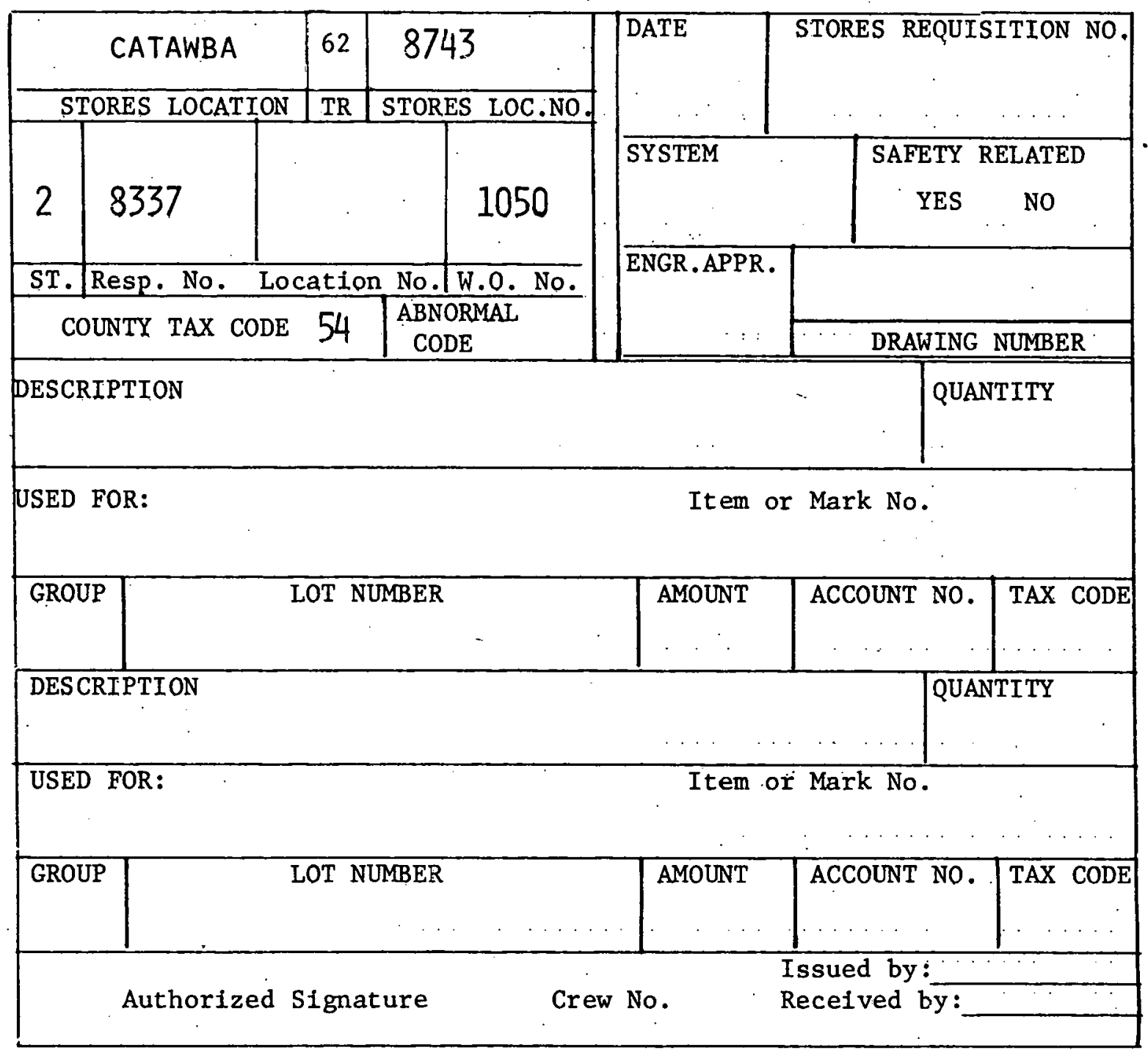




\section{THIS PAGE WAS INTENTIONALLY LEFT BLANK}


ADDENDUM E

SUPPORTING MATERIAL FOR

PUNCH LIST

3

$\because$

E-1 


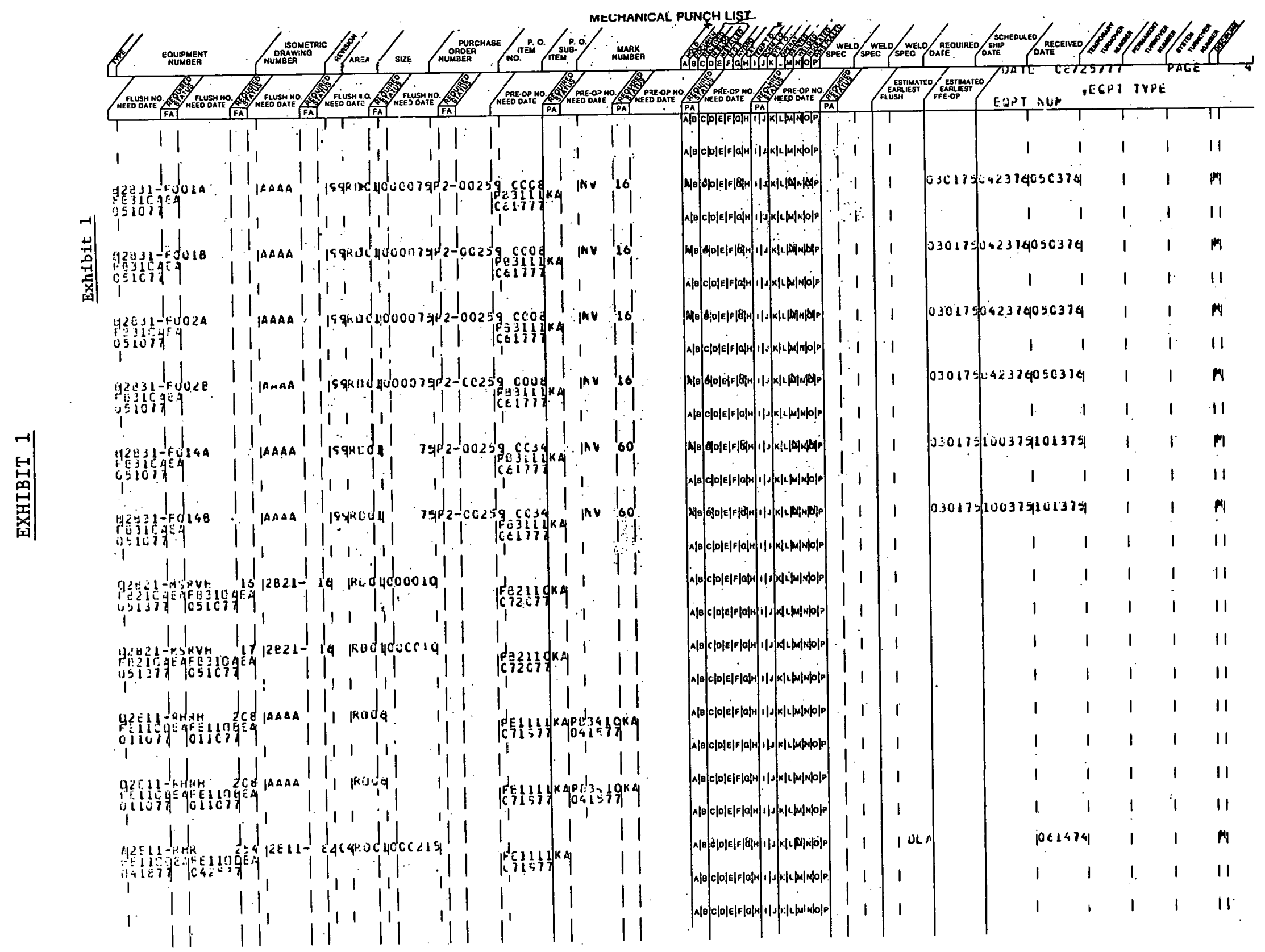




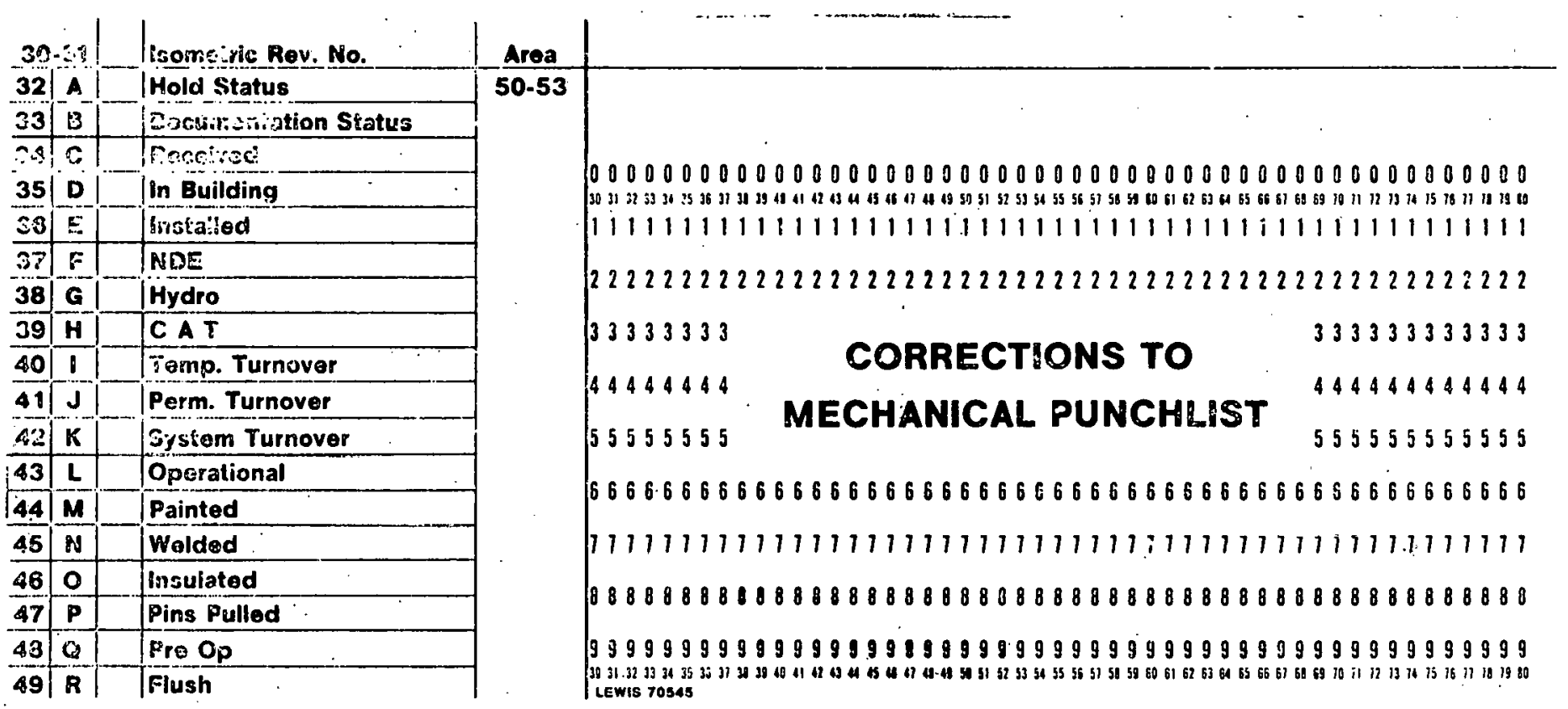




\section{THIS PAGE WAS INTENTIONALLY LEFT BLANK}


ADDENDUM $F$

SUPPORTING MATERIAL FOR

MATERIAL MANAGEMENT INFORMATION SYSTEM

1 
MATERIALS MANAGEMENT INFORMATION SYSTEM PURCHASING DEPARTMENT STATUS REPORT

REPORT NQ. PU5.6ORQZ

PREPARED 4-03-75

BUYER DESCRIPTION

20
PAGE $\frac{1}{1}$

THIS MONTH LAST MONTH

\section{OPEN ORDER STATUS}

ORDERS ISSUED

OPEN ORDERS

PAST DUE

$\begin{array}{ll}0 & 5 \\ 4 & 5 \\ 1 & 2\end{array}$

PROJECT ORDER STATUS

ORDERS ISSUED

OPEN ORDERS

PAST DUE

$\begin{array}{ll}0 & 2 \\ 1 & 2 \\ 1 & 1\end{array}$

SYSTEM REQUISITION STATUS

REQUISITIONS RECEIVED

REQUISITIONS PROCESSED

REQUISITIONS IN PROCESS

REQUISITIONS PAST DUE

$\begin{array}{ll}0 & 8 \\ 0 & 5 \\ 0 & 0 \\ 3 & 3\end{array}$

EXPEDITE ACTION STATUS

ACKNOWLEDGEMENT REQUEST EXPEDITES 0 Z INTERIM REQUEST EXPEDITES

PAST DUE ORDER EXPEDITES

$0+0$

I. I 
MATERIALS MANAGEMENT INFORMATION SYSTEM PURCHASING DEPARTMENT:

REPORT NQ, PUSGDBOZ MONTHLY ACTIYITY REPORT

PREPARED. 4-03-75

$\begin{array}{ll}-1-\text { THIS YEAR -.- } \\ \text { THIS } & \text { YEAR } \\ \text { MONTH } & \text { TO DATE }\end{array}$

PAGE I
AS OF $02-2 B-75$
THIS LAST YEAR ---
MONTH. YOAR
TO DATE

DEPARTMENTAL PROCESSING ACTIVITY

SYSTEM REQUISITIONS

2? RECEIVED

15 PROCESSED

IN PROCESS

PAST DUE

$$
\text { PURCHASE ORDERS ISSUED }
$$

4. PROJECT

I GENERATION CONSTRUCTION

2 PRODUCTION SUPPLIES \& MAINT.

II TRANSMISSION SUBSTATION \& DIST. MISCELLANEOUS

TOTAL

0

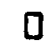

已

20

OPEN PURCHASE ORDERS

PROJECT

GENERATION CONSTRUCTION

PRODUCTION SUPPLIES \& MAINT.

TRANSMISSION SUBSTATION \& DIST.

MISCELLANEOUS

TOTAL

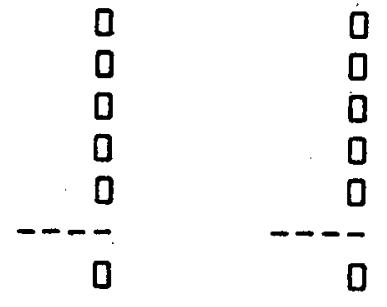

26

PAST DUE ORDERS

PROJECT

GENERATION CONSTRUCTION

PRODUCTION SUPPLIES \& MAINT.

TRANSMISSION SUESTATION \& DIST.

MISCELLANEOUS:

TOTAL

0

0

D

0

0

$--\frac{1}{0}$

$\begin{array}{rr}1 & 2 \\ 0 & 0 \\ 1 & 2 \\ 2 & 4 \\ 0 & 0 \\ -4 & 8\end{array}$

$\begin{array}{ll}4 & 9 \\ 2 . & 2 \\ 1 & 5\end{array}$

\section{EXPEDITING}

7. ACKNOULEDGEMENT REQUEST EXPEDITES

INTERIM REQUEST EXPEDITES

a.

PAST DUE ORDER EXPEDITES

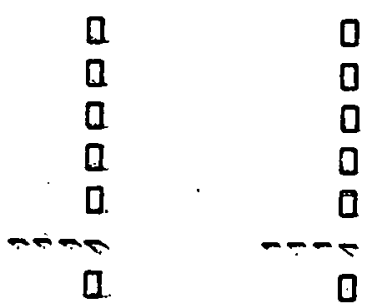




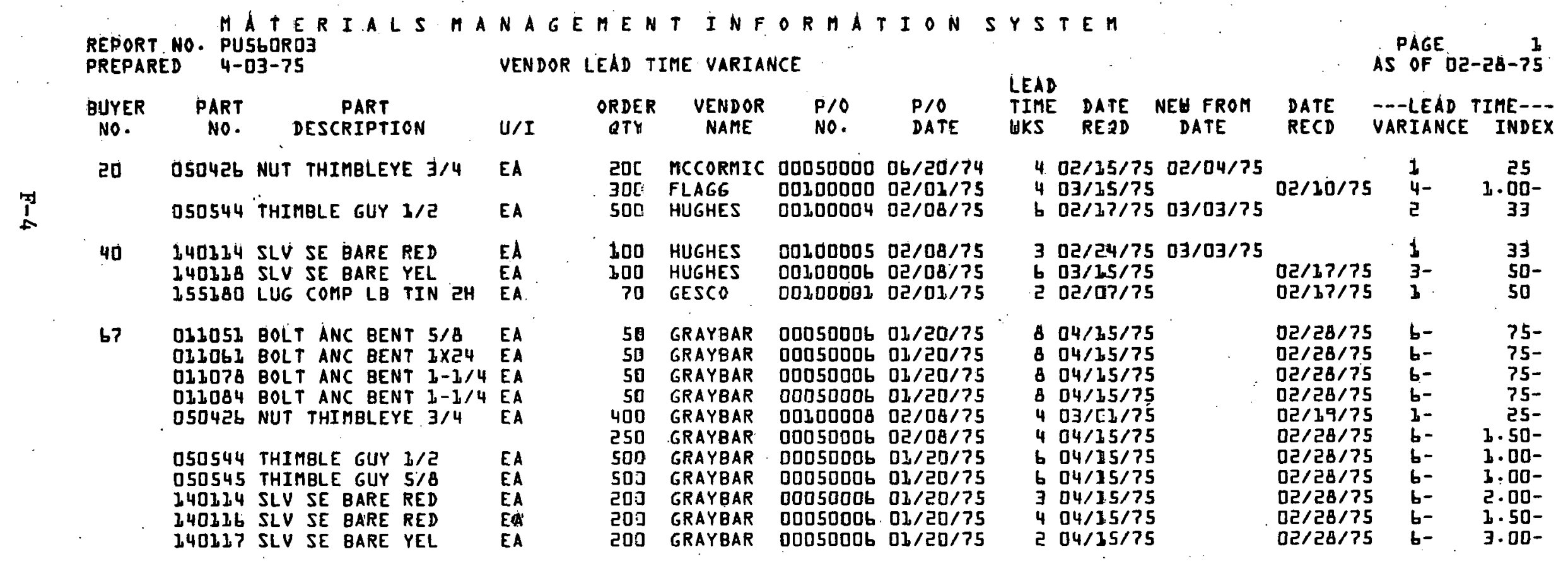




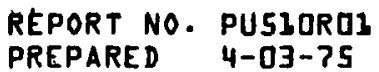

NIP NO. PART

NIP NO. PART

NO. ORDS. NO. DESCRIPTION

尔 BUYER NÓ. ZO VENHOR NAHE: GESCO

DOI $O$ DSO446 NUT THINEYE 3 ,

201 I 050544 THIMBLE GUY b/

$.103 \mathrm{~b}$ Q50545 THIHBLE GUY $5 /$
MATERTALS MANAGEMENT INFORMATION SYSTEM PURCHASE AGREEMENT STATUS REPORT

AS OF $4-03-75$
AGREEMENT AGREEEMNT

$\begin{array}{lll} & \\ \text { QTY U/I UNIT PRICE TOTAL } & \text { THERES } \\ \text { QTY } & \end{array}$ VENDOR NO: 30728D

3000 EA 1.300 2500 EA 3.500
TOTAL RELEASED TOTAL CURRENT\% AMT AGREE AMT

\% TIME START EXPIRE

$\begin{array}{rrrr}1 & 0 & 0 & 1000 \\ 4 & 200 & 0 & 2300\end{array}$

$\begin{array}{ll}4 & 200 \\ 3 & 200\end{array}$
$33 \quad 11 / 03 / 74 \quad 40 / 33 / 6$

$331,102 / 7410 / 31 / 8$ 
MATERIALS HANAGEMENTTINORHATILN SYSTEM REPORT NO. PUSGOROU VENDOR ACTIVITY REPORT

AS OF $03-31-75$

PREPARED $\quad 4-03-75$ PAST TUELVE MONTHS

VENDOR NAME
FLAGG
GESCO
GRAYYBAR

CLASS NAME

NO. OF AVG. WO.DAYS INFO ORDER: ACKNOULEDGE TRACES

PROMISES GLY HARDWARE

CONN. \& LUGS-COMPRESS 2

HUGHES
BOLTS, NUTS, WASHERS

SLEEVES-COMPRESSION
1

\section{2}

2

2

1
O

2

己

1
RECEIVED CHANGED

2
0
0

0

ᄅ

1

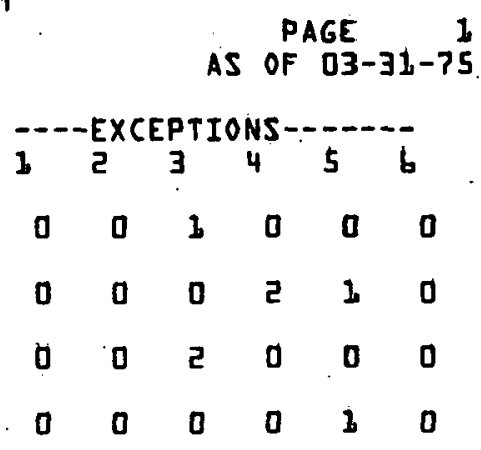




\begin{tabular}{ll}
\hline REQ. NO. & 0 \\
\hline
\end{tabular}

ChANGe to

\begin{tabular}{|c|c|c|c|c|c|c|c|c|c|c|c|c|c|c|}
\hline PART NO. & ORDER QTY. & $\mathrm{U} / \mathrm{I}$ & STD.PKG. & & FPC & OTHER & STRM & LEAD & TIME WEEKS & DATE REQUIRED & BUYER & INSP. & TYPE & SPEC. HAND \\
\hline 030553 & 5 & EA & 1 & 0000 & 00015401 & 000299 & 299 & & 16 & $12 / 27 / 76$ & 20 & 01 & A & 00 \\
\hline
\end{tabular}

SHIP TO ADDRESS:
FLORIDA POWER CORP, -STOREROOM
SR 462, I MI NO ALTERNATE ADDRESS:
WILDWOOD, FLA. 32785 ILDWOOD

INTERIM EXPEDITE

\begin{tabular}{|l|l|}
\hline PART DESCRIPTION: & SPECIAL INSTRECTIONS: \\
\hline POLE WOOD 55 FT, C 3 & \\
\hline
\end{tabular}

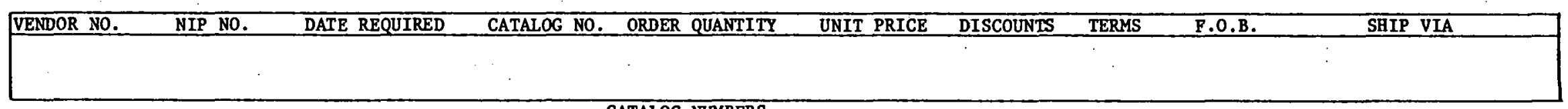

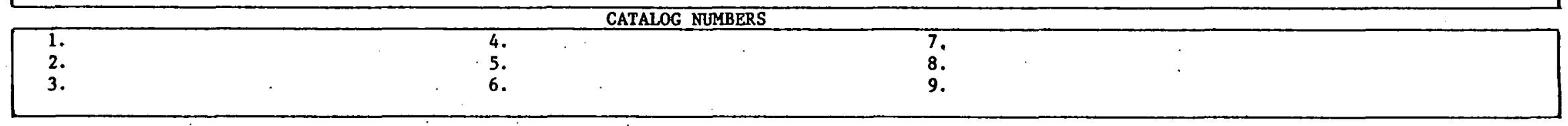

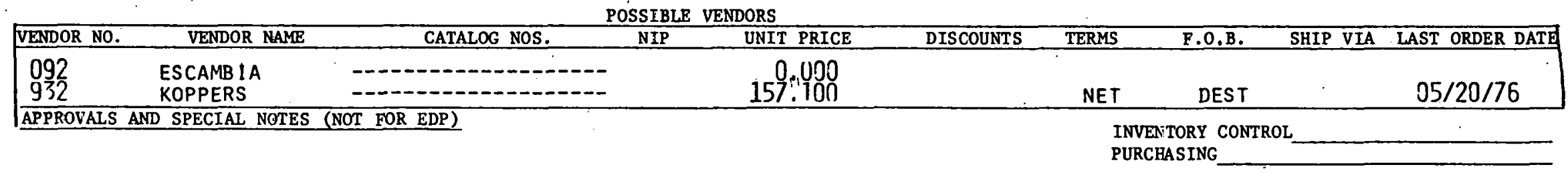


P.O. DATE

$10 / 04 / 75$
FLORIDA POHER CORPORATIOR
PURCHASINC DEPT. P,O, BOX 14042

W. PETERSBURG, FLORIDA 33733 PURCHASE ORDER
$P, 0$,

00106659

\begin{tabular}{|c|c|c|c|c|c|}
\hline T0: & $\begin{array}{l}\text { SEARS \& ROEBUCR CO. } \\
\text { TRUCK TIRE CENTER } \\
1820 \text { MASSARO BLVD. } \\
\text { TAMPA, FLA. } 32208\end{array}$ & & & SIIP TO: & $\begin{array}{l}\text { FLORIDA POWER CORP. - STOREROOM } \\
\text { SR } 462,1 \text { MI. NO. OF NILDWOOD } \\
\text { WILDWOOD, FLA, } 32735\end{array}$ \\
\hline PROJECT NAME & & $B / M$ & NIP NO, & STATUS & VENDOR NO. \\
\hline & & & 000 & MISC & $10 / 23 / 76$ \\
\hline
\end{tabular}

PURCHASE REQUISITION NOS.

2159930

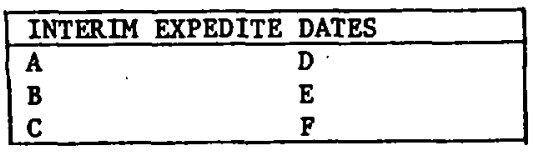

PRICE/TERMS

\begin{tabular}{|cccccc}
\hline ITEM & & & & 0THE \\
\hline 01 & 0000 & 000 & 15401 & 000249 \\
& SEE PKG & & & \\
\hline
\end{tabular}

PART NO.

DESCRIPTION

$\mathrm{U} / \mathrm{I}$

54 GAL. DRUM
ANTI-FREEZE \& COOLANT - PERMANZNT TYPE, ETHYLENE GLYCOL BASE WITH CHEMICAI INHIBITORS

DR 1
718014

I

PRICE/TERMS

178.

TERM NET

1. PLEASE SHOW PURCHASE ORDER NO. ON ALL PACKAGES,

INVOICES, SHIPPING PAPERS AND CORRESPONDENCE,

ASE SUBMIT INVOICES IN TRIPLICATE TO P, O, BOX
42, B-7 ACCOUNTS PAYABLE SECTION, ST. PETERSBURG, FLORIDA 33733 . 


\begin{tabular}{ll|}
\hline TO: & SEARS \& ROEBUCK CO. \\
& TRUCK TIRE CENTER \\
& 1820 MASSARO BLVD. \\
TAMPA, FLA. 32208
\end{tabular}

\section{SHIP TO:}

FLORIDA POWER CORP; - STOREROOY

SR 462, 1 MI: NO. OF WILDWOOD

WILDWOOD, FLA. 32785

\begin{tabular}{|lccccccccc|}
\hline PROJECT NAME & B/M & NIP NO. & BUYER & TYPE & STATUS & VENDOR NO. & STRM & DATE REQD \\
\hline & 000 & 63 & MISC & SYS & 779539 & & 299 & $10 / 29 / 76$ \\
\hline
\end{tabular}

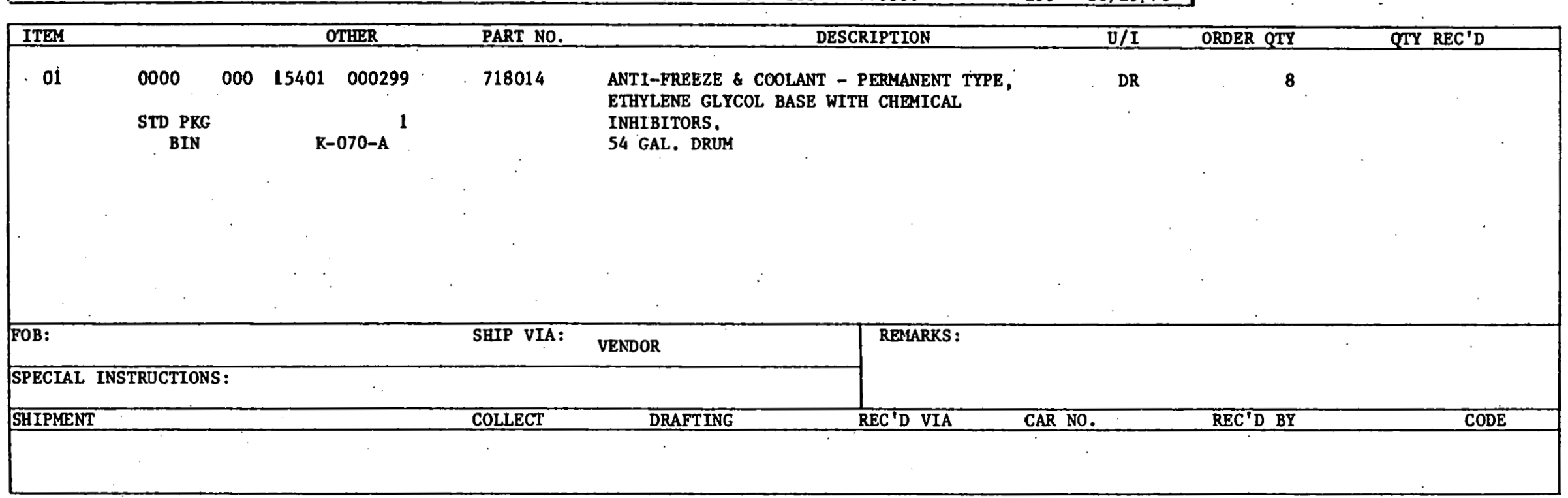


REPORT NO. PUSOOROL

MATERIALS MANAGEMENTTINFORMATION SYSTEM

PREPARED 3-15-75

OPEN ORDER STATUS REPORT

AS OF $3-15-75$

ORDER TYPE: TRANSMISSION

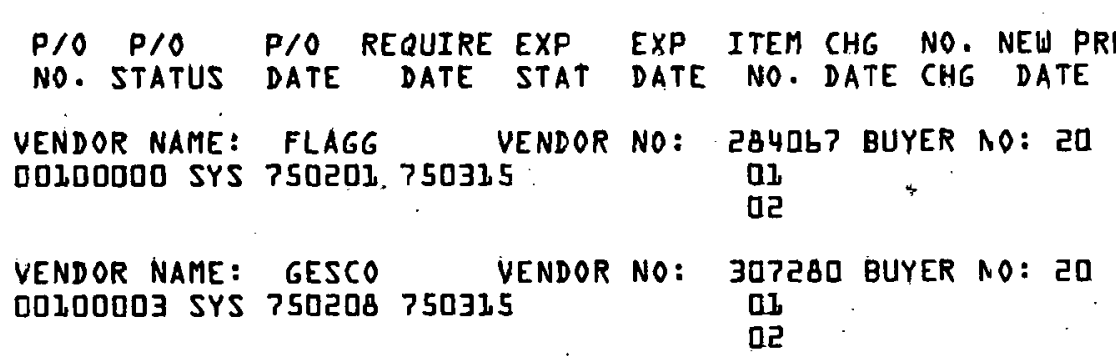

VENDOR NAME: GRAYBAR VENDOR NO: 325944 BUYER AO: 20

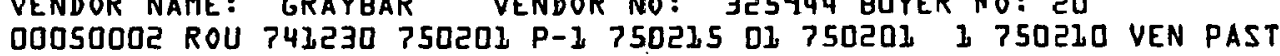

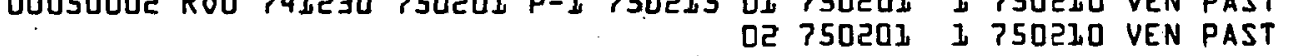

OR
OSD446 NUT TWINEYE $3 / 4$
OK

$\begin{array}{lll}050446 & \text { NUT TWINEYE } 3 / 4 & 300 \text { EA } \\ 050426 & \text { NUT THIMBLEYE } 3 & 300 \text { EA }\end{array}$

ORDER

NO. RECD RECEIPT BAL

$\begin{array}{lllll}\text { OK } & \text { Q50544 THIMBLE GUY } 1 / 2 & 200 \text { EA } & 200 \\ \text { OK } & 050545 \text { THIMBLE GUY } 5 / 8 & \text { I00 EA } & 100\end{array}$

$\begin{array}{lllll}\text { OK } & \text { Q50544 THIMBLE GUY } 1 / 2 & \text { 200 EA } & \text { 200 } \\ \text { OK } & 050545 \text { THIMBLE GUY } 5 / 8 & \text { IOD EA } & 100\end{array}$

$\begin{array}{lllll}\text { OK } & \text { Q50544 THIMBLE GUY } 1 / 2 & \text { 200 EA } & \text { 200 } \\ \text { OK } & 050545 \text { THIMBLE GUY } 5 / 8 & \text { IOD EA } & 100\end{array}$

$\begin{array}{lllll}\text { OK } & \text { Q50544 THIMBLE GUY } 1 / 2 & \text { 200 EA } & \text { 200 } \\ \text { OK } & 050545 \text { THIMBLE GUY } 5 / 8 & \text { IOD EA } & 100\end{array}$

VENDOR NAME: GRAYBAR VENDOR NO: 325944 BUYER NO: b? DODSDOOL ROU 740101 750415 A-1 750215 Q1

02
03
04
05
06
07
08
09
10

OK
OK
OK
OK
OK
OK
OK
OK
OK
OK

CLAMPS SUSP BRZ

IกD EA

100

21051 BOLT ANC BENT 5 OLLOLL BOLT ANC BENT $l$ QLLOZB BOLT ANC BENT I

OLIOS4 BOLT ANC BENT I 050446 NUT TUINEYE $3 / 4$ 05042b NUT THIMBLEYE 3 050426 NUT THIMBLEYE 3
050545 THIMBLE GUY $5 / 8$ 050545 THIMBLE GUY 5/8 $14011 ?$ SLV SE BARE YEL SO EA 240114 SLV SE BARE RED

50 EA
50 EA
50 EA
50 EA
250 EA
$250 E A$
500 EA
$500 E A$
$200 E A$
200 EA




\section{FLORIDA POWER CORPORATION \\ PURCHASING DEPT. \\ P.O. BOX 14042}

3201 34TH STREET SOUTH

FEBRUARY 15,1975
ST. PETERSBURG, FLA. 33733 ACKNOULEDGEMENT REQUEST 2

GRAYBAR ELECTRIC COMPANY, INC.

P.O. BOX 32IL

TAMPA.FL $3 \exists 60]$

SUBJECT: OUR ORDER NUMBER QDO5DOQL DATED: $01 / 01 / 34$

SHIP TO: WILDWOOD FL 3296$]$

WE HAVE RECEIVED NO ACKNOWLEDGEMENT OF THIS ORDER: 'PLEASE -

ACKNOWLEDGE ORDER AND GIVE DATE ORDER WILL BE DELIVERED.

BY

REPLY HERE :

DATE: BUYER: $6 ?$ SIGNED: 
FLORIDA POUER CORPORATION

PURCHASING DEPT.

P.O. BOX 14042

320I 34TH STREET SOUTH

FEBRUARY 22,1975
ST. PETERSBURG, FLA. 33

INTERIM STEP $C$ OF $C$

INTERIM EXPEDITE REQUES

SUBJECT: OUR ORDER NUMBER OOD50004 DATED: II/I5/74 SHIP-TO: WILDWOOD, FL 329bI WILL YOUR SCHEDULE FOR DELIVERY BE MAINTAINED?

BY

REPLY HERE ITEM BY ITEM

DATE :

BUYER: 50

SIGNED: 
FLORIDA POWER CORPORATION

PURCHASING DEPT.

P.0. BOX 14042

320I 34 TH STREET SOUTH

FEBRUARY 15,1975

GRAYBAR ELECTRIC COMPANY INC

P. O. BOX 3210

TAMPA FL 33601

SUBJECT: OUR ORDER NUMBER QDO5ODOZ DATED: 12/30/74

SHIP TO: WILDWOOD, FL 3296]

SUBJECT ORDER IS PAST DUE. PLEASE RESPOND WITH NEW DELIVERY DATES FOR THE FOLLOUING ITEMS.

BY

REPLY HERE ITEM BY ITEM

LINE ITEM OLD DELIVERY DATE NEU DELIVERY DATE

QI

02

$02 / 20 / 75$
ST. PETERSBURG , FLA. 33733

PAST DUE EXPEDITE REQUEST I 
DATE PICKED

\section{INTERSTORES TRANSFER LISTING}

\begin{tabular}{ll}
\hline TRANSFER NO. & 00952 \\
\hline & \\
DATE PREPARBD & $10-01-75$
\end{tabular}

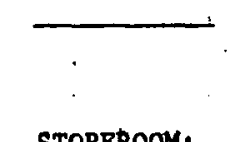
BY 217 PRELIST NO. 00762

PAGB STOREROOM: CLEARWATE ACCOUNT NO: 15401

DELIVERY DATE: 10/07/75

\begin{tabular}{|l}
\hline PRIME BIN \\
LOCATION \\
\hline PAR \\
\hline NUMB \\
\hline
\end{tabular}

$D-061-A$

$E-017-H$

F-064-G

G-013-I

$6-032-C$

G-034-A

G-045-I

$\mathrm{H}-005-\mathrm{C}$

$H-0>1-G$

H-D2D-G

PART

PART DESCRIPTIOA

WEIGHT

VOLUME

U/I TOTAL

QUANTITY

QUANTITY

DIFF.

390122 TAPE 3/4 ELECT.

412123

TAPE J/4 ELECT.

136332

IMPACT ELECTIDO*

STRUP BLED SGL CC $b-41$

250164
230463

142169

SLVTEM CO SCL $b$

250132

LMP MFR YAP IDO W UH

250103

LMP MFR VAP 175 W UH

LUG COMP IH

381264

SH CONDT PLST

$\begin{array}{rrr}24 & 1 & R \\ 6 & 0 & E A \\ 6 ? & 1 & E A \\ 10 & 2 & E A \\ 22 & 2 & E A \\ 4 & 0 & E A \\ 10 & 1 & E A \\ 108 & 18 & E A \\ 1 & 0 & E A \\ b & 1 & E A\end{array}$

$\begin{array}{lr}\text { RO } & 200 \\ \text { EA } & 1 \\ \text { EA } & 40 \\ \text { EA } & 12 \\ \text { EA } & 61 \\ \text { EA } & 200 \\ \text { EA } & 24 \\ \text { EA } & 226 \\ \text { EA } & 50 \\ \text { EA } & 100\end{array}$


STORES MATERIAL REQUISITION

DATE PREPARED 9-30-75

REQUISITION No.9004736

CANCEL CODE

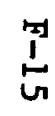

\begin{tabular}{|lcccccccc|}
\hline PART NO & ORDER QTY & U/I & STO,PKG, & ACCOUNT NO. & STRM & LEAD TTME WEEKS & DATE REQUIRED & BUYYR \\
\hline \multirow{2}{*}{142411} & \multirow{2}{*}{3150} & EA & 25 & 15401 & 299 & 6 & $11 / 17 / 75$ & 40 \\
\hline
\end{tabular}

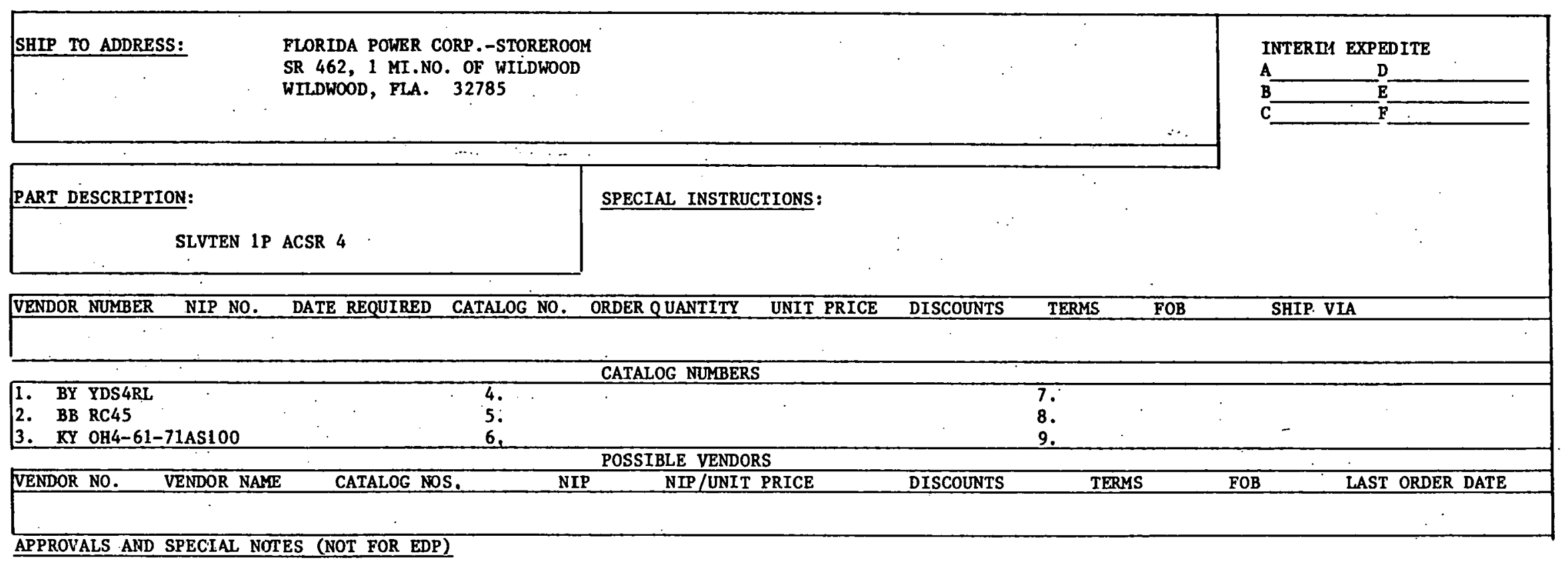

PURCHASING 
MATER I ALS MANAGEMENT INFORMATION SYSTEM

REPORT NO. MMO5DRO5

PREPARED. $20-02-75$

STOREROOM: 236

ST. PETERSBURG

CYCLE COUNT LIST

SOURCE CODE OBL

PAGE

AS OF $10-01-75$

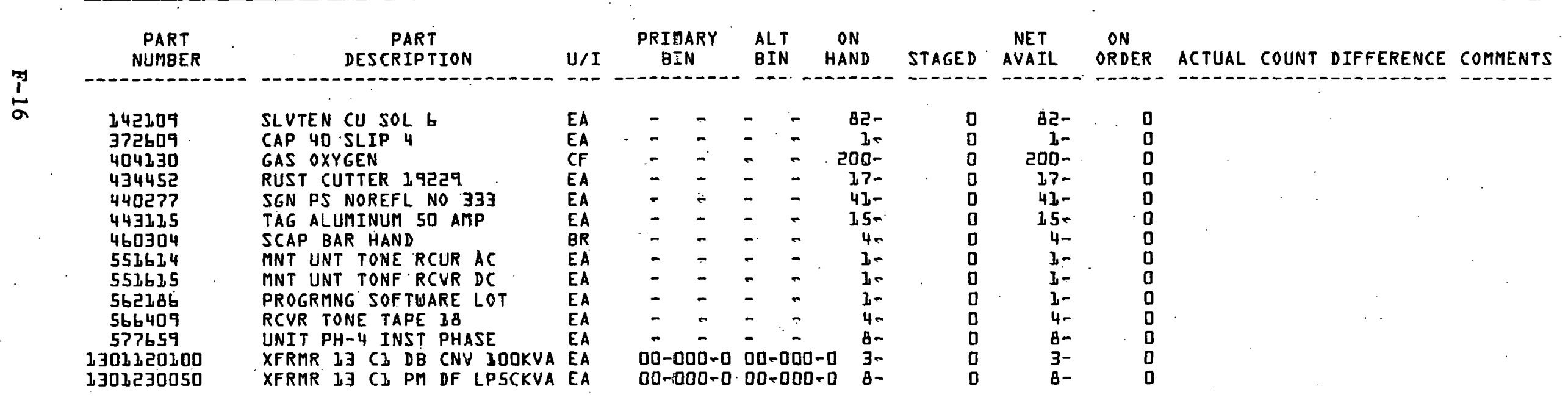




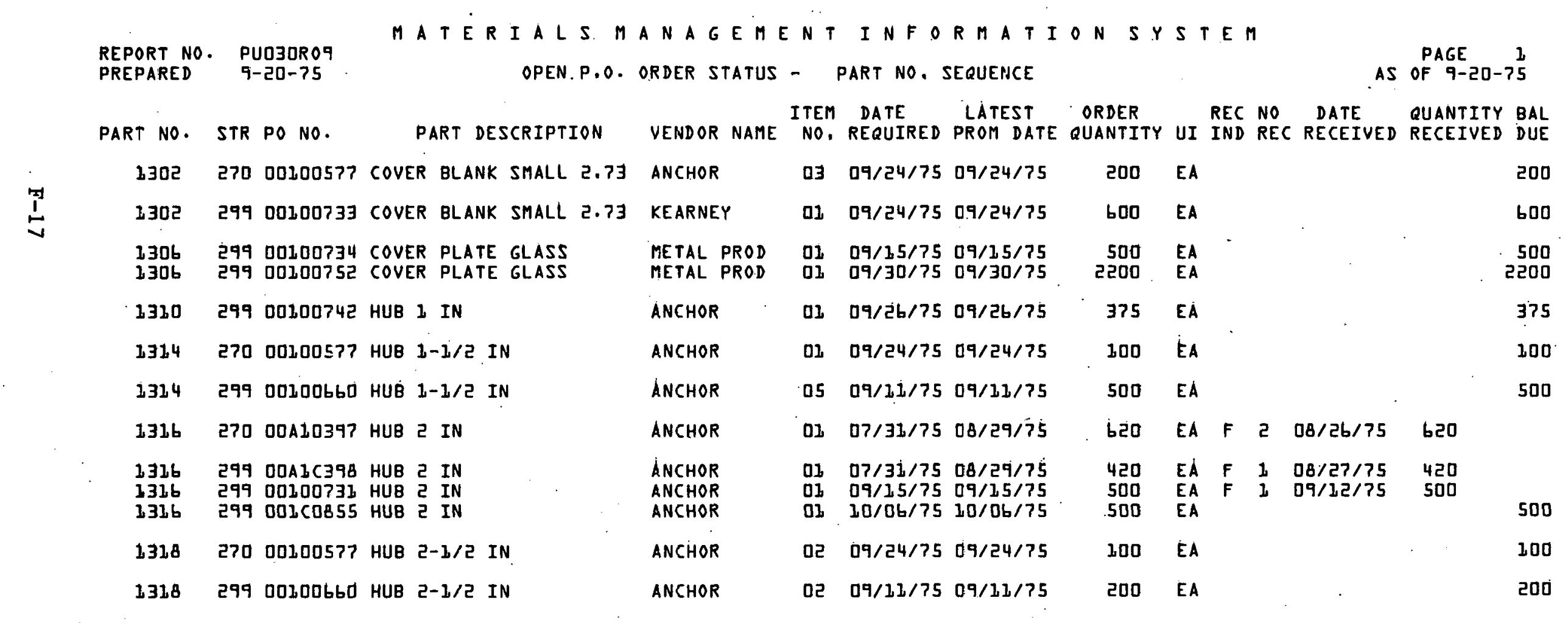


MATERIALSMANAGEMENTINFORMATION SYSTEM FORECAST SIMULATION REPORT - SUMMARY.
PAGE 10 AS of $122-27-74$

$\begin{array}{ll}\text { REPORT NO. } & \text { PUEOROJ } \\ \text { PREPARED } & 12-28-74\end{array}$

STOREROOM: MONTICELLO

ORDER POLICY: S/FOFEC/LOW/TR

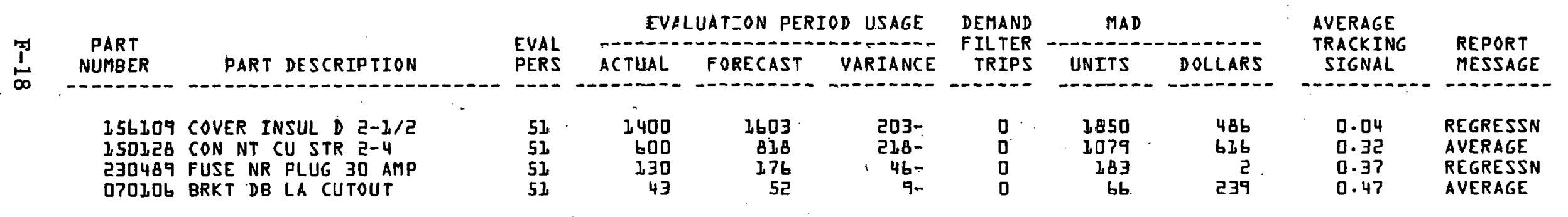


MATERIALS MANAGEMENT INFORMATION SYSTEM

REPORT NO. PUGOROY

PREPARED $\quad \mathrm{D} 2-2 B-74$

FORECAST SIMULATION REPORT - DETAIL

AS OF. $121-27-74$

\section{STOREROOM: MONTICELLO PART NUMBER: b56LQ9}

ORDER POLICY: S/FOREC/LOU/TR DESCRIPTION: COVER INSUL D $2-1 / 2$

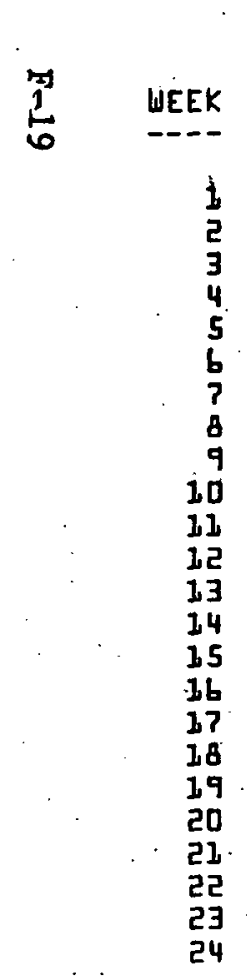

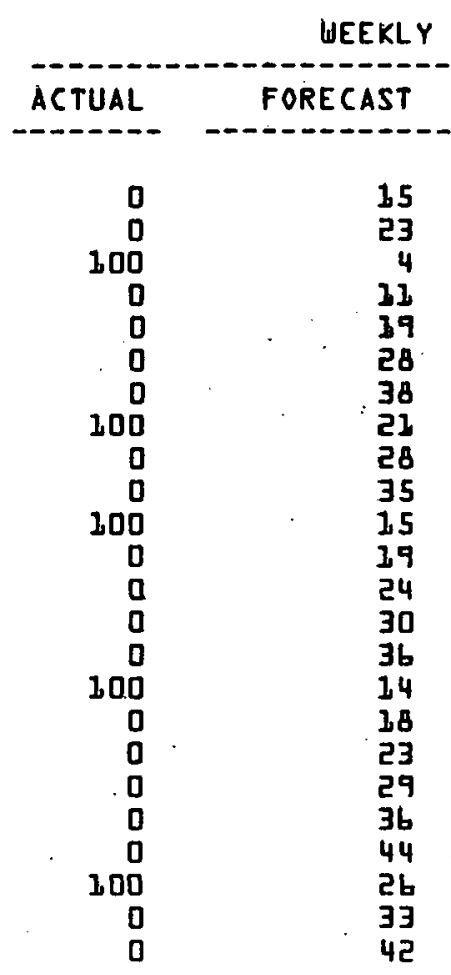

DEMAND

FILTER

VARIANCE

UNITS

\begin{tabular}{ll} 
MAD & \\
\hline UNITS & DOLLARS
\end{tabular}

TRACKING

SIGNAL

0.05

0.02

0.03-

0.26

0.15

$0.2 \mathrm{C}$

0.08

0.01

0.16

0.12

0.06

0.23

0.21

0.18

0.13

0.07

0.25

0.23

0. 20

0.17

0.21

D. 04

0.18

893

74
$33-$

4 2-

914
920

47
47
45

46

0.13 
REPORT NO. MR ATER I A L S MANAGEMENT I NFORMATI O N $S$ Y S T E M

PREPARED $9-13-75$ INVENTORY CONTROL SUMMARY BY INVENTORY CATEGORIES

AS OF $08-31-7 \frac{1}{5}$

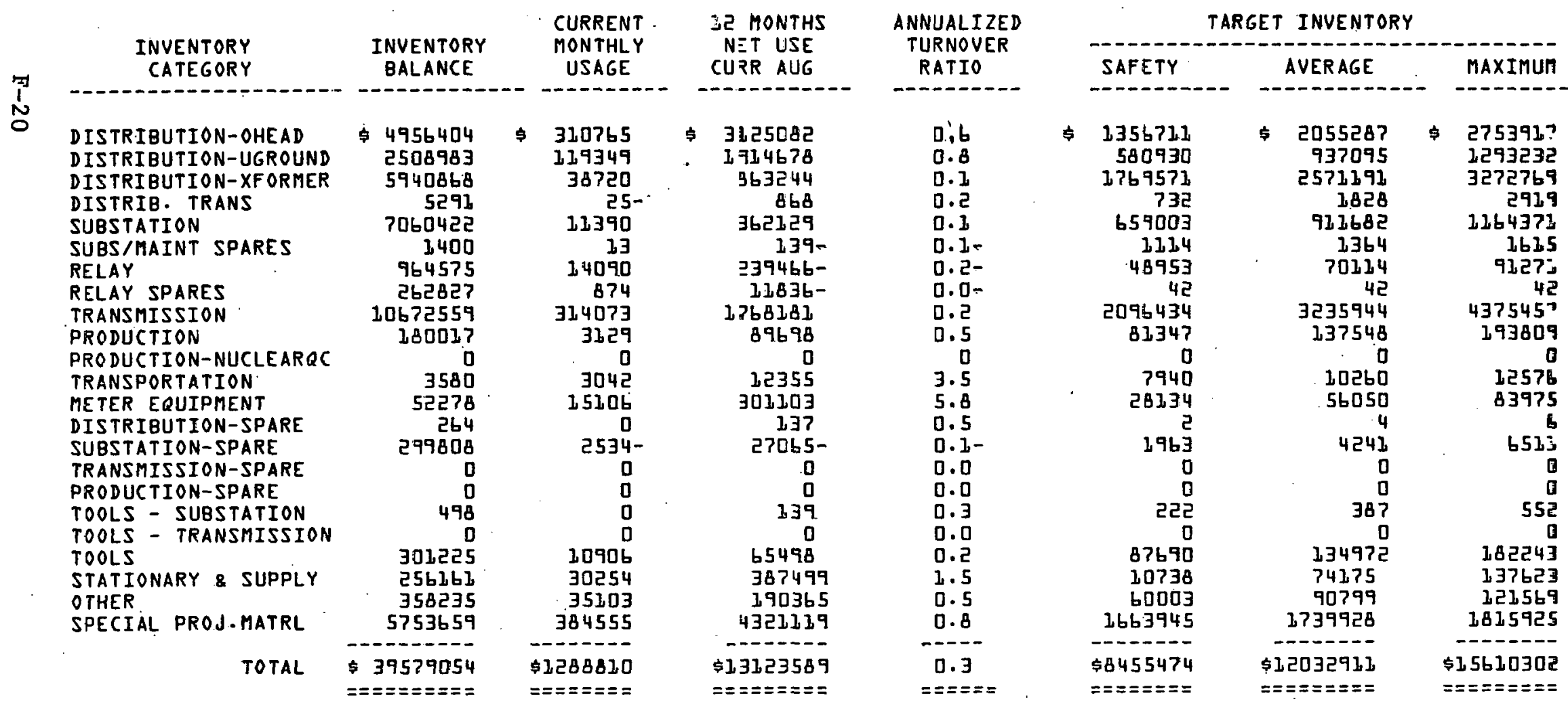




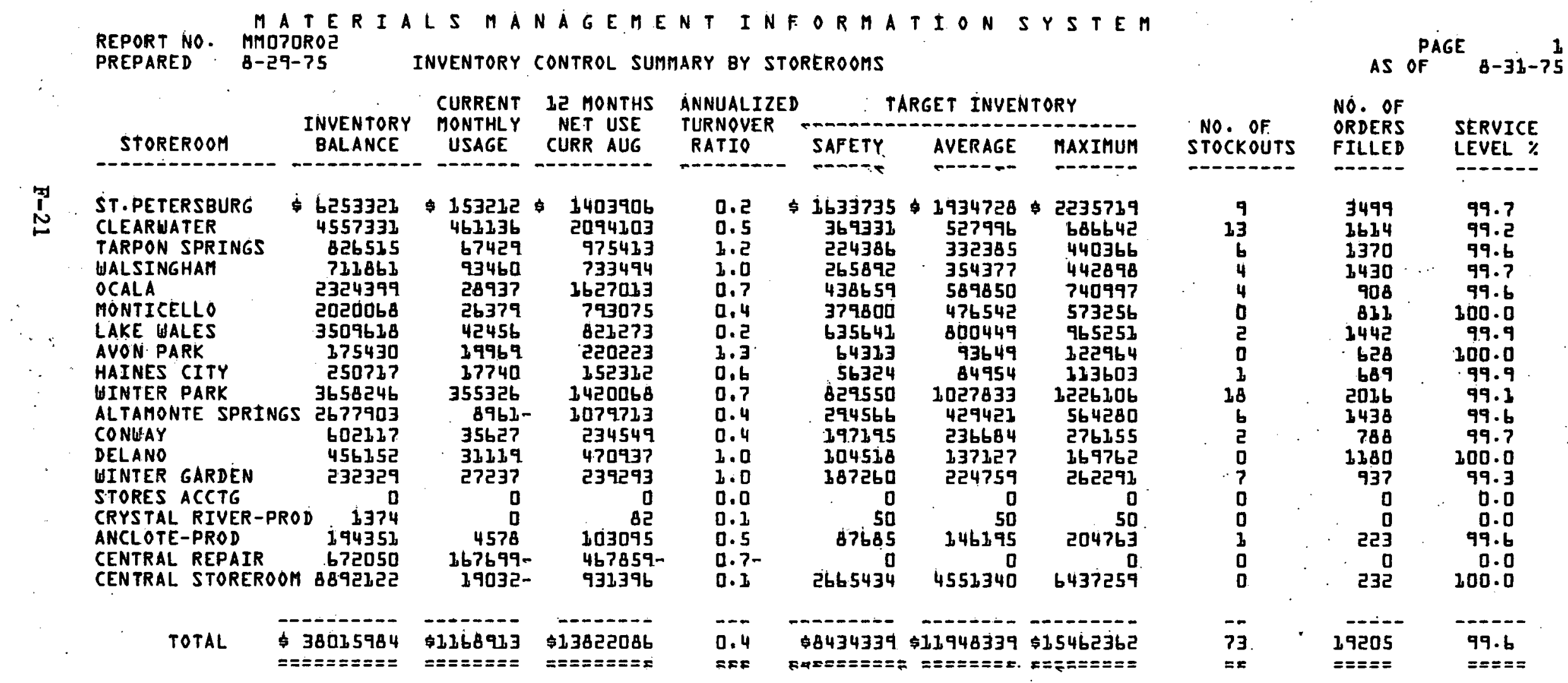


REPORT NO. MMOPORIERI LLS MANAGEMENTTINFORMATION SYSTEM REPORT NO. MMOPORLY ROUTE CAPACITY REPORT

AS OF Ob-30-75

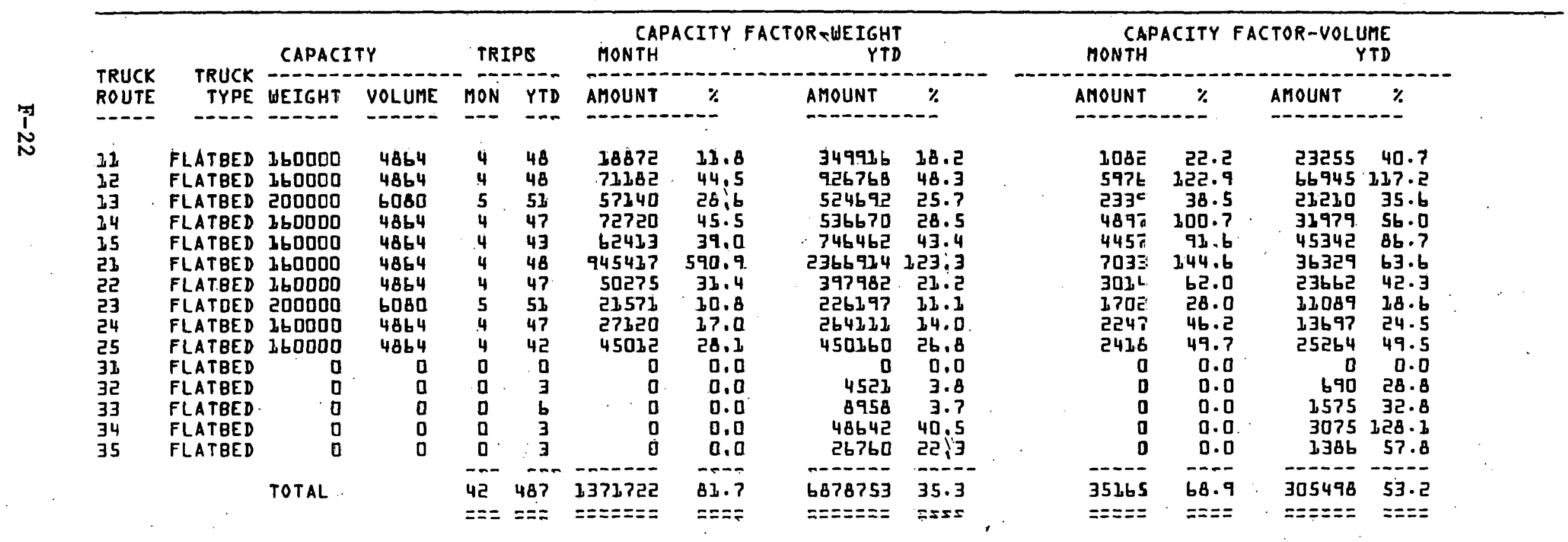


REPORT NO. MMOZOROB

BIN LOCATOR REPORT

PAGE

PREPARED ID-03-75

PART NO BIN LOC

DESCRIPTION

U/O BIN LOC

PART NO

$010052 \begin{gathered}J-043-G \\ C-053-F\end{gathered}$ BLT M G HH $3 / 4 \times J-3 / 2$

EA J-D $43-G$

$C-053-F$

020052

QLOZDI J-040-I BOLT MACH I/4X2-I/2

EA J-040-1

נטסבסט

$010204 \mathrm{~J}-050-C$ BOLT MACH $3 / 8 \times \mathrm{C}$

EA J-050-C

010204

OIO224 J-O46-L BOLT MACH I/2 X I

EA $J-046-L$

010224,

व10225.

$J-075-F$
$C-049-J$ BOLT MACH I/ZXJ-I/4

EA J-075-F

$C-049-J$

010225

DI02ट6 J-075-E BOLT MACH I/ $\times 1 /-1 / 2$ NO-ALT-

EA. J-OT5-E NO-ALT -

QI0228 K-029-D BOLT MACH I/2 X 2

EA. K-02१-D

BIDE2b

QL0230 E-003-D BOLT MACH I/2X2-I/2

EA E-003-D

010228

QLO23? K-027-D BOLT MACH I/2 X.3

EA K-027-D

010230

QIO24L2 - - BOLT MACH $5 / 8 \times 1-1 / 4$

EA - -

미말

Q1.0252 NO-LOC- BOLT MACH $3 / 4 \times 1-1 / 2$

EA NO-LOC-

010242

010256 D-004-M BOLT MACH $3 / 4 \times 2-1 / 2$

EA D-004-M

010252

OIOJI4 $\begin{gathered}\text { E-OL4-J BOLT MACH I/ } \\ \text { NO-ALT- }\end{gathered}$

$E A \cdot E-0,4-J$ NO-ALT-

010256

QI0JIb J-D43-A BOLT MACH I/Z $\times 4$ NO-ALT-

EA J-D $\quad$ A3-A NO-ALT -

010314

QI0320 J-045-A BOLT MACH I/2 X 5 NO-ALT-

EA J-045-A NO-ALT -

010326

वप0320

Q10324 D-OOZ-I BOLT MACH I/Z X 6 NO-ALT-

EA D-ODE-I NO-ALT -

010324

DI0326 K-029-G BOLT MACH I/2 X?

EA K-0ट१-G

010326

QI032B G-033-A BOLT MACH I/2 X \&

EA G-033-A

010328

DLD332 F-OOb-N BOLT MACH I/2 X LD

EA $F-D O G-N$

010332 


\section{THIS PAGE WAS INTENTIONALLY LEFT BLANK}


ADDENDIM G

SUPPORTING MATERIAL FOR

NUMBERING SYSTEMS 
Paragraph

3.1 Purpose , . . . . . . . . . . . . . . .

3.2 Scope . . . . . . . . . . . . . . . .

3.3 Numbering and F1ling Responsibility . . . . . . . . ,

3.3.1 Numbering Responsibility $\because . . . . . . . . . .$,

3.3.2 Filing Responsibility . . ............

3.4 File Numbers . . . . . . . . . . . . . C3-2

3.4.1 First Element - Project Designator . . . . . . . C3-2

3.4.2 Second Element - Discipline Designator . . , . , . C3-4

3.4.3 Third Element - File System Designator . . . . . C3-4

3.4.4 Fourth Element - Category Designator .... . . . C3-4

3.4.5 Fifth Element - Subcategory Designator . . . . . . C3-4

3.5 File systems . . . . . . . . . . . . . . c3-5

3.5.1. Speclfication/Purchase Order (Spec/P,O.)

File System .................. . C3-5

3.5.2 Subject File Systems . . . . . . . . . . . C3-6

3.5.3 Design Calculation File System . . . . . . . . . C C3-6

3.5.4 Bechtel Drawing File System. . . . . . . . . C3-6

3.5.5 Auxiliary Administrative File Systems . . . . . . C3-6

3.5.6 Document Review Notice (DRN) Control
and File System . . . . . . . . . . C C3-8

3.5.7 Georgia Power Construction Drawings File System . . . C3-8

3.5.8 Eng ineering Study File System. . . . . . . . . C3-8

3.6 Master Chron Log and File . . . . . . . . . . C3-9

\section{LIST OF ILLUSTRATIONS}

\section{Figure}

C3-1 File Number Elements and Destgnators ... , , , . . . C3-3

$$
\cos -111 / 1 \mathrm{v}
$$




\section{LIST OF ATTACHMENTS}

Attachment.

Page

A Architectural Spec/P.0. File System , , . , . , , . c3-11

B Civil-Structural Spec/P.O. File System . . . , . . . C3-17

C Electrical Spec/P.0. File System . . . . . . . . . . . c3-23

D Mechanical Spec/P.0. File System . . . . . . . . . . C3-29

E Control Systems Spec/P.0. File System . . . . . . . . . C3-37

F Nuclear Spec/P.0. File System . . . . . . . . . . . C3-41

... FA Construction Spec/P.0. File System . . . . . . . . . C3-48A

G Architectural Subject File System . . . . . . , . . . C3-49

H Civil-Structural Subject File System . . . . . . . . . . C3-55

J Electrical Subject File System . . . . . . . . . . . C3-63

K Mechanical Subject File System . . . . . . . . . . C3-69

L Control Systems Subject File System . . . . . . . . . . C3-77

M Nuclear Subject File System . . . . . . . . . . . . . C3-81

$\mathrm{N}$ Administrative Subject File System . . . . . . . . . . . C3-87

P. PSAR File System. . . . . . . . . . . . . . . . . C3-95

Q PSAR File System (Void - AEC 01d Format) . . . . . . . C3-103

R FSAR File System . . . . . . . . . . . . . C3-109.

S FSAR F1le System (YoId - AEC 01d Format) . . . . . . . . C3-117

T Enylronmental Report File System. . . . . . . . . . , c3-123

U Design Control F1le sysceñ . . . . . . . . . , . , c3e125

Environmental Subject File System (Not Part of
Environmental Report) . . . . . . . . . . C3-139 c3-v/v1 


\author{
PART C \\ ENGINEERING \\ SECTION 3 \\ NUMBERING AND FILING SYSTEMS
}

\title{
3.1 PURPOSE
}

The purpose of this section is to provide the information necessary for assigning and maintalning a numbering and filing system that is used in identifying, filing, and retrieving documentation pertaining to the Vogtle Nuclear Plant project.

\subsection{SCUPE}

This section incorporates procedures for assigning correct file numbers to project documents, and identifies the persons responstble for making such assignments. Also included is a description of the filing systems for the various categories of documents, the persons responsible for maintaining the project files, and a detailed listing of certain file numbering systems associated with the project (Attachments A through V),

\subsection{NUMBERING AND FILING RESPONSIBILITY}

\subsubsection{NUMBERING RESPONSIBILITY}

Project file numbers are assigned to all incoming, outgoing, or intraproject documents except Bechtel drawings and vendor data. (These use the separate numbering systems and number assignments explained in Part $C$, Sections 4 and 5 of this manual.). All incoming documents, regardless of origin or destination, are given an appropriate file number by the project administrator. The numbers selected are then checked for accuracy by the assistant project engineer and/or engineering group supervisor (EGS). For project-oriented documents, the project administrator assigns file numbers only to those generated by project management or by support department personnel. Engineering-generated documents are assigned file numbers by the responsible engineer, the EGS, or the licensing engineer.

\subsubsection{FILING RESPONSIBILITY}

Except for Bechtel drawings and yendor data, which are the responsibility of the drawing and data control section, most other project documents are kept in files matntained by the project secretary, Access to these files is limited to the project secretarial staff, and all project personnel wishIng to retrieve or deposit documents must do so through a member of this staff. The project administrator is responstble for several files, which contain the remainder of the project documents, (Refer to paragraphs 3.5 and 3.6 for details of filing systems).

$$
\text { C3-1 }
$$




\subsection{FILE NUMBERS}

The elements of the file number indlcate the appropriate project, discipline, filing system, and either the document category and subcategory within the filing system, or numerical sequence. Unless otherwise specifled, the file number assigned to a project document is composed of five elements. The elements consist of alphanumeric designators to identify the document and its related filing system. These file number elements and designators are shown in Figure $\mathrm{C} 3-1$.

Although the file numbers and titles listed in Attachments $A$ through $\mathrm{V}$ must not be changed after being assigned, additions or deletions to the file system are permissible. The VNP Project Reference Manual Change Request form must be used to initiate any such change to the file system. Approval of the requested change must be obtained before the file and manual are revised. (For the complete Project Reference Manual change procedure, refer to the Preface of this manual).

File numbers that are no longer needed shall have the title in the listing lined out (with a broken line) and the word "DELETED" added at the end of the title. Although such numbers are not reassigned, the file folders that contain documents are kept intact for record purposes; and retain the deleted numbers.

New file numbers required for the project are assigned by the project administrator in conjunction with the responsible EGS, and with the approval of the project engineer and project manager.

\subsubsection{FIRST ELEMENT - PROJECT DESIGNATOR}

The first element of the file number identifies the project (Figure C3-1), and is the same for all project document file numbers except Bechtel

drawings. (Refer to Part C, Section 4 of this manual.)

Under certain conditions, a prefix is used with file numbers to indicate the plant unit to which a document applies. The use of this prefix is mandatory for engineering requisition file numbers (Part C, Section 8 of this manual), but such a prefix is used on an asmrequired basis for other documents. The unit prefixes are as follows:
$1=$ Unit 1
2 = Unit 2
$3=$ Unit 3
$4=\operatorname{Untt} 4$

$A=$ Comon to units 1 and 2

$B=$ Common to units 3 and 4

$C=$ Common to entire plant 
FILE NUMBER ELEMENTS AND DESIGNATORS

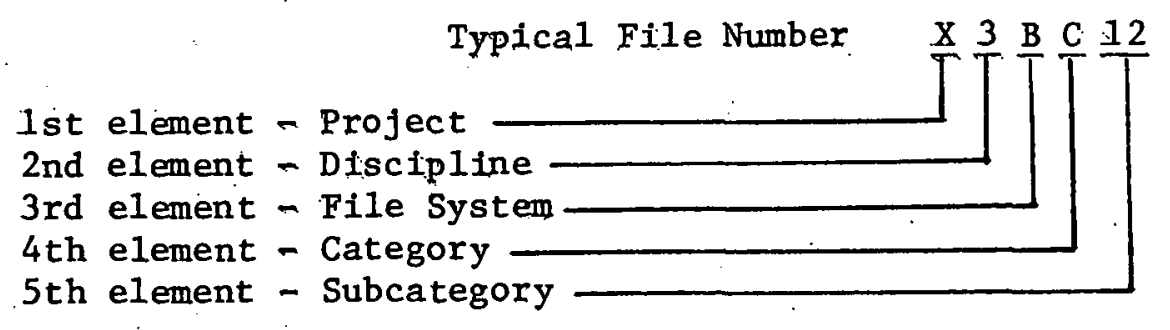

$1 s t$

element

2nd

element

$3 r d$

element

\begin{tabular}{|c|c|c|}
\hline $\begin{array}{c}4 \text { th } \\
\text { element }\end{array}$ & $\begin{array}{l}A, B \text {, etc.; } 01 \text {, } \\
02, \text { etc,; or } \\
001,002 \text {, etc. }\end{array}$ & $\begin{array}{l}=\text { Main category headings within a file } \\
\text { system, or a numerical sequence, Refer } \\
\text { to Paragraph } 3.4 .4 \text {, }\end{array}$ \\
\hline $\begin{array}{l}5 \text { th } \\
\text { element. }\end{array}$ & $\begin{array}{l}01,02 \text {, etc.; } \\
.1, .2 \text {, etc.; } \\
\text { or } A, B \text {, etc. }\end{array}$ & $\begin{array}{l}\text { = Subcategory of a file system, or a numer- } \\
\text { erical sequence. Refer to Paragraph } 3.4 .5 \text {. }\end{array}$ \\
\hline
\end{tabular}

1 = Architectural Discipline

2 = Civil-Structura1 Discipline

3 = Electrica1 Discipline

4 = Mechanical Discipline (Including Plant Design)

5 = Control Systems Discipline

6 = Nuclear Discipline

7 = Administrative

8 = Environmental (Not part of Enviromental Report)

9 = Construction

$A=$ Specification/Purchase Order (Spec/P.O.) File System

$B=$ Engineering and Administrative Subject Fille Systems

$C=$ Design Calculation File System

$\mathrm{D}=$ Bechtel Drawing File System

$L^{\prime}=$ PSAR File System (Void - AEC old Format) *

$F=$ FSAR File System (Void - AEC OId Format) *

$G=$ Georgia Power Construction Drawings

$\mathrm{H}=$ Environmental Report (ER) File System *

$\mathrm{J}=$ Design Control File System *

$\mathrm{K}=$ Scope Change File System *

$\mathrm{L}=$ Document Review Notice Control and File System *

$M=$ PSAR File System *

$\mathrm{N}=$ FSAR File System *

$\mathrm{S}=$ Englneering Study File System

*Auxiliary Administrative File System

Figure C3-1. File Number Elements and Designators 


\title{
3.4.2 SECOND ELEMENT - DISCIPLINE. DESIGNATOR
}

The second element is a onedigit number that identifies the engineering discipline, or an administrative or environmental listing that is appropriate to the document. The numbers used as designators are shown in Figure $\mathrm{C} 3-1$.

\begin{abstract}
NOTE
Element designators 1 through 6 are assigned to documents pertalning to the engineering disciplines; the administrative listing designator, 7 , is assigned to documents pertaining to administratiye functions; the environmental listing designator, 8 , is assigned to environmental documents other than the Environmental Report; and the construction designator, 9, is assigned to all construction department documents.
\end{abstract}

\subsubsection{THIRD ELEMENT - FILE SYSTEM DESIGNATOR}

The third element is a single letter that indicates the particular file system to which the document is assigned. The letters used as file system designators are shown in Figure $\mathrm{C} 3-1$, and the file systems are described in Paragraph 3.5 .

\subsubsection{FOURTH ELEMENT - CATEGORY DESIGNATOR}

The fourth element may consist of a single letter, a two-digit number, or a three-digit number, and may indicate either a main category heading within a file system or a numericäl sequence, (See Figure C3-1).

\subsubsection{FIFTH ELEMENT - SUBCATEGORY DESIGNATOR}

The fifth element may be either a twordigit number, a decimal number, or a single letter (Figure C3-1) and may identify the subcategory of a file sys tem (such as Individual file holders, etc.), or a numerical sequence.

\section{NOTE}

A fifth designator is not required in all file systems. 


\subsection{FILE SYSTEMS}

The file system to which a document is assigned is identiffed by the third element of the file number, Refer to Paragraph $3,4.3$, and see Figure $\mathrm{C3}^{-1}$,

NOTE

One copy of all attachments to any project

correspondence shall be maintained in the subject

file or in the specification/purchase order file. One copy of the transmittal letter only is filed in the master chron file. (Refer to Part B, Section 4 of this manual).

\subsubsection{SPECIFICATION/PURCHASE ORDER (SPEC/P.0.) FILE SYSTEM}

The spec/P.O. file system contains specifications, requisitions, purchase orders, and related documents. These files are reserved for only those materials developed subsequent to the completion of the specification inhouse reviews (but including the document review notices for these reviews). Documentation developed prior to this time normally is flled in appropriate subject files. However, if the appropriate files do not exist, the material may be retained in the spec/P.0. file system. The file systems and designators for the spec/P.0. files are listed in Attachments A through FA. The spec/P.O. file system listed in these attachments is the master list for the project spec/P.0. files. Entries in these lists that are marked "DELETED" cannot be reused, and do not appear on the specification control log. When an entry. is transferred to a different file number on the list, the contents of the corresponding original tile are transteried accordingly. The original file is retained with a cross-reference to the different file number.

The cross-filing of any technical data from the spec/P.0. files to the subject file system may be accomplished by a responsible EGS, who must then notify the project administrator of such action. All cost data is to remain in the $\mathrm{spec} / \mathrm{P} .0$, file system.

NOTE

Part C, Section 8 of this manual contains an explanation of the specification, purchase memorandum, and requisition numbering systems, the specification control $10 \mathrm{~g}$, and the ir relationship to Georgia Power Company purchase orders.

A requisition is assigned the same file number as its corresponding specification, except for a prefix identifying the applicable plant unit (Paragraph 3.4.1) and a "dash letter" added to the file number to Indicate when there is more than one vendor. The dash letter "-A" designates the second vendor, " $-B$ " the third vendor, etc. 
Georgia Power Company purchase orders do.not incorporate the specification number. The requistition number, therefore, is shown on the purchase order to provide traceability for purchase-order-related operations,

The spec/P.0, file system is maintained by the profect secretary. The files are arranged by discipline, with documents filed numerically in folders which include the specification title, Requisttion/P.0,-related documents are filed in the spec/P.0. file in folders with the requisition number and title. Within each folder are four separate folders, one corresponding to each plant unit. Documents applicable to more than one unit are duplicated and filed in the appropriate unit folders.

\subsubsection{SUBJECT FILE SYSTEMS}

Documents containing general information or technical data that are related to a subject or to a project system, and which are not considered as spec/ P.0.-related items, are placed in a subject file, Several such subject file systems are established for this purpose: one for each of the six engineering disciplines, another for the purely administrative file documents, and a third for subject file extensions of the administrative file, which is described in Paragraph 3.5.5. The subject file systems and designators are identified in Attachments $G$ through $N$, and in Attachment $V$.

Technical data from the spec/P.0. files may, at the discretion of the EGS's, be cross-filed to an approprlate segment of the subject file system. Such action must always be brought to the attention of the project administrator.

The subject file systems are maintained by the project secretary. Individual file folders are provided for each listing of Attachments $G$ through $\mathrm{N}$, and Attachment $\mathrm{V}$, with the documents filed in chronological order within the folders.

\subsubsection{DESIGN CALCULATION FILE SYSTEM}

The design calculation file system is described in Part C, Section 9 of this manual.

\subsubsection{BECHTEL DRAWING FILE SYSTEM}

The file system for Bechtel drawings is maintalned by the drawing and data control section, using the drawing number system described in Part C, Section 4 of this manual.

\subsubsection{AUXILIARY ADMTNISTRATIVE RILE SYSTEMS}

The PSAR, FSAR, ER, destgn manual, and scope change ftle systems are classified as admintstrative ftles, and are malntalned by the project adminlstrator/project secretary.

$$
\text { C3-6 }
$$




\section{5,5.1 PSAR, FSAR, and ER. File Systems}

The file numbers listed in Attachments $P$ through $T$ are used in identifying documentation pextaining to the PSAR, FSAR, and ER, The fourth and fifth elements of these file numbers, separated by a decimal point, designate the section and prime paragraph in the section, respectively. For example, file number X7MOI.1 corresponds to section 1, paragraph 1 of the PSAR.

Documents relating to an appendix of any of these regulatory reports are assigned a single-letter fifth element instead of the decimal point and number, e.g., X7M01A, X7M01B, etc.

File numbers assigned to amendment-related material have a two-digit dash number added to the file number of the PSAR, FSAR, or ER file system "General" subcategory. The dash number corresponds to the amendment number. Thus, correspondence regarding amendment 1 is identified with file number X7M00.0-1.

The PSAR and FSAR file systems for the AEC old format, although void and replaced, are included for reference in Attachments $Q$ and $S$.

\subsubsection{Design Control File System}

The design control file system is maintained by the project administrator/ project secretary to control and file all documentation relating to design contro1, which includes Section II, Design Criteria, VNP Design Manual. Both Section II of the Design Manual and the file system are divided into two categories: general.plant criterla and system design criteria.

The material retained in the general plant criteria file is divided into two subcategories. The first contains documents that concern single engineering disciplines, with the file number of each item being X7J1000, followed by a "dash letter" to designate the related discipline. The second contains documents that concern more than one discipline (interdiscipline data), and these are assigned file numbers:in the X7J1001 through X7J1099 block.

System design criteria file numbers consist of $X 7 \mathrm{~J}$ plus an assigned four digit number (X7J1100 and subsequent). The first two digits of this number represent major system areas, whereas the last two digits identify individual systems within the corresponding major system area. These fouradigit numbers relate to those used in the plant tag numbering system. (Refer to Part C, Section 7 of this manual.) The general plant criteria and the system design criteria file numbers are listed in Attachment $U$,

Documents that aure kept in the design control files consist of the following: Individual design review cover sheets; for each of the five design phases (these include revision A - intitial copy, revision B - issue that incorporates comments from review of initial copy, revistion 0 - final copy with resolutions); the document review notices (DRN's) that accompany the revie' cover sheets (less the attachments); approved $\mathrm{Q}$-lists by system; and all correspondence pertaining to related design criteria matertal.

$$
\text { C3-7 }
$$




\section{5,5.3 Scope Change File System}

The scope change file number does not use the fourth and ftfth elements as category and subcategory designators. Instead, only a fourth element is used, and it is a three-digit number (001-299). whtch Indicates the consecutive numbers of the scope changes, For example, a scope change number could be X7K207. The scope change f1le systen is maintained by the profect administrator.

\subsubsection{DOCUMENT REVIEW NOTICE (DRN) CONTROL AND FILE SYSTEM}

Document review notices, which the project administrator distributes for review and approval of in-house documents, are recorded in the DRN control log. This control log, maintained by the project administrator, has entrles consisting of a DRN log number, the file number and title of the related document, and the DRN 1ssue and return due dates. At the conclusion of each review, the completed DRN!s are placed in their respective files. Those for specifications are kept in the spec/P.0. file; DRN's for Project Reference Manual. (PRM) documents go into a file maintained by the project administrator; and the DRN's for design criteria (with the attached material) are also kept in a file maintained by the project administrator. All DRN's for the PRM are discarded one month after the document has been published and issued (or later at the discretion of the project manager or project administrator). Each design criteria DRN shall remaln in the files for 90 days following the acceptance of the corresponding design review/resolution form At that time, disposition of the DRN (wIth the attached material) shall be determined. by the project

englneer.

The DRN $\log$ number is composed of five elements, and consists of the following designators: $X$ - indicates project; two-digit number (01-19) - identifies originating discipline/type of document (from list in DRN control $10 g$ ); L - Identifies file system designation; three-digit number (001-999) corresponds to sequentlal DRN number within.its category; two-digit number (01-99) - corresponds to. revision of related document. The fourth and fifth elements are separated by dashes.

\subsubsection{GEORGIA POWER CONSTRUCTION DRAWINGS FILE SYSTEM}

The file system for Georgla Power Company construction drawings is maintained by the drawing and data control group.

\subsubsection{ENGINERRING STUDY FILE SYSTEM}

The englneering study file system Is described In Part $C_{2}$. Section 12 of this manual. 


\section{3,6 MASTER CHRON LOG AND FILE}

The master chron log (MCL) is a record of incoming and outgoing project documents listed chronologically, and maintained by the project administrator. A master chron file (MCF), kept by the project secretary, contains a copy of each document listed on the MCL except drawing change notices, calculations, estimates, meeting notes, conference notes, and studies, which are filed in individual administrative files. The MCL and MCF are described in Part B, Section 4 of this manual. 
VNP PROJECT REFERENCE MANUAL REV 5 DATE $10-11-74$

\section{CIVIL-STRUCTURAL SPEC/P,Q, FILE SYSTEM}

A. SITE DEVELOPMENT CATEGQRY.

$\begin{aligned} \text { X2AA01 } & \text { Site Survey } \\ 02 & \text { Subsurface Exploration and Laboratory Testing } \\ 03 & \text { Furnishing and Construction of Onste Rallroad } \\ 04 & \text { Fencing and Gates } \\ 05 & \text { Furnishing and Construction of Offsite Railroad } \\ 06 & \text { Asphalt Paving of Roads, Walks, and Parking Areas } \\ 07 & \text { Finish Grading }\end{aligned}$

B. EARTHWORK CATEGORY

$\mathrm{X} 2 \mathrm{AB} 01$ Site Preparation and Earthwork

02 Furnish and Install Storm Sewers

C. UTILITY SYSTEMS CATEGORY

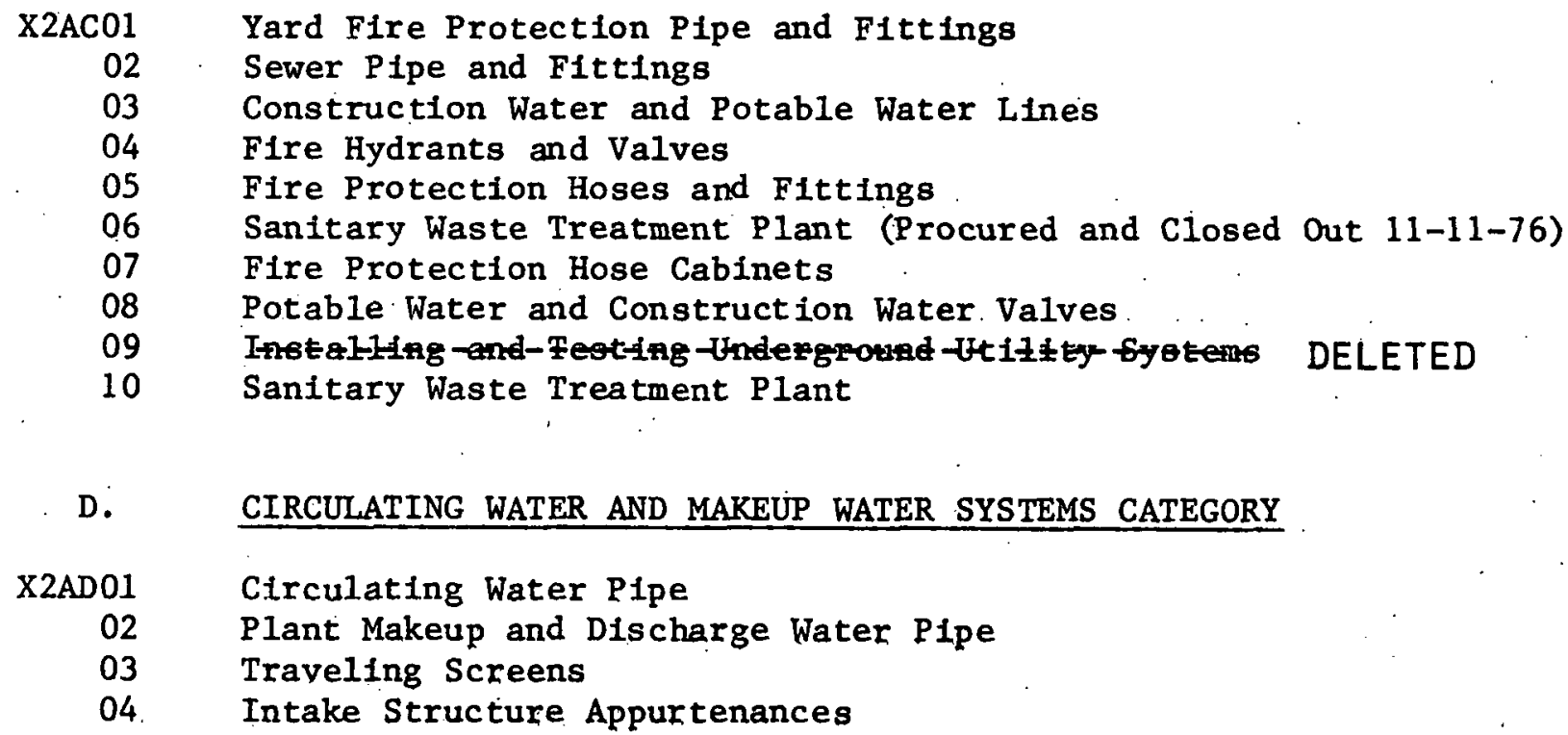

Attachment B. Civ1l-Structural Spec/P,0, P1le System (1 of 5) 


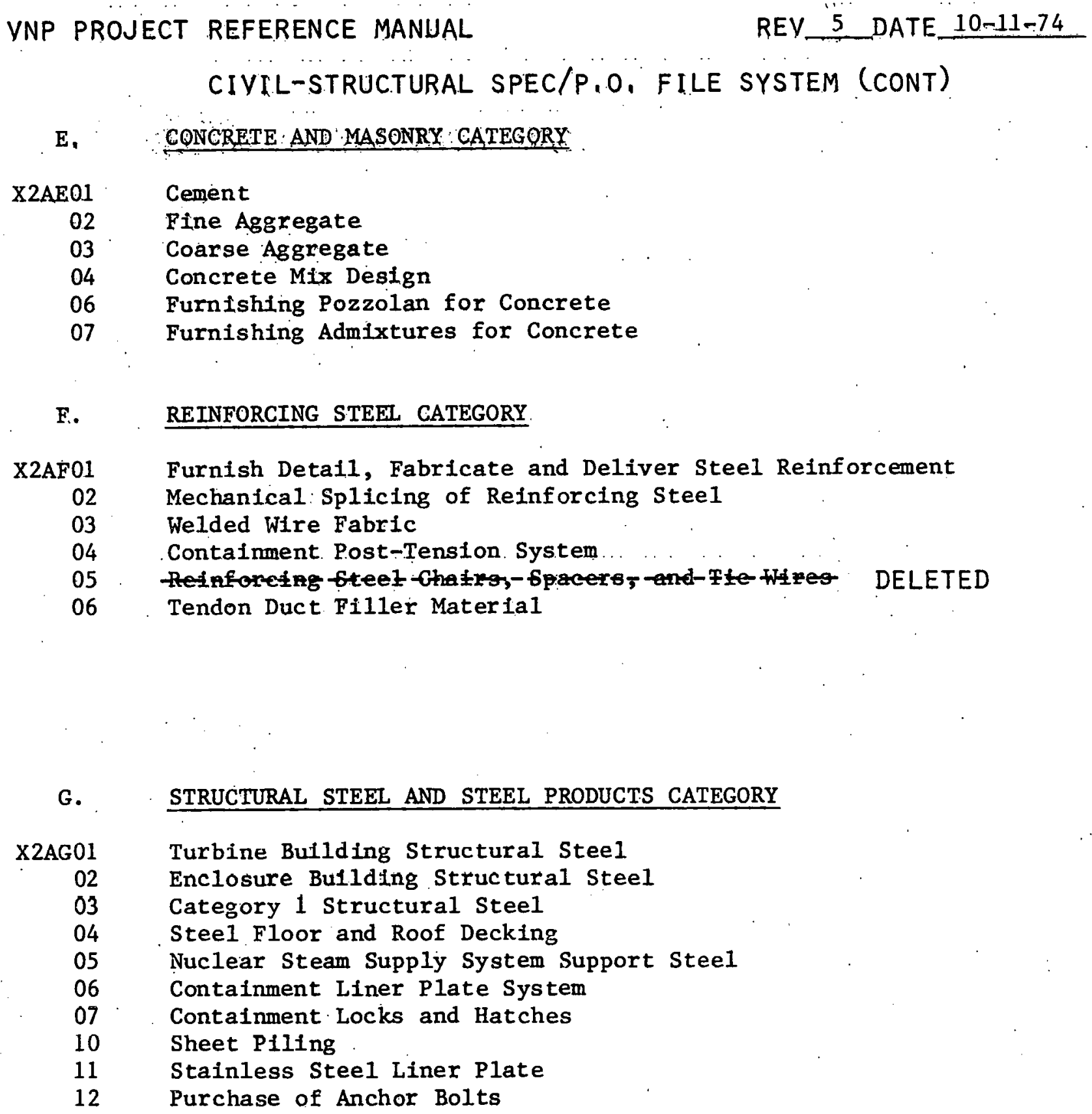

G. STRUCTURAL STEEL AND STEEL PRODUCTS CATEGORY

Attachment B. Civ11-Structural Spec/P,0. File System (2 of 5) 
VNP PROJECT REFERENCE MANUAL

REY 5 DATE $10-11-74$

CIVIL-STRUCTURAL SPEC/P,O, FILE SYSTEM (CONT)

H. MISCELLANEOUS METAL AND EMBEDDED ITEMS CATEGORY

X2AH01 Miscellaneous Category 1.Steel

02 Platforms, Gratings Handrails

03 Catch Basin Frame and Gratings, Manhole Cover and Frames

04 Miscellaneous Category 2 Steel

05 Turbine Pedestal Leveling Studs

06 Equipment Anchor Bolts

07 Miscellaneous Stalnless Steel

08 Fuel Transfer Tube Housing Expansion Bellows

10 Lead Shielding

11 Miscellaneous Grating

12 Miscellaneous Handrails

13 Fuel Pool Gates

14. New and Spent Fuel Storage Racks

J. MISCELLANEOUS NON-METAL PRODUCTS CATEGORY

X2Aj02 Expansion Joint F1ller and Sealer

03 Slide Bearings

04 Chemical Waterproofing

06 Water Stops

K. WELLS CATEGORY

X2AK01 Class 1 Test Water Well

02 Makeup Water We1ls

03 Standby Nuclear Seryice Makeup Pumps and We11s

Attachment B. Civil-Structural Spec/P,O. File System (3 of 5)

C3-19 
L, MARINE FACILITIES CATEGORY

X2AL01 Boat House

M. GRANES ANB \#OHSTS-GAFGGORY-- DELETED (TRANSFERRED TO

X2AM01 Gontainent,folar-Grare DEL, SYCHANICAL

02 Tumbe- Bidge-Grane-- DELETED

03 -Spent-Fuez-Gast-Bridge-Grane DELETED

04 Miseel-eow 6 an DELTED

05 Mreel Heots DELTED

N. MISCELLANEOUS SERVICES CATEGORY

$\mathrm{X} 2 \mathrm{AN} 01$ Unloading and Installing Heavy Equipment

02 Concrete Testing Laboratory Service

03 Steel Testing Laboratory Services

04 Special Concrete Chemical and Property Testing

05. Special Testing

06 Aerial Photography

07 Instrumentation for Heave and Settlement Measurements

08 Obtaining and Recording Foundation Settlement Data Survey

Attachment B, Civil-Structural Spec/P,O, File System (4 of 5)

$$
\text { C } 3-20
$$


VNP PROJECT. REFERENCE MANUAL

REY 3 DATE $1-7-74$

CIVIL-STRUCTURAL SPEC/P,O. FILE SYSTEM (CONT)

P. CIVIL-STRUCTURAL CONSTRUCTION AND ERECTION CONTRACTS CATEGORY:

X2AP01 Construction Specification for C1y 1 1-Structura1 Work Forming, Placting, Finlshing, and Curing Concrete Placing of Reinforcing steel

Erection of Structural Steel

Erecting Miscellaneous Metal.

Erecting Piping

Installation of Watexproofing Material and Water Stops

Installation of Corrugative Metal Piping

Installation of Trumpet Assembly

Attachment B. Civil-Structural Spec/P.0, Ftle System (5 of 5) 
VNP PROJECT REFERENCE MANUAL

CIVIL-STRUCTURAL SUBJECT FILE SYSTEM

\author{
A. SITE DEVELOPMENT \\ X2BA01 Site Enyiroment, General \\ 02 Setismology, General \\ 03 Geology, General \\ 04 Hydrology, General \\ 05 Meteorology, General \\ 06 Sol1 and Foundation Investigation \\ 07 Topography \\ 08 Foundation settlements \\ 09 Soils Report
}

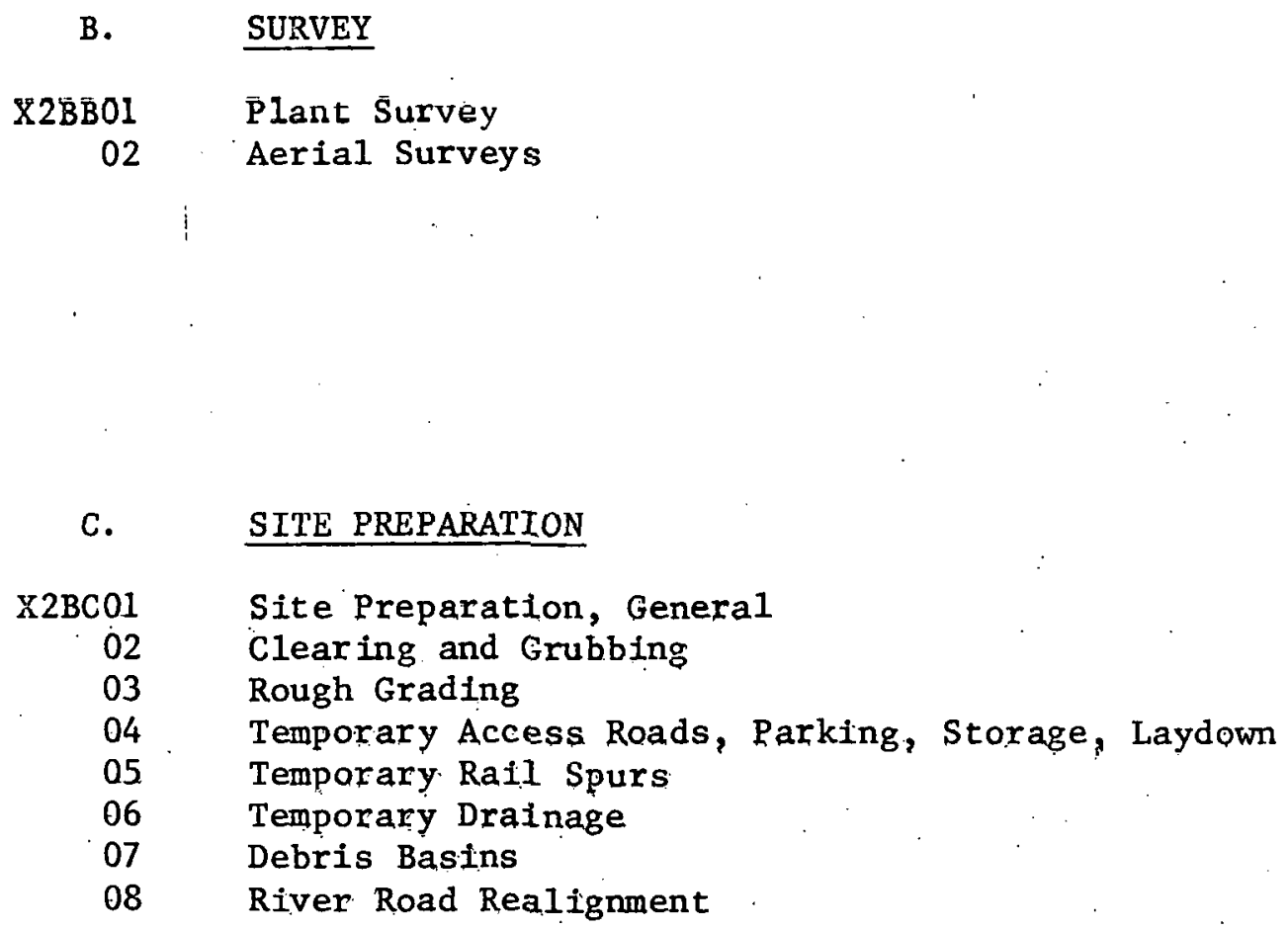

B. SURVEY

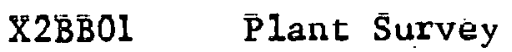

02 Aerial Surveys

C. SITE PREPARATION

X2BC01 Site Preparation, General

02 clearing and Grubbing

03 Rough Grading

04 Temporary Access Roads, Parking, Storage, Laydown

05. Temparary Rail Spurs

06 Temporary Drainage

07 Debris Basins

08 River Road Realignment

Attachment H. Civil-Structural Subject File System ( 1 of 7 ).

$$
\text { C3-55 }
$$$$
\text { G-18 }
$$ 


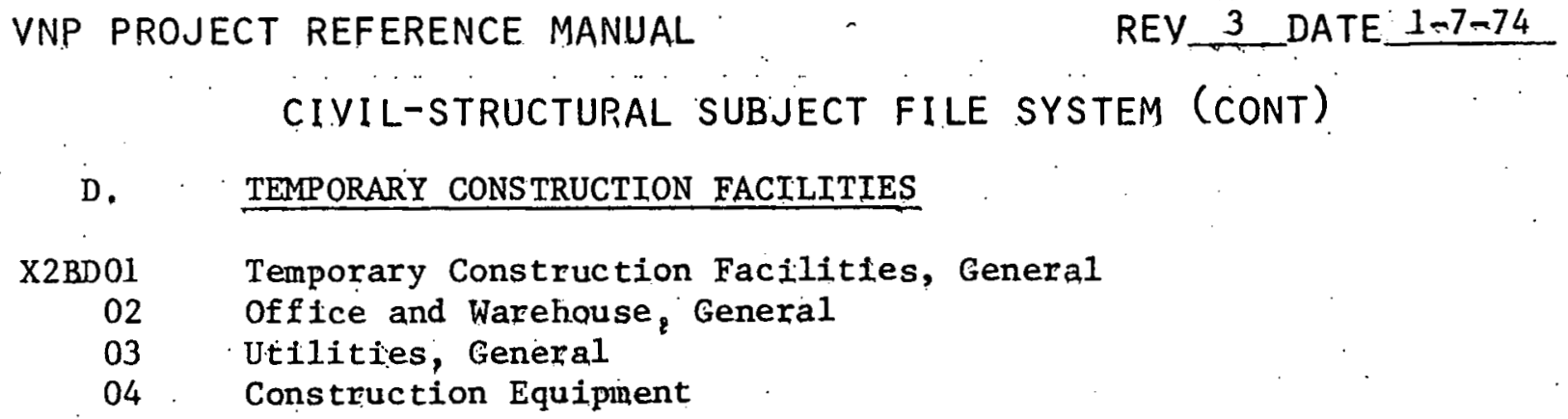

E. SITE DEVELOPMENT (Permanent)

X2BE01 Site Development, General (Planning and P1ant Arrangement)

02 Earthwork and Backfill

03 Drainage and Storm Drain System

04 Finish Grading and Paving

05. Roads, Parking, Storage

06 Rail Spurs

07 Perimeter Fencing and Enclosures

$08 \cdot \quad$ Dewatering

\begin{aligned} \multicolumn{1}{c}{ F. } & YARD UTILITY SYSTEMS (Permanent) \\ X2BF01 & Yard Utility Sys tems (Permanent), General \\ 02 & Water Supply System \\ 03 & Ons1te Water Well \\ 04 & Fire Protection Sys tem \\ 05 & Sanitary System \\ 06 & Plant Effluent System \\ 07 & Outfatz-Struetufe- Changed to X2BL07 \end{aligned}

Attachment H, Civil-Structural Subject File System (2 of 7) : 


\section{CIVIL-STRUCTURAL SUBJECT FILE SYSTEM (CONT).}

\begin{aligned} \multicolumn{1}{r|}{ G. } & $\frac{\text { COOLING WATER SYSTEMS }}{\vdots} \\$ X2BG01 & Cooling Water Systems, General \\ 02 & Makeup Water System \\ 03 & River Intake Structure \\ 04 & Circulating Water System \\ 05 & Nuclear Service Cooling Water System \\ 06 & Natural Draft Cooling Towers \\ 07 & Nuclear Service Cooling Water Cooling Towers \end{aligned}

H. TURBAINE B̈UILDING

X2BH01 Turbine Building, General

02 Turbine Building Foundations (Concrete)

03 Turbine Building Superstructure (Stee1, Concrete, Concrete Block)

04 Turbine Pedesta1 (Concrete)

05 Equipment Foundations (Steel and Concrete)

06 Equipment Design Data

07 Turbine Generator Data

08 Auxiliary Turbine and Pump Data

09 Feedwater Heater Data

10 Condenser Data

J. CONTAIMMENT AND INTERIOR STRUCTURE

X2BJ01 Containment and Interior Structure, General

02 Liner Plate

03 Post-Tensioning System

04 . NSS System Supports

05 Containment Pressure Tests

06 Special Testing

07 Enclosure Building

08 Pipe Restraints and Pipe Whip Criterla

09 . Penetrations Design

10. NSSS Loading - Westinghouse

Attachment H. Civil-Structural Subject File System (3 of 7).

$$
\text { C3-57 }
$$




\section{CIVIL-STRUCTURAL SUBJECT FILE SYSTEM (CONT)}

J. CONTAINMENT AND INTERIOR STRUCTURE (CONT)

$\begin{aligned} \text { X2BJ11 } & \text { Reactor Supports } \\ 12 & \text { Containment Design Pressure } \\ 13 & \text { Containment Subcompartment Design Pressure } \\ 14 & \text { Reactor Cavity Design }\end{aligned}$

K. AUXILIARY BUILDINGS

$\begin{aligned} \text { X2BK01 } & \text { Auxiliary Building, General } \\ 02 & \text { Fuel Handling Building } \\ 03 & \text { Stainless Steel. Liner Plate System } \\ 04 & \text { Spent Fuel Storage Racks } \\ 05 & \text { New Fuel Storage Racks } \\ 06 & \text { New Fuel Elevator } \\ 07 & \text { Fue1 Transfer Sys tem } \\ 08 & \text { Fuel Handling Crane } \\ 09 & \text { Radwaste Facilities } \\ 10 & \text { Cask Handling Bridge Crane } \\ 11 & \text { Control Building, General } \\ 12 & \text { Fuel Handling Building, General }\end{aligned}$

L. YARD STRUCTURES

$\begin{aligned} \text { X2BL01. } & \text { Yard Structures, General } \\ 02 & \text { Transformer Area Foundations } \\ 03 . & \text { Electrical Structures } \\ 04 & \text { Yard Equipment Foundations } \\ 05 & \text { Yard Manholes } \\ 06 & \text { Barge Facilities } \\ 07 & \text { Outfall Structure } \\ 08 & \text { Tank Foundations } \\ 09 & \text { Condensate Storagc Tanke } \\ 10 & \text { Reactor Makeup Storage Tanks } \\ 11 & \text { Refueling Storage Tanks } \\ 12 & \text { Miscellaneous Tanks } \\ 13 & \text { Lube Oil Storage Tanks }\end{aligned}$

Attachment H. Civil-Structural Subject File System (4 of 7)

$$
\text { C3-58 }
$$


VNP PROJECT REFERENCE MANUAL

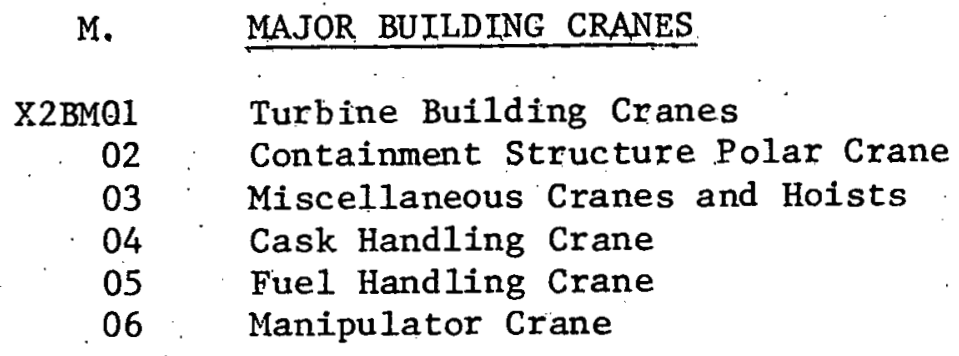

N. SUPPORT BUILDINGS

X2BNO1 Administration and Service Building

02 Warehouse I

03 Warehouse II

04 Guard House

P.. $\quad$ CONSTRUCTION MATERIALS

$\begin{aligned} \text { X2BP01 } & \text { Aggregate } \\ 02 . & \text { Concrete } \\ 03 & \text { Reinforcing Steel } \\ 04 & \text { Structural Steel } \\ 05 & \text { Miscellaneous Steel } \\ 06 & \text { Corrosion Contro1 } \\ 07 & \text { Structural Steel Siding } \\ 08 & \text { Waterproofing } \\ 09 & \text { Steel Decking } \\ 10 & \text { Precast Concrete } \\ 11 & \text { Concrete Block } \\ 12 & \text { Coatings }\end{aligned}$

Attachment H. Civil-Structural Subject File System (5 of 7)

$$
\text { C3-59 }
$$


Q. CIYIL STRUCTURAL SECTION-GENERAL

X2BQ01 Corps of Engineers Permit Data

02 . Design Criteria, General

03 Tornado Data

04 BC-TOP 3-Task Group

05 Heavy Equipment Erection

06 Specifications

$07 \quad$ Electrical Cable Supports

08 Mechanical Pipe Supports and Restraints

09 Layouts and General Arrangement

10 Engineering Interface Schedule and Coordination

R. ENGINEERING STUDIES

X2BR01 Embedded Structures Seismic Analysis

02 Turbine Missile Study

03 Reactor Vessel Supports Study

04 Turbine Missile Shield

S. MISCELLANEOUS CATEGORY 1 STRUCTURES

X2BS01 Diesel-Generator Building

02 Auxiliary Feedwater Pump House

03 Nuclear Service Cooling Water Towers

04 Tanks

05 Pipe Tunnels

0.6 Nuclear Service Cooling Water Standby Makeup Wells

07 Underground Electrical Ducts

08 Diesel Fue1 0i1 Storage Tank. Pump House

Attachment H. Civil-Structural Subject File System (6 of 7)

$$
c 3-60
$$




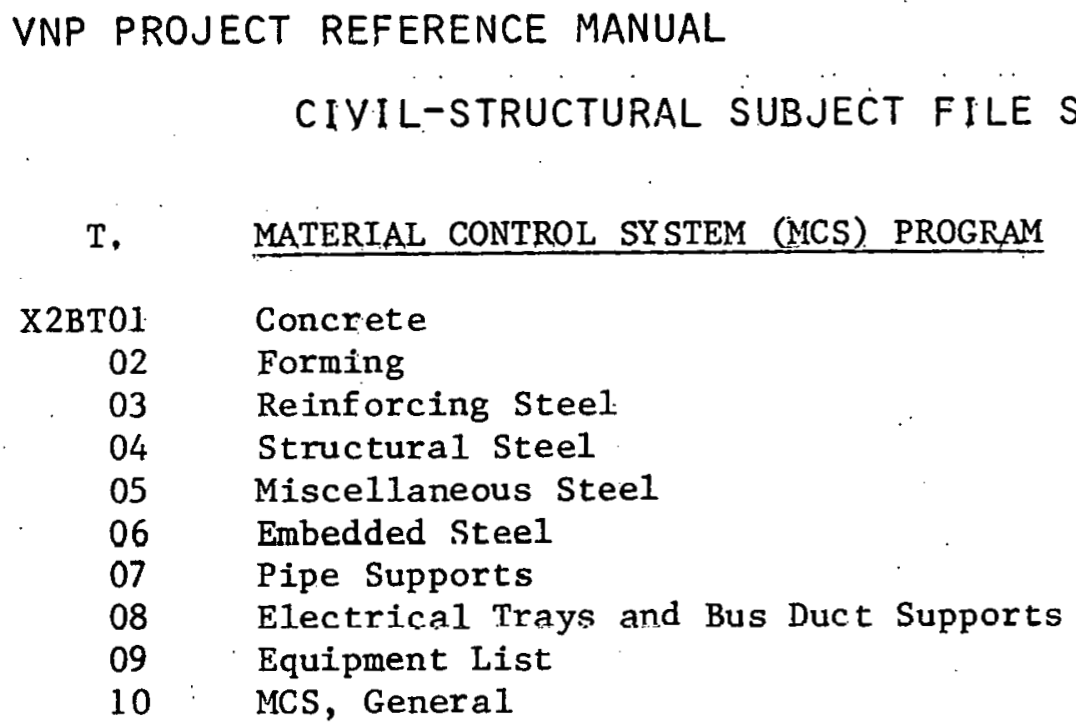

U. DISCIPLINE ADMINISTRATION

$\begin{aligned} \text { X2BU01 } & \text { Man-Hour Budgets } \\ 02 & \text { Consultant Costs } \\ 03 & \text { Computer Costs } \\ 04 & \text { Manpower Schedules } \\ 05 & \text { Time Charges } \\ 06 & \text { Schedules - General } \\ 07 & \text { EsLlmates } \\ 08 & \text { CEBUS } \\ 09 & \text { Scope Changes and Trends } \\ & \\ 11 & \text { SCSI Coordination }\end{aligned}$

V. GPC CONSTRUCTION

X2BV01 Genera1

02 Temporary

03 Bechtel Construction

04 Georgia Power Construction

05 Thermal Power Organization

Attachment. H. Civil-Structural Subject File System (7 of 7)

$$
\text { C3-61/62 }
$$



INFORMATION MANAGEMENT FOR

NUCLEAR POWER STATIONS

APPENDIX C 
TABLE OF CONTENTS

$\underline{\text { Page }}$

CHAPTER I: Purpose, Approach, and Definitions

1.1. Purpose and Approach ..................... 1

1.2 Material Installation Characteristics $\ldots \ldots \ldots \ldots \ldots \ldots . . \ldots 3$

1.3 Component Information ..................... 7

1.4 Methodology for Defining Information Flow .......... 10

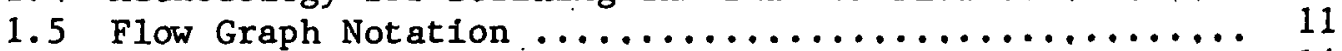

1.6 Mechanical Material Installation Cycles ............ 14

1.6.1 Mechanical - Bulk materials ............... 15

1.6.2 Mechanical - Small components ............. 21

1.6.3 Mechanical - Large components ............. 23

1.7 Civil Material Installation Cycles ............. 25

1.7.1 Civil - Bulk materials ................. 25

1.7.2 Civil - Small components ............... 28

1.7.3 Civil - Large components .............. 31

1.8 Electrical Material Installation Cycles .......... 33

1.8.1 Electrical - Bulk materials .............. 33

1.8.2 Electrical - Small components ............ 35

1.8.3 Electrical - Large components ............. 37

1.9 Methods Engineering ...................... 41

CHAPTER II: Existing and Projected Systems

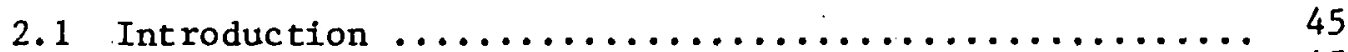

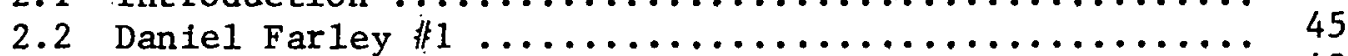

2.2.1 Mechanical Equipment/Piping/Instrumentation ... 48

2.2.2 Heat Number Cross Reference Program ......... 50

2.2.3 Electrical Status Programs ................ 51

2.2 .4 Non-Conformance Reports ................ 51

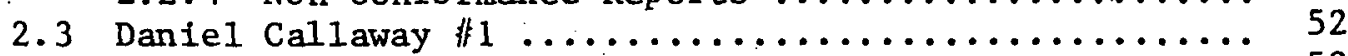

2.3.1 Piping and Related Component Control System ... 52

2.3.2 Electrical Installation System ........... 57

2.4. Danie1 Fermi $\left.\right|_{2} \ldots \ldots \ldots \ldots \ldots \ldots \ldots \ldots \ldots \ldots \ldots \ldots \ldots \ldots . \ldots \ldots$

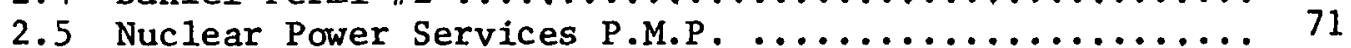

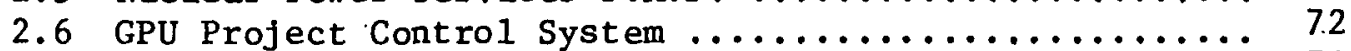

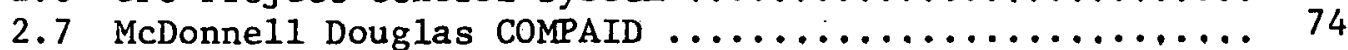

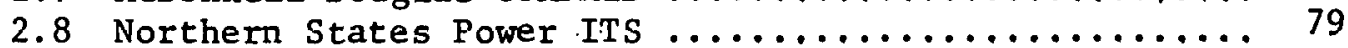

2.9 Bechtel QTS (Quantity Tracking System) ........... 81

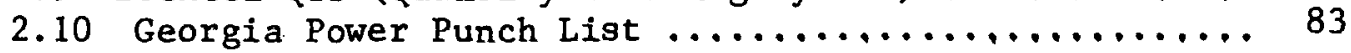

CHAPTER III: Problems with Existing Systems $\ldots \ldots \ldots \ldots \ldots \ldots \ldots 85$ 
REFERENCES $\ldots$

ADDENDUM A:

BULK PIPE MATERIAL INPUT/OUTPUT DATA

ADDENDUM B :

MECHANICAL (SMALL COMPONENT) INPUT/OUTPUT DATA

ADDENDUM C :

MTCIIANICAL (LARGE CONFONENT) INIUT/OUTRUT DATA

ADDENDUM D:

CIVIL (BULK MATERIAL) INPUT/OUTPUT DATA

AUVENNUM E':

CIVIL (SMALL COMPONENT) INPUT/OUTPUT DATA

ADDENDUM F :

CIVIL (LARGE COMPONENT) INPUT/OUTPUT DATA

ADDENDUM G:

ELECTRICAL (BULK MATERIAL) INPUT/OUTPUT DATA

ADDENDUM H :

ELECTRICAL (SMALL COMPONENT) INPUT/OUTPUT DATA

ADDENDUM I:

ELECTRICAL (LARGE COMPONENT) INPUT/OUTPUT DATA

ADDENDUM J :

APPLICATION AREA OUTLINES

METHODS ENGINEERING 
CHAPTER I

\section{Field Construction Control}

Purpose, Approach, and Definitions

\subsection{Purpose and Approach}

The objective of all construction activity is to realize a finished facility at the selected site through the placement of material by labor and equipment resources. The process by means of which materials and components are defined during the engineering phase, procured, and moved to a storage location at the project site has been developed in Appendix B. Field control is concerned with the activities required for the issuance and movement of these materials from the warehouse, laydown area, or storage location to the installation location. Further, it encompasses methods of installation and procedures for turn-over to the accepting start-up team. The material cycle illustrating the interface between Material Tracking and Field Control activities is shown in Figure 1.1.

This process is the backbone of information for all control functions. All information processing requirements interface with this material path. Depending upon the type of material, the individual functions occurring along the material cycle vary. Therefore, two types of functions can be identified: (1) those which are common to all material cycles, and (2) those which are unique to the cycle of a given class of material. For instance, preparation of a requisition and the inherent "take-off" procedure to develop quantities are functions which are common 


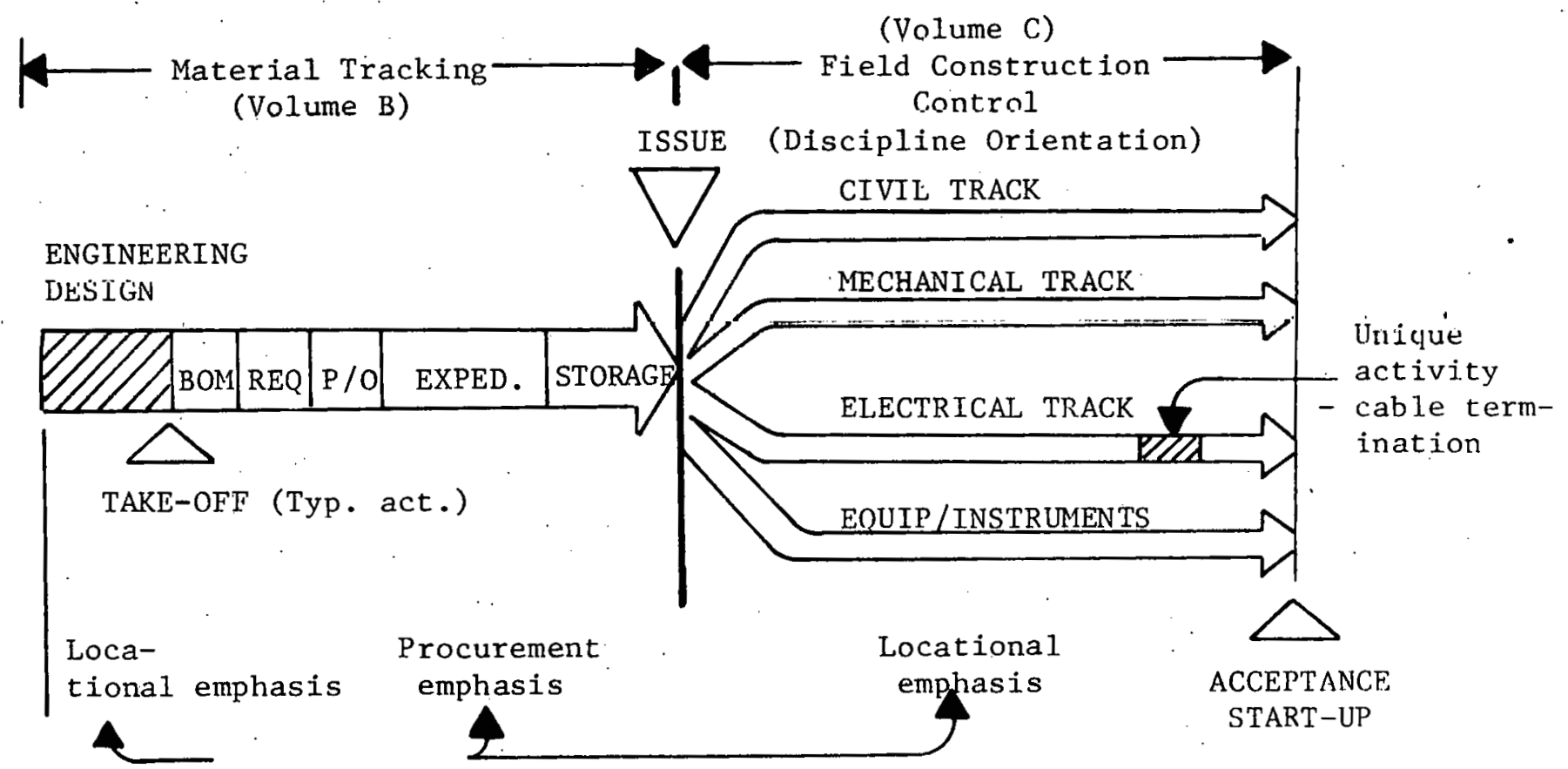

FIGURE 1.1: TOTAL MATERIAL GYCIE

to all material cycles. The cataloging of electrical terminations is unique to the installation of electrical components. Therefore, materials have a discipline orientation which must be considered. - Functions which relate to the definition and movement of materials and components through procurement to project site storage locations are the province of Material Tracking (Appendix B). Functions which relate to the issuance, movement, installation, and acceptance of materials and components during the construction process will be considered Field Construction Control Activities (Appendix C). 
By examining the material cycles of major componenc classes, the basic material cycles for each discipline will be defined. The major disciplines, (1) Civi1, (2) Mechanical, and (3) Electrical, each have component delivery characteristics which set them apart. Within each discipline, material and component class lead to varying installation characteristics. Therefore, within a discipline several installation cycles are possible. The report defines the individual Construction Control cycles for each material class starting with issuance from the warehouse and continuing through acceptance and start-up. The individual modules in each construction cycle will be identified and critical data fed to and generated by each of these functional modules will be developed.

\subsection{Material Installation Characteristics}

Once an item is issued from site storage, the installation activities which are required to install, check, and turn it over (as an end-item or part of a system) vary based on the material type and class. The single track depicted in Figure 1.1 for the material procurement and tracking activity diverges into discipline tracks depending upon the type of material and its placement technology. The four tracks which characterize the installation technology and skills required are:
(1) Civil
(2) Mechanica1
(3) Electrical
(4) Equipment/Instrumentation 
Within these discipline tracks, the delivery activities vary according to the configuration in which the material arrives at the site and is stored. The delivery activities associated with the processing and installation of cement and aggregate differ from those required for the installation of steel ladders, staircases, and grills. Although these materials are considered as civil discipline items for installation, they require differing installation technologies. Similarly, the sequence of tasks involved in installing a switch box differs from those required for cutting and pulling cable. Moreover, some materials are transformed into new configurations by virtue of the processing they undergo to realize construction. They are mixed, bent, cut, stripped, pulled, welded, or processed in some way which causes them to be transformed. Such materials are usually procured and stored on the site in bulk quantities and are transformed by a construction technology at the site. 'l'hese materials are normally referred to as bulk materials. In the remainder of this report, materials which are procured in. bulk quantities and are transformed physically at the construction site will be referred to as bulk materials. Some 1tems are procured in relatively large numbers, but rather than being transformed physically they are installed to become part of a larger system. Such items as small switches and lighting fixtures are good examples of this material class. These items can be thought . of as components since they arrive at the site in an essentially finished configuration ready for installation. The physical 
transformation associated with their installation is minimal. They will be referred to as small components.

The third class of materials within each of the disciplines which exhibits special delivery characteristics consists of relatively large sub-assemblies or systems which have been prefabricated in varying degrees by a vendor at an off-site location. These items arrive at the site ready for installation. Items such as pumps, compressors, transformers, prefabricated or structural steel, and building cladding are typical of this category. These items will be considered large components. Table 1.1 gives a break-out by discipline and materia1 class of some typical items which generate data structures and must be controlled on the site during construction.

The installation cycles associated with bulk material always include a set of tasks which transform the physical configuration of the material. Component cycles (for both large and small components) do not include this transformation sequence. Large components such as heat exchangers, large prefabricated spools, and reactor vessels are in some cases assembled at the site. These are not bulk items, however, and therefore retain the classification of large components in this breakdown. Reinforcing steel can be considered a bulk item or a component. If the steel is configured to a major degree (i.e., bent or cut) at the site, it will be considered a bulk 1tem. Reinforcing steel delivered to the site pre-bent and ready for installation will be classed as a small component. The same rationale applies to 


\section{COMPONENTS/DISCIPLINES}

\begin{tabular}{|c|c|c|c|c|}
\hline $\begin{array}{l}\text { CRITICAL ITEM } \\
\text { (INPUT FORM) }\end{array}$ & CIVIL & MECHANICAL & ELECTRICAL & INSTRUMENT *3. \\
\hline $\begin{array}{l}\text { BULK } \\
\text { (TRANSFORMED) }\end{array}$ & $\begin{array}{l}\text { CEMENT } \\
\text { AGGREGATE } \\
\text { RESTEEL } \\
\text { BACKFILL }\end{array}$ & $\begin{array}{l}\text { SHEET METAL } \\
\text { PIPE } \\
\text { WELDING ROD } \\
\text { INSULATION }\end{array}$ & CABLE & \\
\hline $\begin{array}{l}\text { *SMALL COMPONENTS } \\
\text { (INSTALLED IN } \\
\text { LARGER SYSTEM) }\end{array}$ & $\begin{array}{l}\text { CADWELD } \\
\text { MASONRY } \\
\text { TENDONS } \\
\text { CONDUITS }\end{array}$ & $\begin{array}{l}\text { SCREENS } \\
\text { FILTER } \\
\text { SMALL VALVES } \\
\text { DUCTS (PREFAB) }\end{array}$ & $\begin{array}{l}\text { BOXES } \\
\text { SWITCHES } \\
\text { RACEWAYS } \\
\text { TERMINATION BOARDS }\end{array}$ & $\begin{array}{l}\text { INSTRUMENT } \\
\text { EXAMPLES : } \\
\text { SMALL FLOW } \\
\text { METERS }\end{array}$ \\
\hline $\begin{array}{l}\text { "LARGE COMPONENT } \\
\text { (INSTALLED) }\end{array}$ & $\begin{array}{l}\text { STRUC, } \\
\text { STEEL } \\
\text { STRUC. \& } \\
\text { MISC, } \\
\text { METALS. } \\
\text { LINERS } \\
\text { TILT-UP } \\
\text { PANELS }\end{array}$ & $\begin{array}{l}\text { LARGE SPOOLS } \\
\text { LARGE VALVES } \\
\text { PUMPS } \\
\text { COMPRESSORS } \\
\text { A/C UNI TS } \\
\text { SPECIALI IED } \\
\text { EQUIPMENT }\end{array}$ & $\begin{array}{l}\text { TRANSF.ORMER } \\
\text { MASTER SWITCHES } \\
\text { BREAKERS } \\
\text { RACEWAYS } \\
\text { GENERATORS } \\
\text { TURBINE-GENERATORS } \\
\text { EXCITOR MOTORS }\end{array}$ & $\begin{array}{l}\text { INSTRUMENT } \\
\text { EXAMPLES: } \\
\text { LARGE AUTOMATIC } \\
\text { CUT-OFF } \\
\text { SWITCHES }\end{array}$ \\
\hline
\end{tabular}

IN FINAL CONFIGURATION

FOR INSTALLATION

TABLE 1.1: TYPICAL MATERIALS BY DISCIPLINE AND DELIVER CLASS 
conduit, pipe, and other items of this variety. The point of fabrication will govern its class.

\subsection{Component Information}

A great deal of information is gathered on individual pieces or components. This component information will provide full identification of all the physical components that become a part of the permanent plant. The creation of this information would continue through all phases of the project evolution from preliminary design to operation and maintenance. An example of this evolution would be as follows for the mechanical discipline:

1) A11 process systems identified.

2) Ail equipment, instruments, and pipeline numbers identified within pressure boundaries on startup boundaries of process systems.

3) Complete listing of all componerits such as pipe fabrication spools, valves, supports, welds, instruments, and equipment within the established boundaries.

4) Al1 procurement, installation, quality control, acceptance, preoperational checkout, and operational information will be recorded against this component's list.

The objective will be to provide an accurate material take-off for use as follows:

1) Engineering procurement

2) Basis for estimating, cost control, planning and scheduling

3) Basis for construction craft supervision work planning 
4) Installation progress reporting

5) Tracking QC acceptance of work

6) Preoperation checkout

7) Operations surveillance, maintenance, spare parts listing

8) Permanent plant record

A second objective would be to reduce the redundancy that exists now in the traditional approaches, when most of the above stated groups originate their take-offs individually to support their purposes. The basis of the component information is a Bill of Material. To accomplish this a Bill of Material procedure has to be established and accurately adhered to. The B.O.M. has to be capable of exploding into lowest level subcomponent detail or cascading up to a summary level.

The B.o.M. Information is available to the field engineers for the following purposes:

Material Availability and Work Planning

The field engineer can review the current status of materials and determine what areas can be worked and direct the release of work packages :

\section{Work Package}

Ihis grouping of Information is referred to by. varlous names. such as "Traveler," "Work Order," "Construction Activity," or "Task Assignment." The Bill of Material allows a logical approach to the establishment of the work package. 


\section{Construction Department Technical Assistance}

Many questions are presented to field engineering relating to material specifications, delivery delays, specific problems concerning QC holds, etc. The field engineer can review the information to aid him in researching the questions.

Progress Monitoring

Various departments monitor the installation of components but the field engineer is responsible for directing and accepting the work as it progresses. The construction group and QC department will be recording the installation and acceptance of work in the system, allowing the field engineer to closely monitor progress for his area of responsibility.

The craft supervision can utilize the component information for the following purposes:

Work Availability

The construction department will be able to review the material availability or quality control to determine changed information.

Crew Task Assignment

Specific assignments can be made to the foreman by the use of the work package.

\section{Progress Monitoring}

The construction department will record the erection status of the component, allowing the craft supervision to monitor progress of the work package. 


\section{Crew Productivity}

The craft supervision can review actual charged manhours versus estimated manhours for each work package. Comparisons can be made of estimated productivity versus actual productivity.

\subsection{Methodology for Defining Information Flow}

Since the information structure which controls construction is ultimately tied to the information structure of individual materials, development of required information input and output is tied to the individual events and activities in a given material item's life cycle. That is, information is generated and required at each step of the installation process. Therefore a definition of the data required to control construction must start with a thorough investigation of the installation process required to move material items from issue through acceptance. The sequence of delivery events and activities must be studied to find the data required and the data generated by each step of the process.

In the following sections, flow diagrams for the installation of typical items for each delivery class in each discipline will be deve1oped. The information requirements and dynamics peculiar to each delivery sequence (i:e., installation process) step will bc defined and discussed. These typical component sequences wl11 be investigated to establish the required information flow at each point in the installation sequence. The component types to be studied are: 
(1) Mechanical - Bulk

(2) Mechanical - Small component

(3) Mechanical - Large component

(4) Civil - Bulk - Reinforcing steel

(5) Civil - Small component - Cadwelds

(6) Civil - Large component - Structural steel

(7) Electrical - Bulk - Wire and cable

(8) Electrical - Small component - Termination connectors

(9) Electrical - large Component - Motors

Detailed Information In/Out Sheets for these construction control cycles are included in Addendum A through Addendum I.

\subsection{Flow Graph Notation}

A graphical modeling format for work states and material and information flow modeling can be developed using three basic modeling shapes representing:

1) The active state (square node model) of a work task.

2) The idle state (circle or node model) of a delay position.

3) The directional flow (arc model) of a resource entity as it moves between idle and active states.

The symbols used (see Table 1.2) for each modeling element are designed to be simple and helpful in developing schematic representations 
of the material delivery operation being modeled. Two basic shapes (squares and circles) are used to model active and passive material states; together with directed arrows (arcs) for flow direction, they help to provide a quick visual grasp of the structure of the material delivery cycle.

There are two types of work tasks, the constrained and the unconstrained. An unconstrained work task requires only that the single activity preceding it be completed. It has only one incoming arc. 'l'he constrained activity, on the other hand, has more than one activity preceding it (several incoming arcs). Therefore it is necessary that a11 : preceding activities be completed, Differing time durations or other ? factors of ten do not bring all preceding activities to a simultaneous completion. This constrains the start of the activity in question to the latest completion tlme of the preceding activities. Thus a total of three symbols is required for the modeling of the structure and resource entity flow of construction operations.

\section{TABLE 1.2: BASIC MODELING ELEMENTS}

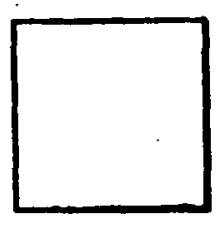

The normal work task modeling element, which may or may not be unconstrained NORMAL in its starting logic and indicates active processing of material flow units. 
$\bigcirc \log ^{\operatorname{mos}}$

ARROW
The idle or delay state of a material unit symbolically representing a queueing up or waiting.

The resource entity directional flow modeling element.

Simple examples of work task activitles are pulling cable, drawing materials, and Quality Control inspection. The definition of a work task thus implies a verbal description of the work task, an indication of the resource entities involved, and an awareness of the time commitment of the resource entities to the work task. There is no requirement to wait until ingredience (i.e., informational or physical) constraints are met. Once the NORMAL work task is commenced; the activating material is captured for the duration of the user-defined delay. The NORMAL element models the time involvement of material in work tasks.

The constrained modeling element is similar to the NORMAL modeling element with the additional logical requirement of meeting a prescribed set of input resources on its input side before the work task can be initialized. Thus all of the logical requirements needed for the constrained work task must be avallable for the work task to proceed. An essential modeling feature of the constrained element is therefore the identification and definition of the ingredience set of input information required to start up the work task being. modeled by the constrained element. 
The idle or passtive state of a resource is modeled by a circle to denote a QUEUE node (or $Q$ node). The $Q$ node is the graphical form; it has an obvious similarity to the concept of units being idle in a waiting line queue. Usually the time a material is delayed in the idle state is unknown and depends on external conditions in a construction operation relating to various work task states and durations and on the efficient design and management of the operation, as we11 as Information requirements. The QUEUE node acts as a storage location for resources entering an idle stace and releases the résources to the following node whenever the node ingredlence logic is satisfled.

An arrow or directed ARC is used to model the direction of resource entity. flow between the various active state "square nodes" and the passive state "queue nodes." The ARC modeling element enables the logic and structure of the operation to be developed. The ARC has no time delay properties and simply models entity flow direction. The material transit time, once initiated, is instantaneous.

The three modeling elements (i.e., the NORMAL and QUEUE nodes and the $A R C$ ) are the basic model-building elements. These elements can be combined in several ways to model material flow cycles, as shown in the next sections.

\subsection{Mechanical Material Installation Cycles}

The three mechanical material installation cycles to be discussed are those for field fabricated pipe (bulk), small valves (small components), and pumps (large components). Each of these material classes 
has an associated high data density or pedigree which is required during installation and which leads to the generation of further information during the processing cycle.

\subsubsection{Mechanical - Bulk materials}

Bulk pipe or spool material has been selected for consideration since a large amount of the data associated with the pipe portion of many spool lines is generated in the field. This occurs since almost all of the small to medium spool lines are fabricated in the field, and at some plants all piping is fabricated in-place. Typically the number of spool pieces required for a nuclear unit is on the order of 10,000 small spools (2" diameter and below) and 5,000 large spools (21/2" diameter and above). This represents about 250,000 to 350,000 LF of piping (2). Each of these spool pieces has a long data "tail" by the time systems are turned over to the plant operational force. Certain portions of this data are available at the time the material is issued from site storage. Typically, this data is compiled into a central file which is called a "traveler." The "traveler" becomes the central location for data pertaining to a given spool piece.

The traveler at the time a bulk piece of small bore spool material is issued for fabrication consists of the following data items:

(1) Sequence Form

(2) Weld Record

(3) Detail fabrication drawings (Isometrics)

(4) Fabrication Bill of Materials 
(5) Index and Instrumentation

(6) Material Record (Heat No.)

(7) Welder. I.D. and Qualification

Typical work order files for fabrication and erection of spool lines are shown in Figure 1.2.

SMALL BORE FABRICATION
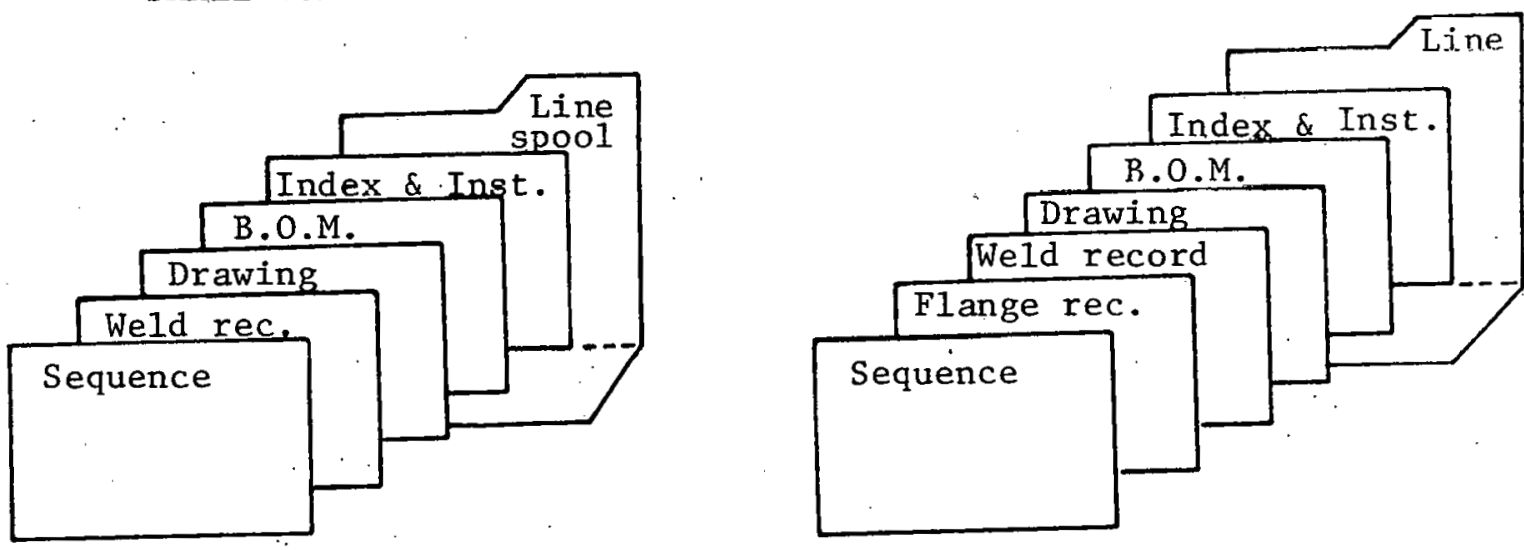

FIGURE 1.2: TYPICAL WORK ORDER FILES

In this case, the Bill of Material (B.0.M.) acts as the field requisition required to withdraw the material. All forms in the work order file are filled in as issue, weld-out, and installation occur. In this sense; they record information generated during the installation cycle as well as providing information required for fabrication and installation. Generation of the work order file requires access to the following items of information: 
(1) Primary Engineering Drawings

(2) Drawing Change Notices

(3) Engineering Change Notices (ECN)

(4) Field Change Requests (FCR)

(5) Specifications

(6) Other work order files (e.g., other spool pieces, fabrication W.O., erection W.0., pneumatic instrument W.O., hanger W.0., etc.)

(7) Requisitions

(8) Purchase Orders

(9) Expedite Reports

(10) Material Receiving Reports

(11). Bulk Material Status (availability)

(12) QC information

The work order file triggers issuance of the materials and the beginning of the fabrication sequence. The fabrication, installation, and acceptance cycle is shown graphically in Figure 1.3.

The total cycle consists of 13 work tasks, as follows:

(1) Issuance of pipe material and weld material

(2) Movement of material to fabrication shop

(3) Cut and perform weld end prep.

(4) QC inspection (in-shop)

(5) Move to installation location

(6) Up and center-tack welds

(7) Final. weld 


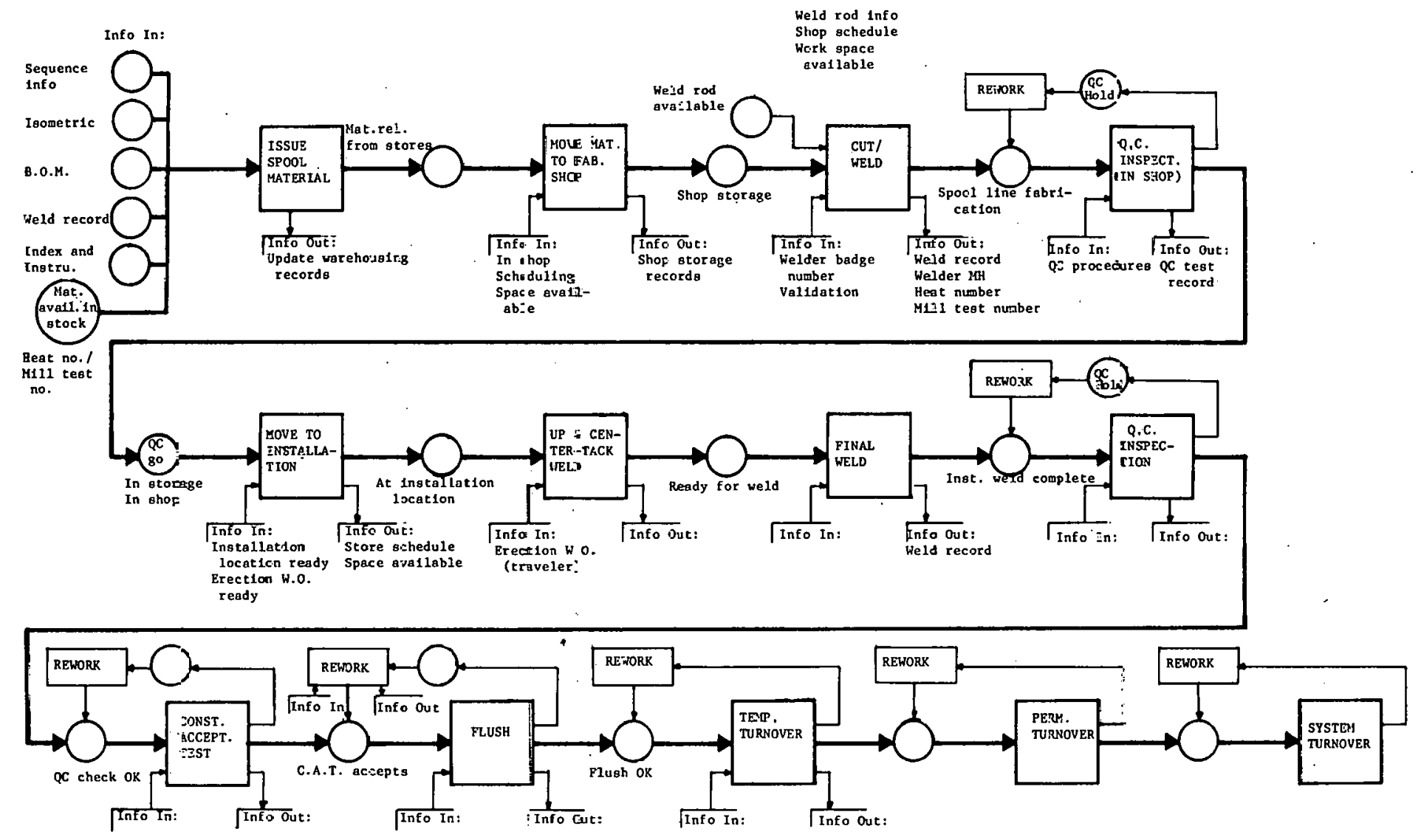

FIGURE 1.3: BULK PIPE MATERIAL CYCLE 
(8) QC inspection (X-ray)

(9) Construction Acceptance Test (CAT)

(10) Flush

(11) Temporary turnover

(12) Permanent turnover

(13) System turnover

In addition to the 13 mainline activities, rework activities are associated with the QC inspection activities (4) and (8), as well as with the Construction Acceptance Test, the flush, temporary, permanent, and system turnover activities. The purpose of flow diagramming is to detect and document information in-flow and out-flow. Associated with each of the 20 work tasks are two sets of information. The 40 sets of Information In/Out are described in detail in Addendum A. In some cases, there are null sets since the information generated from a work task completion or required for commencement of a work task is not critical or significant enough to be included in this discussion of the information structure. Certain representative information types have been included on some of the Information In/ Out symbols. The work order file information itself (e.g., sequence information, etc.) releases the start of activity Issue spool material. An analysis of the Information In/Out indicates that certain classes of information are either required or generated as follows:

(1) Design related information

(2) Material characteristics (including weld material)

(3) Scheduling information (space, manpower avallability) 
(4) Stock control information

(5) Inspection related information (to include acceptance/rejection)

(6) Work completion entries

(7) Productivity information

(8) Cost information

(9) Worker qualification information

Every time a work task commences or completes, Information of this variety is either required or generated and therefore must be retrieved or passed from or to the information structure. Addendum A contains detailed listings.

The Isometric Drawings are a typical example of design-related information. They interpret to the fabricator in the shop the information on the primary design documents (e.g., Piping and Instrument Drawings) so that he can utilize this schematic information in a threedimensional format. Material information such as heat numbers and mill test reports for the bulk stock become part of the completed spool line's information structure. The availability of manpower and space in the fabrication shop as well as activity requirements from higher level schedules dictate the shop schedule and, therefore, influence the processing of materials and fabrication priorities. Upon issuance from site storage, stock control records must be updated to indicate reduction in inventory levels. Quality Control information generated during inspection must be recorded and dictates whether rework and additional effort is required. After completion of each work task, the question of whether a status change is recorded must be 
considered. Work completion leads also to the tabulation of total manhour and cost expenditures. Productivity information can be derived from this cost and manpower reporting. As part of the quality control, the qualification of the welder and his last retest become a matter of record.

\subsubsection{Mechanical - Small components}

Small valves have been selected as an example of small components because of the data needed to control this process and the sheer number of these types of devices. There are normally 20,000 valves and specialty items to be installed in the piping systems of a nuclear project. Figure 1.4 schematically represents the installation of valves.

In the beginning of the process, a work order is prepared. When the valve installation is needed, the work order is issued to the field. The foreman sends a requisition to retrieve the article and it is brought to the area of installation. The valve is placed and fitted and permanently installed. At this time it is inspected for conformance to the drawings and specifications. The item then is run through a group of tests and is finally released or turned over permanently.

There are many data elements that are associated with the installation of a small valve. These can be divided into three main categories. First the material itself is tracked by such data as purchase order, system number, vitality, etc. Second, the personnel 


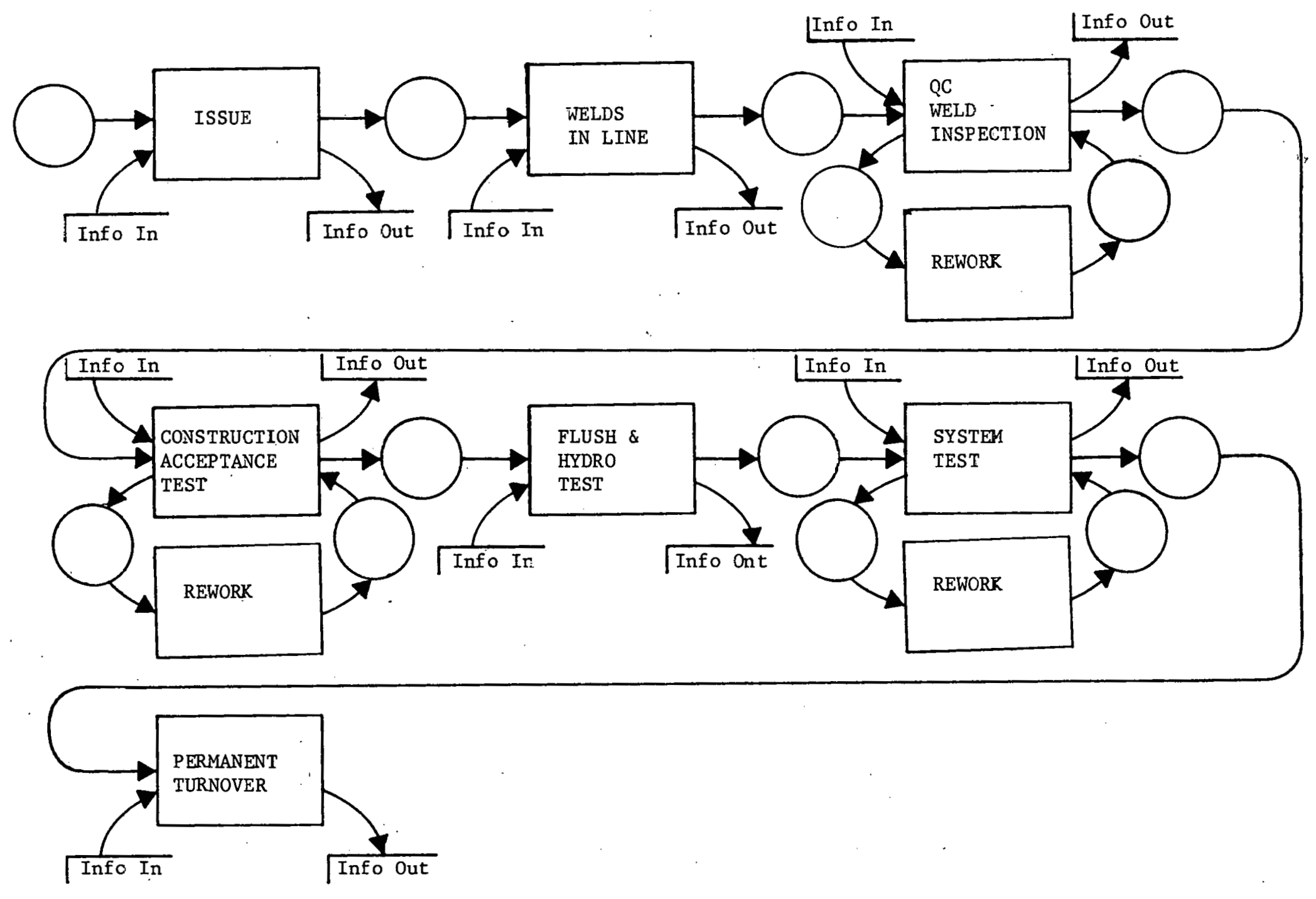

FIGURE 1.4: MECHANICAL (SMALL COMPONENT)

Small Valves 
add data to the pedigree such as welder qualification number, procedure, method of installation, time used, and conditions of installation. Third, QC and testing add pertinent information to the item, such as acceptance reports, rejection reports, minor variation reports, inprocess reports, etc. Each adds pertinent and important information to the pedigree of the installation. For a more complete list of inputs and outputs of each operation, see Addendum B.

\subsubsection{Mechanical - Large component's}

Large pumps have been selected for inspection because they are the items in this category with the most data associated with them. Figure 1.5 shows the installation of these components.

The unit first must be scheduled for work. Because of size, a forklift must be scheduled as well as the heavy equipment crane. The personnel who operate this equipment must be scheduled and set aside for this work in advance. Because of the multi-disciplinary nature of setting a pump, decisions must be made as to the type of crafts needed and the number of each to be used.

Before the pump can be placed, an equipment pad must be built to hold the item. This must be done in accordance with proper manufacturer drawings and specifications.

When the pump is released for installation, a forklift and crane must transport it to its location and wait while the pre-placement fitting is performed; subsequently, it is installed in its final position. There is usually some rework and possibly some drawing changes 

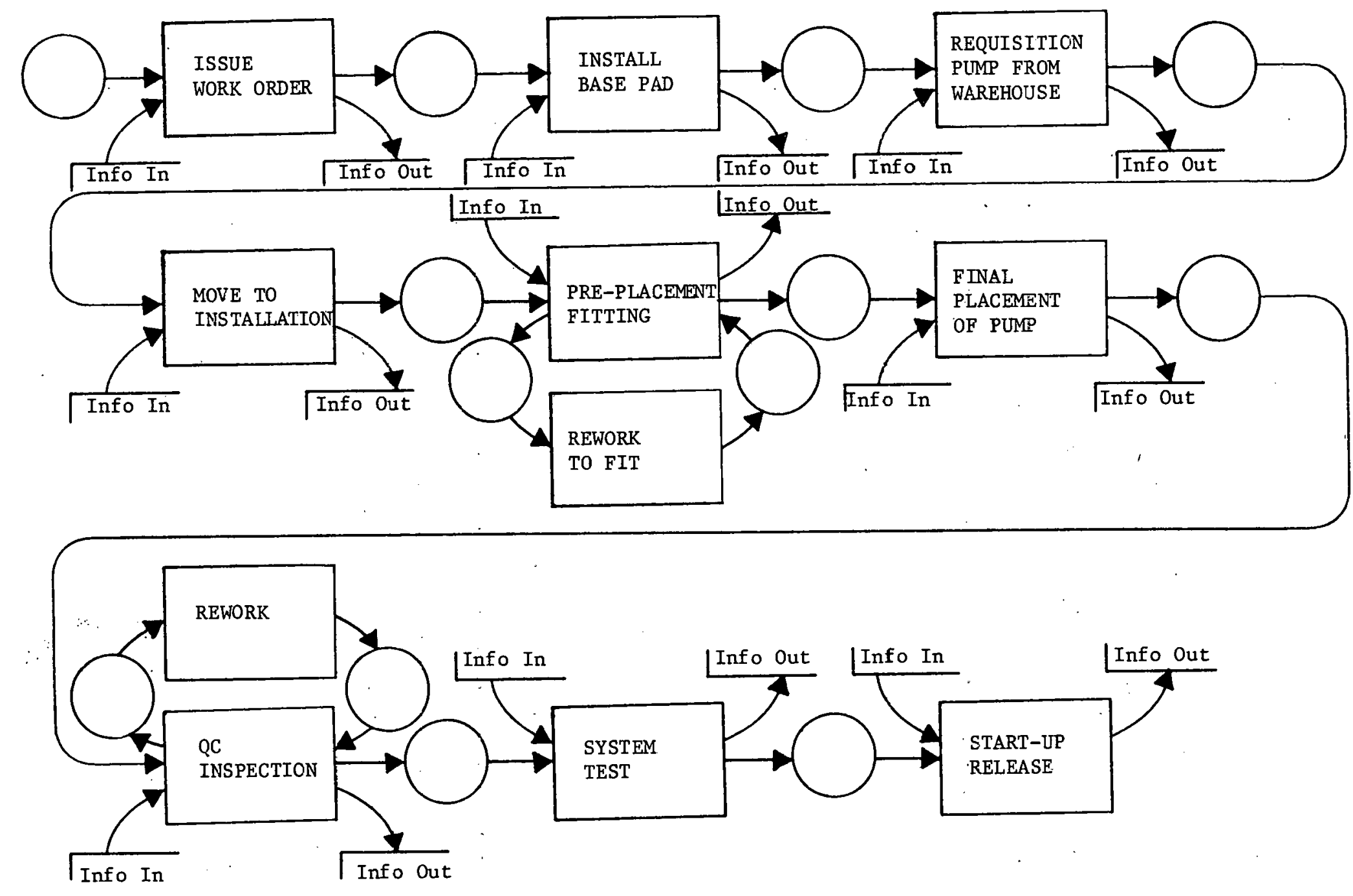

FIGURE 1.5: MECHANICAL (LARGE COMPONENT)

Pumps 
that are necessary in order to accomplish this.

At this point, QC documents the work, including any calibrated tools or special procedures employed, and accepts or rejects the installation by virtue of the specifications and procedures.

It should be mentioned that the system will probably contain electrical controls and operators that will need to be connected. These are mentioned in the electrical sections which can be consulted there for further information.

After all work is complete, the pump will undergo the same testing as any other component. Information from these tests will be attached to the pump. All information is turned over to the Start-Up Group for final testing and release to the customer. Addendum $C$ contains a listing of information generated in the installation of a pump.

\subsection{Civil Material Installation Cycles}

\subsubsection{Civil - Bulk materials}

A typical bulk material within the civil discipline is reinforcing steel. Certain installations require that rebar be ordered in bulk quantities and fabricated at the job site. An example would be when rebar must be formed in an unusual shape or fitted around an irregular object which requires field dimensions and fabricating. This method eliminates costly fabrication errors and schedule delays. 
However, costs for fabrication on-site are generally higher than for fabrication done in a cutting and bending shop.

The bulk reinforcing steel is usually ordered in standard lengths by size ( $(15, \# 8, \# 11$, etc.) and by grade (40 or 60). The approximate quantities are determined from the contract drawings and specifications and then shop drawings and fabrication detail sheets are developed. The fabrication detail sheets are usually incomplete and require field dimensioning. The bulk reinforcing steel material is then transformed from stock lengths into a fabricated component ready for installation.

The information flow for field fabricated reinforcing steel is directly linked to the steps involved in its field life cycle from storage to installation. Figure 1.6 depicts the events that occur throughout the rebar cycle at the field level. For a detailed listing of information input and output, see Addendum D. Each of the rectangular blocks represents a physical process in the transformation from bulk material to a finished product. The transformation activities include removal from storage, transporting to the bending and cutting area, cutting and bending the bars, Quality Control check of fabrication, transporting it to the installation area, installation, and final QC check. The nodes between each activity represent potential delays. For instance, a typical delay between storage and transporting it to the fabrication area would be a delay in obtaining a crane or truck due to scheduling problems. 
Shop drawings,

speci; other

drawings,

QC 0 R

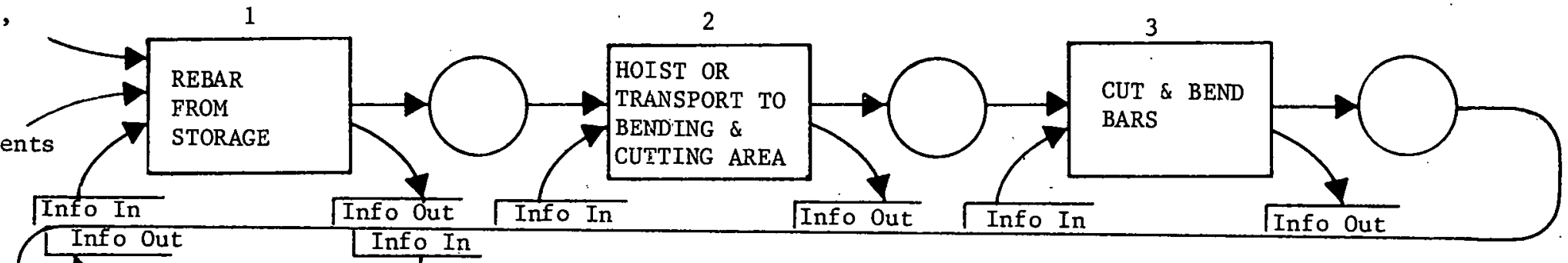

Physical

requirement

(f orms

etc.)

Info out

Info In

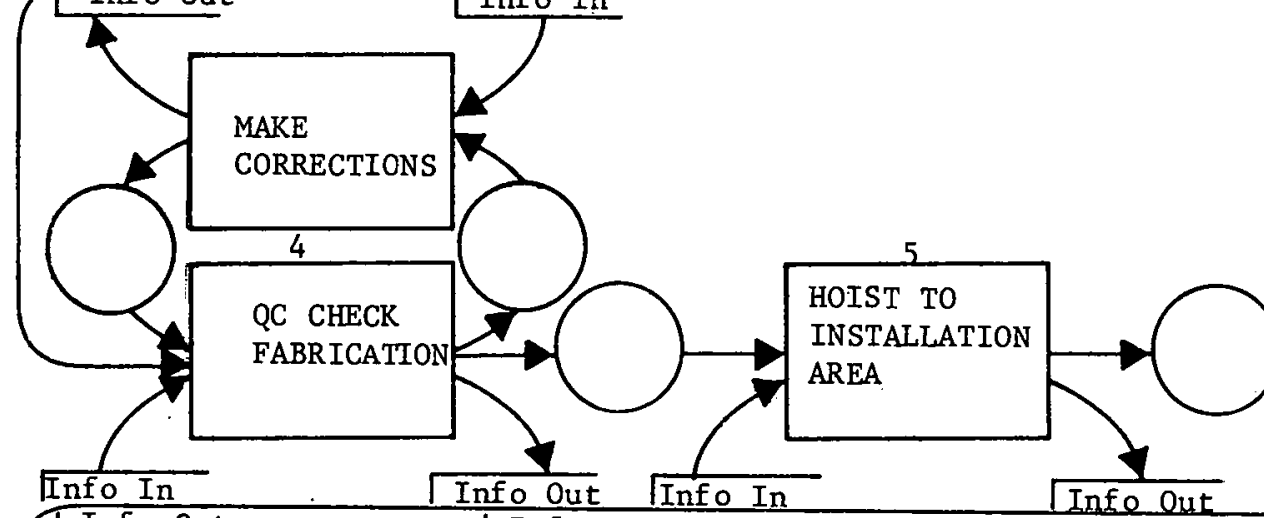

Info In

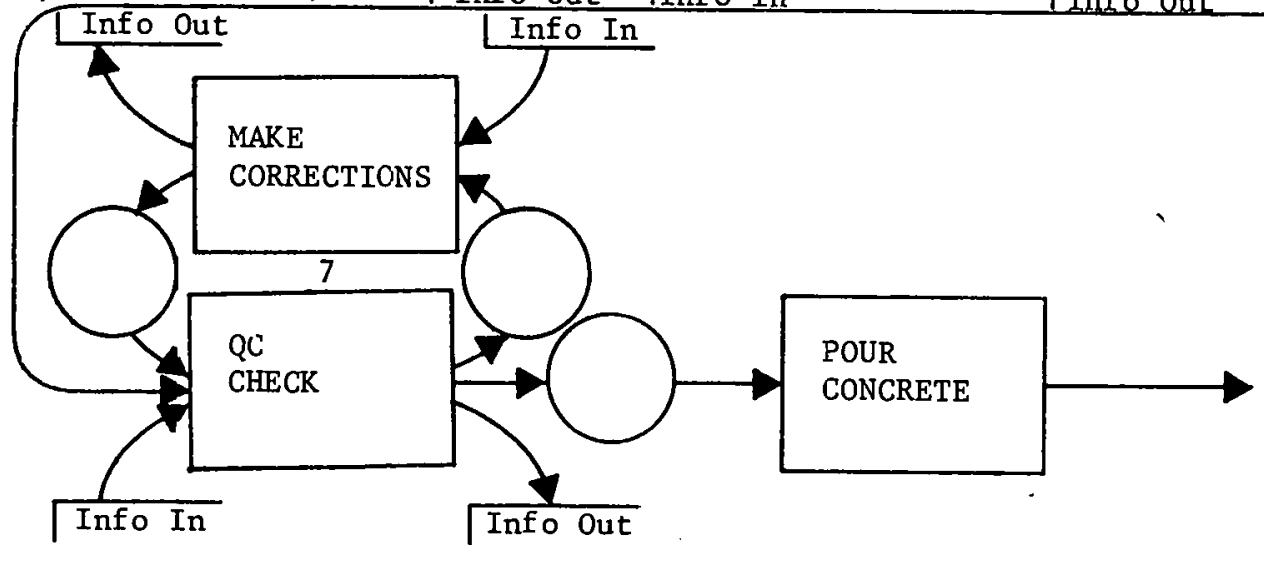

FIGURE 1.6: CIVIL (BULK)

Reinforcing Steel 
The reinforcing steel transformation process is usually initiated by some physical requirement being met. The requirement could be that formwork in the particular area should be $50 \%$ complete before fabrication is begun. Another requirement may be that a special embedded item must be installed. When shipments are behind schedule, the rebar delivery to the job site will start the fabrication cycle. Generally, some physical requirement dictates the start of the rebar field life cycle. Addendum $D$ lists, in detall, the Information input and output for the reinforcing steel field life cycle. Typical information input for all activities in the cycle includes: shop drawings and fabrication $\therefore$ sheets, work activity numbers, crew number assigned, cost code number, time allotted for the activity, and notification that the previous activity is complete. However, the hoisting and transporting activities typically require pounds and quantity of rebar to be lifted or transported, pick-up and destination points, and usage time required in addition to the previously listed input items. Typical output information * includes items such as: manhours, equipment hours, materials to be charged against the work activity number and cost code number, start and completion dates, crew or equipment status, and notification of activity completion.

\subsubsection{Civil - Small components}

Cadwelds are an example of a small component within the civil discipline. Cadwelds fit the definition of a small component since they arrive at the job site in an essentially finished state and are transformed 
silightly during the installation process. Cadwelds are used to weld critical rebar joints in lieu of overlapping the bars. The welding process, which is essentially a chemical reaction, is the minimal transformation that takes place.

The reinforcing steel vendor typically includes cadwelds in their shop drawings and indicates the location of each weld. The cadweld quantities are initially determined by contract drawing takeoff and then verified through the shop drawing process. Cadwelds are usually packaged when they arrive at the job site and must be stored in a secure and protected environment due to the chemical reactants involved.

The information flow involved with cadwelds is directly linked to the activities of their life cycle, from job site storage to installation. This cycle is shown in Figure 1.7. Again the rectangular boxes represent physical processes, and the nodes are indications of typical delays. The life cycle activities for cadwelds are fewer in number due to the item not being involved in a field fabrication process. Typical field activities associated with cadwelds include: removal from storage, transporting to the work area, Quality Control check prior to installation, installation, and final QC check. A typical delay encountered in the cadweld activities may be the inability to obtain approval of a particular cadweld mechanic from QC. Satisfying some physical requirement initiates the cadweld cycle. In general, the main requirement would be that the required reinforcing steel is installed and ready for cadwelding. 


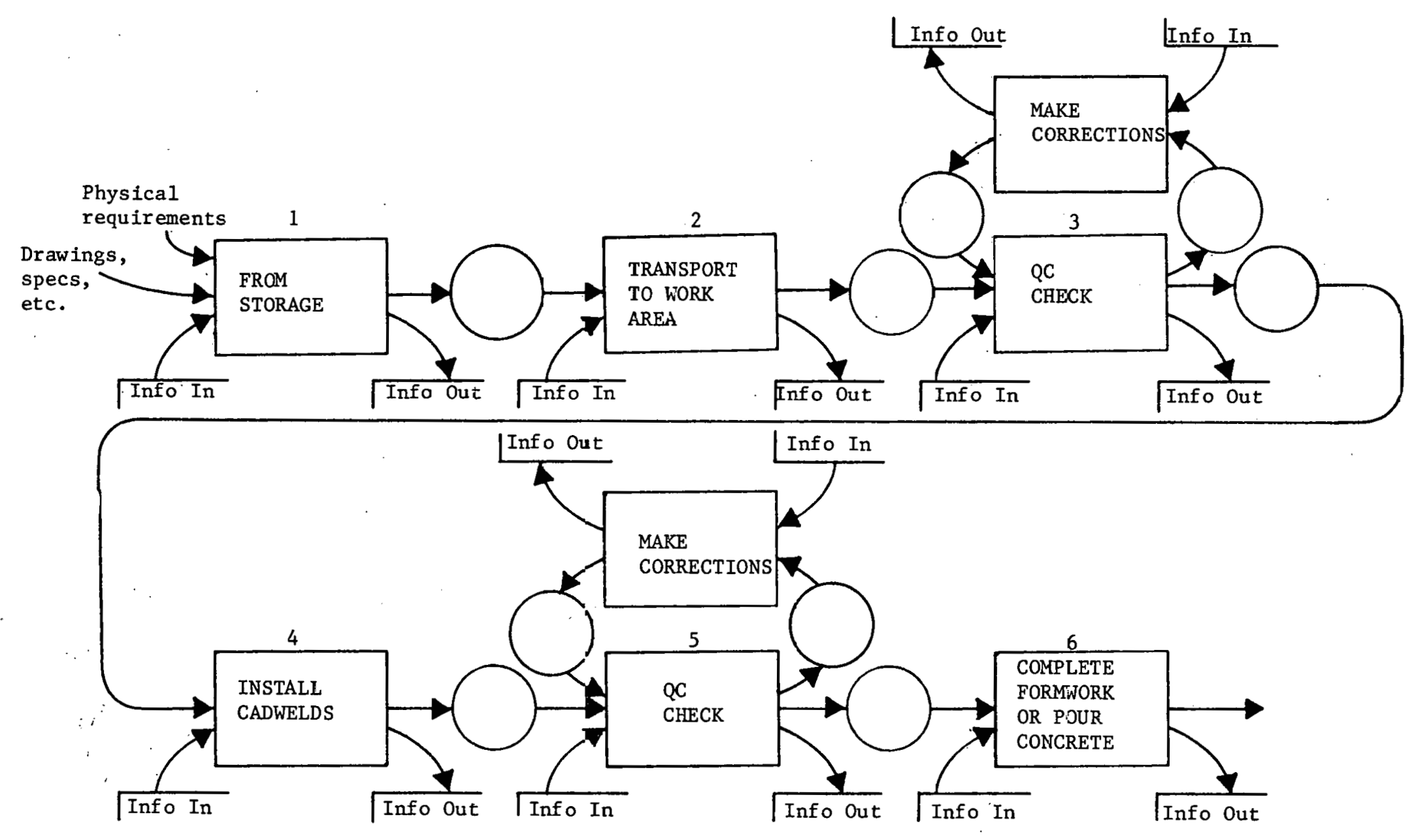

FIGURE 1.7: CIVIL (SMALL COMPONENT) Cadwelds 
Addendum $\mathrm{E}$ gives a detailed listing of information input and output required at each activity. Most activities in the cadweld.cycle require information input such as: shop drawings, work activity number, cost code number, crew number assigned, scheduled duration of the activity, cadwelder qualification approval, and notification that the previous activity is complete. The transportation and hoisting activities play a minor role in the cadweld cycle due to their relatively small size in comparison to the bulk rebar case. However, since cadwelds are critical items, Quality Control plays a large role in approving storage and installation. In addition to the above input information, Quality Control would require welder qualifications for all mechanics installing the cadwelds. Typical output information includes: manhours, equipment hours, or materials to be charged against the work activity number and cost code number, start and completion dates, crew or equipment status, and notification of activity completion.

\subsubsection{Civil - Large components}

The process of erecting structural steel in a nuclear power plant is similar to conventional construction. The major difference is the close check kept on Quality Control. Initially, a work order must be prepared. This documentation process would describe the "piece" of construction needed to be completed. Some of the information which must be available might be the amount of material required, an approximate estimate as to the manpower required, consumables required, etc. Much of this same information then becomes output and is funneled to the 
appropriate departments to start the coordination of the field erection process. Addendum $F$ contalns a detailed listing.

After the work order has been prepared, the materials must be issued. It is important in this step for the correct materials to be issued. The warehouse must be supplied with which pieces are required and when they are required. The information which is recorded might be which pieces are issued, to whom they are issued, at whose authurlizaliul, what the amount remaining in stock is, etc.

Quality Control enters the sequence at this point. Structural steel is considered a large component, particularly in large and more complex members, and is the result therefore of some sort of fabrication process. Although the fabrication process was carried out under a Quality control environment, it must be verified that the steel will fit in the structure as built. Therefore, such information as as-built drawings, fabrication drawings, fabrication location, etc. would be needed. Al this point the information produced would conslst of the dimensions of the fabricated piece and its status.

In order to erect the steel, it must be moved to the actual site of erection. Information necessary in this step includes the availability of manpower, weight of the piece for determining rigging equipment, size, etc. The information recorded might include the crew involved, equipment used, etc.

The erection of the steel is the end objective of these efforts. In order to insure proper erection, drawings will be required, along with approximate quantities, information as to fasteners (welding rods, bolts), 
Information as to qualified welders, etc. After being placed, the steel will be inspected to keep track of equipment used, welders making specific welds, the crew which erected the piece, etc.

After erection a final Quality Control check is made. It is necessary to know the elevation of the steel, its orientation, fastening condition, etc. Information output would consist of a description of the work done and how closely it complies with the design spectfication. Figure 1.8 depicts the work process flow from Prepare Work Order to QC Final Check.

\subsection{Electrical Material Installation Cycles}

Three electrical material delivery cycles have been chosen, because of the data density associated with them. Wire and cable will be used as an example of bulk materials, terminations will be used as an example of small components, and electric motors will be used as an example of large components.

\subsubsection{Electrical - Bulk materials}

Bulk wire has been selected as an example of this category because of its data density and the large amount of it placed in a nuclear plant. It is not uncommon to require the placing of four to five million feet of cable in a nuclear plant. This can keep 100 men busy handling reels, pulling cable, and removing empty reels to the wire yard. The pull is initiated by forming a pull package, which includes informational cards on each wire to be pulled. These cards include cable number, routing, 


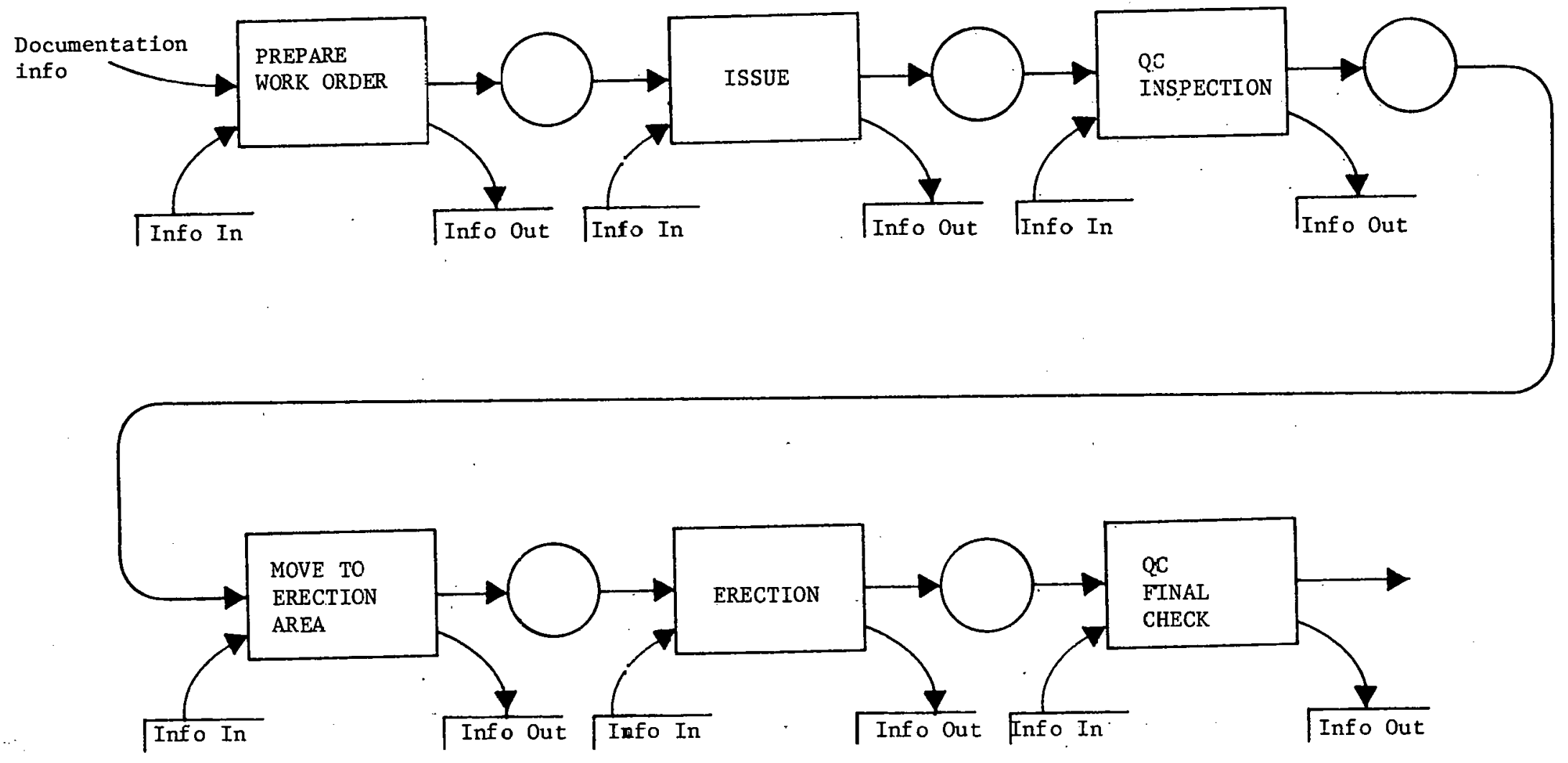

FIGURE 1.8: CIVIL (LARGE COMPONENT)

Structural steel 
origin, destination, length of cable, cable reel number, size, number of conductors, and voltage rating. The field supplies information as to the crew that performed the work, date, footage actually installed, pull method, pulling force, time, and men involved. For a complete listing of inputs and outputs, see Addendum G. The wire is drawn from the wire yard, set up at the pull location, pulled into the conduit or tray, and excess cable is returned to the wire yard. The cable 1s then identified by floater and tested by applying a high potential to it and checking leakage rates (megger testing).

This operation is done under the direct view of QC personnel. These inspectors have the authority to stop the pull and to inspect or test any part of the pull. After the pull is complete they certify that the pull has been completed in accordance with the QC procedures. Documents associated with these operations include work orders or travelers, installation reports, pull cards, QC reports, and wire usage reports. Figure 1.9 shows the installation process.

\subsubsection{Electrical-Small components}

The sma11 component selected for illustration is the termination lug because of its importance and the large number involved. There are approximately 125 - 135 thousand wires to be terminated on a typical job. This is a strict and tedious job requiring strict attention to detail to insure correct procedures and location. Special types of cable such as high voltage power cable can take up to 8 hours per termination and require speclalized instructions. 

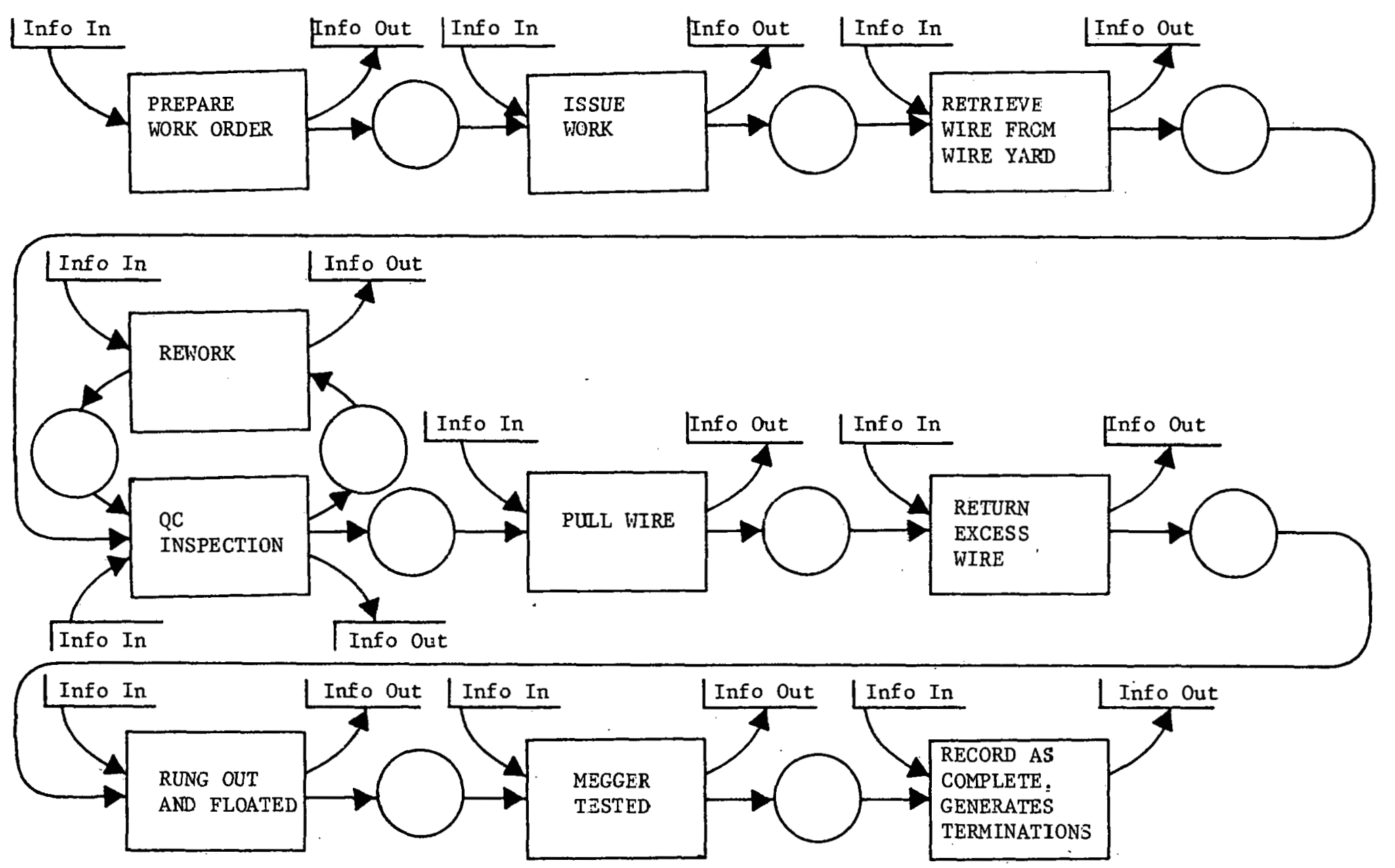

FIGURE 1.9: ELECTEICAL (BULK MATERIAL) Cable Pulling 
The termination is initiated by a termination card sent to the field. This card contains information on location, size of conductor, diagram of connection number, circuit number, and type of connection. The craftsman is assigned the connection, locates it, terminates it according to the diagram of connection, and reports his activities.

The QC inspector then verifies the termination and generates a historical document to validate the work.

Forms involved in this process include termination request forms, termination reports, and QC reports. A list of inputs and outputs generated from these operations is shown in Addendum $\mathrm{H}$.

Figure 1.10 depicts the work process.

\subsubsection{Electrical - Large components}

The last type of component to be considered will be the "large component" class. Motors are typical of this class. A work order is prepared upon demand and sent to the field. The foreman requests the release of the item which is then transported to the work area and set on its foundation. Conduit is then brought to the motor and terminations are made. Quality Control inspects the work and releases it for further testing. The motor is then hi-potted, which involves placing a high potential across the line to observe loss and check systems. The motor is then released to Operational Testing.

In each of the operations above, certain information is needed and information is generated. See Addendum I for lists of inputs and outputs 

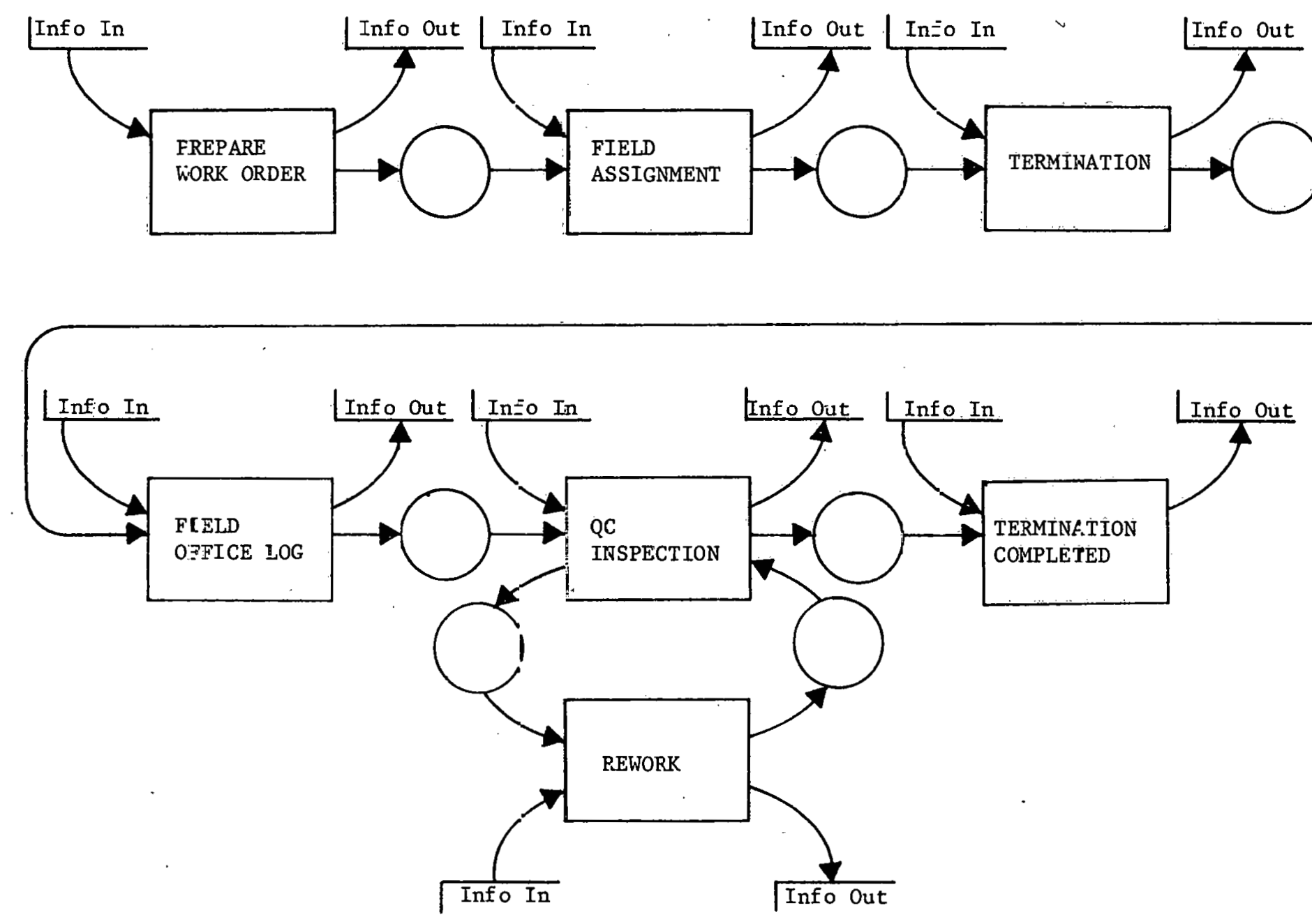

FIGURE 1.13: ELECTRICAL (SMALL COMPJNENT) Terminations 
associated with each. Figure 1.11 follows the installation of the large electrical items.

Within the electrical discipline, materials can be segregated into the categories mentioned previously. It is felt that the processes performed and the inputs and outputs can be more easily understood if explained in a work orientation. On any job the electrical discipline is separated into three distinct groups. The conduit crews install all condult, tray, and physical equipment. The wire pulling crews are responsible for installing wire and cable, and the terminators terminate the wire left by the wire crews to the equipment left by the conduit crews. All components used by any one group flow to the field and are installed in exactly the same way because they are used by the same people in the same types of systems. To explain accurately the routing of equipment to installation, one would need to explain not how bulk materials are handled in general but rather how bulk materials are handled by the conduit people, how bulk materials are handled by wire pulling crews, and how bulk materials are handled by the termination crews. The same process would hold true for small components and large components. See Table 1.3 for a breakdown of these categories. 

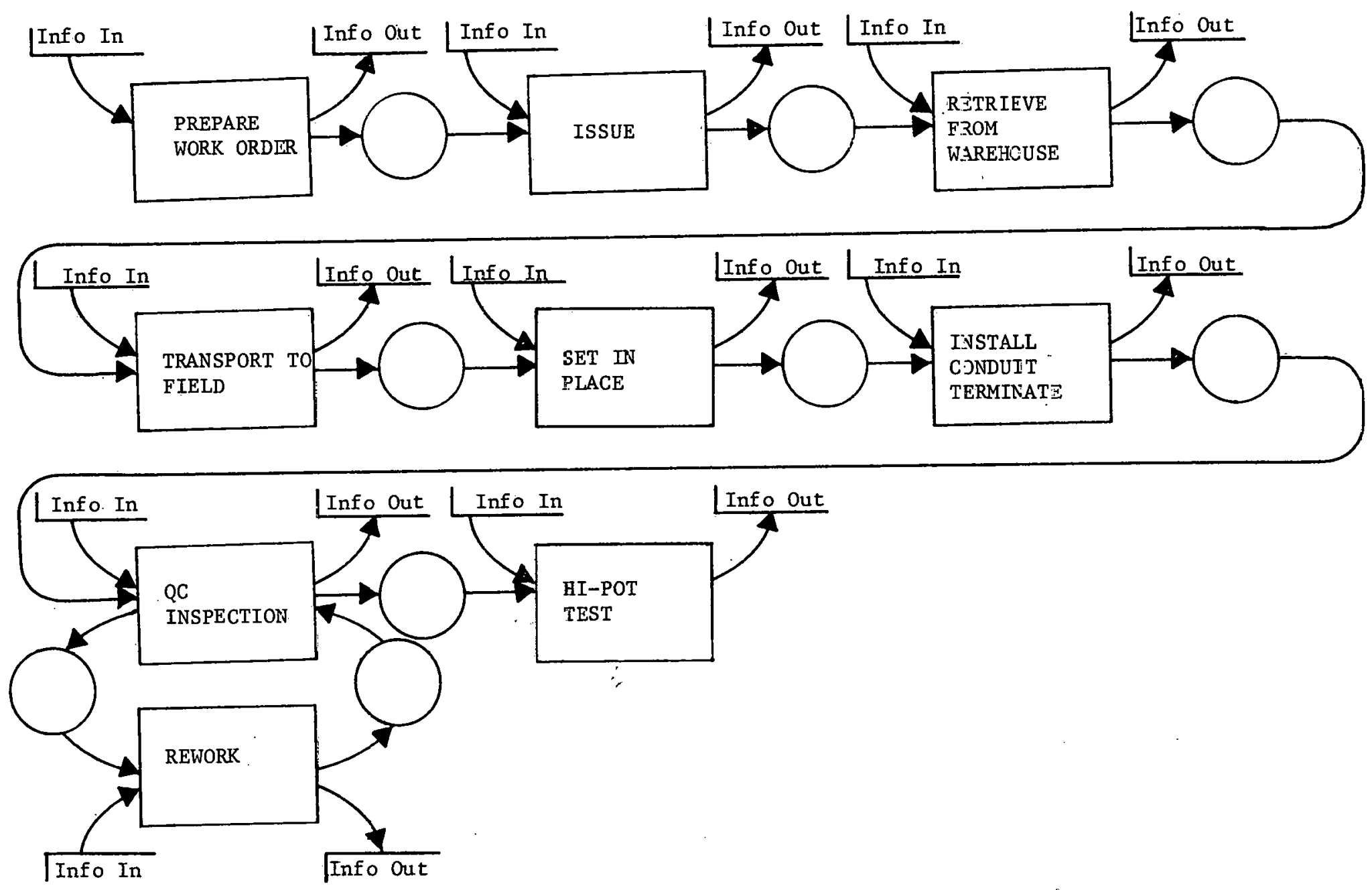

FIGURE 1.11: ELECTRICAL (LARGE COMPONENT) Motors 
Wire Wire and cable

pullers Floater material

\begin{tabular}{llll} 
Term- & & & \\
Inators & $\begin{array}{l}\text { Shrink tubing } \\
\text { Glass tubing }\end{array}$ & $\begin{array}{l}\text { Lugs, connectors } \\
\text { Termination kits }\end{array}$ & \\
\cline { 2 - 4 } & $\begin{array}{l}\text { Conduit } \\
\text { Unistrut } \\
\text { Flex } \\
\text { Welding rod } \\
\text { Color code (ro11s) } \\
\text { ETC. }\end{array}$ & $\begin{array}{l}\text { Conduit connectors } \\
\text { Breakers } \\
\text { Instruments } \\
\text { Boxes } \\
\text { Heaters } \\
\text { ETC. }\end{array}$ & $\begin{array}{l}\text { Transformers } \\
\text { Switch gear } \\
\text { Generator } \\
\text { Excitor }\end{array}$ \\
& & $\begin{array}{l}\text { Feeder panels } \\
\text { ETC. }\end{array}$ \\
\hline
\end{tabular}

TABLE 1.3

\subsection{Methods Engineering}

Methods Engineering is a systematic investigation of the work done on a project. Individual work assigments are closely observed and analyzed. The objective is to attain the best possible use of the men, machines, and material available by eliminating waste. Results are compiled and presented to the project management as a means of more efficiently managing the project with known resources.

A great many processes are involved in analyzing work methods. The job is recorded by listing all details as being currently performed. Basic questions must be raised with respect to each activity:

(1) What is the purpose of the activity?

(2) Is it being completed in the best manner possible?

(3) Is it timed correctly with respect to preceding and following activities? 
(4) Is it placed in the optimum location (if there is a cholce)?

(5) Are the personnel performing the work the best qualified individuals?

The job layout, tools, equipment used, materials used, material flow, and safety aspects must be evaluated. It may be possible to rearrange activities resulting in better sequencing. There may also be some opportunity for simplifying activities and for achieving greater ease and speed. It is important to include all persons who have an inherent interest in the analysis. Lastly, the changes resulting must be sold to management for effective implementation.

A good working relationship is required with other functional areas so as to permit achievement of the best possible results. Close coordination is required with Quality Control/Quality Assurance to best time when these functions should be accomplished, so as to minimize the effort required to uncover concealed items. Project management must be sold on the validity of the results of the studies. If managenent is not completely convinced, then implementation will probably be less than cotal. Cost Control can prove or disprove the validity of making the suggested changes by indicating if costs have increased or decreased. The measurement of the costs may have to be modified to reflect true costs if methods have been changed. The changed methods may result in significant savings in time, and thereby alter schedules, which could involve the planning and Scheduling function. Changing methods may also require different types of equipment or different sequences of equipment, necessitating consultation with Construction Equipment Control. 
In order for Methods Engineering to be effective, a great deal of information is required and produced. Required information can be broken down into five broad categories: the project physical layout, the project organization, the project estimate, the system for assigning and scheduling work, and the project manpower requirements. The produced information consists of detailed productivity information on individual activities and proposed modifications.

Methods Engineering involves crossing into the political arena of project management, and must therefore be approached with the utmost sensitivity. Initial meetings should be scheduled with the Project Manager, Assistant Project Manager, Construction Manager, and the Controls Manager to discuss the parameters of the program. Next, it is important to become completely familiar with the data requirements. Upon reviewing the avallable information and meeting with project management, objectives and strategies for implementing a Methods Engineering program should be proposed.

In analyzing activities, several reports may be 'used. A weekly tabulation of the detailed breakdown of elements for the crew showing the main work activities is produced. Also, a weekly tabulation covering each crew's performance for the current period and for the two preceding periods, with a three-week sliding average for each of the major ele ments (Direct Activity, Support Activity, and Delays), is produced. The typical Manpower Activity Analysis Report will consist of:

(1) a cover letter;

(2) a one-page summary giving a multi-element breakdown for each 
day of the period along with the current and previous report period's statistics and with the changes from period to period;

(3) listings of the crews in each craft, giving the percentage of breakdowns for both crew and craft, along with the project breakdowns; and

(4). Hstings of the crews in each craft, giving major elemental breakdowns for the previous three week period along with the total project major elemental statistics.

Graphs may be presented at specified intervals; these should show the three major elements (Direct Activity, Support Activity, and Delays) for each week for the total project and for each craft. 


\section{CHAPTER II}

\section{Existing and Projected Systems}

\subsection{Introduction}

Several systems which follow the material cycle from site storage to start-up will be presented in this section. Some of these systems are in operation while others are under development. Table 2.1 summarizes the major tracking systems studied and the level of coverage. Systems are described in terms of what discipline components they track and during which period of the life cycle of the material they maintain status. Codes are as follows:

(1) "1" = System tracks component from eng ineering to receipt and storage on site. Normally, this level tracking includes information regarding requisitioning, purchase order, expediting, receipt, and project site storage location.

(2) "2" - System provides status information regarding material from issue to installation.

(3) "3" - System tracks components from installation through acceptance by start-up.

This report is concerned with those systems which are included in Codes 2 or 3.

\subsection{Danie1 Farley 非}

The followlng is a list of computer status programs that are presently in operation at Farley Nuclear Plant Unit 1, Dothan, Alabama for monitoring 
CODES: 1 - 'Iracks Engineering \& Procurement

2 - Tracks Construction Installation

3 - Tracks Start-Up/Pre-Op

Daniel Daniel Daniel Nuclear General McDonnellFarley Callaway Fermi Pow.Ser Public Douglas

MAJOR COMPONENTS Unit 非 Unit \#1 Unit 非 P.M.P. Utilities Compaid.

\section{CIVIL}

Concrete Pours

Forms

Rebar

Concrete

Embedments

Cadwelds

Structural Steel

Equipment

COMBINED

Paint-Arch/Equip/Pipe

Insulate-Arch/Equip/Pipe

MECHANICAL

Equipment

Pipe Spools

$\quad 1-2$

Sma11. 1-2

Welds $1-2$

Valves/Specialties $1-2$

Hangers/Supports $\quad 1-2$

Pneu.Instruments $\quad 1-2$

Loose Materials

HVAC Equipment

Duc twork

$\begin{array}{ccccc}1-2 & 1-2-3 & & 1- & \\ & 1-2-3 & 1-2 & 1-2 & 1-2 \\ 1-2 & 1-2-3 & & 1- & \\ 1-2 & 1-2-3 & 1-2 & 1- & 1-2 \\ 1-2 & 1-2-3 & 1-2 & 1- & \\ 1-2 & 1-2-3 & & 1- & 1-2 \\ & & & 1- & 1- \\ & 1-2-3 & & 1- & \end{array}$

ELECTRICAL

Equipment
Raceway
Cable
Cable Tray/Supp
Elec. Instrumen
OTHER
Minor Buildings
Minor Systems

TABLE 2.1: REVIEW OF EXISTING COMPUTERIZED

COMPONENT INFORMATION SYSTEMS. 


\section{CODES: 1 - Tracks Engineering \& Procurement \\ 2 - Tracks Construction Installation \\ 3 - Tracks Start-Up/Pre-Op}

\begin{tabular}{|c|c|c|}
\hline & $\begin{array}{l}\text { Northern } \\
\text { States Pro- }\end{array}$ & $\begin{array}{l}\text { Bechte1 } \\
\text { Corp. }\end{array}$ \\
\hline MAJOR COMPONENTS & posed ITS & Q.T.S. \\
\hline
\end{tabular}

CIVIL

Concrete Pours

Forms

1-2

Rebar

1-2

Concrete

Embedments

$1-2$

Cadwelds

Structural Steel

Equipment

$1-2$

COMBINED

Paint-Arch/Equip/Pipe

Insulate-Arch/Equip/Pipe

$1-2$

MECHANICAL

\begin{tabular}{lllc}
\hline Equipment & $1-2-3$ & $1-2$ & $1-2-3$ \\
Pipe Spools Large & $1-2-3$ & $1-2$ & $-2-3$ \\
Welds Sma1l & $1-2-3$ & $1-2$ & 2 \\
Valves/Specialties & $1-2-3$ & $1-2$ & $-2-3$ \\
Hangers/Supports & $1-2-3$ & $1-2$ & $-2-3$ \\
Pneu. Instruments & $1-2-3$ & $1-2$ & $-2-3$ \\
Loose Materials & & $1-2-3$ & \\
HVAC Equipment & & & $-2-3$ \\
$\quad$ Ductwork & & &
\end{tabular}

ELECTRICAL

\begin{tabular}{lrr}
\hline Equipment & $1-2-3$ & $1-2$ \\
Raceway & $1-2-3$ & $1-2$ \\
Cable & $1-2-3$ & $1-2$ \\
Cable Tray/Supports & & \\
Elec. Instruments & $1-2-3$ & $1-2$
\end{tabular}

OTHER

Minor Buildings

Minor. Systems

TABLE 2.1: REVIEW OF EXISTING COMPUTERIZED

COMPONENT INFORMATION SYSTEMS (continued) 
the components for permanent plant installation.

- Mechanical Equipment Status

- Large Bore Off-Site Prefabricated Piping Spool Status

- Radiographs Status for the Large Bore Prefabrication .

- Sma11 Bore Site Prefabricated Piping Spool Status

- o Hanger/Support Status for Large Bore Prefabricated Off-Site

- Hanger/Support Status for Small Bore Engineered and Prefabicicaced On-Site

- Valve Status

- Pneumatic Instrument Status

- Weld History

- Welder Qualification/Welder Performance

- Heat Number Cross Reference Program

- Electrical Equipment Status

- Electrical Instrumentation Status

- Electrical Cable Program.

- Nonconformance Report (NCR) Status and Trends

Table 2.2 is a list of systems now in use for Farley Unit 1 . The table indicates the frequency of reports ard the approximate number of print lines. The automation of information at Farley has a monthly output of $4,324,400$ printlines.

\subsubsection{Mechanica1 Equipment/Piping/Instrumentation}

To proper ly manage much of the information necessary for the construction of Farley, Daniel had to consolidate and organize information 
TABLE 2.2

FARLEY NÜCLEAR PLANT UNIT 1

The following is a list of Application/Systems:

\section{App1ication/System}

I. Construction Status Reporting

1. Update master file

2. Report preparation

- Instrumentation

- Hangers

- Valve status

- Spool status

- Mechanical equipment

- Electrical equipment

- Cable status \& pull schedule

- Raceway

3. Drawing and Document CTL
Frequency

Print Lines
Weekly

Weekly

Weekly

Weekly

Weekly

Weekly

Weekly

Weekly

Monthly

$$
\begin{array}{r}
7,000 \\
75,000 \\
100,000 \\
250,000 \\
75,000 \\
2,400 \\
5,200 \\
300,000 \\
- \\
300,000 \\
, 558,400
\end{array}
$$

II. Planning and Scheduling (use PROJECT/2: run by Southern Services from Birmingham)

III. Project Cost Control

1. Labor cost

2. Material cost

IV. General Accounting

1. Payroll

2. Purchase Order status

3. Accounts payable

V. Quality Control

1. Welder qualification

2. Weld history and performance

3. Heat no. cross-reference

4. Non-conformance reporting

5. Concrete testing
Weekly

Monthly
$5,0,000$

250,000

$\begin{array}{ll}\text { Weekly } & 30,000 \\ \text { Weekly } & 30,000 \\ \text { Twice weekly } & 15,000 \\ & \frac{90,000}{90}\end{array}$

Weekly

Monthly

Weekly

Weekly

Monthly
2,000

100,000

15,000

10,000

18,000

226,000

TOTAL PRINTLINES

4,324, 400 (Monthly) 
coming from a variety of sources. Alabama Power had utilized Bechtel Corporation in designing the containment and auxiliary areas, while Southern Company Services designed the turbine hall and outside areas. Each A/E had differing report and component indentification methods. In addition separate contracts were placed for large bore pipe prefabrication and large bore size hanger and support prefabrication. Each company had separate report formats and identiflcation systems. In addition, Daniel had to develop a weld numbering system, establish control over welds, welders, radiographs, etc., to meet the quality assurance requirements.

To properly coordinate this information from various sources in different report formats, a set of reports with common headings was prepared. The intent of these reports was to consolidale all available information.

\subsubsection{Heat Number Cross Reference Program}

A method was developed to aid the Quality Control engineers with verification of heat numbers. Components used for critical piping systems have heat number or manufacturing code numbers engraved on them and recorded on installation records.. The QC engineer must match the number on the component with the number on the record and then verify that proper mill test reports are on file in Document Control.

A cross reference report was developed listing heat numbers, manufacturing control numbers, purchase order, and description of the item with the capability of sorting numerically by any column of information. 
The QC department inspects the components when they are received at the warehouse, approves mill certification and keypunches the information into the program. Once each week the program is run in the various sort capabilities and provided to the QC engineer.

\subsubsection{Electrical Status Programs}

Bechtel Corporation, as the architect/engineer for the containment and auxiliary areas, provided automated engineering programs to support installation of raceway and cable. To these programs Daniel added an automated status program for equipment, electrical instruments, and site.. information for cable status. The update, status input, and reports are handled by the field electrical engineering department.

The field electrical engineering department also provides labor time charges and progress quantities to the site cost engineering department.

\subsubsection{Non-Conformance Reports}

To properly monitor the large volume of non-conformance reports that were initiated at the site and to inform all the involved parties in a timely manner, the NCR Status and Analysis program was developed. The types of NCR's were coded into the program to indicate trends that might be developing and also to analyze if any one manufacturer or group was receiving an unusually 'large number of NCR's. 


\subsection{Danie1 Callaway \#1}

The computerized Piping and Related Components Control System will maintain design and status information on each of the following component types: spools, valves, hangers, equipment, and instruments. This system will contain all mechanical components with their related status and descriptive information. The reporting phase of the system has been designed with the user in mind. In addition, a number of systams for use by the electrical disciplines were also developed. The Electrical. Installation System maintains the status of cables, terminations, raceways, equipment, and instruments.

\subsubsection{Piping and Related Component Control System}

Specific inter-relationships w111 be established through the use of the weld numbers which will provide automated monitoring of associated components. For exaluple, a valve ie to be welifed to a piece of pipe and the weld is identffied to each item. If the weld is made and accepted by Quality Control, then it is apparent that the two pieces (valve and pipe) were properly installed. The system will therefore be able to check the appropriate status conditions of each item to verify that these 1tems were received, issued, and reported by the field as installed. This type of reporting will provide the project with automated monitoring capabilities. The reports that will be available from the system fall into three general classes: Detail Component Reports, Exception Type Reports, and File Maintenance/Audit Trail Reports. 
System Input

Initial master file creation will be produced by keying from the Bechtel reports for spools, valves, hangers, equipment, and instruments. Once the files are loaded, then the Bechtel QTS reports will reflect only changed data each month and will be keyed directly from the latest reports. The system will use the following sources of information to obtain current status and component revisions.

Initial File Creation - will use the Bechtel QTS (Quantity Tracking System) Reports to create the files for hangers, valves, instruments, equipment, and large spools. Small spools will come from the Iso detail drawings prepared by the project.

File Maintenance - will use the Isometric and area drawings for component revisions and new items. A source for status changes to the master file would be the QTS reports that could list only monthly activity.

Material Receiving Report (MRR) - will be used for receipt information including entry of the MRR number, date, and weight of each component. Not applicable for small items not assembled, such as hangers. Bill of Material (BOM) - will use the BOM issued in the traveler package for material issues to the field. A copy of the BOM is furnished to Engineering each time an item is issued to the field from the warehouse.

Field Material Requisition (FMR) - will be used for issuance of mechanical equipment and specialty items not shown on the BOM. Approval control for issuance will rest with Engineering. 


\section{Foreman's Daily Time Report (FDR) - will be used by the fleld}

personnel to indicate the installation and other various work status of each component. This will be verified by Engineering prior to the input status for installation being prepared.

Weld Control Record (F101) - different parts of this document will be used to represent the two status conditions that are to be input to the system (i.e., welded and accepted). 'lhe buff cupy wi.11 indicatc the weld has been made and the pink copy will represent QC acceptance of the weld. This source of data will come from QC as a byproduct of the input to their Weld History System.

\section{System Processing}

Status transactions will be keyed at the project on Sycor and transwitted to the central computer center in st. Louls, whese Lhey will be processed and edited. The resulls will le returncd to tho project in the form of an Audit Trail Edit Report. The Sycor 440 Intelligent Terminal will be used at the project for keying input data, for transmitting data for processing, and for receiving the smaller reports for printing from the Union Electrlc data center.

\section{System Output}

Two basic sets of reports will be produced by the system: a standard fixed format detail report with fixed contents which will contain the routine edits, update activities, detall master file listings, and variable exception reports which will have flexible sorting selection 
criteria. These will be the special request reports that are required by the project when they need to review certain component items by area, system, or other selection criteria.

Some of the possible sort sequences that the reports might use are: area code, component ID, system code, start-up number, MRR number, received date, ISO, valve generic mark number, and class/service line number. Certain combinations of these sort sequences might be used in the report selection process.

The following is a brief description of the reports that are proposed for this system.

Spool and Related Component Status - this report will list all spools on the master file along with their related components. The purpose of these reports is to provide component status as they are related to each other through a common weld number.

Valve Details - this report will contain all valves with their related status. Included on this report will be related data, such as: Generic Mark number, MRR number, P.O. number; weight, received date, area number, and related spool sequence number. The purpose of this report will be to identify all valves and their respective status for tracking and monitoring.

Hanger Details - this report will contain all hangers with their related status. Included on this report will be related data, surch as area number, $Q$ class, MRR number, and related spool sequence number. The purpose of this report will be to identify all hangers and their related status for monitoring and tracking. 
Equipment Log - this report will contain all mechanical equipment with related status. Also included on this report w11l be related data, such as spec number, description, MRR number, weight, date received, area number, and related spool sequence number. The purpose of this report is to define and monitor all mechanical equipment components.

Instrument Index - this report will list all Instrument components (only mechanical items are presently considered) with their related status. Also included on this report are some other data, such as description, P\&ID number, spec number, area code, design class cule, panel/rack number, ISO number, Q class, and associated spool sequence number. The purpose of this report will be to identify all instruments and their status for tracking and monitoring.

Edit/Update (Audit Trail) - there will be several of these reports produced, each for the specific master file maintenance being performed. The report will provide a reference for all exit errors, successful updates (changes and additions), and deletes to the master files. Each report will show the before and after contents of each changed record. All edit errors encountered will be listed for each transaction. Corrections will be made on this report and returned to Data Processing for. re-entry. During the update cycle there will be certain exception criteria that will be monitored. These items, such as: installed but not received, already received; or received against different area numbers, will be reported out separately from the edit/update reports. This report will be used by the Mechanical Engineering System Coordinator to track down potential problems, and will provide an automated source for 
referencing invalid entries or for various other problem conditions. Exception Summaries - these reports will show various data sorted in selected sequences depending on the type request from the user department. The volume of output can be excessive; therefore, limits such as line counts or time will be placed in these programs to better control this output. Examples of these type of reports are: items on hold, items not received, items installed, systems completed, remaining welds, all components in given area(s), all materials available, all materials avallable but not issued, all valves by Generic Mark number, footage of a given line within a system, pipe size totals for each status by area and/or system, items not installed past start-up, spools received against different area number, sub-assembly (module) item listings, and items shown as welded but no status shown for received, issued, and/or installed.

\subsubsection{Electrical Installation System}

The computerized Electrical Installation System will maintain design and status lnformation on each of the following component types: cable and termination, raceway, equipment (electrical), and instruments (electrical). The four programs will operate independently in the area

of processing design and status information, but will be dependent on each other for information.

Cable and Termination - the program will be set up using the Bechtel Power Corporation's EE-553 Program Computer Tape with site added information. Figure 2.1 shows the system information flow and 
estimated quantities to be handled in the system. Figure 2.2 indicates the interface between the cable and raceway programs.

Raceway - the program will be set up using the Bechtel Power Corporation's EE554 Program Computer Tape with site added information. Figure 2.3 shows the system information flow and estimated quantities to be handled by the system.

Equipment - Electrical - the program will be set up using Bechte1 Power Corporation's hard copy of their "Equipment Index" for electrical equipment. The jobsite program will utilize the following information from the Bechtel printout: equipment number, item ID and description, location, QC, separation, specification number, and connection drawing number. In addition to the above items, the jobsite program will also have the following inputs: present location, storage requirements, equipment status, Quality Control inspector number and date, and remarks. The input of the jobsite items will be by means of "feedback" trom the Electrical Engineering Department. Revisions to the Bechtel information will be input once a month at the site based on update information from Bechtel. See Figure 2.4 for system information flow.

Instruments - Electrical - the program will be set up using a Bechtel Power Corporation hard copy of their "Instrument Index" for Electrical Instrument action. The program will utilize the following information from the Bechtel printout: instrument number, description, QA, separation group, P\&ID drawing number, specification number, location, panel or rack number, connection drawing number. In addition to the above items, the jobsite program will also have the following inputs: instrument 


\section{CALLAWAY CABLE AND TERMINATION PROGRAM \\ SYSTEM INFORMATION FLOW}

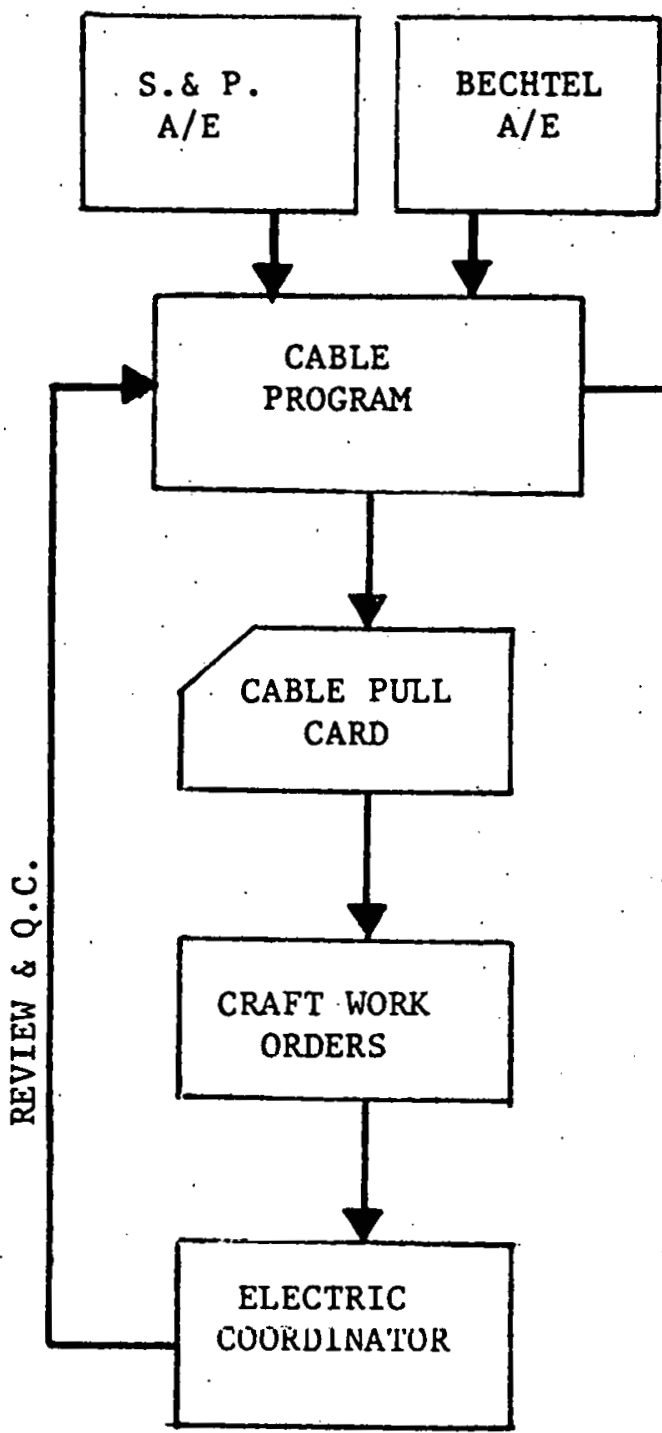

When all raceways have been installed he will issue request to pull cable.

He checks equipment status, then issues request to terminate.

Each cable can have three (3). work orders:

(I) Pull cable

(2) Terminate one end

(3). Terminate other end 
CALLAWAY INTERFACE BETWEEN CABLE AND RACEWAY PROGRAM SYSTEM INFORMATION FLOW

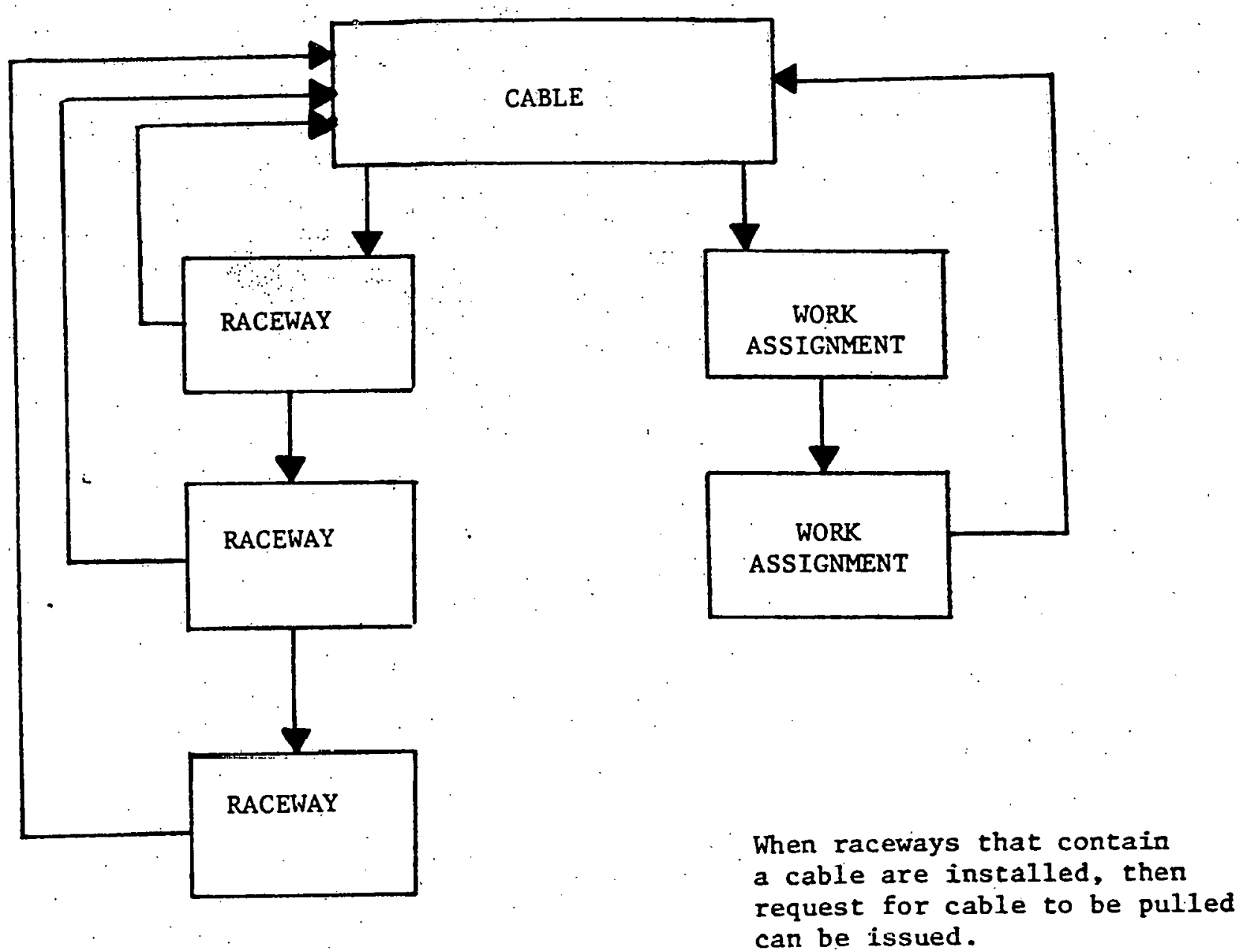

FIGURE 2.2 
CALLAWAY RACEWAY PROGRAM

SYSTEM INFORMATION FLOW

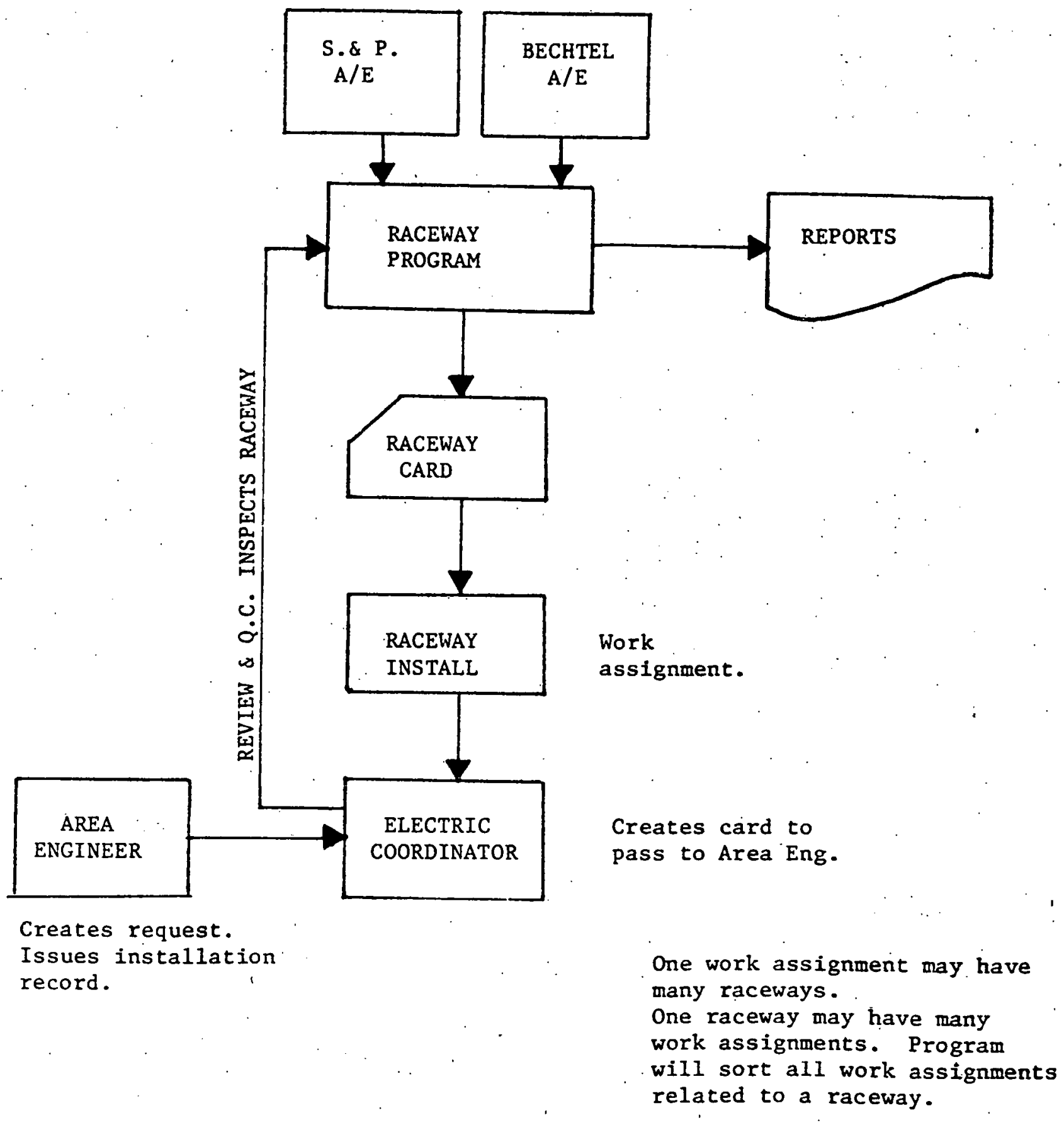

FIGURE 2.3 


\section{CALLAWAY ELECTRICAL EQUIPMENT PROGRAM \\ SYSTEM INFORMATION FLOW.}

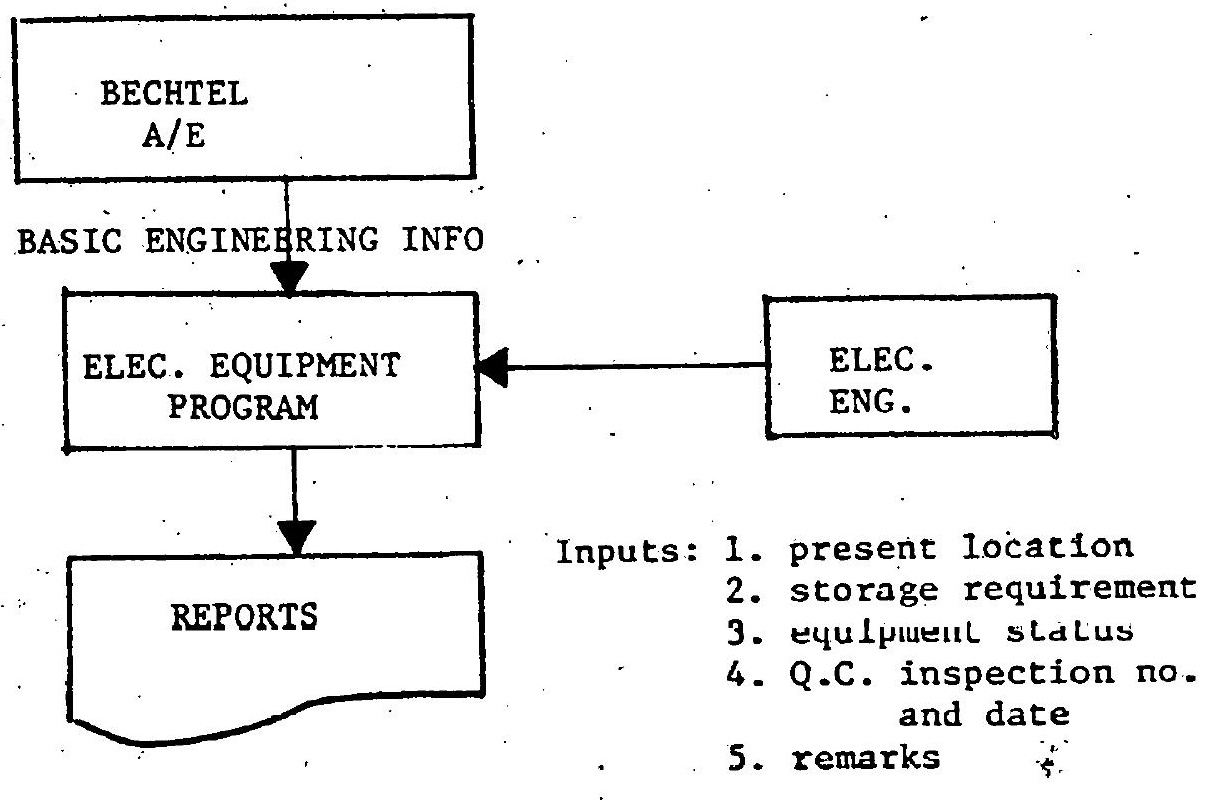

CALLAWAY ELECTRICAL INSTRUMENT PROGRAM

SYSTEM INFORMATION FLOW

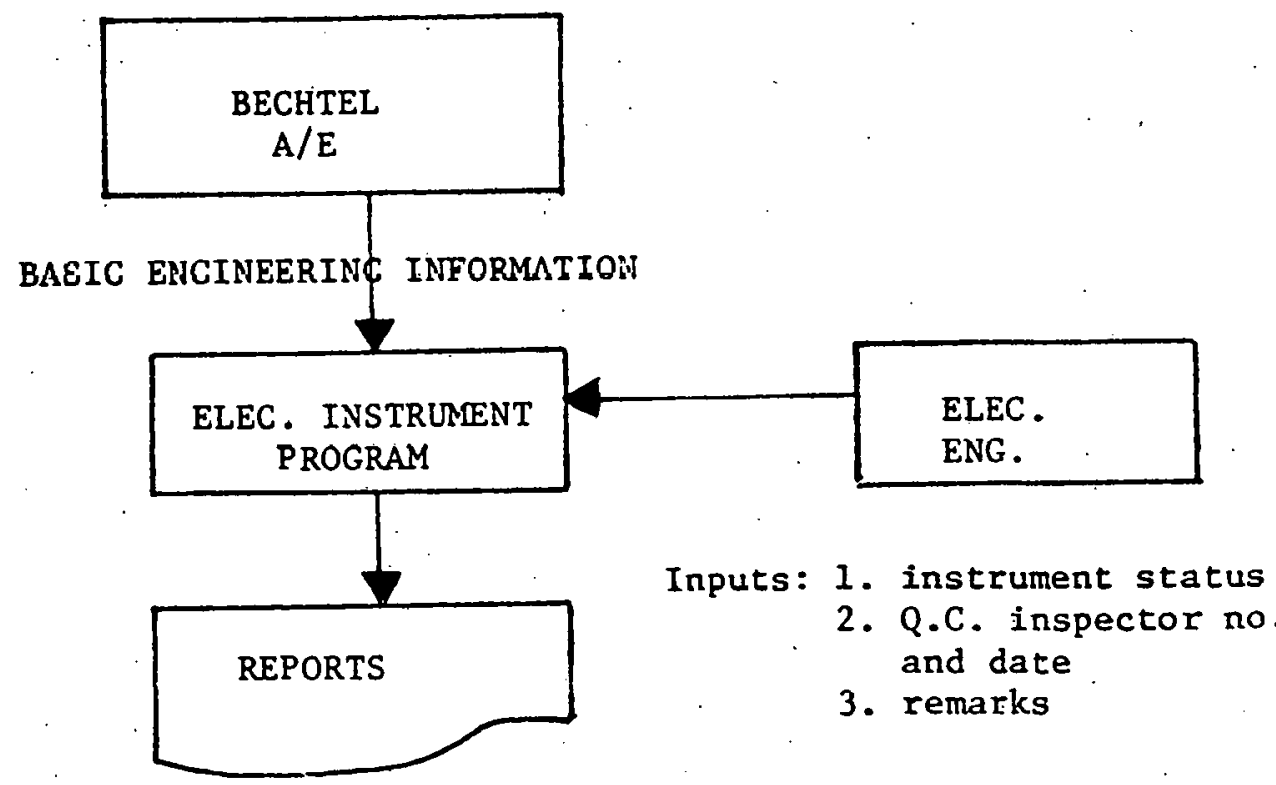

FIGURE 2.4 
status, Quality Control inspector number and date, and remarks. The input for the jobsite added items will be by means of "feedback" from the Electrical Engineering Department. Revisions to the Bechtel information will be input once a month at the site based on update information from Bechtel. See Figure 2.4 for system information flow.

\subsection{Danie1 Fermi 非}

The Component Control System will provide component information to aid construction installation and start-up of the power facility. Daniel International will employ several automated systems at Fermi II for Detroit Edison. The planned project Construction Control systems will be as follows:
(1) Component Control System
(2) Document Indexing and Retrieval
(3) Material Status Control
(4) Engineering Documents Register
(5) Scheduling - PROJACS
(6) Field generated documents
(7) Payrol1

The following is a discussion of the Component Control system that will be employed at Fermi II as it relates to Construction Control. The basic information relating to a reportable component will be stored in the computer in an organized format so that it can be retrieved and sorted in a variety of ways. Figure 2.5 shows the general layout of the Component Control System. The component number is the basic 
SPECIFIC DATA APPLICABLE

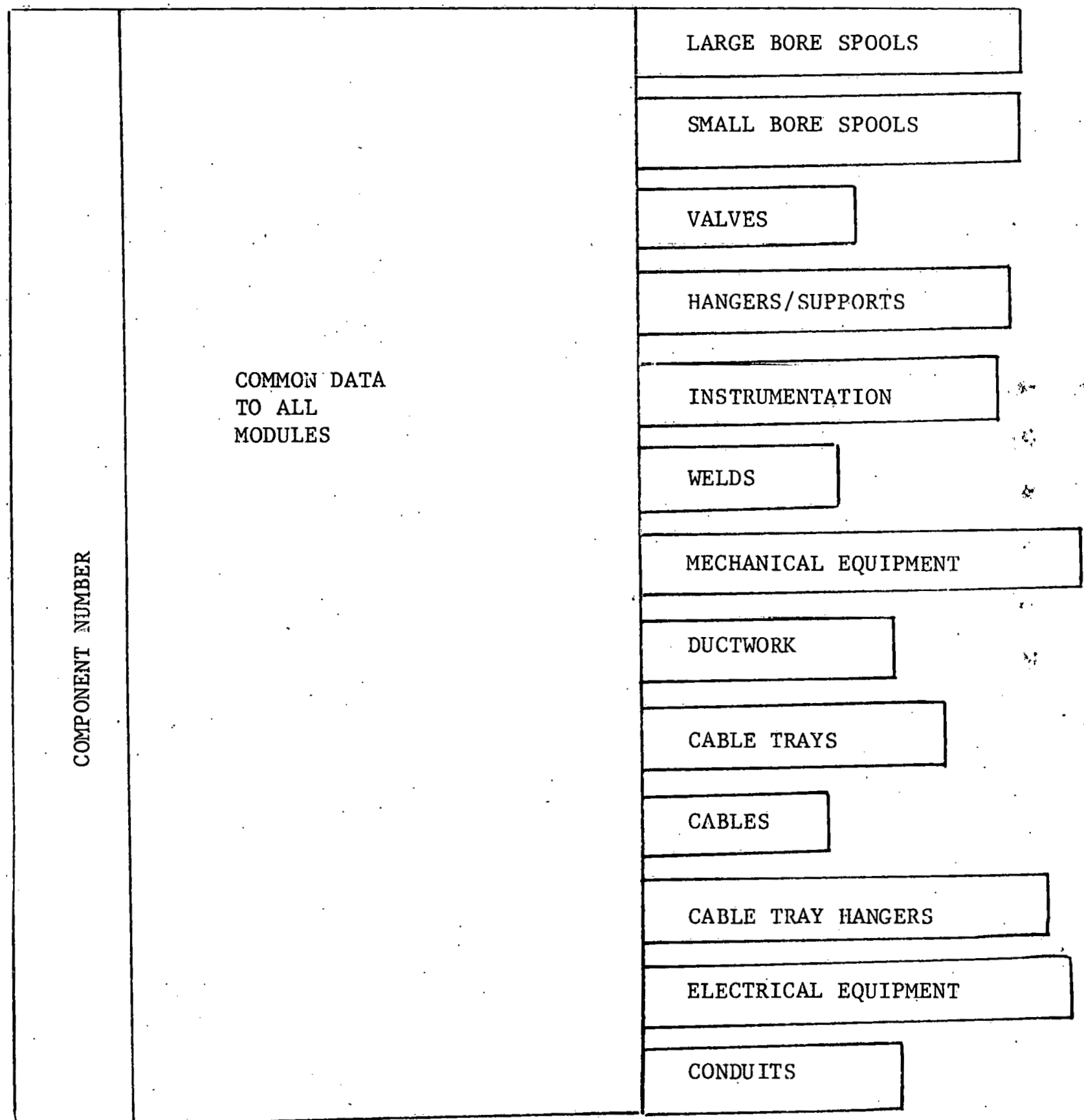

FIGURE 2.5 
identifier for all items. There is a block of data which is maintained that is common to a11 components. The components are then broken down into modules which cater to the particular needs of various types of components. The volume of information to be handled by this system is immense. Figure 2.6 illustrates the magnitude of data to be controlled by the Component Control System. Two sub-systems can be attached to the Component Control System if desired.' These sub-systems are the Welder Performance System and the Welder Qualification System; and they can function jointly with the "Welds" module.

Retrieval of Information from the Component Control System may. be performed by subcontractors, Estimating, Warehousing, QC/Engineering, Cost Control, Scheduling, Start-Up groups, and the Operations group. The information must be updated by the same groups with the exception of subcontractors. The key update group will be Estimating, since they will be responsible for initiating each component entry. Input supplied by this group includes plant system identification, permanent plant location, safety classifications, design document references, and component level data. The deletion or revision of a component will be controlled by this group: Table 2.3 lists the data elements in the Component Control System which are common to a11 modules. Figure 2.7 is a sample input sheet for the data.

Software on Daniel's central computer facility will support data communications with the jobsite, high volume batch processing, remote job entry, and generalized inquiry/report preparation. The following types of standard reports will be generated: 
Large Bore Spools

Small Bore Spools

Valves

Hangers/Supports

Instrumentation:

Fabricated racks

Rack mounted

Locally mounted

Air operated valves

Tubing $3 / 8^{\prime \prime}$ and under

Tubing $1 / 2^{\prime \prime}$

Supports

Welds

Mechanical Equipment

Ductwork

Cable Trays

Cables

Cable Tray Hangers

Electrical Equipment

Conduits

\begin{tabular}{c|c} 
TO BE & TOTAL \\
PLANT
\end{tabular}

FIGURE 2.6: ESTIMATED NUMBER OF COMPONENTS FOR EVERY MODULE 
TABLE 2.3

DATA ELEMENTS

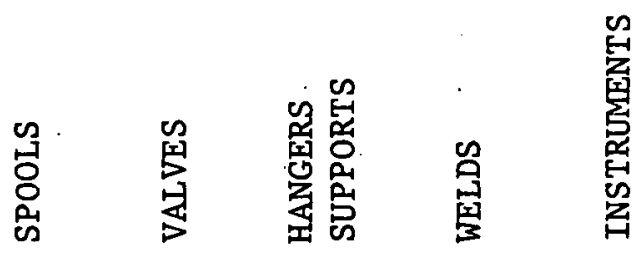

1.

1. Unique Identification

2. PIS Number (Plant Info. System)

3. Vendor ID

4. Building/Area

5. Elevation

6. Drawing Number

7. Scheduled to Receive

8. Received Date

9. QC Hold

10. Installed or Erected

11. Completion Sign off

12. Cost Code

13. Start Up Number

14. ISO Number

15. Safety Class (ASME)

16. Material

17. Bill of Material Number

18. Vendor Part Number

19. Warehouse Location

20. Date Issued

21. Field Requisition Number

22. Hydro Test Code

23. Check Documentation Comp1.

$\begin{array}{lllll}\mathrm{X} & \mathrm{X} & \mathrm{X} & \mathrm{X} & \mathrm{X} \\ \mathrm{X} & \mathrm{X} & \mathrm{X} & \mathrm{X} & \mathrm{X} \\ \mathrm{X} & \mathrm{X} & \mathrm{X} & & \mathrm{X} \\ \mathrm{X} & \mathrm{X} & \mathrm{X} & \mathrm{X} & \mathrm{X} \\ \mathrm{X} & \mathrm{X} & \mathrm{X} & \mathrm{X} & \mathrm{X} \\ \mathrm{X} & \mathrm{X} & \mathrm{X} & \mathrm{X} & \mathrm{X} \\ \mathrm{X} & \mathrm{X} & \mathrm{X} & & \mathrm{X} \\ \mathrm{X} & \mathrm{X} & \mathrm{X} & & \mathrm{X} \\ \mathrm{X} & \mathrm{X} & \mathrm{X} & \mathrm{X} & \mathrm{X} \\ \mathrm{X} & \mathrm{X} & \mathrm{X} & \mathrm{X} & \mathrm{X} \\ \mathrm{X} & \mathrm{X} & \mathrm{X} & \mathrm{X} & \mathrm{X} \\ \mathrm{X} & \mathrm{X} & \mathrm{X} & \mathrm{X} & \mathrm{X} \\ \mathrm{X} & \mathrm{X} & \mathrm{X} & \mathrm{X} & \mathrm{X} \\ \mathrm{X} & \mathrm{X} & \mathrm{X} & \mathrm{X} & \mathrm{X} \\ \mathrm{X} & \mathrm{X} & \mathrm{X} & \mathrm{X} & \mathrm{X} \\ \mathrm{X} & \mathrm{X} & \mathrm{X} & \mathrm{X} & \mathrm{X} \\ \mathrm{X} & \mathrm{X} & \mathrm{X} & & \mathrm{X} \\ \mathrm{X} & \mathrm{X} & \mathrm{X} & & \mathrm{X} \\ \mathrm{X} & \mathrm{X} & \mathrm{X} & & \mathrm{X} \\ \mathrm{X} & \mathrm{X} & \mathrm{X} & & \mathrm{X} \\ \mathrm{X} & \mathrm{X} & \mathrm{X} & & \mathrm{X} \\ \mathrm{X} & \mathrm{X} & \mathrm{X} & \mathrm{X} & \mathrm{X} \\ \mathrm{X} & \mathrm{X} & \mathrm{X} & \mathrm{X} & \mathrm{X}\end{array}$

SUBCONTRACTOR RELATED

DATA ELEMENTS

24. Engineering Hold

25. Contractor Cost Code

26. Contractor Schedule No.

27. Fabric. Work Package

28. Erection Work Package

29. Estimated Manhours

30. Actual Manhours

$\begin{array}{lllll}\mathrm{X} & \cdot \mathrm{X} & \mathrm{X} & \mathrm{X} & \mathrm{X} \\ \mathrm{X} & \mathrm{X} & \mathrm{X} & \mathrm{X} & \mathrm{X} \\ \mathrm{X} & \mathrm{X} & \mathrm{X} & \mathrm{X} & \mathrm{X} \\ \mathrm{X} & \mathrm{X} & \mathrm{X} & \mathrm{X} & \mathrm{X} \\ \mathrm{X} & \mathrm{X} & \mathrm{X} & \mathrm{X} & \mathrm{X} \\ \mathrm{X} & \mathrm{X} & \mathrm{X} & \mathrm{X} & \mathrm{X} \\ \mathrm{X} & \mathrm{X} & \mathrm{X} & \mathrm{X} & \mathrm{X}\end{array}$


COMPONENT CONTROL SYSTEM

BUILDING / ZONE

SYSTEM/ASSEMBLY

ISOMETRIC

Q.A.

GROUP

GENERAL ARRG. DWG.
COMPONEHT INITIATION FORM

$$
\begin{aligned}
& \text { ACTION CODE } \\
& \text { ' } b \text { ' -add } \\
& \text { ' } c \text { ' -change } \\
& \text { ' } d \text { '. -delete- }
\end{aligned}
$$

\section{DATE}

SHEET $\overline{O F}-$

EXTENDED BY

CHECKED BY

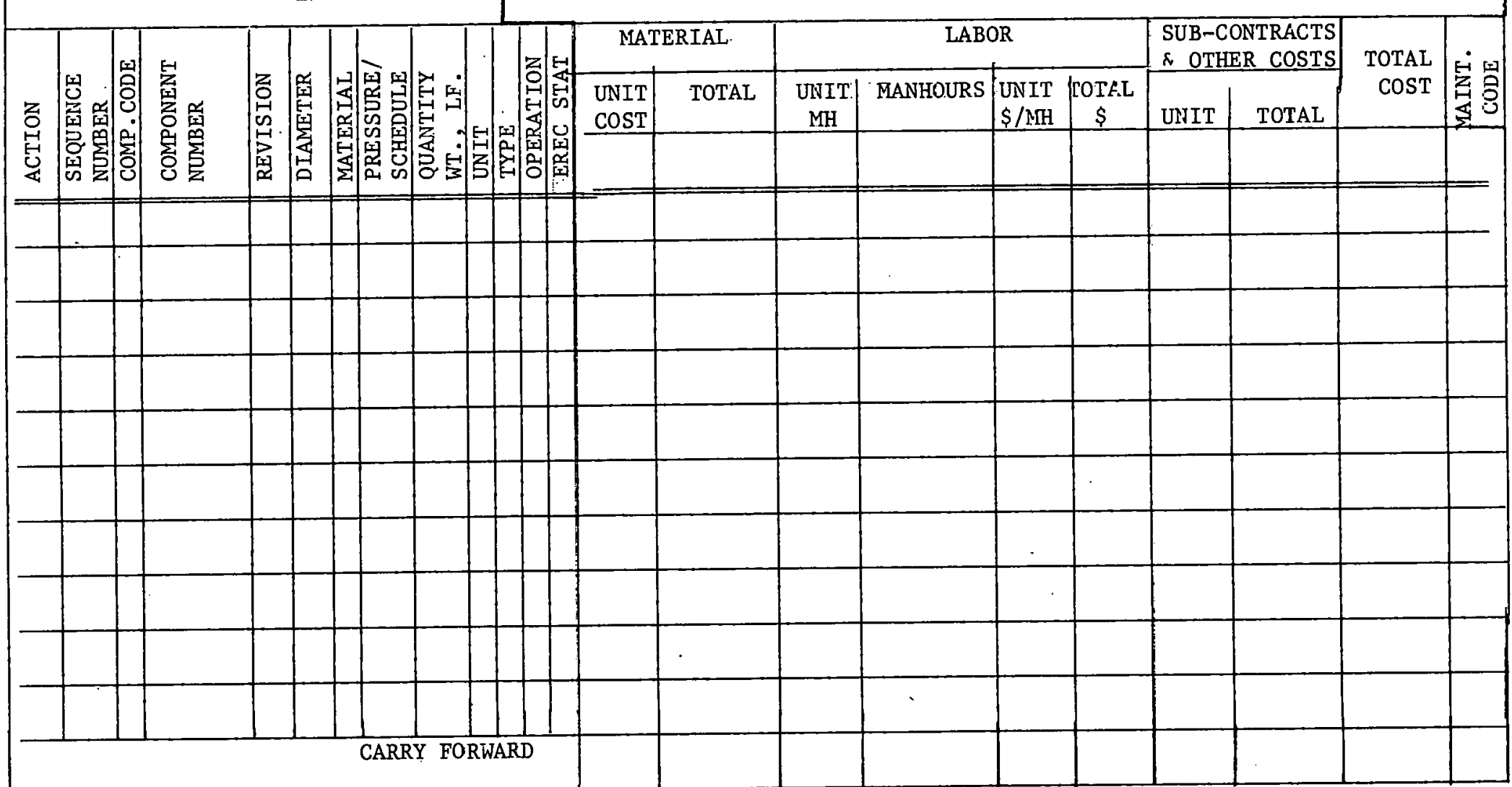

FIGURE 2.7 
- Status of all components

- Summary types of reports

o Building/elevation sorts for planning

o Start-Up Number sort

o Welder Performance Report

High level compilers such as COBOL, Data Base Management Systems, communications, and remote job entry software are currently available on the central computer at Greenville, South Carolina. Remote job entry software will permit the jobsite to submit jobs to the central computer, have the central computer execute the request based on priority and resource availability, and transmit the results back to the project site.

The overall project Construction Control system is illustrated in Figure 2.8. This shows an outline of the basic scope of the overall system and the relationships which will be implemented in computerized format. The broken lines represent manual flow and dependency of information between individual sub-systems. Ultimately the relationship between the Component Control System and the Document Indexing and Retrieval System will have great importance to the start-up and operation of the plant. One contains the engineering information for every component and the other contains all available documentation for every component. The key is the component number, but several others will be used for searching. For example, the following data will be in both systems: system number, location (bullding, elevation), start-up number, type of component, drawing number, etc. One of the most important 


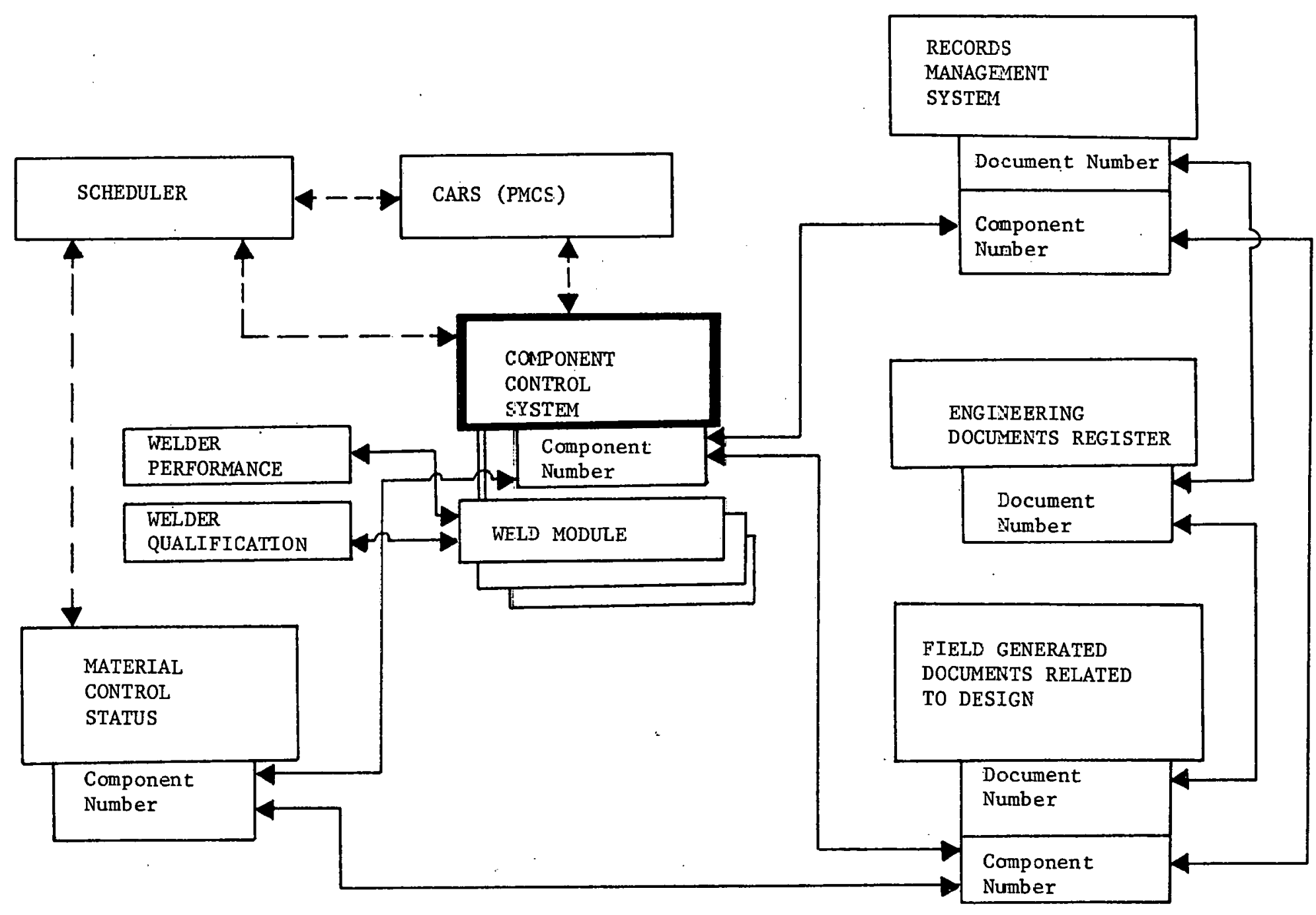

FIGURE 2.8: GENERAL OUTLINE OF SYSTEMS SCOPE AND RELATIONSHIPS 
benefits of the relationship between these two sub-systems will be to determine that all required documentation for every component was generated and is available.

\subsection{Nuclear Power Services P.M.P.}

During the initial construction phase of Fermi II, Nuclear Power Services, Inc. had implemented a Plping Management Program to handle quantities, costs, and procurement functions. The program was discontinued with the shutdown of construction in 1974. Daniel International was selected as Construction Manager to restart the construction of Fermi II in 1ate 1976, and has utilized information in the Piping Management Program to help establish the installed portion of the plant.

This program consists of sub-programs for spools, hangers, valves, and some miscellaneous items. Under this system, data preparation and take-off was prepared by NPS personnel in New York. The report cycle was set up on a one-month basis with the shortest turn around cycle of 7 to 10 days (cycle time includes sending information-processing in New York and recelving printouts at the project site).

The information was entered into the program by four input card types. Input card type 1: Title card for piping drawings.

3: Title card for hanger drawings.

5: Pipe spools, valves, miscellaneous, hangers, and information.

7: Pipe spools, valves, miscellaneous, hangers, and information. 
The program maintained delivery information, vendor status, installation status, building zone, basis for required delivery, and descriptive information for the pipe spools, valves, and hangers. Welds were also included and referenced back to isometric drawings.

\subsection{GPU Project Control System}

The GPU Project Control System consists of five separate computer programs. The five programs are: Accounting, Estimating and Cost Reporting, Expenditure Forecasting, Scheduling, and Material Control.

All five programs are based on the work package identification numbers and purchase order numbers, which provide a coding and sorting mechanism for data manipulation. All reports. were designed to satisfy a threetiered hierarchy of end user:

(1) Corporate/Interagency - one page functional report combining numerous work packages into eight (8) functional groupings for management overview. Also, a one page overview report of the same information by prime Federal Power Commission (FPC) account classification.

(2) Project Management - a three or four page summary level report by work package for exception analysis.

(3) Field/Working level - detailed reports by purchase order, dollar commitments, EPC subaccounts, etc., sorted by work package. The data is input at the construction site and transmitted via site terminals to the central computer complex for processing. The edited list is automatically transmitted back to the site terminals for error correction and review. Low volume output reports are printed at the 
construction site, while detailed high volume reports are printed on high speed printing equipment in district offices. Accounting Module

The accounting module records all of the commitments and expenditures for each project. Each commitment and expenditure is coded by purchase order number, work package number, and FPC account number. Estimating and Cost Reporting Module

This module compares the current month's estimate with the prior month's estimate and the base estimate for the job. The current estimate includes actual to date expenditures and commitments as well as adjustments authorized by the project cost engineer. Some of the standard monthly reports are: a summary by eight function groups, a summary by FPC Prime Accounts, a Package Analysis (summary leve1), a Detall Package Analysis by FPC subaccounts, a commitment ledger, and Directury of authorized account and packages.

\section{Expenditure Forecasting Module}

The module permits the end-user to forecast the anticipated future expenditures by work package. The program permits the user to assign a standard forecast "profile" of expenditure to each work package or to input a hand-tailored expenditure profile.

\section{Schedule Module}

GPU only puts "once through" work in the schedule network. This Includes only direct labor with immediate crew support that is planned within a typical estimating crew make-up. It does not include indirect labor, overhead, and support labor. The module utilizes critical path 
method techniques (CPM) to identify the most critical activities in a project for management attention and corrective action. The system utilizes precedence logic with overlap and can provide resource leveled schedules, forecasted installation rates, and craft manning levels. These programs are updated and run weekly, bi-weekly, or monthly, depending on the maturity of the project, and reports can be on 28 different sorts. Each activity is keyed to a work package such that various scheduling reports can be produced for each construction package.

\subsection{McDonne11 Douglas COMPAID}

COMPAID is a computer system for the drawing of pipework isometrics and the control of piping material and cost. The system correlates planning, engineering, estimating, purchasing, costing, stock control, accountancy, and construction functions. The system was developed over a number of years by The Power-Gas Corpuration (a member of the Davey-Ashmore Group) following liaison between Power-Gas, London (petrochemical plants); Power-Gas, Stockton (chemical plant) and the Davy-Ashmore Computer Services Division. Because of the diversity of projects undertaken by Power-Gas, it was essential that the system should be flexible and as comprehensive in application as possible. The result is an integrated system capable of operation in a wide range of projects requiring many types of specifications. COMPAID is an engineering contractor's system which can do the following: 
o Draw piping isometrics

o Produce Bills of Materials

- Prepare order documents

- Do preliminary material take-offs

- Produce various control reports for piping materials

o Estimate labor and material for piping projects

- Compare actual labor and material costs with projections

The system is available for lease through McDonnell Douglas Automation Company. They provide the following:

(1) Full user documentation of the system covering: systems, programs, operating procedures, piping component numbering system, and general user manuals together with full program listings and flow charts.

(2) Implementation and testing of user machine.

(3) Training for user staff.

COMPAID is available on IBM, Control Data, and Univac computers.

The isometric drawings can be produced off-line but, in a multiprogramming environment, the plotting can be done with a separate program using a tape unit and about 2K (1CL 1900 Series) of core. The system is constructed on the "building block" principle which means that it can be used for material take-offs only or for isometric drawings plus material take-off. Additionally, material cost, fabrication, and erection cost can be included as can schedule requirements and various forms of material and stock control. 


\section{Inputs}

Specifications: When piping specifications have been written in the standard manner by the engineer, the basic code for the type of component specified is selected from the code directory and the size range for that type of pipe entered. If there is more than one type of pipe in the basic specification he enters all the basic codes for these with the size ranges. He then does the same for flanges, fittings, bends, bolting, and gaskets. The computer then generates the code numbers for all the items that could be covered by that specification and puts these into its store.

Preliminary Material Take-offs: A preliminary material take-off can be made from an engineering flow sheet or layout. The take-off man writes down for each line the amount of pipe, etc. and the computer will total all like material for ordering. As the job progresses further, more accurate material take-offs can be made and input to the machine, and the computer will produce a report showing the laresc requiremenls, the previous requirements and the balance.

Isometric Drawing and Material List: Working from a model or general arrangement drawing the draftsman first enters the parameters of the line and then, starting from one end, works along the pipe from one change of direction to the next, indicating the component required.

Care has been taken to simplify data preparation. All input documents are carefully validated before acceptance by the machine, and incorrect entries are listed and returned to the user for immediate action. 


\section{Operation}

Order Control: On request the computer will examine the latest. estimated requirements, take into consideration the quantity of free stock in stores, and produce additional orders were necessary. The required delivery dates are included.

Progress Control: On request, a report is produced which indicates the quantities of material on order but not yet delivered, with required and expected dates.

Production Drawing and Information: One form of material take-off includes minimum directional details which enable isometric drawings to be produced. The isometric includes a full material list divided into shop and site items, full line parameters, and any special notes that apply generally to the drawing. The computer compares the material required to produce the isometrics with the material delivered to the fabricator and produces (a) a list of the isometrics' which can be completed, (b) a material list for the said 1sometrics, (c) a list of the outstanding lines and (d) a material list for the outstanding lines with expected delivery dates to enable the fabricator to plan his forward loading.

Stock Control: On request, the computer will produce requisitions on stores to deliver material to specified destinations. This material may have entered stores temporarily until the opening of a site, or it may be stock as returned from previous contracts. The computer keeps a paper record of the stores stock position. This enables stores to insure that stock allocated to a contract is not issued except for that contract. 
Data Files: The computer keeps a material price library, a schedule of fabrication and erection rates, and a specification file for 1ts own use.

Fabrication and Erection Cost: Fabrication and erection cost are produced automatically from the isometric input data and the contractor rates. This includes painting and insulation cost. Feedback from site on the completed operations enables strict control of construction. Output

- Price-description library

- Specifications

- Material take-off details with summary

- Valve schedule

o Order documents

- Comparison of allocation and requirements

- Current position of material on order

- Purchase Order expediting report

o. Stores dispatch/advice nutes

- Isometric drawing and material list

- Line fabrication schedule

o Stock position

- Line schedule

- Material totals for batch of isometrics

- List of missing prices

- Fabrication/erection schedules

- Estimated fabrication and erection work content 
- Comparison of estimated and measured work content

- Analysis of measured fabrication and erection work content

- Insulation quantities and cost reports

- Paint quantities report

$\underline{\text { Summary }}$

The Rust Engineering Company, Birmingham, Alabama, has made several trial runs and is now depending fully on the COMPAID system in a paper mill installation using the material control portion without the drafting service. To date they are very satisfied with the system performance. The quantity take-off people find the input sheets easy to use after a short period of use. It is a definite improvement over the manual stock cards system used for many years to allocate the material. Requisitions are still rewritten before transmitting to Purchasing because the computer form is not accepted by the Purchasing Department. The construction supervision use the Bill of Materials printed by the computer and like the summaries available.

\subsection{Northern States Power ITS}

Northern States Power has developed a system to account for the purchase, delivery, installation, and testing of all items contained in the computer files. There are eleven (11) files maintained in the computer.

(1) The Master Punch List file consists of all known problems, discrepancies, and punch list items with emphasis on systems nearing pre-op testing. It tracks only unresolved items and can sort reports 
by responsibility, by system, by pre-op definition, by document, and by priority code and/or date.

(2) The Summary Black \& Veatch Purchase Order file lists all purchase orders issued by Black \& Veatch for units 1 and 2 . Reports can be issued based on status of equipment not received at site, status of all equipment purchased, equipment status by schedule activity number, equipment status for contractors, and status of equipment to be delivered off-site.

(3) The Valve Files list individually ali valves by tag number. Reports can be issued on status by tag number, status by purchase order number, status of undelivered valves, and status of motor-operated and control valves.

(4) The Accessory Equipment/Instrument files list all instruments by tag number. The issued reports can sort on status by purchase order number, undelivered status by purchase order number, status by contractor, local instrument status, and status by accessory equipment code.

(5) Component Equipment files list equipment in detail for status information. They 1ssue reports that can sort by status by purchase order number, undelivered status by purchase order number, status for contractors, and listing of equipment by system.

(6) The Schematic Drawing files list schematic drawings in the detail required for turnover of electrical systems from the contractor to the QC engineer. The report checks electrical systems checklist status. 
(7) The Special Data files combine data from the Valve, Accessory Equipment, and Component Equipment files. Combining data from multiple files offers an expanded range in reporting status. These files issue exception reports that can sort on status by start-up preop definitions; component and accessory equipment installation, checkout status; component and accessory equipment installation, checkout status by area; and status by schematic drawing number.

(8) Status of pipe and hanger pieces furnished by Black \& Veatch.

(9) The Door Status Report Iists the status of all doors furnished by Black \& Veatch.

(10) The Structural Steel file is used to maintain delivery status of all pieces. Its reports show status by area number, status by shop number (vendor's shop control number), and status by load number (vendor's bill of lading number).

(11) Current status of a11 computer files.

\subsection{Bechte1 QTS (Quantity Tracking System)}

QTS is a system developed by the Bechtel Corporation to keep track of material. It was originally designed to supplant independent systems used by each of the three major power plant construction divisions within Bechtel (San Franclsco, Washington area, and Los Angeles). These three formerly independent entities were combined into the ThermoNuclear Power Organization. It then became necessary to standardize the information exchange between these divisions. Preliminary designs called for an all-inclusive system. Implementation proved so difficult 
that interim systems were developed to be used prior to implementation of the overall system.

The basic thrust of the QTS system is to track items in order to determine through which part of the procurement cycle they have proceeded. Only items designated as unique were tracked in this system. The method of tracking quantities is based on a principle known as the increasing accuracy method. Each quantity has a theoretical final number. As the project matures from design through construction, the numbers begin to get closer and closer to this net quantity (which is of course modified as changes occur). Tracking quantities accurately allowed the development of useful cash flow predictions.

The basic interaction of QTS in the procurement cycle can best be shown by Figure 2.9. The basic card produced for the QTS system was a five-part carḍ indicating receipt, issue, installation, and a file copy.

The use of QTS allowed an evaluation of vendors. Sorts on vendor number were possible. With the accumulation of delivery data determinations could be made as to the relative reliability of different vendors. In evaluating late deliveries, however, resource constraints were considered. As an example, if work is proceeding in a particular area and some component has arrived after work had moved to another area, it may not delay the job if the delivery was one or ten days late, provided resumption of work was constrained to begin more than ten days later. 


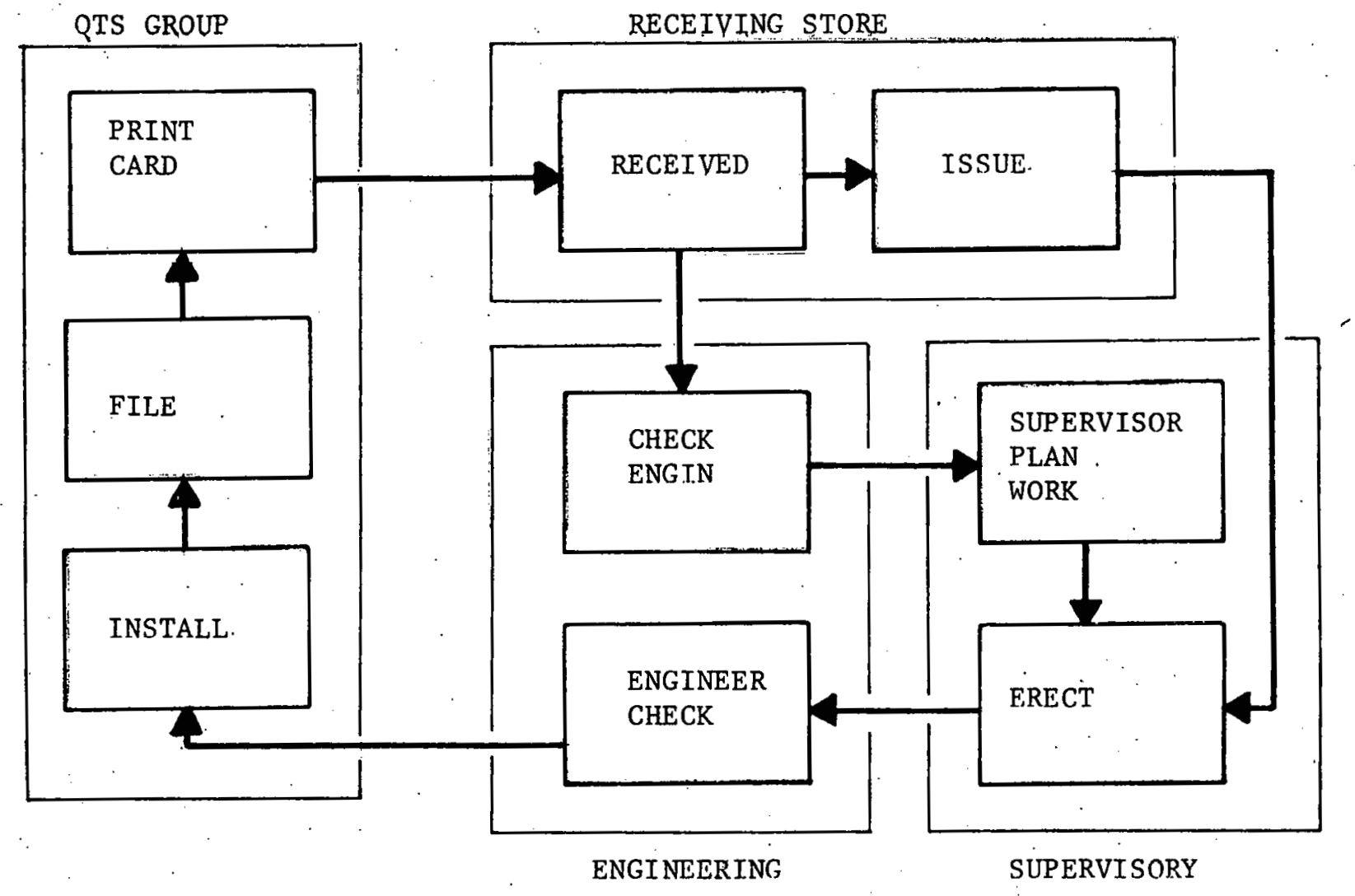

FIGURE 2.9: INTERACTION OF QTS IN THE PROCUREMENT CYCLE

\subsection{Georgia Power Punch List}

The Punch List Program has been reviewed in detail in Appendix $B$. In terms of field construction control, 14 different completion points can be monitored. They are In Building, Installed, NonDestructive Testing, 
Hydro Test, Construction Acceptance Test, Temporary Turnover, Permanent Turnover, System Turnover, Operational, Painted, Welded, Insulated, and Pins Pulled.' For further detalls the reader is referred to page 52. of Appendix B. 
CHAPTER III

\section{Problems with Existing Systems}

The great number of simultaneous activities that take place on a nuclear power plant site requires a well coordinated master plan. Area Engineers in charge of the various work areas must be organized, knowledgeable of schedule requirements, and have the managerial skills to efficlently complete the work at hand.

To enable the first level management to complete the work, certain Items of information are needed to maintain a smooth, orderly flow of construction activity. These items of course vary from discipline to discipline and work face to work face. Basically, however, material, manpower, money, and equipment are necessary for the accomplishment of a work task. Direction on how, when, and where is supplied through management based on the items of information at hand.

In terms of materials, the first level manager must be aware of any design changes being made or already made to the work being performed. He must make an immediate decision whether to stop work and complete other work or go ahead with Quality Assurance's approval of the work at hand. This manager's primary concern is not with costs, but his immediate supervisor is very concerned with costs. At this level code numbers are transformed into names and descriptions. Regulations are verbalized rather than quoted by number. The manager must also be informed of shortages of materials on hand. If he is aware of any 
material inadequacies, he can make more efficient use of the manpower on hand.

Most of the problems inherent in the systems discussed in this report have already been discussed in the section on material tracking systems and the reader is invited to review that material. 


\section{REFERENCES}

(1) Bonny, J. B. and Joseph P. Frein, Editors, Handbook of Construction Management and Organization, New York: Van Nostrand Reinhold Company, 1973, page 6.

(2) Budwani, Ramesh, "Nuclear Plant Lead Time, Costs, Labor, and Material Takeoffs," Power Engineering, April 1974.

(3) Budwani, Ramesh, "Nuclear Power Plants,". Power Engineering, June 1975.

(4) Nilsen, Arthur L., "SACCS: Schedule and Cost Control System," AACE Bulletin, February 1975.

(5) Kanga, B. K., "SNUPPS: An Experience in ..." Civil Engineering, July 1977. 
ADDENDUM A

BULK PIPE MATERIAL INPUT/OUTPUT DATA 
RATIONALE FOR INPUT/OUTPUT INFO. SHEETS

Answer the following questions based on information needed or generated for the following areas:

1. Design related

2. Material characteristics

3. Scheduling

4. Stock control

5. Safety related

6. Inspection related

7. Work completion entries

8. Productivity $r \in$ lated (manhours or equipment)

9. Cost

10. Worker qualifications 


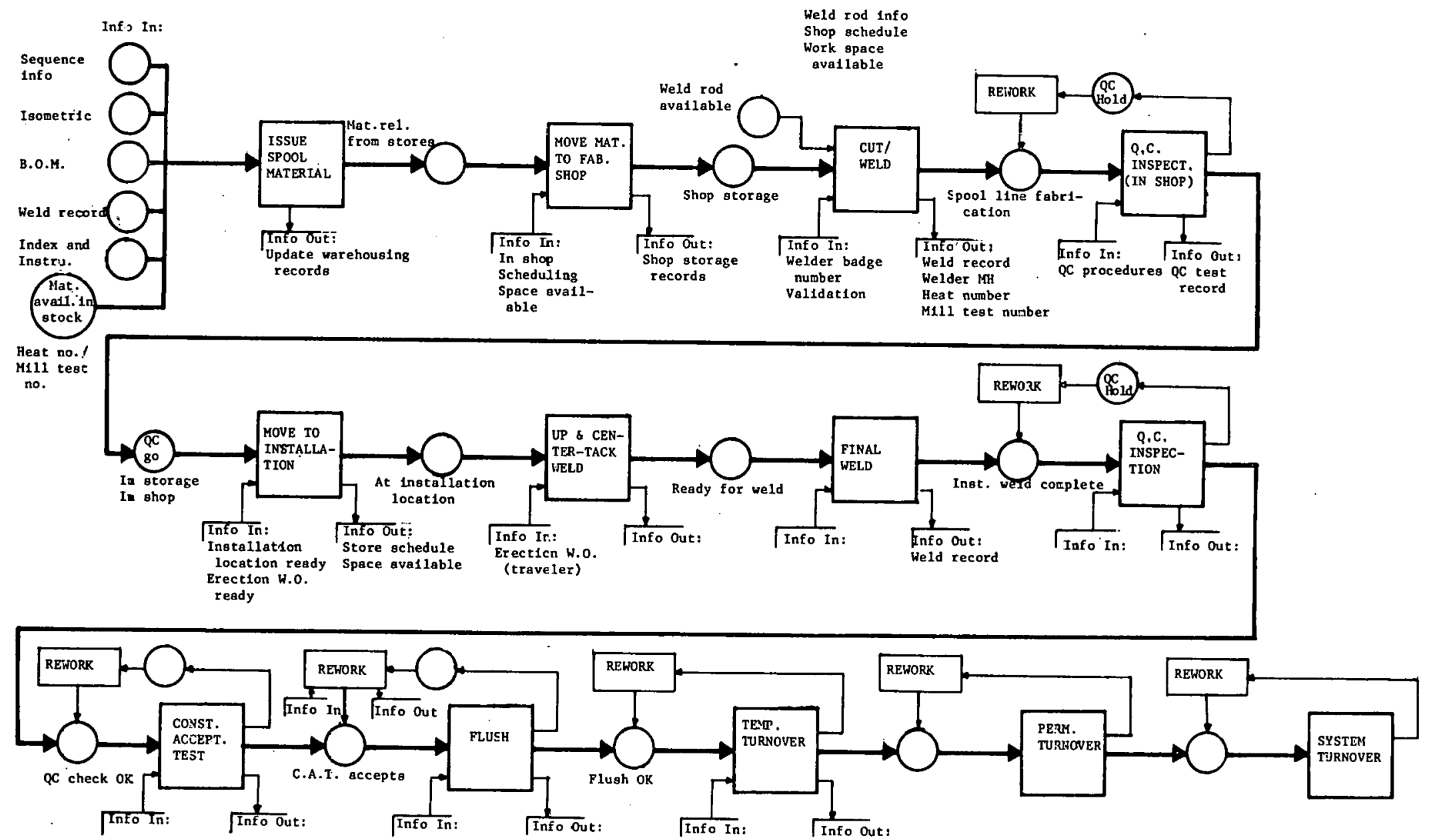


MECHANICAL (BULK MATERIAL)

Pipe

Activity

Issue spool

material

(1)

Move material to fabrication shop

(2)

Cut/Prepare end weld

(3)
Information In

Sequence information (Schedule)

Isometr1cs drawings

B. O.M.

Weld record

Index and Instrumentation

Requirements

Material availability

Q.A. Process sheet

Work space availability

Normal fit into work schedule

Welder badge number

Welder qualification/ validation

Weld rod available

Welding procedures

Material record
Information Out

Update warehouse inventory

Foreman of issue

Account number

Date of issue
Shop storage records

Weld record

Welder MH

Heat number

Mill test number
Q.C. inspection (in-shop)

(4)
Q.A, procedures

All weld information

All material data
Report (hold or release) 


\section{Activity \\ (cont'd) \\ Move to in- stallation \\ (5) \\ Up and center- tack weld}

(6)

Final weld

(7)

\section{Q.C. inspection}

(8)

Construction

Acceptance Test

(9)

Flush test and hydro test

(10)
Information In

Information Out

All design and spec.
data

Location ready

Rigging equipment. ava ilability

Work area access

Check location on drawings

W.o. ready

Hangers positioned

Installation procedure

W.o. (traveler)

Preheat (proper welding procedures followed)

Welder qualification

Q.A. procedures

Weld data

Material data
All previous weld and material data

Pipe in place and sealed

Valves in place

for testing
Release shop fab. work area

Update schedule of pipe in place

Plan next section of pipe

Update schedule

Weld data

Update schedule

Report (hold or release)
Release to allow static
test on pipe

Report for next test and turnover 
MECHANICAL (BULK MATERI

Pipe.

Activity

(cont'd)

Temporary turnover

(11)

Permanent turnover

(12)
Information In

Clean area around pipe for maintenance

Accepted from prior tests

Acceptable condition for Operation (Production) Department
Information Out

Maintain for system tests

Report 
ADDENDUM B

MECHAN ICAL (SMALL COMPONENT) INPUT/OUTPUT DATA 

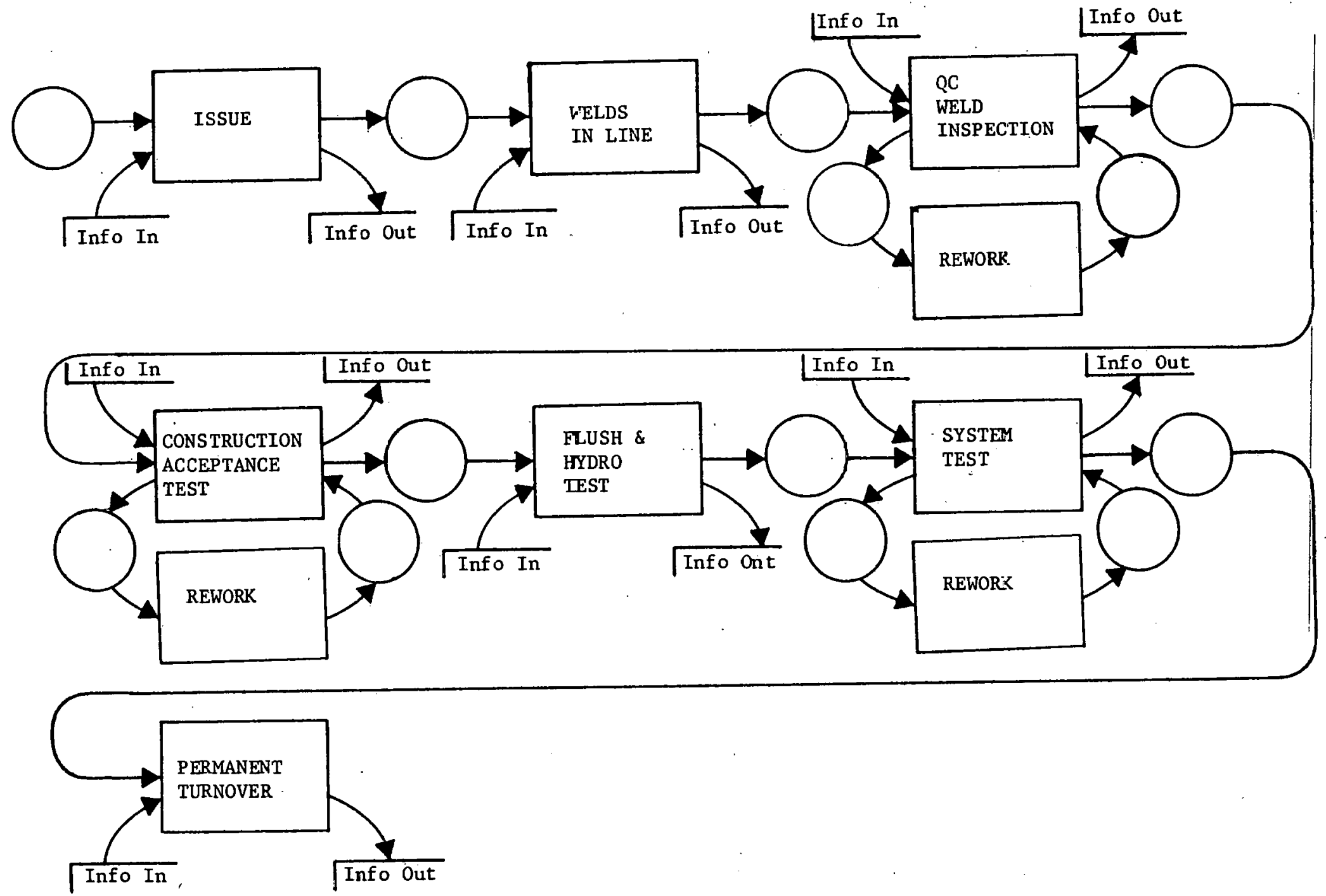


\section{Input/Output Sheet}

MECHANICAL (SMALL COMPONENT)

Small valves

Activity

Issue

(1)

We1ds in line

(2)

Q.C. weld inspec=tion

(3)
Information In

Field requisition

Schedule

Isometric drawings

Index

Area of installation

Valve number

Weld location

Isometric drawings

Notification

Outputs from "welds in 1ine" activity
Information Out

Foreman of issue

Account number

System number

Date of issue

Warehouse record update

Priority

Welder qualification no. Rod heat no., size, type

Batch number

System number

Area elevation

Condition

Number of amps used

Rate of trave1

Heat of "re pass"

Results of:

Visual Inspection

Liquid Penetrant Test U1trasonic Inspection $\mathrm{X}$-Ray test

Inprocess verification of: Weld speed

Heat of "repass" 
Activity

Information In

(cont'd)

Construction Acceptance test

(4)

Flush and Hydro test

(5)
Notification of completion

Q.C. records

System status

Production completion reports

Q.C. records

Specifications

Previous recorde

All Q.C. and Production documents to customer
Information Out

Amps used and volts Rod number Length of pass Slag embedment Carbon content

Acceptance
System test

(6)

Permanent turnover

(7)
Test results

Test number

Acceptance report 
ADDENDUM C

MECHANICAL (LARGE COMPONENT) INPUT/OUTPUT DATA 

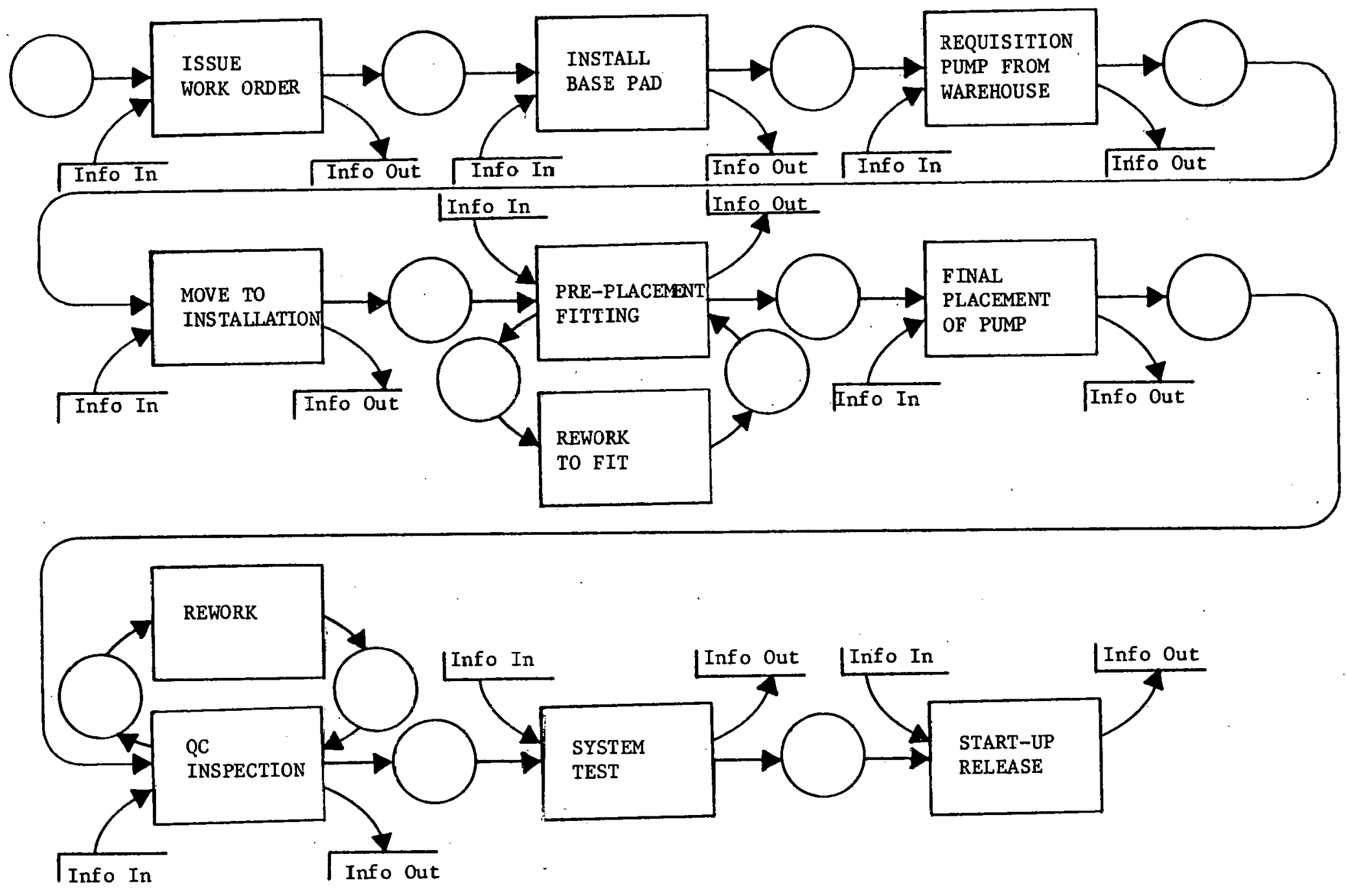


\section{Input/Output Sheets}

MECHANICAL (LARGE COMPONENT)

Pumps

\section{Activity}

Issue Work Order

(1)

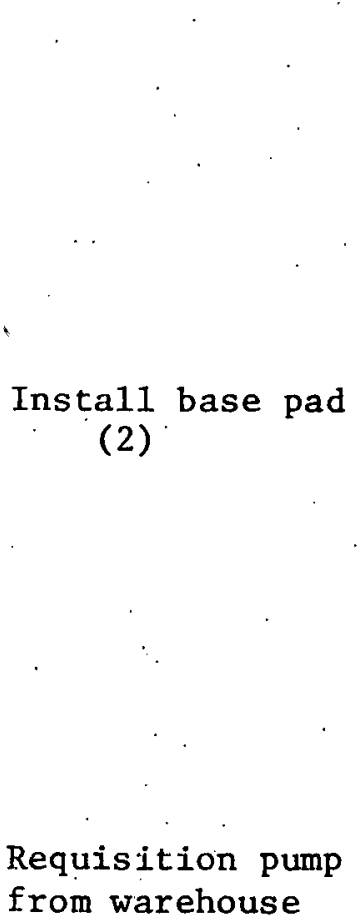

(3)

\author{
Information In \\ Design drawings \\ Scheduling information \\ Pump I.D. number \\ System number
}

Area and elevation

Work Order number, as before

Vendor requirements

Design drawings

Procedures

Field requisition
Information out

Foreman to do work

Priority

Account number

Date of issue

Concrete pour and batch number

Foreman

Materials used

Time used

Account number

Foreman of issue

Date

System number

Pump number

Update material records

Move to installation. Request for fork $1 \mathrm{ft}$ location

(4)

Amount of fork lift time

Amount of crane time

New location status 
Activity

Pre-placement

fitting

(5)

Final placement

of pump

(6)

Q.C. inspection

(7)

System test

(8)

Start-Up

Release

(9)
Information In

Design drawings

Vendor drawings

Location

Manhours

Account number

System number

Bystem updato

Notification

Specifications

Procedures

Manufacturer's specs.

Manufacturer's drawings

$a$
Information Out

Problem reports

Manhours

Crew size

Foreman

Installation repori
Acceptance report

Rejection report

Minor Variation report

Documentation of work procedures report
Qualification report

Change in status

Change in status
All previous documents

All documents 
ADDENDUM D

CIVIL (BULK MATERIAL) INPUT/OUTPUT DATA

D-1 
Shop drawings,

specs, other

drawings,

QC OK

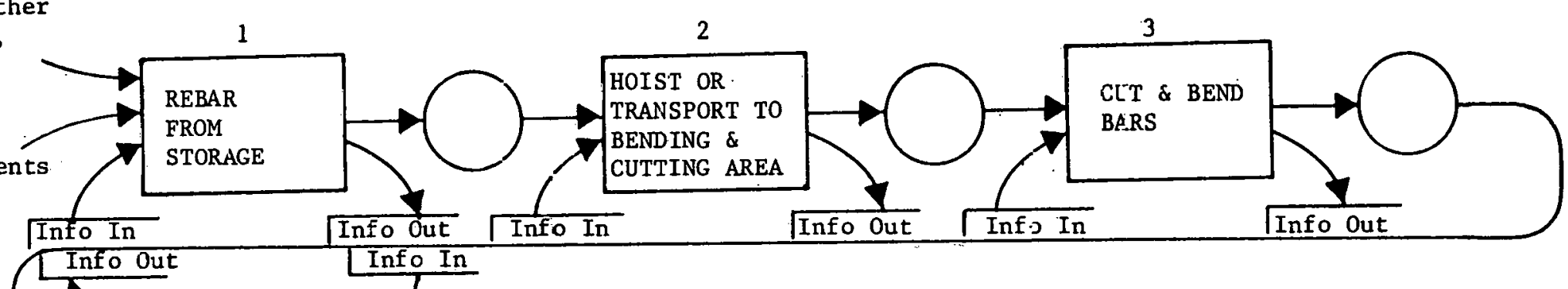
requiremen

(f orms,

etc.)

Info In

Info Out
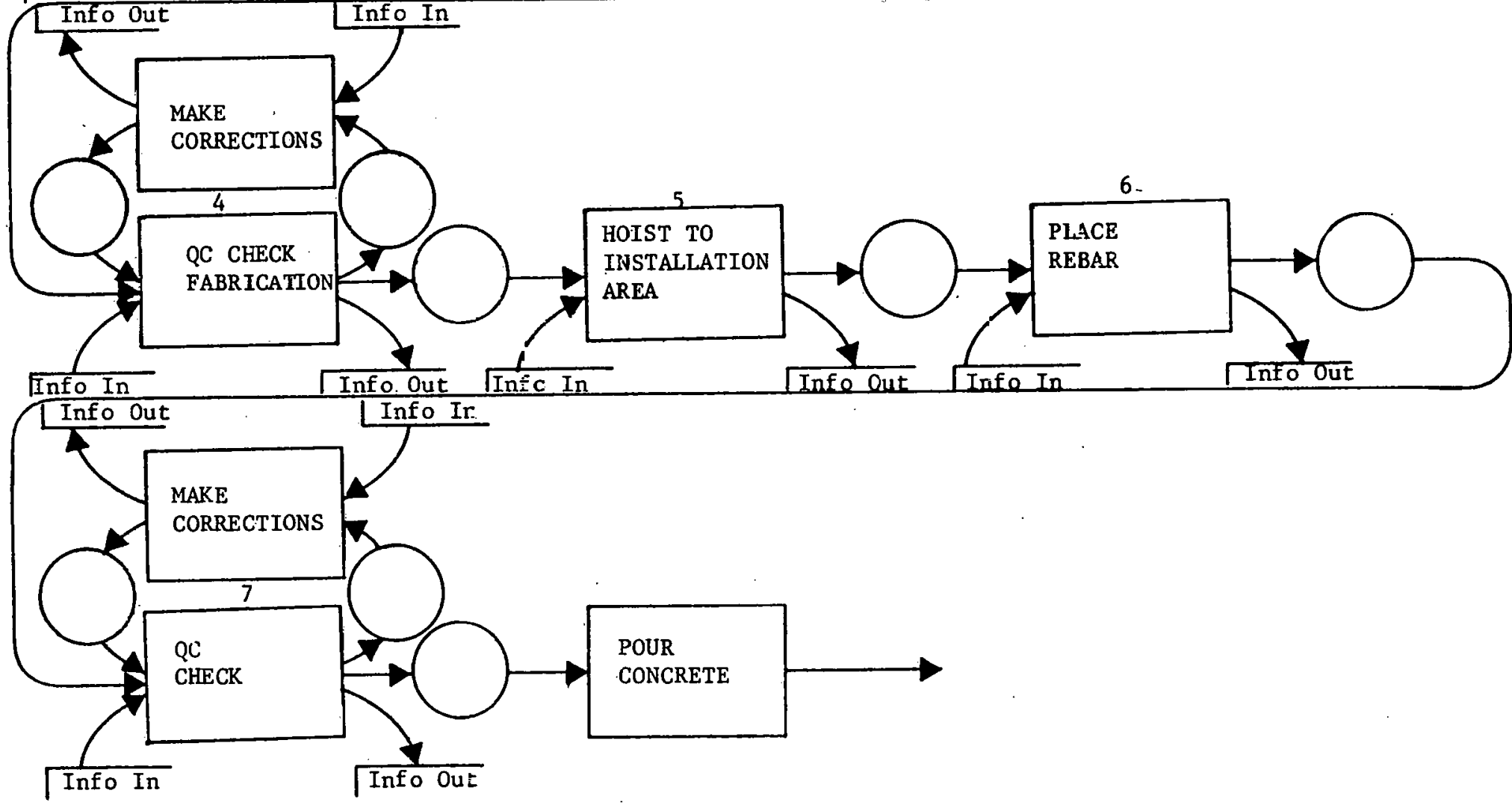
Input/Output Sheet

CIVIL (BULK MATERIAL)

Reinforcing Steel

\section{Activity \\ Rebar from \\ storage}

(1)

\author{
Information In \\ Rebar Shop Drawing \\ Rebar Fabrication \\ Sheets \\ Foreman name and \\ crew number \\ Work Activity number \\ Area Number \\ Cost Code number \\ Date requested from \\ storage \\ Authority order or \\ Work Order
}

Hoist or transport Notice from warehouse to Bending and Cutting Shop

(2) or storage area

Weight

Numbers to be hoisted or transported

Foreman in charge and crew number

Pickup and destination points

Approximate time requilred

Date hoisting needed Activity number Cost Code number Area number
Information out

Record of rebar removed and report to Material Control (quantity, type, size, heat number, mill test|number, storage area)

Removial date

Work:Activity number charged against

Cost Code number with manhours and materials charge

Notify Transport group

Equipment assigned to do work

Number hours equipment used and date

Manhours used

Quantities transported

Work Activity Number charged against

Cost Code number charged against

Crew number and status

Equipment status 
CIVIL (BULK MATERIAL)

Reinforcing steel

\section{Activity}

Cut and bend bars

(3)
Q.C. check fabrication

(4)

Make corrections to fabrication

(5)
Information In

Rebar in cutting and bending area

Activity number

Cost Code numbers

Shop Drawing

Cut and bending sheet

Crew assignment for bending and cutting

Duration for the acllvity

Area number

Contract drawings and specifications

Shop drawings

Activity number

Area number

Crew number doing

fabrication and foreman

Date complete

Pour date

Corrections and/or conflicts (fabrication)

Inspection Report

Crew number assigned

Work Activity number

Area number

Cost Code number
Information out

Manhours used against each Cost Code

Activities worked and code against time

Date completed and date started

Corrections or conflicts arising from fabrication

Bending and cutting complete to Material Control

Srew number and status

Notification to Q.C.

Inspection Report

Area number and descriptio

Corrections or approval

Crew number installing bars

Corrections complete

Manhours against Cost Code number and Work Activịty numb Crew number and status. 


\section{Activity}

Hoist to installation area

(6)

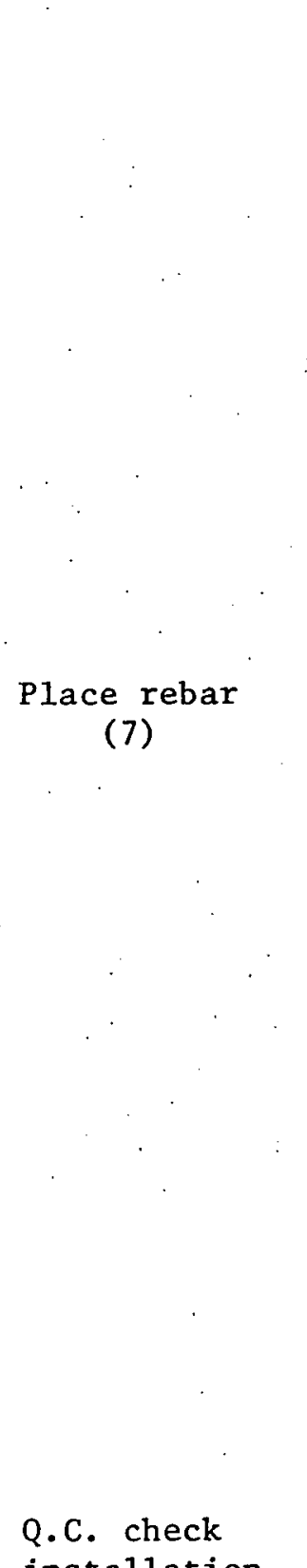

installation

(8)
Information In

Q.C. approva1

Lbs. to be hoisted

Crew number and foreman assigned

Pickup and destination points

Time required

Date needing hoisting

Activity number

Cost Code number

Area number

Formwork ready

Crew number assigned

Tools availability

Activity number and duration

Cost code number

Rebar hoisted and ready

Cut sheets

Shop drawings

Contract drawings

Notification from installatión liew

Shop drawings and cut sheets

\section{Information Out}

Equipment assigned to work

Manhours

Equipment hours

Quantities hoisted

Work Act1vity number charged

Cost Code number charged

Crew number and status

Equipment status

Notification to Q.C. of completion

Manhours against Work Activity number and Cost Code number

Date completed and date started

Corrections or conflicts arising from installation

Installation completion to Material Control

Crew number and status

Tools status

Inspection Report

Notification of pour approval 
CIVIL (BULK MATERIAL)

Reinforcing steel

Activity

(cont'd)

Make installation corrections

(9)
Information In

Contract drawings and specifications

Activity number

Area number

Crew number doing installation

Date completed

Pour date

Corrections and/or conflicts from installation

Inspection Report

Crew number assigned

Work Activity number and duration

Área number

Cost Code number

Tools available
Information Out

Corrections complete to Q.C.

Manhours against Aclivity number; Cost Code numbers

Crew number and status

Tools status 
ADDENDUM E

CIVIL (SMALL COMPONENT) INPUT/OUTPUT DATA 


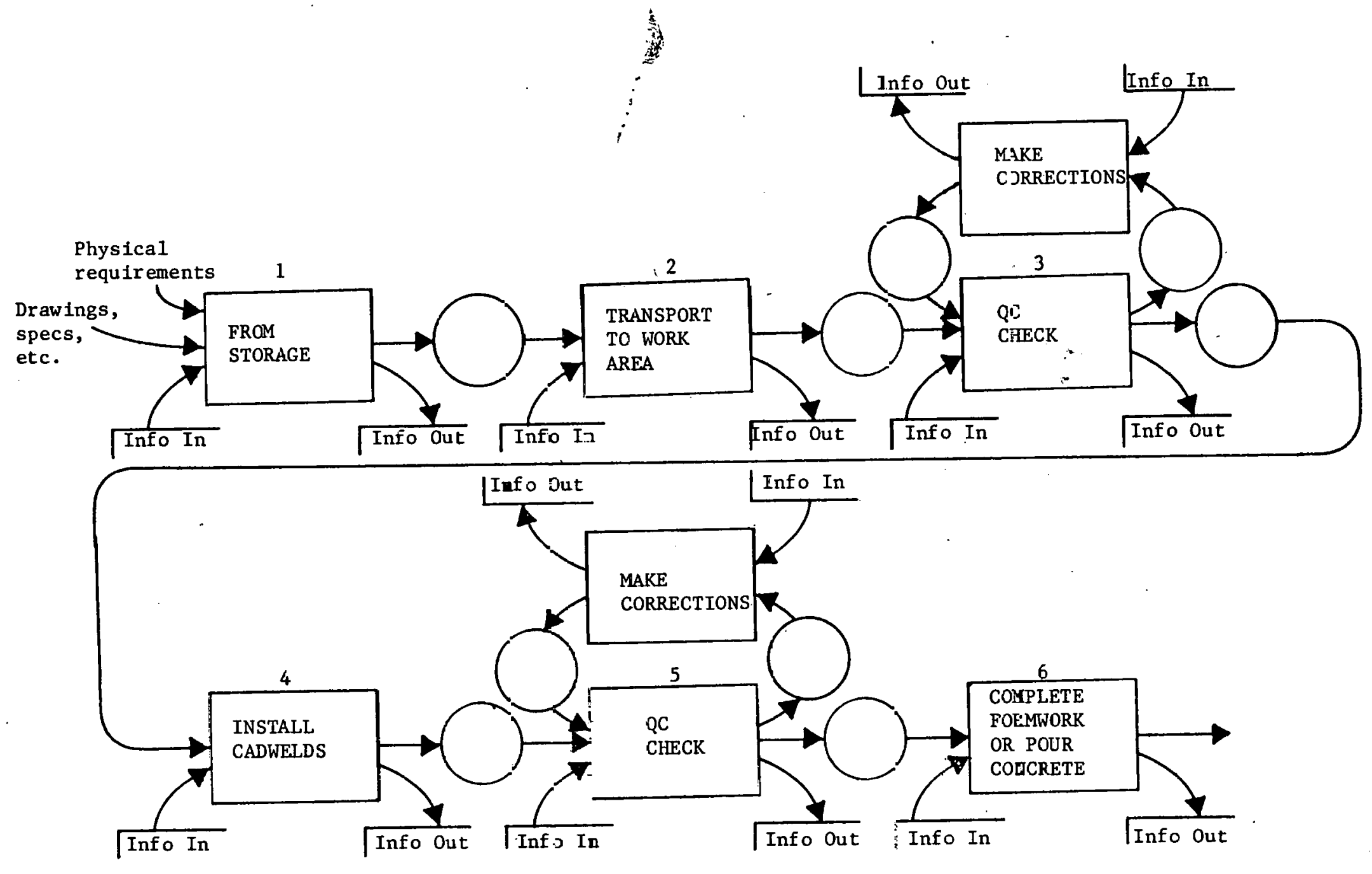




\section{Input/Output Sheet}

CIVIL (SMALL COMPONENT)

Cadwelds

$\begin{array}{ll}\text { Activity } & \text { Information In } \\ \begin{array}{l}\text { Cadwelds from } \\ \text { storage }\end{array} & \begin{array}{l}\text { Rebar shop drawing } \\ \text { and cadweld listing }\end{array} \\ & \text { Work Order } \\ & \text { Foreman name and } \\ \text { crew number } & \text { Work Activity number } \\ & \text { Area number } \\ & \text { Cost code number }\end{array}$

Transport to work area

(2) or Storage Area
Information Out

Record of cadwelds removed and report to Matertal Control (size, quantity, balance remaining, Storage Area number)

Date cadwelds issued

Hours against Work Activity number

Hours against Cost Code number

Materials against Cost Code number

Notify Transport group

Notice from warehouse

Equipment assigned to do work

Quantities to be transported

Number of hours equipment used against Cost Code

Foreman in charge and

Date equipment used crew number

Pick-up and destination points

Time required

Hours against Activity

number

Hours against Cost Code number

Crew number and status

Date transporting

needed

Equipment status

Activity number

Cost Code number

Q.C. approval of field storage

Area number 


\section{Activity}

Q.C. check

(3)

\section{3)}

Make corrections

(4)
Information In

Contract drawings and specifications

Shop drawings and cadweld list

Activity number

Area number

Foreman and crew number to perform installation

Welder qualifications

for all mechanics

Date from storage

Field storage approval

Inspection Report

Crew number assigned

Work Activity number

Cost Code number

Area number

Tools available

Rebar ready

Formwork ready

Crew number assigned

Welder qualifications

for crew

Tools available

Activity number

Duration of work
Information Out

Inspection Report

Cadwelds approved

Cadwelds missing

Cadwelds not approved

Area number

Crew number
Corrections complete

Hours against Cost Code numb

Hours against Activity numbe

Crew number, status

Tools status

Notify Q.C. of completion

Hours against Activity numbe

Hours against Cost Code numb

Date started and completed

Record of conflicts and clarifications

Installation to Materia! Control 
Activity

(cont'd)

Q.C. check

(6)

Make corrections

(7)
Information In

Cost Code number

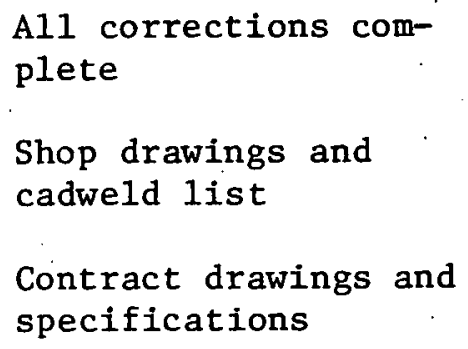

A11 corrections complete

Shop drawings and cadweld list

Contract drawings and specifications

Notification of completion

Contract drawings and specifications

Shop drawings and cadweld list

Activity number

Area number

Crew number and

foreman

Welder qualifications

Record of conflicts

and clarifications

Inspection Report

Crew number assigned

Work Activity number

Cost Code number

Area number

Tools available
Information Out

Crew number and status

Tools status
Inspection Report

Cadwelds approved

Cadwelds not approved

Area number

Crew number
Corrections complete

Hours against Cost Code number

Hours against Activity number

Crew number and status

Tools status 


\section{ADDENDUM $F$}

CIVIL (LARGE COMPONENT) INPUT/OUTPUT DATA 
Documentation
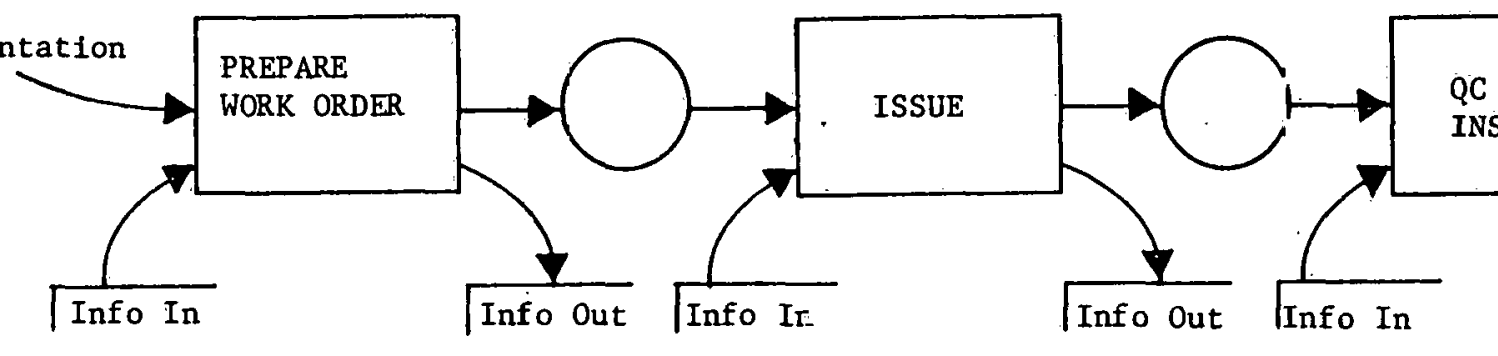

QC

INSPECTION

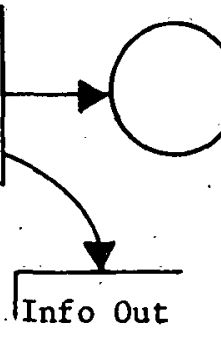

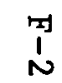

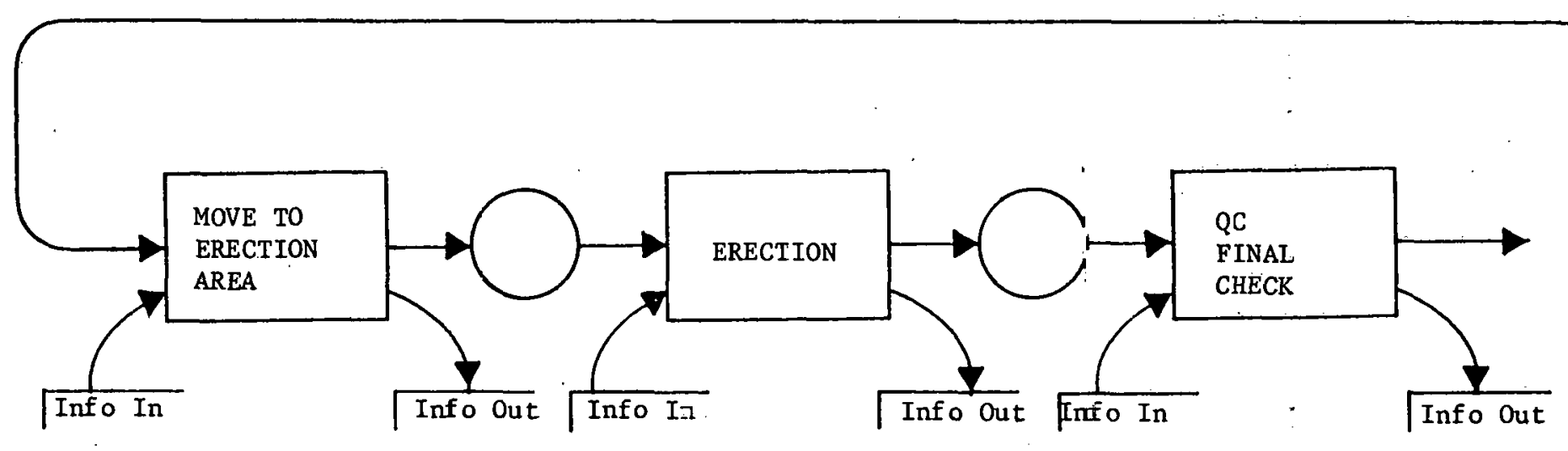


Input/Output Sheet

CIVIL (LARGE COMPONENT)

Structural steel

\section{Activity \\ Prepare Work \\ Order.}

(1)
Information In

Sequence information

Drawings
Information Out

Equipment required

Materials required

Approximate manpower requirements

Approximate time required
Issue materials

(2)

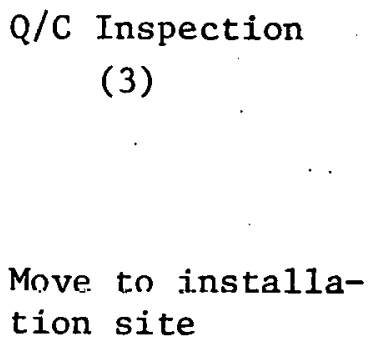

Material available in stock

Heat number

Mil1 test number

Material required (I.D. number)

Who requests materials

Who authorizes material requests

Appropriate drawings

Q/C procedures

Appropriate drawings

Member size

Member weight

Required crew size
Updating of warehouse records

Who requests material

Who authorizes material request

Cost information
Q/C Test records

Cost information

Crew performing work

Equipment used

Cost information 
CIVIL (LARGE COMPONENT) Structural steel

Activity

(cont'd)

Installation

(5)

Q/C Fina1 Inspection.

(6)
Information In

Required equipment

sizes

Installation location

Drawings

Required crew size.

Required equipment

sizes

Member size

Member weight

Q/C procedures

Appropriate drawings
Information Out

Crew performing work

Equipment used

Cost information

Q/C information

Q/C Test records

Cost information 
ADDENDUM G

ELECTRICAL (BULK MATERIAL) INPUT/OUTPUT DATA

G-1 

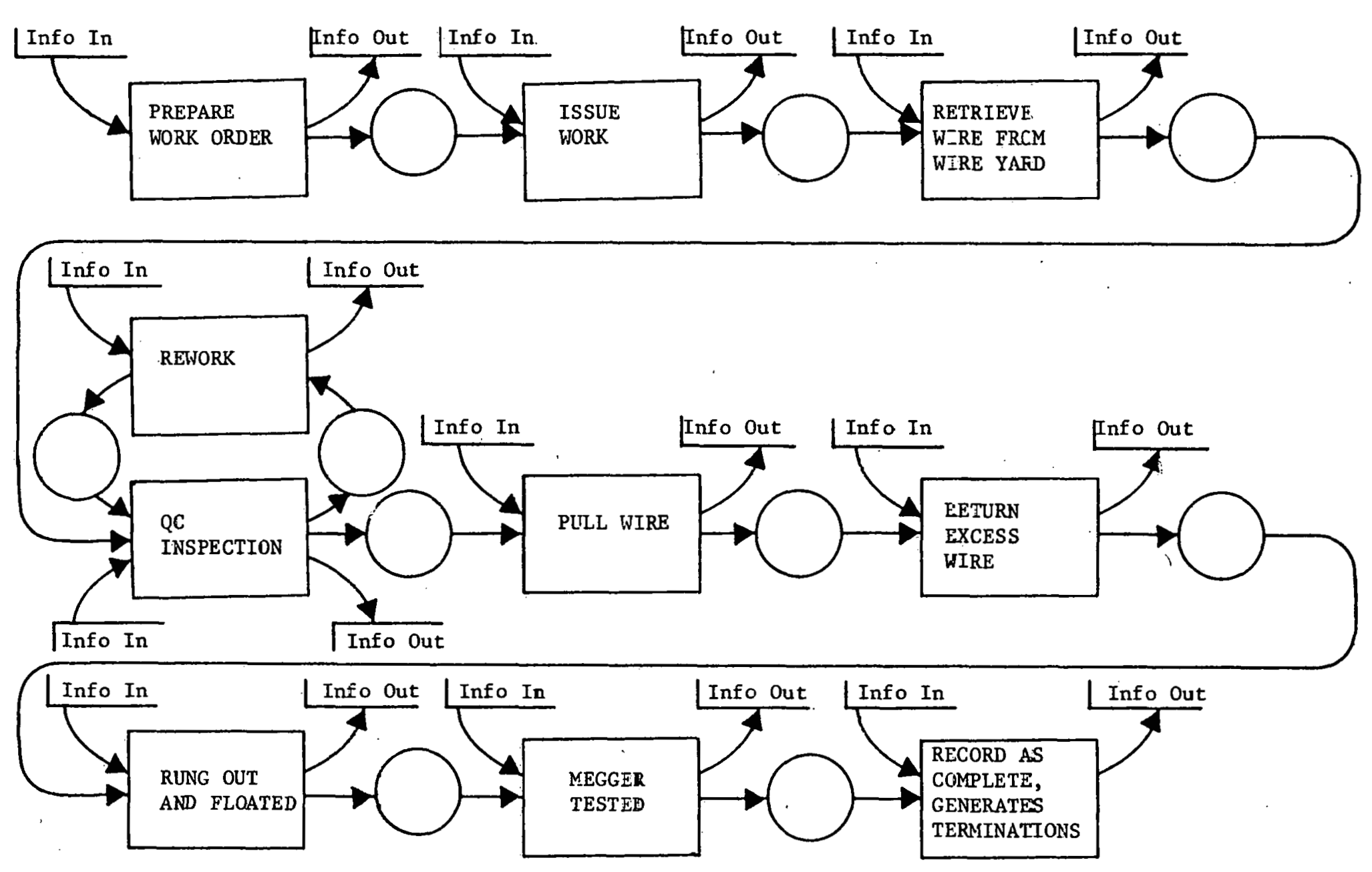


\section{Input/Output Sheets}

ELECTRICAL (BULK MATERIAL)

Builk cable

\section{Activity}

Prepare Work

Order (traveler)

(1)

\section{Information In}

CKTs put in packages for pull

Routings specified

Instructions

Vitality

To \& from locations

Estimated lengths

System number

\section{Issue}

(2)

Requests wire

from yard

(3)
Conduit status

Q.C. status

Manpower availability

Material availability

Engineers or field request

Length required

Type required

Area and elevation of usage

Foreman responsible

W. 0 . package used for

\section{Information Out}

Work Order number

List of work to precede W. 0 . pull (conduit installation)
Work assignment to superintendent

Memo to Q.C. for process inspection

Transmittal number

New status in field
Spool number

Length left at issue

Update. wire log

Update wire location $\log$ 
ELECTRICAL (BULK MATERIAL)

Bulk cable

\section{Activity}

Pulls wire

(4)

Returns excess

wire to yard

(5)

Megger test

(6)
Information In

Materials

Manpower

'Equipment

ฉ.r. insperstinr

Wire used

CKTs uscd for

Specifications/ procedures
Information Out

Q.C. report

Pull tension

Clew Lhál jet [urimed พัork

Type and no. of pulling

instrument

Wire reel numbers

Lengths of each reel

by CKT (circuit)

Pull date

Inspector's number

Wire logs updated

Megger test results

Accept or reject

System voltage.

Test voltage

'lemperature

Humidity

Weather

Tes t equipment number

Test equipment calibration

date

Tester's name 
ELECTRICAL (BULK MATERIAL) Bulk cable

$\begin{array}{ll}\text { Activity } & \text { Information In } \\ \begin{array}{l}\text { Floaters added, } \\ \text { rung out }\end{array} & \begin{array}{l}\text { Request for floaters } \\ \text { of CKT numbers }\end{array}\end{array}$

Information Out

Floatcrs placed

Number of floater 
ADDENDUM II

ELECTRICAL (SMALL COMPONEINT) INPUT/OUTPUT DATA

$\mathrm{H}-1$ 

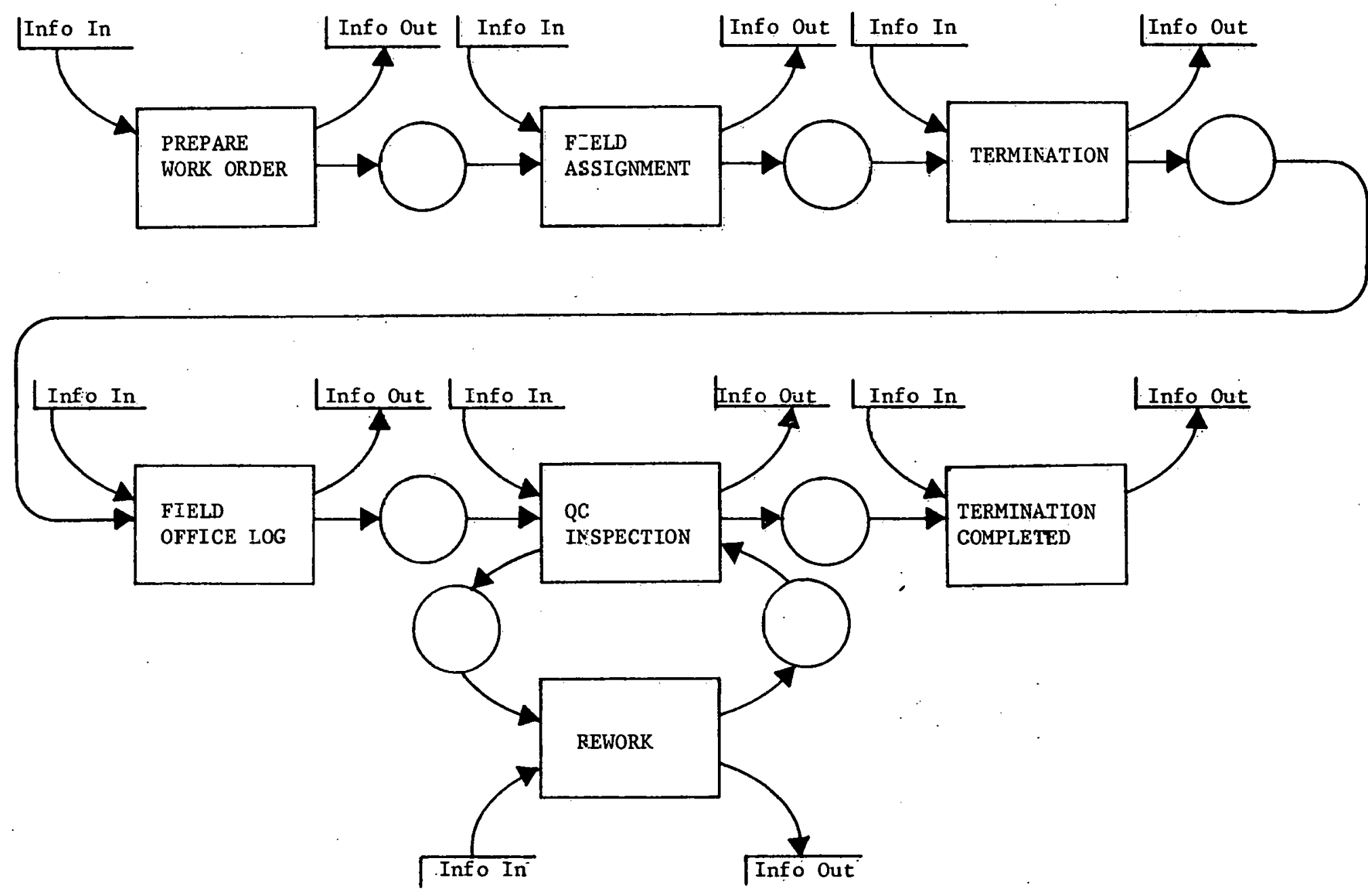
ELECTRICAL (SMALL COMPONENT)

Terminations

\section{Activity}

Prepare Work

Order

(1)

To field.

(2)

Terminates

(3)

\section{Information In}

Request

Wire installed report

Wire meggered and

floated

QC papers

W.0. package

Assigns worker

Foreman assigned

Materials
Information Out

Work Order

Diagram of connections

Termination location

Transmittal of W.o. package

Priorities

Assigns worker

Name

Too1 number

Lug used

Connected by drawing no.

Time

Qualification number

Tool calibration date

Notifies Q.C.

Notifies status 
ELECIKLCAL (SMALL COMPONENT) Terminations

\section{Activity}

Q.C. inspection (5)

\section{Information In}

Data from termination sheet
Information Out

Verifies ( 3 ) outputs

\section{Signs}

Képort and report

number generated

Notifīès Production

Ctatus of résulls

Log complete

Log. complete

(6) 
ADDENDUM I

ELECTRICAL (LARGE COMPONENT) INPUT/OUTPUT DATA 


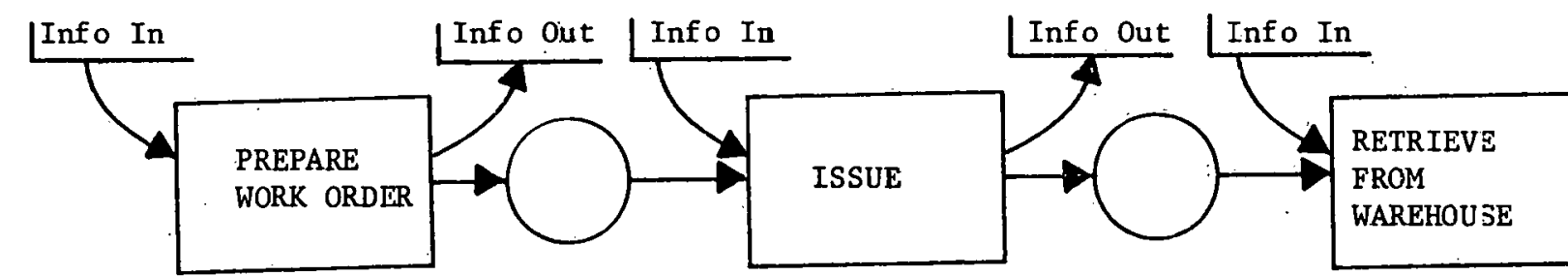

Info Out

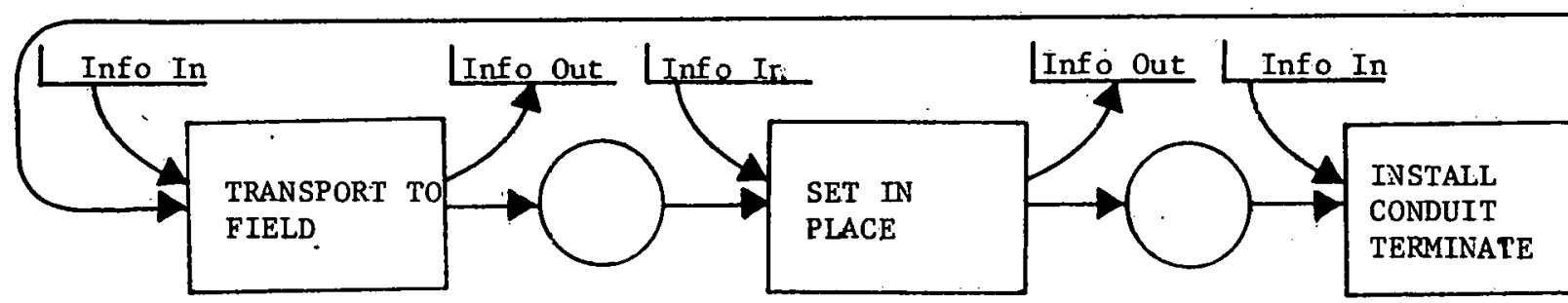

Info Out
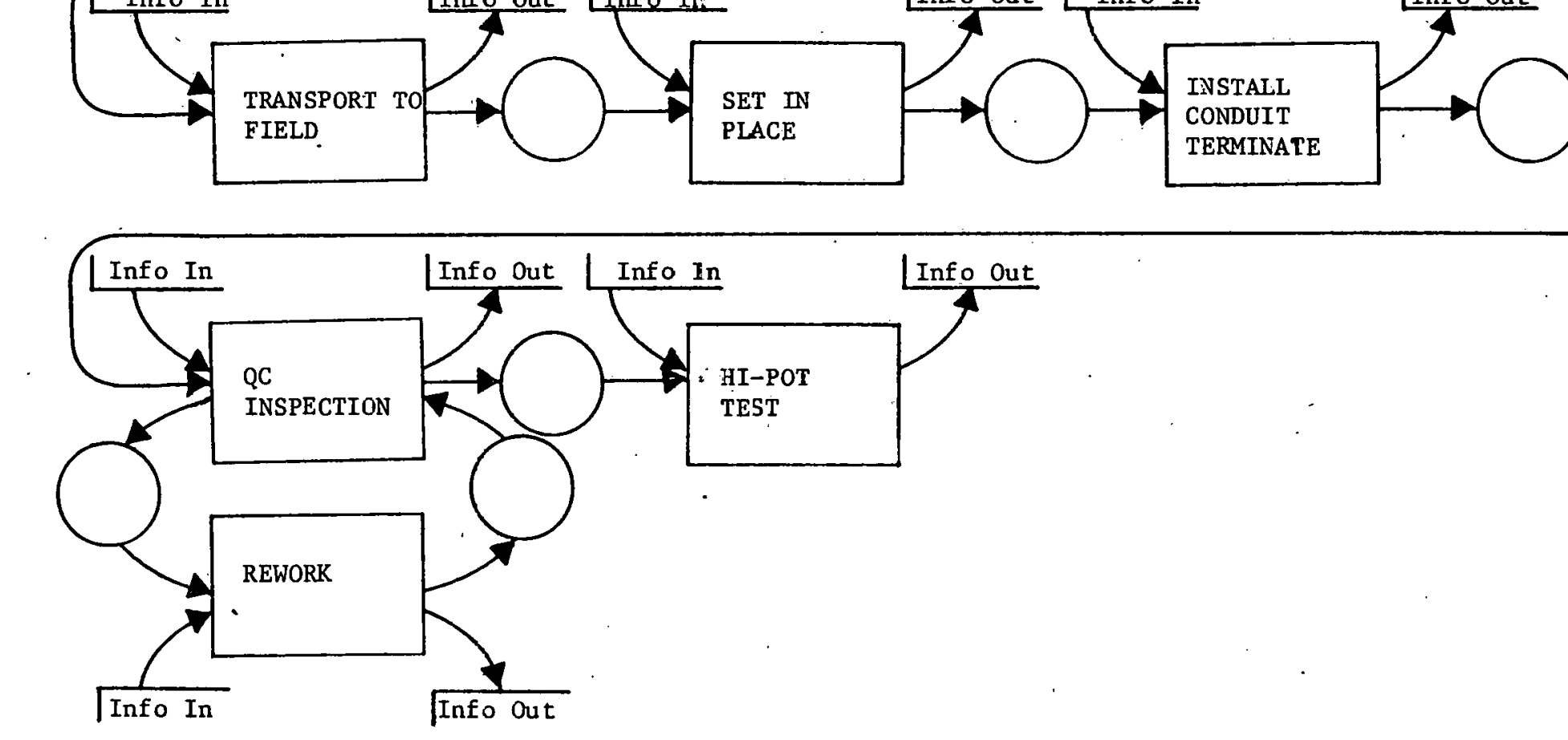


\section{Input/Output Sheets}

ELECTRICAL (LARGE COMPONENT)

Motors

Activity

Prepare Work

Order.

(1)

Issue

(2)

Issue from warehouse

(3)

Transport to field

(4)

Set in place

(5)
Information In

Pad ready

Manpower available

Memo requesting work

Material available

Material requisition

Request, to work

Work Order number

Schedule fork lift

Schedule bridge crane

Installation instructions
Information Out

Work Order
Person issued to and date

Date issued

Storage conditions

Status change

Transportation costs
Installed by whom

Installed with what tools

Calibrated when

How protected

Q.C. notified 
ELECTRICAL (LARGE COMPONENT) Motors

Activity

Install conduit, terminate

(6)

Q.C. inspection

(7)

Hi-pot tes $t$ of system

(8)
Information In

Notice to conduit

for installation

Notice to wire pul1

for installation

Notice to terminators

for installation

Design Documents

Specifications
Results of test

Record of conditions

Ton.1 ngerl

Calibration dates

People involved

Conduit Installation Report

Wire Installation

Keport

'l'ermination tơrü

Notification of each to Q.i.

Verifies installation

Assigns no. to report 
ADDENDUM J

APPLICATION AREA OUTLINE

METHODS ENGINEERING

$$
\text { J-1 }
$$


Exhibit 1

APPLICATION AREA: Methods Engineering

\section{INDEX}

1.U Description

2.0 Objectives

3.0 Functions.

3.1 Methods Engineering

3.1a Description

3.1b Relationship to other functions and application areas

3.1c Data requirements

3.1d Data generated within the function

3.1e Processing

3.1f Reports to users

4. 0 Code number or keys

3.0 Documentat 10 n 


\subsection{Description}

An investigation by means of a systematic approach of the work done on a project. Individual work assignments are closely observed and analyzed with resulting recommendations presented to the project management.

\subsection{Objectives}

To attain the best possible use of the men, machines, and materials available by eliminating waste.

\subsection{Functions}

\subsection{Methods Engineering}

3.1.a Description

(1) Record the job by listing all details of the job as it is currently being performed.

(2) Questioning the purpose of an activity.

(3) Questioning the manner of completion of an activity.

(4) Questioning the timing of an activity.

(5) Questioning the placing of an activity.

(6) Questioning the qualifications of the personnel employed.

(7) Evaluating job layout; the tools, equipment, and material used; material flow; and safety.

(8) Rearrange for better sequencing.

(9) Simplifying for ease and speed.

(10) Consulting with others who have an inherent interest.

(11) Implementation after acceptance by management.

3.1.b Relationship to other functions and application areas

(1) QA/QC -- close coordination necessary to minimize the cffort requiled to uncover concealed items.

(2) Project Management -- cooperation required to insure effective implementation of suggested modifications. 
(3) Cost Control -- will prove or disprove the economic advisability of making the suggested changes.

(4) P1anning/Scheduling -- significant savings in time required to complete tasks may permit upgrading of schedules or resequencing of events.

(5) Construction equipment control -- different types of equipment or different sequences may be required.

3.1.c Data requirements

(1) The project physical layout.

(2) The project organization.

(3) The project estimate.

(4) The system for assigning and scheduling work.

(5) Project manpower requirements.

3.1.d Data generated within Methods Engineering

(1) Detailed productivity information on individual activities.

(2) Proposed modifications of methods.

3.1.e Processing

(1) Schedule an initial meeting with the Project Manager, Assistant Projoct Manager, Construction Manager, and the Controls Manager to discuss parameters of the program.

(2) Review and become familiar with the data requirements.

(3) Upon reviewing the physical layout and meeting with project management, develop written objectives and a strategy for implementing a Methods Engineering Program.

\section{1.f Reports to users}

(1) A weekly tabulation of the detailed breakdown of elements for the current period, for each crew, showing the main work activities.

(2) A weekly tabulation covering each crew's performance for the current period and for the two preceding periods with a three-week sliding average for each of the three major elements (Direct Activity, Support Activity, and Delays). 
(3) The typical Manpower Activity Analysis Report . will consist of:

- A cover letter

- One-page sumary giving a multi-element breakdown for each day of the period along with the current and previous report period's statistics, along with the changes from period to period.

- Listings of the crews in each craft, giving percentage of breakdowns for both crew and craft along with the total project breakdowns.

- Listings of the crews in each craft, giving major elemental breakdowns for the previous three-week period along with the total project major elemental statistics.

- Graphs may be presented at a specified interval which show the three major elements (Direct Activity, Support Activity, and Delays) for each week for the total project and for each craft. 
THIS PAGE

\section{WAS INTENTIONALLY}

LEFT BLANK

$r$

$$
\text { J-6 }
$$



INFORMATION MANAGEMENT FOR

NUCLEAR PONER STATIONS

APPENDIX D 
TABLE OF CONTENTS

$\underline{\text { Page }}$

CHAPTER I: Quality Assurance

1.1 Introduction $\ldots \ldots \ldots \ldots \ldots \ldots \ldots \ldots \ldots \ldots \ldots \ldots \ldots \ldots$

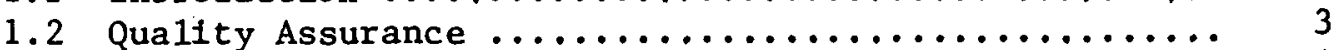

1.3 Quality Assurance Organization ................. 4

1.4 Basis for a Quality Assurance Program ............. 7

1.5 Scope of the Quality Assurance Program ............ 8

1.6 The Role of the $Q A / Q C$ Program ................. 14

CHAPTER II: Quality Control

2.1 Quality Control Procedures ................. 17

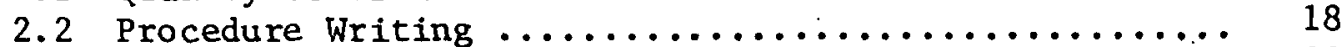

2.3 Vendor Location Quality Control ............... 22

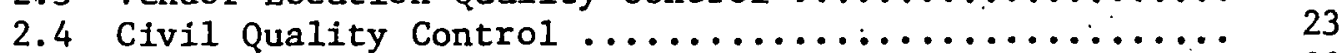

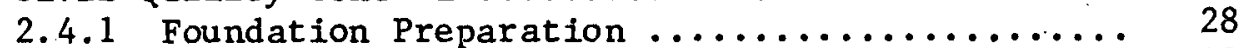

2.4.2 Assembly and Erection of Structural Steel .... 28

2.4.3 Structural Steel Bolted Connections ......... 29

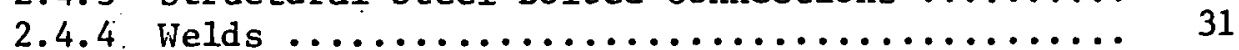

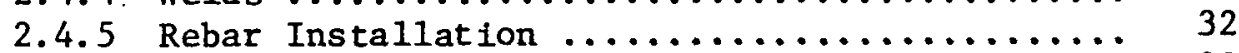

2.4.6 Erection of Forms and Shoring ............ 32

2.4.7 Quality Control Procedures for Concrete ...... 33

2.4.8 Post-P lacement Concrete Quality Inspection ... 35

2.5 Mechanical Quality Control .................. 37

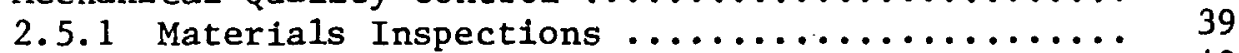

2.5.2 Equipment Installation ............... 40

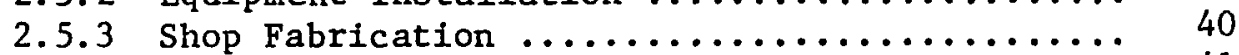

2.5 .4 Hanger Installation ................. 41

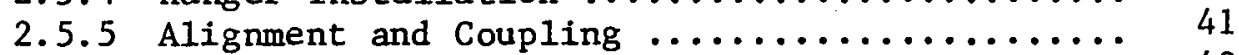

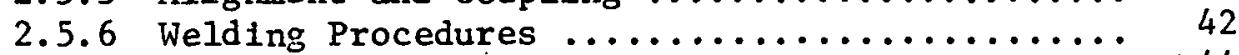

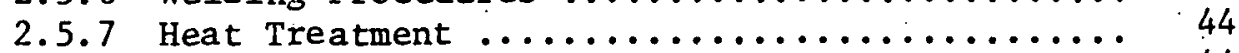

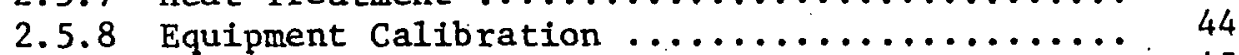

2.6 Electrical Quality Control .................. 45

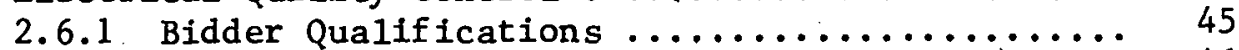

2.6 .2 Vendor Surveillance .................. 46

2.6.3 QC Recelving Procedure ................ 47

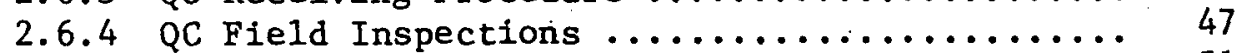

2.6 .5 Instrument Calibration $\ldots \ldots \ldots \ldots \ldots \ldots \ldots \ldots \ldots \ldots$

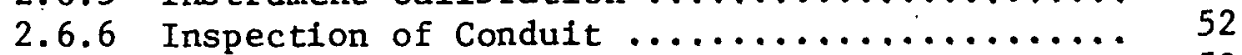

2.6.7 Grounding Equipment Inspection ........... 52

2.6.8 Wire Pulling In-Process Inspection .......... 53

2.6.9 High Potential (Hi-Pot and Megger). Testing ... 53

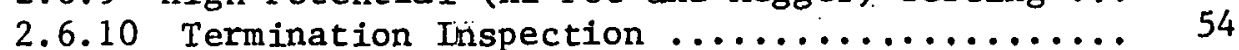

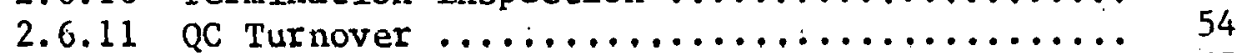

2.7 Conclusion $\ldots \ldots \ldots \ldots \ldots \ldots \ldots \ldots \ldots \ldots \ldots \ldots \ldots \ldots \ldots \ldots \ldots \ldots$ 
CHAPTER III: Document Control

3.1 Introduction $\ldots \ldots \ldots \ldots \ldots \ldots \ldots \ldots \ldots \ldots \ldots \ldots \ldots$

3.2 Quality Assurance Record System ...............

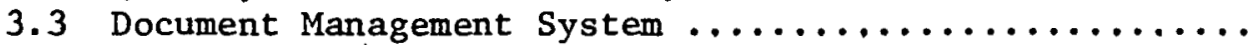

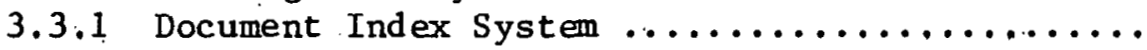

3.3.2 Document Index and Retrieval System .........

3.3.3 Document Management and Retrieval System ......

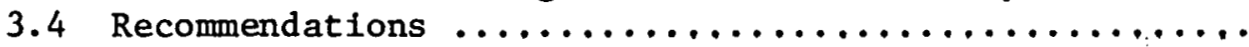

3.4.1 Quality Assurance Records Management System ...

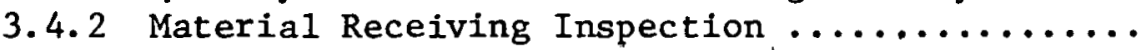

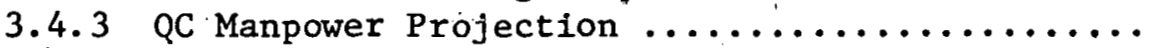

3.4 .4 Verification of Material Traceability .........

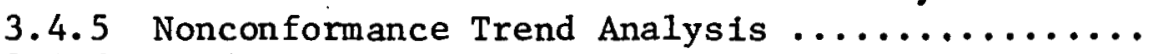

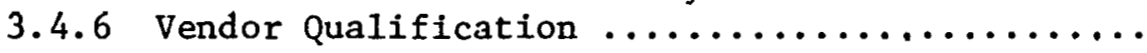

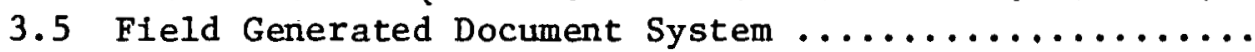

CHAPTER IV: Start-UP

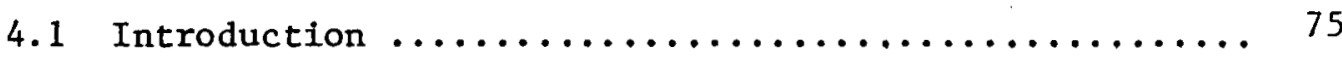

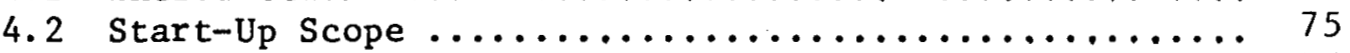

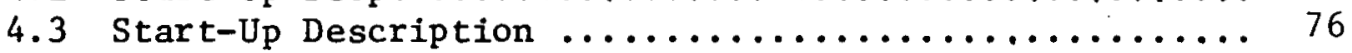

4.4 Description of General Programs that Support StartUp ............................... 82

4.5 Design Interface with Start-Up ...............

4.6 Construction Interface with start-Up ............ 89

4.7 0ther Interfaces with Start-Up ................. 91

4.8 Information Developed at the Station ............. 91

4.8.1 Station Equipment Data Base (Duke) ......... 92

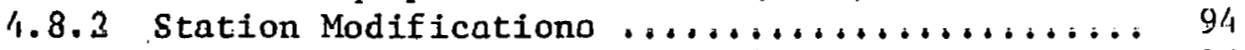

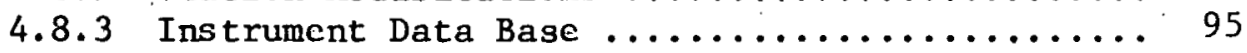

4.8.4 Nuclear Plant Reliability Data ............ 96

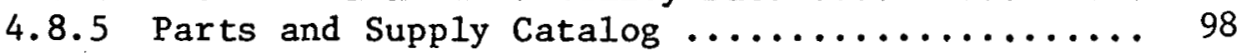

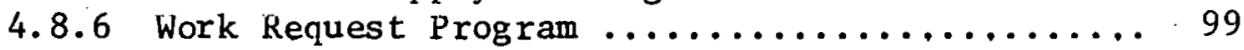

4.8.7 Instrument Pre-Installational Checkout ...... 100

4.9 Need for an Integrated Data System .............. 101

ADDENDUM A NRC Requirements Description

ADDENDUM B Sample Types of Permanent and Non-Permanent Records

ADDENDUM C Field Generated Document System Example Reports

ADDENDUM D Duke Power Company: Data Base Management Control and Engineering System

ADDENDUM E Duke Power Design Document list

ADDENDUM $F$ Mechanical Instrumentation and Control List

ADDENDUM $G$ 


\section{CHAPTER I}

\section{Quality Assurance}

\subsection{Introduction}

The high technology and need for safe operation characteristic of nuclear power plant construction has led to unprecedented requirements in the area of quality control and documentation. This level of control and inspection has been a common practice in the aerospace industry for many years. The demands on the part of the traveling public and government regulatory bodies to insure the safeness of aircraft have led to what is generally acknowledged as the highest quality control standards in use. Other manufacturing areas such as the appliance industry have been under pressure by consumer groups to improve monitoring and control of product quality. Figure 1.1 below qualitatively indicates the level of quality control exercised by various industries on a scale of $0-100$ with the aerospace industry at 100 .

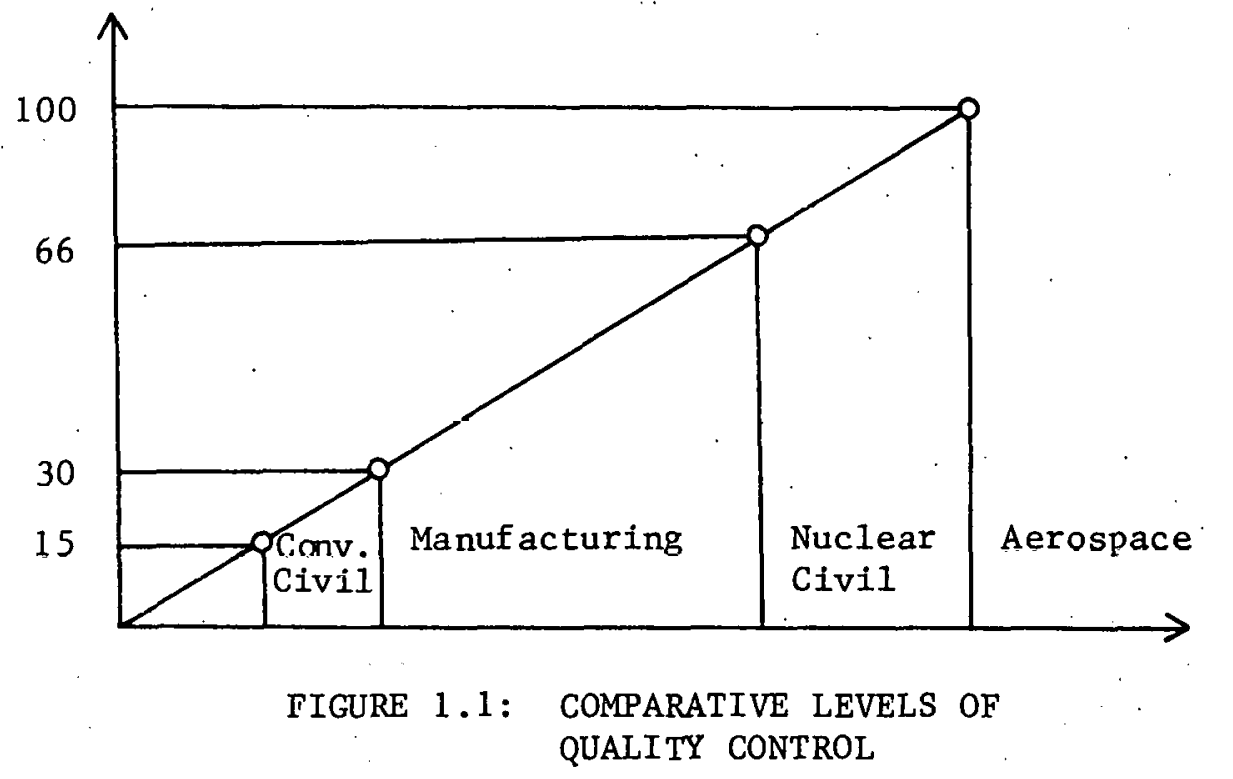


The level of quality control practiced in conventional construction is low due to the problems of the site, the conservative level of design, and many. other factors which tend to influence the cost-safeness relationship. Due to the potential failure hazard inherent in nuclear power plants, the public and the government have required a considerably higher level of quality.control and documentation on nuclear construction projects. Ihis requirement is high and increasing in its restrictiveness and cost implications. Largely because of the desire to reduce the probability of nuclear accidents, the positive cost relationship favoring nuclear vs. fossil fuel power plants has been declining at an accelerated rate. The relationship between safety, regulation, and quality control requirements is shown in Figure 1.2. The demand for a greater guarantee of safe operation has led to a higher level of quality control. This, in turn, has generated a requirement for better document control. Start-up of the

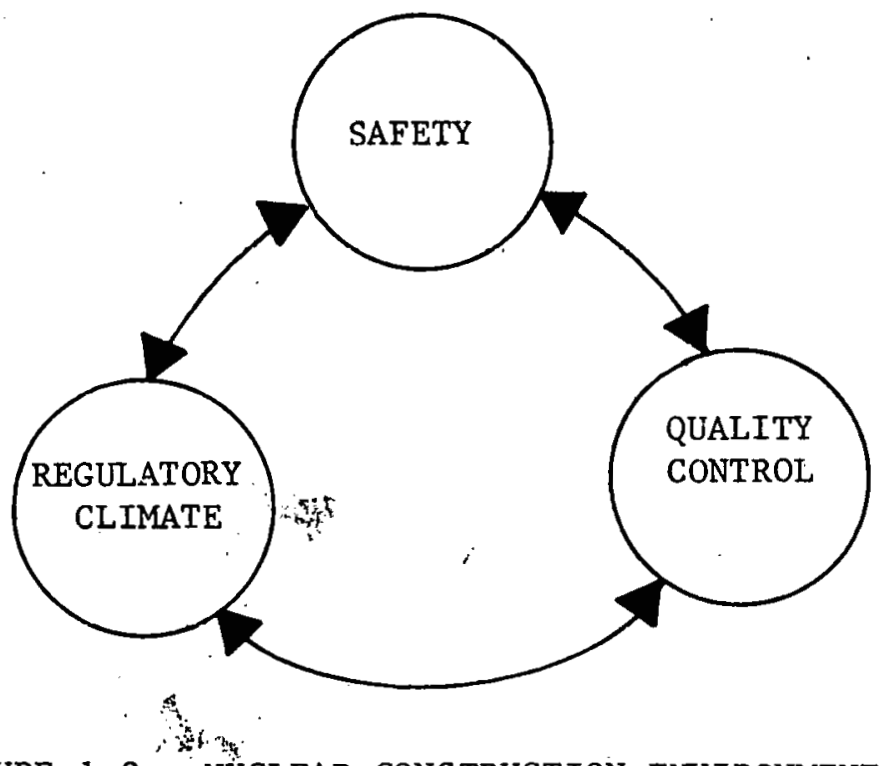

FIGURE 1.2: NUCLEAR CONSTRUCTION ENVIRONMENT 
plant is closely linked to documentation of systems and acceptance based on this documentation by the start-up team. This volume addresses the information requirements which are generated by the quality control, document control, and start-up application areas. The presentation is organized sequentially starting with a discussion of factors influencing quality assurance and its relationship to quality control discussed in this chapter. Quality control inspection criteria for various types of components is presented in Chapter 2. The requirements for document control (Chapter 3) and the information environment intrinsic to the start-up function complete the information application areas discussed in this volume. This sequence approximates chronologically the life cycle of a data element or group which is generated during engineering or quality control, passed to document control, and eventually is required to release a system for start-up.

\subsection{Quality Assurance}

The Quality Assurance Program is a written set of procedures that is conditional to the specific design standards, codes, and practices adopted by the project. These procedures will vary in format, detail, and subject matter depending upon the individuals responsible. The task of outlining or describing a specific quality assurance system loses meaning without minute attention to detail. Major aspects considered significant to the understanding of how a QA/QC program operates in a "typical" environment will be presented. 
A quality assurance program is the formalization of the design, construction, and operation of a nuclear power plant to assure compliance to standards required to:

(1) Operate the plant reliably;

(2) Prevent accidents that might cause undue risk to the health and safety of the public;

(3) Mitigate the consequences of such accidents if they wère to occur; and

(4) Determine the cause of an accident or malfunction such that corrective and preventive action can be taken.

This requires documentation and precise definition by means of written procedures involved in all activities affecting the quality of structures, systems, and components. This documentation will be required throughout the entire process of installation, including designing, purchasing, shipping, handling, storing, fabricating, cleaning, installing, erecting, inspecting, testing, operating, maintaining, repairing, refueling, and modifying.

\subsection{Quality Assurance Organization}

The criteria governing the organization of a quality assurance program is stated in 10CFR50 Appendix B, "The persons and organizations performing quality assurance functions shall have sufficient authority and organizational freedom to identify quality problems; to initiate, recommend, or provide solutions; and to verify implementation of the solutions. Such persons and organizations performing quality assurance 
functions shall report to a management level such that this required authority and organizational freedom, including sufficient independence from cost and schedule when opposed to safety considerations, are provided."

As allowed, this organization may, take various forms, but typically an organization as in Figure 1.3 is adopted:

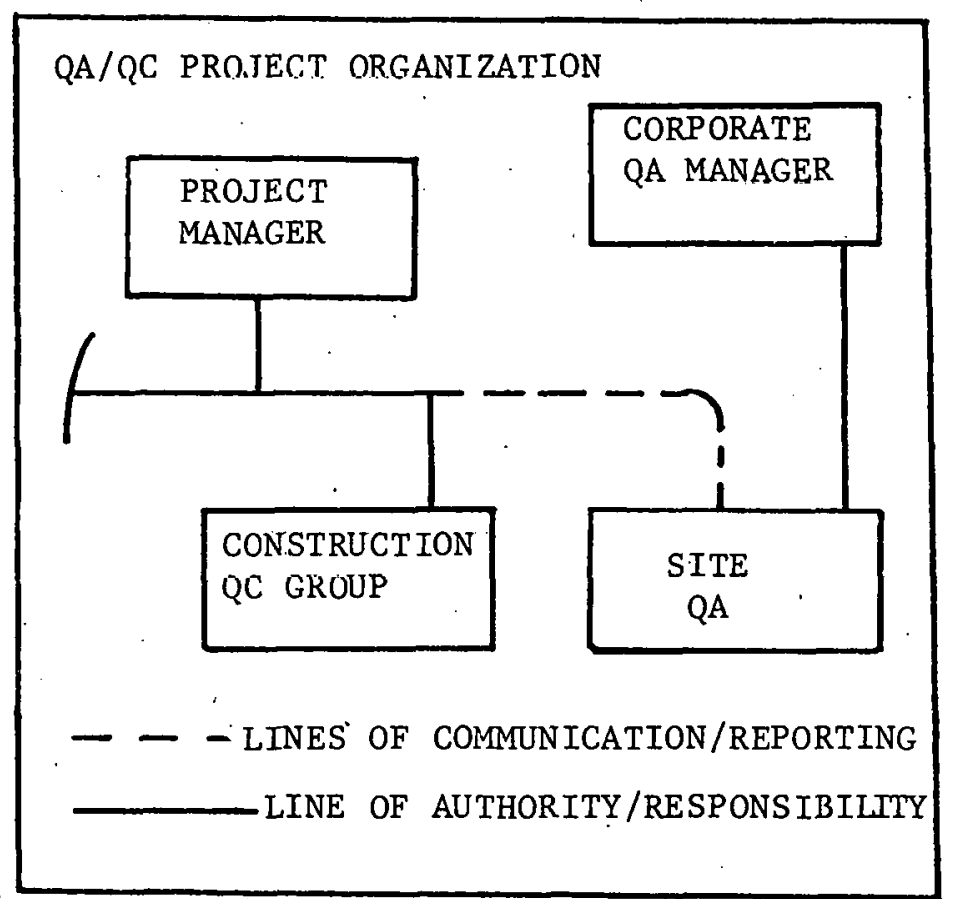

FIGURE 1.3 Q/A Q/C PROJECT ORGANIZATION

The organizational chart illustrates the direct administrative lines of authority for QA to Corporate Management. QA personnel in design or in the field may receive QA scheduling direction from Project Management, but personnel control and authority would rest with Corporate Málidy ement. 
The chart also portrays Quality Control as a separate organizational group from Quality Assurance. Functionaliy, QC is viewed, in most instances, as the implementation of the Quality Assurance Program. The QA group assumes responsibility for developing and writing the QA manual describing the Quality Assurance Program. Included in this manual is a description of the responsibilities of the QA group and the QC group.

The majority of projects assigns the QA group the role of determining $\mathrm{QA}$ policies, training of $\mathrm{QA}$ related personnel, and performing audits; the QC group assumes the tasks of inspection, testing, review, ; and documentation in the field. Actual procedures are written by the QC group and reviewed by the QA group. Management of the QC group is : through Project Management; conflicts compromising quality are resolved through the QA site group.

Variations of the $Q A / Q C$ organization structure are more modifications in emphasis rather than total change. The $Q \mathrm{C}$ group performs all inspections, testing, review, and documentation, while the actual approval of all results is vested in the QA site group. All documentation flows through the QA group. The relationships of the QA group and QC group to Project and Corporate Management are the same as shown in the prcvious structure. The decision to use either approach is dependent upon the situation and circumstances. 


\subsection{Basis for a Quality Assurance Program}

It is the responsibility of a plant owner to establish, execute, and enforce a quality assurance program as part of the Preliminary Safety Analysis Report. As a minimum criterion, the quality assurance program.must be consistent with the following standards:

10CFR 50 Appendix B

ANSI N45.2

ANSI N45.2.2

ANSI N45.2.3

ANSI N45.2.5

ANSI N45.2.6

ANSI N45.2.8

ANSI N45.2.9

ANSI N45.2.10

ANSI N45,2.11

ANSI N45.2.12
Criteria for Nuclear Power Plants and Fuel Reprocessing Plants

Quality Assurance Program Requirements for Nuclear Power Plants

Packaging, Shipping, Receiving, Storage, and Handling of Items for Nuclear Power Plants (during the construction phase)

Housekeeping during the Construction Phase of Nuclear Power Plants

Supplementary Quality Assurance Requirements for Installation, Inspection and Testing of Structural Concrete and Structural Steel during the Construction Phase of Nuclear Power Plants

Qualifications of Inspection, Examination, and Testing Personnel for the Construction Phase of Nuclear Power Plants

Supplementary Quality Assurance Requirements for Installation, Inspection and Testing of Mechanical Equipment and Systems for the Construction Phase of Nuclear Power Plants

Requirements for the Collection, Storage, and Maintenance of Quality Assurance Records for Nuclear Power Plants

Quality Assurance Terms and Definitions

Quallity Assurance Requirements for the Design of Nuclear Power Plants

Requirements for Auditing of Quality Assurance Programs for Nuclear Power Plants 
ANSI N45.2,13

ANSI N45.2.17
Quality Assurance Requirements for Control of Procurement of Equipment, Materials, and Services for Nuclear Power Plants

Quality Assurance Requirements for Control of the Welding Process for Nuclear Power Plant Construction

The above listing of standards is a sample of the basic requirements. Additional references can be found in Appendix A.

\subsection{Scope of the Quality Assurance Program}

The Quality Assurance Program must describe adequately the policies, procedures, methods, or Instructions for any project rclated activity affecting quality. This can extend beyond the boundaries defined as a minimum in nationally accepted design and construction standards, as well as the specific codes governing the design, construction, and operation of a nuclear power plant.

Figure 1.4 illustrates the various components of a nuclear project that must be properly documented by a QA program. These components are referenced from codes and standards for a QA program, and they are the commonly accepted minimums.

To present a more detailed perspective of the requirements of a QA program, the following list of components describes the expectations of a QA progran as part of a PSAR:

Organization -- Define the authority and duties of persons and organizations performing the QA functions;

Provide organizational charts outlining functional responsibilities including those of the owner, the architect-engineer (A/E), the nuclear steam system supplier (NSSS), the constructor, and the construction manager; 
FIGURE 1.4: "EL EMENTS DOCUNENTED BY OA PROGRAM

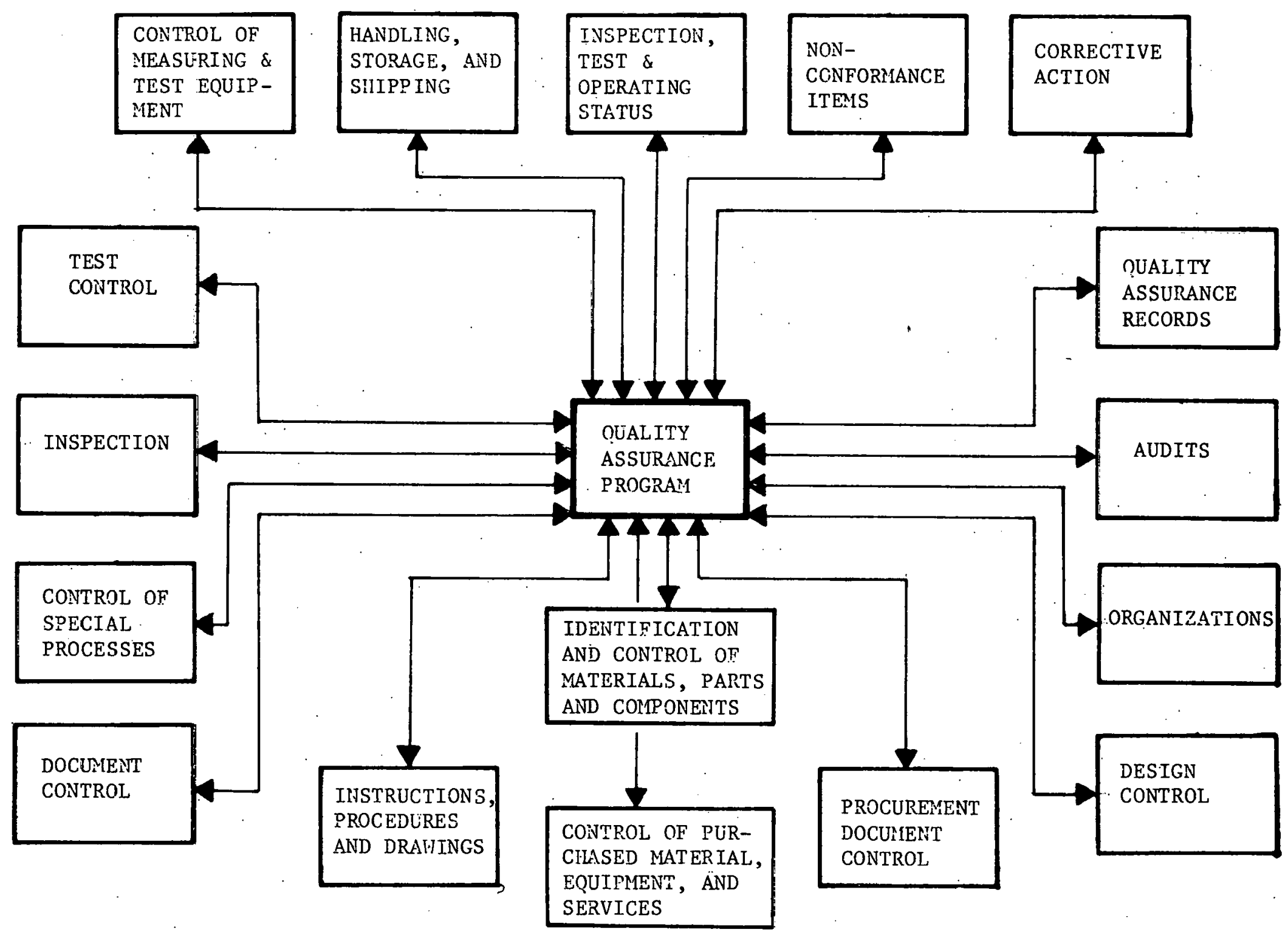


Indicate what position has overall authority and the lines of reporting communication;

Describe the extent and method of delegating QA authority and responsibility to external contractors or vendors;

Quality Assurance Program -- Assure that the QA program will be documented by written policies, procedures, and instructions;

Define the extent of the standards, codes, or practices to be used by the $Q A$ progran;

Identify the safety related structures, systems, and components controlled by the QA program;

Describe the QA program implementation schedule;

Summarize corporate QA policies, goals, and objectives;

Provide for the adequate indoctrination and training of individuals performing QA/QC related tasks;

Document the qualifications for all QA/QC related positions;

Assure regular management revicw of the QA program by groups internal and exterial to the owner's organization;

Conduct regular audits of contractor QA programs;

Maintain QA program descriptions current.

Design Control -- Assure that design bases, regulatory requirements, codes, and standards are correctly translated into specifications, drawings, procedures, or instructions;

Control deviations from such standards;

Doscribe measures th assure verification or checking of design adequacy, such as design reviews, alternative calculation methods, or performance of qualification testing;

Identify and control design interfaces among participating design groups; 
Control design and field changes for review and approval by the originating design organization.

Procurement -- Assure that the procurement of material, equipment, Document or services includes adequate documentation or

Control

reference to quality assurance standards;

Specify required supplier or vendor documentation;

Describe review, surveillance, or approval of supplier's QA program and QA records;

Establish document and procedural control for spare or replacement items consistent with original equipment standards.

Instructions, -- Assure that all documented instructions, procedures, Procedures, and drawings affecting quality will include quantitaand Drawings tive (such as dimensions, tolerances, and operating limits) and qualitative (such as workmanship samples and weld radiographic samples) acceptance criteria.

Document Control -- Describe measures to control the distribution and issuance of documents such as instructions, procedures, drawings;

Identify documents to be controlled and the originating group responsible for review, approval, and changes;

Maintain a master document index to preclude the use of outdated or inappropriate documents;

Review documents for adequacy and legibility;

Implement method for document storage, retention, and retrieval.

Control of - Inspect procured items on-site or at service;

Purchased

Material,

Equipment, Audit, review, and certify supplier periodically for conformance to standards.

and Services

Identification -- Describe measures, methods, or coding schemes used and Control of Materials, Parts, and Components to identify control items, including prefabricated assemblies, to prevent use of incorrect parts (i.e., heat number, part number, serial number, batch number, etc.) 
Maintain a record of identification traceable to the item throughout fabrication, installation, and operation;

Relate the identification method to the appropriate drawing, specification, or technical document;

Provide traceability to speclfic test or inspection records as required by codes, standards, or specifications.

Contro1 of Special Processes
Inspection -- Implement a program for the inspection of activities affecting quality by individuals independent of the work completed;

Describe written procedures lo specify the inspection, measurement, testing, or qualification as necessary to verify quality and conformance to technical standards prior to performing the inspection;

Specify mandatory hold points which require witnessing or inspection by the Authorized Inspector;

Maintain current record of inspector's qualification or certffication;

Assure that rework items are inspected in accordance to original inspection requirements.

Test Control -- Establish a test program to identify all testing required to demonstrate that structures, systems, and components will perform satisfactorily in service;

Include, as appropriate, prototype qualification tests, proof tests prior to installation, pre-operational test, and operational tests as required to verify continued satisfactory performance during operation; 
Assume prerequisites for a test have been met; adequate instrumentation available; qualified personnel used;

Document and reyiew test results with the responsible authorfty to assure satisfaction of standards.

Control of Measuring -- Establish means to assure that measuring and Test tools, gauges, instruments, test equipment, and Equipment inspection devices are presently controlled and calibrated to required limits;

Define a basis for calibration if no national standard exists;

Evaluate the validity of previous inspections if a measuring device is found to be out of calibration;

Maintain records indicating calibration status and schedule for periodic calibration.

Handling, -- Establish a method to control the handling, storage, Storage, and shipping, including cleaning, packaging, and and Shipping preservation of material in accordance with codes, standards, procedures, drawings, or specifications to prevent damage, deterioration, and loss;

Assure proper attention to special markings or labeling adequate to identify procedures for handling, shipping or storage.

Inspection, -- Define methods to indicate the status of inspections Test, and Operating Status and tests performed with markings such as tags, stamps, labels, or other means;

Outline the authority of individuals involved in the application or removal of the marking systems;

Clearly identify the non-conformancy items.

Non-Conforming -- Describe means to control non-conforming material; Matertalis, Parts; or Components parts, or componenes;

Document procedure for the disposition of non-conformance material;

Esta.blish non-conformance notification procedure; 
Provide for means to control further processing, delivery, or installation;

Develop a non-conformance analysis or quality trend reporting mechanism.

Corrective -- Establish measures to assure that conditions such Action as failures, deviations, malfunctions, and deficiencies are promptly identified and corrected.

Quality Assurance -- Assure sufficient records are maintained to Records furnish evidence of activities concerning quality;

Provide to management the results of reviews, inspections, tests, audits, monitoring of work performance, material analysis, and personnel qualification $\log s$;

Establish record requirements for storage retention, and security in the facility to minimize damage from. deterioration and prevent losses.

Audits -- Conduct comprehensive planned and periodic audits to verify compliance to all aspects of the QA program;

Assess the effectiveness of the QA program;

Schedule external audits of the QA program and prin-. cipal cuntracturs;

Document audit results for review by management for the area audited with follow-up action and re-audit in deficient areas.

\section{6 'l'he kole of the QA/QC Program}

Intrinsically, a QA/QC program will not guarantee the reliable operation of a nuclear plant or prevent accidents from occurring. Decisions involving the design of the plant, its process and specifications ultimately determine plant performance. However, sound design decisions must be satisfactorily executed in practice and this is where QA/QC 
emerges as a formalized process to insure compliance to design specifications.

The major role of QA/QC is enforcement: enforcement of quality related activities to standards, practices, codes, and specifications adopted by the project. QA/QC must demonstrate that all work affecting quality must be inspected or certified by qualified individuals and the results formally documented. Enforcement assumes three traits: the qualification of individuals; the inspection or review of quality related activities; and the documentation of results.

The qualification of individuals is the first and most critical link in the enforcement chain. Any individual, including worker and inspector, in a quality related activity must qualify against standards for training, experience, and performance. Performance measures are actual working tests which verify the level of work quality expected. The second link is more methodical; for the inspection, testing, or review of quality related activities, written procedures must clearly Indicate an orderly pattern for inspection, testing, or review as well as the level of individual qualification required for compliance. The methods used may be as simple as a visual inspection or as complex as a testing procedure with extensive analytical calculations. The third link, documentation of procedures, test results, and inspections, is perhaps the weakest. The strain stems from the avalanche of documents that must be maintained in an orderly manner over the five (5) to eight (8) year life of the project. Current estimates of 1.2 million to 2.5 million documents are common with expectations 
of increased volume as standards and regulations change over time. Not only must these documents be stored, but the retrieval mechanism must establish a clear audit trail or path recreating all quality related activity affecting a system or system's components from design to operation.

With the major emphasis of QA/QC on enforcement and the three traits of qualification, inspection, and documentation, little attention ' is given to the preventive role of $Q A / Q C$, providing information on similar quality related items after a malfunction. The preventive nature of $Q A / Q C$ is inferred, and is not a direct requirement of a QA/QC program. The inference is taken from QA/QC's responsibility to monitor quality to, "... prevent accidents that could cause undue risk to the health and safety of the public; ..." and the retention of documents "... which would be of significant value in determining the cause of an accident or malfunction of an item." If a valve or weld fails in operation, it is often desirable to perform a preventive reinspection of other items potentially inferior in quality such as other welds by the same welder; other welds by the same inspector; other welds from the same vendor; other welds with the same filler material; and other welds using similar NDE techniques or equipment.

Accepting a preventive role for QA/QC would not receive universal agreement as a function for $Q A / Q C$. The rationale is based upon $Q A / Q C^{\prime} s$ intimacy with both documentation requirements and audit trail concepts. It is this merger of documentation needs and multi-path audit trails that will present QA/QC with its most pressing challenge. 
CHAPTER II

Quality Control

\subsection{Quality Control Procedures}

The physical inspection of bulk material, fabricated components, plant systems, and testing gear is an ongoing function throughout the construction period and is carried out by. teams specially trained and qualified in the area of quality control. Since the inspected items themselves have varying characteristics based on discipline (e.g., mechanical, electrical, etc.), discipline oriented QC teams and inspectors carry out inspections at varying points in the item's life cycle. Five points in a material item's life cycle are of interest:

(1) Specification and procedure writing: During engineering or prior to commencement of construction installation, specifications and procedures regarding installation and procedures for inspection are written.

(2) Inspections regarding compliance with the specifications are carried out at the vendor's location for safety related items which are fabricated off-site.

(3) Inspections are conducted upon receipt of material at the site warehouse or storage location.

(4) In-process inspections are carried out during the installation process.

(5) Following installation, final quality control inspections are made and final disposition of all qual1ty control records is made. 
In the following sections, examples of the inspection format and requirements at each of these points for Civil, Mechanical, and Electrical will be presented and discussed.

\subsection{Procedure Writing}

Writing QA/QC procedures is critical to the smooth construction and ultimate licensing of a nuclear power plant. It requires the marriage of a myriad of NRC and Jtility requirements in such a manner as to produce the exact procedure to specify, order, transport, receive, handle, insta11, inspect, and/or test every nuclear class material on the site. The procedures will determine to a large extent the success of the contractor on the job. They will dictate the manpower needed, the direct QA/QC budget, the craft productivity, and the schedule accuracy. In short, every department and activity will be affected.

The method for writing procedures greatly impacts the data structure of a nuclear power plant and therefore must be considered carefully. The power utility has total responsibility for the QA/QC programs of every contractor working on the site. The utility can subcontract this work to someone else, such as an architect/engineer (A/E) or an independent contractor. The primary responsibility, however, still rests with the utility. The A/E normally first writes up the specifications for the bid package which is reviewed and accepted by the utility. When the contract for construction has been let, the constructor (who also has a utility approved QA program) must then begin to develop the procedures that shall be used for the construction of the plant. The 
merging of these requirements to realize approved QC procedures is shown schematically in Figure 2.1 .

By this time the group writing the procedures has six major groups of codes, specifications, and requirements to meet. Table 2.1 lists the major standards; an explanation of each is found in Appendix A. It will be noticed that there are three main groups of regulatory documents related to nuclear power plant construction. First there are the NRC rules and regulations. These are the basic authorizing documents for nuclear construction. They form the basis for all regulatory activity. Second, the "Selected Codes and Standards" must be considered. The NRC tries to use industry standards instead of developing their own wherever possible. These documents and standards are referenced in the NRC regulations found in Title 10.

Thirdly, there are "Guides and Information." These are clarifications of the previous NRC requirements and guides on how to submit EPA reports, the PSAR, FSAR, and other necessary documents.

After the procedure has been written, it must be reviewed and approved by the Utility or his representative. This is to insure that all of the QA/QC programs on the site are compatible with the PSAR submitted at the beginning of the project. Once the procedure has been incorporated, it becomes law and must be followed to the letter until it is revised. 


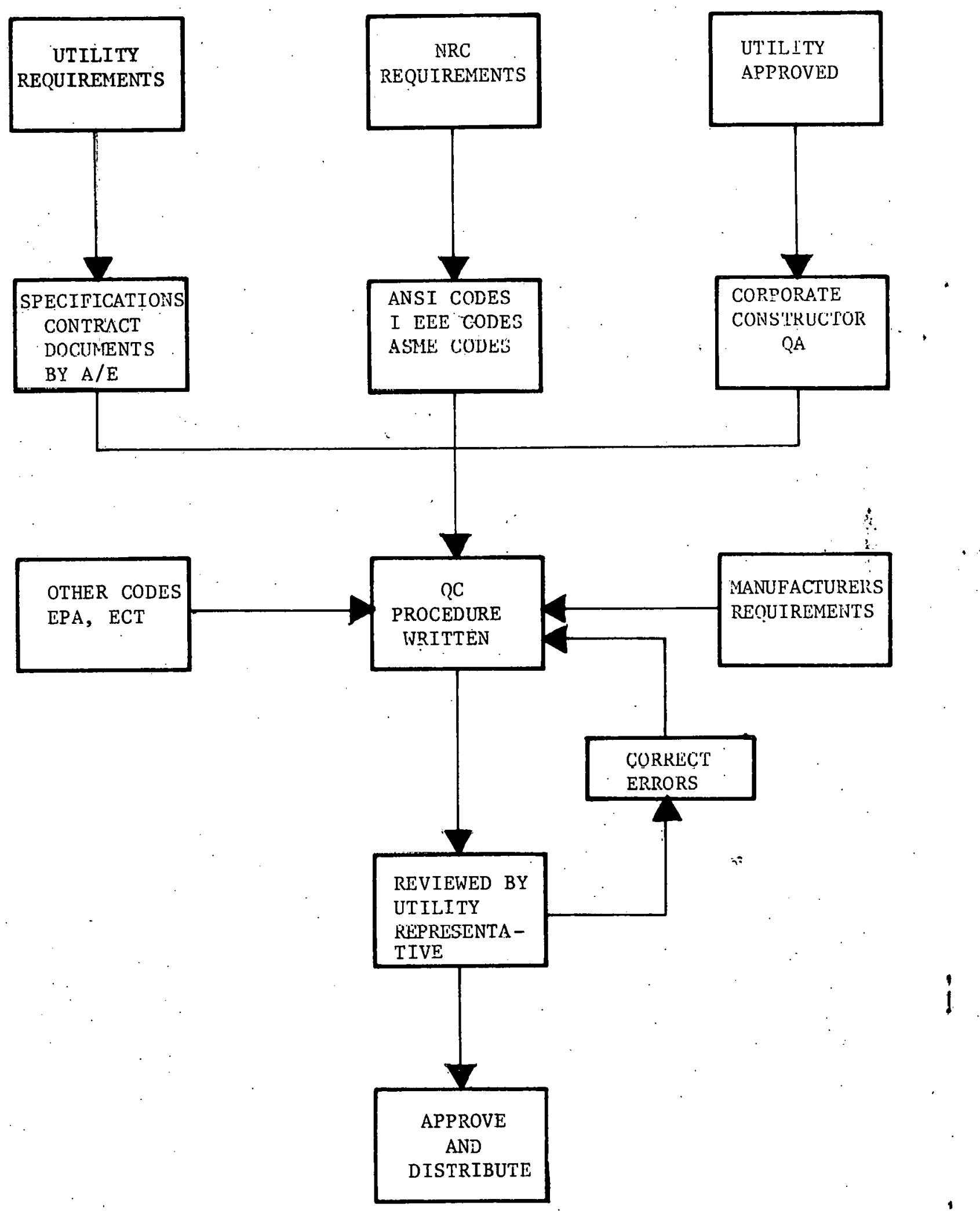

FIGURE 2.1: QC PROCEDURE DEVELOPMEIT 
TABLE 2.1: IMPORTANT DOCUMENTS RELATED TO NUCLEAR POWER PLANT

CONSTRUCTION AND OPERATION

\section{NRC R:1les \& Regulations}

Code of Federal Regulations -Title 10

Part 20 - Standards for Protection against Radiation

Part 50 - Licensing of Production \& Utilization Facilities

PSAR

Technicel Specifications

FSAR

Part $55^{\circ}$ - Operators' Licenses

Part 71 - Peckaging of Radioactive Vaterial for Transport and Transportation of Radioactive Material Under Certain Conditions

Part 73 - Physical Protection of Plants and Materials

Part 100 -. Reactor Site Criteria
II. Selected Codes \& Standards

ASME Boiler and Pressure Vessel Code

Section II - Materials Specifications Section III - Nuclear Power Plant Components

Section V - Nondestructive Examination

Section VIII - Pressure Vessels

Section IX - Welding and Brazing Qualifications

Section XI - Rules for Inservice Inspection of Nuclear Power Plant Components

IEEE-279 - Criteria for Protection Systems for Nuclear Power Generating Stations

IEEE-336 - Installation, Inspection, and Testing Requirements for Instrumentation and Electric Equipment During the Construction of Nuclear Power Generating Stations

ANSI N18. Series - Design Criteria, Safety, and Operations of Nuclear Power Plants

ANSI N45.2 Series - Quality Assurance Program Requirements for Nuclear Power Plants

SNT-TC-1A - Recommend Practice for Nondestructive Testing Personnel Qualification and Certification
III. Information \& Guides

TID 14844 -- Calculation of Distance

Factors for Power \& Test Reactor Sites

NRC Regulatory Guides

ORNL Technical Manuals

ORNL Compilation of Nuclear Standards

NCR Standard SAR Format

Guide to the Preparation of Environmental Reports for Nuclear Power Plants

WASH 1283 - Guidance on Quality Assurance Requirements During Design and Procurement Phase of Nuclear Power Plants (Gray Book)

WASH 1309 - Guidance on Quality Assurance Requirements During the Construction Phase of Nuclear Power Plants (Green Book)

WASH 1284 - Guidance on Quality Assurance Requirements During the Operations Phase of Nuclear Power Plants (Orange Book)

NRC Standard Review Plans 


\subsection{Vendor Location Quality Contro1}

Quality Control activities at vendor locations consist of six (6) basic activities. These activities are practically identical for bulk, small, and large materials. The activities are as follows:

(i). Notification to QC that vendor materials are ready for inspection.

(2) QC verification that vendor fabricatlun facilities, tools, equipment, and materials meet requirements.

(3) QC verification that product has been fabricated in compliance with all requirements, including physical correctness, identification of items, etc.

(4) QC verification that storage and shipping procedures meet requirements.

(5) Compilation and submittal of inspection reports to QC manager for approval.

(6) Filing reports with Document Control. The requirements that a Quality Control inspector checks are usually detailed in the Quality Control procedures. These procedures are detailed for the various types of vendor fabricated items. Such materials as reinforcing steel, miscellaneous steel, structural steel, and precast concrete members will have individual requirements which specifically deal with that material.

Notification to Quality Control that a vendor's materials are ready for inspection usually flows from Construction Supervision. The vendor will notify and coordinate the inspection with Construction 
Field Supervision and they, in turn, contact Quality Control. This notification is the signal for the initialization of the inspection process that will, in most cases, follow a material item from fabrication through testing and operational turn-over.

The three verification activities involve checking whether or not a vendor has complied with the various requirements for the material being supplied. An important "spin-off" of the verification activities is the case of non-compliance. When this occurs, the vendor makes the corrections needed and calls for a reinspection.

The final steps of the QC vendor inspection deal with compiling an inspection report and forwarding it to the appropriate QC manager. The report is reviewed and, if no corrections are needed, is issued to Document Control for distribution.

An example of the QC activities and their relationships for reinforcing steel is shown in Figure 2.2. Table 2.2 lists the information input and output associated with each activity.

\subsection{Civil Quality Contro1}

The philosophy and development of the QC plan cannot be overemphasized. Quality assurance and control measures literally control a nuclear power plant construction site. The civil construction effort includes excavation, foundations, concrete work, structural steel, and nuclear containment which constitutes half of the total field effort. The materials required to complete this effort on a typical single unit project include 175,000 cubic yards of concrete, 18,000 tons of reinforcing 
FIGURE 2.2:

QUALITY CONTROL ACTIVITIES Vendor Location Inspection

Reinforcing Steel

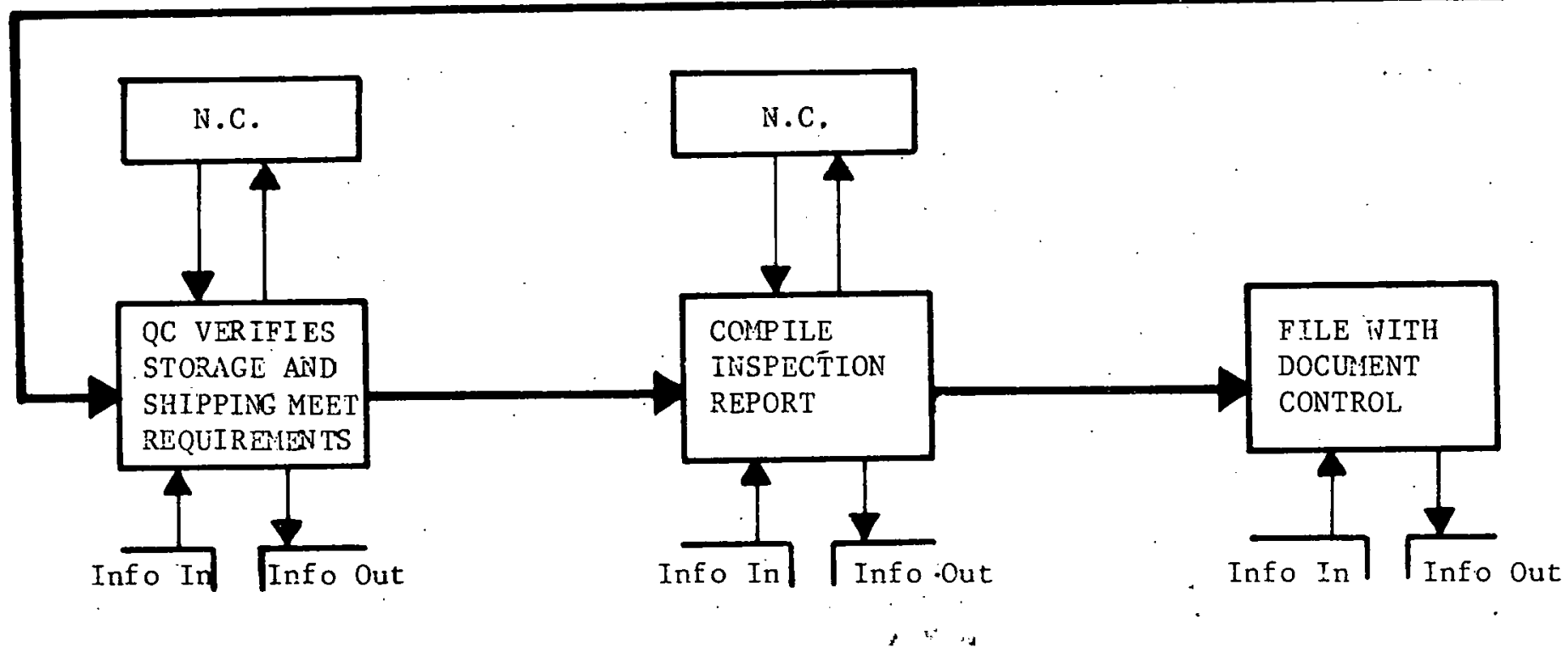

$\because$ N.C. = NOT-CONFORMANCE 
TABLE 2.2: QC VENDOR LOCATION INPUT/OUTPUT SHEET

Activity

Notification for QC inspection

(1)

$Q C$ verifies that facilities, tools, equipment, mechanics meet requirements

QC verifies that fabrication meets requirements

(3)

QC verifies storage and shipping meets requirements

(4)

Compile report and submit

(5)

\section{Information In}

Rebar complete:

Area number

Drawing number

Bending Sheet number

Date inspection needed by

Delivery date

Vendor location and descriptive info

Contact at vendor

Requirements to be met: Codes number

Standards number

Drawlings number

Specifications number

Bending Sheets number

Equipment and tool tests, certifications, and calibration

Mechanics' certifications

Requirements to be met (see 2 above)

Mill tests and numbers

Heat numbers

Date fabrication complete

Requirements to be met (see 2 above)

Storage location

Shipping equipment

Method of shipping

Date stored

Date to ship

Inspection checklist

Vendor

Rebar inspected:

Area number

Drawing number

Bending sheet number

Date of Inspection

QC inspector

Inspection number
Information Out

Date set for inspection

QC inspector assigned

Compliance Report

Partial Compliance Report Non-Compliance Report

Compliance Report

Partial Compliance Report Non-Compliance Report

Compliance Report

Partial Compliance Report Non-Compliance Report

Date to QC Manager

Date of approval

Corrections needed

Date to Document Control

Distribution reports 
Activity

File with Document

Control

(6)
Information In

Inspection report number

Number of copies and

distribution

Date received
Information Out

File number

Distribution \& copies

Date distributed

Signature sheets 
steel, 8,000 tons of structural steel, and over $1 \frac{1}{2} \mathrm{million}$ square feet of formwork. These figures indicate to some degree the magnitude of the work involved. The figures do not, however, begin to indicate the complexity that is involved with the addition of QA/QC. Throughout this section references are made to drawings which contain dimensions and specifications. The typical power plant requires over 100,000 of these drawings. The following breakdown of civil functions attempts to convey to the reader the information environment in which the mass of data pertaining to $\mathrm{QA} / \mathrm{QC}$ monitoring within a project must be processed. 


\subsubsection{Foundation Preparation}

Foundations are a critical factor in nuclear power facilities in that any differential settlement or tilt could cause pressure leaks, cracks in the structure, or upset the operation of the reactor generating system. For this reason Class I structures usually require bedrock for a foundation base. All other structures are required to meet certain specifications of foundation quality that are tested by the normal ASTM standard test. A full analysis of foundation soils is made to include in-place moisture, density, and visual description, as well as a particle size distribution analysis, liquid limit (an arbitrary moisture content that defines the boundary between liquid and plastic states of the soil), and plastic limit (similar to liquid limit, separating the plastic and semi-solid phases of the soil). QC monitors the results of all tests to insure compliance with specifications.

\subsubsection{Assembly and Erection of Structural Steel}

Structural steel forms the supportive framework of a building and is therefore subject to very rigid standards for QC. Strict adherence to drawings is required for size and shape of all members. Connections must also conform exactly to drawings or plan specifications. Alignment of members to maintain squareness must be accomplished as erection pro-

gresses. Bearing plates for all columns must be level, aligned, and cleaned prior. to grouting. Major damage to members such as kinks, bends, or distortion requires replacement. Other minor imperfections or gouges 
in edges are removed by grinding or by welding and then grinding. All re-entrant corners must also be ground to $\frac{1}{2}$ " radius. At completion of erection all discrepancies and non-conformance reports are listed and reviewed before final approval is given.

\subsubsection{Structural Steel Bolted Connections}

In structural steel framing the unit is only as strong as the connections between members. This naturally develops a need for QC to monitor this aspect of steel construction. The QC report for a single joint is referenced to a specific drawing and also states the inspector, date of inspection, structure, discrepancies, non-conformance reports, and a final approval. Since there are many different types of bolted joints the procedures and checkoff items for QC are reclprocally much more complicated. The first phase of inspection involves checking all bolts, nuts, and washers for conformance to the grades, sizes, and types specified in the drawings. The fasteners must also bear the prescribed coating, galvanizing, or paint as enumerated in the drawings as well as being free of any rust, corrosion; or imperfections. In the connection being inspected the proper number of bolts must be used and rest squarely against the member on each end. Any enlarging of holes that is required to obtain a proper $f$ it for fasteners must be accomplished by approved methods which prohibit the use of cutting torches. On any slope. which exceeds 1 unit in 20 a beveled washer must be used to obtain square fit. The bolt length will conform to design specifications or to a length which extends beyond the face of the nut when tightened, 
whichever is greater. Other standards must additionally be applied to high strength bolted connections. Due to compressibility no gasket material is allowed between bolted parts. Requirements state that all parts should fit together solidly after bolting. On all washers and load bearing surfaces, the surfaces should be free of dirt, oil, loose scales, pits, and any other raised markings which could affect the distribution of stress or the strength of the connection. Only paint is allowed on contact surfaces and then only if so stated in the specifications or on members less than $24^{\prime \prime}$ deep.

The bolts on a connection are tightened by an approved method in a sequence that begins at the most rigidly fixed part of the connection. After initial tightening all bolts are "touched up" or retightened to remove any slack caused by contraction of the joint during tightening. All fasteners must recelve a final check for tightness and conformance to predetermined torque specification. If a joint should fail the torque test it is marked and then re-tested. All equipment used in tightening the bolts must be in proper working order. The wrench used in tightening bears a unique identification number so its use can be traced through a given structure should a defect be found in its mechanism or wear cause inaccurate torquing of bolts. 
2.4 .4 welds

Welds on all structural and mechanical units are monitored very closely due to the wide range of weld strengths that can occur if proper procedures are not used. To begin surveillance of a weld the ends to be joined must be fit up and cleaned. To begin the weld the rate of flow on the purge gas must be checked before preheating is begun. The root is then set and welded in place. On each successive pass an interpass temperature must be checked and entered on a chart. A series of final inspections must be made on the weld before final approval is passed. The penetration test is run; which involves cleaning a weld with wire brushes and solvents, then coating it with a red dye, then cleaning with solvents again and spraying a white powder substance over the weld. If any cracks are in the metal or the weld they will appear as a red line on the surface of the powder substance.

A post weld heat treatment is also run on the weld. This involves wrapping the joint with a heating element and raising its temperature to the point of recrystallization and holding it there for several hours. This allows the metal to shift to relieve internal stress and then recrystallize. A radiograph test is also run to insure a quality weld before final. 


\subsubsection{Rebar Installation}

Due to the important role that reinforcement plays in the strength of a concrete member, a strict set of standards exists to govern its placement and condition. QC makes both progressive and final inspections of reinforcement in every pour. References are made to a specific drawing to insure that reinforcement conforms to proper length, grade, diameter, and shape. Codes must be met which specify. the length of lap splices, cover, spacing, and wire fabric overlap. QC must also check the condition of the reinforcement to ascertain the absence of corrosion, seams, mill scale, mud, oil, loose mortar, and other substances which might affect the bond strength of the reinforcement. Final approval of all reinforcement must be obtained before a pour can be made.

\subsubsection{Erection of Forms and Shoring}

Forms and shorings are subject to both progress and final QC inspections. Forms are cross checked with drawings to determine proper tolerances and dimensions. The forms must be clean and properly coated to prevent adhesion to the concrete surfaces. Once debris and water are removed and the proper sndp ties, water seals, chomfers, and fillets are installed as required, final approval is given and pouring of concrete can begin. 


\subsubsection{Quality Control Procedures for Concrete}

Due to the varied characteristics of concrete which involve many different strengths and properties, a very rigid system of QC is required to ascertain that each pour meets the standards set in the specifications. For each pour on a project an individual inspection report is filled out which includes the production facility, inspector, date of inspection, description and number of pour, and all. of the following test and acceptance criteria. When the concrete is received on site the standard test (ASTM) is run to insure its quality at delivery.

These tests include a slump test which involves placing the concrete in a nearly cylindrical form, then removing the form and measuring the distance the top surface drops. This is a test which measures consistency of the $\mathrm{mix}$ and gives a numerical value to the workability of the concrete. Air content test is another measure for quality control which involves measuring the amount of air which is dispersed or entrained in the mix. Air content in a mix plays an important role in workability, permeability, and strength. Therefore it is an integral part of quality control. Unit weight is also an important test in calculating in-place building weights as well as unit density which is proportional to strength of a mix. The final test run on concrete received is the casting, curing and testing of sample cylinders. These cylinders are cured to simulate field conditions and then tested for compressive strength. This test gives actual proof of the concrece meeting design standariss. 
In addition to these sampling tests, each component is checked to insure its quality before mixing. The cement is checked as to type, manufacturer, and certificate number as well as the quantity procured, method of unloading, and storage vessel. The aggregate (all sizes) is also monitored to include source, quantity, certificate number, stockpile or silo number, and the procedures for proper storage (continuous wetting, etc.). All admixtures must also be checked to include type, source, and method of storage to guard against any possible contamination.

The condition of the delivery vehicle is also important in determining the quality of the concrete. A report must be filed which includes interior drum condition and wear, compliance with stated manufacturer's suggested mixing and agitating speed, and accuracy of gauges, measuring amount of mixing and water injection. As a backup system a daily $\log$ is kept for cach batch plant. The $\log$ denotes all material items listed above and also includes a scale check, beginning and ending time of each pour, total yards produced per pour, amounts of ice used in batching, and the total amount of concrete batched per day. 


\subsubsection{Post Placement "Concrete Quality Inspection}

The receiving and acceptance phase of QC for concrete must be complete before a pour is begun. However, once a pour is in place an entirely new set of criteria must be set up to monitor finishing, curing, form removal, and repairs. These reports must be referenced to a certain project, structure, date, inspector, and drawing number. In addition to these references, pertinent factors on the day of the pour must also be'listed which include average wind velocity, atmospheric temperature, average relative humidity, and temperature of the concrete.

The QC involved with finishes on concrete surfaces is dictated by requirements of the drawing or work package. These requirements vary from a'certain grade of roughness for friction to a particularly smooth surface which might receive a special floor covering or membrane at a later date. There are some other QC requirements which prohibit the use of dry cement to smooth over irregularities and absorb moisture on the surface because it would affect the durability of the finish. One final QC measure is to check all surfaces for proper drainage slope.

The curing of concrete is very cruclal to the strength developed of a pour. Since most procedures for the curing of concrete are standardized, the only QC involvement is monitoring the application of these processes. 'This is accomplished by a daily check of items critical for curing conditions. The most important factor involved would be the type of curing method used, such as: ponding (flooding 
surface), wet sand, wet straw or hay, waterproof paper, plastic film, absorptive mats (continuously wet), continuous sprinkling, lịquid curing compounds, or continuous steam (below $150^{\circ} \mathrm{F}$ ). Some other factors monitored are mean dry bulb temperature each day and the high and low concrete surface temperatures.

Several factors related to form removal require QC monitoring. Possibly the one most important consideration is the time elapsed before form removal. If forms are removed early, specimen tests must be run to determine in-place strength. These test results are evaluated by an engineer to determine if any damage was caused by the early removal. On floor slabs and beams, shoring must be replaced to prevent excessive creep during the early curing stages. Immediately after all form removal, curing is begun and also honeycombing as well as other damages are noted and reported for repairs. Concrete repairs become necessary when the concrete tails to pass QC. The repairs are also monitored by QC to insure they are made properly. If concrete is unsatisfactory as formed, it must be stripped down to sound concrete. If patches are minor the area must be kept wet for 24 hours before patching, coated with epoxy compouind if necessary, and then patched with the proper gruut mix. If major (deep) patches are required, anchors, keys, or dovetails must be used to insure proper bonding. Curing must be started immediately after all patching. Patching of concrete marks the end of QC monitoring and is therefore followed by a listing of all discrepancies, non-conformance reports, and final approval of the pour. 


\subsection{Mechanical Quality Control}

QC documentation required on a typical nuclear power project is very large and complex. In the welding area alone hundreds of pages of documentation are maintained on each welded pipe. With thousands of welds in a typical plant, the data generated for each weld becomes immense. The backup documentation is so important that if it cannot be found for a certain weld, the weld is often cut out and re-welded. The documentation is so detailed that one can establish the name of each welder who worked a given weld, when, for how long, with what rod, and every other data element that might be pertinent.

To document the inspection processes typically found in this area, it is helpful to follow the work flow from beginning to end as follows:

(1) Materials inspections

(2) Equipment installation inspections

(3) Shop fabrication Inspections

(4) Hanger inspections

(5) Alignment and coupling inspections

(6) Welding process inspections

(7) Heat treatment

(8) Equipment calibrations

The following sections discuss in greater detail the types of inspections that are typically utilized by the mechanical QC section of a nuclear power plant project. Figure 2,3 gives an illustration of this flow. 

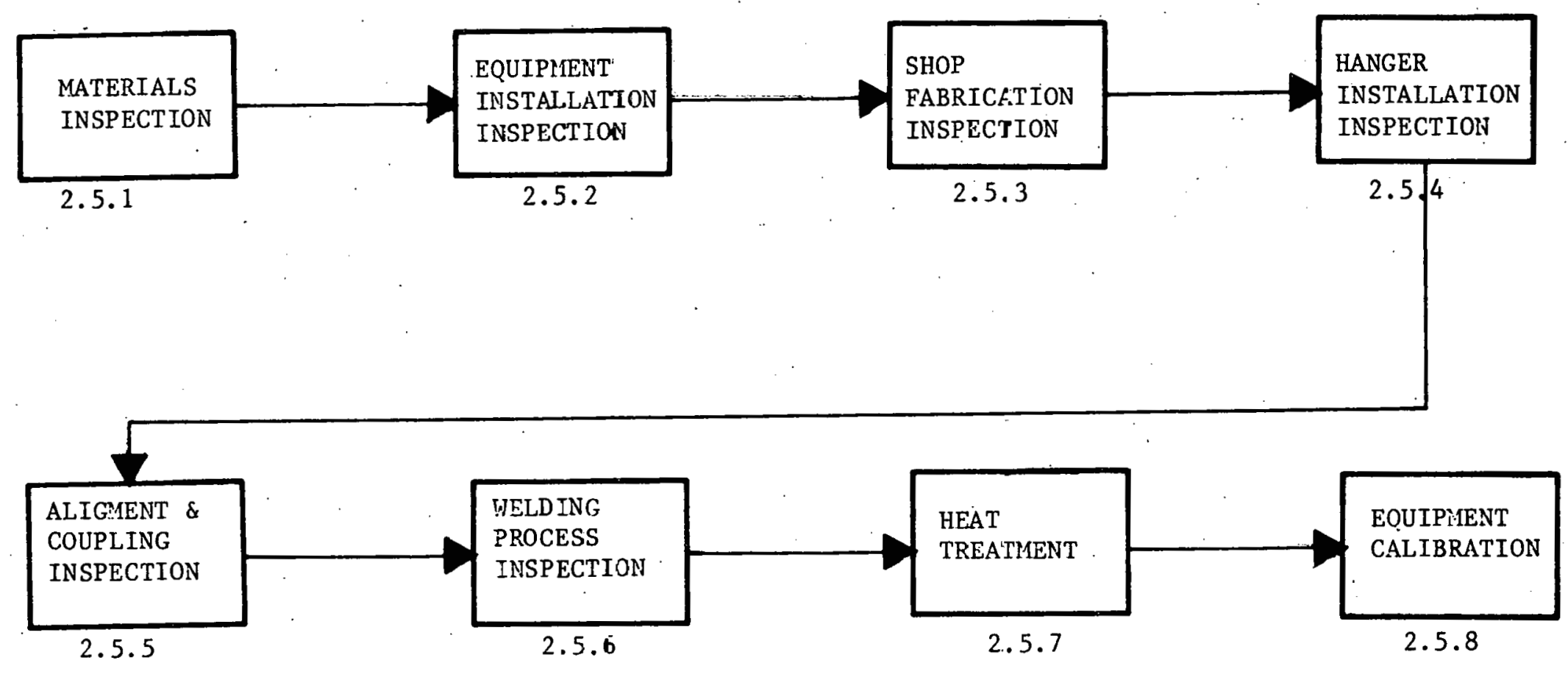

FIGURE 2.3: MECHANICAL DISCIPLINE

WNORK FLOW 


\subsubsection{Materials Inspections}

Materials typically received in the mechanical area include turbines, pumps, large and small bore piping. As items are received, they must be inspected and accepted by QC inspectors. There are three general areas that are important to inspect upon receipt. These areas can be classified as General Condition, Protection, and Paperwork.

The first area inspected is the "General Condition" of received products. This inspection documents that the materials were received in good condition and that the instructions on the Purchase order were carried out. An inspector is required to inspect for the condition of the metal. This includes checking for oxidation, scratches, and dents, or any other signs of mistreatment that might indicate improper packing or shipping procedures.

The matcrial must be packed in such a way as to be protected from the elements and accidental damage as required by the specifications and instructions on the Purchase order. This could include such things as sealing the ends with a protective covering, proper crating, protective coverings or coatings. If required, part of the protection could include special environments such as limits on humidity and temperature or use of an inert gas purge.

The receiving inspector must also check that all documentation has been received. This involves mill certification, letters of compliance, instructions, specifications, drawings, and any other documents specified in the Purchase Order. 


\subsubsection{Equipment Installation}

Because of the importance of much of the equipment, inspections are made to insure proper installation. Typical inspections that would be made are fit-up inspections, flange inspections, alignment and coupling inspections. After the equipment is intalled, continued inspections might include motor rotation inspections and lubrication inspections.

The fit-up inspection is made to insure the equipment is leveled properly and that the manufacturer's recommendations have been followed. This insures that the warranties will be valid and will also decrease down time on the equipment during plant operation due to improper installation.

Flange inspections deal with the connection of piping insuring a tight seal and proper fit of the equipuent to the pipe. This also insures the proper amount of cleanliness is maintained in the system.

\subsubsection{Shop Eabrication}

Certain items must be fabricated in the shop before being taken to the field to be installed. When this is the case, inspections must be performed before the system can be released to the field for installation. These inspections include all welding related inspections, dimension verification, and final checks. The topic of weld related inspections will not be treated here but rather in a future section on weld inspections. 
When the system is being put together, hold points are established. These allow the QC inspectors to verify that the design documents have been correctly translated dimensionally into a finished product. The inspectors also check the general quality of the work.

As the system is completed and ready to be transferred to the field, a final inspection takes place checking that the work is acceptable and that the supporting paperwork is in order.

\subsubsection{Hanger Installation}

Hangers installed to support piping must be rigidly inspected. Usually a group of hanger designs is approved for a specific plant. A certain hanger can be designated to support a certain section of piping or the designer could allow the field to choose the most suitable hanger. In elther case the hanger must be physically designaled in the field as to its type. An inspector will inspect hangers for conformance to drawings, and check to see that the proper welding and material documentation exists to support the work.

\subsubsection{Alignment and Coupling}

Alignment and coupling inspections deal with the link of the driving mechanism to the driven element. They ensure that minimum levels of vibration and runout are maintained.

After the equipment is installed, it must be maintained in operational condition prior to operation, This includes rotation of the motor at set intervals to relieve strains within the system. 
It also requires proper maintenance of lubrication levels. Records must be maintained on these items to assure that the warranties will not be invalidated. In many environments a heater coil is included to prevent condensation within the equipment. If it is included, then the inspector must verify proper operation of these heaters.

\subsubsection{We1ding Procedures}

One of the most controlled activities on a nuclear site is welding. Welders must be qualified by successfully welding a test sample under controlled conditions. The welding materials must be documented and their distribution controlled. The actual welding must be supervised and tested.

Welders are qualified in each position by welding, in that specific position, a test coupon. The coupon is divided into strips and put through a series of tests. Welders are qualified for a certain period of time in a certain position for a certain type of welding. If a large percentage of a welder's welds are rejected in the field, he can be disqualified and be forced to re-qualify.

Materials used in the welding process are rigidly controlled. Rod received must contain mill certiflcation and letters of compliance stating its compliance to the specifications. It must then be kept in a controlled environment until it is shipped to the field for use.

Once in the field the rod is kept in temperature controlled ovens. The rod is checked out to a welder for use on a specific weld section for four-hour periods. At the end of a four-hour period 
the rod is then put back in the oven to dry out until the next day. The afternoon rod is checked out from another oven. Temperature in the oven is recorded periodically and kept as a permanent record. A rod control issue list is kept and records the heat number, the welder the rod was issued to, the date and time, the weld the rod was going to be used on, the rod consumed, and the stubs returned.

Welding in. the field is inspected at regular intervals. The inspection will include checking the voltage, the amperage, the interpass temperature, the rate of travel, the rod used, the carbon content, purge gas flow rate, and the general appearance of the work. Each report is filed against the particular weld. Also in the packet of pertinent weld documentation for piping a tack inspection as well as a root pass inspection will appear.

Each of these inspections requires the signature of a qualified. inspector. To be qualified, an inspector must have an eye examination and must take a test and demonstrate a complete knowledge of the applicable codes and standards.

During the weld process certain tests are run on the weld section. These include radiograph, ultrasonic, and die penetrant testing. These types of tests check for weaknesses in the metal and are kept as an historical record.

All of the above inspection reports are kept filed against a spectfic weld. 'They certify that the weld has been effected properly. 


\subsubsection{Heat Treatment}

After a weld has been made it is often required, because of the special operational conditions, to be stress relieved. This is done by wrapping the weld area with a heating blanket, increasing the temperature to just below the critical temperature of 1000 to $1200^{\circ} \mathrm{F}$, and. holding it there for a few hours. After the heating process is complete the metal is allowed to cool slowly, thus completing the process of stress relief annealing.

The types of records kept are temperature graph, dates, heat rate, heating time, and cooling rate in of/hr. These records are also filed. with the weld information for a specific weld.

\subsubsection{Equipment Calibration}

All equipment used to verify construction procedures is required. to be calibrated periodically. Types of equipment that would typically be certified include torque wrenches, pyrometers, carbon testers, amp and volt gauges, and rod oven temperature gauges. Many times on a job site there is a calibration and standards lab that calibrates all the gauges and tools on the site. Each tool is numbered and dated as to the last date of certification. These tests insure that the tools used in the field are correct and accurate by measuring them against a known standard. 


\section{6 Electrical Quality Control}

The $Q A / Q C$ documentation required for the electrical division of the average nuclear power plant encompasses 100,000 sheets of reports, inspections, procedures, and dispositions. Many sheets of that documentation will never be used. At the present time, regulatory bodies have not made it clear what backup paper is required to adequately document the $Q A / Q C$ programs. As a result of this, the genera1 consensus within the industry is to document everything that could possibly be questioned. It is realized that some support paper can always be disregarded if found to be too extensive, but if necessary paper is not available, it can be disastrous.

In the following pages, the QC process will be examined from beginning to end, explaining, to some extent, how this paper is generated, why it is needed, and how it is used. To accomplish this, the following five main topics wi.1. be discussed as they relate to the electrical QA/QC division:

1) Bidder qualifications

2). Vendor surveillance

3) QC procedure upon receipt of materials

4) QC field inspection

5) QC following installation

\section{6 .1 Bidder Qualificalluns}

1.0 CFR 50 Appendix. B, the Bible of nuclear Quality Control, states in Title Seven that "Measures shall be established to assure that purchased 
materials, equipment, and services, whether purchased directly or through contractors and sub-contractors, conform to the procurement documents. These measures shall include provisions, as appropriate, for source evaluation and selection ..."

Therefore, it is a responsibility of QC to evaluate the bidders and to determine if they will be allowed to bid on the materials or equipment to be used in Quality Control applications.

This is done by first reviewing the QA/QC program of the applicant to determine if it is adequate. If it should be found acceptable, then an audit at the source is in order to determine if, in fact, the $Q A / Q C$ program is actually in force and active.

Having met these sometimes stringent requirements, the bidder can be allowed to bid on the materials for which he has been cleared.

\subsubsection{Vendor Surveillance}

Section Seven of 10 CFR 50, Appendix B, also states that "the effectiveness of the control of quality by contractors and subcontractors shal1 be assessed by the applicant or designee at intervals consistent with the importance, complexity, and quantity of the product or services." This requires that all vendors be audited at their installation at varying intervals consistent with the importance of the item supplied.

This surveillance usually takes the form of a QC audit, checking procedures for compliance. The auditor will check all available backup paper to assure that it is in order. He may also check any other aspect of the vendor's manufacturing, storage, and shipping 
procedures. The audit reports are then filed for future reference.

\subsubsection{QC Receiving Procedure}

The same section of the NRC requirements mentioned in previous sections states that it is required to inspect materials as they are received on site. Upon receipt of Quality items, notification will be given to QC. A Quality Control inspector will then assemble the required documentation that is available, including relevant specifications, purchase orders, and vendor documents. He will then check the material against each criterion outlined in those documents. He will then assure that all vendor certifications and letters of compliance that were required have been received and are in proper order. With this documentation and inspection, he can then release the item for construction.

If the item falls one of these categories, it is placed into a material hold area until such time as the difficulties are corrected.

\subsubsection{QC Field Inspections}

These inspections are numerous and sometimes extensive. For ease of understanding, we shall follow the pattern set forth previously. That is, a fictitious piece of equipment will be followed through its installation cycle to see what inspections are given in its route to turnover.

A large motor has been chosen for tracklng because it requires almost every inspection that is found in the electrical division of QC. F1gure 2.4 


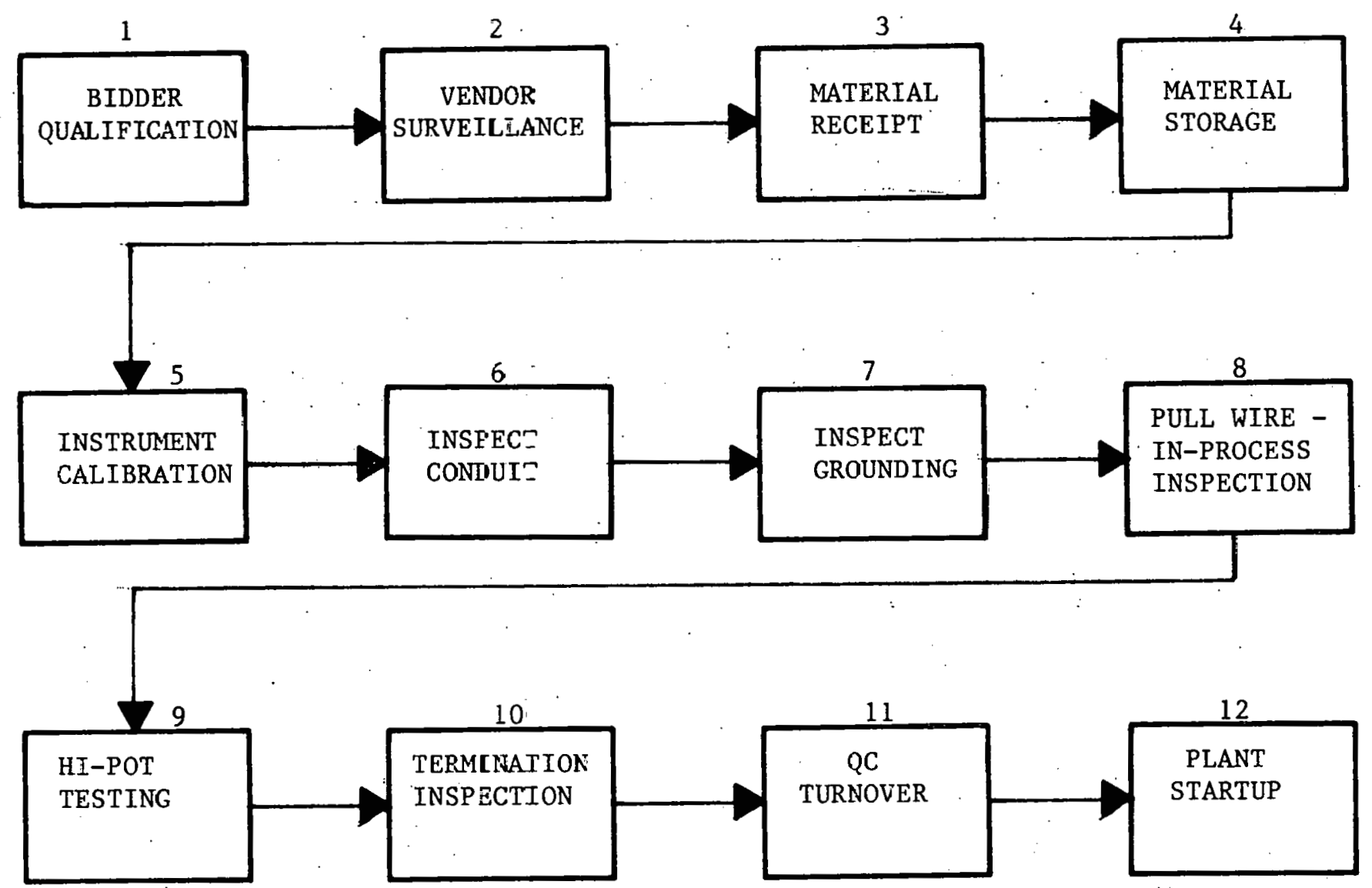

FIGURE 2.4: QC ELECTRICAL WORK FLOW 
TABLE 2.3: QC ELECTRICAL

INPUT/OUTPUT SHEET

$\frac{\text { Activity }}{\text { Bidder qualificat }}$
(1)
Vendor sur-
veillance
$(2)$
Material receipt

(3)

Material storage

(4)

Instrument calibration

(5)

Inspect conduit

(6)

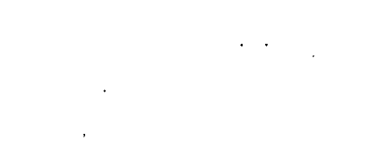

(7)

\section{Information In}

Vendor QA/QC program

Specifications

Material requirements

Specification of vendor QA/QC program

Specifications

Procedures

Audit points

Notification of receipt

Purchase order

Specifications

Procedures

Material requirements

Certification

Letter of compliance

Bill of lading

Manufacturers' requirements

Specifications

Procedures

Periodic inspection

Specifications

Procedures

Known reference block

Conduit installation

form

Specifications

Procedures

Drawings

Equipment Installation

Report

Specifications

Procedureo

Drawings
Information Out

Approval QA/QC program (Vendor)

Qualification status

Verification of vendor

QA/QC program

Report of Audit

Acceptance report

Non-Conformance Report (NCR)

Minor Variation Report (MVR)

Hold tag, inc. Hold Area

location

Verification of conditions

NCR

MVR

Hold tag

Certification

NCR

Conduit Inspection Report

NCR

MVR

Hold tag

"Approved for pull" status

MVR

NCR

Hold

Equipment Installation Inspection Report

(continued) 
Activity

Pull wire -

in-process

inspection

(8)

\section{Hi-pot testing \\ (y)}

Termination inspection

(10)

QC turnover

(11)
Information In

WIWS package

Calculated pu11 tension

Drawings

Specifications

Procedures

Notification of $Q$ pull

Notification of pull

Procédures.

Specifications

Termination Installation

worksheet

Diagram of connections

Location code

Procedures

Specifications

All documentation made previously
Information Out

MVR

NCR

Wire pul1 Installation Inspection Report:

Pull tension

Method

Date

Comments

Bends between pull points

Megger sheet

HL-pot IUim

Termination Installation Inspection

Hold

MVR

NCR

Al1 documentation made previously 
shows the inspections along the path of procurement, installation, and primary testing. Input and output items for each activity in the cycle are to be found in Table 2.3. Since the procedures of inspection up to QC receipt at the warehouse have been discussed in some detail in the preceding sections, we will begin at Step Five, Instrument Calibration, and proceed through to Step Eleven, or QC Turnover.

\subsubsection{Instrument Calibration}

All instruments and tools critical to the proper operation of the nolor must be periodically checked, calibrated, and certified to determine that they are within tolerance. A few examples will be cited.

If the motor hold down bolts must be torqued down to a specific pressure, then the torque wrench used must be calibrated to give accurate readings within specified limits. The wrench, therefore, must be periodically tested and calibrated against a known quantity to assure accuracy of installation.

Within the electrical division, termination of high voltage cable is very critical. If mechanical wire strippers are used, they must be calibrated to assure that the jaws don't "nick" the conductor, thus reducing the cross-sectional area of the cable and causing electrical stress poincs in the cable itself. If a hydraulic crimping tool is used to install the lug, it must be calibrated to assure that it will not break strands in the connection. 
Each of these operations requires the tools or instruments to be calibrated periodically and accurate records kept of the results. Reference 10 CFR 50, Appendix B, Section 12.

\subsubsection{Inspection of Conduit}

There are typically six thousand quality related conduits in a nur.lear plant, A test program must be instituted tó àssure that the conduit is installed, supported, and grounded in accordance with the specifications and drawings:

A sampling plan is usually set up to inspect a representative number of installations. This plan is'adhered to unless the rejection rate increases. In that case the inspection rate could go to $100 \%$. The inspector typically inspects the conduit as to routing accuracy, using the conduit drawings as a source; the type of support system, using drawings of approach hangers as a reference; and the grounding method, assuring himself and documenting that the method of grounding is in accordance with the specifications and approved in the procedures. The installation must also be visibly, physically documented with tape on the pipe indicating color code for vitality and marks on the support system indicating the type Identification of the hanger for reference.

\subsubsection{Grounding Equipment Inspection}

Quality equipment must be grounded to insure proper operation and safety. It is the responsibility of $\mathrm{QC}$ inspectors to assure that the 
grounding is as required in the specifications and procedures. A report is issued to that effect and kept as documentation for that equipment.

\subsubsection{Wire Pulling In-Process Inspection}

There are two types of inspection processes. The first is the hold point variety, where the work process is accomplished and no further work proceeds until the inspection takes place. This type has been illustrated in the previous two types of inspections, namely, in conduit inspection and grounding equipment inspection. The second is a surveillance type of inspection or "in-process" type. In this type the inspector watches the work in progress and documents the processes used. Wire pulling is a prime example of an "in-process" type of inspection. As wire is being pulled, the inspector would check the pull tension and method used and would document any problems that might arise. If a problem came up that threatened the integrity of the wire, he has the authority to shut the pull down until the problem has been cleared up.

\subsubsection{High Potential (Hi-Pot and Megger) Testing}

After a circuit has been pulled and certified by the wire pulling inspector, a voltage is applied across each conductor, usually equal to approximately $1 \frac{1}{2}$ Llie uperating voltage, and the current leakage to ground is measured. This proves the integrity of the wire and insulation. If the insulation has been scraped off, this test will indicate a prohlem with the wire. 
This test is done on every wire and cable, and the results are recorded in a file with other information on the circuit for reference.

\subsubsection{Termination Inspection}

After the installation is complete and the termination has been made, a QC inspector is required to inspect the termination. This process is also done by using a sampling of approximately 10\% of all terminations (i.e., as in conduit inspections). The inspector checks that the circuit is laid down on the correct terminal as per the "Diagram of Connections" drawing. He checks that the lug is the correct size for the wire used, and the terminal on which the connection has been made is the correct one. The inspector checks that the wires are formed neatly in the cabinet and that they meet all of the other requirements that might be imposed by the drawing and the procedures manual.

\subsubsection{QC Turnover}

After all the previous inspections have been passed, the item is ready for turnover to start-up. To do this, all support documentation that has been accumulated on a particular item is assembled and put into a QC turnover package, 


\subsection{Conclusion}

The quality control procedures which have been briefly described in the preceding sections imply the maintenance and updating of large volumes of data. Neglect of this data maintenance responsibility can lead to a chaotic situation. Use of manual methods" to handle this requirement is costly, time-consuming, and inefficlent. Th1s data envi.ronment is clearly well suited to the use of computerized methods, A cursory examination of the preceding sections on quality control indicates that large registers of data must be maintained for:

(1) Individua 1 welds completed

(2) Weld rod control

(3) Welder qualification

(4) Receiving inspection of materials and vendor certification/ letters of compliance

(5) Hangers installed

(6) Individual circuits installed and cables pulled

(7) Tool calibration records

(8) Installation hold point and "in process" inspection data

(9) Electrical integrity (high potential). tests

(10) Reinforcing steel control

Although this list is not exhaustive and is really just the "tip of the iceberg," it indicates the massive amounts of data which must be acquired, processed, and retrieved.

The number of drawings required for a single nuclear. plant is in excess of 100,000 and accounting for these drawings is a major activity. 
Some drawings have as many as six or seven revisions which reach the field site and must be distributed and controlled. Over two million documents must be retained in the form of "as-built" documentation of the plant. A typical plant contains 20,000 valves, 45,000 welds, and 20,000 instruments, all of which require extensive "as-built" documentation. This level of information flow and accountability is unprecedented in "conventional" construction. Access to and retrieval of this information is critical to the proper control of nuclear power construction projects.

The data base concept provides a suitable environment for a sophisticated user-oriented data retrieval system. Data used and generated at the project level is stored and maintained in a highly integrated structure instead of in separate application files. This approach permits organization of data in a hierarchical or relational system. For example, given the scheduling network number of an activity of interest, other information such as associated cost codes, required resources, equipment utilized, associated pour numbers, bills of materials, materials purchased, and material received can be retrieved.

The data are organized around strategically selected "keys" at several hierarchical levels. Typical keys are cost code numbers, activity numbers, TPNS (Total Plant Numbering System) numbers, startup numbers, drawing numbers, purchase order numbers, concrete pour numbers, personnel badge numbers, equipment numbers, work locations, and vendor codes. This organization insures the retrievability of data which crosses several levels of data structure. Reports can be prepared 
using the information maintained by several departments. The structure also provides the means for a systematic approach to collection and utilization of information.

The system being designed must be capable of information retrieval in real time via display terminals. Report retrieval language is designed so that nonprogramming personnel can use the system. Exceptional and ad hoc reports can be processed within a few minutes or hours depending on the complexity of the report.

Data base schema design has to reflect the operational characteristics of the project. The definition of every data element has to be in terms of its relative position in the schema and the site, as well as according to its content, maintenance responsibility, and security. requirements. The relational grouping of data is established according to reporting and update experience. A comprehensive data dictionary is being developed to maintain the data in the schema. The project control manager will have a data base administrator in his group who is fully responsible for maintenance and management of the data base and for its usage. Every user receives a subschema of the data base containing the information he needs. The schema or subschema has mapping characteristics that structure the data and define relationships within the structure. Figure 2.5 indicates the concept of relationships between data and applications through a schema. In Figure 2.6, a simple example of the hierarchy of a concrete pour schema is shown. The information is directly related to every pour number and, through cross-referencing, to a cost code or schedule activity number. 
The information can be retrieved in this format. If a report is required relating the information to facility components, this can also be summarized. One might be interested in a report parameter such as the unit manhours per cubic yard of concrete placed in the outside walls of an auxiliary building during January and February at E1.100. This information can be retrieved provided the data is available and proper relationships have been established. The data base application is most useful when a large variety of exceptional reporting is required.

This set of data and the elements thereof influence the speed of construction. QC and quality assurance control data are typical of this type of information. Other elements are required for final inspection and licensing inspections. Finally, the operation of the plant requires that certain information be readily available for maintenance and safety purposes. It, for instance, a weld rupluses, it will be important to determine immediately who made the weld and what other welds were made during the same time period. Maintenance of this massive amount of data requires a structuring which allows immediate retrieval based on a wide variety of access criteria. It is the objective of this research to design an information control system which will be responsive to these requirements- 
Document Control

\subsection{Introduction}

The Document Control function is defined in 10 CFR 50, Appendix B, Section 17. This section states that:

"Sufficient records shall be maintained to furnish evidence of activities affecting quality. The records shall include at least the following: Operating logs and the results of reviews, inspections, tests, audits, monitoring of work performance, and materials analyses. The records shall also include closely-related data such as qualification of personnel, procedures, and equipment. Inspection and test records shall, as a minimum, identify the inspector or data recorder, the type of observation, the results, the accoptability, and the action taken in connection with any deficiencies noted. Records shall be identifiable and retrievable. Consistent with applicable regulatory requirements, the applicant shall establish requirements concerning record retention, such as duration, location and assigned responsibility."

The NRC also mandates compliance with ANSI N45.2, which dictates that Lhe Document Control function must establish measures to control the issuance of documents, review, approve and release documents by authorized personnel. This regulation requires further that the distribution of documents to the appropriate activity be properly controlled. 
The Document Control system must insure changes are reviewed by the originating organization, maintain current and updated distribution lists, and review documents for legibility adequacy. Document Control has been established to meet these government requirements and organizations and duties are regulated by them.

In the industry today, the amount of documentation required varies from site to site, but can be as large as 8 million documenl sheets. Because of the large volume of documents and the complicated control measures needed, the Document Control departments are increasing in size and complexity. Figure 3.1 illustrates the volume. of documents that is created on a typical site in the construction phase of a project.

There are many documents that must be controlled. These include:

(1) Design Documents - drawings, specificat1ons, design verification.

(2) Vendor, Supplier Documents - drawings, specifications, manuals, instructions, $\mathrm{QA}$ documents.

(3) Constructor Documents - field generated drawings, instructions.

(4) QA/QC Documents - Certification Inspection records, Non-Conformance Reports, audits, specifications, manuals.

(5) Start-Up Documents - specifications, lay-out, results, certifications, procedures.

(6) General Documents - memos, correspondence. See Figure 3.2 for interfaces. 


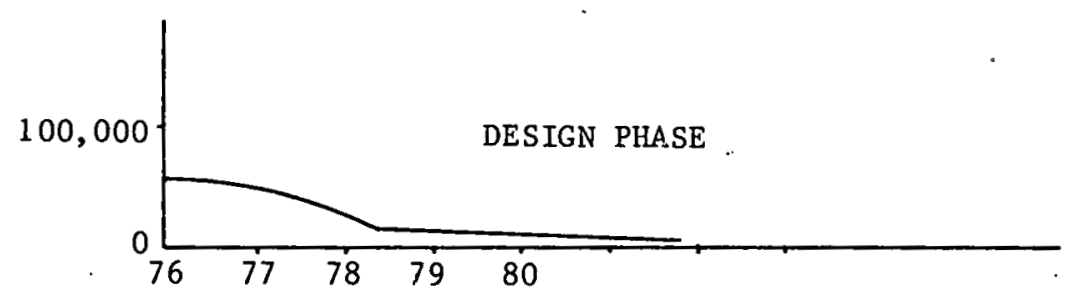

YEARLY RATES OF

RECORDS OCCURRENCES

DOCUMENTS

GENERATED

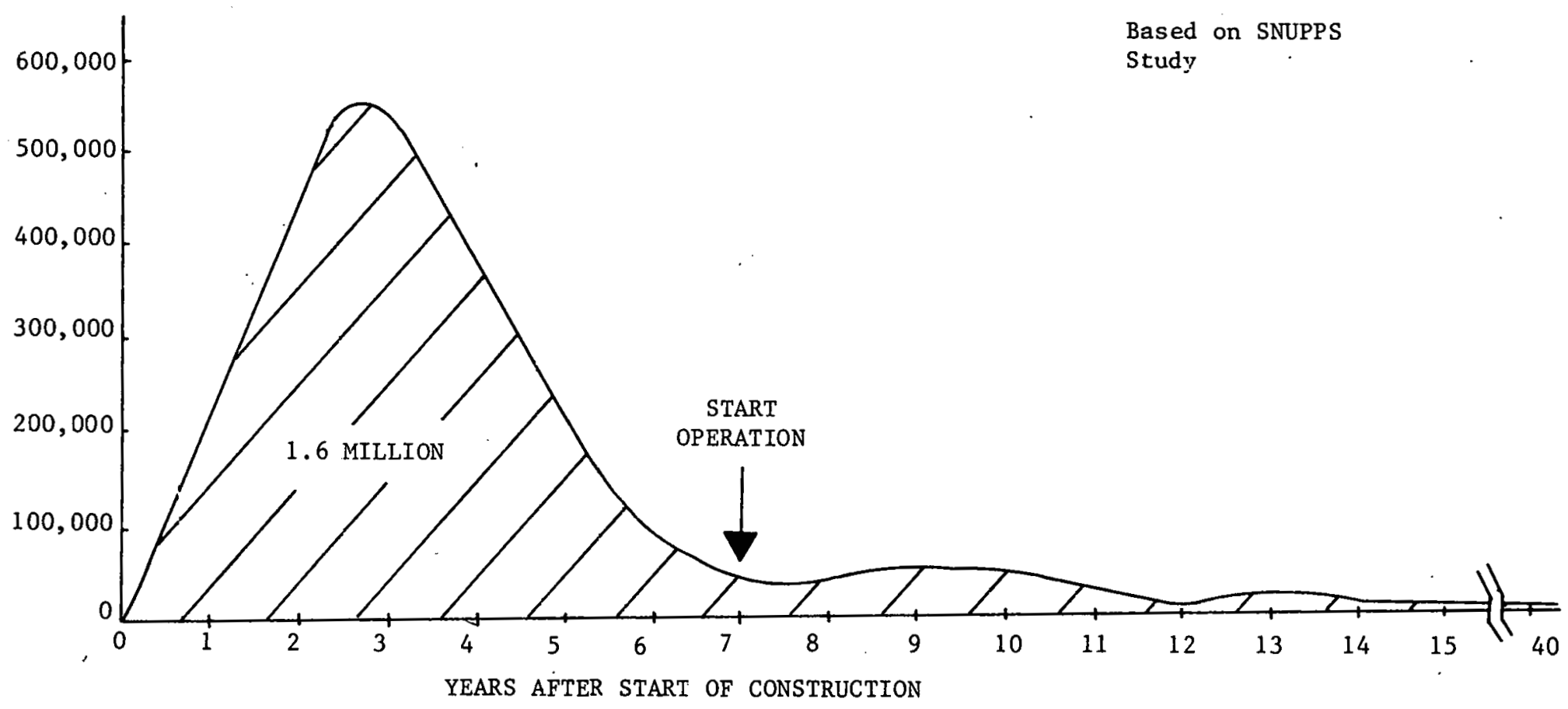

FIGURE 3.1: TYPICAL NUCLEAR PLANT UNIT-CONSTRUCTION AND OPERATION 


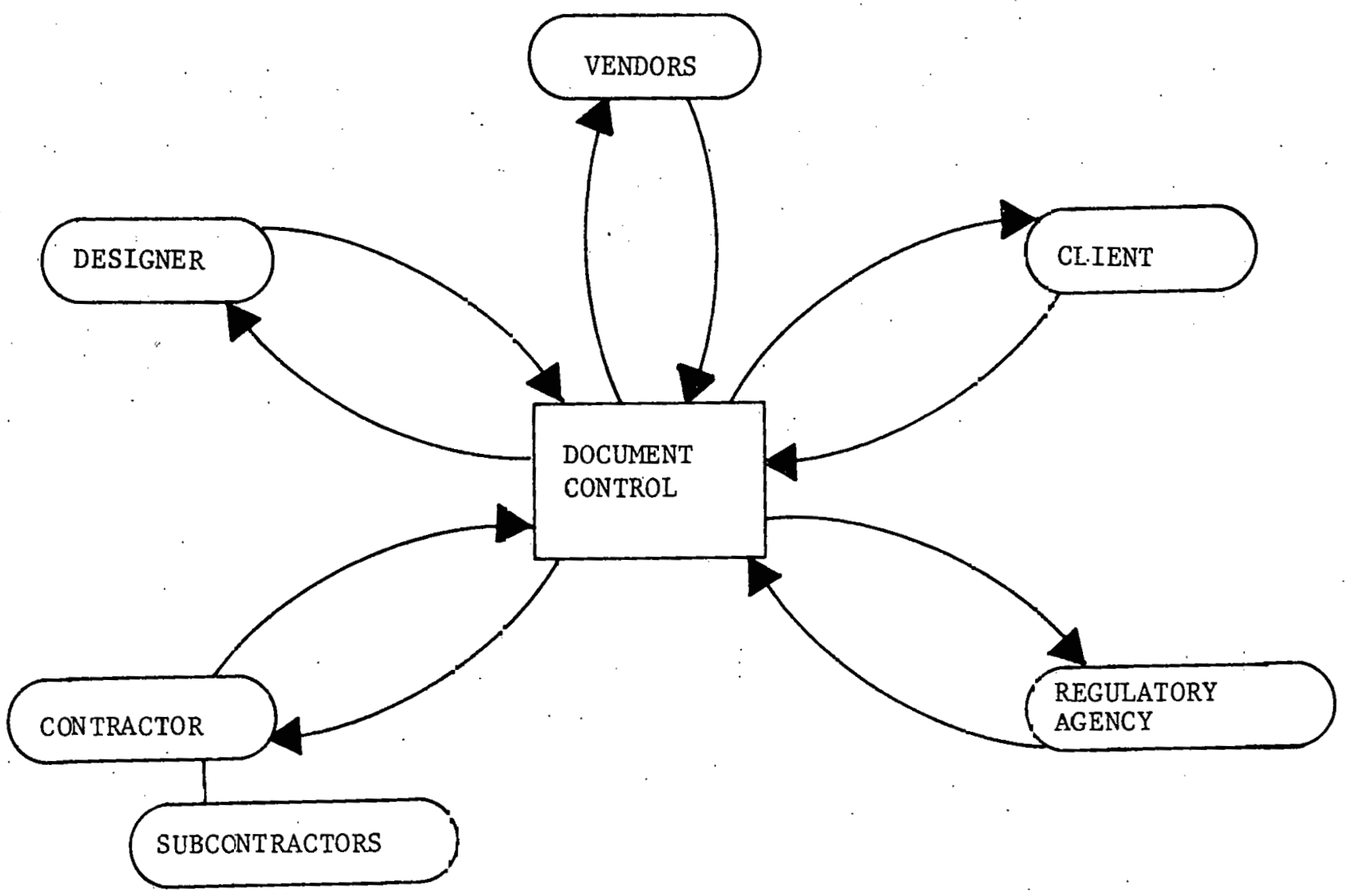

FIGURE 3.2: MAJOR SOURCES AND RECEIVERS OF DOCUMENTS 


\subsection{Quality Assurance Record System}

Requirements such as retention, traceability, indexing, identification, and retrievability, which are intrinsic to "Quality Assurance Records," are slowly beginning to merge with "Document Control." This is changing the overall complexion of document control. Specifically, these QA Records requirements are:

I. RETENTION: Two categories of QA records are to be established: A) Lifetime Records

(1) Possessing significant value in demonstrating capability for safe operation;

(2) Possessing significant value towards maintaining, reworking, repairing, replacing, modifying an item;

(3) Possessing significant value in determining the cause of an accident or malfunction of an item;

(4) Providing required baseline data for inservice operation.

B) Non-permanent Records

These are documents other than those above which are required to provide evidence that an activity was performed according to applicable standards. These documents need not be retained for the life of the item.

II. TRACEABILITY: When codes, standards, or specifications require traceability of material, parts or components to specific inspection or test records, the document control system shall be designed to provide such traceability. 
II.I. INDEXING: QA records shall be listed in an index to indicate, as a minimum, record retention time, where the record is to be stored, and the location of the record within the storage area.

IV. IDENTIFICATION: QA records shall provide sufficient information to permit identification between the record and the item or items, or activity to which it applies.

V. RETRIEVABILITY. Storage Eys tems shall provide for the arcurate retrieval of information without undue delay.

In order to meet these five requirements, a system has emerged that is more than a document control system. It might more appropriately be labelled a document management system. Examples of permanent and non-permanent records can be found in Appendix $B$.

\subsection{Document Management System}

Efforts to develop an adequate "document management system" have been undertaken by many of the member groups of the plant construction team. The utility systems department, the constructor, the designer (as in the case of Bechtel's Records Management System, RMS); and private organizations (e.g., Zytron, Florida Computing) have been working to develop a comprehensive approach to document management.

In general, three classifications or levels of capability have emerged:

I. Document Index System: simplest, least cost, most direct.

II. Document Index and Retrieval System: more complex.

III. Document Management and Retrieval System: in developmental stage only; currently not available. 
Common to all three systems is the use of microform for document storage.

\subsubsection{Document Index System}

The DIS approach to document control is outlined below, in

Figure 3.3.

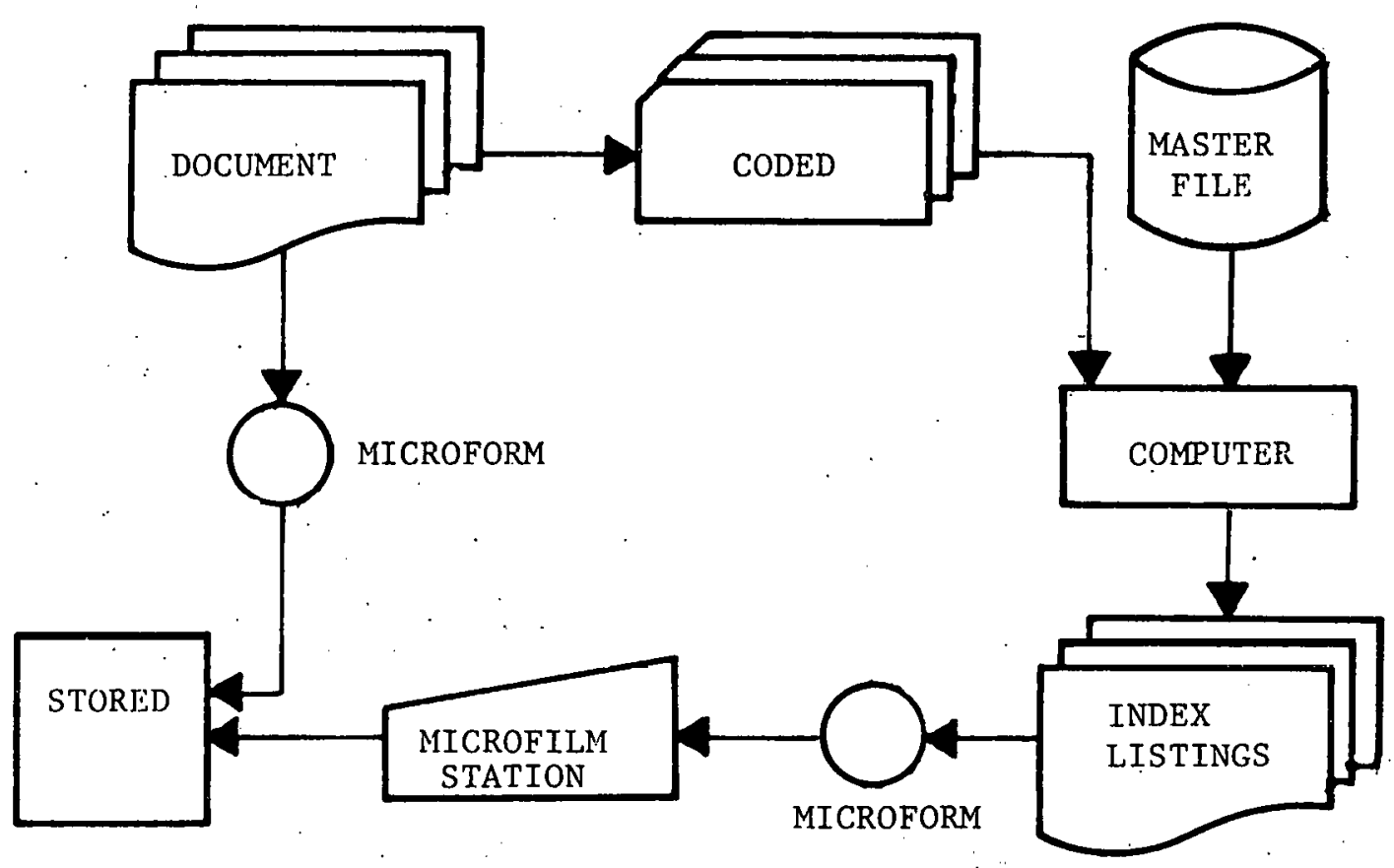

FIGURE 3.3: DOCUMENT INDEX SYSTEM

$\Lambda$ coding or classification system is developed. As a document is received it is coded accordingly. Typical codes are drawing number and sequence number, with additional information such as status code, 
retention code, document type code, revision number, originator, location, etc. This code is entered into the computer. The document is then microfilmed,

The computer periodically prints separate lists of all these documents sorted on various data fields. This printout is converted to microform (microfiche) and is available at each microfilm viewer station. The user consults the appropriate microfiche listing of a11 documents to obtain the document's microform storage location number.

This type of system is widely used by utilities and design companies since it adapts well to design drawing control. Extension of this approach to other documents compounds the complexity of the classification system. The burden of maintaining an index listing exceeding 500,000 lines per listing makes this system unwieldy.

\subsubsection{Document Index and Retrieval System}

The DIRS approach to document control is outlined below, in Figure 3.4.

The difference between this system and the previous DIS is essentially the retrieval of a microfilmed document's location via the computer and not by consulting a manually printed list.

Documents are coded according to a classification system and entered on the computer. The document is microfilmed. Requests for cross-referenced documents can be entered by the terminal and a search of the data file will produce a reference to qualified documents. 


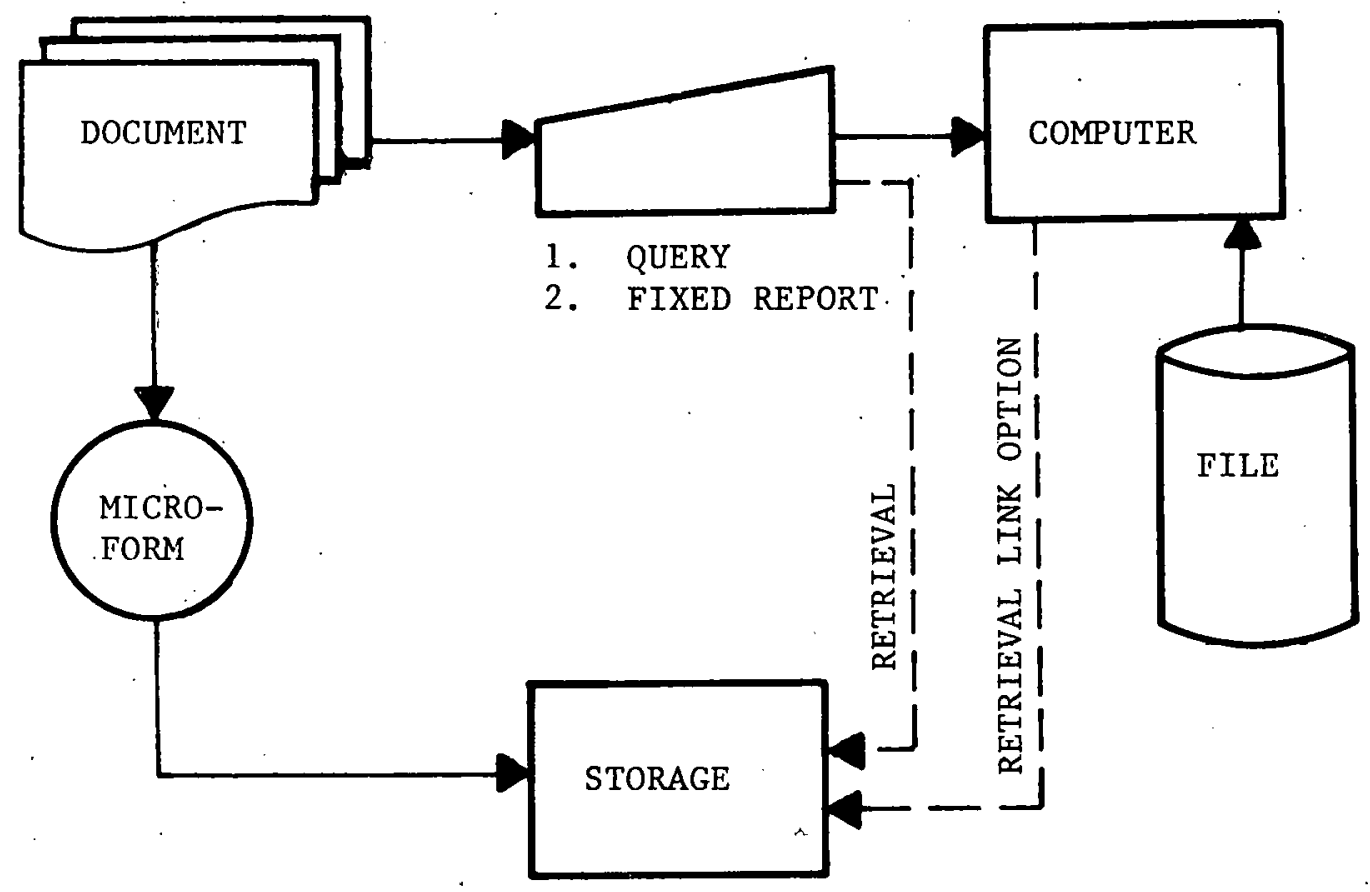

FIGURE 3.4: DOCUMENT INDEX AND RETRIEVAL SYSTEM

A variation on this theme is the use of an automated microfilm retrieval mechanism linked into the computer which will automatically retrieve the desired microfilmed document as soon as the computer completes its search.

The advantage of this method is the ability to quickly access a sequence of records tied to a specific problem. If designed properly, material traceability is easily accomplished.

Systems of this type are currently available from two or three companies. Due to the volume of documents (e.g., 2 million), a selfsufficient mini-computer is used to $10 \mathrm{ad}$ and retrieve the data. Since 
this is a relatively new product, it will be at least chree yeals before-a user evaluation is available.

\subsubsection{Document Management and Retrieval System}

The DMRS approach to document control is shown conceptually in Figure 3.5 .

Since this syscell ls lu llie developmental otngoc, dotailed information is not available. The concept is an extension of the DIRS with the added feature of a database link to a component control/ management system. The intent is to link the requirement for information or documentation to a component and then deteraine if the documentation has actually been completed.

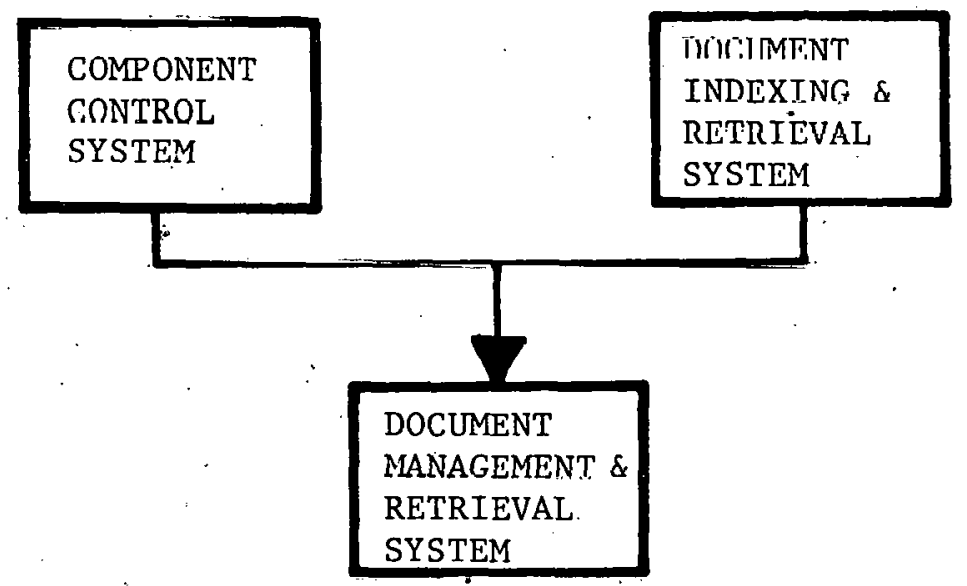

FIGURE 3.5: DOCUMENT MANAGEMENT AND RETRIEVAL SYSTEM 


\subsection{Recommendations}

There are certain areas of $Q A / Q C$ that would benefit from a construction information management system. Some of the more prominent areas are:

(1) Quality Assurance Records Management

(2) Material Receiving Inspection

(3) QC Manpower Projection

(4) Verification of Material Traceability

(5) Nonconformance Trends

(6) Vendor Qualification

Each of the above will be discussed below.

\subsubsection{Quality Assurance Records Management System}

This is the most critical need in QA/QC. As malfunctions occur, QA/QC is required to retrieve all "related" documentation. Presently, this retrieval is a manual search of all files unless the search can be logically limited to a certain section of the file. While manpower is provided to conduct this search when necessary, it is generally acknowledged that these manual searches may not be entirely complete. Since certain information is nearly impossible to retrieve, some questions are never asked or go unanswered. This need is recognized and systems have been developed to provide some solutions. 


\subsubsection{Material Receiving Inspection}

The tracking and receipt of materials, in most instances, is a manual process. Delays in inspection by QC can be caused by unexpected equipment delivery since time is lost in searching for the inspection requirements for. the equipment.

There are several possible solutions to this problem and one direct approach is to utllize the mácerlals reculviıb system. Mont vondors will notify Receiving a week or two in advance of actual delivery date. This information, made available to QC, would provide sufficient lead time to insure all specifications are prepared for the receipt inspection.

\subsubsection{QC Manpower Projection}

Since the qualifications of many QC inspectors are highly specialized, a certain amount of lcad time is necessary to hire and certify the inspector. It can happen that construction will hire a person qualified for a certain special process. Unless QC has an inspector available for this special process, no work can be done.

In order to anticipate this problem, two interfaces would be helpful. One would provide a close tie with construction's workforce projections (by number of individuals, not manhours), and the second would. link to the personnel request system. Information from both can assist QC in maintaining a staffing level sufficient to keep pace with the construction workforce. 


\subsubsection{Verification of Material Traceability}

Standards require that $Q A / Q C$ must demonstrate traceability of certain items or material. This is a tedious clerical process that at times may be overlooked or deferred to a later time. Merged with a records management system, this process could be automated. Included would be items such as mix and batch numbers, heat number, weld filler material, welder qualification, measuring instrument calibration, test results, as well as nonconformance reports.

\subsubsection{Nonconformance Trend Analysis}

Nonconformance trending is available, but at times is limited in the data available for analysis. Nonconformance trending has a potentially large impact on a project's performance. The problem is to find the significant variable, be it the vendor, the inspector, the worker, the system, or even the specification of the material.

\subsubsection{Vendor Qualification}

There are times when $Q A / Q C$ discovers a problem reflecting back to the vendor. Notification to procurement usually is lost in the mass of paperwork. Ideally a QC status flag (controllable by QC) could be set in a vendor master file to prevent further procurement until the problem is resolved. This flag could also be used to automatically trigger a list of all items on order, delivery, or even installed for further inspection if needed. 


\subsection{Field Generated Document System}

This system has been implemented on the Enrico Fermi nuclear power plant site. Its primary purpose is to control Quality Control paperwork. The field documents controlled by this system are generated by the Quality Control Department, Engineering, and subcontractors. The documents controlled are part of the design documentation of the plant and, since they are dynamic in nature, the control of the origination, follow-up, and completion is very important for the construction effort.

The following documents are typical of the types of reports derived

from this data:

Deviation Disposition Request

Surveillance Report

Design Change Request

Request for Clarification of Information

As Built Documents

Design Change Notice

Field Modification Request

The system provides key information about every document. This information includes status, relation to components, drawings, design documents, and relation to individual groups and disciplines at the project. The documents also have assigned category classification which is important to evaluate the types of activities and disciplines which are most affected by these documents.

The system serves the following purposes:

(1) Status control of active documents related to design

(2) Verification that the documents were included in new permanent drawing revision 
(3) Maintenance of the list of components which were affected by these changes

(4) Maintenance of a list of permanent drawings affected by these documents

(5) Statistical evaluation of major categories, areas, or conditions which cause deviation

Several thousand documents of these types are generated on a project site, and it is necessary to track all such documents through their life cycle. Samples of the reports and forms are shown in Addendum C. The Quality Control Department is fully responsible for the document maintenance in the system. The system is implemented using an intelligent terminal in combination with a large computer master file. The terminal edits and validates the information and prepares it for transmission to the master file. 
THIS PAGE

\section{WAS INTENTIONALLY \\ LEFT BLANK}


CHAPTER IV

$\underline{\text { Start-Up }}$

\subsection{Introduction}

Start-up of a nuclear power generating facility is a long and complex task. It may involve a group of over 250 technically trained persons working for a period in excess of six years. During this period, start-up programs are established which generate and process vast amounts of information and data. Virtually all procedures, data systems, and information files that are required for commercial operation are actually developed during the start-up phase of a nuclear station. This chapter examines these procedures, data, and information requirements.

\subsection{Start-Up Scope}

The term start-up is of ten used to describe the transition of a nuclear facility from the construction phase to the operation phase. This definition is accurate, but to understand start-up, it must be expanded upon.

In most companies, the operating group is actually responsible for plant start-up. This ensures a smooth transition from the startup phase lu cummerclal operation. In this chapter, the start-up group will be defined as the operating group during the start-up phase of a nuclear station. 
The start-up phase of a nuclear station typically lasts for several years. Even before construction begins, start-up personnel need to be involved in the development of an integrated "construction start-up" schedule. This schedule is extremely important because it coordinates construction and start-up activities that may span as many as 12 years. Start-up is complete when the plant is proven to meet all required regulations for safe commercial operation.

\subsection{Start-Up Description}

One of the initial major tasks of the start-up group is to establish the start-up organization. It is very important to assemble a staff which is adequately qualified for the various technical positions that exist at a nuclear station. This organizational development lasts throughout the start-up phase and ultimately determines the success. of the start-up group. Figure 4.1 is a typical nuclear plant organization.

The first phase of plant start-up involves the transfer of systems/ structures from the construction group to the start-up group. Systems are transferred to the start-up group for maintenance, for operalion, and for testing. To accomplish this task, a turnover procedure is . developed to assure that there is complete understanding of who has responsibility for plant equipment at all times. Usudlly a LuL huvel package is put together for each system. Types of information that may be found in these packages are system boundary descriptions, system drawings, Quality Assurance acceptance documentation, reference 


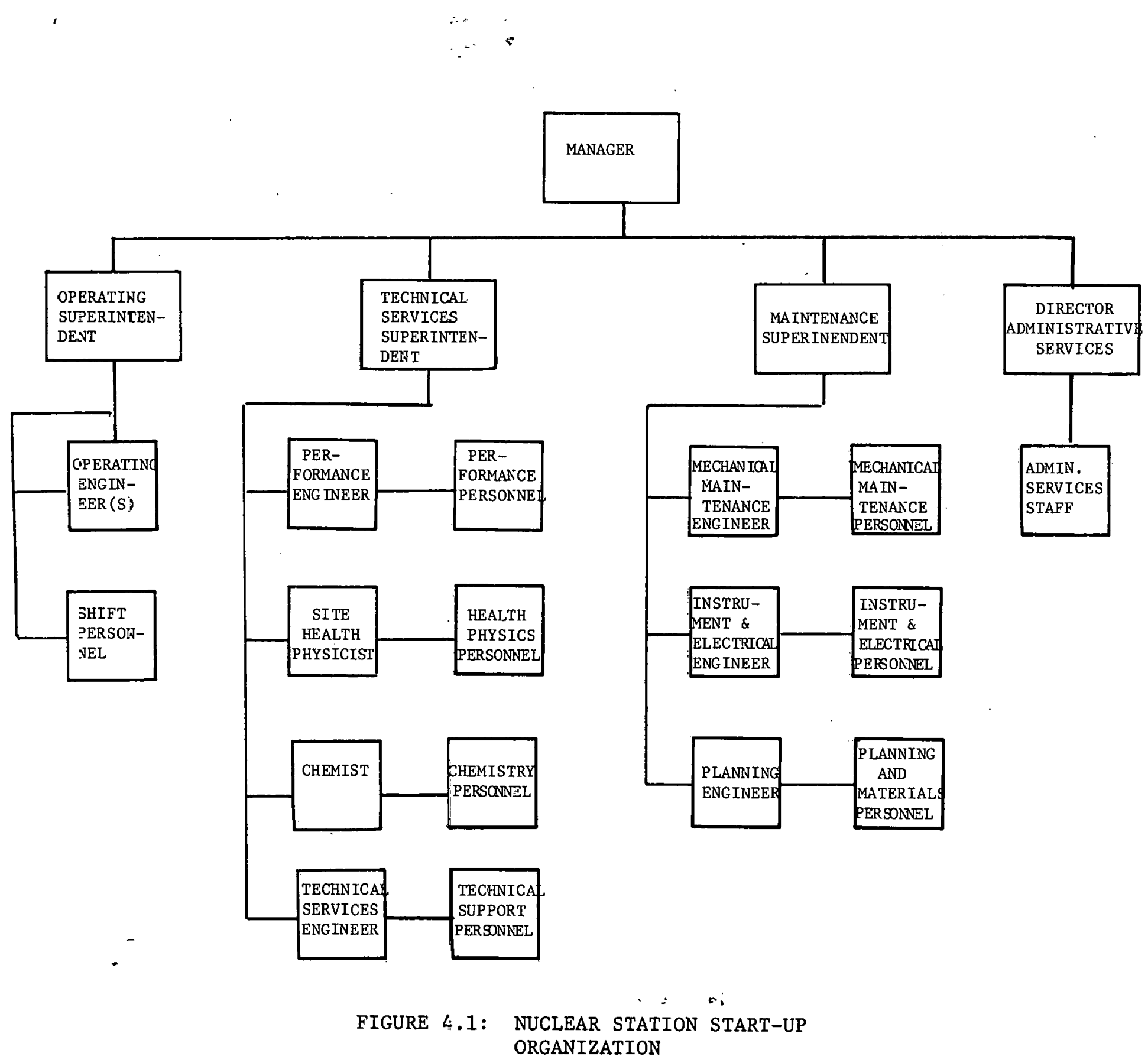


documents, and turnover exceptions. All transfers eventually become permanent. It may be necessary, however, to transfer some systems temporarily. This allows the start-up group to test, operate, and maintain the system at a time prior to final construction completion. At the completion of final construction work on a system, the start-up group should verify that all construction work is complete and that copies of all reference documents for the system are available biefore accepting final turnover.

Before systems are turned over to the start-up group, system boundaries, and turnover packages boundaries within those systems, should be completely defined. This task often becomes the responsibility of the start-up group requiring considerable time and research. System scoping should be accomplished, if possible, in the design phase of the project.

Also, before systems are turned over to the start-up group, the start-up group should visually inspect the system in the field. Many problems are easily seen in the field and it is often advantageous to clear these problems before system transfer. This pre-turnover check may be referred to as acceptance testing. Data Sheets or work request forms may be used to document these tests as is specified in the appropriate project procedure.

Flushing to remove foreign debris from pipes, tanks, pumps, and instrument lines may be completed by construction or the start-up group depending on the lines of responsibility. Flushing is completed and documented in accordance with established procedures. Hydro testing 
of systems usually follows flushing and insures that there are no leaks and that the system can safely handle design pressure.

Because of the many areas of interface between construction and start-up groups during system/structure turnover, it is important that these groups communicate and work constructively together. In this effort, construction/start-up interface meetings are held on a regular basis (usually week1y) to coordinate work activities.

An engineer is usually assigned the responsibility for the initial operation of a particular system. The engineer must become familiar with the system, its subsystems and its interface with other systems. He must also insure that all construction work is complete, that acceptance testing is complete, and that flush and hydro are complete. The system is then ready for preoperational maintenance which includes instrument calibration, instrument loop checks, and mechanical aligninent of components. Following preoperational maintenance, main components may need to go through an operate-adjust cycle to bring the components to full performance.

The engineer will next be involved with preoperational testing of the system using detailed, step-by-step test procedures. Major objectives of preoperational testing are as follows:

(1) To verify that systems meet design requirements and commitments.

(2) To verify that all safety and control systems meet license requirements that are prerequisites to initial fuel loading and power ascension testing. 
(3) To bring systems to the best performance possible during cold plant condition. Preoperation testing requirements are given in the station FSAR document. Nuclear safety related systems are required to be preoperationally tested and it is highly desirable to test all systems preoperationally. Besides verifying system performance, preoperational testing also gives station personnel an opportunity to gain experience in operating station equipment before actual station operation.

After all individual systems have been tested, hot functional testing can begin. Hot functional testing verifies integrated plant operation under hot, no-load conditions before nuclear fuel is loaded. Hot operating conditions are achieved by using reactor coolant pumps to generate heat in the primary water and pressurizer heaters to increase pressure in the primary systen.

Some plants choose to perform hot functional testing after fuel is loaded, using the reactor to heat water to operating temperature and pressure. In this case, an integrated system test is completed prior to loading fuel.

Integrated system or hot functional test results are one of many Nuclear Regulatory Commission (NRC) requirements that are reviewed by the NRC before issuing an operating license to the station. This license must be obtained before fuel can be loaded into the reactur. The NRC sends a review committee to the station to observe start-up testing and to randomly review documented test results. 
After fuel is loaded, all systems are verified as ready for power ascension. Reactor power is then increased in predetermined steps, with tests performed prior to each increase. Power ascension continues until the reactor reaches 100 percent power. The final responsibility of start-up verifies that safe and control operation can be maintained at 100 percent reactor power. 


\subsection{Description of General Programs that Support Start-Up}

There are many programs which must be developed during the startup phase of a nuclear station. They imply a data structure which will support.start-up. These programs must support start-up activities as well as further plant operations. Programs are also developed to ensure that the safety of employees and the public is maintained at all times. Finally, programs must be developed in order to comply with government regulations.

An extensive training program is part of the start-up phase of a nuclear station: All station personnel should receive training in the areas of radiation protection and basic station operation and administration. In addition, technical groups receive additional training in their areas of responsibility. The main objective of this program is to develop a well trained and experienced staff that is capable of handling the complex operation of a nuclear station.

One of the most time-consuming activities during start-up is that of developing procedures. The procedures that must be developed are designated chemistry, health physics, operating, instrument, periodic test, maintenance, preoperational, and emergency. The number of procedures developed is well over 1000 per unit. Some companies choose to have outside vendors assist in procedure writing.

With the vast number of documents at a nuclear site, a document control system must be developed. Types of information in this system are drawings, manufacturer's manuals, reference material; and controlled documents. A distribution index lists all documents that are in the 
document control system. Copies of all documents coming to the station are sent to either a master file or a plant file. If needed, satellite files can be set up to keep information close to where it is needed.

Another important filing system must keep track of all Quality Assurance (QA) records. Many types of information are generated by QA during the design, construction, start-up, and operation of a nuclear station. This information must be collected, stored, and maintained in accordance with applicable regulatory requirements. These requirements must be met prior to obtaining an operating license.

Early in the start-up phase, a Materials Management System is established. This system should maintain an adequate stock of all repair parts and consumables to support the plant maintenance effort. The methods of procurement are established using standardized requisition forms. To keep track of spare parts and consumables, an inventory system and a warehousing system are established. Material control and storage environments must meet Quality Assurance acceptance criteria. As start-up progresses, maintenance work activities begin to accelerate at a high rate, necessitating the development of a maintenance program. The heart of this program is a work order or work request form which coordinates, controls, and documents all maintenance work activities. This form can also be used to record equipment history in an effort to determine preventive maintenance measures. Also, because some equipment requires regular maintenance, a periodic maintenance schedule should be developed and administered through the maintenance program. 
A very important program, that should be developed during startup, lists all major components such as instruments and valves. This program may take the form of a master component list or an equipment data base. Whatever the form, its purpose is to keep track of and to provide information on all station components. This information supports the activities of all plant groups. The master component list should include all information regarding pertinent installation, purchasing, and maintenance dala.

During start-up, a station chemistry program must be established to accomplish the following tasks:

(1) Provide potable drinking water for station personnel

(2) Monitor waste discharge points

(3) Establish a stock of process expendable items

(4) Test and operate - waste, sampling, and chemical addition systems used during start-up

(5) Maintain wet lay-up of systems

In addition, a health physics program is developed (1) to measure and control the radiation exposure of personnel, (2) to continuously evaluate and review the radiological status of the plant, (3) to make recommendations for control or elimination of radiation hazards, (4) to train personnel in radiation safety, (5) to assist all personnel in carrying out their radiation safety responsibilities, and (6) to prolect the health and safety of the public both on-site and in the surrounding site area. 


\subsection{Design Interface with Start-Up}

A great deal of information for start-up and operation is developed during the design phase. This information is generated during detail design of systems and components. Information such as component type, purchase specifications, component storage requirements, drawing references, and equipment numbers are all part of the mass of information that is determined during design. Design information is generated to meet the needs of the designer. It is, however, important to functions performed by the start-up and construction groups.

Ideally, this information should be available in the form of a data base accessible to all groups requiring this information. The design data base used at Duke Power (Figure 4.2) provides an easy means by which the start-up group can obtain needed information. A list of available sorts makes it easy to obtain information in certain areas. Special provisions have also been made to process special request sorts as the need arises. Addendum $D$ gives a list of all files in the Duke Power design information data base. Standard sorts that are most of ten used by station personnel provide information in the following report formats :

(1) Cable routing

(2) Electrical system status

(3) Electrical specifications :

(4) Electrical load

(5) Electrical one line drawings

(6) Valve list 


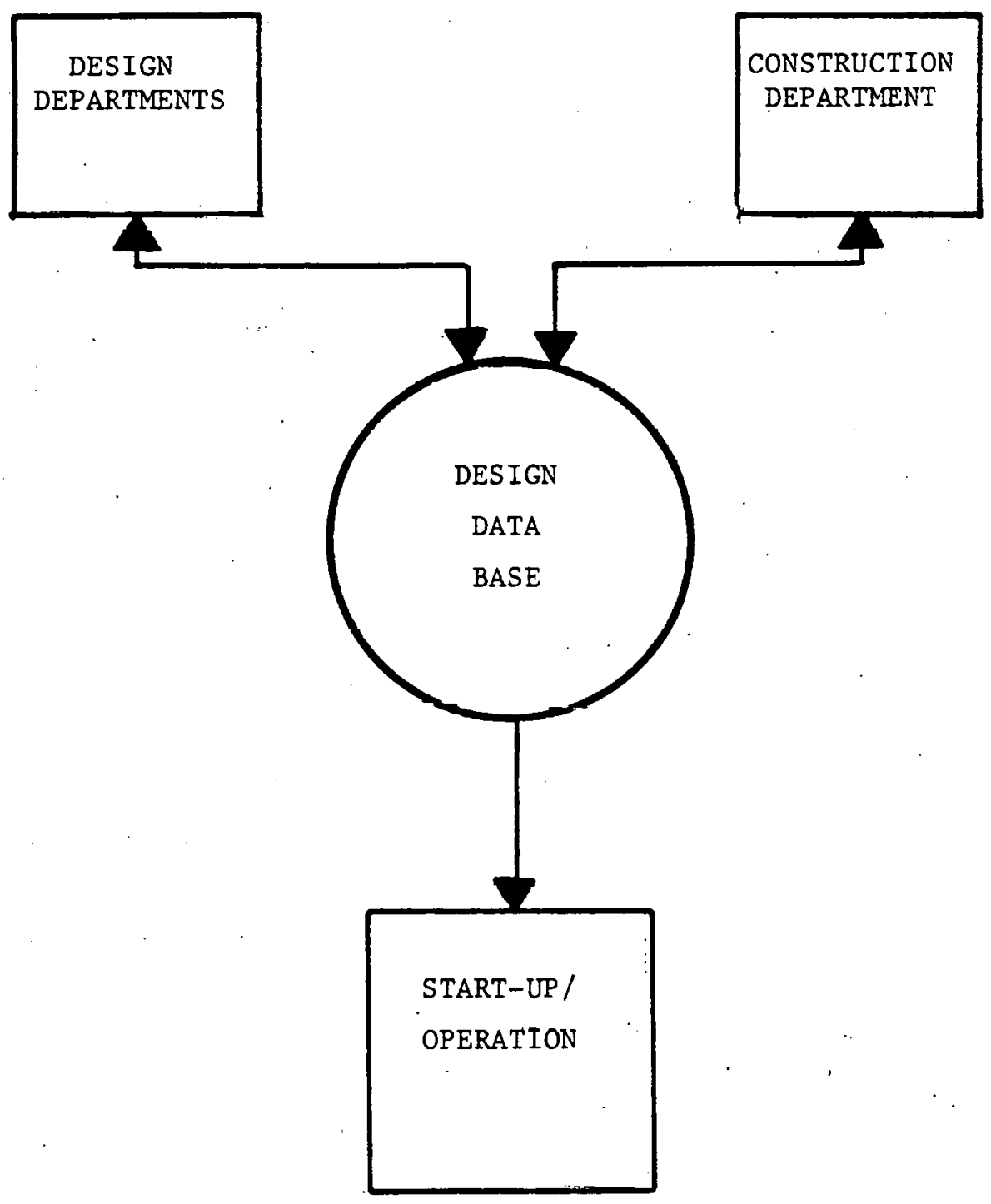

FIGURE 4.2: CONCEPTUAL DIAGRAM OF DESIGN DATA BASE INTERFACES 
(7) Valve cross reference

(8) Valve status

(9) Annunciator list

(10) Monitor light list

(11) Status indication light list

(12) Wire tabulations

(13) Event recorder list

(14) Mechanical pipe hanger list

(15) Variation Notices and nonconforming items

Appendix E lists those Duke Power design drawings and documents that are sent to the station from the design element. This list includes drawings and manuals originating within Duke as well as vendor drawings and manuals*. Each category of information receives an alphanumeric code that serves as a distribution code. Also, each manual and each drawing receives an individual alpha-numeric code for identification purposes. All documents coming to the station via the design distribution are controlled by the plant master file.

One controlled document that is of prime importance to the startup/operating group is the Mechanical Instrumentation and Control List. The basic element in this list is the instrument. Each instrument is identified by a unique number:

V WW XX YYY Z

$\mathrm{V}=$ Unit designation

* Vendor manuals not shown in Appendix $E$. 


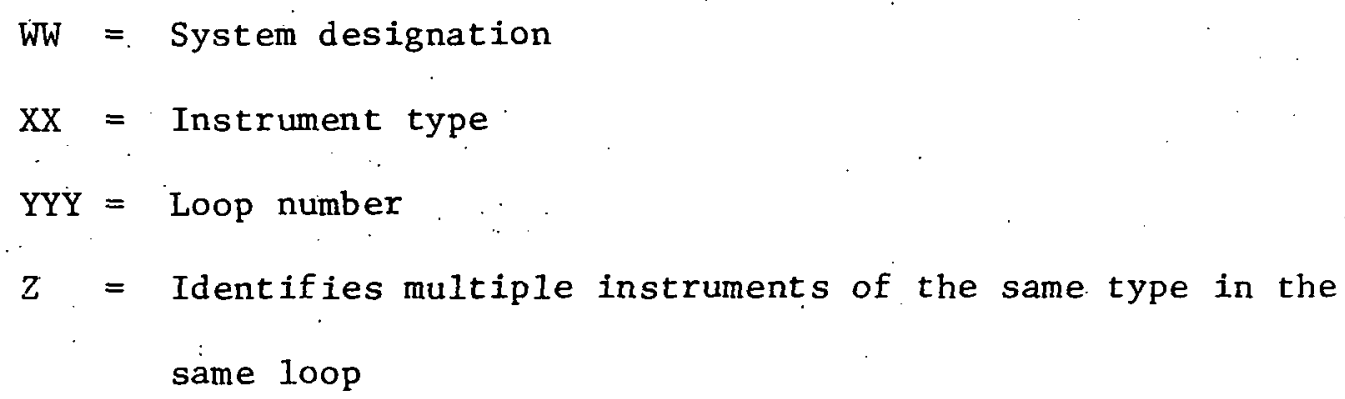

This list is eventually replaced by an equipment data base that will be controlled by station personnel.

The Station Problem Report is another major control document. This report provides a mechanism for initiating corrective action on a problem associated with a pre-operational nuclear unit. It provides a concise statement of problems which cannot be resolved in a timely manner by informal means: These problem reports are generated by start-up/ operating personnel and are then routed to the designer for resolution. Each problem report receives a unique number: .

$\underline{X} \underline{\underline{Y Y Y Y}}$

$\mathrm{X}=$ Unit number

YYY = Sequential number assigned as reports are processed This form consists of statements of problems, recommended solutions, economic justification, and priority. After design document resolution of the problem, the completed Station Problem Report is returned to the station to be filed. 


\subsection{Construction Interface with Start-Up}

An integrated schedule must be developed that coordinates activities between construction and start-up. This schedule should be developed as soon as possible before or just after construction begins at the site. The composite construction/start-up network can exceed 30,000 individual activities. * The integrated schedule should be entered into a computer where updated information can be maintained in an available and easily retrievable form.

Developing a schedule of this magnitude is an extremely complex task. All construction and start-up activities must be identified. It is usually helpful if start-up numbers or codes are assigned to these activities in order to easily identify a sequence of events. Some of the major activities that should be included in this schedule are:

(1) Installation

(2) NDE

(3) System/Structure turnover

(4) Acceptance testing

(5) Flush

(6) Ilydro

(7) Calibration

(8) Preoperational testing

Before a system is turned over from construction to the start-up group, a turnover package must be assembled for that particular system.

*The composite network on Hatch II Nuclear Plant utilized a network of this size. 
The main purpose of the turnover package is to document system or turnover boundaries and system status prior to turnover. The turnover package may also be used to transfer system documents to the start-up group. Typical information that is found in a turnover package is listed below:

(1) System boundary descriptions

(2) Equipment records verification

(3) Mechanical design and inspection status

(4) Electrical design and inspection status

(5) Piping design and inspection status

(6) Instrumentation design and inspection status

(7) Support/restrain design and inspection status

(8) System drawings

(9) Manufacturers' drawings and manua1s

(10) Setpoint information

(11) Turnover exceptions

(12) Cleared turnover exceptions

(13) Temporary turnover documentation

(14) Provisional turnover documentation

(15) Final turnover documentation

(16) Variation Notices

(17) Non-Conforming Item Reports 


\subsection{Other Interfaces with Start-Up}

In addition to design and construction groups, vendor and regulatory organizations also interact with start-up. The degree to which start-up interfaces with outside vendors will depend on the needs of the individual start-up organization. The major interface with vendors is in relation to vendor supplied equipment. In some instances, vendors also provide start-up support personnel to assist the station start-up group.

The Nuclear Regulatory Commission (NRC) sends a review committee to each nuclear plant applying for an operating license. Required documents must be on hand, in order, and accurate. of particular importance to the NRC is the station Quality Assurance (QA) program. The QA program must follow regulatory requirements such as 10CFR50, ANSI N18.7-1972, and ANSI 1N45.2-1971. As noted in Chapter 2, ANSI N45.2.9 outlines the requirements for collection, storage, and maintenance of QA records. The station QA department may or may not be considered part of the startup group.

\subsection{Information Developed at the Station}

A detailed investigation of all areas of information development during start-up of a nuclear station is beyond the scope of this discussion. This section will, however, describe some of the major data systems in use at nuclear stations. These data systems rely heavily on information that is transferred to the station from outside groups. The discussion is based on systems utilized by Uuké Pówèr. 


\subsubsection{Station Equipment Data Base (Duke)}

Duke Power has developed an equipment data base to meet equipment data requirements during start-up and operation. Much of this data already exists in independent files (Figure 4.3). The equipment data base greatly reduces time that is presently spent looking for information. The key element in the data base is the component. Types of components fall into either mechanical, electrical, or instrumentation categories. The basic equipment number is defined as follows:

\begin{tabular}{lllllll}
\multicolumn{9}{c}{ Digit } & \# & & \\
\hline 1 & 234 & 56 & 78910 & 11 & 12 & 13
\end{tabular}

Unit Number $\quad \underline{N}$

System designation AAA

Type of equipment $\quad \underline{A A}$

Equipment number

Supplementary number (if required),$\quad \underline{A ~} \mathrm{~N}$

The first phase of data base development consists of the collection of data via data entry forms and by the transfer of data from existing files. Update of information is made via on-line terminals. A description is given in Addendum $G$.

The second phase of data base operation consists of developing data output formats as report requests are received. Custom printout capability is provided to allow quick access to the data contained in the file. This data base is used to generate drawing cross reference 1 ists, 


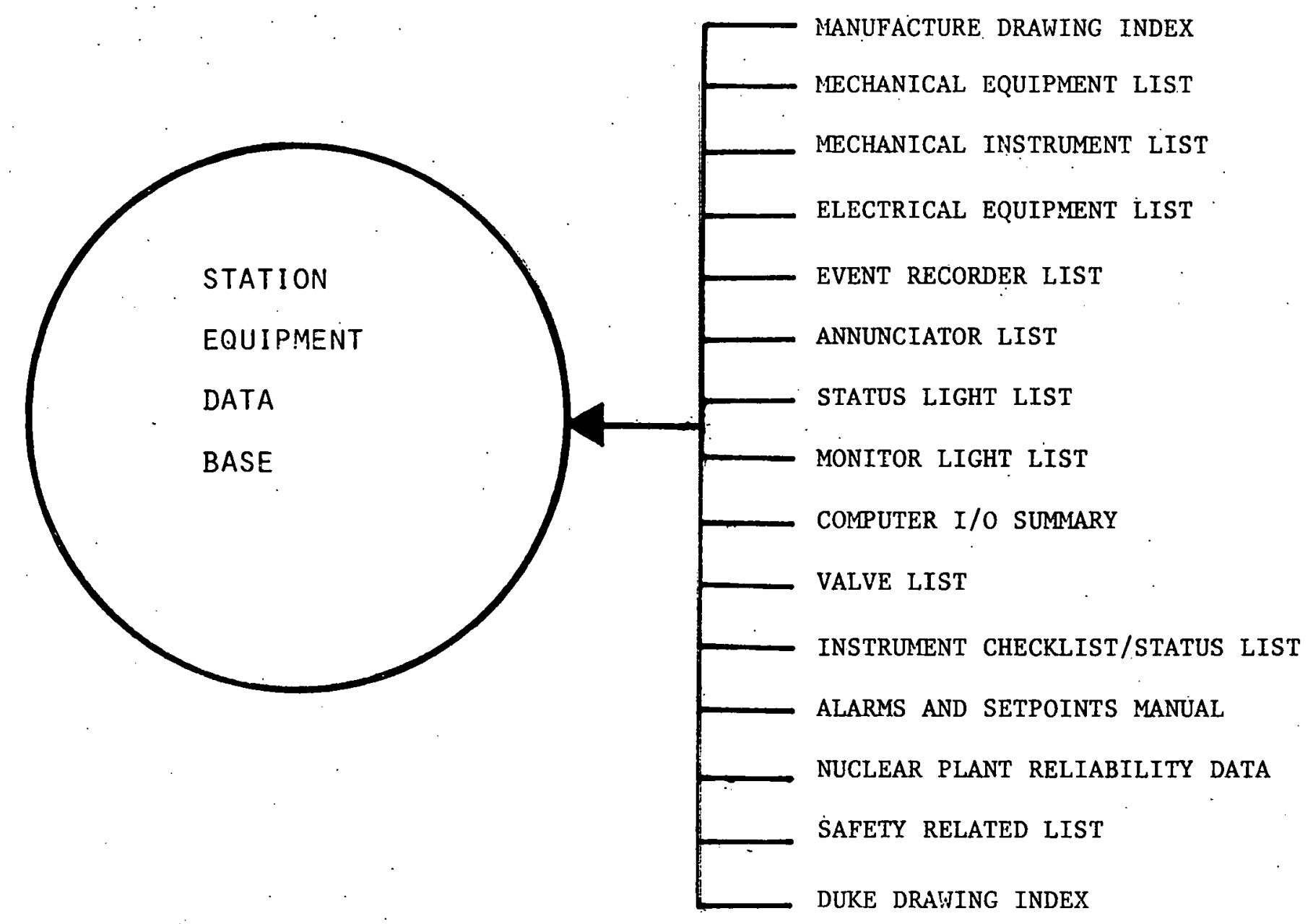

FIGURE 4. 3: EQUIPAENT DATA BASE 
set point lists, manufacturers' and model lists, calibration and preventive maintenance reports, as well as nuclear plant component reliability data. Capability will also be provided to generate a list of work or repair orders for any component listed.

\subsubsection{Station Modifications}

Station modification forms document modifications to station structures, systems, or components that have been finally transferred to the start-up/operating group. To InLtiate a slation modification, a station modification request form is first completed. This form should contain the following information:

(1). Station

(2) Unit

(3) Structure, system, or component

(4) Description of proposed modification

(5) Reason for proposed modification

(6) Suggested modification priority

(7) Required completion date

(8) Unique identification number

The unique identification number is assigned in accordance with the following breakdown:

$$
\text { NSM - XX - YYY Rev - ZZ }
$$

where:

$$
\begin{aligned}
& X X=\text { Station designation } \\
& Y Y Y=\text { Serial number }
\end{aligned}
$$


$\mathrm{ZZ}=$ Revision number

The modification process may involve interface with several station groups as well as general office personnel, regulatory agencies, and vendors. This interface should be documented and put together into a modification package. The modification package should contain the following' types of information:

(1) Modification request form

(2) Documentation of safety evaluation

(3) Summary of solution

(4) Nuclear Regulatory Commission authorization for modification:

(5) Amended technical specification sections

(6) Quality Assurance review

(7) Procedures used to implement modification

(8) Drawings that are applicable

(9) FSAR revisions

\subsubsection{Instrument Data Base}

An instrument data base has been developed to keep track of instrument calibration status and to serve as a quick information reference. Types of information included in this data base are:

(1) Unit number

(2) System

(3) Instrument identification number

(4) Type instrument

(5) Manufacturer 
(6) Model number

(7) Loop status

(8) System status

(9) References

This data base also makes it easy to sort instruments by calibration status, manufacturer, system, type instrument or by model number.

\subsubsection{Nuclear Plant Reliability Data}

The Nuclear Plant Reliability Data (NPRD) System was developed by the Edison Electric Institute to collect reliability data on nuclear station, safety-related equipment. The objective of this program is to supply reliability data reports to nuclear utilities, regulatory agencies, and to the designers of nuclear, safety-related equipment. . Nuclear utilities throughout the United States are participating in this program by filling out standard format input reports. Four scandard format input reports are used:

(1) General unit information

(2) Engineering description of system/component

(3) Quarter1y operating reports

(4) Failure reports

Types of information that are required for the engineering description are listed below:

(1) Type of nuclear unit

(2) Nuclear Steam System Supplier

(3) NPRD system or component code 
(4) Utility's component or system code

(5) In-service date

(6) Manufacturer serial number

(7) Supplier/vendor serial number

(8) Safety class code

(9) Norma1 Operation mode

(10) Environment code

(11) Applicable manufacturer code or standard

(12) Manufacturer reference number

(13) Mode1 number

(14) Source drawing or document number

A failure report must be prepared for each failure of a safetyrelated system or component. Types of information that are needed for this form are:

(1) Type of nuclear unit

(2) Nuclear Steam System Supplier

(3) NPRD failure code

(4) Utility's component or system identification number

(5) Number of times component has failed

(6) Date of failure

(7) Date failure ended

(8) System status at time of failure

(9) Failure description code *

(10) Cause of failure code *

(Ii) Corrective action code * 
(12) Mode of failure code*

(13) Effect of failure code *

(14) Failure detection code *

*These are NPRD assigned codes.

\subsubsection{Parts and Supply Catalog}

The parts and supply catalog is an important part of materials management. It should list all spare parts and consumables that are necessary to support the station maintenance program. It is helpful if the parts and supply catalog is capable of supplying cross reference and interchangeability data. The start-up group is usually responsible for gathering data for the parts and supply catalog. A list of this data follows:

(1) Part description

(2) Reference drawing number

(3) Manufacturer

(4) Manufacturer order/model/part number

(5) Supplier

(6) Supplier order/model/part number

(7) Field location of part

(8) Warehouse location

(9) Equipment used on 


\subsubsection{Work Request Program}

A work request system coordinates, documents, and controls all maintenance activities at the station. The following information may be found on a work request form:

(1) Unit number

(2) Work priority

(3) Work request number

(4) Uriginator

(5) Date originated

(6) Approval date

(7) Availability date

(8) Complete by date

(9) System abbreviation

(1.0) Component number

(11) Location

(12) Description of work

(13) Safety-related or non-safety-related

(14) Retest requirements

(15) Radiation Work Permit requirements

(16) Quality Control requirements

(17) Red tag placement

(18) Department responsible for work

(19) Procedure number if required

(20) Technical specification requirements

(21) Materials réquired 
(22) Special tools/equipment

(23) Clearance to begin work

(24) Action taken

(25). Performed by

(26) Reviewed by

(27) Tests results satisfactory or not satisfactory

(28) Heaith Physics remarks

(29) Quality Control remarks

(30) Accepted by

(31) Job supervisor

(32) Approved by

\subsubsection{Instrument Pre-Installational Checkout}

As instruments arrive on site a pre-installational checkoul is performed to verify that the correst instruments were shipped and to verify that all instruments can be calibrated within acceptable ranges. Pre-installation checkout also allows instrument technicians an opportunity to become familiar with instruments and calibration procedures. The first part of the instrument pre-installation test report contains basic instrument information that is usually filled out by construction personnel:

(1) Service description

(2) Mark number

(3) Detail number

(4) Diagram number 
(5) Process

(6) Instrument type

(7) Catalog number

(8) Manufacturer

(9) Tap location

(10) Item number

(11) Type

(12) Pressure range

(13) $P \& I D$

(14) Manufacturers

(15) Size

(16) Flow

(17) Temperature range

(18) Scale

(19) Tnput. signal range.

(20) Output signal range

After calibration, additional data is entered on the form to document calibration results.

\subsection{Need for an Integrated Data System}

An integrated data base system could bring together data from the designer, the constructor, regulatory agencies, and from station start-up/ operation groups. Information for a data base system that is required for start-up and operation is shown on Figure 4.4. 


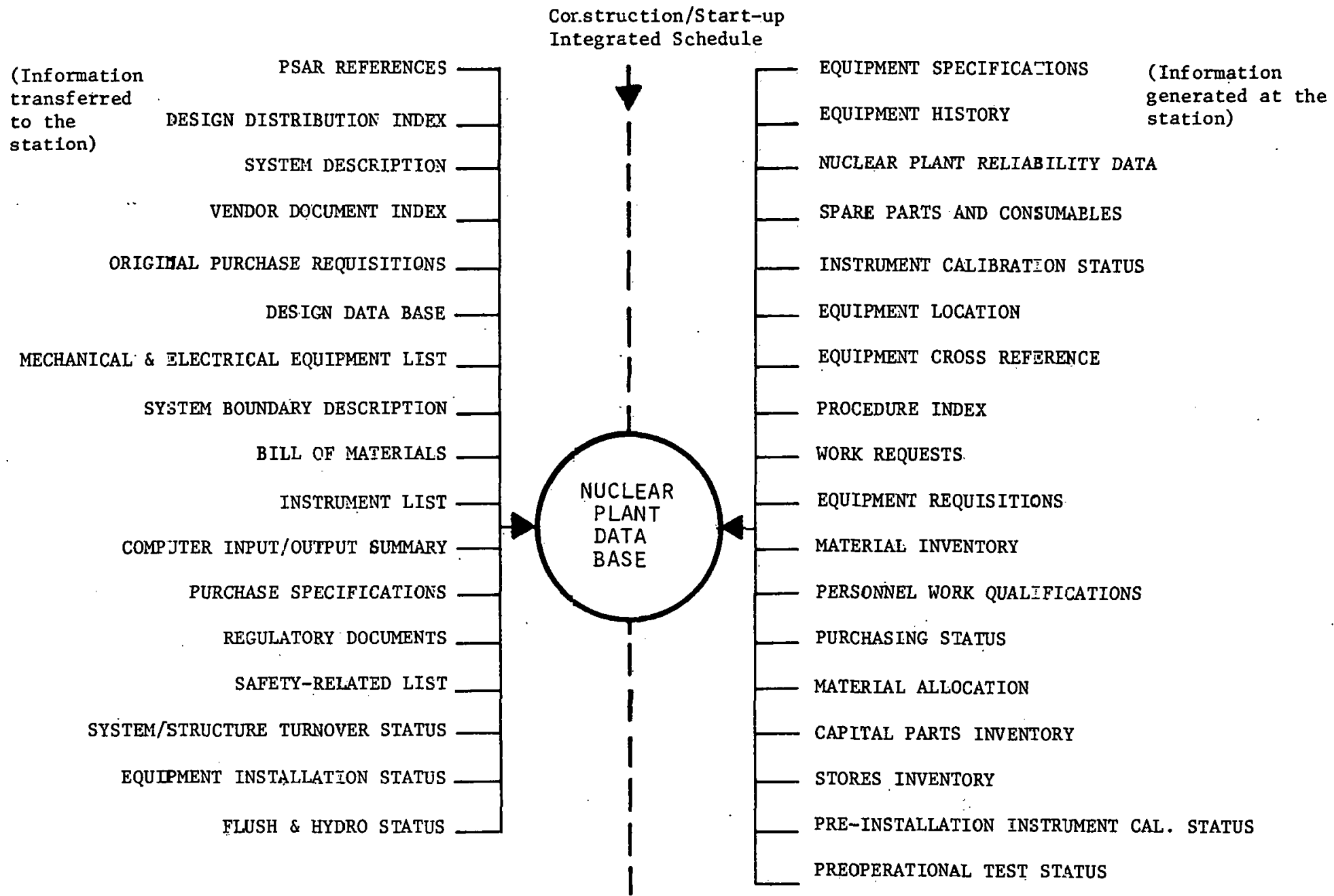

FIGURE 4.4: INTEGRATED IAATA SYSTEM FOR NUCLEAR PLANT START-UP 
One of the major advantages in this data base system is the capability of generation of start-up oriented reports. Presently, most of the information that is sent to the start-up group is in the format used by another department. Thus, much information in these reports is redundant and not properly formated for start-up usage. Also, needed information has often been omitted. The computer offers the capability of retaining this information and making it accessible to start-up in the proper format. There is, of course, no one format for information that could satisfy all start-up needs. Information must be sorted in different ways to meet different start-up requirements. Therefore, a data base: can be extremely helpful in meeting these needs.

Another problem with existing data systems is that the start-up group has no easy method of adding new or additional information. For example, the designer may supply a list of all instruments to the startup group. This list could contain instrument specifications, model, and setpoints - but it would not contain calibration status. Genera1ly, the instrument group at the station develops its own method for keeping track of calibration status. This results in additional manhours and redundancy of information. 


\section{THIS PAGE \\ WAS INTENTIONALLY LEFT BLANK}


ADDENDUM A

NUCLEAR REGULATORY COMMISSION

RULES, REGULATIONS, AND REQUIREMENTS

A SUMMARY

A-1 


\section{Introduction}

The following is a short description and explanation of selected documents which have important bearing on the structure and content of the $\mathrm{QA} / \mathrm{QC}$ program of a nuclear power plant. It is the purpose of this compilation to present the material such that the interrelationships and regulatory implications of these documents are made clear. The recognition and proper application of these documents is essential to the successful execution of a nuclear power plant project.

I. Nuclear Regulatory Commission Rules and Regulations:

Title 10 - Chapter I Code of Federal Regulations.

This document is the basic foundation document for all NRC regulation activities. The following group of major "parts" play a significant role in the writing of procedures for construction of nuclear power plants.

A. Part 20 -- Standards for Protection Against Radiation

These standards are directed towards the utility and state restrictions on radiation exposure, methods for determining accumulated exposure, and the need for personal monitoring requirements. It also states exposure limits for different cases.

Specifications are given for radiation identification and marking. This section deals with administrative procedures on how to deal with radioactive materials and what records must be kept about their usage and disposal.

B. Part 50 -- Licensing of Product and Utilization Facilities (such as Nuclear Power Plants)

This section specifies the classification of licenses to use radioactive materials and the procedures to obtain each. These include the PSAR and FSAR. 
Also included are rules for design activities, technical specifications, and certain limitations on construction permits and licenses. Specifically the part includes specifications and requirements for the following:

(1) General Design Criteria

(2) Environmental Policy and Procedures

(3) Emergency Plans and Requirements

(4) Quality Assurance Criteria

(5) Preliminary Safety Analysis Report (PSAR)

(6) Final Safety Analysis Report (FSAR)

(7) Technical Specifications

(8) Technical Specifications on Emissions

C. Part 55 -- Operators Licenses

This part describes the requirements, rules, and regulations for the issuance of an operator's 11cense. It also contains the terms and conditions upon which the Commission will issue these licenses.

D. Part 71 -- Packing of Radloactive Material for Transport and Transportation of Radioactive Materials under Certain Conditions

The regulations in this part apply to each person authorized by specific licenses issued by the Commission to receive, possess, use or transfer licensed materials to a carrier for transport of such material outside the confines of his plant. It governs all packaging and transport of radioactive materials.

E. Part 73 -- Physical Protection of Plants and Materials

This part details the protection necessary to be given to all materials and plants that use nuclear materials. It details the protective barriers and intrusion detection devices at fixed sites to provide early detection of an attack. It also examines deterrence to attack by means of armed guards and escorts and liaison communication with law enforcement authorities capable of rendering assistance to counter such attacks.

F. Part $100--$ Reactor Site Criteria

This part specifles siting requirements, including geological studies necessary and weather requirements. 


\section{Selected Codes and Standards}

The following codes and standards are among those most prominently applied to nuclear power plants. They are to varying degrees designated by the NRC as mandatory parts of applications related to safety and quality considerations. There is currently underway a major national effort to expand these standards and to develop additional standards to greatly increase the scope now in existence. More than 140 new standards and codes for nuclear applications are now in preparation. The following codes and standards form the basis for most of the current quality assurance practices (although quality assurance is only one of the major areas covered by these documents).

\section{A. ASME Boiler and Pressure Vessel Code}

This code has long been the standard for design practice of the power, chemical, and petroleum industry. It consists of eleven (11) principal sections with various mandatory and nonmandatory appendices. Only some of the sections are directly applicable to nuclear power plants. The mafor sections which currently apply to nuclear power plant practices include the following:

$\begin{array}{lll}\text { Section II } & -- & \text { Material Specifications } \\ \text { Section III } & -- & \text { Nuclear Power Plant Components } \\ \text { Section V } & -- & \text { Nondestructive Examination } \\ \text { Section VIII } & -- & \text { Division 1 - Pressure Vessels } \\ & & \text { Division 2 - Alternative Rules for Pressure Vessels } \\ \text { Section IX } & -- & \text { Welding and Brazing Qualifications } \\ \text { Section XI } & -- & \text { Rules for Inservice. Inspection of Nuclear Power } \\ & \text { Plant Components }\end{array}$

B. IEEE Standard 279 - Criteria for Protection Systems for Nuclear Power Generating Stations

This is the principal standard in general use to meet regulatory requirements for plant protective system design. It provides requirements for preparation of formal design bases, application of single failure criteria and design analysis, and equipment testing by type and classification. Requirements are also outlined for isolation, single random failure protection analysis, on-line testing, projection of the possibility of multiple fallures resulting from single credible events, system capability for sensor checks, and design features to provide Individual channel removal, or bypass from service during operation.

\section{ANSI N45.2 - Quality Assurance Program. Requirements for Nuclear Power Plants}

This is the lead document of a series which includes many substandards. The lead document is essentially a more restrictive version of 10CFR50, 
Appendix B. The "daughter" standards are all reliated to quality assurance and include the following:

N45.2.1 Cleaning of Fluid Systems and Associated Components for Nuclear Power Plants

N45.2.2 Packaging, Shipping, Receiving, Storage, and Handling of Items for Nuclear Power Plants

N45.2.3 Housekeeping During the Construction Phase of Nuclear Power Plants

N45.2.4 Installation, Inspection and Testing of Instrumentation and Electric Equipment During the Construction of Nuclear Power Generating Stations (also an IEEE Standard)

N45.2.5 Supplementary Quality Assurance Requirements for Insta1lation, Inspection and Testing of Structural Concrete and Structural Steel During the Construction Phase of Nuclear Power Plants

N45.2.6 Qualifications of Inspection, Examination and Testing Personnel for the Construction Phase of Nuclear Power Plants

N45.2.8 Supplementary Quality Assurance Requirements for Insta1lation, Inspection and Testing of Mechanical Equipment and Piping for the Construction Phase of Nuclear Power Plants

N45.2.9 Requirements for Collection, Storage, and Maintenance of Quality Assurance Records for Nuclear Power Plants

N45.2.10 Quality Assurance Terms and Definitions

N45.2.11 Quality Assurance Requirements for the Design of Nuclear Power Plants

N45.2.12 Requirements for Auditing of Quality Assurance Programs for Nuclear Power Plants

N45.2.13 Quality Assurance Requirements for Control of Procurement of Items and Services for Nuclear Power Plants

N45.2.14 Supplementary Quality Assurance Requirements During the Design and Manufacture of Class IE Instrumentation and Electric Equipment for Nuclear Power Generating Stations

N45.2.15 Requirements for the Control of Hoisting, Rigging, and Transporting of Items at Nuclear Power Plant Sites 
N45.2.16 Supplementary Requirements for the Calibration and Control of Measuring and Test Equipment Used in the Construction and Maintenance of Nuclear Facilities

N45.2.17 Quality Assurance Requirements for Control of Welding for Nuclear Power Plants

N45.2.18 Supplementary Quality Assurance Requirements for Insta1lation, Inspection, and Testing of Precast, Prestressed, Preplaced and Heavy Aggregate Concrete During the Construction Phase of Nuclear Power Plants

N45.2.19 Supplementary Quality Assurance Requirements Related to Soil and Foundations During the Construction Phase of Nuclear Power Plants

N45.2.20 Supplementary Quality Assurance Requirements for Subsurface Investigations Prior to the Construction Phase of Nuclear Power Plants

N45.2.21 Quality Assurance Program Requirements for Nuclear Power P1ant Fuels

N45.2.22 Supplementary Requirements for Inspection of Dimensional Characteristics

N45.2.23 Qualification of Quality Assurance Program Audit Personnel for Nuclear Facilities

D. IEEE Standard 336 - Installation, Inspection and Testing Requirements for Instrumentation and Electric Equipment During the Construction of Nuclear Power Generating Stations

The title of this standard is self-explanatory. It applies to Class 1 and Class $1-E$ electric power. It also applies to related auxiliary equipment such as cables, raceway penetrations, primary elements, signal transmitting systems, fluid systems, switch gear, panels, enclosures and mountings.

This standard is also designated as N45.2.4 (described above under Paragraph C). It lists nine (9) more mandatory standards which are related to electrical design, equipment manufacture, installation, and testing. The documents are as follows:

IEEE Standard 279 Criteria for Protection Systems for Nuclear Power Generating Stations

IEEE Standard 308 Criteria for Class 1-E Electric Systems for Nuclear Power Generating Stations 
IEEE Standard 317 Electric Penetration Assemblies in Containment Structures for Nuclear Fueled Power Generating Stations

IEEE Standard 323 Guide for Qualification of Class 1 Electric Equipment for Nuclear Power Generating Stations

IEEE Standard 334 Guide for Type Tests of Continuous-Duty Class 1 Motors Installed Inside the Containment of Nuclear Power Generating Stations

IEEE Standard 338 Trial-Use Criteria for the Periodic Testing of Nuclear Power Generating Station Protection Systems

IEEE Standard 344 Trial-Use Guide for Seismic Qualification of Class 1 Electric Equipment for Nuclear Power Generating Stations

ANSI N18.2

Nuclear Safety Criteria for the Design of Stationary Pressurized Water Reactor Plants

ANSI B 31.7

Nuclear Power Plant. Piping

Note: ANSI B31.7 is included in this 1isting. However, a proposed revision to 10CFR50 contained in the Federal Register, Vol. 39, No. 187, would remove the requirements to comply with B31.7. Section III of the ASME Boiler and Pressure Vessel Code would be invoked in its place.

E. ANSI N18. Series

This is a series of ANSI standards which is based on considerations of nuclear design criteria. Some of the standards which are included in this group are the following:

N18.1-1971 Selection and Training of Personnel for Nuclear Power. Plants

N18.2-1973 Nuclear Safety Criteria for the Design of Stationary PWR Plants

N13.2a Nuclear Safety Criteria for the Design of Stationary PWR Plants (Supplement and Revision to ANSI N18.2-1973)

N18.3-1972 Fuel Assembly Tdentification

N18.4 Vibratory Ground Motion for the Design Earthquake 
N18.5-1974 Earthquake Instrumentation Criteria for Nuclear Power Plants

N18.6 Decay Energy Release Rates Following Shutdown of Urantum-Fueled Thermal Reactors

N18.7-1972 Administrative Controls for Nuclear Power Plants (Under Rev.)

N18.8 Criteria for Preparation of Design Bases for Systems that Perform Protection Functions in Nuclear Power Generating Stations

N18.9-1972 Program for Testing Biological Shielding in Nuclear Reactor Plants

$\mathrm{N} 18.10$

Fire Protection Criteria for Safety-Related Structures and Equipment for Water-Cooled and Moderated Nuclear Power Generating Plants

N18.17-1973 Industrial Security for Nuclear Power Plants.

Of particular interest in the above series is ANSI N18.1, which the NRC has accepted as a basis for selection and training for nuclear power plant personnel.

ANSI N18.1 - contains requirements for qualifications of managers, supervisors, technical support personnel, operators, technicians, and other personnel necessary for operation of licensed nuclear power plants. Definition and guldance are provided for training of personnel, including those to be licensed by the NRC for reactor operator and senlor reactor operator qualifications. Minimum education and experience standards for selection and training of personnel are also provided.

F. SNT-TC-1A - Recommended Practice for Nondestructive Testing Personnel Qualification and Certification

'lhis document is a collection of several separate publications on the various methods of nondestructive testing; i.e., radiography, ultrasonic, dye penetrant, magnetic particle, etc. Each section covers the individual techniques, limitations, applications, procedures, and standards for interpretation of results for one of the various testing methods described in the standard. 


\section{Information and Guides}

There is available a wide variety of documents which are intended to assist in interpretation of regulatory requirements and preparation of material for permit and license applications. These documents suggest methods by which owners of nuclear power plants may meet NRC requirements, and they reflect current NRC thinking.

Compliance with the following documents is not always required by regulating agencies; however, adherence to the suggestions, methods, and procedures described in these documents provides a method of solving problems which is acceptable to the NRC. Use of alternative methods must be demonstrated to be equivalent to the satisfaction of the NRC. It is generally advisable to follow the guides as much as possible. This minimizes delays in regulatory reviews which might otherwise be encountered if strange or untested methods of problem solution are employed.

\section{A. TID 14844 - Calculation of Distance Factors for Power and Test Reactor Sites}

This document describes a method of analysis of the results of maximum critical accidents (MCA) to determine predicted dose rates and distance factors for exclusion areas, low population zones, and population centers. Acceptance release rates are given for key fission products to provide a basis for conservative calculations. Suitable allowance is made for major recognized intangibles. Also, acceptable analytical methods are outlined for calculating inhalation doses and external gamma doses based on a definitive model for atmospheric diffusion and dispersion of fission products for operating reactors. Assumed saturation values under these conditions are stated for specific isotopes of particular importance; e.g., iodine, xenon, and krypton.

\section{B. NRC Regulatory Guides (Safety Guides)}

Formerly called Safety Guides, these documents are issued by the Nuclear Regulatory Commission. They are directed toward frequently recurring safety and regulatory questions and cover a wide variety of subjects, such as loss of coolant accident analysis, personnel selection and training, analysis of steam line breaks for BWR's, on-site meteorology programs and others. There are over 100 Regulatory Guides currently, issued and in use. They are organized in a standard format which includes a preliminary discussion of problems and a formally stated regulatory position. There are more guides under development. There are now ten major divisions, and of particular importance are the following:

Division I Power Reactor Guldes

Division III Fuel and Materials Facilities Guides 


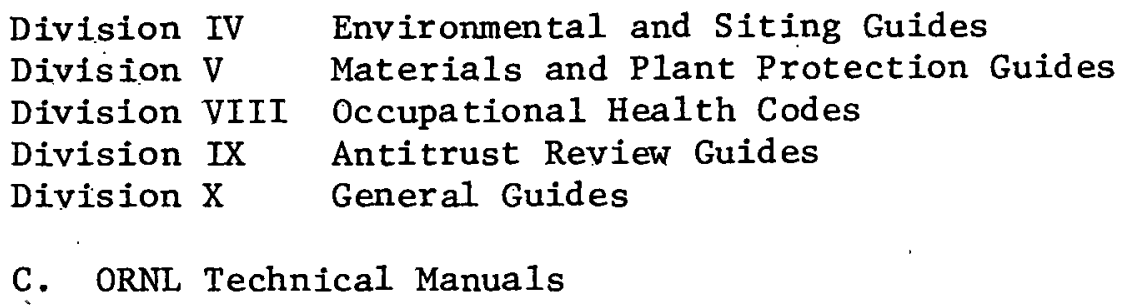

There are a number of publications of general topical interest to designers and owners of nuclear power plants. These have been prepared and issued through the Oak Ridge General Engineering Division. Typical of these reports are the following:

1. ORNL-TM-3645 - "Nuclear Piping Design".

This document addresses the piping designer who must reconcile the requirements of the ASIE Boller and Pressule Vessel Code, Section III, with similar requirements of ANSI Standard Code for Pressure Piping, B31.7, "Nuclear Power Piping." Various requirements of the Codes are interpreted and guidance is given for the preparation of nuclear power plant piping design spectfications.

2. ORNL-TM-3782 - "The Selection and Procurement of Pressure Relief Valves for Light Water-Cooled Nuclear Reactor Systems"

This document is devoted to the design, selection, and spectflcation of relief. valves for various reactor applications. It describes the basic types of valves which are currently acceptable for reactor service. Suggestions are provided for maintenance and test programs for both PWR and BWR reactor systems.

D. Standard Format and Content of Safety Analysis Reports for Nuclear Power Plants, prepared by the NRC Regulatory Staff.

This publication describes organization and contents of PSAR's and FSAR's. It includes detailed requirements for design description (12 chapters), operation and testing (2 chapters), accident analysis, and QA program description (1 chapter each). Representative subjects are outlined for technical speciflcations and description of general design, construction, and operation. NRC Regulatory Guide 1.70.6 covers SAR format and content of SAR's.

E. Guide to the Preparation of Environmental Reports for Nuclear Power Plants (Regulatory Guide 4.2)

Each applicant proposing to build a nuclear power plant is required to submit a report detailing the impact on the environment by the plant.

$$
\text { A-10 }
$$


The NRC utilizes the information presented in this Environmental Report to aid it in assessing the potential environmental effects of the plant as required by NEPA.

This Guide prescribes a standard format and content for the report. Subjects must be treated in sufficient depth to permit independent review. Sample topics that the Guide instructs the applicant to discuss are:

1. The site - ecology, hydrology, regional historic and natural landmarks.

2. The plant - its objectives and composition, water usage, radwaste system, etc.

3. Effects of plant construction and operation.

4. Effluent measurement and control - thermal, radiological, chemical, environmental monitoring.

5. Alternate energy sources and sites - cooling systems, transmission facilities, fossil plants, etc.

6. Summary cost-benefit analysis.

The Giide further provides assumptions to be used in the analyses of effects of postulated accidents upon the environment. It contains tables and forms, the completion of which provides voluminous information and data related to the impact of the plant on the eco-systems present. It should be noted that the Guide also applies to the preparation of an Environmental Report - Operating License Stage, which is an update of the Environmental Report - Construction Permit Stage, described above.

F. WASH 1283 - Guidance on Quality Assurance Requirements During Design and Procurement Phase of Nuclear Power Plants (Rev. 1 May 24, 1974)

This is a compilation of selected regulatory guides, regulatory references, and drafts of proposed ANSI standards which were originally adopted in 1973 by the NRC. In addition, there is some staff guidance which was developed to be used in conjunction with this "Gray Book," as the document has come to be known in the industry.

G. WASH 1309 - Guidance on Quality Assurance Requirements. During the Construction Phase of Nuclear Power Plants (May 10, 1974)

This is a compilation of selected regulatory guides, regulatory references, and drafts of proposed ANSI standards which were originally adopted in 1973 by the NRC. In addition, there is some staff guidance 
which was developed to be used in conjunction with this "Green Book," as the document has come to be known in the industry.

H. WASH 1284 - Guidance on Quality Assurance Requirements During the Operations Phase of Nuclear Power Plants (October 26, 1973)

This document (commonly referred to as the "Orange Book") was issued at about the same time as the Gray. Book and Green Book described. above. Its contents are generally similar to those documents except that it is directed more toward operational considerations. Together these three documents comprise the "Rainbow Series." Recently it became known that an additional "Yellow Book" and "White Book" are being prepared.

\section{Standard Review Plans}

These are issued by the NRC and are numbered to correspond to the individual sections of the Safety Analysis Report. They are used as detailed checklists by the Directorate of Licensing in reviewing the application for completeness. An incomplete application (a Directorate of Licensing judgment) may result in the return of the application with an attendant licensing delay. 
ADDENDUM B

SAMPLE TYPES OF PERMANENT

AND NON-PERMANENT: RECORDS 
The following is a list of types of Quality Assurance records with the minimum retention periods indicated according to ANSI N45.2.9-1974, "Requirements for Collection, Storage, and Maintenance of Quality Assurance Records for Nuclear Power Plants:"

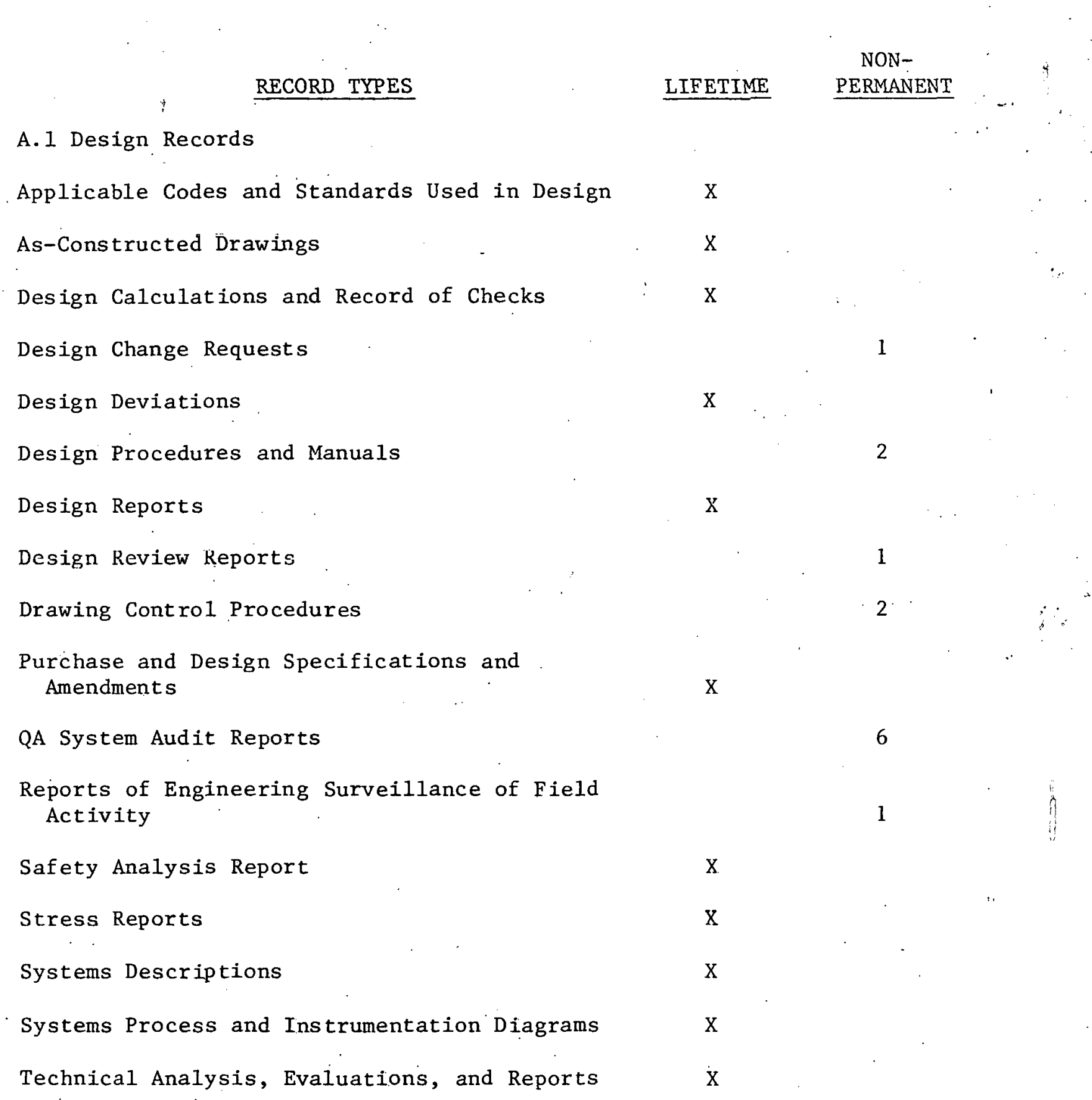


A. 2 Procurement Records

Audit Reports 6

Procurement Procedures $\quad 0$

Procurement Specification . X

Purchaser Order (Unpriced) Including Amendments

Purchaser's Pre-Award Quality Assurance Survey

Receiving Records

Supplier's Quality Assurance Program Manua1

A. 3 Manufacturing Records

Applicable Code Data Reports X X

As-Built Drawings and Records $\mathrm{X}$

Certificate of Inspection and Test Personnel Qualification

Certificates of Compliance

$\mathrm{X}$

Cleaning Procedures

Eddy-Current Examination Procedure

Eddy-Current Examination Final Results . X

Electrical Control Verification Test Results . 2

Ferrite Test Procedure $\quad \cdot \quad 2$

Ferrite Tect Results X

Forming and Bending Procedure Qualiflcations : 0

Heat I'reatment Procedures $\quad 0$ 
A.3 Manufacturing Records (cont'd)

Heat Treatment Records

$\mathrm{X}$

Hot Bending Procedure

0

Inspection and Test Instrumentation and

(Until reTooling Calibration Procedures and Records calibrated)

T.i.quid Penẹțant Examination Procedure

2

T.iquid Penetrant Examination. Final Results X

Location of Weld Filler Material · . X

Magnetic Particle Examination Procedure

Magnetic Particle Examination Final Results X

Major Defect Repair Records . X

Material Properties Records X

Nonconformance Reports - X

Packaging, Receiving, Storage Procedures

Performance Test Procedure and Results Records : X

Pipe and Fitting Location Report X

Pressure Test Procedure

Pressure Test Results . . . X X

Produce Equipment Calibration Procedure

(Until recal:ibrated)

Produce Equipment Calibration Records (Until reralihrated)

QA System Audit Report

QA Manuals, Procedures and Instructions.

2

Radiographic Procedures 
$\Lambda .3$ Manufacturing Records (cont'd)

Radiographic Review Forms and Radiographs . X

Ultrasonic Examination Procedures: $\quad 2$

U1trasonic Examination Final Results $\quad X$

Welding Materials Control Procedures 2

Welding Personnel Qualification 2

Welding Procedure Qualifications and Data Reports 2

Welding Procedures $\quad \therefore \quad \mathrm{X}$

Work Processing and Sequencing Documents · 2

A. 4 Installation-Construction Records

A.4.1 Receiving and Storage

Inspection Reports for Stored Items

Nonconformance Reports $\quad \mathrm{X}$

Receipt Inspection Reports on Items. 1

Receiving, Storage, and Inspection Procedures 2

Storage Inventory and Issuance Records 0

Vendor Quality Assurance Releases 0

A.4.2 Civil

Aggregate Test Reports . 1

Batch Plant Operation Reports . . I

Cement Grab Sample Reports $\quad$ -

Clieck-off Sheets for Tendon Installation X

Concrete Cylinder Test Reports and Charts X 


\section{A.4.2 Civil (cont'd)}

Concrete Désign Mix Reports . X

Concrete Placement Records X

Inspection Reports for Channe1 Pressure Tests . X

Material Property Reports on Containment Liner and Accessories

Material Property Reports on Metal Containment Shell and Accessories

$\mathrm{X}$

Material Property Reports on Reinforcing Steel $\ddot{X}$

Material Property Reports on Reinforcing Steel Splice Sleeve Material

$\mathrm{X}$

Material Property Reports on Steel Embedments In Concrete

$\mathrm{X}$

Material Property Reports on Steel Piling X

Material Property Reports on Structural Steel and Bolting

Material Property Reports on Tendun Fabrication Material

Miy Water Chemical Anadysis

$\mathrm{X}$

Pile Drive Log

Pile Loading Test Reports · X X

Procedures for Containment Vesse1 PressureProof Test and Leak. Rate Tests and Results

$\mathrm{X}$

Reinforcing Steel Splice Operator Qualification Reports

Releases to Plate Concrete

0

Reports for Periodic Tendon Inspection

$\mathrm{X}$ 
A.4.2 Civil (cont'd)

Reports of High-Strength. Bolt Torque Testing

Slump Test Results ,

Soil Compaction Test Reports

$\mathrm{X}$

User's Tensile Test Reports on Reinforcing Steel

User's Tensile Test Reports on Reinforcing Steel Splices

\section{A.4.3 Welding}

Ferrite Test Procedures

Ferrite Test Results

$\mathrm{X}$.

Heat Treatment Procedures

0

Heat Treatment Records

$\mathrm{X}$ •

Liquid Penetrant Test Procedures

Liquid Penetrant Test Final esults

$\mathrm{x}$

Magnetic Particle Test Procedures

Magnetic Particle Test Final Results

$\mathrm{X}$

Major Weld Repair Procedures and Results

$\mathrm{X}$

Radiographic Test Procedures

Radiographic Test Final Results

$\mathrm{X}$

Ultrasonic Test Procedures

Ultrasonic Tesi Final Results

$\mathrm{X}$

Weld Fit-Up Reports

Weld Location Diagrams 
A.4.3 Welding (cont'd)

Weld Procedures

$\mathrm{X}$

Weld Procedures Qualifications and Results

Welding Filler Metal Material Reports

$\mathrm{X}$

Welding Matèrials Contro1 Procedures

Welding Personnel Qualifications

\section{A.4.4 Mechanica1}

Chemical Composition User's Test (Drab Samples)

for Thermal Insulation

Chemical Tests of Water Used for Mixing Insulation Cement

Cleaning Procedures and Results

Code Data Reports

$\mathrm{X}$

Construction Lifting and Handling Equipment

Test Procedures, Inspection and 'l'est vata

Data Sheets or Logs on Equipment Installation, Inspection, and Alignment

Documentation of Systems Check-Off (Logs or Data Sheets)

Erection Procedures for Mechanical Components

Hydro-Test Procedures and Results

$\mathrm{X}$

Installed Lifting and Handling Equipment Procedures, Inspection and Test Data

Lubrication Procedures

Lubrication Records 
A.4.4 Mechanical (cont'd)

Material Property Test Reports for Thermal

Insulation

Pipe and Fitting Location Reports

Pipe and Fittings Material Property Reports

Pipe Hanger and Restraint Data

Safety Valve Response Test Procedures

Safety Valve Response Test Results

\section{A.4.6 General}

Nonconformance Reports

Special Tool Calibration Records

Specifications and Drawings
$\mathrm{X}$

$\mathrm{X}$

$\mathrm{X}$

$\mathrm{X}$

$\mathrm{X}$

$\mathrm{X}$

(Until recalibrated)

A. 5 Preoperational and Startup Test Records

Automatic Emergency Power Source Transfer Procedures and Results

Final Systems Adjustment Data

Flushing Procedures and Results

Hydrostatic Pressure Test Procedures and Results

$\mathrm{X}$

Initial Heatup, Hot Functional and Cooldown Procedures and Results

$\mathrm{X}$

Initial. Plant Loading Data

$\mathrm{X}$

Initial Reactor Criticality Test Procedures and Rësults

Instrument AC Systems and Inverters. Test

Procediues and Keports 
A. 5 Preoperational and Startup Test Records (cont'd)

Main and Auxiliary Power Transformer Test Procedures and Résults.

$\mathrm{X}$

Off-Site Power Source Energizing Procedures and Test Reports

$\mathrm{X}$

nn-Site Emergency Power Source Energizing

Procedure and Test Reports $\mathbb{X}$

Plant Load Ramp Change Data X

Plant Load Step Change Data $\overline{\mathrm{X}}$

Power Transmission Substation Test Procedures and Results $\mathrm{X}$

Preoperational Test Procedures and Results X

Primary and Secondary Auxiliary Power l'est Procedures and Results . X X

Reactor Protection System Test and Results X

Startup Logs.

Startup Problems and Resolutions $\quad \therefore \quad 6$

Startup Test Procedures and Results X

Station Battery and DC Power Distribution
Test Procedures and Reports

System Lubricating Oil Flushing Procedures 2

Water Chemistry Reports . X

A. 6 Operation Phase Activity Records

A.6.1 Operation, Maintenance and Testing

Records and Drawing Changes Reflecting Plant Design Modifications Made to Systems and Equipment Described in the Final Safety Analysis Report. 


\begin{abstract}
A.6.1 Operation, Maintenance, and Testing (cont'd)

New and Spent Fuel. Inventory, Transfers of Fuel, and Assembly Histories

Plant Radiation and Contamination Survey Records X

Off-Site Environmental Monitoring Survey Records X

Radialion Exposure Records of All Plant Personnel, and Others Who Enter Radiation Control Areas X

Radioactivity Levels of Liquid and Gaseous Waste Released to Environment

Transient or Operational Cycling Records for Those Plant Components That Have Been Designed to Operate Safely for a Limited Number of Transients or Operational Cycles

Current Individual Plant Staff Member Qualifications, Experience, Training, and Retraining Records

Reactor Coolant System In-Service Inspection Record

Minutes of Meetings of the Plant Nuclear Safety Committee and Company Nuclear Review Board

Normal Nuclear Unit Operation, Including Power Levels and Periods of Operation at Each Power Leve1

l'rincipal Maintenance Activities, Including Inspection, Repair, Substitution or Replacement on Principal Items of Equipment Pertaining to Nuclear Safety

Pertodfc Checks, Inspections and Calibrations Performed to Verify that Surveillance Requirements are Being Met. 
NON-

RECORD TYPES

LIFETIME PERMANENT

A.6.1 Operation, Maintenance, and Testing (cont'd)

Speciai Reactor Test or Experiment Records

Changes Made in the Operating Procedures

Radioactive Shipment Records 
ADDENDUM $\mathrm{C}$

FIELD GENERATED DOCUMENT SYSTEM

EXAMPLE REPORTS 
NONCONFORMANCE REPORT - DANIEL CONSTRUCTION COMPANY OF ALABAMA 1

Form 360-3 (Rev. 2-76)

NCR NO,

Page

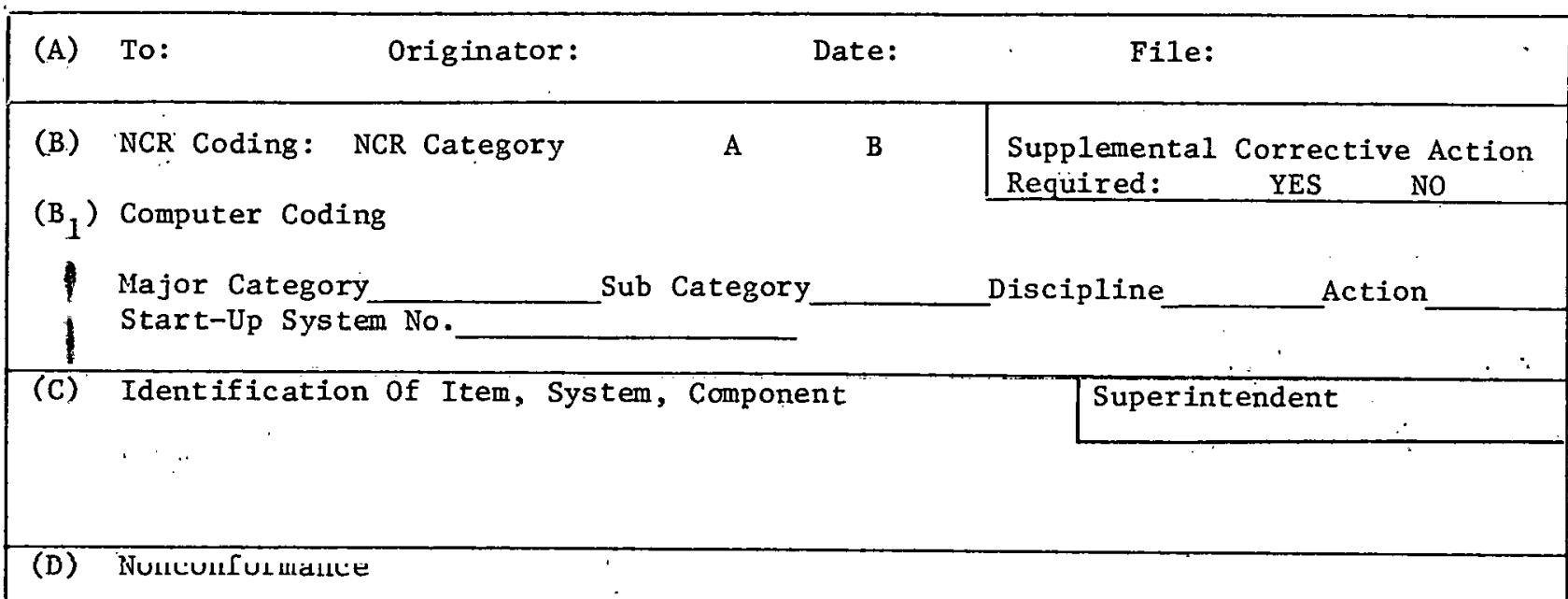

$+$

(E) Disposition

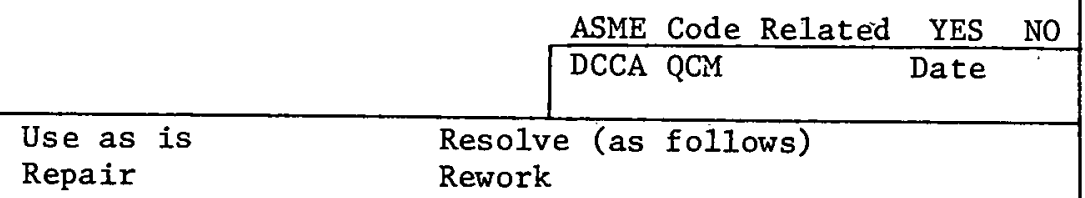

Corrective Action Required YES NO

(F) Rework Inspection Satisfactory

$+3$

\begin{tabular}{|ll|}
\hline DCCA PDE & Date \\
\hline DCCA QCM & Date \\
\hline APCO QA & Date \\
\hline
\end{tabular}

QC Inspector

Date

(G) Remarks:

Refer to Page 
NCR STATUS AND ANALYSIS BASIC REPORT

DATE I2/25/7b

\begin{tabular}{|c|c|c|c|c|c|c|c|c|c|c|}
\hline NCR NO. & $\begin{array}{l}\text { NO. NCR } \\
\text { SUF SUF }\end{array}$ & $\begin{array}{l}\text { NCR } \\
\text { CAT }\end{array}$ & $\begin{array}{l}\text { DATE } \\
\text { OPENED }\end{array}$ & $\begin{array}{l}\text { DAYS } \\
\text { OPEN }\end{array}$ & $\begin{array}{l}\text { ACCTN } \\
\text { AGCY }\end{array}$ & $\begin{array}{l}\text { SYST } \\
\text { STUP }\end{array}$ & $\begin{array}{l}\text { MUST } \\
\text { CLOSE }\end{array}$ & $\begin{array}{c}\text { EST } \\
\text { CLOSE }\end{array}$ & $\begin{array}{l}\text { P.O. } \\
\text { NUMBER }\end{array}$ & $\begin{array}{l}\text { MANU } \\
\text { FACTURER VENDOR }\end{array}$ \\
\hline
\end{tabular}

****************************************************************************************************

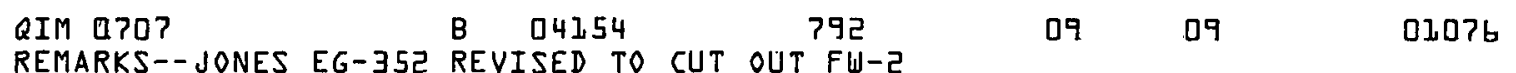

REMARKS--JONES EG-352 REVISED TO CUT OUT FW-Z

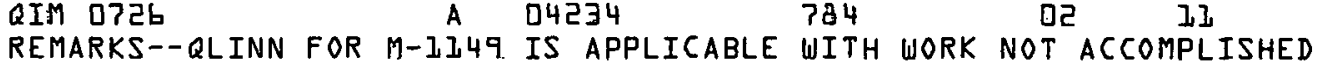

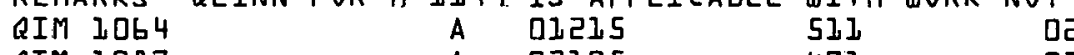

QIM IDB?
REMARKS--WELDON PIPING ENG TO ORDER REPLACEMENT PARTS

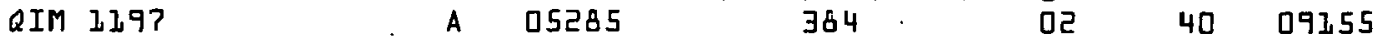

REMARKS--J JONES ENG TO ISSUE WO TO REPAIR AND ORDER NEW ACTUATOR
QIM IZIZ
A $\mathrm{D} 6235$
358 व
NA
NA
NA

QIM

$342 \quad 05 \quad 40$

REMARKS--BECHTEL IN PROCESS OF ACCEPTING TANKS ACCEPTANCE LETTER FORTHCOMING

QIM IZG

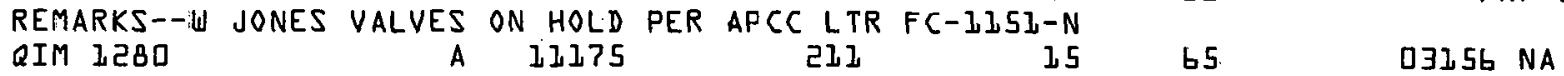

REMARKS--CROFT ACTION TO BE INITIATED FOR REPAIR PARTS

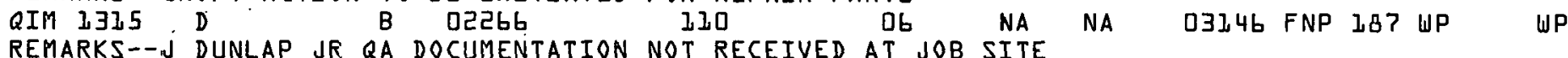

$\begin{array}{lllll}\text { REMARKS--.J DUNLAP JR QA DOCUMENTATION NOT RECEIVED AT JOB SITE } & \\ \text { QIM I3Z3 } & \text { A DJOZb. } & 105 & \text { DZ }\end{array}$

REMARKS--U JONES DOCUMENTATION ID DOES NOT AGREE UITH VALVE DATA PLATE

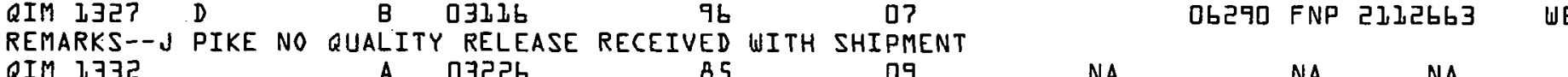

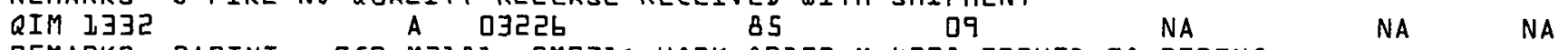

REMARKS--PAPINI - FCR MZIBI, SM931; WORK ORDER M-429B ISSUED TO PIPING 
CARDPUNCH DAZA

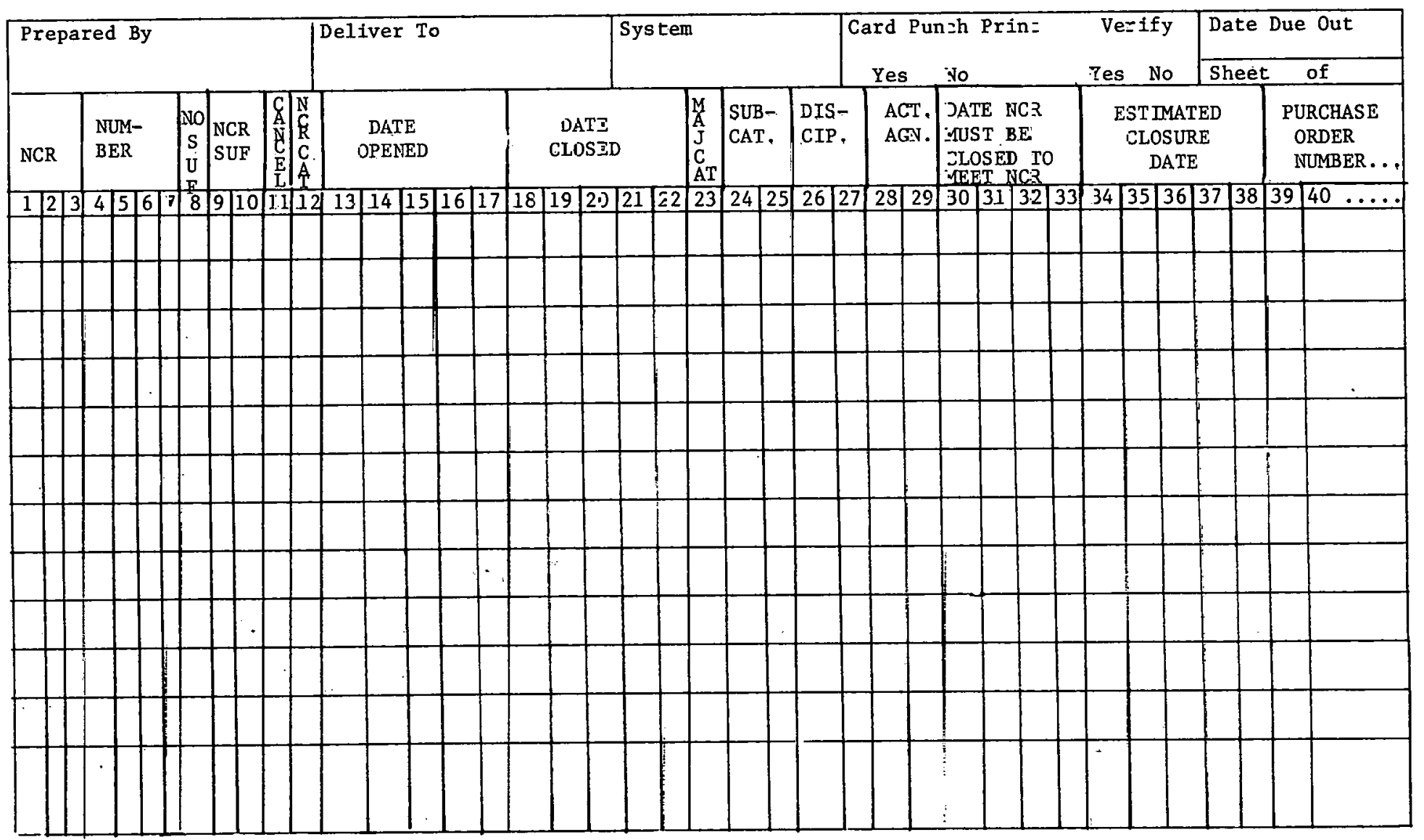


FARLEY NUCLEAR PLANT, DOTHAN, ALABAMA NCNCONFORMANEE REPORTING SYSTEM
OPEN NCR RECAP ****************
DATE $06 / 75 / 76$ PACE I

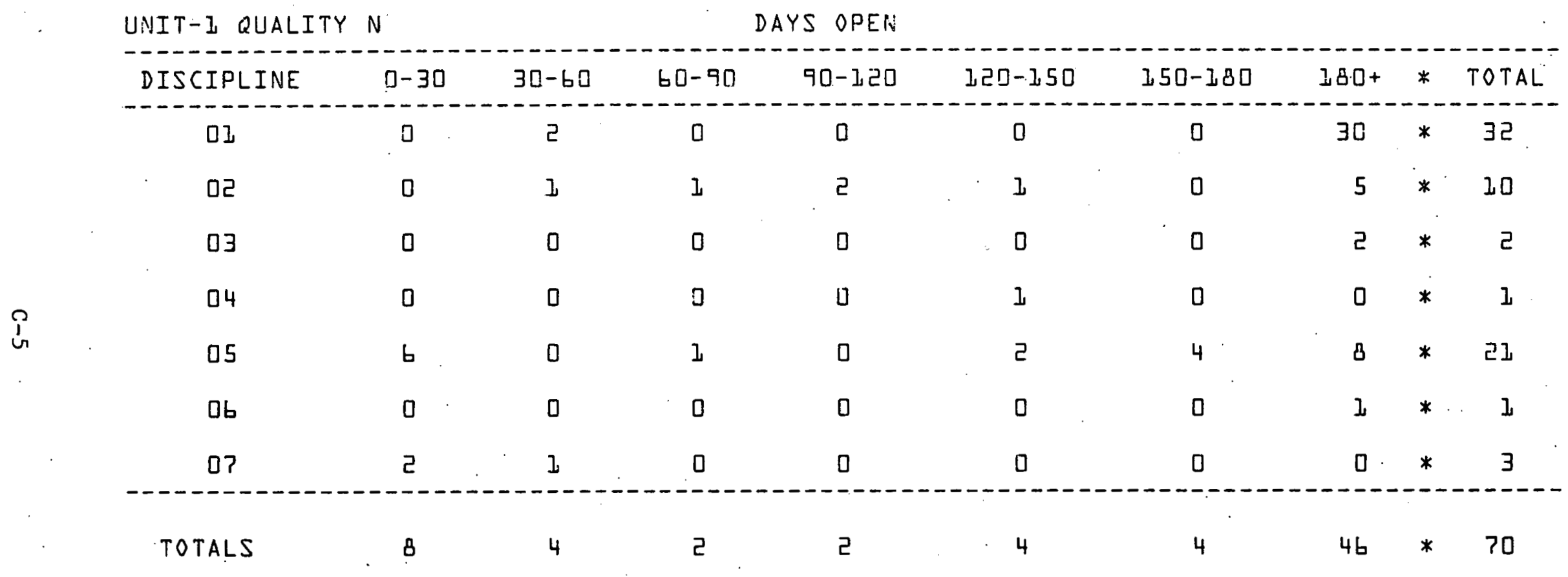


FARLEY NUCLEAR POUER PLANT, DOTHAN, A-ABAMA NONCONFORMANCE REPORTING SYSTEM
OPEN NCP, RECAP

***************
DATE $06 / 15 / 76$ PAGE 4

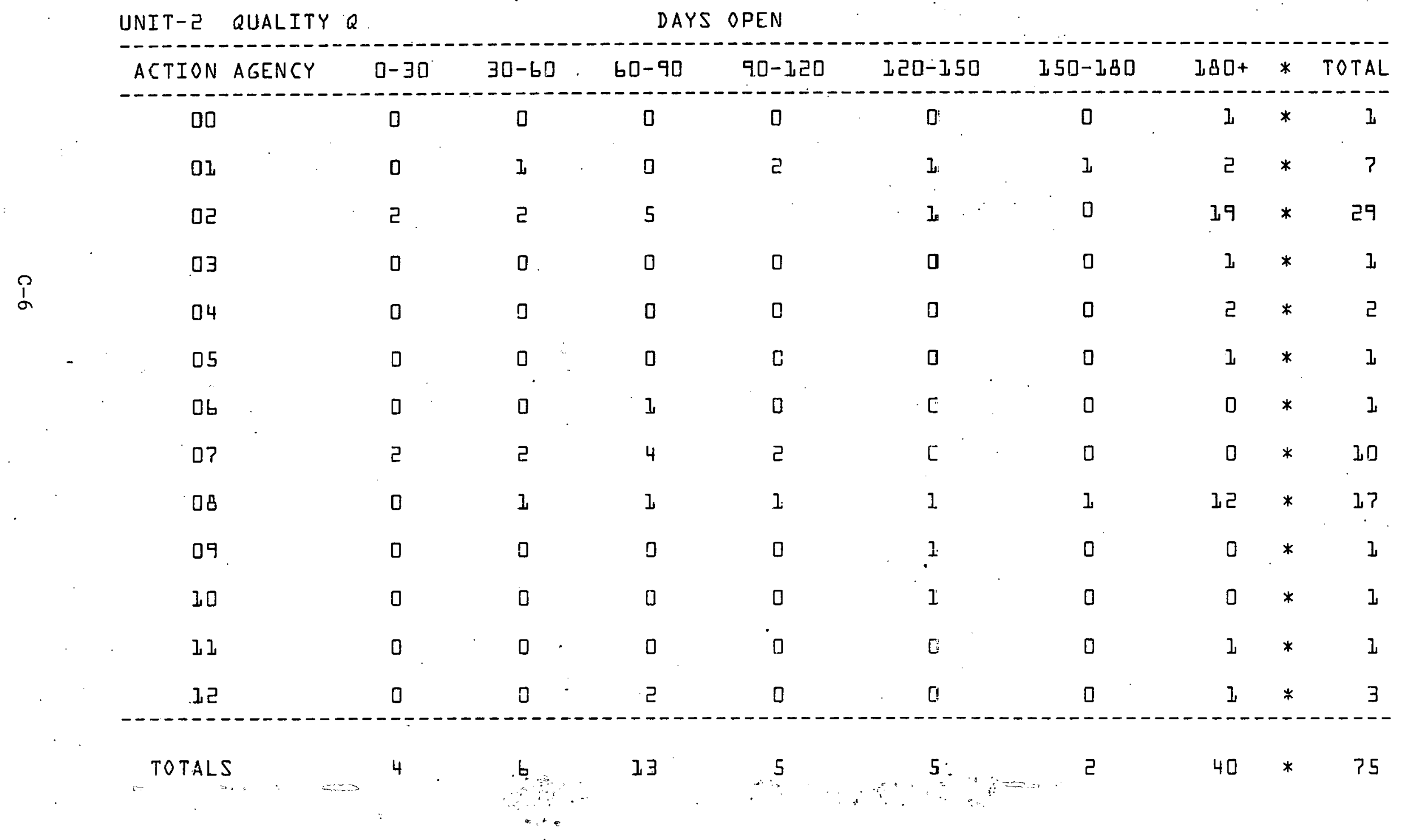




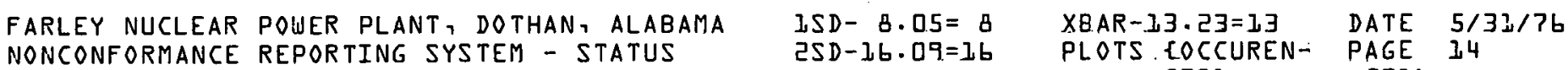
$\begin{array}{lllll} & \\ \text { LAND ANALYSIS } & & \end{array}$ UNIT-I QUALITY-Q DISCIPLINE-M MAJOR CATEGORY-A

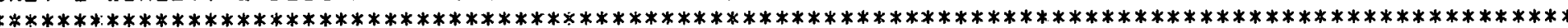

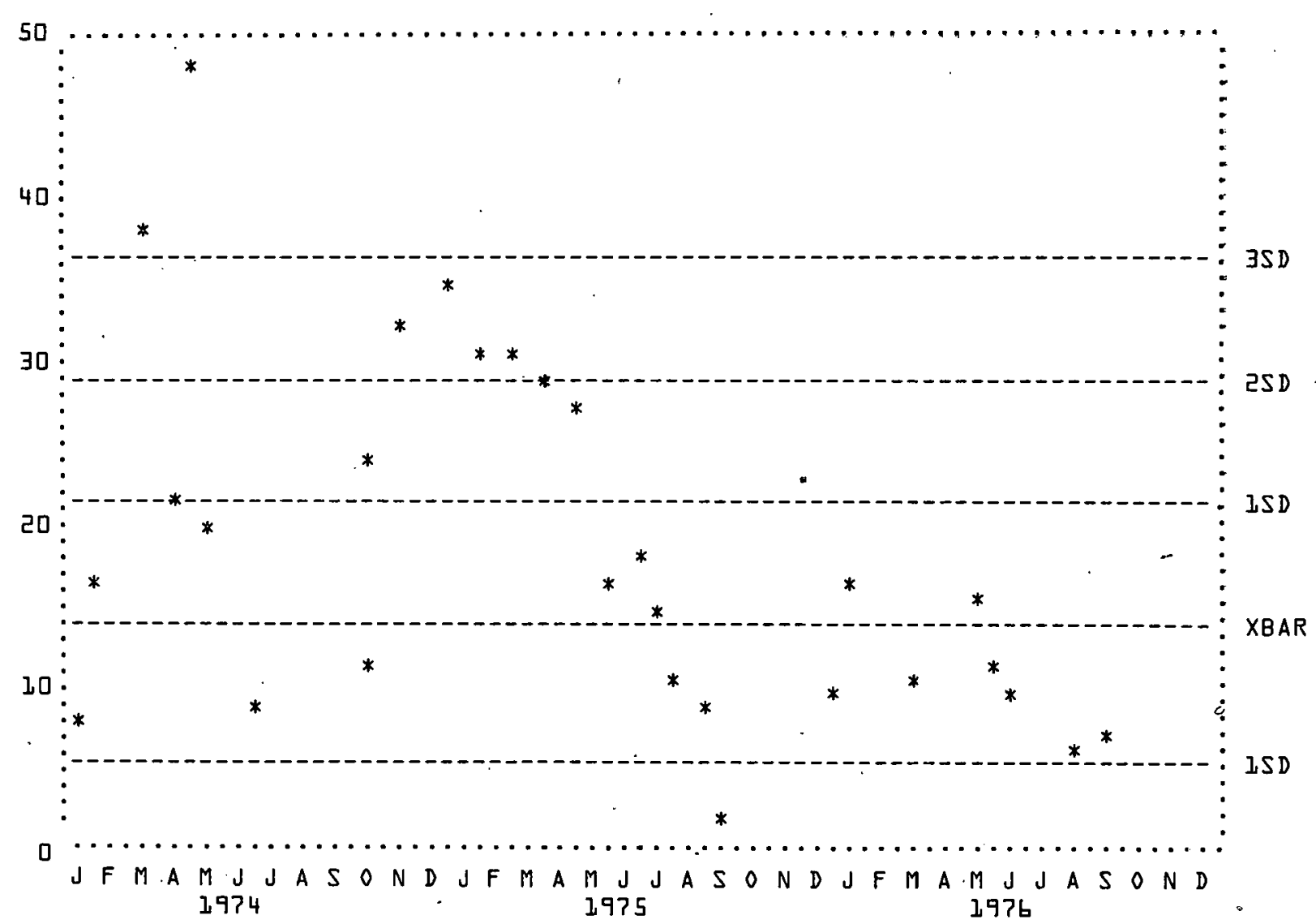




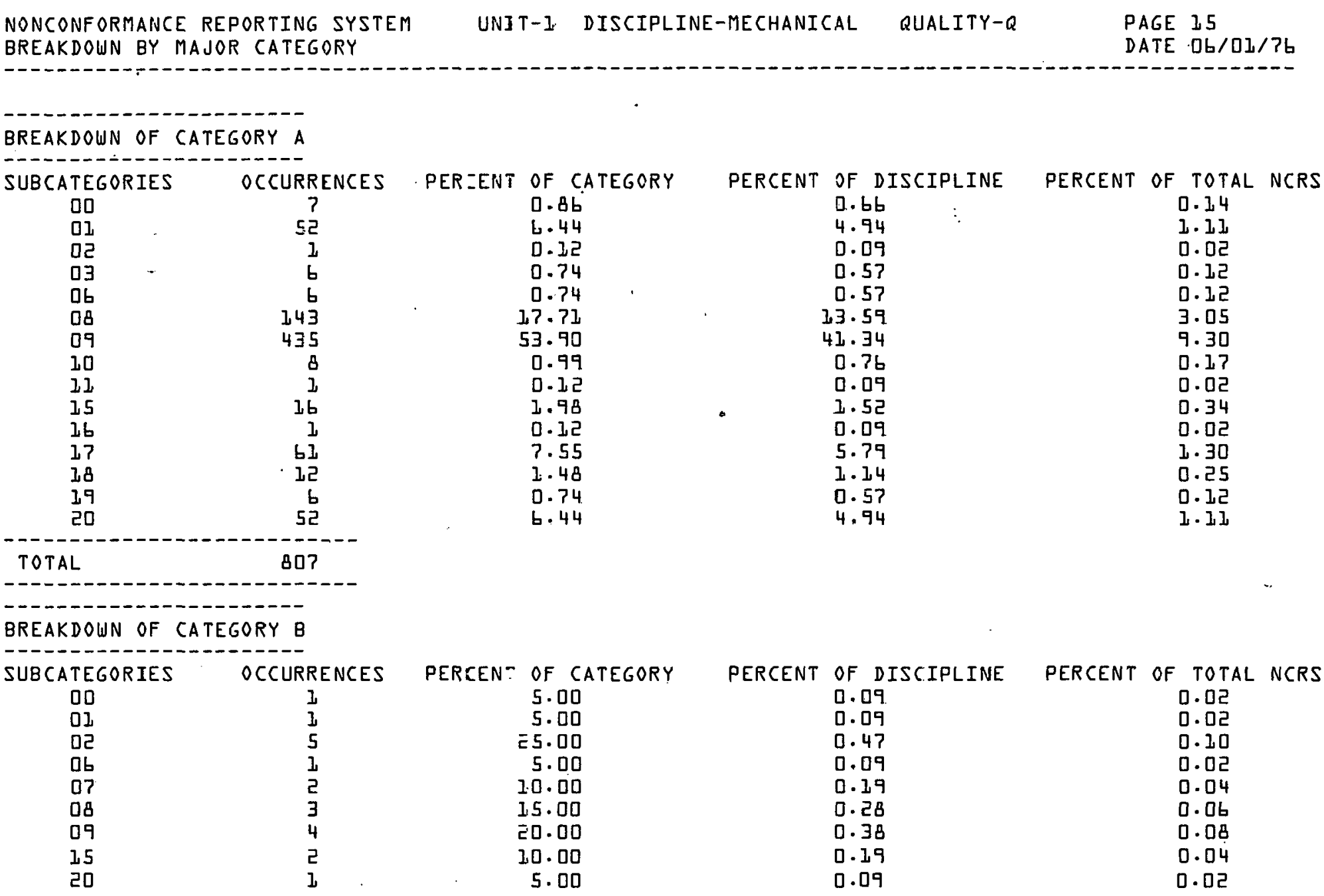


FARLEY NUCLEAR POWER PLANT, DOTHAN, ALABAMA ISD - $2,4 . \mathrm{T}=2$ NONCONFORMANCE REPORTING SYSTEM - STATUS ZSD- $4.82=5$

$$
\text { AND ANALYSIS }
$$

ISD $-4.82=5$
$3 S D-7.23=7$

XBAR- $2.49=\overline{2}$

PLOTS LOCCUREN-

DATE $5 / 31 / 76$

-I QUALITY-Q DISCIPLINE-C MAJOR CATEGORY-A

\section{***********************************************************************************************)}

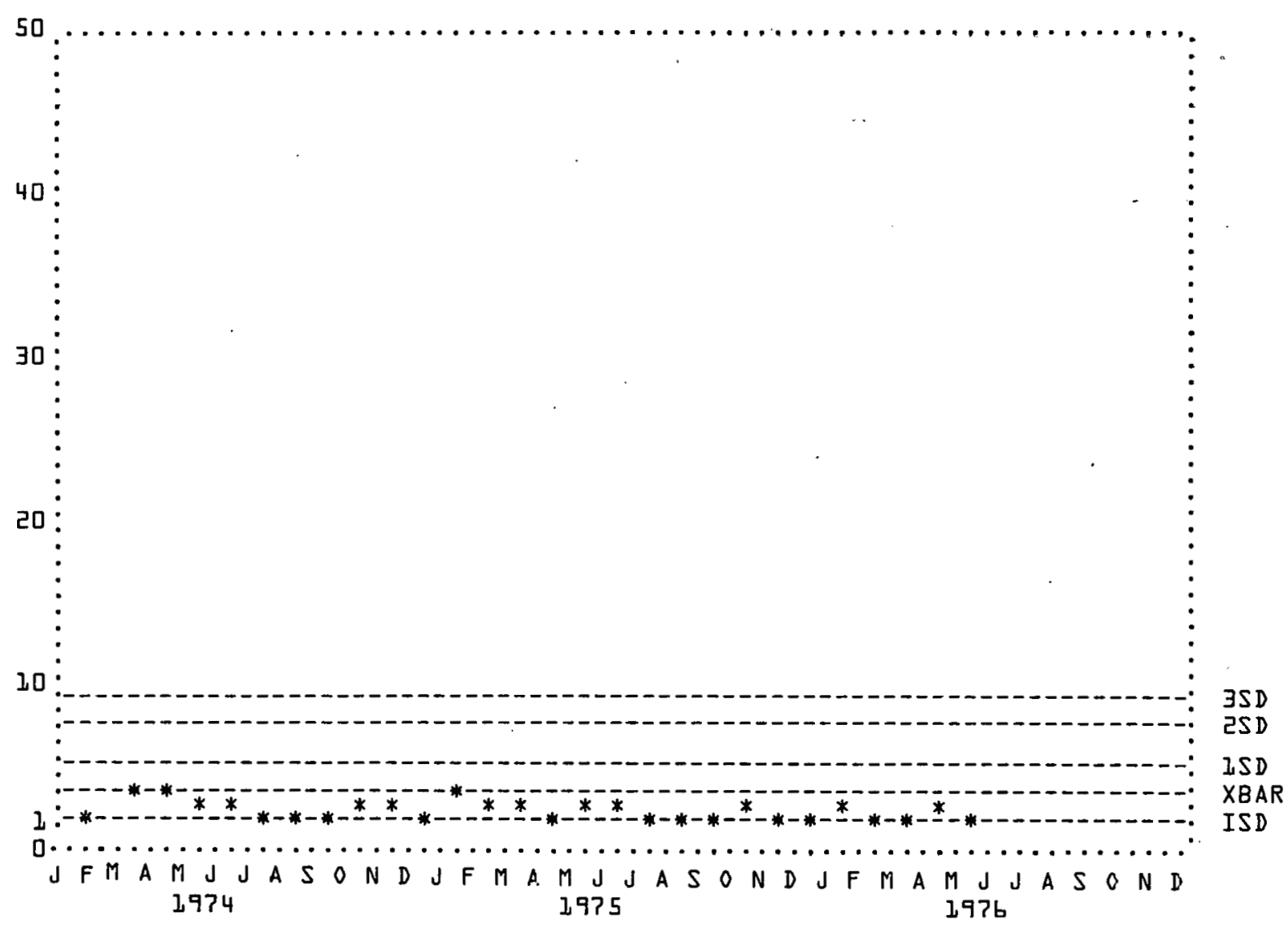




NONCONFORMANCE REPORTING SYSTEM UNIT-I DISCIPLINE-CIVIL QUALITY-Q PAGE ID
BREAKDOUN BY MAJOR CATEGORY DATE OL/DI/TG

- - - - - - - - - - - - - - - - -

BREAKDOWN OF CATEGORY A

\begin{tabular}{cc} 
SUBCATEGORIES & OCCURRENCES \\
01 & 20 \\
03 & 1 \\
06 & 2 \\
08 & 47 \\
09 & 24 \\
20 & 1 \\
15 & 14 \\
79 & 1 \\
20 & 57 \\
\hdashline TOTAL & 157 \\
\hline
\end{tabular}

PERCENT OF CATEGORY

b. $3 b$

0.63

I. 27

29. 93

15.28

0.63

B. 91

0.63

$36 \cdot 30$

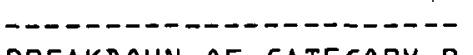

BREAKDOWN OF CATEGORY B

SUBCATEGORIES OCCURRENCES

\begin{tabular}{cc} 
OD & OCCURRENCES \\
02 & 3 \\
07 & 4 \\
$0 B$ & 2 \\
09 & 3 \\
\hdashline$T O T A L$ & 3 \\
\hline TO & 13
\end{tabular}

PERCENT: OF CATEGORY

53. [?

30.76

$15 . \equiv 8$

7.69

23. 0 ?
TOTAL
PERCENT OF DISCIPLINE

ㄹ. 1

0.21

$0.4 \overline{\mathrm{C}}$

$10.0 \bar{c}$

5.1 .1

0.21

ट, $9 E$

․ㄹㄹㅣ

$12 \cdot 1,5$

PERCENT OF IEISCIPLINE

0.63

0.85

0.42

Q. 21

0.63
PERCENT OF TOTAL NCRS

$0.5]$

$0.0 \mathrm{D}$

0.04

1. 00

0.51

0.05

0.29

0.02

1.21 
FARLEY NUCLEAR POUER PLANT, DOTHAN, ALABAMA NONCONFGRMANCE REPORTING SYSTEM - STATUS AND ANALYSIS

UNIT- 1 QUALITY-Q DISCIPLINE-M MAJOR CATEGORY-A

ISD $-7 \cdot 93=8$ टSD $-15.86=16$

$X B A R-75: 9 B=13$ PLOTS EOCCUREN-

CES\}
DATE $3 / 4 / 75$

PAGE Ib

335

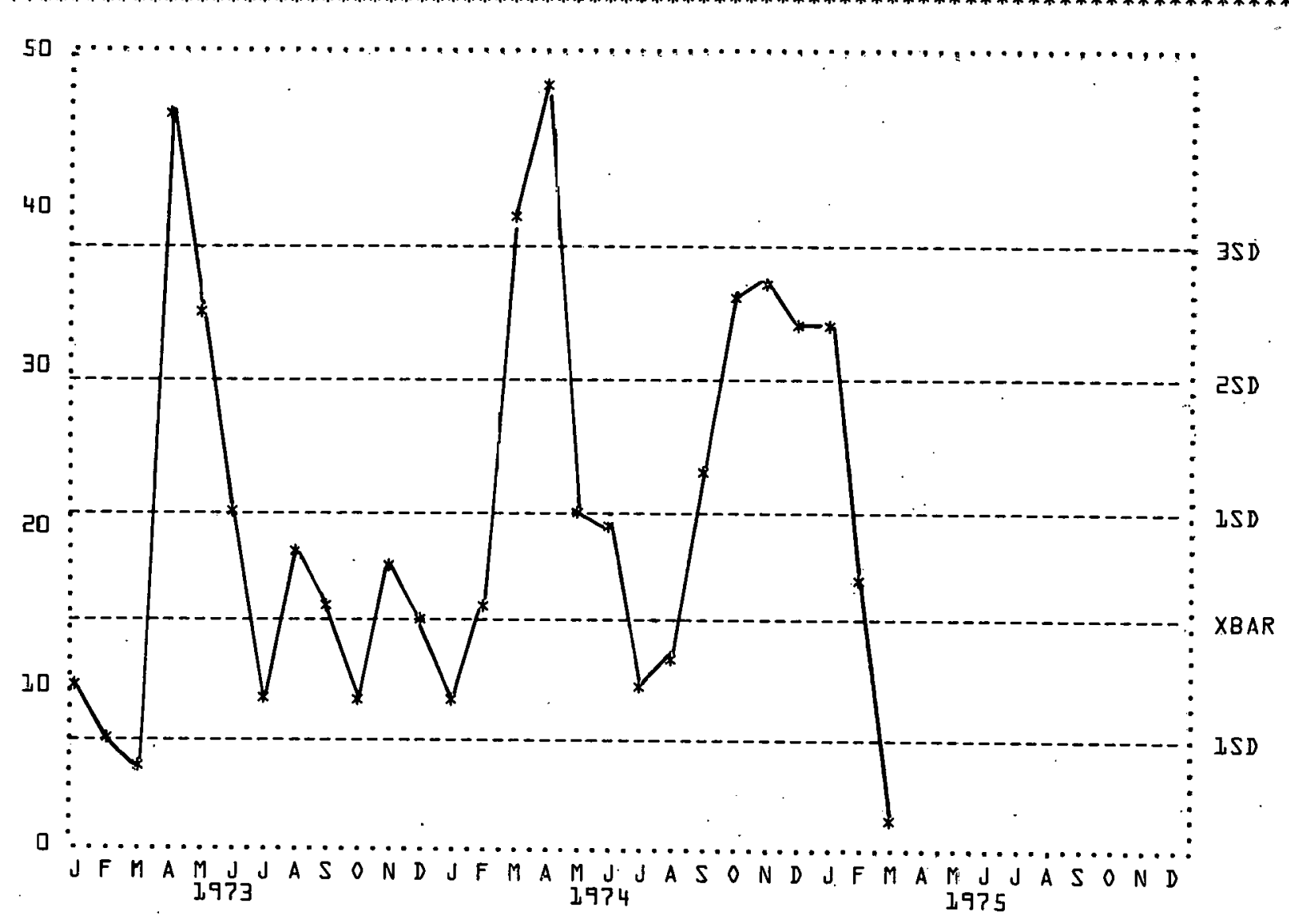




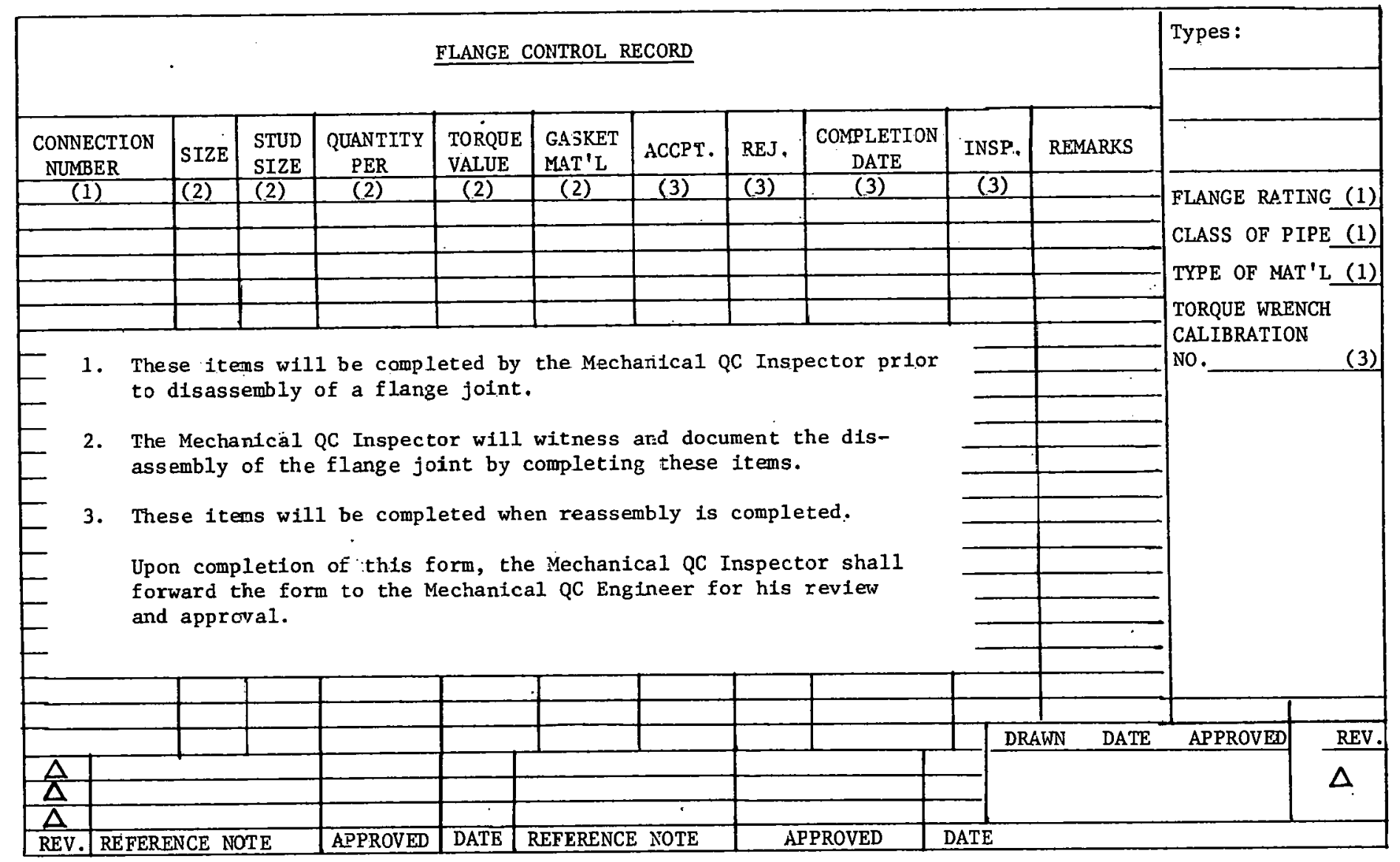


DCCA - FARLEY NUCLEAR PLANT

CONSTRUCTION COMPLETION AND TEST

CONSTRUCTION WORK AUTHORIZATION NO. A47.

$\frac{1}{\text { Mo.Day Yr. }}$ DATE

TO: DATE REQUIRED:

Unit Building Area Elev

- Equipment Name TPNS

Authority/Purpose of Work

Present Status: Safety Tags

Physical Test

Support Requirements: Vendor Dwg/Inst.

Location Dwg. Installation Dwg.

Special Tools/Material PON

Name of Vendor Rep. \& Lo.

(If Applicable)

\section{Direction}

*Quality Control Hold Point

Resp. CC\&T Engr.

Work Completed By Distribution:

Date PDQCE

CC\&T File

Craft Supervision

Page _ of 
FARLEY NUCLEAR PROJECT

INITIAL RUN OF

ROTATING EQUIPMENT

DATA SHEET

FILE TPNS

TPNS

STARTUP SYSTEM: NO.

NAME

EQUIPMENT NAME

NAMEPLATE DATA:

MANUFACTURER

SERIAL NO.

MODEL NO . TYPE RPM

SIZE CAPACITY $\mathrm{TDH}$

VOLTAGE

CURRENT

PREREQUISITES:

DATE TEST ENGR.

QC PROCEDURE 5.6.4.2 MOTOR ROTATION TEST

QC PROCEDURE 5.6.3.10 EQUIPMENT LUBRICATION

QC PROCEDURE 5.6.3.9 AL IGNMENT \& COUPLING

\section{ELECTRICAL DATA}

STARTING CURRENT AMPS VOLTAGE VOLTS

RUNNING CURRENT AMPS APPROX, FLOW

REMARKS : 
OPERATING DATA :

BEARING TEMPERATURES:' (NOTE: TO BE TAKEN AFTER TEMPERATURES HAVE STABILIZED)

SPECIFIED MAX. $\quad$ MEASURED

DRIVER OUTBOARD

DRIVER INBOARD

COUPLING DRIVER END

COUPLING DRIVEN EIND

DRIVEN INBOARD

DRIVEN OUTBOARD

AMB IENT TEMP

APPROX. FLOW

QC INSPECTOR

VIBRATION :

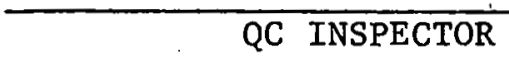

NOTE: READINGS IN MILS DISPLACEMENT. SPECIFIED MAXIMUM MILS VENDOR REPRESENTATIVE COMPANY

DATA RECORDED BY DATE RESULTS REVIEWED BY $\therefore$ QC INSPECTOR DATE

C-15 
DOCUMENTAT ION TURNOVER REQUEST

A. To:

DCCA QCDS

Please prepare the file(s) listed on Attachment I for Formal

Turnover and forward them to this office for review.

APCO PLANT MANAGER

$\overline{\text { DATE }}$

B. To:

APCO Plant Manager

The file(s) which accompany this form are released to you (as requested/with exceptions as listed on Attachment II).

$\overline{\text { DCCA QCDS }} \overline{\text { DATE }}$

APPROVED

$\overline{\mathrm{APCO} N \mathrm{NPD}}$

$\widehat{\mathrm{DATE}}$

C. APCO Production Department acknowledges receipt of the file(s) listed in Attachment $I$ of this request (with the exception of those listed on Attachment II) and accepts responsibility for the proper storage and maintenance of these files.

APCO PLANT MANAGER

$\overline{\mathrm{DATE}}$

DISTRIBUTION: DCCA File - Original

APCO Plant Manager - Copy

APCO QA Supervisor - Copy

DCCA QCDS Supervisor - Copy

APCO Nuclear Project Director - Copy 
FARLEY NUCLEAR PROJECT

CONSTRUCTION WORK REQUEST

FILE TPNS A47. WORK NO. REQUESTED COMPLETION DATE

WORK TO BE PERFORMED BY CONSTRUCTION UNDER: BLUE. TAGS OR ORANGE TAGS REASON FOR WORK:

BOUNDARIES OF SYSTEM RETURNED:

CC\&T RETEST REQUIREMENTS

START-UP RETEST REQUIREMENTS

STATUS OF. SYSTEM AND REMARKS

WORK REQUEST APPROVALS:

NAME

1)

2)

3)

4)

WORK COMPLETION APPROVALS:

1)

2)

3)

4)
TITLE

Originator Start-Up Supervisor NPD (As Applicable) CC\&T Supervisor
DATE

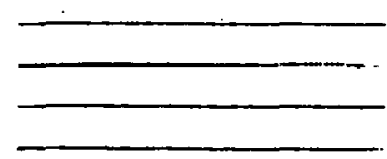

Discipline Engineer

QC Manager CC\&T Supervisor $\mathrm{S} / \mathrm{U}$ Supervisor (As applicable) 
Field Test Engineer:

\begin{tabular}{|c|c|c|c|}
\hline Check List Item & Yes & No & $\mathrm{N} / \mathrm{A}$ \\
\hline 1. Is approved Test Procedure being utilized? & & & \\
\hline 2. Does test equipment have valid calibration tags? & & & 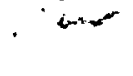 \\
\hline 3. Are Test Procedure Support Documents present? & & & \\
\hline 4. Were Special Precautions observed? & & & \\
\hline 5. Were the Prerequisites performed prior to test? & & & \\
\hline $\begin{array}{l}\text { 6. Was the Test Procedure being followed during } \mathrm{QC} \\
\text { surveillance? }\end{array}$ & & & $\because$ \\
\hline $\begin{array}{l}\text { 7. Were Data and Test results entered during QC } \\
\text { surveillance? }\end{array}$ & & & \\
\hline $\begin{array}{l}\text { 8. Was the Test Procedure Acceptance Criteria met } \\
\therefore \text { during surveillance? }\end{array}$ & & & \\
\hline 9. Are correct control tags installed? & & & $\therefore$ \\
\hline
\end{tabular}

Comments: (Identify activity covered by this surveillance.)

DCCA QC Inspector Date

DCCA Discipline QC Engineer Date 


$\begin{array}{cc}\text { DANIEL CONS TRUCTION COMPANY } & \text { CIVIL } \\ \text { OF ALABAMA } & \\ \text { FARLEY NUCLEAR PROJECT } & \text { MECHANICAL } \\ \text { STRUCTURE/AREA TURNOVER SUMMARY } & \text { ELECTRICAL }\end{array}$

1.0 Description

1.1 Structure/Area (Name)

1.2 Location (Define 1.1 using column lines, coordinates, etc.)

2.0 Completeness

2.1 The Structure/Area defined in 1.0 above is complete except as , noted in 2.2 .

Project Discipline Engineer, Date.

2.2 Exceptions:

3.0 Quality

3.1 There are no outstanding QC Punchlist Items or Nonconformance Reports against the Structure/Area defined in 1.0 above. Final

- inspections (copies attached) are complete and acceptable except as noted in 3.2 .

Project Discipline QC Engineer Date

3.2 Exceptions: 


\subsection{Documentation}

4.1 Al1 Document Control Files relative to the Structure/Area defined in 1.0 are accounted for and complete except as noted in 4.2 .

4.2 Exceptions:

5.0 Review

5.1 QC Manager

5.2. Discipline Manager

Date

Date

6.0 Acceptance

6.1 APCO Nuclear Project Director

6.2 APCO Plant Manager

$\overline{\text { Date }}$

- Date 
CALIBRATION DATA FOR INSPECTING TORQUE WRENCHES

Project:

Location:
Reviewed by/Date:

PAGE OF

ACTUAL BOLT TORQUE

\begin{tabular}{|c|c|c|c|c|c|c|c|c|c|}
\hline DATE. & TIME & INSPECTOR & WRENCH IDENT. & $\frac{\mid A C C E P T . T E}{\text { AOLT SIZE }}$ & $\begin{array}{l}\text { ENS ION VALUE } \\
\text { MIN, TENSION }\end{array}$ & \begin{tabular}{|l|} 
ACTT \\
BOLT 311 \\
\end{tabular} & $\begin{array}{l}\text { BOLT TC } \\
\text { BOLT \# } 2\end{array}$ & $\frac{0 \text { ORQUE }}{\text { TBOLT } \| 3}$ & INSPEC. \&AVG.VALUF \\
\hline & & & & & & & & & \\
\hline & & & & & & & & & \\
\hline & & & & & & & & & \\
\hline & & & & & . & & & & \\
\hline & & & & & & & & & \\
\hline & & & & & & & & & \\
\hline & & & & & & & & & \\
\hline & & & & & & & & & \\
\hline & & & & & & & & & \\
\hline
\end{tabular}


CALIBRATION DATA FOR INSPECTING POWER WRENCHES

Project:

Location:
Reviewed by/Date

PAGE

OF

\begin{tabular}{|c|c|c|c|c|c|c|c|c|c|}
\hline & & & & & ACCEPTANCE & IENS ION VALUES & AC_UAL & BOLT TEN & ION \\
\hline DATE & TIME & INSPECTOR & TYPE WRENCH & WRENCH IDENT. \# & BOLT SIZE & TENS ION RANGE & BOLT $\|]$ & BOLT $\# 2$ & BOLT \#3 \\
\hline & & & & & & & & & \\
\hline & & & & & & - & & & \\
\hline & & & & & & & & & \\
\hline & & & & & & . & & & \\
\hline & & & & & . & & & & \\
\hline & & & & & & . & & & \\
\hline & & & & & & & & & \\
\hline - & & & & . & & & & & - \\
\hline & & & & & & & & & \\
\hline
\end{tabular}




\begin{abstract}
ADDENDUM D
DUKE POWER COMPANY

DATA BASE MANAGEMENT CONTROL AND ENGINEERING SYSTEM

FILE LIST
\end{abstract}

D-1 


\section{ADDENDIM D}

DUKE POWER COMPANY

DATA BASE MANAGEMENT CONTROL AND ENGINEERING SYSTEM

FILE LIST

\section{FILE ID}

A1

A3

A4

A5

$\mathrm{A} 6 \mathrm{M}$

$\mathrm{A} 7 \mathrm{M}$

A8

A9

B1

B2M

B3

B4M

B5

B7

B8

B9

C1

C2

C3

C4

C6

C7

C8

C. 9

D1

D2M

D3

D4

D5

D6

D7

D8

D9

E1

E2

E3

\section{DESCRIPTION}

Integrated Schedule Filc

Drawing File

Schedule Interface Requirements File

Specification Schedule

Motor and Load File

Valve File

Annunciator File

Electrical Device File

Time Records

Cable Status File

Cable File

Valve Item File

Licensing File

Events Recorder File

Mechanical Pipe Hanger File

Eng. Services 1977 Cost Estimate File Drawing-System Schedule

Drawing Symbol File

System Cable Info File

System File

Experiment File

Wire List File

Data Base Files File

Data Base Reports File

Variation Notice and Non-Conforming, Items File

Engineering Applications

Station Battery Report

Delayed System Status

System Data Sets File

Graphics Job File

Graphics Number File

Graphics Operator Number File

Failure Mode and Effect Analysis

Miscellaneous Work. Requests

Material File

Inventory Equipment File 


\section{DESCRIPTION}

E4

E5

E6

E7

E8

E9

F1

F 2

F3

F4

F5

F 6

F7

F8

F 9

GI

G2

G3

G4

G5

G6

G7M

G8

G9

$\mathrm{Hl}$

$\mathrm{H} 2$

H3

H4

H5

H6

H7

H8

H9

II
Manufacturer's File

Engineering Drawing Index File

Switchyard Equipment

Load Power Source File

Motor and Load Calculation Tables File

Drawing and Rev File

Mftr's Dwg to Resp Engineering

Cross Reference

Plan View File

Layout File

Safety File

One Line Diagram Rev Cross Reference File

Wire Tab File

Protective Relay File

Electrical Equipment File

Cable Type Inventory File

Eng. Services Cost Estimate File

Equipment Component File.

Tray File

Bill of Materials

Elect. Cost Est File

Equipment Type File

Requisition Number File

Plant Computer Software Status File

Low Voltage Breaker File

Cable Termination Status File

Transducer File

Correspondence. Index File

Systems Turnover File

Instrumentation and Control File

Requisition File

Item Price File

Inventory File

Cable Termination File 


\section{THIS PAGE \\ WAS INTENTIONALLY \\ LEFT BLANK}

D-4 
ADDENDUM E

DUKE POWER DESIGN DOCUMENT LIST

(MCGUIRE NUCLEAR STATION)

E-1 
DUKE POWER DESIGN DOCUMENT LIST

(MCGUIRE NUCLEAR STATION)

(1) General Arrangements (Civil)

(2) Yard Layouts

(3) -General Arrangement Layouts \& B/M's (Electrical)

(4) Conduit, Cable Tray Layout \& Grounding Dwgs \& B/M's

(5) Panel General Arrangements FV Outline

(6) Computer Cable Routing Drawings

(7) W/D and Panel Connections and $B / M^{\prime} s$

(8) One Line Diagrams

(9) Lighting Drawings and $B / M^{\prime}$ 's

(10) Pressure Switches, Temperature Switches, Solenoids Level Switches, List, etc.

(11) Cable Installation Materials

(12) EE Elem. and AC Elem.

(13) Plant Communication Systems Drawings and B/M's

(14) Event Recorder List

(15) System Descriptions (Electrical)

(16) Protective Device Settings

(17) Wire Tabulations

(18) Instrumentation (Inst. Details)

(19) Flow Diagrams and Change Orders

(20) System Descriptions (Mechanica1)

(21) Mechanical Instrument and Control List

(22) Logic Diagrams

(23) Construction Schedule

(24) Recommended Procedures for Installation and Testing. (EGS)

(25) Station Piping System Identification and Electrical Instrumentation Power, and Control Identification

(26) Valve Nomenclature List

(27) Computer I.0. Summaries

(28) Standardized Draft Tech. Spec.'s

(29) Electrical Schematics Licensing Stage

(30) Mechanical and Electrical Equipment List 


\section{ADDENDUM $F$}

MECHANICAL INSTRUMENTATION AND CONTROL LIST

$F-1$ 


\section{ADDENDUM $\mathrm{F}$}

MECHANICAL INSTRUNENTATION AND CONTROL LIST

COLUMN HEADING

Loop Numbering

Item Number

Component

Use

Manufacturer

Vendor Mark No.

Duke Mark Number

Mi 11 Power order No.

Miscellaneous Information

Service Engraving

Catalog Number

Type of Instrument

Dial Size

Signa1 Output/Input of Instrument

Process Connection

Instrument Connection

Maximum Temperature

Ordering Date - Last Month/When Ordered

Process Range of Instrument

Maximum Pressure

Maximum Velocity

Maximum Flow

Position of Gauge in Gage UN

Type of Mounting

Bourdon Material

MPR 3.2

Arrangement Identification

Straightening Vane Required

Primary Element Type

Class. Selected if Std Det

Well Type

We11 Material

Immersion Leng th

Instrument Detail Number

Revision Number

Duke Diag. Dwg. No.'Ref

Pipe Size

Pipe Type

Mfgr. Outline Dwg. NC Ref.

Process \& Inst. Diagn. No. Ref.

Data Sheet Drawing No.

Tap Loc. \& Zone. Piping Dwg.

Inst. Loc. \& $\mathrm{Zn}$. Piping Dwg.
COLUMN HEADING ABBREV.

Loop No.

Item No.

Comp.

Use

Manuf acturer

Vend Mk \#

Duke Mk \#

MPO 非

Misc Info.

Service

Catalog No.

Inst Type

Dial Size

Signa1 Range

Proc Connect

Instr Connect

Max Temp

Cutoff/Actual

Process Range

Max Pressure

Max Velocity

Max: F'Low

G/PCS

Mounting

Bourdon

MPR 3.2

Arrn ID

St Vanes

Pri Elem

Class

Well Type

Well Mat

Immer Len.

Detail Number

Revi \#\#

Duke Diag No.

Pipe Size

Pipe Type

Out Dwg. No.

$P \&$ I Diag No.

Data Sh Dwg No.

Tap Location

Ins Location 
ADDENDUM G

$$
\text { G-1 }
$$




\begin{tabular}{|c|c|c|c|c|}
\hline ABV & DATA & $\begin{array}{l}\text { CHARACTER } \\
\text { FIELD } \\
\end{array}$ & $\begin{array}{c}\text { ALPHA } \\
\text { NUMERIC } \\
\end{array}$ & $\begin{array}{l}\text { SORT/ } \\
\text { NON-SORT }\end{array}$ \\
\hline STA & Station Name & $2{ }^{\circ}$ & A & $\mathrm{s}$ \\
\hline UNIT & Unit Number & 1 & $\mathrm{~N}$ & $\mathrm{~S}$ \\
\hline SYSTEM & System Designation & 3 & A & S \\
\hline EQUIPIYHE & Equipment Type & 2 & A & $\mathrm{S}$ \\
\hline LOOP & Loop Number & 4 & A & $S$ \\
\hline AUX & Auxiliary Loop Number & 3 & A & $S$ \\
\hline REV & Revision Number & 1 & A & 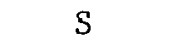 \\
\hline IN SERVICE & In Service Date & 6 & $\mathrm{~N}$ & $\mathrm{~S}$ \\
\hline OUT SERVICE & Out of Service Date & 6 & $\cdot \mathrm{N}$ & $S$ \\
\hline SERVICE . & Service Engraving & 40 & A & $\mathrm{N}$ \\
\hline MFGR & Manufacturer & 15 & A & N \\
\hline MFR CODE & MFR Code & 4 & $A$ & $\mathrm{~S}$ \\
\hline VENDOR & Vendor Code & 4 & A & $S$ \\
\hline MODEL \# & Equip Model Number & 16 & A & $S$ \\
\hline SER NO & Equip Serial Number & 16 & $\Lambda$ & S \\
\hline VENDOR'S ID & Vendor Tag Number & 16 & A & $s$ \\
\hline SAFETY CLÄSS. & Safety Classification & 2 & $\Lambda$ & $\mathrm{S}$ \\
\hline PUR IN RANGE & As Supplied Input Range & 16 & A & N \\
\hline CAL IN RANGE & Calibrated Input Range & 16 & A & $\mathrm{N}$ \\
\hline CAL OUT RANGE & Calibrated Output Range & 16 & A & $\mathrm{N}$ \\
\hline TIME DELAY & Time Delay Setting & 12 & A & $\mathrm{N}$ \\
\hline SIGNAL S.P. & Signal Set Point & $: 1: 2$ & A & $\mathrm{N}$ \\
\hline PROCESS S.P. & $\begin{array}{l}\text { Process Equivalent Set- } \\
\text { point Value }\end{array}$ & 12 & A & $\mathrm{N}$ \\
\hline
\end{tabular}




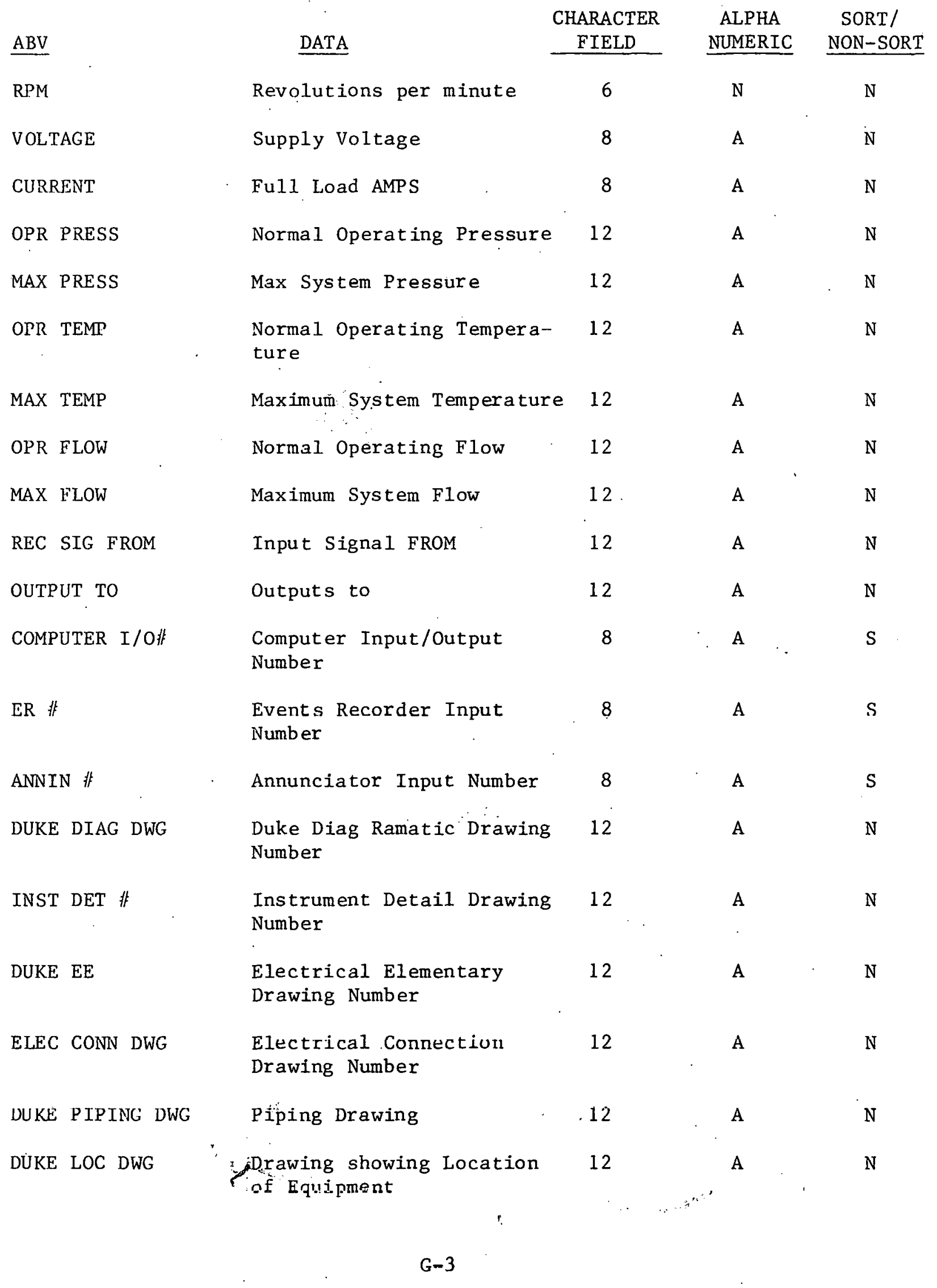


$\underline{\mathrm{ABV}}$

MANF OUTLINE

MANF INST BK

PHYS LOC

CAL FREQ

LAST CAI.

NEXT CAL

PM FREQ

LAST PM

NEXT PM

SPARES ORDERED

MIN/MAX

STOCK NO.

SEQ NUMBER

RESP GROUP

EQUIP STATUS

REPAIR ORDER
DATA

Manufacturer's Outline Drawing

Manufacturer's Instruction Book

Physical Location of Equipment

Calibration Frequency

Last Calibration Date

Next Calibration Date

Preventive Maintenance

Frequency

Last PM Date

Next PM Date

Date Spares Ordered

Minimum/Maximum Stocking

Leve1

Duke Stock Number

Materials Sequence Number

Responsible Group or Dept.

Equipment Status

Repair Order Number
CHARACTER ALPHA SORT/

FIELD

12

12

A

N

16

A

N

6

6

$\mathrm{N}$

$S$

S

6

S

6

N

S

6

N

S

6

N

S

6

N

S

8

N

$N$

16

A

$\mathrm{s}$

10

A

N

3

A

$-N$

3

A

N 